\title{
Disparity Between Reality and Theoretical Models - Predicting Moisture and Mould Growth in New Zealand Houses
}

\author{
By Sarah Buet
} the degree of Master of Architectural Science (Research) 


\section{Acknowledgements}

I would like to acknowledge and thank the following people, many of whom have supported me, not only during this thesis but also throughout my academic career.

Firstly, the staff at BRANZ, namely Manfred Plagmann, Greg Overton, and Steve McNeil who have provided me with guidance and countless hours of tutorials and feedback. Also, the BRANZ Staff for providing me with the Pilot Housing Survey data and always being available and willing to answer any questions that I had. Additionally, I would like to thank BRANZ for awarding me the Building Research Scholarship which helped fund this thesis.

Secondly, I would like to thank my supervisor Nigel Issacs, for his guidance and feedback throughout my research. And lastly, I would like to thank my friends and family for support me and helping me step away from my work at times and ensuring that I maintained a healthy work life balance. In particular, I would like to thank Griffin Cherrill for his constant support and friendship over the last five years at university. 


\section{Preface}

This thesis was submitted in fulfilment of the requirements of the degree for Master of Architectural Science (Research) to the School of Architecture, Victoria University of Wellington.

\section{Author}

Sarah Buet

School of Architecture

Victoria University of Wellington

Email: s.buet@hotmail.com

\section{Supervisor}

Dr. Nigel Isaacs

Senior Lecturer

School of Architecture

Victoria University of Wellington

Email: nigel.isaacs@vuw.ac.nz 


\section{Abstract}

A common goal amongst building practitioners is to create warmer, healthier, and drier houses. A key barrier to this is the presence of excessive moisture, the leading cause of mould growth within buildings. New Zealand Building Code Clause E3 'Internal Moisture' has been set out to control internal moisture within a house, however, there is currently no prescribed method which practitioners can use to demonstrate compliance. Tools such as ASHRAE Standard 160 'Criteria for Moisture Control Design Analysis in Buildings'can be used to predict internal conditions; however, studies have shown that such tools rely upon a range of possibly inappropriate assumptions and may not give accurate results. When looking specifically at ASHRAE Standard 160, the Indoor Design Temperature and Indoor Design Humidity application requires assumptions such as the presence of heating systems, a minimum heating setpoint, ventilation rates, and moisture generation rates of occupants. This research aimed to understand whether, considering the assumptions it makes, can ASHRAE Standard 160 be used in New Zealand to predict mould growth? It went on further to understand how the results produced by ASHRAE Standard 160 aligned with measured data?

Using the yearlong records of New Zealand houses' external conditions (temperature and relative humidity) collected from the 2015 Pilot Housing Survey, two 'Design Parameters', the Indoor Design Temperature and Indoor Design Humidity (Simplified and Intermediate Method), were applied from ASHRAE Standard 160. These two 'Design Parameters' were the only two parameters assessed due to the limitations of the data that was able to be used from the Pilot Housing Survey. Other 'Design Parameters' in ASHRAE Standard 160 include exposure conditions and material properties, as well as a Full Parameter Calculation of Indoor Design Humidity, however, there was insufficient information from the 2015 Pilot Housing Survey to compare these parameters to. Having applied the Indoor Design Temperature and Indoor Design Humidity formula, year-long records of the same houses' internal conditions (temperature and relative humidity) were then used to identify discrepancies between the measured data and the theoretical conditions developed by ASHRAE Standard 160.

To understand how discrepancies may be occurring, it was important first to understand the assumptions that ASHRAE Standard 160 is making when applying the Indoor Design Temperature and Indoor Design Humidity formula. The five most critical assumptions that these two 'Design Parameter' were implementing were:

- A minimum heating setpoint of $21.1^{\circ} \mathrm{C}$ would be applied whenever the running 24hour average outdoor temperature dropped below $18.3^{\circ} \mathrm{C}$.

- Under the Simplified Indoor Design Humidity, the indoor relative humidity was closely dependent on the running 24-hour average outdoor temperature.

- The number of occupants in a house was dependant on the number of bedrooms within the house.

- Each occupant generates approximately 3L per day.

- The buildings' infiltration is either $0.2 \mathrm{ACH}$ for a standard construction or $0.1 \mathrm{ACH}$ for an airtight construction. 
Having compared and analysed the measured indoor conditions and the conditions outlined by ASHRAE Standard 160, a number of discrepancies became evident. This in turn suggested that the above assumptions that ASHRAE Standard 160 made in order to apply Indoor Design Temperature and Indoor Design Humidity (Simplified and Intermediate Method) are not reflective of New Zealand. The key conclusions from this research were:

- The minimum heating setpoint of $21.1^{\circ} \mathrm{C}$ is not applicable in New Zealand houses.

Instead, the application of the $T_{024 h}+2.8^{\circ} \mathrm{C}$ formula across all outdoor temperatures was favourable. Alternatively, further research could suggest a more applicable minimum heating setpoint for New Zealand.

- Overall the Simplified Indoor Design Humidity is a more suitable method of determining the Indoor Design Humidity than the Intermediate Indoor Design Humidity

It was found that overall, the Simplified Indoor Design Humidity matched the measured indoor relative humidity better than the Intermediate Indoor Design Humidity. This was concluded to be due to the fact that the assumptions in the Intermediate Indoor Design Humidity did not reflect the reality of New Zealand houses. However, there is the possibility for the Intermediate Indoor Design Humidity to be altered to reflect the reality of New Zealand houses better.

- The Intermediate Indoor Design Humidity parameters are altered to reflect the reality of New Zealand houses better.

This research identified that the two main parameters, Design Moisture Generation and Design Ventilation Rate, do not reflect how New Zealanders occupy their houses. By undertaking further research into refining these parameters, the application of the Intermediate Indoor Design Humidity may become more suitable for New Zealand.

Having identified discrepancies and the reasons for these discrepancies, this research began to investigate areas in which further research could improve the suitability of ASHRAE Standard 160 in New Zealand. This included additional information such as occupant moisture generation rates and any significant renovations on the houses, being gathered in future Pilot Housing Surveys. Further analysis could be undertaken on inputs such as the Moisture generation Rate and the Design Ventilation Rate by gathering this additional information. This in turn would allow for the alternative inputs to be analysed to understand how these 'Design Parameters' could be altered to reflect the reality of New Zealand houses better. 


\section{Contents}

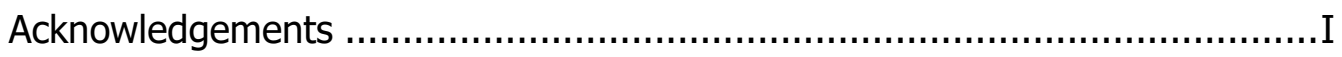

Preface

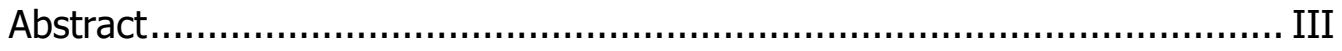

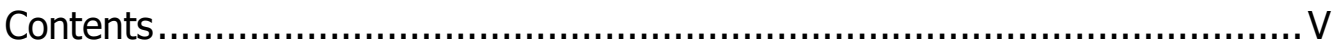

List of Abbreviations .......................................................................

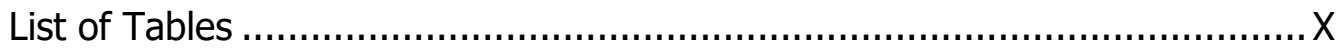

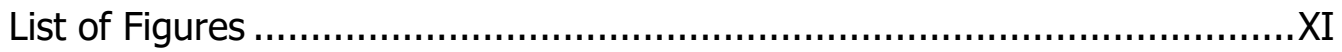

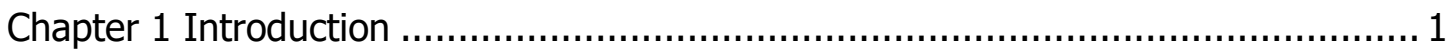

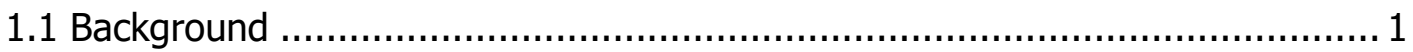

1.1.1 The New Zealand Building Code...................................................... 2

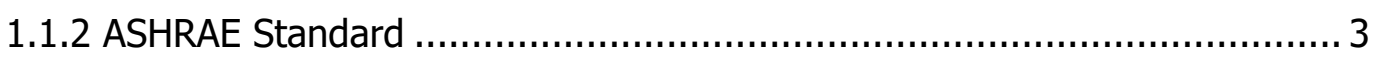

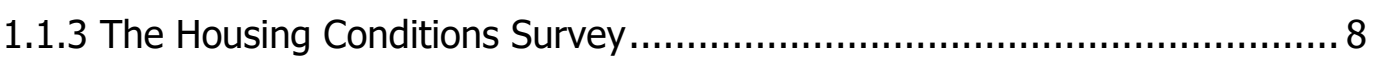

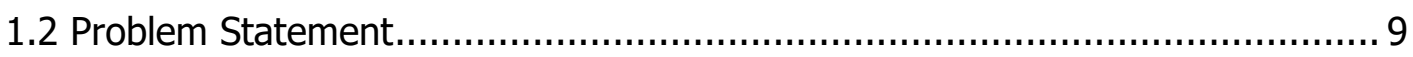

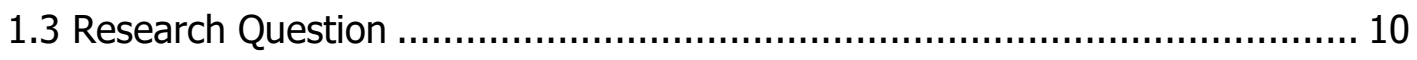

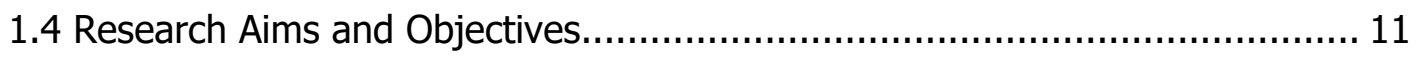

1.4.1 Research Objectives ................................................................... 11

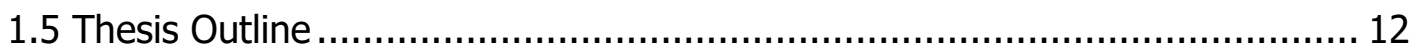

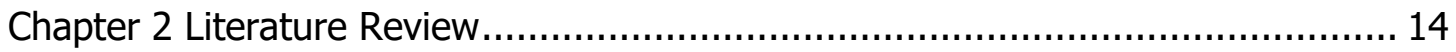

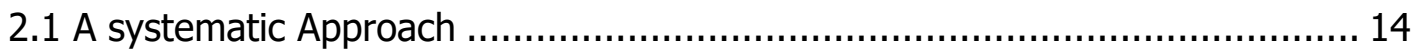

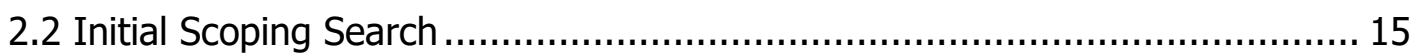

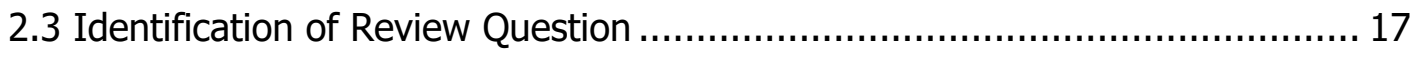

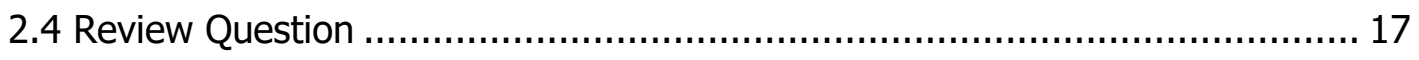

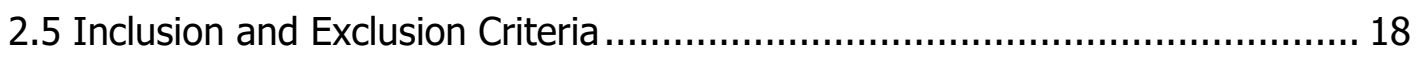

2.6 Searching Strategy and Literature Searching .......................................... 19

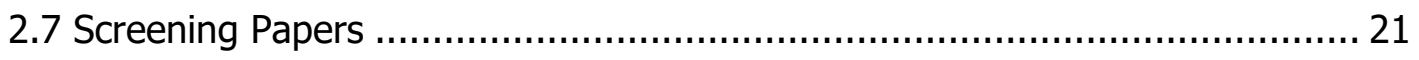

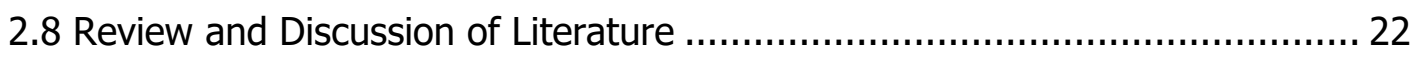

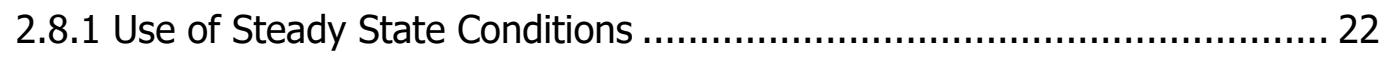

2.8.2 Sensitivity of Models...................................................................... 25

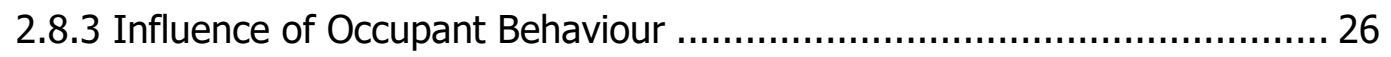

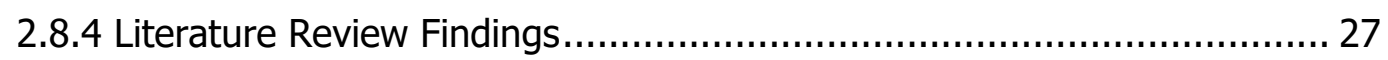

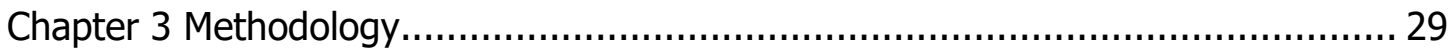

3.1 Determining 'Design Parameters' to Assess ................................................. 30 


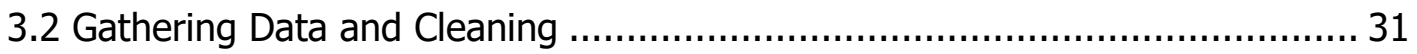

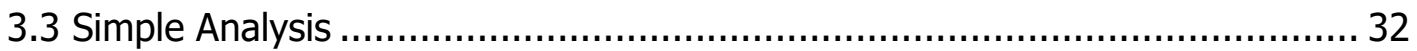

3.4 Hygrothermal Simulation and Analysis .................................................. 32

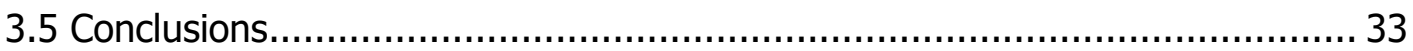

Chapter 4 Moisture Analysis and Mould Prediction Tools .................................... 34

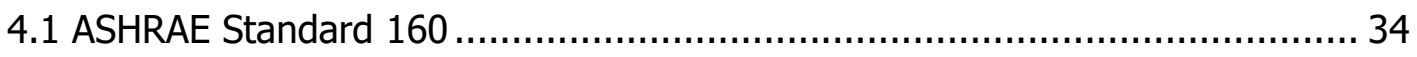

4.1.1 The ASHRAE Standard 160 Process ............................................... 35

4.1.2 WUFI and the VTT Mould Index Model ......................................... 42

4.2 Selection of 'Design Parameters' to Assess ............................................ 42

Chapter 5 Chapter Five - Data Gathering and Cleaning ................................... 46

5.1 Gathering Relevant Data.................................................................... 46

5.1.1 Exclusion of Data ........................................................................ 47

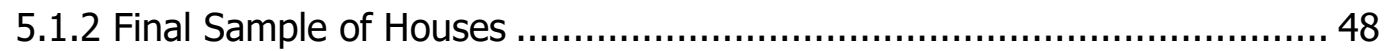

5.2 Determining 'Typical' Measured Indoor Conditions................................... 49

5.3 Final Dataset................................................................................. 50

Chapter 6 Chapter Six- Analysis of Indoor Design Temperature ......................... 51

6.1 Application of Indoor Design Temperature ........................................ 51

6.2 Indoor Design Temperature Analysis .................................................. 52

6.2.1 Measured Indoor Temperature................................................ 52

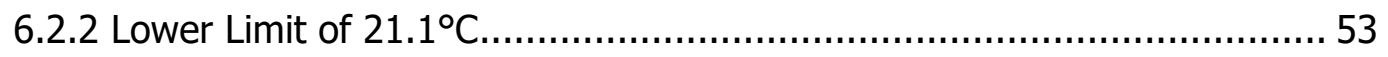

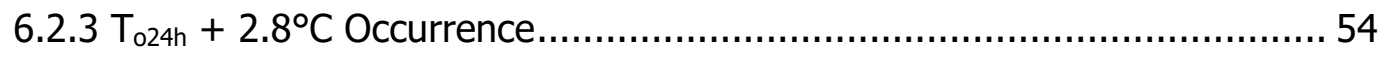

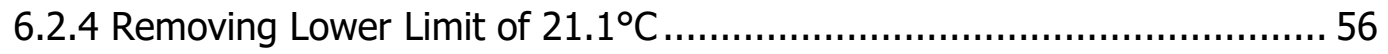

Chapter 7 Chapter Seven - Analysis of Simplified Indoor Design Humidity ............. 58

7.1 Application of Indoor Design Humidity: Simplified Method......................... 58

7.2 Indoor Design Relative Humidity: Simplified Method analysis ...................... 59

7.2.1 Fluctuation in Measured Indoor Relative Humidity .............................. 59

7.2.2 General Trends in Indoor Design Humidity Simplified Method ................60 60

7.2.3 Indoor Design Humidity Simplified Method Trend 1 ............................60 60

7.2.4 Indoor Design Humidity Simplified Method Trend 2 ........................... 61

7.2.5 Indoor Design Humidity Simplified Method Trend 3 .............................. 61

7.2.6 Indoor Design Humidity Simplified Method Trend 4 ............................6 62

7.2.7 Lower and Upper limits of 40\% and 70\% Relative Humidity.................. 63

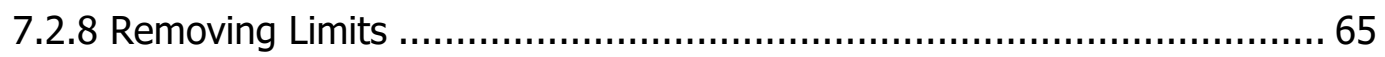

Chapter 8 Chapter Eight - Analysis of Intermediate Indoor Design Humidity.......... 67 
8.1 Application of Indoor Design Humidity: Intermediate Method .................... 68

8.2 Input parameters of the Intermediate Method......................................... 69

8.2.1 Design Moisture Generation Rate .................................................. 70

8.2.2 Design Ventilation Rate ........................................................... 71

8.3 Indoor Design Humidity: Intermediate Method Analysis........................... 72

8.3.1 Maximum Indoor Design Humidity ............................................. 73

8.3.2 Revised Design Ventilation Rate................................................. 74

8.3.3 Fluctuations in the Indoor Design Humidity................................... 77

8.3.4 Indoor Design Humidity: Simplified vs Intermediate Method ................. 78

Chapter 9 Comparative Mould Index Analysis ............................................... 82

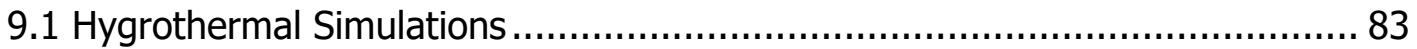

9.2 Analysis of Hygrothermal Simulation................................................. 83

9.2.1 Sensitivity of Intermediate Method Conditions................................. 84

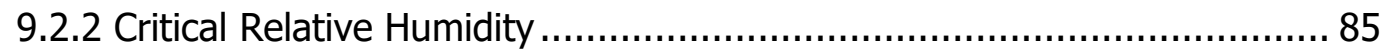

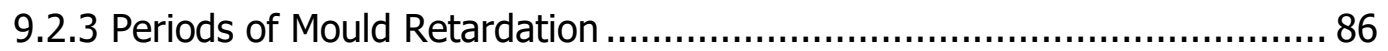

9.3 Comparison to in-situ mould predictions .......................................... 88

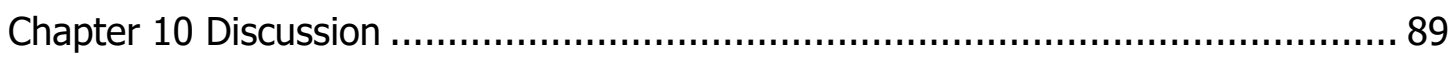

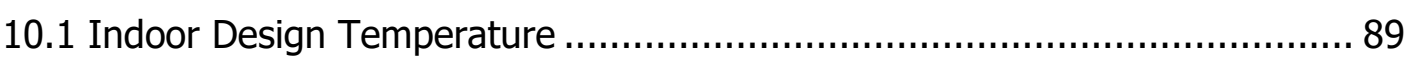

10.2 Indoor Design Humidity: Simplified Method....................................... 90

10.3 Indoor Design Humidity: Intermediate Method ................................... 91

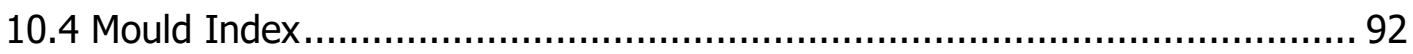

10.5 Connection to previous research..................................................... 93

10.6 Use of ASHRAE Standard 160 in New Zealand ......................................... 94

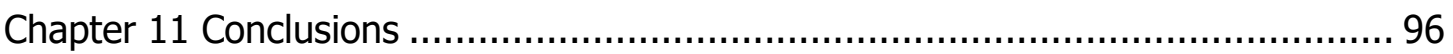

11.1 Research Objective One................................................................ 96

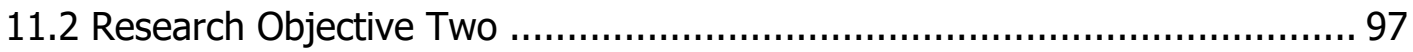

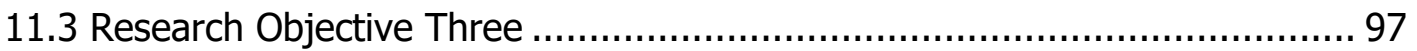

11.4 Research Objective Four .............................................................. 98

11.5 Research Objective Five ............................................................ 98

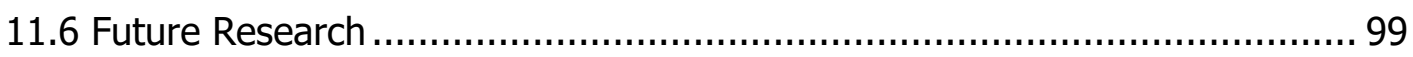

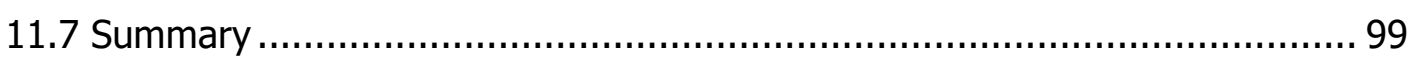

Chapter 12 Works Cited ................................................................... 101

Chapter 13 Appendices ..................................................................... 104

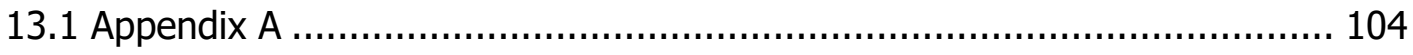




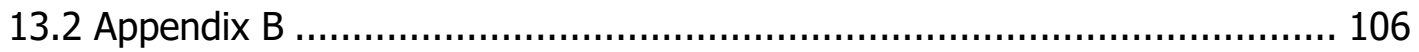

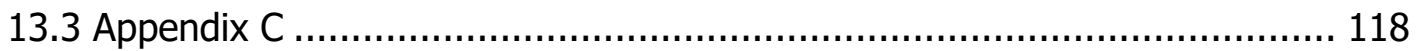

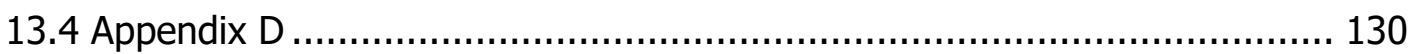

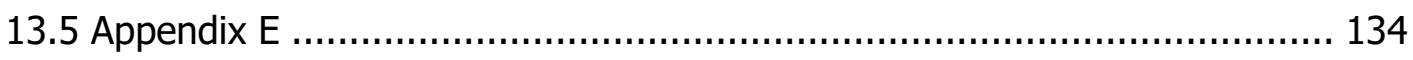

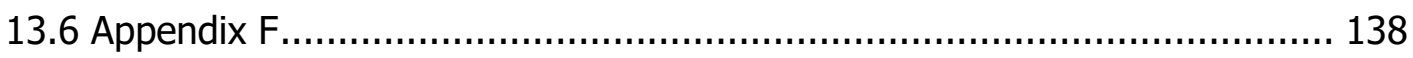

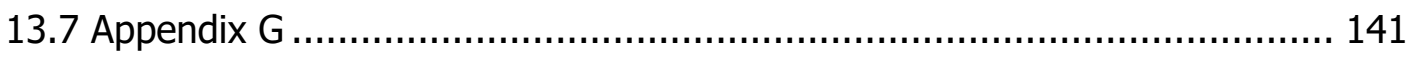

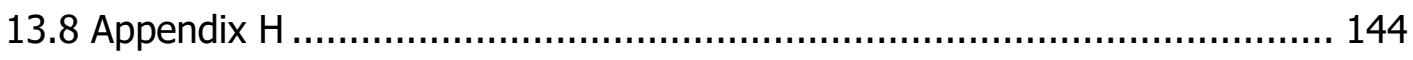

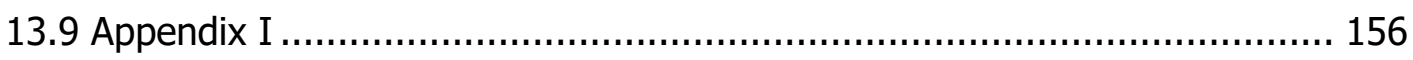

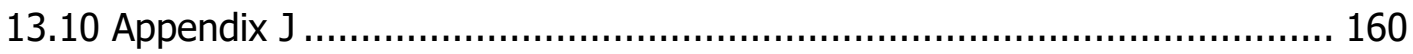

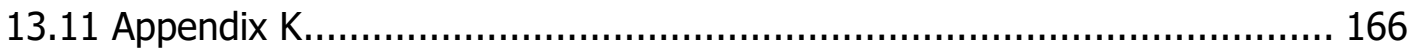

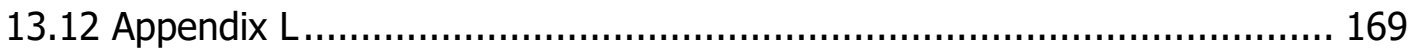

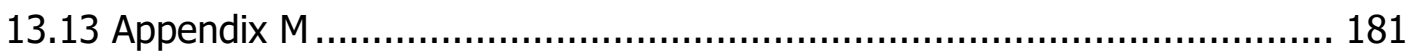




\section{List of Abbreviations}

$\begin{array}{ll}\text { ACH } & \text { Air Changes Hour } \\ \text { AH } & \text { Absolute Humidity } \\ \text { ASHRAE } & \text { American Society of Heating, Refrigeration and Air-Conditioning Engineers } \\ \text { BRANZ } & \text { Building Research Association of New Zealand } \\ \text { EECA } & \text { Energy Efficiency Conservation Authority } \\ \text { HAM } & \text { Heating and Moisture } \\ \text { HCS } & \text { Housing Conditions Survey (2015) } \\ \text { HEEP } & \text { Housing Energy End-use Project } \\ \text { HNZ } & \text { Housing New Zealand } \\ \text { IDH } & \text { Indoor Design Humidity } \\ \text { IDT } & \text { Indoor Design Temperature } \\ \text { IEA } & \text { Energy Information Administration } \\ \text { MBIE } & \text { Ministry of Business, Innovation, and Employment } \\ \text { NIWA } & \text { National Institute of Water and Atmospheric Research } \\ \text { NZ } & \text { New Zealand } \\ \text { NZBC } & \text { New Zealand Building Code } \\ \text { PHS } & \text { Pilot Housing Survey (2015) } \\ \text { RECS } & \text { Residential Energy Consumption Survey } \\ \text { RH } & \text { Relative Humidity } \\ \text { To24h } & \text { 24-hour average outdoor temperature } \\ \text { VTT } & \text { WUFI Mould Index VTT }\end{array}$




\section{List of Tables}

Table 1 US climate zones and the corresponding representative city (Smith \& Mago, 2014) ..............5

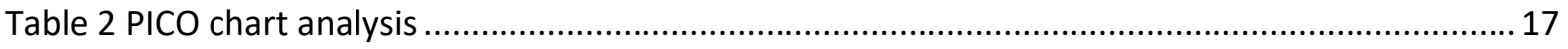

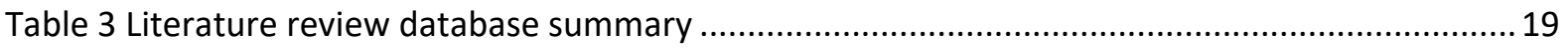

Table 4 Search results from different search terms using various databases .....................................20

Table 5 Exposure factor from table 4.6.1 in ASHRAE Standard 160-2016 ........................................ 37

Table 6 Indoor Design Temperature formulae from table 4.2 in ASHRAE Standard 160-2016 ............37

Table 7 Indoor Design Relative Humidity, Simplified Method formulae from table 4.3.1 in ASHRAE

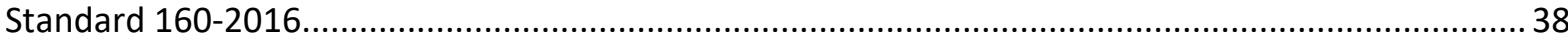

Table 8 Residential Design Moisture Generation Rates from table 4.3.2 in ASHRAE Standard 160-

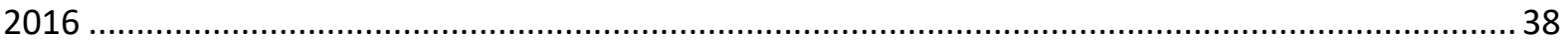

Table 9 Mould index values from the VTT Mould Index Model with corresponding descriptions of the

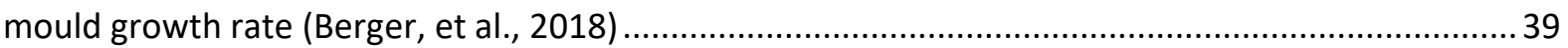

Table 10 Recommended mould sensitivity classes for various materials from table 6.1.1 in ASHRAE

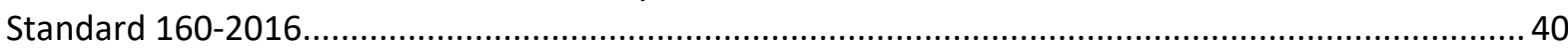

Table 11 Parameters for equation 10 and equation 11 from table 6.1.2 in ASHRAE 160-2016 ..........41

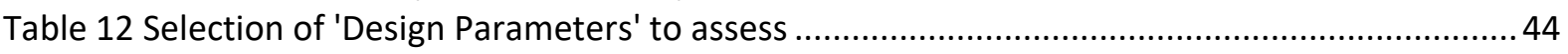

Table 13 Comments and justification regarding choice of 'Design Parameters' .................................. 45

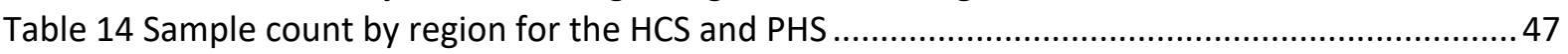

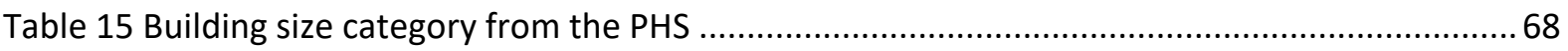

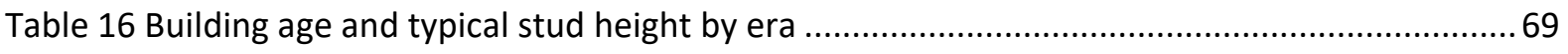




\section{List of Figures}

Figure 1 ASHRAE Standard 160 process (Authors own image)......................................... 4

Figure 2 Isoline graph illustrating the range of temperatures and relative humidities in New Zealand and the USA (Authors own image).....

Figure 3 Graph showing the variation in temperature vs relative humidity in the three New Zealand climate zones and three climate zones within the US (Authors own image) ............ 7 Figure 4 Energy use breakdown of a typical US household (left) and a typical New Zealand household (right) (Authors own image) ..................................................................... 9

Figure 5 Section through a typical New Zealand wall construction (Overton, 2019) .......... 16 Figure 6 Literature review screening process workflow (Authors own image) .................... 21 Figure 7 Relative humidity and temperature schedules used to understand the impact of transient conditions on mould growth (Johansson, et al., 2013) ..................................... 23 Figure 8 Impact of uncertainty in relative humidity values on the mould index (Glass, et al.,

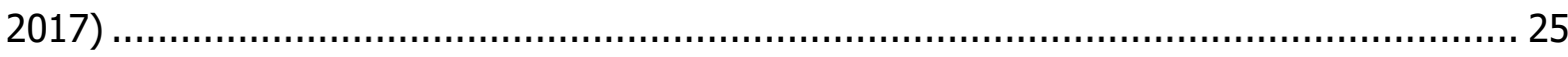

Figure 9 Process to develop measured indoor conditions for the whole house (Authors own

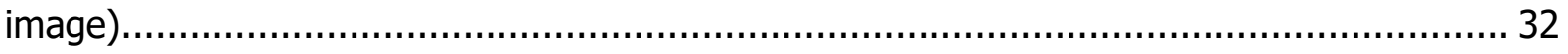

Figure 10 Hygrothermal simulation process (Authors own image).................................. 33

Figure 11 Map showing spread of houses throughout the different regions (Authors own

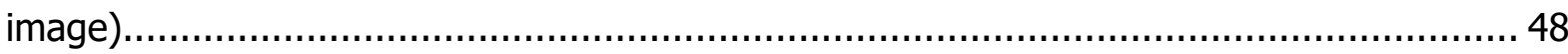

Figure 12 Example of resampling process using humidity conversion formula from Vaisala

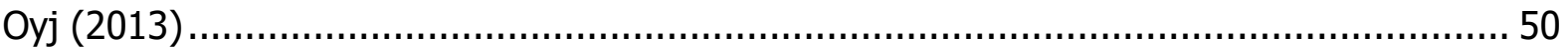

Figure 13 Indoor Design Temperature and measured indoor temperature of House 136 ... 54 Figure 14 The average difference between the Indoor Measured Temperature and the Simplified IDT across all assessed properties ............................................................. 54 Figure 15 Indoor Design Temperature and measured indoor temperature of House 125 .... 55 Figure 16 Indoor Design Temperature and measured indoor temperature of House 140 ... 56 Figure 17 The average difference between the IDT and the Measured Indoor Temperature and the average difference between the IDT with no lower limit and the Measured Indoor Temperature across all assessed properties ................................................................ 57 Figure 18 Indoor Design Humidity: Simplified Method and measured indoor relative humidity

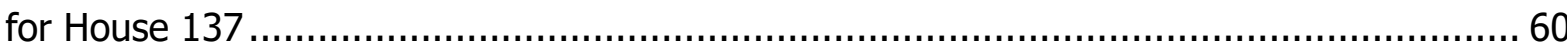
Figure 19 Indoor Design Humidity: Simplified Method and measured indoor relative humidity

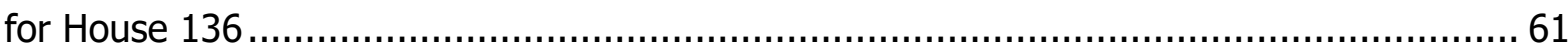
Figure 20 Indoor Design Humidity: Simplified Method and measured indoor relative humidity

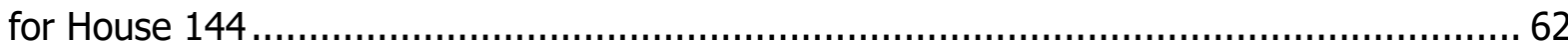

Figure 21 Indoor Design Humidity: Simplified Method and measured indoor relative humidity

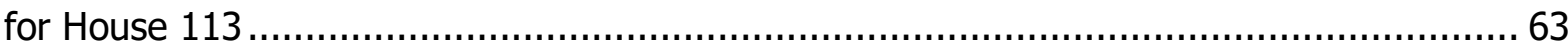
Figure 22 Indoor Design Humidity: Simplified Method and measured indoor relative humidity

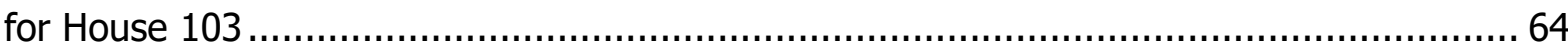
Figure 23 Indoor Design Humidity: Simplified Method and measured indoor relative humidity

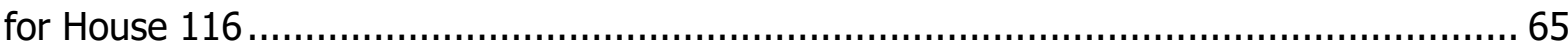

Figure 24 The average difference between the Simplified IDH and the Measured Indoor Humidity and the average difference between the Simplified IDH with no upper or lower limit and the Measured Indoor Humidity across all assessed properties. 
Figure 25 Number of occupants based on ASHRAE Standard 160 versus the number of occupants from the PHS (Authors own image)

Figure 26 Graph showing an increase in airtightness of New Zealand houses over the years

(Rupp \& McNeil, 2018)

Figure 27 Indoor Design Humidity: Intermediate Method and measured indoor relative

humidity for House 113 .

Figure 28 Indoor Design Humidity: Intermediate Method Original $\mathrm{ACH}$ and Revised $\mathrm{ACH}$ and measured indoor relative humidity for House 129.

Figure 29 Indoor Design Humidity: Intermediate Method Original ACH and Revised ACH and

measured indoor relative humidity for House 144. 75

Figure 30 Indoor Design Humidity: Intermediate Method Original ACH and Revised ACH and

measured indoor relative humidity for House 143 76

Figure 31 The average difference between the Intermediate IDH and the Measured Indoor Humidity and the average difference between the Revised ACH Intermediate IDH and the Measured Indoor Humidity across all assessed properties 76 Figure 32 The average Intermediate IDH and the average measured indoor relative humidity of all the assessed properties. 77

Figure 33 Indoor Design Humidity: Intermediate Method and measured indoor relative humidity for House ID 104

Figure 34 Indoor Design Humidity: Intermediate Method and Simplified Method, and measured indoor relative humidity for House 104

Figure 35 The average difference between the Simplified IDH and the measured indoor relative humidity and the Intermediate IDH and measured indoor relative humidity across all assessed properties.

Figure 36 Indoor Design Humidity: Intermediate Method and Simplified Method, and measured indoor relative humidity for House 143.

Figure 37 Mould index values of the three different internal conditions of House 144

Figure 38 The critical relative humidity plotted against the internal surface relative humidity

and temperature of House 148

Figure 39 Mould index values of the three different internal conditions of House $148 \ldots \ldots . .86$

Figure 40 Mould index values of the three different internal conditions of House $120 \ldots \ldots . .87$

Figure 41 The critical relative humidity plotted against the internal surface relative humidity and temperature of House 120 


\section{Chapter 1 Introduction}

\subsection{Background}

The need for accurate criteria for moisture design in residential houses is one that is an ever-pressing topic and numerous research efforts have been made to improve the accuracy of existing hygrothermal models. Whilst internal moisture and mould occurs in residential houses internationally, this issue is also one that pertains particularly to New Zealand. A Housing Conditions Survey (HCS) was undertaken in 2015 by the Building Research Association of New Zealand (BRANZ) and randomly selected a number of houses to form a representative group of the countries living conditions. The HCS identified that of the assessed properties, $46 \%$ of owner-occupied properties, and $54 \%$ of rented properties experience mould growth (White, et al., 2017). Whilst the HCS did not survey all New Zealand houses, it does suggest that the issue of mould growth is one which can greatly impact a significant number of New Zealanders.

A common method that practitioners can implement to assess mould risk is by implementing moisture analysis tools to understand the likely behaviours of moisture in various wall systems. Whilst analytical mould prediction tools are becoming more sophisticated due to rapid improvements in computer-based moisture analysis software, minimal attention is generally paid to the advancements of appropriate inputs. These inputs are required in order to effectively run these computer-based moisture simulations and have often been found to be an area in which inaccuracies commonly occur; particularly inputs in the external climate and internal conditions (TenWolde, 2008). 


\subsubsection{The New Zealand Building Code}

Excess moisture is just one area within a building that can impact the integrity of a building's performance as well as decrease the safety for the building's occupants. Internationally, building codes were established to prescribe adequate performance in a range of areas such as lighting, ventilation, and fire protection, all to ensure the safety and comfort of building occupants. Established in 1992, the New Zealand Building Code (NZBC) was one of the world's first performance-based codes and is designed to ensure that all buildings are safe, healthy, and durable for all of those who may occupy them (Ministry of Business, Innovation, and Employment, 2020). Being a performance-based code, as opposed to a prescriptive code, the NZBC stipulates how a building must perform rather than stating how it must be constructed and this is outlined through 38 technical clauses. A clause can be achieved through either an alternative solution of the use of either an;

a) Acceptable Solution: A step-by-step construction method which provides construction details and often specifies building materials, systems, or methods which should be adhered to; or a

b) Verification Method: A calculation test, laboratory test, or in-situ test which can be used to demonstrate acceptable compliance with that clause within the NZBC.

Whilst each of these 38 technical clauses set out separate objectives and functional requirements, several of them tend to work in conjunction with one another. This idea is demonstrated in Clause E3 'Internal Moisture' where it has been deemed that adequate ventilation shall be attained either naturally or mechanically and in accordance with Clause G4/AS1 (Ministry of Business, Innovation, and Employment, 2017).

Clause E3 'Internal Moisture' of the New Zealand Building Code (NZBC) was created with two key objectives in mind:

a) To safeguard people against illness, injury, or loss of amenity that could occur as a result of an accumulation of internal moisture; and

b) Protect household units and other property from damage that could be caused by internal moisture within another household unit which is in the same building.

In order to achieve these two key objectives, three functional requirements were determined. These were that a building must be constructed in such a way to avoid the likelihood of:

a) Fungal growth or other contaminants accumulating on building elements

b) Free water or overflow penetrating an adjoining house or unit 
c) Damage to building elements as a result of excess moisture

Whilst each of these functional requirements is critical demonstrate compliance with Clause E3, the topic of this research specifically looks at the first functional requirement of mitigating fungal growth.

There is no one governing voice that provides advice to occupants to minimise excess moisture and mould growth, particularly in houses built pre-NZBC. However, several agencies provide information regarding preventative actions. Government agencies and research associations such as the Minister of Business Innovation and Employment (MBIE), Housing New Zealand (HNZ), the Energy Efficiency and Conservation Authority (EECA), and the Building Research Association of New Zealand (BRANZ), generally agree on the best measures to take. The general advice for the prevention of mould is a combination of increasing insulation, heating to an appropriate level, and ventilating appropriately (BRANZ, 2018; EECA, 2017; HNZ, 2019; MBIE, 2019).

NZBC Clause E3 stipulates that occupants will determine their own methods and levels of heating, simply stating that it is typically necessary and sufficient for indoor temperatures to be $5^{\circ} \mathrm{C}$ to $7^{\circ} \mathrm{C}$ degrees above external temperatures to control and minimise condensation given that the space is ventilated appropriately (Ministry of Business, Innovation, and Employment, 2017). Whilst the advice given to occupants is based on sound research, designers and practitioners implement tools and models at a design stage to show how their design shall prevent mould growth. Mould prediction tools and models such as ASHRAE Standard 160 'Criteria for MoistureControl Design Analysis in Buildings' are then able to be implemented to provide designers with more guidance on this matter.

\subsubsection{ASHRAE Standard}

ASHRAE Standard 160 was designed and developed in North America to provide guidance on how to best design buildings with adequate moisture control features to mitigate excess moisture and mould issues within houses (ASHRAE, 2016). To use this Standard, several inputs are required which are based upon a building's typology, its construction, the climate in which it is located, and the internal conditions it experiences. Whilst the typology and the construction of the building are easily defined, inputs as complex as climate and indoor conditions are not so easily able to be constrained to one of a few general parameters.

ASHRAE Standard 160 can be broken down into two key areas, the inputs, and the outputs known as evaluation process. If all necessary inputs are known, then the initial stages of the standard which determine the inputs can be disregarded, and the outputs and analysis can be simply run. However, in an instance where the inputs are unknown, such as the internal conditions, then ASHRAE Standard 160 can be utilised to specify the inputs and conditions which are likely to occur. This process has been outlined in Figure 1. ASHRAE Standard 160 makes assumptions about building 
typologies, constructions, use of space conditioning systems, and occupant behaviour to develop these likely conditions and inputs.

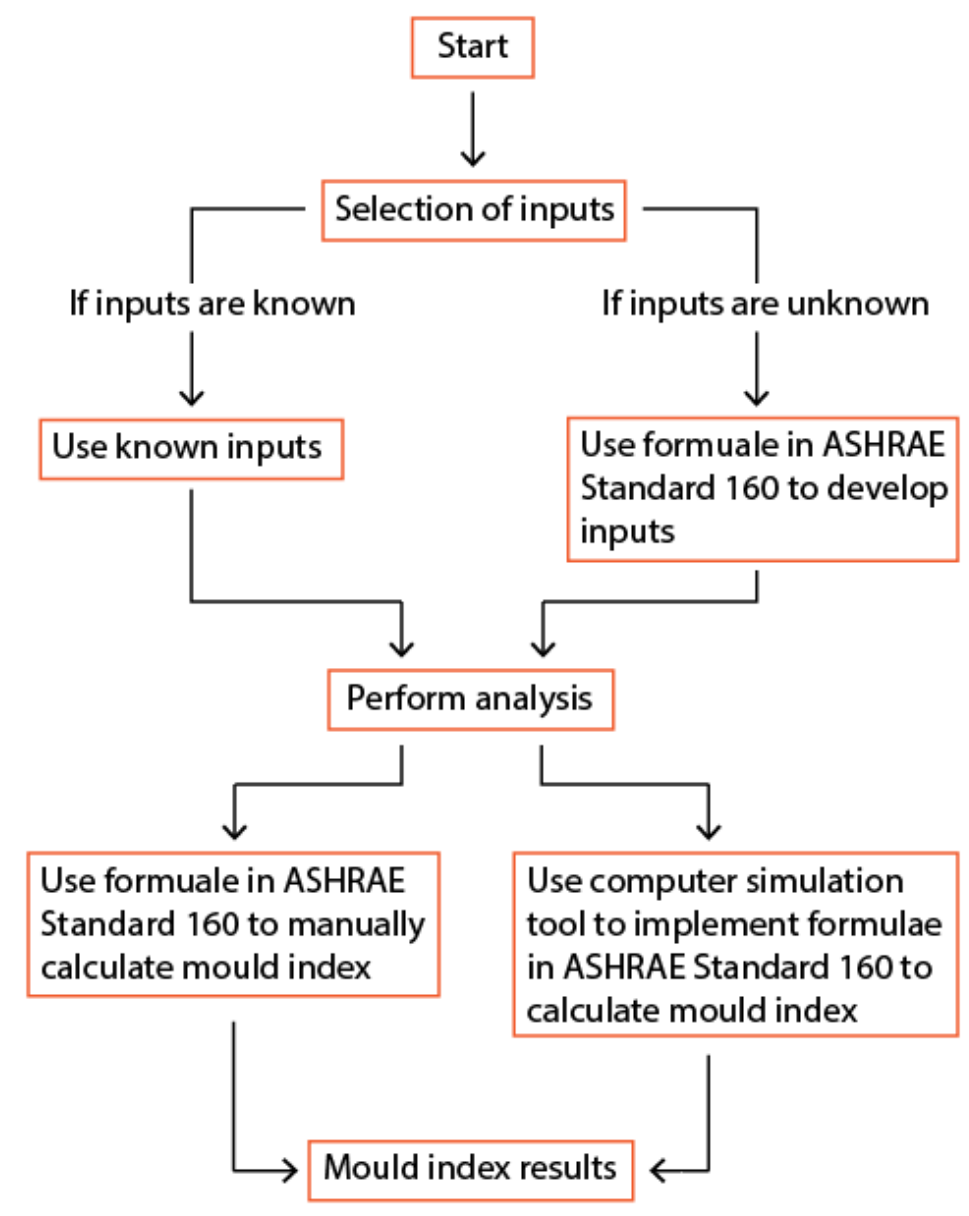

Figure 1 ASHRAE Standard 160 process (Authors own image)

Working alongside ASHRAE Standard 160 is ASHRAE Standard 90.1 'Energy Standard for Buildings Except Low-Rise Residential Buildings'in which 24 climate zones (eight climate zones each with three marine types) are applied as appropriate (ASHRAE, 2001). The United States, where this ASHRAE Standard 160 was developed, experiences 16 of these different climatic zones. Using weather files of the most typical year for each climate zone, the 16 different climate zones with the most representative US city for each of the climate zone were assessed. A study by Smith and Mago (2014) determined that the most suitable city for each climate zone was as follows: 


\begin{tabular}{ccc}
\hline Climate Zone & Type & US City \\
\hline 1A & Very hot, humid & Miami, FL \\
\hline 2A & Hot, humid & Houston, TX \\
\hline 2B & Hot, dry & Phoenix, AZ \\
\hline 3A & Warm, humid & Atlanta, GA \\
\hline 3B - Coast & Warm, marine & Los Angeles, CA \\
\hline 3B & Warm, dry & Las Vega, NV \\
\hline 3C & Warm, marine & San Francisco, CA \\
\hline 4A & Mild, humid & Baltimore, MD \\
\hline 4B & Mild, dry & Albuquerque, NM \\
\hline 4C & Mild, marine & Seattle, WA \\
\hline 5A & Cold, humid & Chicago, IL \\
\hline 5B & Cold, dry & Boulder, CO \\
\hline 6A & Cold, humid & Minneapolis, MN \\
\hline 6B & Cold, dry & Helena, MT \\
\hline 7 & Very cold & Duluth, MN \\
\hline 8 & Sub-Arctic & Fairbanks, AK \\
\hline
\end{tabular}

Table 1 US climate zones and the corresponding representative city (Smith \& Mago, 2014)

An isoline graph of the environmental conditions of each of the climate zones that apply to the US is shown in Figure 2 and has been compared to the environmental conditions of a city within each of the three climate zones that New Zealand experiences. Figure 2 was created by plotting the temperature against the relative humidity of each climate zone throughout the year to identify the range of environmental conditions that were experienced. This graph demonstrates that the US experiences a much larger range of temperature and relative humidity than New Zealand. The average air temperature in the US ranges from $-45.6^{\circ} \mathrm{C}$ to $46.1^{\circ} \mathrm{C}$ whilst the average relative humidity ranges from $2 \%$ to $100 \%$. This wide spread of both air temperature and relative humidity explains why the US is able to be broken down into 16 different climate zones, it does raise the question of how one single standard (ASHRAE Standard 160) is able to cater to such a wide variety of climates and in turn how this would relate to the New Zealand climate? 


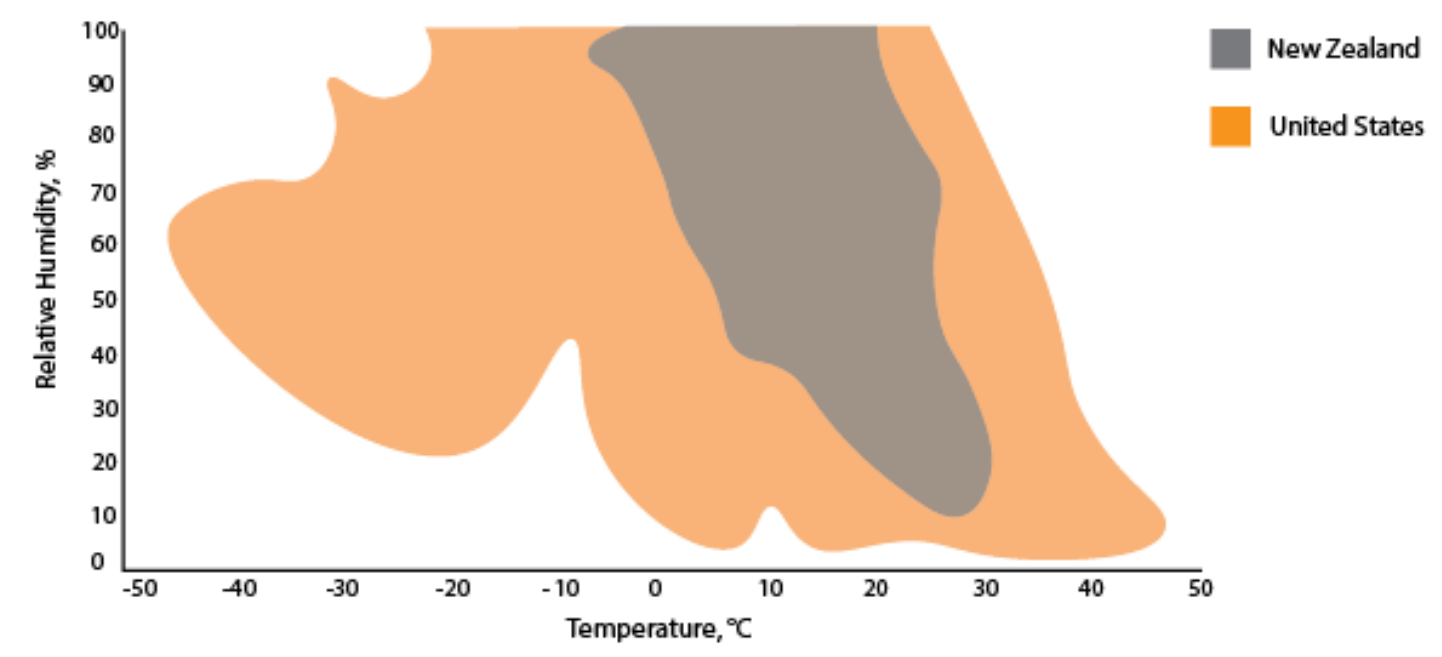

Figure 2 Isoline graph illustrating the range of temperatures and relative humidities in New Zealand and the USA (Authors own image)

NZS 4218:2009 'Energy Efficiency - Housing and Small Building Envelope', defined three climate zones within New Zealand which have been determined using climate data, energy use in buildings as well as taking into consideration territorial authority boundaries (Standards New Zealand, 2009). However, in contrast to this ASHRAE Standard 90.1 classifies New Zealand as one climate zone - climate zone 4, however does not specify what marine type New Zealand fits (ASHRAE, 2001). The three different mild, marine types of climate zone 4 are represented by the cities Baltimore (humid), Albuquerque (dry), and Seattle (marine). When plotting them against the weather files of three New Zealand cities, each representing the three climate zones of New Zealand, it is clear that when looking at the average trend lines, climate zone 4C (mild marine) is the best fit (Figure 3). 


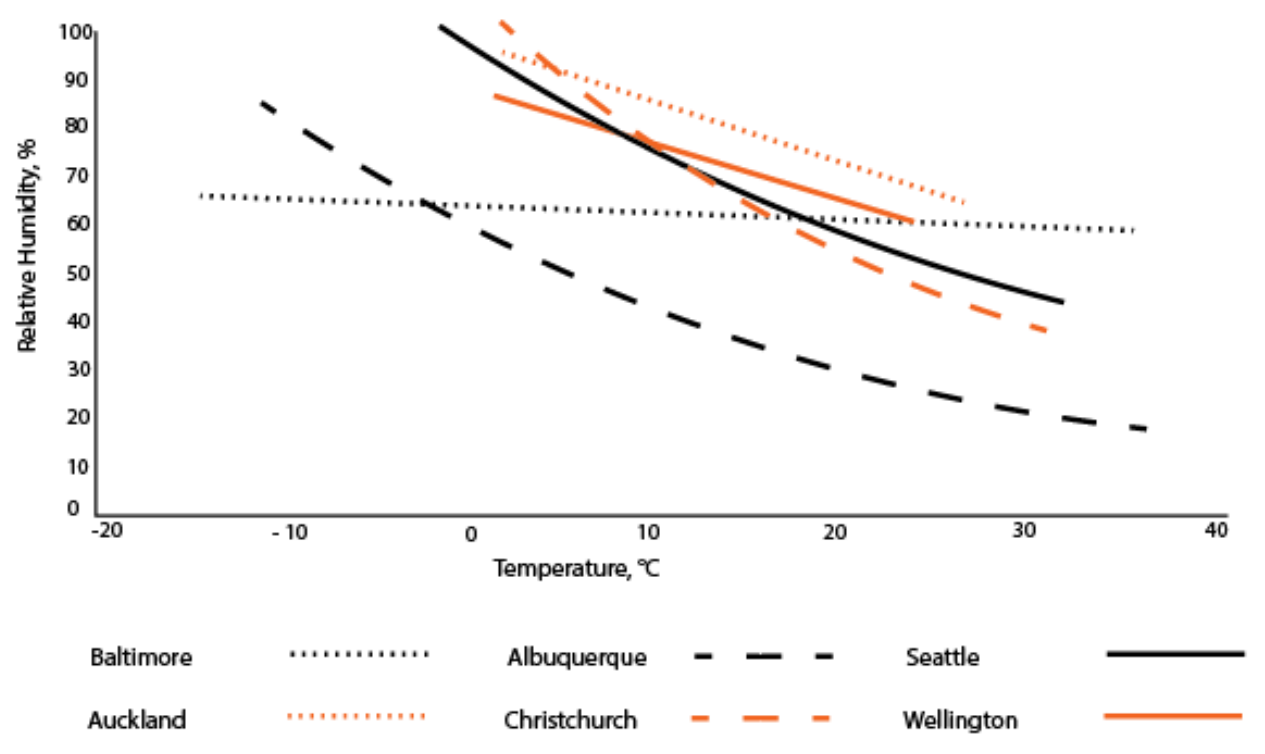

Figure 3 Graph showing the variation in temperature vs relative humidity in the three New Zealand climate zones and three climate zones within the US (Authors own image)

As New Zealand can be categorised into one of the 16 different climate zones, it is reasonable to assume that its external climate therefore falls under the scope of ASHRAE Standard 160. However, whilst Figure 3 shows that the US cities encompassed under climate zone 4 saw an average variance of approximately $50^{\circ} \mathrm{C}$ throughout the year, the New Zealand climate sees an average air temperature variance of $30^{\circ} \mathrm{C}$ throughout the year. This means that the New Zealand climate is much more consistent than that of the US when considering air temperature. Additionally, when looking at the range in relative humidity between Baltimore, Albuquerque, and Seattle and Auckland, Christchurch, and Wellington it shows that again the New Zealand climate is far more consistent. The US cities have a wide range of average relative humidities between $20 \%$ and $100 \%$ whilst New Zealand average relative humidities between $40 \%$ and $100 \%$.

The most significant finding from this initial analysis of both the US, in particular climate zone 4, and the New Zealand climate is that the US experiences a significant range in both air temperature and relative humidities throughout the year, whilst New Zealand comparatively is much milder and more consistent. Whilst both the variety in climates experienced by the US and New Zealand do fall under the scope of ASHRAE Standard 160, the question of precision regarding applicability to the New Zealand climate is raised. If we think of the US climate as the overall target and the New Zealand climate as the bullseye, how effectively can ASHRAE Standard 160 hit the bullseye when the overall target is so large?

The two key inputs where discrepancies may arise due to oversimplification and generalisations were the climate and the internal conditions (TenWolde, 2008). Internal conditions, as specified by ASHRAE Standard 160, are the indoor temperature 
and indoor humidity, with other factors such as moisture generation, ventilation, and heating and cooling being included within these (ASHRAE, 2016). Temperature and relative humidity are greatly impacted by occupant behaviour such as the presence and use of a space conditioning system, opening and closing of windows, and type of activities undertaken in the space such as air-drying clothes.

\subsubsection{The Housing Conditions Survey}

The Housing Conditions Survey (HCS), last undertaken by BRANZ in 2015, undertook a comprehensive survey of New Zealand's housing stock and obtained data on building characteristics and living conditions. One significant element was the presence and use of heating. It was found that nearly all of the houses had some form of heating however it found that during winter $5 \%$ of the houses did not heat their living spaces and almost half did not usually heat occupied bedrooms (White $\&$ Jones, 2017). It was concluded that the presence of a heating appliance does not necessarily equate to its use and that a number of factors contribute to heating habits such as affordability, need, and preferences. White and Jones (2017) also noted that without any heating system it was unlikely that the indoor temperature of these spaces would meet the World Health Organisation minimum of $18^{\circ} \mathrm{C}$.

The HCS also showed that there is a gap in housing conditions between owneroccupied and rental properties, with owner-occupied properties tending to be better maintained than rentals. The poorer conditions of the rental properties were most evident when looking at the presence of mould in these spaces with $46 \%$ of the assessed owner-occupied properties and $54 \%$ of the assessed rented properties experiencing mould growth (White, et al., 2017). However, when looking at the data gathered regarding the presence of a heating system, $1 \%$ of owner-occupied properties and $2 \%$ of rental properties did not have any form of heating (White \& Jones, 2017). This therefore indicates that the type of tenure does not dictate the presence of heater as a majority of the properties have some form of heating. However, the type of tenure is potentially critical to consider when taking into consideration occupant behaviour and how certain actions may increase the risk of mould growth.

As mentioned in White and Jones (2017) heating habits within New Zealand are greatly influenced by several factors such as affordability, need, and preferences. Occupant behaviour is strong driver of all three of these factors and there is potential for these preferences to differ from US occupants to New Zealand occupants. Using data gathered from the US Energy Information Administration (EIA) Residential Energy Consumption Survey (RECS) and the BRANZ Household Energy End-use Project (HEEP) a breakdown of the energy uses in US and New Zealand houses in 2009 and 2010 respectively is presented in Figure 4. 

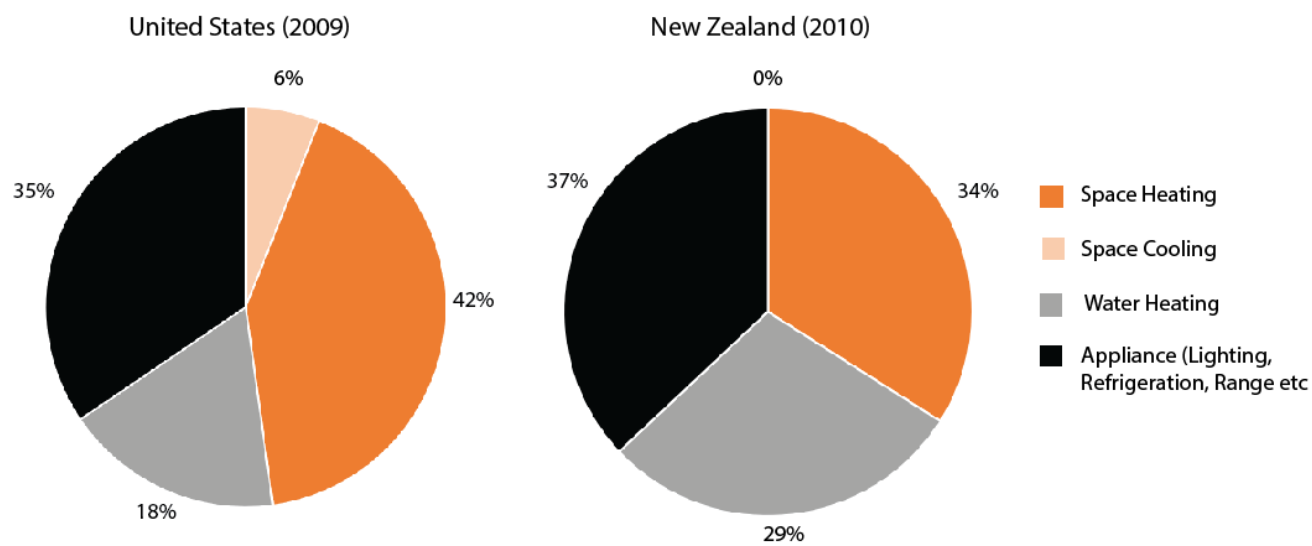

Figure 4 Energy use breakdown of a typical US household (left) and a typical New Zealand household (right) (Authors own image)

From the graphs presented in Figure 4, a discrepancy is evident, most notably in the use of energy to condition a space. When looking at the energy use dedicated to space conditioning, New Zealand houses typical expend $34 \%$ of total energy use in this area, whilst US houses use $48 \%$, with $6 \%$ of this coming from cooling, something of which is rarely implemented in New Zealand houses.

Both US and New Zealand houses implement heating systems however, from the data shown, the US tend to expend more energy use (proportionality $8 \%$ more) on heating than New Zealand houses. When considering both the air conditioning and the space heating, US houses use proportionally more energy to condition their space than those in New Zealand. Whilst it is likely this comes as a result of a reaction to the outdoor climate and the more variant conditions that US experiences, it does also allude to the fact that these systems are being used more frequently in the US and thus may also reflect a difference in personal preference to climate between New Zealand and US occupants.

From the above analysis and background, occupancy behaviour varies from house to house in New Zealand and even more so when comparing New Zealand and the US. The critical question arises that if ASHRAE Standard 160 has made assumptions on the climate and of the behaviour and preference of US occupants and, specifically regarding space conditioning, how transferable are these assumptions to a New Zealand context?

\subsection{Problem Statement}

The following is a summary of the points that were discussed in Section 1.1:

1. Based upon findings from the HCS, mould is a prevalent issue in New Zealand houses and Clause E3 of the NZBC aims to mitigate internal moisture and subsequent mould issues that arise in new houses. 
2. ASHRAE Standard 160 is a common method implemented by building practitioners at the design phase to understand the likely behaviours of moisture in various wall systems.

3. ASHRAE Standard 160 can be implemented into a wide variety of climates

4. Using the international climate zones specified in ASHRAE Standard 90.1, the US is subject to 16 of these climate zones whilst New Zealand can be represented by only one. As a result, it is evident that the New Zealand climate does not vary as much as the US in terms of temperature and relative humidity.

5. ASHRAE Standard 160 considers several inputs which are reliant on occupant behaviour such as space conditioning. Based on energy consumption data there are differences in how New Zealanders and Americans use their homes, specifically when looking at space heating.

Based upon the above statements the following problem and gap in knowledge is identified:

Problem:

ASHRAE Standard 160 was developed in North America and as a result, assumptions on climate and occupant user behaviours have been used to set various parameters. However, it is unknown how reflective these assumptions are of a New Zealand context and how significant these assumptions are in impacting the results produced from ASHRAE Standard 160.

\section{Gap in knowledge:}

It is unknown the extent to which the assumption made in ASHRAE Standard 160 reflect the reality of housing conditions in New Zealand and in turn how greatly these discrepancies in these housing conditions impact the outputs and mould predictions developed by ASHRAE Standard 160.

Identifying the discrepancies between measured data and the predicted inputs that ASHRAE Standard 160 suggest may help in addressing this gap in knowledge. In turn, the identification of these discrepancies may aid in improving the suitability of ASHRAE Standard 160 within a New Zealand context.

\subsection{Research Question}

Having identified the gap in knowledge the following research question is able to be established:

Can ASHRAE Standard 160 be used in New Zealand, considering the assumptions it makes, to predict mould growth? How do the results produced by ASHRAE Standard 160 align with measured data? 


\subsection{Research Aims and Objectives}

The 2015 HCS found that approximately $50 \%$ of the assessed houses experienced mould growth, suggesting that this is a prevalent issue within New Zealand and one which can not only adversely affect the building but also the occupant's health. Clause E3 of the NZBC has been set out to mitigate excess moisture issues which may result in mould growth, however, there is currently no prescribed method of which designer can use to demonstrate compliance. ASHRAE Standard 160 is a standard that aims to provide guidance on how to best design buildings to mitigate moisture and mould issues. In the scenario in which the required inputs to run the analysis through ASHRAE Standard 160 are unknown, this standard provides guidance on how to determine the internal conditions and inputs. This guidance is based upon assumptions on a building's construction, the external climate, and the likely behaviour of the occupants. There are several differences between the climate of the US and New Zealand and how occupants use their houses, specifically heating regimes. Consequently, the question that arises is how transferable are these assumptions to a New Zealand context and therefore how applicable is this standard within New Zealand?

The aim of this thesis is to identify the suitability of the implementation of ASHRAE Standard 160, and whether the assumptions made within the standard, in regards to the indoor conditions and the occupant behaviour, reflect the reality of New Zealand houses.

The hypothesis is that several of the assumptions made within ASHRAE Standard 160 will not reflect the reality of New Zealand houses. Consequently, the internal conditions under ASHRAE Standard 160 will not reflect the actual internal conditions of these houses and thus discrepancies shall occur. It is thought that these discrepancies may have an impact of the predictions of mould growth and in order to appropriately apply ASHRAE Standard 160, several of the assumptions may need to be altered.

\subsubsection{Research Objectives}

To achieve the overall aim of this research, the following research objectives have been established:

1. Identify existing research on various mould prediction tools, the assumptions that are required within these tools, and how discrepancies arise because of these assumptions.

2. Apply ASHRAE Standard 160 across a number of case study houses, noting the assumptions that are made to apply this standard. Compare the conditions specified by ASHRAE Standard 160 and the recorded in-situ conditions and identify any discrepancies between the two datasets.

3. Utilising the conclusions drawn from the objective 1 , understand whether the discrepancies between the two datasets can be attributed to the assumption made when applying ASHRAE Standard 160. 
4. Understand how the mould prediction results may be impacted due to any potential discrepancies that have been identified between the theoretical and in-situ internal conditions.

5. Understand what this means for the application of ASHRAE Standard 160 in a New Zealand context.

\subsection{Thesis Outline}

The following section outlines this thesis and what is discussed in each of the sections.

Chapter Two: Outlines a systematic literature review process and presents the findings from this literature review.

Chapter Three: Presents the methodology that was used to undertake this research and specifies what information is required at various stages of this research.

Chapter Four: Introduces moisture analysis and mould predictions tools and outline the process of implementing ASHRAE Standard 160 and the VTT Mould Index Model; two tools which are assessed in this research. This chapter also outlines which 'Design Parameters' of ASHRAE Standard 160 are to be analysed and provides justification as to why particular parameters were either included or excluded.

Chapter Five: Discusses the process of gathering the relevant data from the Pilot Housing Survey in order to undertake an appropriate analysis. The data that is required to be gathered has been outlined in Chapter Four. This chapter also discusses the process of cleaning the data and excluding any irrelevant data and how to determine a 'typical' measured indoor conditions dataset for each house.

Chapter Six: Uses the data gathered in Chapter Five to implement the Indoor Design Temperature formula from ASHRAE Standard 160. The Indoor Design Temperature that is produced is then compared to the measured indoor temperature and discrepancies are identified, analysed, and discussed.

Chapter Seven: Uses the data gathered in Chapter Five to implement the Indoor Design Humidity Simplified Method formula from ASHRAE Standard 160. The Indoor Design Humidity that is produced is then compared to the measured indoor relative humidity from the PHS and discrepancies are identified, analysed, and discussed.

Chapter Eight: Discusses how the impact of increasing the number of variables in a model and raises the idea of altering these variables to better reflect a New Zealand context. This chapter then goes on to use the data gathered in Chapter Five to implement the Indoor Design Humidity Intermediate Method formula from ASHRAE Standard 160. The Indoor Design Humidity that is produced is then compared to the measured indoor relative humidity and discrepancies are identified, analysed, and discussed.

Chapter Nine: Using the data gathered from the Pilot Housing Survey to create constructions of various houses within the survey and the internal conditions gathered 
from ASHRAE Standard 160 and discussed in Chapter Seven, Eight, and Nine. A comparative mould index analysis was undertaken. This analysis compared three different internal condition scenarios within the same house to understand how the different conditions that came as a result of ASHRAE Standard 160, impacted the predictions of mould growth.

Chapter Ten: Discussed how the major findings of the research and the meanings behind these findings. This chapter also outlines how the findings from this research relate to work others have undertaken as well as the limitations to these findings.

Chapter Eleven: States the key conclusions of this research and discussed the implications of these conclusions on the research question and any suggested further research. 


\section{Chapter 2 Literature Review}

\subsection{A systematic Approach}

For this particular literature review, it was determined that a systematic approach (Boland, et al., 2017), was the most applicable. A systematic literature review has many advantages, most notably that this method can greatly reduce the risk of bias due to its strict adherence to a set procedure and methodology. This adherence to a systematic literature review structure typically enables conclusions to be drawn that tend to be less biased than a narrative review (O'Brien \& McGuckin, 2019). It is worth noting that whilst it has been identified that a systematic approach can greatly reduce the risk of bias; it does not completely eradicate this risk. A systematic literature review requires the application of inclusion and exclusion criteria which in its own nature are predisposed to a level of bias. For this reason, to further mitigate any bias, all relevant research wherever possible should be identified and assessed using a standardised procedure (O'Brien \& McGuckin, 2019).

Boland, et al., 2017, identified an eight-step method to undertake an effective systematic literature review. The steps are as follows:

1. Perform a scoping search, identify the review question, and write a protocol: A scoping search is used to identify background research that will aid in identifying and refining research objectives. The research objectives shall also aid in setting inclusion and exclusion criteria as well as establishing a protocol that enables an approach to be set. 
2. Literature searching: Using identified key terms, papers relating to the review question can be identified from relevant databases.

3. Screening titles and abstracts: This step entails reviewing all the titles and abstracts of the papers identified in the previous step and culling and discarding any papers that are irrelevant to the research objectives. The most relevant papers remain.

4. Obtaining papers: From the remaining papers full texts shall be obtained and any full papers that cannot be obtained due to availability shall be excluded from this review.

5. Selecting full-text papers: At this stage, the inclusion criteria that were specified in the primary stages are applied and any papers which do not relate to these inclusion criteria are excluded from this review.

6. Quality assessment: The remaining papers are assessed for their quality using an appropriate quality assessment tool. If it is deemed that any paper does not meet this quality assessment, it shall be excluded from this review. Additionally, if further barriers occur such as a paper being published in a foreign language, these papers shall be acknowledged but excluded from this review.

7. Data extraction: The remaining papers are read in full and any relevant information pertaining to the review question is extracted and summarised in a clear and organised format. At this stage, any user-added papers from the initial scoping search and snowball references are added (after having gone through the quality assessment process).

8. Analysis and write up: Any relevant information and data gathered from reading the full papers shall be analysed to understand how it applies to the review question. The write up involves identifying and discussing the relevance of the gathered information, concluding, and disseminating findings.

\subsection{Initial Scoping Search}

Whilst developing this research proposal and undertaking an initial scoping search, discussions with industry professionals directed the focus of this research towards a research paper undertaken by BRANZ in 2019. This research paper set out to consider how hygrothermal modelling would be able to be used in conjunction with mould assessment tools to form a basis for which practitioners can demonstrate the compliance of a wall system under the NZBC (Overton, 2019). Overton, 2019, identified that within New Zealand, a third of failed residential inspections can be attributed to moisture issues such as indoor moisture and rainwater penetrations into the building envelope.

The NZBC is a performance-based code, that is, the code states how a building must perform, and this may be achieved by a practitioner through either implementing an Acceptable Solution or a Verification Method. Clause E3 within the NZBC emphasises mitigating moisture issues within a building, however, there is no recognised method of which practitioners can implement to demonstrate that they comply (Ministry of Business, Innovation, and Employment, 2017). Historically, New Zealand residential buildings have been compromised of external walling systems such as the one shown 
in Figure 5, and as a result of there being little evidence to show any systematic issues with this walling system, compliance is often demonstrated via historic use (Overton, 2019).

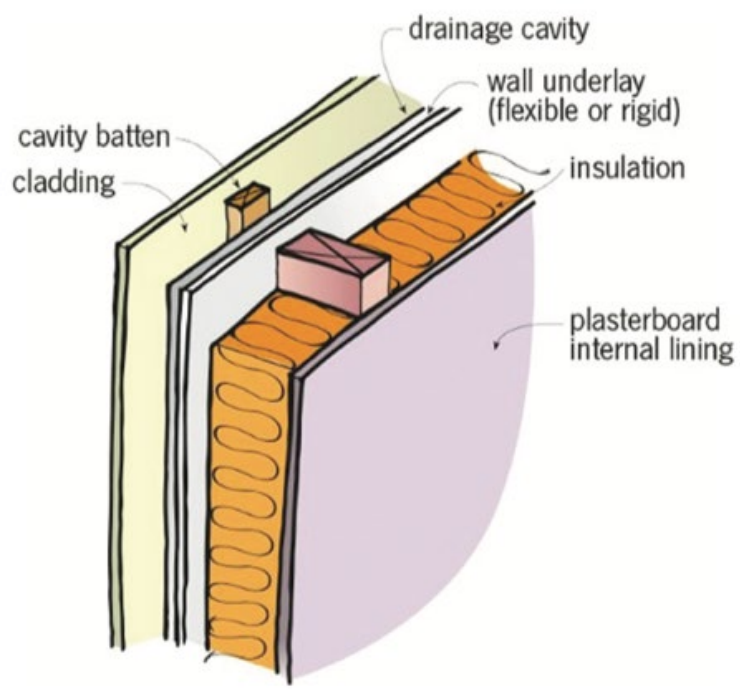

Figure 5 Section through a typical New Zealand wall construction (Overton, 2019)

When looking to assess whether a wall system is prone to condensation, dew point calculation such as the Glaser method and ASHRAE profile method can be implemented to ascertain whether condensation would likely occur. Whilst these two methods vary slightly, they both essentially look at the vapour pressure profiles and steady-state temperatures through a structure and determine whether the vapour pressure is likely to exceed the saturation vapour pressure at a particular point. If this occurs, condensation will occur and thus the structure may be deemed as unacceptable in terms of moisture issues (ASHRAE, 2009). In addition to vapour pressure profiles and steady-state temperatures, these methods both utilise indoor and outdoor conditions which are assumed values, which are often under contention, and also vary between the two models. Overton, 2019, suggested that there is a need for an assessment method that relies less upon assumptions and correlates more with field experience.

Through a series of experiments analysing various wall systems, Overton, 2019 identified discrepancies between these two models. Using the 2009 ASHRAE 160 model which uses an assumed relative humidity of $80 \%$, only one of the wall systems would pass. However, when implementing the VTT mould index criteria, with an assumed relative humidity of $70 \%$, all but one of the wall systems would pass. Therefore, according to the ASHRAE 160 model, a majority of New Zealand houses should have a degree of mould growth as a result of significant internal moisture issues. However, according to the statistics on failed residential building inspections, we know this to not be true (Overton, 2019). Overton, 2019, begins to establish the discrepancies between the different models as well as begins to look at how these could be utilised to establish a verification method for Clause E3 of the NZBC. This research aims to carry on from the initial conclusions in Overton 2019 and further analyse the accuracies 
or inaccuracies of theoretical models. By utilising measured data an additional layer of analysis can be examined which identifies discrepancies between the in-situ internal conditions we see in New Zealand houses and the predicted internal conditions through using theoretical models.

\subsection{Identification of Review Question}

Boland, et al., (2017) describe using a PICO table and the research question, and research objectives to establish a review question that can then be broken down into inclusion and exclusion criteria. These inclusion and exclusion criteria can be used to gather relevant resources. The goal of the literature review is not to answer the research question but rather to gather sufficient relevant information to aid in developing background knowledge and a methodology that can be implemented to answer the research question. Therefore, this literature review aims to understand different methods that can be used to assess the various parameters within a mould prediction model. Understanding this will aid in creating a methodology that can be implemented into this research and identifying various background studies to support this research.

A review question aids in this process by focusing the scope of the research into this specific area. The information presented in Table 2 is a breakdown of the four relevant areas that form review questions: population, intervention, comparator, and outcome.

\begin{tabular}{lll}
\hline P & Population & $\begin{array}{l}\text { Assumed inputs which have been used to simplified mould } \\
\text { prediction models such as relative humidity and temperature. }\end{array}$ \\
\hline I & Intervention & $\begin{array}{l}\text { The impact of simplification methods of mould prediction tools } \\
\text { on the predicated outputs. }\end{array}$ \\
\hline C & Comparator & $\begin{array}{l}\text { The different inputs for various mould prediction tools and the } \\
\text { assumptions that are made when implementing these inputs. }\end{array}$ \\
\hline O & Outcome & $\begin{array}{l}\text { Identify how assumptions made when implementing mould } \\
\text { prediction tools to develop particular conditions, differ from the } \\
\text { in-situ conditions. }\end{array}$ \\
\hline
\end{tabular}

Table 2 PICO chart analysis

\subsection{Review Question}

To achieve the outcome stipulated in Table 2, a review question can be developed. This review question will dictate the inclusion and exclusion criteria for the literature review and aim to provide both qualitative and quantitative data. The review question is:

What are the common assumptions regarding conditions made when implementing mould prediction models? How do these assumptions contribute to differences in the specified conditions in comparison to the in-situ conditions? 


\subsection{Inclusion and Exclusion Criteria}

Irrespective of whether the previously defined review questions (2.4) are seeking to find qualitative or quantitative data, it is vital to implement some form of inclusion and exclusion criteria (Boland, et al., 2017). Whilst considering the review question, studies shall be included or excluded based on the following criteria:

\section{Studies will be included if they:}

a) Are published in English or have an English language abstract Whilst limiting resources to those published in English does bring up the potential for a language bias within the study is it to be noted that whilst undertaking the initial scoping search it was found that very few resources were not in English. On the occasion that a resource was published in a different language, many of these had been translated into English.

\section{b) Report data that is unsuccessful}

To avoid publication bias resources shall be considered even if they report unsuccessful data. These types of resources are generally considered grey literature as they often go unpublished or are limited to conference proceedings.

\section{Studies will be excluded if they:}

a) Compare one mould prediction model to another model prediction model.

Resources that compare one model to another shall be excluded because these are comparing the process of models and assessing their accuracy to another model as opposed to assessing the types of simplification and the impact on predictions, which is the aim of this literature review.

b) Pertain to the impact of mould on occupant health.

It is well known that mould has a negative impact on occupants' health in a variety of ways and whilst this is important to remember, this research does not aim to look at the immediate impact on occupants. Therefore, any resources that are directed towards medical studies in this area shall be excluded.

\section{Caution will be taken when identifying studies that:}

a) Report information on outdated mould prediction models which has since been amended or surpassed, such as ASHRAE 160:2009.

These types of studies shall be utilised to examine the methodology and assessment methods, however, specific details regarding the input values which have been simplified shall not be noted as this information no longer pertains to the most recent version of the mould prediction model. 


\section{b) Implement a methodology which requires the gathering of data over a prolonged period.}

Studies that implement an assessment methodology that requires data to be gathered over a prolonged period shall be excluded. This is due to the limitations and time constraints of this research and as a result, this type of methodology would not be able to be implemented into this study.

\subsection{Searching Strategy and Literature Searching}

Having defined the review questions and implemented inclusion and exclusion criteria, a searching strategy can be developed which allows for relevant information to be gathered. Boland et al, 2017 identify four key steps to undertaking a literature search.

1. Consider the various types of information and literature available.

2. Identify the specific databases that will aid in gathering relevant literature.

3. Identify the key search terms to be used.

4. Search databases and gather relevant resources.

Two different types of literature can be used in this literature review; published literature and grey literature. Published literature includes journal articles, commercially published reports, and academic books whilst grey literature includes conference proceedings, dissertations or theses, and legislation. For this literature review, both published and grey literature resources shall be used to ensure that a broader scope of information is examined. The benefits of using published literature are that this type of literature is generally simple to locate and are systematically examined as well as often being peer-reviewed. Utilising grey literature, which may be peer reviewed, reduces the risk of publication bias and allows for the literature search to identify unpublished work or ongoing studies which can often be the most up to date research.

To examine both published and grey literature six databases were used; Google Scholar, ProQuest, Scopus, Science Direct, Web of Science, and SAGE Journals. It was also important to ensure that the databases gave full access to the texts. Table 3 summarises the relevance of each of the six databases.

\begin{tabular}{lcccl}
\hline Database & $\begin{array}{c}\text { Grey } \\
\text { literature }\end{array}$ & $\begin{array}{c}\text { Published } \\
\text { literature }\end{array}$ & $\begin{array}{c}\text { Full } \\
\text { access }\end{array}$ & Discipline \\
\hline Google Scholar & $\checkmark$ & $\checkmark$ & $\checkmark$ & Multidisciplinary \\
\hline ProQuest & $\checkmark$ & $\checkmark$ & $\checkmark$ & Multidisciplinary \\
\hline Scopus & & $\checkmark$ & $\checkmark$ & Multidisciplinary \\
\hline Science Direct & & $\checkmark$ & $\checkmark$ & Science \\
\hline SAGE Journals & & $\checkmark$ & $\checkmark$ & Science \\
\hline
\end{tabular}

Table 3 Literature review database summary 
Using the above databases, key search terms shall be used to gather relevant information. Whilst undertaking the initial scoping search, key search terms began to become evident. Whilst this research is looking specifically at mould within residential spaces, the term hygrothermal is frequently used when discussing this area. The term hygrothermal pertains to the movement of heat and moisture within a building, an occurrence that acts as a catalyst for mould growth. Considerations in Variations in American and British English were also identified in the initial scoping search when discussing "mould" or "mold" therefore this became a boolean search term to ensure that resources were found regardless of the authors choice of English. Lastly, the initial scoping search identified that the terms "mould prediction tool" and "mould prediction model" are used interchangeably. Therefore, the key search terms that shall be used are:

1. "Mould OR Mold" AND "Assessment OR Performance" AND "Prediction Model"

2. "Hygrothermal" AND "Assessment OR Performance" AND "Prediction Model"

3. "Hygrothermal" AND "Assessment OR Performance" AND "Mould OR Mold"

4. "Mould OR Mold" AND "Assessment OR Performance" AND "Prediction Tool"

5. "Hygrothermal" AND "Assessment OR Performance" AND "Prediction Tool"

Using the above search terms and the databases identified in Table 3, the following search results were produced, shown in Table 4. Google Scholar produced the most results across all the search, this was thought to be due to Google Scholar gathering results from a number of databases. Having produced the search results, the titles with relevant ones being extracted. This process resulted in 97 papers applying the screening papers process which has been outlined in Figure 6 .

\begin{tabular}{lccccc}
\hline \multirow{2}{*}{ Database } & \multicolumn{5}{c}{ Search term and number of results } \\
\cline { 2 - 6 } & $\mathbf{1}$ & $\mathbf{2}$ & $\mathbf{3}$ & $\mathbf{4}$ & $\mathbf{5}$ \\
\hline Google Scholar & 9180 & 612 & 770 & 1070 & 75 \\
\hline ProQuest & 397 & 14 & 8 & 319 & 4 \\
\hline Scopus & 16 & 9 & 173 & 2 & 1 \\
\hline Science Direct & 8 & 92 & 12 & 124 & 96 \\
\hline SAGE Journals & 140 & 6 & 145 & 13 & 2 \\
\hline
\end{tabular}

Table 4 Search results from different search terms using various databases 


\subsection{Screening Papers}

Having undertaken the database searches the process of screening the papers as identified in Boland et al, 2017 is implemented and has been summarised in the flowchart shown below in Figure 6 .

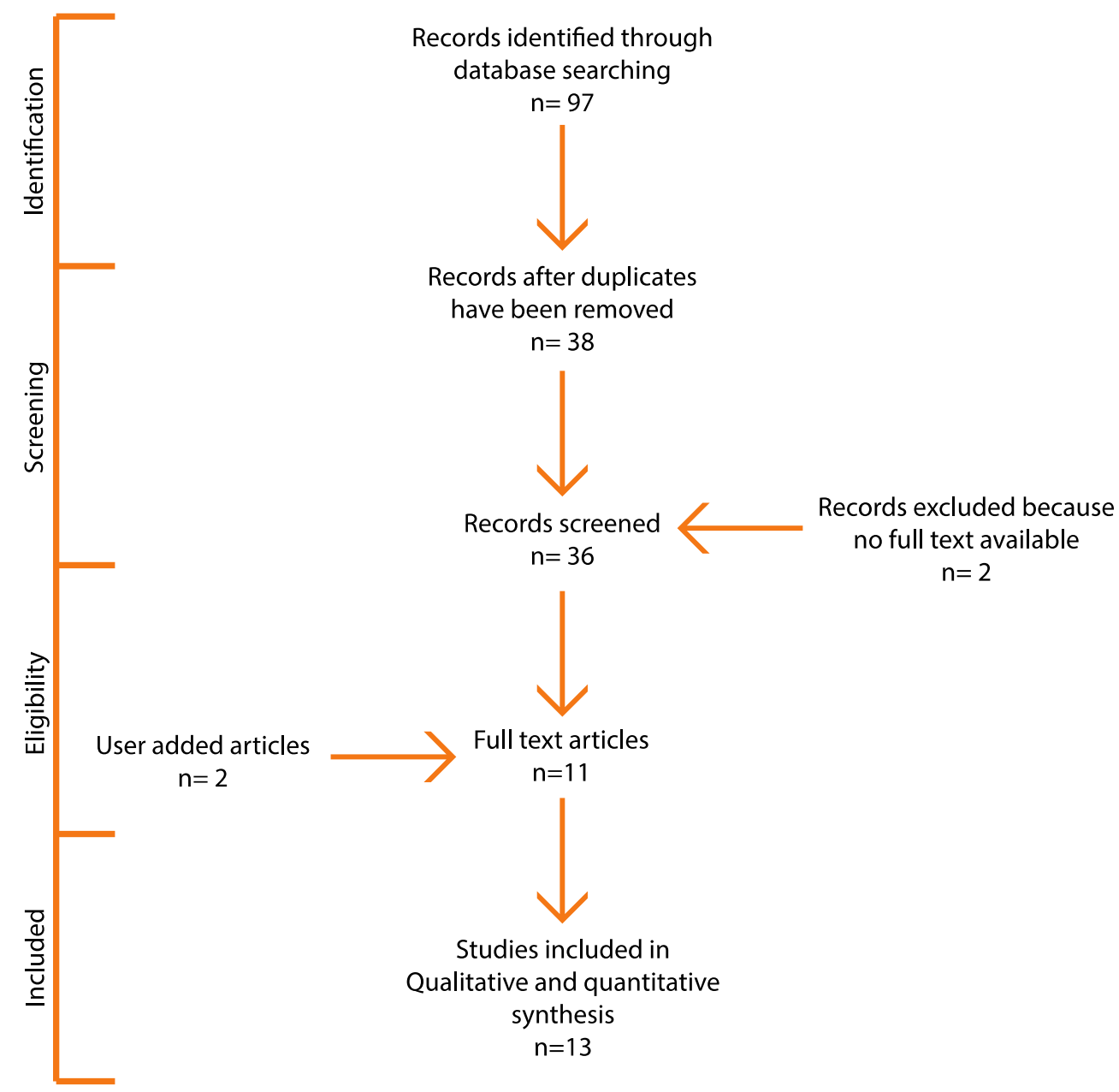

Figure 6 Literature review screening process workflow (Authors own image)

The process of screening the article required firstly reading the abstract of the article and applying a quality assessment process. The quality assessment process ensured that each article that was selected would provide enough relevant information and the information that was provided was trustworthy. There were three key criteria in order for an article to pass the screening process:

1. The article discusses a mould growth tool and the assumptions and discrepancies of this tool.

2. The article comes from a reputable academic source e.g. journal article or conference proceeding, not information from a personal blog.

3. The article did not contain any of the exclusion criteria outlined in section 2.5 
Having applied the quality assessment process, the full articles were read, and any further papers were excluded, at this stage two articles were manually added. These two articles did not appear in the initial search of databases as they are not published articles and are not publicly available. They did both pass the quality assessment process as despite not being yet published, they were undertaken by or under the guidance of BRANZ, a reputable research association.

\subsection{Review and Discussion of Literature}

Whilst numerous mould prediction models can be used to assess mould risk within building components, they are generally able to be categorised into one of two types; basic prediction parameters models or in-depth deterministic models. Basic prediction parameters use simplistic methods, such as time-of-wetness or Johansson's indices which take into consideration the surface relative humidity, surface temperature, and the duration of exposure to unfavourable conditions. In contrast, the more in-depth deterministic models such as the VTT model, isopleths systems, or the Biohygrothermal model, begin to take into consideration other influencing factors such as material sensitivity and impact of wind-driven rain (Vereecken \& Roels, 2012). Despite identifying that a majority of mould prediction models can be categorised into one of these two model types, it was widely accepted that all types of models in some way simplify the extremely complex process of mould growth (Vereecken, et al., 2015; Vereecken \& Roels, 2012; Berger, et al., 2018).

The use of the same input parameters in terms of relative humidity and temperature was favoured amongst many studies, however, the method of assessment varied amongst studies. Vereecken et al. (2015), Vereecken and Roels (2014), and Johansson et al. (2013) choose to compare the same inputs against various situation e.g. the influence of thermal bridges, materials sensitivity, or winddriven rain. All these studies choose to assess these different scenarios against the same model to understand how sensitive the predictions are to various scenarios. In contrast to this Vereecken et al. (2011), Berger et al. (2018), and Glass et al (2017) choose to assess the same input parameters against various models to illustrate that by using different models, different predictions are often attained. This has been identified by Glass et al. (2017) as one of the most significant shortcomings to a variety of simplifications that are made across the range of models.

\subsubsection{Use of Steady State Conditions}

In regards to the methods of gathering these inputs, these again varied amongst studies. Berger et al. (2018) and Vereecken et al. (2011), implemented computer simulations and utilising a building Heat and Moisture (HAM) simulation program to gather surface temperatures and surface relative humidities that were then able to be implemented into the model. In contrast Vereecken et al. (2015) and Johansson et al. (2013) ran experiments using incubation chambers and specified the surface relative humidity and temperature that was maintained throughout the entire experiment. The critical similarity between these two methods of gathering inputs is that these both produce steady-state conditions. The natural environmental conditions 
of relative humidity and temperature seldom lend themselves to these steady-state conditions, particularly over a prolonged period of time within a building. This variance in relative humidity and surface temperature, also known as variant conditions, provides both favourable and unfavourable conditions for mould growth which can influence mould growth retarding effects (Johansson, et al., 2013). The danger of the application of these steady-state conditions is that these are often the parameters of which these mould prediction models are developed.

Johansson, et al., 2013, investigated the impact of transient conditions by undertaking a laboratory study that assessed mould growth at a range of relative humidities (from $60 \%-90 \%$ ) and temperature conditions (between $5^{\circ} \mathrm{C}$ and $22^{\circ} \mathrm{C}$ ). These transient conditions were compared to steady-state conditions to understand the impact of fluctuating conditions on mould growth. Shown below in Figure 7 are the schedules of the five test scenarios that were assessed.
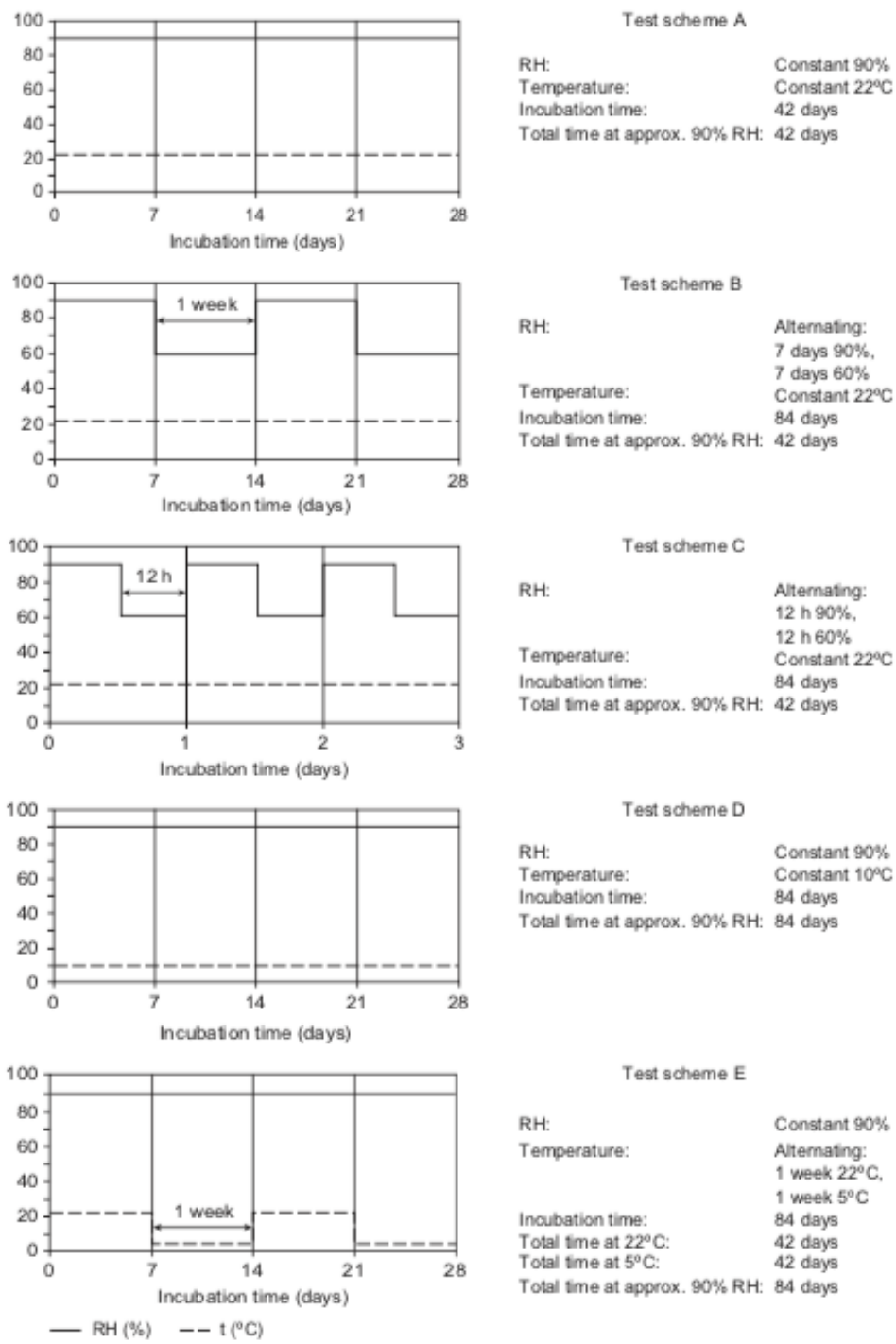

Figure 7 Relative humidity and temperature schedules used to understand the impact of transient conditions on mould growth (Johansson, et al., 2013) 
It was found that relative humidity and exposure time are the most critical conditions for mould to grow because fungal growth can occur over a wide range of temperatures, with most fungi being able to grow between temperatures of $5^{\circ} \mathrm{C}$ to $35^{\circ} \mathrm{C}$ providing the moisture conditions are favourable. It was found that the fluctuations of temperature conditions between $5^{\circ} \mathrm{C}$ and $22^{\circ} \mathrm{C}$ were comparable to a steady-state temperature of $10^{\circ} \mathrm{C}$. The relative humidity had far more influence on the growth of mould as it was seen that the fluctuation of this led to slower mould growth due to periods of unfavourable conditions being experienced regardless of the temperature. The experience of unfavourable conditions allows for mould growth retarding to occur which is a critical factor that should be considered in prediction models. Johansson et al. (2013) went on further to conclude that is it neither the mean surface relative humidity that a building material is exposed to nor the total time that favourable conditions occur that governs the growth rate of mould but rather the duration of both the favourable and unfavourable conditions. Using steady state conditions over a prolonged period may consequently omit periods of favourable or unfavourable mould growth which will negatively impact the model in producing realistic predictions of mould growth.

Whilst many of the aforementioned studies placed a focus on assessing the outputs of these models Berger et al. (2018) and Glass et al. (2017) choose an alternative method of assessing the robustness of the VTT model and ASHRAE 160 by looking at the influence of the inputs on the predictions produced. Berger et al. (2018) utilised steady-state conditions to identify the possibility of errors should the input parameters be incorrect. Having attained mould growth prediction with the initial set of conditions, a secondary set of conditions was set which modified the daily parameters by $1 \%$. Over a 700 -day period, this $1 \%$ modification to the parameters leads to a relative error of almost $100 \%$ in regard to the mould growth predictions. Berger et al. (2018) noted that the this indicates that mathematical formulation of the VTT model may be overly sensitive as parameters may not be able to be defined within less than a $1 \%$ error and therefore this model could produce grossly inaccurate results, particularly when considering these parameters were steady-state conditions.

Glass et al. (2017) also investigated the impact of the uncertainty of the relative humidity on the mould index. Whilst this study gathered in-situ measurements it was noted that the sensors which gathered this data were not placed on the surface of the materials that were being tested and therefore may vary slightly. To understand the impact of this uncertainty, two further tests were run where the measured relative humidity was increased by $3 \%$ and decreased by $3 \%$. The results of these additional tests can be seen below in Figure 8 and they illustrate the importance of accurate input parameters to provide accurate predictions. 


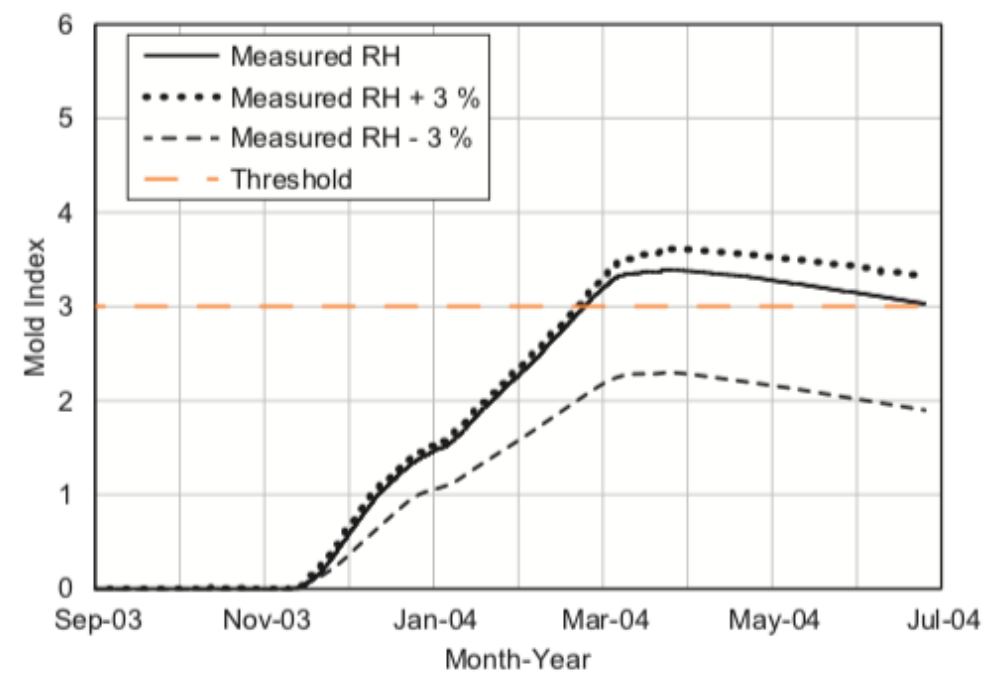

Figure 8 Impact of uncertainty in relative humidity values on the mould index (Glass, et al., 2017)

Through their studies both Berger et al. (2018) and Glass et al. (2017) were able to identify the sensitivity of these input parameters and highlight the importance of ensuring that these inputs are accurate. The discussion and conclusions in Johansson et al. (2013) identified that this level of accuracy may not be attainable through the use of steady-state inputs or models that have been developed using steady-state inputs.

\subsubsection{Sensitivity of Models}

The importance of the type of input parameters was discussed when Vereecken and Roels (2014) and Glass et al. (2017) specifically investigated the impact of additional variables. Surface temperature and relativity humidity are inputs that all mould prediction models utilise, however more sophisticated models have begun to implement further parameters such as material sensitivity class and the influence of wind-driven rain. The VTT mould index model as discussed by Vereecken and Roels (2014) Glass et al. (2017) and Vereecken et al. (2015) implements a material sensitivity class that places the surface material under investigation into one of four sensitivity classes.

$$
\frac{d M}{d t}=\frac{1}{7 \cdot \exp (-0.86 \ln T-13.9 \ln R H+0.14 W-0.33 S+66.02)} k_{1} k_{2} \quad \text { Equation } 1
$$

The above formula shown in Equation 1 is the calculation method for the VTT model with the $k_{1}$ coefficient relating to the material sensitivity class. This formula has been discussed in Section 4.1.1. Each sensitivity class gives a different $k_{1}$ coefficient which accounts for the changes in mould growth intensity depending on the material. Different materials react differently to mould and this was illustrated by Ojanen, et al., 2010, when they assessed mould growth models with various building materials. 
The impacts of wind-driven rain were discussed in Vereecken and Roels (2014) and the impact of the thermal bridges were also considered in Vereecken et al. (2011) both of which were found to be an area of importance when considering mould predictions. Wind-driven rain was found to induce an increased mould risk and thermal bridges are areas within a building construction that tend to perform the worst in regards to internal condensation and hence increase the likelihood of mould growth (Vereecken \& Roels, 2014). In comparison to the simplistic methods, the studies which assessed the more complex mould prediction models began to understand the influence and importance of input parameters on the mould predictions. By looking at more inputs the aim is to make the model more accurate, however, this can also have an adverse effect as illustrated before. As the number of inputs increase the sensitivity of the model increases and consequently the chance of error increases if these parameters are not inputted correctly.

In regards to analysis Clarke et al. (1997) developed a design tool that predicted the likelihood and extent of mould based upon six generic mould categories. The idea was to identify which type of mould would likely occur based on the environmental conditions. However, these generic mould categories were formulated on the minimum combination of temperature and relative humidity and failed to consider the time of exposure and the impact of the time of unfavourable conditions. These factors have since been identified as critical areas of consideration as discussed by Johansson et al. (2013).

\subsubsection{Influence of Occupant Behaviour}

Whilst many studies investigated the potential for mould growth under ideal circumstances and others began to investigate the influence of real-world implication such as thermal bridges (Vereecken \& Roels, 2014; Aien, et al., 2019) and transient conditions (Johansson, et al., 2013), Salonvaara (1998) was the only study found to consider the influence of occupancy. Whilst developing a model to predict the hygrothermal performance of building envelopes, it was noted that the relative humidity within a building is transient by up to $\pm 5.8 \%$ as a result of occupancy behaviour.

A study undertaken by Ganda (2017) aimed to investigate the extent to which occupancy behaviour and household activities can generate moisture in New Zealand households. Ganda (2017) found that based on the activity profile identified in the study, a household of 2.7 occupants (the average household size in New Zealand) produced approximately 11,300 grams of moisture daily. This equates to approximately $4.2 \mathrm{~L}$ per person per day. Whilst this study did not make any clear conclusions into how this may result in an increased risk of mould, it did allude to the idea that this increase in moisture due to occupancy activity is an area that should be considered in the design phase.

In addition to the discussion of the impact of occupancy activity on moisture generation, Salonvaara (1998) also went on further to reference two studies (Ronnberg, et al., 1989; Reardon \& Shaw, 1997) which discussed the idea that 
occupancy behaviour can greatly influence ventilation within a building. These studies found that bedrooms can often be under-ventilated due to closed doors and windows despite the rest of the house being adequality ventilated. These two ideas of increased humidity and decreased ventilation are critical for mould prediction as humidity is one of the critical influences on mould growth (Johansson, et al., 2013) and ventilation is one of the most effective strategies to mitigating mould risk (Ministry of Business, Innovation, and Employment, 2017).

\subsubsection{Literature Review Findings}

This literature review aimed to understand how assumptions regarding the conditions such as temperature and relative humidity may differ from the in-situ conditions and consequently may impact the mould prediction results. From the above analysis of previous mould prediction model assessments, three key areas where potential discrepancies in prediction can occur have been identified.

\section{More complex mould prediction models are highly sensitive}

Complex mould prediction models, such as the VTT mould index, require the implementation of additional input parameters other than the common surface temperature, relative humidity and time of exposure. The goal of additional input parameters such as the wind-driven rain and material sensitivity class is to improve the accuracy of the predictions of these models, however, due to the increase in the number of input parameters, this allows for more error when inputting which can negatively influence the predictions.

\section{Use of steady-state conditions to develop mould prediction models}

At the time of the development of these mould prediction models as well as initial assessments of these tools, steady-state conditions are frequently utilised. In regards to temperature and humidity, the two main influencing factors of mould growth, these environmental factors seldom occur in steady states. Johansson et al. (2017) investigated the impact of steady state and transient conditions and showed that the use of the steady state conditions, often omitting duration of periods of favourable growth, will not aid in producing realistic predictions of mould growth.

\section{Lack of consideration of occupancy behaviour}

Humidity is one of the most critical conditions for mould growth and that ventilation is one of the most effective strategies recommend to occupants to mitigate mould risk. However, it has also been established that household internal moisture generation and ventilation are highly dependent on occupant behaviours. Currently, within many simplified mould prediction models the influence of occupant behaviour is not considered.

These three key areas where potential discrepancies in prediction can occur were identified and aid in achieving the aims of this research. By understanding common areas of potential discrepancies these can begin to form methodology for this 
research and act as a basis for investigation to understand whether these areas relate to ASHRAE Standard 160. 


\section{Chapter 3 Methodology}

To effectively answer the research question, a methodology must first be set out. The steps as specified below outline the methodology that this thesis will follow to identify any potential discrepancies between the theoretical model of ASHRAE Standard 160 and the measured data. It will also aid in identifying potential improvements within this standard to better represent reality and thus improve mould predictions within a New Zealand context, particularly during the design phase.

1. Determine 'design parameters' within ASHRAE Standard 160 that should be evaluated

a. Going through ASHRAE Standard 160, and using lessons gathered from the literature review, note any 'design parameters' which would greatly impact mould growth

2. Gather any relevant data needed to assess these 'design parameters'

a. Determine what data is required from the PHS (explained in Section 5.1) to assess the chosen 'design parameters', gather this data and ensure that it is appropriately 'cleaned'

\section{Simple analysis}

a. Compare the assumption in ASHRAE Standard 160 to the relevant measured data

b. Determine the criteria to identify a discrepancy and apply to this analysis 
c. Suggest potential improvements to ASHRAE Standard 160 based on where these discrepancies are occurring

d. Assess these improvements and identify whether they provide a better representation of the measured indoor conditions

\section{Hygrothermal simulation}

a. Ensure that there is adequate relevant information to perform a hygrothermal simulation using appropriate software

b. Run a 'base model' simulation using the information gathered from the PHS

c. Using the conditions specified in step 3d run the hygrothermal simulations again but with these alternative internal conditions

d. Compare mould predictions from the base model and the alternative internal conditions

\section{Conclusions}

a. Based on the simple analysis and the computer-based analysis, suggest potential improvements to the 'design parameters' in ASHRAE Standard 160

b. Draw conclusions on the suitability of ASHRAE Standard 160 for use in the New Zealand context

\subsection{Determining 'Design Parameters' to Assess}

ASHRAE Standard 160 (2016) 'Criteria for Moisture Control Design Analysis in Buildings' was created with the aim of specifying performance-based criteria in order to predict, mitigate and/or reduced internal moisture within a buildings envelope as well as its components, systems, and materials (ASHRAE, 2016). The revised 2016 version works on the premise of providing selection criteria of analytic procedures as well as relevant inputs (such as boundary conditions, material composition, and indoor conditions) and provides criteria for evaluation and general use of outputs. This standard specifies a number of criteria which have been described as 'Design Parameters' and these form the basis for the inputs that are used in the evaluation criteria formula or in accordance with a computer-based moisture analysis tool such as WUFI (explained in Section 4.1.2). These 'Design Parameters' are the subject of analysis within this research as they are the area which have been identified that ASHRAE 160 would need to make assumptions which could potentially impact the mould prediction results. The 'Design Parameters' are as follows.

- Design initial moisture content of building materials

- Indoor Design Temperature

- Indoor Design Humidity

- Design air pressure differentials and flows

- Moisture design weather data

- Design rain loads on walls 
Whilst these are all areas which could impact mould growth within a building, they cannot all be incorporated in the analysis as this research is limited to the information that is available through the PHS. For example, both the Indoor Design Temperature and the Indoor Design Humidity can be analysed as the PHS recorded the temperature and relative humidity. However, Design rain loads on walls considers factors such as exposure which is based upon the typography surrounding the building and the height of building; information which is not available through the PHS. Consequently, each of the 'Design Parameters' will need to be investigated to understand whether or not they will be applicable for this research and are within the bounds of the data gathered in the PHS.

\subsection{Gathering Data and Cleaning}

The BRANZ PHS gathered a large amount of both qualitative and quantitative data on 80 houses throughout New Zealand, however, for this research not all this data and information is relevant. The type of information that is used is dependent on the stage of analysis with the simple analysis looking firstly at the quantitative data and the more in-depth analysis of the mould index model looking at both.

In regards to quantitative data, the PHS is the largest national housing assessment survey undertaken within New Zealand since the 1930s, collecting detailed data on the occupants and their houses in approximately 80 houses in various locations over a 12-month period. Six sensors were placed in each of the houses: one external; one in the roof space; one in the living room; and the remaining three in bedrooms. Each of the sensors recorded the temperature and relative humidity at approximately 15-minute intervals for approximately a year (Jones 2018). This process was undertaken by BRANZ.

Regarding data cleaning, BRANZ have ensured that each tag reads as a uniform time, however, any uncalibrated tags or unusual or unexpected data must be identified. Once these outliers in the data are identified they need to be examined in order to understand why they may have occurred, for example, is there a heating system in the space that wasn't recorded which has resulted in a uniform indoor temperature. Based on this examination a decision needs to be made as to whether they should be included or excluded from the analysis.

As well as recording the temperature and relative humidity, the basic amenities, moisture management techniques, tenure, region, age, and construction were surveyed within each house. This information will be used to help form a 'profile' of each of the buildings which is able to be used to form a basis of any assumptions that are made within the analysis. An example of this would be when assuming the airtightness and construction of the building based upon age of the building. The PHS did not gather data on the complete construction of each of the buildings however, by using the date of construction and the cladding type, a wall 'typical' wall construction of that era can be created. This in turn would be able to be used to establish other factors such as the airtightness of the building. 
Based on the data that is available through the PHS and is gathered from this step, the 'Design Parameters' that are required to be assessed may change. If adequate data is not available to assess a 'Design parameter' then it shall be excluded from this research.

\subsection{Simple Analysis}

Having determined the 'Design Parameters' that are going to be analysed, there is a two-step process to assess these. The simple analysis will be used to assess each of the individual 'Design Parameters', and the computer simulation analysis will look at the impact of these 'Design Parameter' inputs on the overall result and mould predictions.

Each of the appropriate 'Design Parameters' will be compared to the relevant measured data from the PHS. e.g. Indoor Design Humidity with the relative humidity recorded from the internal tags. ASHRAE Standard 160 identifies the internal conditions of the whole house, however, the PHS data identifies the internal conditions for each room. In order to be able to compare these two sets of data, another dataset of the measured internal conditions shall be created using the average temperature and relative humidity. This process has been briefly outlined in Figure 9. Whilst each house will initially be assessed individually the aim is to identify patterns in discrepancies that occur across several houses.

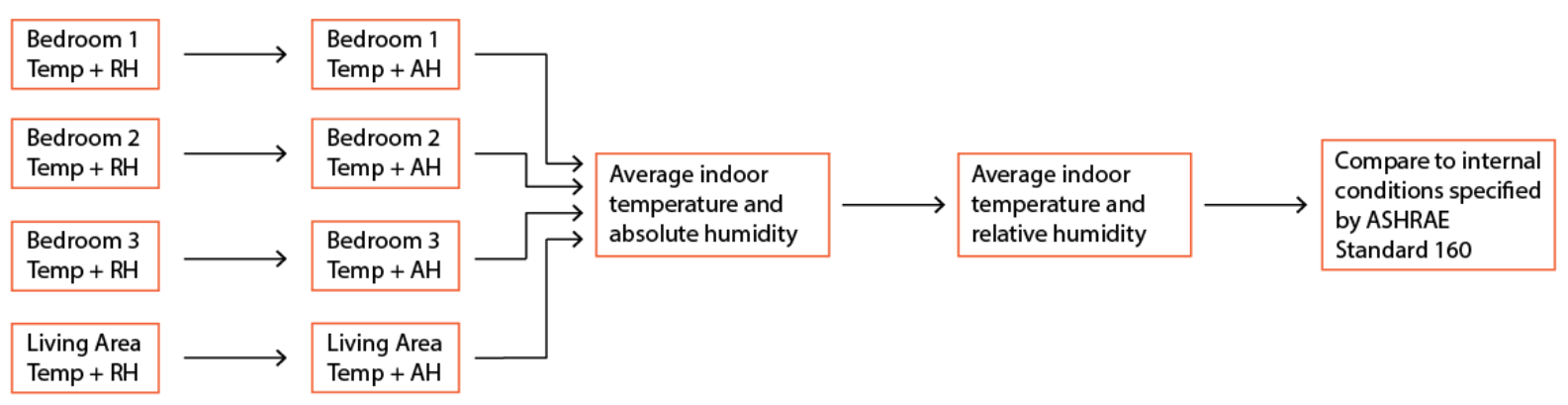

Figure 9 Process to develop measured indoor conditions for the whole house (Authors own image)

\subsection{Hygrothermal Simulation and Analysis}

The use of a computer simulation tool such as WUFI, creates a simulation model which traces various moisture conditions over a period of time and uses an assessment method to determine whether these conditions are suitable for mould growth. The computer simulation has been run using the same construction under various conditions which have been specified through either in situ measurements or the conditions specified through ASHRAE Standard 160. This process has been outlined in the workflow shown in Figure 10.

Just as the relevant data was gathered in order to undertake the simple analysis of the ASHRAE 160 'Design Parameters', relevant information from the PHS will need to be gathered to undertake a more sophisticated computer-based analysis with 
software such as WUFI Pro. As previously discussed, several of these inputs, such as building construction, may have to be assumed based upon other known variable such as the building age and the 'typical' construction of that era. In these instances, any assumptions shall be noted.

Software add-ons, such as WUFI Mould Index VTT, are used in conjunction with tools such as WUFI Pro by utilising the climate that is established through running an analysis in WUFI Pro. WUFI Mould Index VTT implements the Viitanen model to provide a mould index which describes the degree of mould growth on the surface in question.

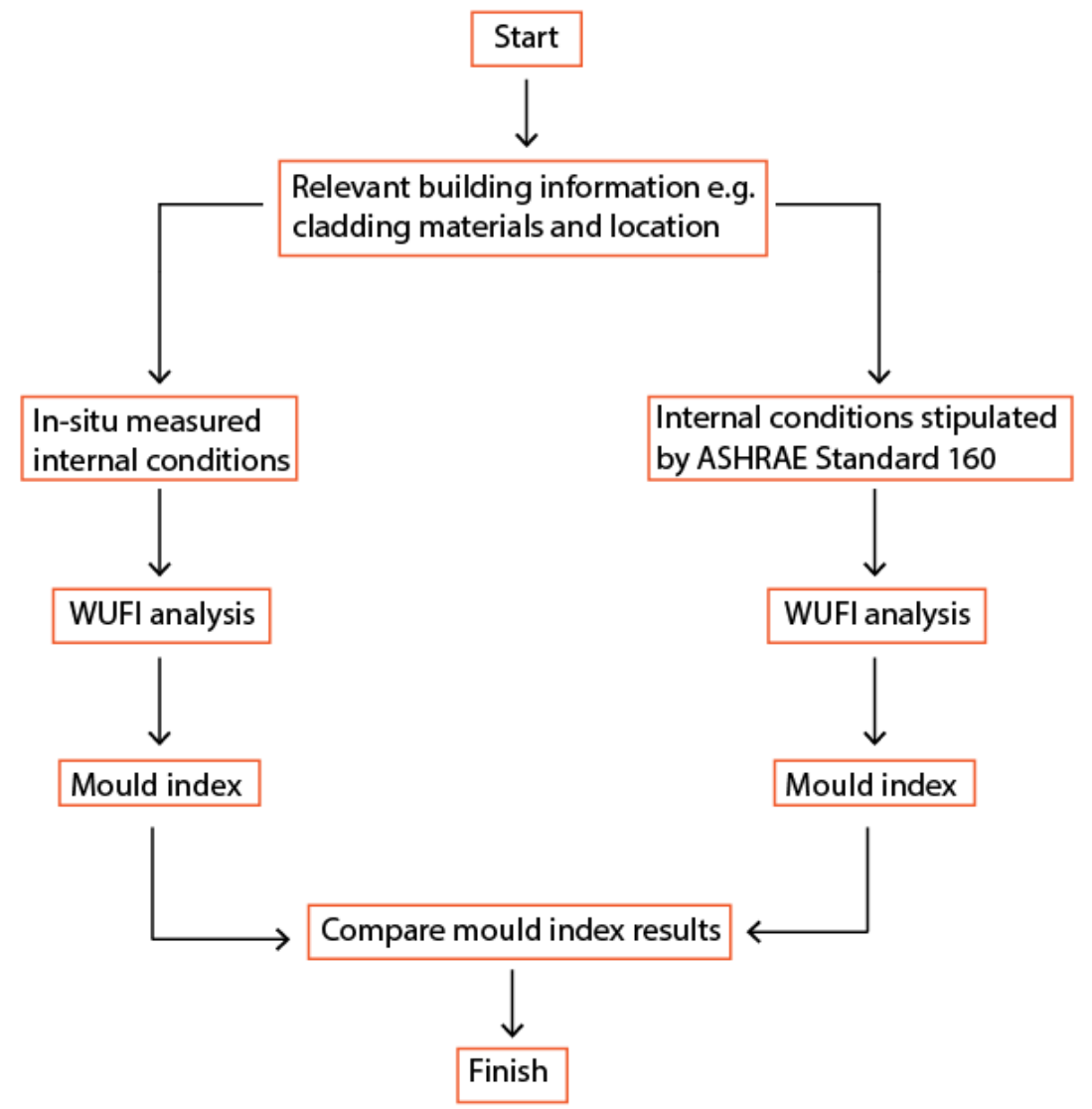

Figure 10 Hygrothermal simulation process (Authors own image)

\subsection{Conclusions}

Based upon the simple analysis and the computer-based analysis, conclusions shall be drawn as to the suitability of ASHRAE Standard 160 within a New Zealand context and suggestions shall be provided to suggest methods of which this standard could be altered to better represent the indoor conditions of New Zealand houses. This analysis will have looked at both the standalone 'Design Parameter' inputs as well as the impact of these inputs on the overall mould predictions results. Based upon this analysis, conclusions shall be drawn which aim to understand the impact of these inputs on the overall results and to understand where discrepancies are occurring which result in incorrect predictions. 


\section{Chapter 4 Moisture Analysis and Mould Prediction Tools}

\subsection{ASHRAE Standard 160}

Currently, there are numerous standards and authorities that exist to provide occupants with advice on how to conditions their houses in order to minimise internal moisture and in turn mitigate mould issues. EECA utilises general advice from ASHRAE Standards recommending that the relative humidity should not be above $65 \%$ (ASHRAE, 2016) nor should the temperature drop below $18^{\circ} \mathrm{C}$ (ASHRAE, 2017). Whilst this advice is generally considered sound, this approach does not consider vital aspects into the likelihood of mould growth such as time-of-wetness and the time-to-humidity link in which the amount of time that a surface is exposed to a critical humidity impacts the likelihood of mould germination (Riordan \& Tsongas, 2016). Thus, a test is necessary which considers whether the exposure of favourable conditions for mould growth is experienced and maintained for long enough that mould is able to germinate. ASHRAE Standard 160 is a moisture analysis method which considers the frequency of the favourable and unfavourable conditions and begins to show whether the frequency of unfavourable conditions is sufficient to halt the mould germination process.

ASHRAE Standard 160 'Design Criteria for Moisture Control in Buildings' was initially developed in 2009 as 'Prevention of Moisture Damage'. This standard initially aimed to define the role that moisture played in the degradation of building materials, component systems, and furnishing. However, it was soon recognised that there was an emerging need for criteria for moisture design analysis and in 2016 ASHRAE 
Standard 160-2016 superseded the previous 2009 with a redefined purpose and scope. Within this research any reference to ASHRAE Standard 160 shall be discussing the 2016 version, with any discussion of the 2009 being clearly stated.

The new purpose of ASHRAE Standard 160 is to specify a performance criterion for which moisture damage can be predicted, mitigated, or reduced. The critical difference between the 2009 and 2016 versions of ASHRAE Standard 160 came in the means of assessment. ASHRAE Standard 160-2016 began to understand that different materials react differently to excess moisture and consequently some are more susceptible to mould growth than others. In turn the 2016 version placed a focus on material sensitivity classes and added this as one of the variable inputs into the standard with materials being able to be classified into one of four classes; very sensitive, sensitive, medium resistant, and resistant (ASHRAE, 2016).

ASHRAE Standard 160-2009 utilised a simplified mould growth criterion which focused on a 30-day running period and specified that over this time-period the average relative humidity should not exceed $80 \%$ in order to prevent mould germination (ASHRAE, 2009). The 2016 version uses the Viitanen mould index model (also known as VTT). As well as considering building material sensitivity to mould growth VTT mould index model also considers factors such as the duration of favourable growth conditions and the impact of unfavourable growth conditions (ASHRAE, 2016).

\subsubsection{The ASHRAE Standard 160 Process}

When undertaking an investigation into the potential for excess moisture and mould growth within a building and utilising ASHRAE Standard 160 an assessment tool, there is a seven-step process which should be followed in order to gathered the appropriate inputs required and to run the assessment. The steps are as follows:

\section{Define the building assembly}

Defining the building assembly requires identifying the layers of materials within a building construction. Various layers such as the cladding, the insulation level, and the internal lining are all critical factors when considering the impact of mould growth.

\section{Assign material properties}

Within each of the building assembly layers, the material properties such as the density, specific heat capacity, thermal conductivity, and thickness will vary and each of these impacts the materials resistivity to moisture. Each material needs to be assigned with its appropriate properties in order for it to perform as it would in-situ.

\section{Select initial conditions}

The initial conditions specify the initial moisture content of a construction material within a new construction. This condition utilises either EMC90 or EMC80, which is the moisture content of a material when expressed as a ratio of the mass of 
water to the over-dry mass when the material is in equilibrium with air at $20^{\circ} \mathrm{C}$ at either $90 \%$ relative humidity (EMC90) or $80 \%$ relative humidity (EMC80). For this standard two times EMC90 is used for concrete and two times EMC80 is used for all other materials (ASHRAE, 2016).

\section{Select outdoor climate}

This analysis requires the use of weather data that is either an average of a minimum of ten consecutive years or the moisture design reference year. The weather data shall be in the format of hourly data and include:

a. Dry-bulb air temperature

b. Vapour pressure, dew-point temperature, wet-bulb temperature, relative humidity, or humidity ratio

c. Total solar insolation on a horizontal surface

d. Average wind speed and direction

e. Rainfall

f. Cloud index

\section{Select exposure conditions}

The exposure conditions predominantly focus on the design rain loads on the walls and can be determined through either the use of a comprehensive wind-driven rain analysis or, in the absence of this, the amount of rain striking a building vertical surface can be calculated using the following formulae:

$$
r_{b v}=F_{E} \times F_{D} \times F_{L} \times U \times \cos \theta \times r_{h}
$$

Where:

$\mathrm{F}_{\mathrm{E}}=$ Rain exposure factor

$\mathrm{F}_{\mathrm{D}}=$ Rain deposition factor

$\mathrm{F}_{\mathrm{L}}=$ Empirical constant, $0.2 \mathrm{~kg} \cdot \mathrm{s} /\left(\mathrm{m}^{3} . \mathrm{mm}\right)$

$\mathrm{U}=$ Hourly average wind speed at $10 \mathrm{~m}, \mathrm{~m} / \mathrm{s}$

$r_{h}=$ Rainfall intensity, horizontal surface, $\mathrm{mm} / \mathrm{h}$

$r_{b v}=$ Rain deposition on vertical wall, $\mathrm{kg} /\left(\mathrm{m}^{2} . \mathrm{h}\right)$

$\theta=$ Angle between wind direction and normal to the wall

The rain exposure is determined from the table below: 


\begin{tabular}{llll}
\hline \multirow{2}{*}{$\begin{array}{l}\text { Building Height, } \\
\mathbf{m}(\mathbf{f t})\end{array}$} & \multicolumn{3}{l}{ Type of Exposure Category } \\
\cline { 2 - 4 } & Severe & Medium & Sheltered \\
\hline \hline$<10(<33)$ & 1.4 & 1.0 & 0.7 \\
$>10$ and $\leq 20$ & 1.4 & 1.2 & 1.0 \\
$(>33$ and $\leq 66)$ & & & \\
$>20(\leq 66)$ & 1.5 & 1.5 & 1.5 \\
\hline
\end{tabular}

Table 5 Exposure factor from table 4.6.1 in ASHRAE Standard 160-2016

The rain deposition factor is determined by one of the following factors:

a. Walls below a steep-slope roof: $F_{D}=0.35$

b. Walls below a low-slope roof: $F_{D}=0.5$

c. Walls subject to rain runoff: $F_{D}=1.0$

\section{Determine indoor conditions}

There are three different factors that should be considered when determining the indoor conditions: Indoor Design Temperature, Indoor Design Humidity, and design air pressure differentials and flows. It is important to note that ASHRAE Standard 160 provides an idea of what the indoor conditions may be based upon the outdoor conditions. If the actual indoor conditions are known, then these should be used in place of those that are specified through ASHRAE Standard 160.

If the design or operation specify as specific indoor operating temperature then that shall be the indoor design temperature, otherwise the indoor design temperature shall be specified through the use table shown in Table 6.

\begin{tabular}{|c|c|c|}
\hline \multirow{2}{*}{$\begin{array}{l}\text { 24-Hour Running Average of } \\
\text { Outdoor Temperature }\end{array}$} & \multicolumn{2}{|c|}{ Indoor Design Temperature, ${ }^{\circ} \mathrm{C}\left({ }^{\circ} \mathrm{F}\right)$} \\
\hline & Heating Only & Heating and Air Conditioning \\
\hline$T_{a, 24 h} \leq 18.3^{\circ} \mathrm{C}\left(T_{a, 24 h} \leq 65^{\circ} \mathrm{F}\right)$ & $21.1^{\circ} \mathrm{C}\left(70^{\circ} \mathrm{F}\right)$ & $21.1^{\circ} \mathrm{C}\left(70^{\circ} \mathrm{F}\right)$ \\
\hline $18.3^{\circ} \mathrm{C}<T_{a, 24 h} \leq 21.1^{\circ} \mathrm{C}\left(65^{\circ} \mathrm{F}<T_{o, 24 h} \leq 70^{\circ} \mathrm{F}\right)$ & $T_{a, 24 h}+2.8^{\circ} \mathrm{C}\left(T_{o, 24 h}+5^{\circ} \mathrm{F}\right)$ & $T_{a, 24 h}+2.8^{\circ} \mathrm{C}\left(T_{a, 24 h}+5^{\circ} \mathrm{F}\right)$ \\
\hline$T_{a, 24 h}>21.1^{\circ} \mathrm{C}\left(70^{\circ} \mathrm{F}\right)\left(T_{a, 24 h}>70^{\circ} \mathrm{F}\right)$ & $T_{o, 24 h}+2.8^{\circ} \mathrm{C}\left(T_{a, 24 h}+5^{\circ} \mathrm{F}\right)$ & $23.9^{\circ} \mathrm{C}\left(75^{\circ} \mathrm{F}\right)$ \\
\hline
\end{tabular}

Table 6 Indoor Design Temperature formulae from table 4.2 in ASHRAE Standard 160-2016

When determining Indoor Design Humidity, one of three methods is to be used: simplified, intermediate, or full parameter calculation. Similarly, to the Indoor Design Temperature, if an operating system is used which specifies a humidity, then this value shall be used, otherwise one of the aforementioned methods is able to be implemented. The Indoor Design Humidity Simplified Method, shall be specified through the use of the table shown in Table 7. 


\begin{tabular}{|c|c|c|c|}
\hline $\begin{array}{l}\text { Daily Average } \\
\text { Outdoor Temperature, }{ }^{\circ} \mathrm{C}\end{array}$ & $\begin{array}{l}\text { Design RH, \% } \\
\text { (Based on }{ }^{\circ} \mathrm{C} \text { ) }\end{array}$ & $\begin{array}{l}\text { Daily Average } \\
\text { Outdoor Temperature, }{ }^{\circ} \text { F }\end{array}$ & $\begin{array}{l}\text { Design } \mathrm{RH}, \% \\
\text { (Based on }{ }^{\circ} \mathrm{F} \text { ) }\end{array}$ \\
\hline Below $-10^{\circ} \mathrm{C}$ & $40 \%$ & Below $14^{\circ} \mathrm{F}$ & $40 \%$ \\
\hline$-10^{\circ} \mathrm{C} \leq T_{a, \text { daily }} \leq 20^{\circ} \mathrm{C}$ & $40 \%+\left(T_{a, \text { daily }}+10\right)$ & $14^{\circ} \mathrm{F} \leq T_{a, \text { daib }} \leq 68^{\circ} \mathrm{F}$ & $40 \%+\left(T_{a, \text { daily }}-14\right) / 1.8$ \\
\hline Above $20^{\circ} \mathrm{C}$ & $70 \%$ & Above $68^{\circ} \mathrm{F}$ & $70 \%$ \\
\hline
\end{tabular}

Table 7 Indoor Design Relative Humidity, Simplified Method formulae from table 4.3.1 in ASHRAE Standard 1602016

The intermediate method begins to introduce more parameters which will impact the relative humidity within a space. This method utilises a formula which determines the indoor vapour pressure which in turn is able to be converted to the indoor relative humidity. This equation is shown below:

$$
P_{i}=P_{024 h}+\frac{c m}{Q}
$$

Where:

$\mathrm{P}_{\mathrm{i}}=$ Indoor vapour pressure, $\mathrm{Pa}$

$\mathrm{P}_{024 \mathrm{~h}}=24$-hour running average outdoor vapour pressure, $\mathrm{Pa}$

$\mathrm{c}=1.36 \times 10^{5} \mathrm{~Pa} \cdot \mathrm{m}^{3} / \mathrm{kg}$

$\mathrm{m}=$ Design moisture generation rate, $\mathrm{kg} / \mathrm{s}$

$\mathrm{Q}=$ Design ventilation rate, $\mathrm{m}^{3} / \mathrm{s}$

The design moisture generation rate is determined by the number of expected occupants within the space. This can be determined by the table shown in Table 8.

\begin{tabular}{|c|c|c|c|c|}
\hline \multirow{2}{*}{$\begin{array}{l}\text { Number of Bedrooms } \\
1 \text { bedroom }\end{array}$} & \multirow{2}{*}{$\begin{array}{l}\text { Number of Oecupants } \\
2\end{array}$} & \multicolumn{3}{|c|}{ Moisture Generation Rate } \\
\hline & & 7 L/day & $0.8 \times 10^{-4} \mathrm{~kg} / \mathrm{s}$ & $0.64 \mathrm{lb} / \mathrm{h}$ \\
\hline 2 bedrooms & 3 & 9 L/day & $1.0 \times 10^{-4} \mathrm{~kg} / \mathrm{s}$ & $0.83 \mathrm{lb} / \mathrm{h}$ \\
\hline 3 bedrooms & 4 & $10 \mathrm{~L} /$ day & $1.2 \times 10^{-4} \mathrm{~kg} / \mathrm{s}$ & $0.92 \mathrm{lb} / \mathrm{h}$ \\
\hline 4 bedrooms & 5 & 11 L/day & $1.3 \times 10^{-4} \mathrm{~kg} / \mathrm{s}$ & $1.0 \mathrm{lb} / \mathrm{h}$ \\
\hline Additional bedrooms & +1 per bedroom & +1 L/day & $+0.1 \times 10^{-4} \mathrm{~kg} / \mathrm{s}$ & $+0.1 \mathrm{lb} / \mathrm{h}$ \\
\hline
\end{tabular}

Table 8 Residential Design Moisture Generation Rates from table 4.3.2 in ASHRAE Standard 160-2016

The design ventilation rate is determined through the use of one of two formulae depending upon the air exchange rate. Equation 4 is used for a new building with standard construction and an air exchange rate of $0.2 \mathrm{ACH}$ whilst Equation 5 is used for a new building with an airtight construction and an air exchange rate of $0.1 \mathrm{ACH}$.

$$
Q=5.6 \times 10^{-5} V
$$




$$
Q=2.8 \times 10^{-5} V
$$

Where: $\mathrm{V}=$ Building volume in $\mathrm{m}^{3}$

A Full Parameter Calculation for Indoor Design Humidity requires comprehensive inputs in order to effectively analyses the hygrothermal response of building elements, finishes and furniture. The required inputs are as follows:

a. Hygrothermal properties of any building materials, furnishes, and furniture

b. Design initial moisture conditions

c. Design indoor temperatures

d. Design ventilation rates

e. Design moisture generation rates

f. Effect of active dehumidification systems

g. Design pressure data

h. Design weather data

i. Deign rain loads

The air pressure differentials and flow are the air pressure differentials between indoors and outdoors and shall be calculated using the design ventilation rates if it is not already managed.

\section{Perform analysis}

As previously stated, ASHRAE Standard 1602016 utilises the VTT mould index model which assigns a mould index from 0 to 6 where the descriptions are given in Table 8. This is in place of the binary models that either state that there is or is not mould, and this places more emphasis on the coverage of a surface in mould. Adequate performance requires a mould index value of less than 3 .

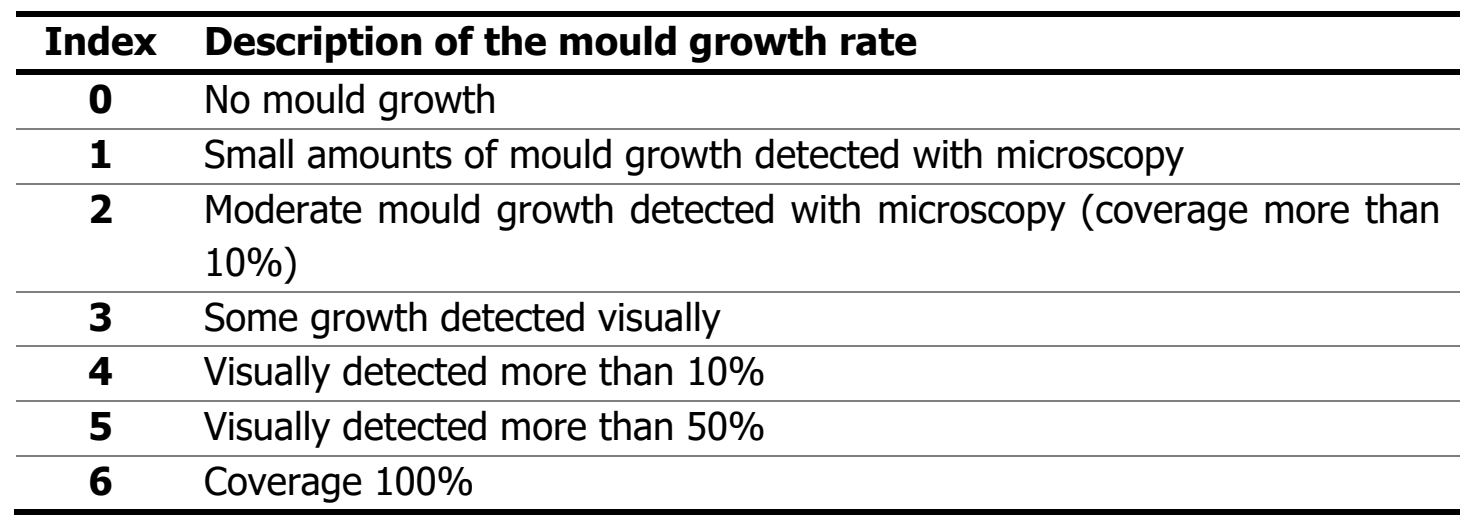


To determine the mould index, the first step is to assign the building surface to one of four material sensitivity classes, as shown below in Table 10.

\begin{tabular}{ll}
\hline Sensitivity Class & Materials \\
\hline \hline Very sensitive & Untreated wood; includes lots of nutrients for biological growth \\
Sensitive & Planed wood, paper-coated products, wood-based boards \\
Medium resistant & Cement or plastic based materials, mineral fibers \\
Resistant & Glass and metal products, materials with efficient protective compound treatments \\
\hline
\end{tabular}

Table 10 Recommended mould sensitivity classes for various materials from table 6.1.1 in ASHRAE Standard 160-2016

Having selected the appropriate material sensitivity class, the mould index (M) is calculated with the initial mould index value set to zero $(M=0$ at time $t=0)$, and for each hour following the mould index is accumulated using the following formula.

$$
M_{t}=M_{t-1}+\Delta M
$$

Equation 6

Where:

$M_{t}=$ Mould index for the current hour

$\mathrm{M}_{\mathrm{t}-1}=$ Mould index for the previous hour

$\Delta M=$ Change in mould index, calculated for each hour using Equation 9 or Equation 12

If the surface temperature $\left(T_{s}\right)$ is greater than $0{ }^{\circ} \mathrm{C}$, then Equation 7 (for Very Sensitive Class or Sensitive Class or Equation 8 (for Medium Resistant Class or Resistant Class) is used to calculate the critical surface relative humidity ( $\mathrm{RH}$ crit) for mould initiation.

$$
\begin{aligned}
& R H_{\text {crit }}=-0.00267 T_{s}^{3}+0.160 T_{s}^{2}-3.13 T_{s}+100 \text { when } T_{s} \quad \text { Equation } 7 \\
& \leq 7^{\circ} \mathrm{C}, 80 \text { when } T_{s}>7^{\circ} \mathrm{C} \\
& R H_{\text {crit }}=-0.00267 T_{s}^{3}+0.160 T_{s}^{2}-3.13 T_{s}+100 \text { when } T_{s} \\
& \leq 7^{\circ} \mathrm{C}, 85 \text { when } T_{s}>7^{\circ} \mathrm{C}
\end{aligned}
$$

If the relative humidity of the materials surface $\left(\mathrm{RH}_{\mathrm{s}}\right)$ when expressed as a percentage is greater than the $\mathrm{RH}_{\text {crit }}$ at that current hour, then the increase in the mould index is calculated using the following formula: 


$$
\Delta M=\frac{k_{1} k_{2}}{168 \times \exp \left(-0.68 \ln T_{s}-13.9 \ln R H_{s}+0.14 W+66.02\right)}
$$

Where:

$\mathrm{k}_{1}=$ Mould growth intensity factor selected from Table 11

$\mathrm{k}_{2}=$ Mould index attenuation factor calculated using Equation 10

$\mathrm{W}=$ Parameter selected from Table 11 for material sensitivity class in Table 10

\begin{tabular}{|c|c|c|c|c|c|c|}
\hline \multirow[b]{2}{*}{ Sensitivity Class } & \multicolumn{2}{|l|}{$k_{1}$} & \multirow[b]{2}{*}{$\boldsymbol{W}$} & \multirow[b]{2}{*}{$A$} & \multirow[b]{2}{*}{$B$} & \multirow[b]{2}{*}{ C } \\
\hline & (if $M<1$ ) & (if $M \geq 1$ ) & & & & \\
\hline Very sensitive & 1 & 2 & 0 & 1 & 7 & 2 \\
\hline Sensitive & 0.578 & 0.386 & 1 & 0.3 & 6 & 1 \\
\hline Medium resistant & 0.072 & 0.097 & 1 & 0 & 5 & 1.5 \\
\hline Resistant & 0.033 & 0.014 & 1 & 0 & 3 & 1 \\
\hline
\end{tabular}

Table 11 Parameters for equation 10 and equation 11 from table 6.1.2 in ASHRAE 160-2016

$$
k_{2}=\max \left\{1-\exp \left[2.3\left(M-M_{\max }\right)\right], 0\right\}
$$

Where:

$M_{\max }=$ The maximum mould index which corresponds to the surface temperature and surface relative humidity at the current hour, which is calculated using Equation 11.

$$
M_{\text {max }}=A+B\left(\frac{R H_{c r i t}-R H_{s}}{R H_{c r i t}-100}\right)-C\left(\frac{R H_{c r i t}-R H_{s}}{R H_{c r i t}-100}\right)^{2}
$$

Equation 11

The coefficient A, B, and C are all selected from Table 11 according to material sensitivity class.

If an instance occurs where $\mathrm{T}_{\mathrm{s}} \leq 0^{\circ} \mathrm{C}$ or $\mathrm{RH}_{\mathrm{s}} \leq \mathrm{RH}_{\text {crit }}$ at that current hour, then the decrease on the mould index shall be calculated using the following formula:

$$
\Delta M=\left\{\begin{array}{c}
-0.00133 \times k_{3} \text { when } t_{\text {decl }} \leq 6 \\
0 \text { when } 6<t_{\text {decl }} \leq 24 \\
-0.000667 \times k_{3} \text { when } t_{\text {decl }}>24
\end{array}\right.
$$

Where: 
$\mathrm{K}_{3}=$ Mould index decline coefficient that is specific to the material surface. If there is no specific test data for the appropriate material surface, the recommended value shall be 0.1

$\mathrm{T}_{\text {decl }}=$ Number of hours from the moment when the conditions for mould growth altered from favourable $\left(T_{s}>0^{\circ} \mathrm{C}\right.$ and $\left.R_{s}>R H_{c r i t}\right)$ to unfavourable $\left(T_{s} \leq 0^{\circ} \mathrm{C}\right.$ and $\left.\mathrm{RH}_{\mathrm{s}} \leq \mathrm{RH}_{\text {crit }}\right)$

\subsubsection{WUFI and the VTT Mould Index Model}

When implementing ASHRAE Standard 160 the overall process can be broken down into two key stages: the inputs and the analysis. In a scenario where the appropriate inputs are known then these should be used first however, when the inputs are unknown e.g. indoor temperature, then ASHRAE Standard 160 specifies formulae which can be implemented to determine these inputs.

When analysing, there are also two methods which can be utilised. The first is through manually going through the process specified in step seven of section 4.1.1 or alternatively a simulation tool is able to be utilised which utilises the same formula. Using a simulation tool automates the evaluation and analysis process of ASHRAE Standard 160.

Warme Und Feucte Instationar (WUFI) is a software family that allows for realistic calculations of heat and moisture transport within walls and multilayer building components that are exposed to natural weather (Fraunhofer, 2018). WUFI Pro is a standard program within the WUFI family and runs one-dimensional hygrothermal calculations on cross sections of specific building components. Simulations from WUFI Pro produce temperature and relative humidity measurements at critical positions within the wall's construction such as the interior surface, or the interface between the interior insulation and the wall (Fraunhofer, 2019).

In conjunction with WUFI Pro, add on's such as WUFI Mould Index VTT can be used. WUFI Mould Index VTT allows for easy application of the VTT mould index model which is the method of assessment used in ASHRAE Standard 160. This add on contains the mould growth criteria according to ASHARE Standard 160 and allows for differentiation between the four different materials sensitivity classes (Fraunhofer, 2018).

Through utilising both WUFI Pro and WUFI Mould Index VTT, the assessment process of ASHRAE Standard 160 is much faster to implement and able to produce results which are both almost instantaneous and reliable.

\subsection{Selection of 'Design Parameters' to Assess}

The process of implementing ASHRAE Standard 160 requires the selection of several Design Parameters including assigning material properties, selecting initial conditions, and outdoor and exposure conditions, and determining the ideal indoor conditions before performing the final analysis to determine acceptable performance. 
As Vereecken \& Roels (2014) discussed, with the increase in number of parameters, the accuracy of the model increase, however, so does the potential of error. Within this research it is critical to investigate the appropriate parameters which are likely to influence the final mould predictions. However, there is also the constraint of what can be investigated based upon the informant provided in the PHS.

The consensus throughout the literature review was that relative humidity, exposure time, and air temperature were the greatest determinants of mould growth. When looking at the Design Parameters within ASHRAE Standard 160 both relative humidity and air temperature can be considered through the selection of indoor conditions sections. Regarding exposure time, there is no specific Design Parameter which considers this; however, this is determined in the Moisture Performance Evaluation Criteria which was outlined in section 4.1.1.

The Design Parameters that dictate indoor conditions include Indoor Design Temperature, Indoor Design Humidity, and Design Air Pressure Differentials and Flows. As has been previously determined, temperature and humidity are two of the key determinates of mould growth therefore Indoor Design Temperature and Indoor Design Humidity shall be considered in this assessment. However, Air Pressure Differentials and Flows were not identified in the literature review to be a critical factor regarding mould growth and thus will not be considered. Additionally, ASHRAE Standard 160 states that the analysis of the effect of this Design Parameter is optional therefore further indicating that this is not a critical aspect to assess. Regarding Indoor Design Temperature there is only one specified method which can be used and has been shown in table 4.2 of ASHRAE Standard 160. In contrast to this Indoor Design Humidity can be specified through one of three methods; Simplified, Intermediate, or Full Parameter Calculation. When considering learnings from the literature review, namely that the more parameters a model includes the greater the chance of error is, all three methods of the Indoor Design Humidity methods should be assessed. By doing this, it will begin to explore the ideas that Vereecken \& Roels (2014) expressed when discussing that whilst more inputs can result in a higher chance of error, they can also improve the accuracy. By using the same data and three different methods, it can be seen whether these same conclusions would be able to be drawn for ASHRAE Standard 160 . However, whilst it would be beneficial to assess all three of these methods, the ability to assess these methods relies on the level of information that has been gathered from the PHS and whether it is suitable for this assessment. The table shown below in Table 12 outlines what information is required to assess the aforementioned chosen Design Parameters and whether or not relevant data has been gathered through the PHS and consequently whether they are able to be assessed. 


\begin{tabular}{|c|c|c|c|}
\hline $\begin{array}{c}\text { ASHRAE Standard } \\
160 \text { 'Design } \\
\text { Parameters' } \\
\end{array}$ & $\begin{array}{c}\text { What data is } \\
\text { needed to test each } \\
\text { 'Design Parameter' }\end{array}$ & $\begin{array}{l}\text { Is this data } \\
\text { available? }\end{array}$ & $\begin{array}{c}\text { Is this 'Design } \\
\text { Parameter able } \\
\text { to be tested? }\end{array}$ \\
\hline \multirow[t]{2}{*}{$\begin{array}{l}\text { Indoor Design } \\
\text { Temperature }\end{array}$} & $\begin{array}{l}\text { 24-hour average } \\
\text { outdoor temperature }\end{array}$ & Yes & \multirow[t]{2}{*}{ Yes } \\
\hline & Indoor temperature & Yes & \\
\hline \multirow{2}{*}{$\begin{array}{l}\text { Indoor Design } \\
\text { Humidity } \\
\text { (Simplified } \\
\text { Method) }\end{array}$} & $\begin{array}{l}\text { Daily average outdoor } \\
\text { temperature }\end{array}$ & Yes & \multirow{2}{*}{ Yes } \\
\hline & $\begin{array}{l}\text { Indoor relative } \\
\text { humidity }\end{array}$ & Yes & \\
\hline \multirow{3}{*}{$\begin{array}{l}\text { Indoor Design } \\
\text { Humidity } \\
\text { (Intermediate } \\
\text { Method) }\end{array}$} & $\begin{array}{l}24 \text { hour running } \\
\text { average outdoor } \\
\text { vapour pressure }\end{array}$ & Yes $^{1}$ & \multirow{3}{*}{ Yes } \\
\hline & $\begin{array}{l}\text { Design moisture } \\
\text { generation }\end{array}$ & Yes $^{2}$ & \\
\hline & Design ventilation rate & Yes $^{3}$ & \\
\hline \multirow[t]{9}{*}{$\begin{array}{l}\text { Indoor Design } \\
\text { Humidity (Full } \\
\text { Parameter } \\
\text { Calculation) }\end{array}$} & $\begin{array}{l}\text { Hygrothermal } \\
\text { properties of building } \\
\text { materials, finishes, } \\
\text { and furniture }\end{array}$ & $\mathrm{No}^{4}$ & \multirow{9}{*}{$\mathrm{No}^{10}$} \\
\hline & $\begin{array}{l}\text { Design initial moisture } \\
\text { conditions }\end{array}$ & $\mathrm{No}^{5}$ & \\
\hline & $\begin{array}{l}\text { Design indoor } \\
\text { temperature }\end{array}$ & Yes & \\
\hline & $\begin{array}{l}\text { Design moisture } \\
\text { generation }\end{array}$ & Yes & \\
\hline & Design ventilation rate & Yes & \\
\hline & $\begin{array}{l}\text { Effect of active } \\
\text { dehumidification } \\
\text { system }\end{array}$ & $\mathrm{No}^{6}$ & \\
\hline & Design pressure data & $\mathrm{No}^{7}$ & \\
\hline & Design weather data & Yes $^{8}$ & \\
\hline & Design rain loads & $\mathrm{No}^{9}$ & \\
\hline $\begin{array}{l}\text { Moisture } \\
\text { Performance } \\
\text { Evaluation }\end{array}$ & $\begin{array}{l}\text { Conditions necessary } \\
\text { to minimise mould } \\
\text { growth }\end{array}$ & Yes $^{11}$ & Yes \\
\hline
\end{tabular}

Below in Table 13, are comments which expand upon the judgements made about whether variables are able to be assessed based upon the data available.

Based on the analysis shown in Table 12 and Table 13, the 'Design Parameters' that shall be assessed are: Indoor Design Temperature, Indoor Design Humidity (Simplified Method), Indoor Design Humidity (Intermediate Method), and the Moisture Performance Evaluation. Using data gathered from the PHS, assumptions can be made about the various inputs required and moisture conversion formulas are able to be applied in order to gain unknown variable e.g. vapour pressure. 


\begin{tabular}{|c|c|}
\hline Note & Comment \\
\hline 1 & $\begin{array}{l}\text { The 24-hour running average outdoor vapour pressure will have to be } \\
\text { calculated using the outdoor temperature and outdoor relative humidity data. }\end{array}$ \\
\hline 2 & $\begin{array}{l}\text { Within ASHRAE Standard 160, Design Moisture Generation assumes the } \\
\text { number of occupants based on the number of bedrooms within the house. } \\
\text { Each house within the PHS was allocated six tags to record data in different } \\
\text { locations, three of these tags were allocated to bedrooms if there were three } \\
\text { bedrooms available for assessment. In the instance of there being four } \\
\text { bedrooms within a house, only three were able to be assessed. Therefore, } \\
\text { any assumptions about the number of occupants based upon the number of } \\
\text { bedrooms may be inaccurate. Houses and the number of occupants will be } \\
\text { assessed on a case by case scenario to make the most accurate assumptions } \\
\text { for moisture generation rate. }\end{array}$ \\
\hline 3 & $\begin{array}{l}\text { Within ASHRAE Standard } 160 \text {, Design Ventilation Rate is determined by two } \\
\text { critical factors: the volume of the building and the effective leakage area. } \\
\text { The PHS recorded the floor area of each house within a } 50 \mathrm{~m}^{2} \text { range (e.g. } \\
150-200 \mathrm{~m}^{2} \text { ) therefore assumption will need to be made regarding the stud } \\
\text { height and the floor area within the range. Regarding effective leakage area, } \\
\text { ASHRAE Standard } 160 \text { assumes either } 0.1 \mathrm{ACH} \text { or } 0.2 \mathrm{ACH} \text { for each house, } \\
\text { therefore assumption on the most suitable leakage area will need to be made } \\
\text { for each house based on its construction and age. }\end{array}$ \\
\hline 4 & $\begin{array}{l}\text { Although the hygrothermal properties of the building materials and finishes } \\
\text { would be able to be assumed, the PHS has no information on the type of } \\
\text { furniture within the space. }\end{array}$ \\
\hline 5 & $\begin{array}{l}\text { The EMC } 80 \text { and EMC } 90 \text { values for each construction are unknown and there } \\
\text { is not enough information in the PHS to make sound assumptions. }\end{array}$ \\
\hline 6 & $\begin{array}{l}\text { The PHS does not provide enough information regarding any potential } \\
\text { dehumidifying systems within each house - information is only provided into } \\
\text { the heating systems in various rooms. }\end{array}$ \\
\hline 7 & $\begin{array}{l}\text { Within ASHRAE Standard 160, Design Pressure Data is based on the Design } \\
\text { Air Pressure Differentials and Flows which is state to be optional. Additionally, } \\
\text { the PHS does not provide enough information to understand what the air } \\
\text { pressure differentials between indoors and outdoors. }\end{array}$ \\
\hline 8 & $\begin{array}{l}\text { A number of inputs are required for the Moisture Design Weather Data, and } \\
\text { whilst these are not available through the PHS, they would be able to be } \\
\text { gathered from a site such as NIWA and an appropriate weather file with the } \\
\text { all the appropriate inputs able to be developed. }\end{array}$ \\
\hline 9 & $\begin{array}{l}\text { A number of factors are required for the Design Rain Loads, however the } \\
\text { PHS does not have enough data to consider and determine factors such as } \\
\text { rainfall intensity, exposure factor, and the angle between the wind direction } \\
\text { and the wall which are all necessary for Design Rain Loads. }\end{array}$ \\
\hline 10 & $\begin{array}{l}\text { To assess the Indoor Design Humidity - Full Parameter Calculation, several } \\
\text { inputs are required. PHS data limitations means not all of the information for } \\
\text { each of these inputs is accessible and therefore is out of the scope of this } \\
\text { research and is unable to be tested at the present time. }\end{array}$ \\
\hline 11 & $\begin{array}{l}\text { Through utilising computer-based simulation programs such as WUFI Pro and } \\
\text { the VTT Mould Index Model, the conditions necessary to minimise model } \\
\text { growth would be able to be effectively and efficiently tested across several } \\
\text { conditions and houses. }\end{array}$ \\
\hline
\end{tabular}

Table 13 Comments and justification regarding choice of 'Design Parameters' 


\section{Chapter 5 Chapter Five - Data Gathering and Cleaning}

\subsection{Gathering Relevant Data}

As previously discussed, data gathered from the PHS was utilised within this research; however, the raw data from the PHS needed to be gathered, cleaned, and culled appropriately in order to create a suitable dataset. The PHS allocated six tag dataloggers which each recorded at approximately 15 minutes intervals for the majority of a year. The tags were placed in various spaces throughout the house: one in the living area, one outside, one in the roofspace, and the final three in any available bedrooms. If there were only two bedrooms within a house, then the third 'bedroom' tag would be allocated to another space within the house, e.g. the bathroom or an entranceway.

The houses where this data was gathered came from a more comprehensive survey undertaken by the BRANZ called the Housing Conditions Survey (HCS). The HCS surveyed 832 houses throughout New Zealand in 16 different regions, and the PHS included 82 of these houses across 12 different regions (BRANZ, 2020). The sample count by region has been outlined below in Table 14 . 


\begin{tabular}{ccc}
\hline Region & $\begin{array}{c}\text { HCS Survey } \\
\text { Count }\end{array}$ & $\begin{array}{c}\text { PHS Survey } \\
\text { Count }\end{array}$ \\
\hline Auckland & 122 & 7 \\
\hline Bay of Plenty & 65 & 13 \\
\hline Canterbury & 145 & 10 \\
\hline Gisborne & 32 & 6 \\
\hline Hawke's Bay & 25 & 5 \\
\hline Manawatu-Wanganui & 92 & 11 \\
\hline Marlborough & 9 & 1 \\
\hline Nelson & 9 & 0 \\
\hline Northland & 31 & 0 \\
\hline Otago & 53 & 9 \\
\hline Southland & 27 & 5 \\
\hline Taranaki & 22 & 3 \\
\hline Tasman & 14 & 2 \\
\hline Waikato & 85 & 0 \\
\hline Wellington & 98 & 10 \\
\hline West Coast & 3 & 0 \\
\hline Total & 832 & 82 \\
\hline
\end{tabular}

Table 14 Sample count by region for the HCS and PHS

Each house was randomly assigned a house ID number used throughout this research to ensure that the respondents' confidentiality is maintained.

\subsubsection{Exclusion of Data}

Whilst a large amount of data was gathered in the PHS, not all of the data gathered was necessary or applicable for this study. Roofspaces are out of the scope of ASHRAE Standard 160, and therefore all information associated with tags placed in these locations can be excluded from this study. Wet spaces such as bathrooms and laundry rooms have high moisture content and generally have unique ventilation and moisture requirements and therefore are also out of the scope of ASHARE Standard 160. For this reason, data gathered from the tags placed in wet spaces were also excluded. For a house to be assessed, there needs to be an external tag and at least one internal tag; however, it is preferable that there are several indoor tags. In most instances, tags for the external environment, the living area, and several bedrooms are present.

There were two circumstances in which a house and its subsequent data were excluded from this research. The first would be that the minimum requirement of data from an external tag not being met. The external data is necessary as this is required to implement ASHRAE Standard 160 and develop the likely internal conditions that are then to be compared to the measured indoor conditions. Six of the 82 houses had no external data, and thus these six houses were excluded. The second is when data is gathered, but the sample is not large enough to infer a pattern over a year. To determine which houses may be excluded for the aforementioned reason, each house's data was converted from a quarter-hourly time series into an hourly timeseries. The 
number of data points was then counted for each house. Ideally, each house would have 8760 data points (a full years' worth); however, houses with around 4000 data points were considered as this would be able to be used to infer seasonal trends at a minimum. These 4000 data points referred to both the internal and the external data points. The table shown in Appendix A summarises the number of data points from each house and shows that a further 19 houses are to be excluded, resulting in a final total of 54 houses. The rows highlighted in orange indicate the houses excluded based on the number of data points they have. The houses may have been excluded due to a lack of data, either internally or externally.

\section{1 .2 Final Sample of Houses}

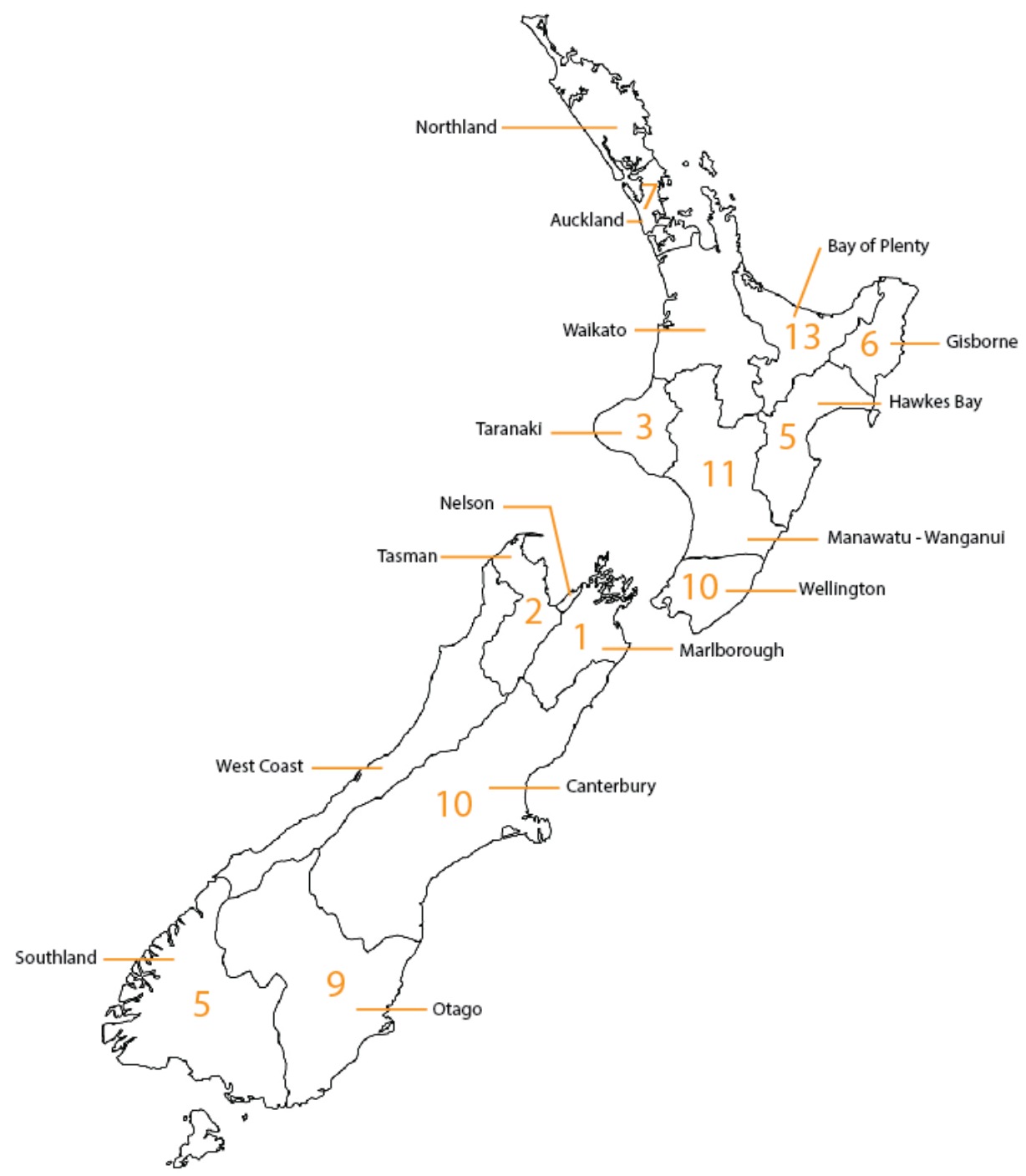

Figure 11 Map showing spread of houses throughout the different regions (Authors own image)

Of the final 54 houses, these houses are spread throughout 11 regions of New Zealand (Figure 11). This ensures that the sample used for this research is still able to represent a variety of climate zones throughout New Zealand and represent a variety of tenure and construction types. 
As previously discussed, whilst it may have been determined that there were a suitable number of data points for a house not to be excluded from this research, there may not be enough data points to make conclusions about a full year. Instead, many houses would be able to conclude seasonal trends. If the data points exceeded more than six months of the year, it was deemed that these houses would be classified as yearly trend houses as they cover three seasons. $53 \%$ of the houses were able to show yearly trends, whilst the remaining $47 \%$ of the houses showed seasonal trends. The table shown in Appendix A also shows a breakdown of which houses were used for seasonal trends or yearly trends.

Upon determining which houses would be used to show seasonal or yearly trends, a further five houses were excluded. These houses were excluded due to the period over which the data was gathered. For each of these houses, the internal and external data was not recorded simultaneously, resulting in an overlap period of only a month. This overlap did not span for long enough for these houses to even be considered to show seasonal trends, e.g. the overlap period was less than three months.

\subsection{Determining 'Typical' Measured Indoor Conditions}

The PHS provides a large amount of data on several rooms across numerous houses throughout New Zealand. Each of these rooms is likely to have different moisture generation, ventilation, and thermal requirements based on occupancy and space use. However, the indoor conditions specified by ASHARE Standard 160 do not differentiate between these different types of rooms; instead, it specifies one set of conditions throughout the whole house. As a result of this, the measured data from the PHS cannot be directly compared to the conditions specified by ASHRAE Standard 160. Therefore, the 'typical' measured conditions were specified from the multiple indoor sensors. To specify the 'typical' measured conditions, the measured indoor conditions' average needed to be determined, as discussed in Section 3.3 in Figure 9.

Therefore, the PHS data needed to be processed to better reflect the entire house conditions rather than a single room's conditions. Some factors, such as temperature, were averaged over all the interior tags in order to achieve this. However, as relative humidity depends on other factors such as the temperature, this could not be averaged. Therefore, each tag's relative humidity was converted to absolute humidity and then using the average temperature, the average absolute humidity was converted back to relative humidity. This process was undertaken for each datapoint with each house once an hour using humidity conversion formulas gathered from Vaisala Oyj (2013). An example of this process has been shown in Figure 12. 


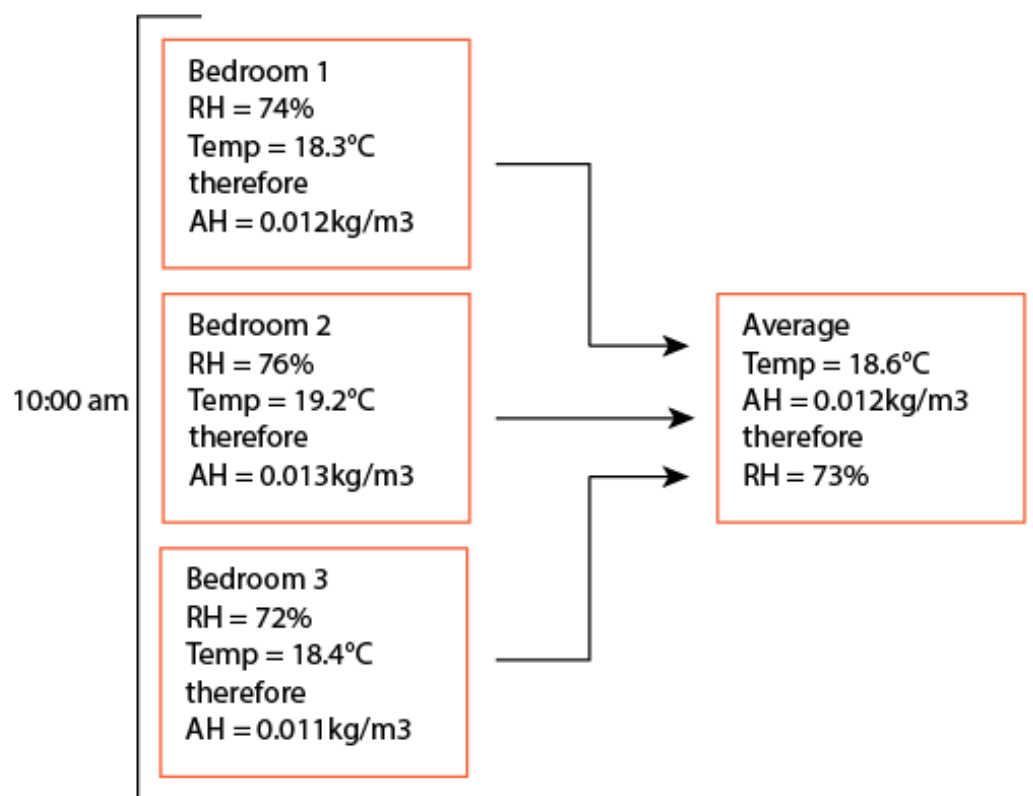

Figure 12 Example of resampling process using humidity conversion formula from Vaisala Oyj (2013)

\subsection{Final Dataset}

Having culled and cleaned the original PHS data, a final dataset has been created that was used to assess the applicability of the use of ASHRAE Standard 160 in New Zealand. This final dataset consists of 53 houses across 11 different New Zealand regions. Whilst also considering various climate regions, this dataset consists of various tenure types, building sizes, and construction and cladding types. 


\section{Chapter 6 Chapter Six- Analysis of Indoor Design Temperature}

In an instance where the indoor conditions are not known, the simplest method, which ASHRAE Standard 160 allows for the indoor conditions to be determined, uses Indoor Design Temperature (IDT) and Indoor Design Humidity: Simplified Method (Simplified IDH). To implement both of these, the only variable required is the outdoor temperature which can be gathered through a weather file. For this research, the outdoor temperature can be gathered using the external tags associated with each house.

\subsection{Application of Indoor Design Temperature}

ASHRAE Standard 160 assumes that the IDT is directly related to the outdoor temperature and is specified as one of three values, dependent on the 24-hour running average of the outdoor temperature $\left(\mathrm{T}_{024 \mathrm{~h}}\right)$. These three values and the appropriate equations have been shown in Table 6 . If the building code, design or operation of a building does not specify the indoor operating temperature, then the formulas given by ASHRAE Standard 160 specifies an indoor temperature. The equations in Table 6 demonstrate that the IDT assumes a minimum heating setpoint within a space of $21.1^{\circ} \mathrm{C}\left(70^{\circ} \mathrm{F}\right)$. The heating setpoint is based on the idea that if the $\mathrm{T}_{024 \mathrm{~h}}$ falls below $18.3^{\circ} \mathrm{C}\left(65^{\circ} \mathrm{F}\right)$, then the indoor temperature would fall below a comfortable 
temperature, thus requiring heating to a minimum of $21.1^{\circ} \mathrm{C}$. Therefore, ASHRAE Standard 160 assumes that all spaces assessed with the IDT have some form of space heating to ensure this minimum temperature would be achieved regardless of the outdoor temperature. The minimum heating setpoint is significant when considering how this applies to a New Zealand context. The NZBC Clause G5 specifies that 'Habitable Spaces'shall have provisions for maintaining an internal temperature of no less than $16^{\circ} \mathrm{C}$ whilst the space is adequately ventilated. This performance specification only applies to old people's homes and early childhood centres (Department of Building and Housing, 2011). Therefore, these initial assumptions that ASHRAE Standard 160 makes regarding space heating always being present in houses are not a certainty in a New Zealand context.

Using the cleaned and culled data from the PHS, a $\mathrm{T}_{024 \mathrm{~h}}$ was generated for each day for house, and consequently, an IDT was produced for each house. This IDT was then graphed and compared to the measured indoor temperature prepared from the process shown in Figure 12.

\subsection{Indoor Design Temperature Analysis}

Having created a graph of the IDT and the measured indoor temperature of each of the houses within this study, several trends and points of interest become evident. These graphs are shown in Appendix B. A number of these points of interest can be attributed to the formulas applied to the external data under ASHARE Standard 160.

\subsubsection{Measured Indoor Temperature}

Having plotted the measured indoor temperature against the IDT, initial trends in the measured indoor temperature become evident. The most notable trend is that the measured indoor temperature follows a clear seasonal trend. The spaces become warmer in the summer months and cooler throughout the winter months. In conjunction with this trend, it is clear that the measured indoor temperature is highly dependent on the outdoor temperature for a majority of the houses. This trend is shown through the peaks and troughs in the indoor measured temperature data, which shows both the seasonal trend and the daily variations in the temperature as the external temperature changes daily. A smooth trend of the measured indoor temperature would indicate that a house was being conditioned and that the external temperature was not a significant influence on the indoor temperature. From the lack of a consistent measured indoor temperature throughout the year, the data suggests that the houses within this sample either do not have any space conditioning systems or are only using them at certain times of the day.

Information gathered in the PHS shows that $21 \%$ of the assessed properties had no form of space heating, $55 \%$ had heating in either the living area or bedroom, and $24 \%$ had heating in both the bedrooms and the living area. Whilst nearly threequarters of the houses have some form of space heating, the measured indoor temperature suggests that these systems are not being utilised to maintain a 
comfortable temperature. This supports the idea that White and Jones (2017) discussed in which the presence of a heating appliance does not necessarily equate to its use. It is also imperative to note ASHRAE Standard 160 assumes an absolute minimum IDT of $21.1^{\circ} \mathrm{C}$, which in New Zealand would only be achieved in winter through the use of a heating appliance. As the initial analysis of the measured indoor temperature suggests that New Zealanders are not constantly heating their houses, this already begins to pose the question of the suitability of the heating lower limit.

\subsubsection{Lower Limit of $21.1^{\circ} \mathrm{C}$}

One of the most notable trends is that the minimum IDT of $21.1^{\circ} \mathrm{C}$ is applied $100 \%$ of the time for nearly half of the year (April - October) over all the assessed houses apart from two (House 140 and House 144). This instance of the minimum IDT of $21.1^{\circ} \mathrm{C}$ is applied whenever the $T_{024 h}$ drops below $18.3^{\circ} \mathrm{C}$. The application of this formula is important to analyse as the specification of a lower limit is specifying steady state conditions for a prolonged period of time. Johansson et al. (2013) discussed the significance of implementing these steady states conditions as they can minimise the potential for favourable or unfavourable mould growth conditions to occur. Periods of favourable or unfavourable mould growth conditions are vital to consider in mould growth prediction tools.

From the IDT produced, it is clear that the external temperature is rarely above $18.3^{\circ} \mathrm{C}$ in winter throughout the country. Of the two houses (House 140 and House 144) that did not apply the minimum $21.1^{\circ} \mathrm{C}$ setpoint throughout the entire winter, neither of the houses have any unique features or factors that differentiate them from any other houses within the study. However, the IDT is dependent on the external temperature; therefore, the house's design is not necessarily of interest but rather the location and region of the houses. House 140 is located in the Canterbury region, and House 144 is located in the Southland region; but within this study, there are eight other houses in the Canterbury region and three others in the Southland region. Both the Southland and Canterbury regions are geographically, relatively large, and therefore are likely to experience some variation in outdoor air temperatures throughout the region. This, therefore, shows that the location of a house can significantly impact the IDT.

As well as being applied to all houses between April - October, several instances occur where the indoor minimum $21.1^{\circ} \mathrm{C}$ is required to be assumed over a series of days in the middle of summer. The application of the $21.1^{\circ} \mathrm{C}$ IDT occurs for several days at a time in at least one house in every region. There are several instances that this lower limit is applied more often than not in the summer months, and these tended to be in houses in the more Southern regions of New Zealand. An example of this is House 136, shown in Figure 13. 
House 136

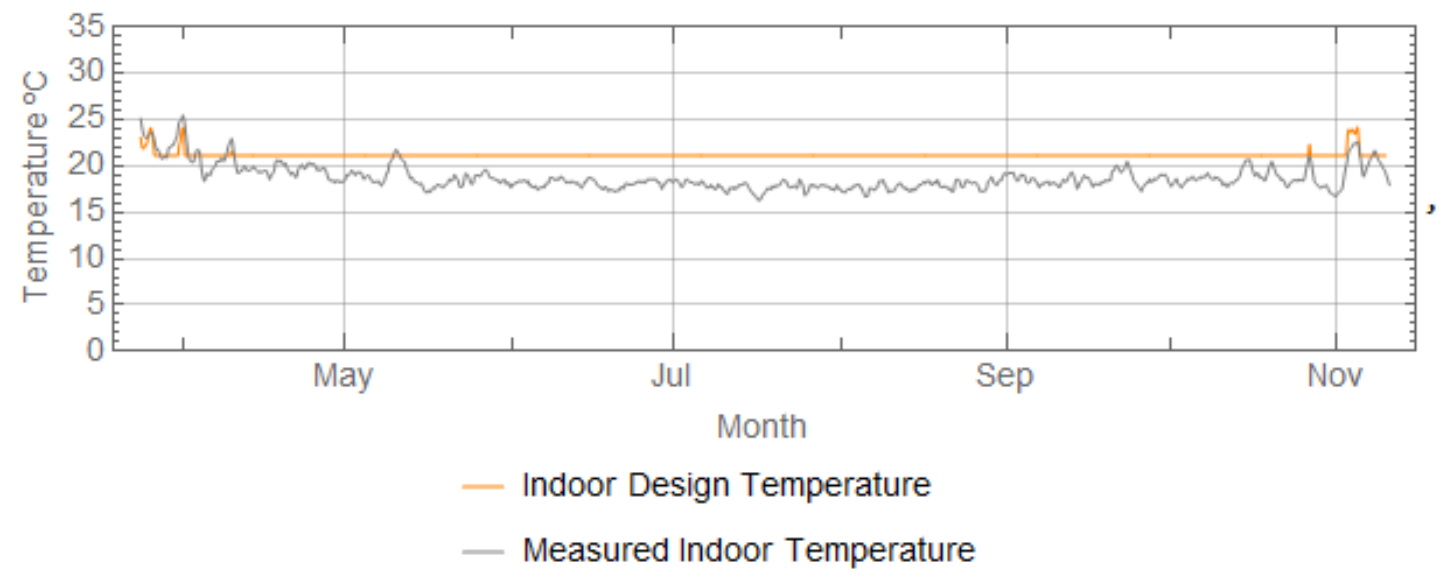

Figure 13 Indoor Design Temperature and measured indoor temperature of House 136

Over the period where the minimum heating setpoint of $21.1^{\circ} \mathrm{C}$ was set, the measured indoor temperature was consistently lower in all of the houses. The difference between the measured indoor temperature and the Simplified IDT between June - August (winter) ranged from $4^{\circ} \mathrm{C}-8^{\circ} \mathrm{C}$ shown in Figure 14 . This difference in temperature over the winter months indicates that the Simplified IDT expects warmer temperature than are being measured.

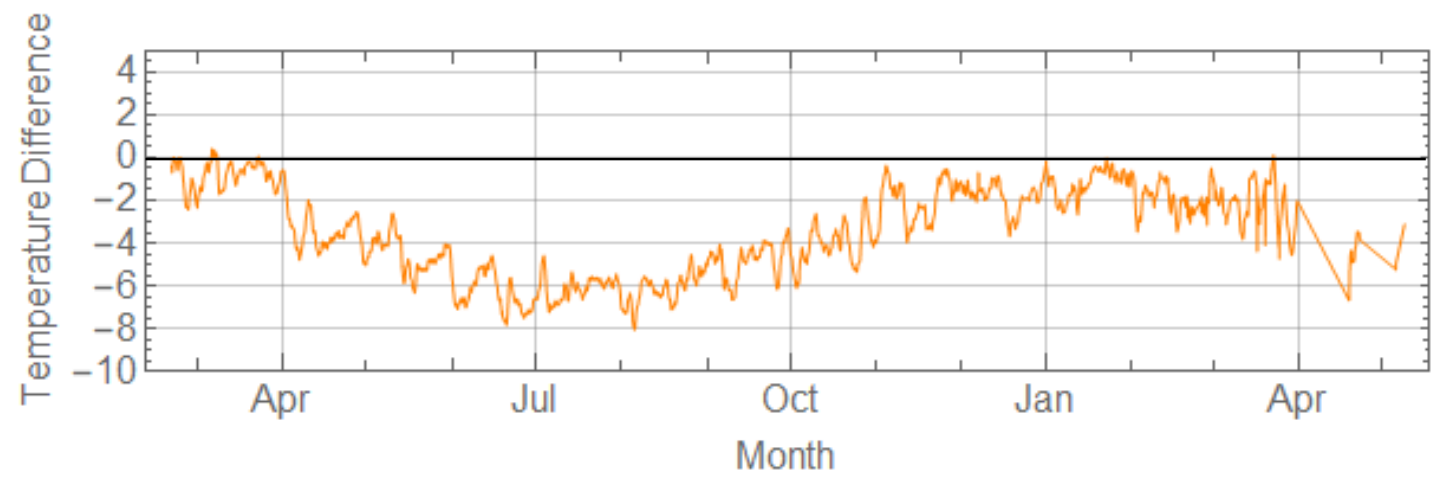

Figure 14 The average difference between the Indoor Measured Temperature and the Simplified IDT across all assessed properties

\section{$6.2 .3 \mathrm{~T}_{024 \mathrm{~h}}+\mathbf{2 . 8}^{\circ} \mathrm{C} \mathrm{Occurrence}$}

If the $\mathrm{T}_{024 \mathrm{~h}}$ exceeds $18.3^{\circ} \mathrm{C}$, ASHRAE Standard 160 assumes the IDT to be the $\mathrm{T}_{024 \mathrm{~h}}+2.8^{\circ} \mathrm{C}$. It is assumed that if the outdoor temperature exceeds $18.3^{\circ} \mathrm{C}$ then there is no need for space conditioning within a house, and therefore the indoor temperature is much more reliant on the outdoor temperature. This formula is applied in all the assessed houses throughout the year, but most commonly in the summer months. This trend is expected as New Zealand is generally exposed to a relatively warm climate over summer. 
It is evident that when this formula is applied, it follows the measured indoor temperature more closely than just a fixed limit of $21.1^{\circ} \mathrm{C}$. As previously discussed, when looking at the measured indoor temperature, it is evident that the houses do not generally utilise heating appliances. Over the periods when this formula is applied, the IDT accurately follows the measured indoor temperature trend. When there is a spike in the measured temperature, the IDT also spikes. This is true for all houses when the formula is applied and indicates that the indoor temperature is closely dependent on the outdoor temperature in the houses within this study. An example of this has been shown in House 125, shown in Figure 15, with the critical points circled in orange. For four months the indoor temperature was so low that ASHRAE 160 required it be set to a fixed $21.1^{\circ} \mathrm{C}$, but outside this period the IDT closely followed the measured indoor temperature.

House 125

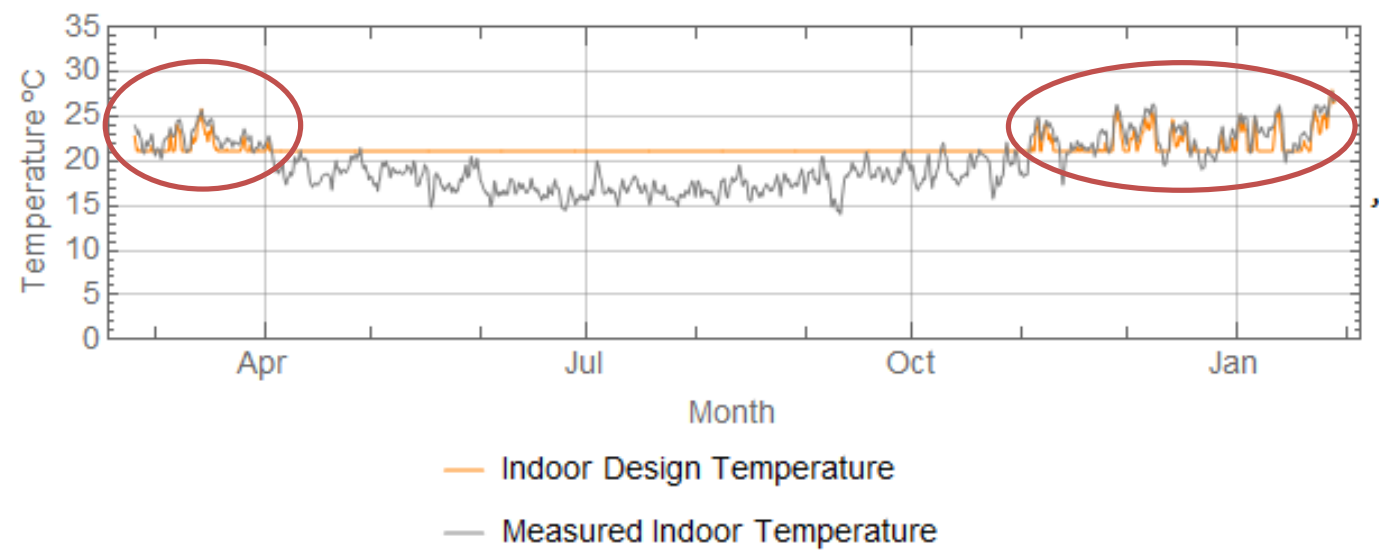

Figure 15 Indoor Design Temperature and measured indoor temperature of House 125

Although the overall trend and pattern of the IDT matches that of the measured indoor temperature when using this formula, how close this is, varies from house to house. Of the houses that required this formula, $87 \%$ had an IDT that differed between $0^{\circ} \mathrm{C}$ and $3^{\circ} \mathrm{C}$ from the measured indoor temperature. The other $13 \%$ of houses had an IDT with over a $3^{\circ} \mathrm{C}$ difference from the measured indoor temperature although these houses were spread across different regions (Otago, Canterbury, and Southland) with different sizes and typologies. There is no apparent connection between these houses or any clear distinction between these houses and the other $87 \%$ of houses where this formula is much more accurate. It is worth noting that two of the houses where this formula was not as accurate were House 140 and House 144. In the previous section, these two houses were discussed as they were the only two houses to apply this formula at some stage in the winter months.

Whilst several houses experienced over a $3^{\circ} \mathrm{C}$ difference between the IDT and the measured indoor temperature, House 140 experienced differences over $12^{\circ} \mathrm{C}$ in the middle of winter, seen in Figure 16. 
House 140

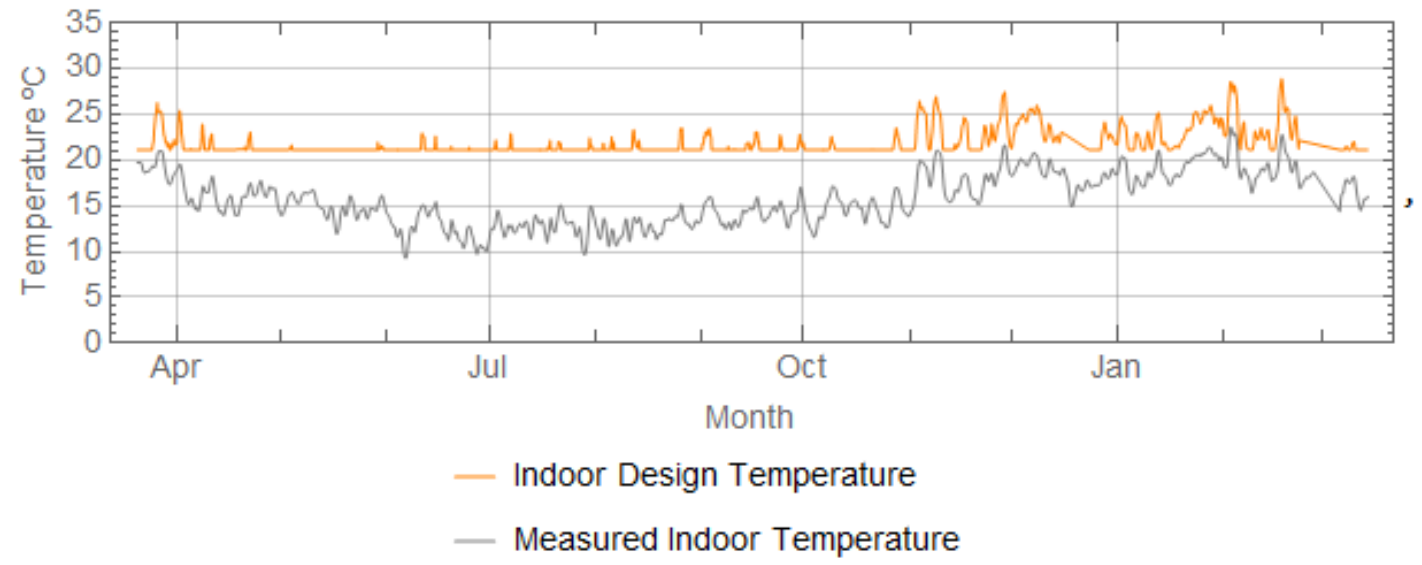

Figure 16 Indoor Design Temperature and measured indoor temperature of House 140

Interestingly, from the graph shown in Figure 16, during winter the measured indoor temperature is exceptionally low. House 140 is located in Canterbury so therefore without the use of heating, indoor temperature these low temperatures are plausible. However, when looking at the IDT, these numbers seem strange. Periodically over the winter months (between June - September), the $\mathrm{T}_{024 \mathrm{~h}}+2.8^{\circ} \mathrm{C}$ formula is applied because the external temperature exceeds $18.3^{\circ} \mathrm{C}$. However, at no instance between June - September did the indoor temperature exceed $18.3^{\circ} \mathrm{C}$, indicating that over this period the measured indoor temperature is cooler than the outdoor temperature.

\subsubsection{Removing Lower Limit of $21.1^{\circ} \mathrm{C}$}

It is evident that within a New Zealand context, the assumption that houses are heated to a minimum of $21.1^{\circ} \mathrm{C}$ when the outdoor temperature drops below $18.3^{\circ} \mathrm{C}$ is not realistic. Instead, the assumption that the indoor temperature is heavily reliant upon the outdoor temperature is much more applicable. From the previous analysis the formula of $\mathrm{T}_{024 \mathrm{~h}}+2.8^{\circ} \mathrm{C}$ is much more applicable for a New Zealand context.

To further understand the influence of the $21.1^{\circ} \mathrm{C}$ minimum setpoint and how greatly it differs from the measured indoor temperatures, a secondary set of graphs was produced of the IDT. These secondary graphs removed the lower limit if $21.1^{\circ} \mathrm{C}$ and implemented the $\mathrm{T}_{024 \mathrm{~h}}+2.8^{\circ} \mathrm{C}$ equation across all temperature in order to assess the suitability of this formula to match the measured indoor temperature better. These graphs have been shown in Appendix C.

To assess whether removing the lower limit of $21.1^{\circ} \mathrm{C}$ improved the accuracy of the IDT, a graph was produced that looked at the average difference of the IDT and the measured indoor temperature as well as the average difference of the IDT with no lower limit and the measured indoor temperature (Figure 17). 


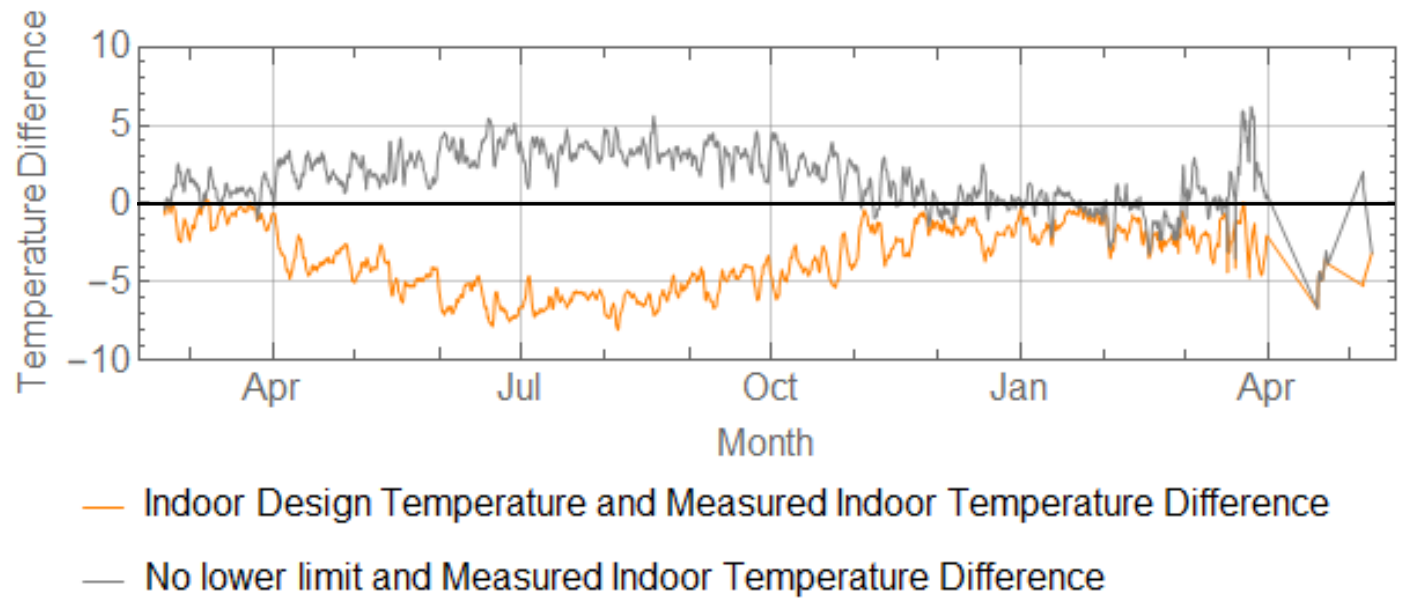

Figure 17 The average difference between the IDT and the Measured Indoor Temperature and the average difference between the IDT with no lower limit and the Measured Indoor Temperature across all assessed properties

From the graph shown in Figure 17, it can be seen that by removing the lower limit of $21.1^{\circ} \mathrm{C}$, the difference between the IDT and the measured indoor temperature was reduced. In the original IDT formula, over the winter months, the IDT was between $-0.5^{\circ} \mathrm{C}$ to $-8^{\circ} \mathrm{C}$ difference from the measured temperature, however when removing the lower limit, the IDT is between $1^{\circ} \mathrm{C}$ to $5^{\circ} \mathrm{C}$ difference from the measured indoor temperatures. Over winter the instances when $21.1^{\circ} \mathrm{C}$ is applied, the average difference drastically increases, however, when this limit is removed and a blanket $\mathrm{To}_{24 \mathrm{~h}}+2.8^{\circ} \mathrm{C}$ is applied, the average difference remains relatively stable throughout the year. Removing the lower limit of $21.1^{\circ} \mathrm{C}$ reduced the difference between the IDT and the measured indoor temperature thus showing that the lower limit is not applicable for a New Zealand context.

The graph in Figure 17 further suggests that whilst the $\mathrm{TO}_{24 \mathrm{~h}}+2.8^{\circ} \mathrm{C}$ is an improvement on the $21.1^{\circ} \mathrm{C}$ limit, it may too need to be altered to better reflect New Zealand conditions as the average difference reached up to $5^{\circ} \mathrm{C}$. 


\section{Chapter 7 Chapter Seven - Analysis of Simplified Indoor Design Humidity}

The second indoor condition that ASHRAE Standard 160 implements is Indoor Design Humidity (IDH), using the Simplified Method (Simplified IDH) or the Intermediate Method (Intermediate IDH). Similar to the Indoor Design Temperature, the only variable that is required is the outdoor temperature.

\subsection{Application of Indoor Design Humidity: Simplified Method}

Just as ASHRAE Standard 160 assumes that the IDT is directly proportional to the outdoor temperature, the same applies to the IDH. There are three different equations for the Simplified IDH based upon the $T_{024 h}$, as shown in Table 7. The equations shown in Table 7 demonstrate that the Simplified IDH assumes that the relative humidity will always be between $40 \%$ and $70 \%$. In order to calculate the Simplified IDH, if the $\mathrm{T}_{024 \mathrm{~h}}$ are between $-10^{\circ} \mathrm{C}\left(14^{\circ} \mathrm{F}\right)$ and $20^{\circ} \mathrm{C}\left(68^{\circ} \mathrm{F}\right)$, then the relative humidity is $40 \%+\left(\mathrm{T}_{024 \mathrm{~h}}+10\right)$. If the $\mathrm{T}_{024 \mathrm{~h}}$ is below $-10^{\circ} \mathrm{C}$ the relative humidity is fixed at $40 \%$, and if the $\mathrm{T}_{024 \mathrm{~h}}$ is above $20^{\circ} \mathrm{C}$, then the relative humidity is fixed at $70 \%$.

The NZBC does not specify an ideal relative humidity. The equation for relative humidity is as follows: 


$$
\text { Relative humidity }=\frac{\text { Vapour pressure }}{\text { Saturation vapour pressure }}
$$

As air temperatures differ, so does the saturation vapour pressure. At a lower temperature that can only hold 10 molecules of moisture, if there are 10 molecules of moisture in the air, the relative humidity would be $100 \%$. However, at a higher temperature which can hold 20 molecules of moisture, the same 10 molecules of moisture in the air would mean that the relative humidity is now $50 \%$. The amount of moisture in the air has not changed however, the relative humidity has. From Equation 13 it can be derived that whilst the temperature influences the relative humidity, other factors are also considered, most notably the moisture content in the air.

The indoor air's moisture content depends on numerous factors such as outdoor absolute humidity, occupancy level, occupancy activity, and ventilation. The Simplified IDH does not consider these factors; however, the Intermediate IDH does, and this will be discussed in Chapter Eight.

\subsection{Indoor Design Relative Humidity: Simplified Method analysis}

Having created a graph of the Simplified IDH and the measured indoor relative humidity for each of the study houses, several trends and points of interest become evident. These trends are discussed in the following sections.

\subsubsection{Fluctuation in Measured Indoor Relative Humidity}

Unlike the measured indoor temperature where there are clear seasonal trends, there is no seasonal trend present with the measured relative humidity with no clear shift in the summer months compared to the winter months - see for example Figure 18. This raises some questions when considering the trend seen in the indoor temperature and the principles previously discussed regarding relative humidity and saturation vapour pressure.

If the outdoor temperature dropped whilst the moisture content (absolute humidity) remained the same, when brought inside and warmed it would be expected that the indoor relative humidity would also drop in the winter months. However, as the indoor relative humidity does not have these seasonal trends this indicates that the moisture content inside is fluctuating throughout the year. During the winter any increase in moisture content is likely to be due to higher occupancy and for longer durations as well as reduced ventilation due to occupants not airing out the space because of cooler outside temperatures. This initial analysis suggests that occupancy behaviour has a vital impact on the moisture content within a space and consequently the relative humidity.

Another noticeable trend is that in approximately $75 \%$ of the houses regardless of location, the measured indoor relative humidity fluctuates throughout the year by up to $40 \%$, between the range of $50 \%-90 \%$. 
However, in contrast in approximately $25 \%$ of the houses the relative humidity is more consistent and only fluctuates by $20 \%$ (generally between $50 \%-70 \%$ ). There is no clear indication as to why a quarter of these houses experience a more consistent relative humidity, although they are located in more southern regions with houses in the Manawatu-Wanganui region being the most northern.

\subsubsection{General Trends in Indoor Design Humidity Simplified Method}

An initial analysis of the Simplified IDH in comparison to the measured indoor relative humidity found the accuracy varied from house to house. There were four key trends from this initial analysis which each house was able to be allocated:

1. Overall the Simplified IDH and the measured indoor relative humidity varied throughout the year however, there was generally a difference between the two of about $10 \%$.

2. Both the Simplified IDH and the measured indoor relative humidity follow each other closely with minimal difference, particularly in the winter months.

3. There was no clear relationship or trend between the Simplified IDH and the measured indoor relative humidity.

4. The Simplified IDH followed a much more consistent trend and appeared to smooth out the extreme fluctuations of the measured indoor relative humidity.

\subsubsection{Indoor Design Humidity Simplified Method Trend 1}

The first trend covers $26 \%$ of the assessed properties, as given in Appendix D. Although only covering a five-month period between April to September, House 137 (shown in Figure 18) is a clear example of the first trend in which they follow the same pattern although the measured relative humidity is consistently higher than the IDH.

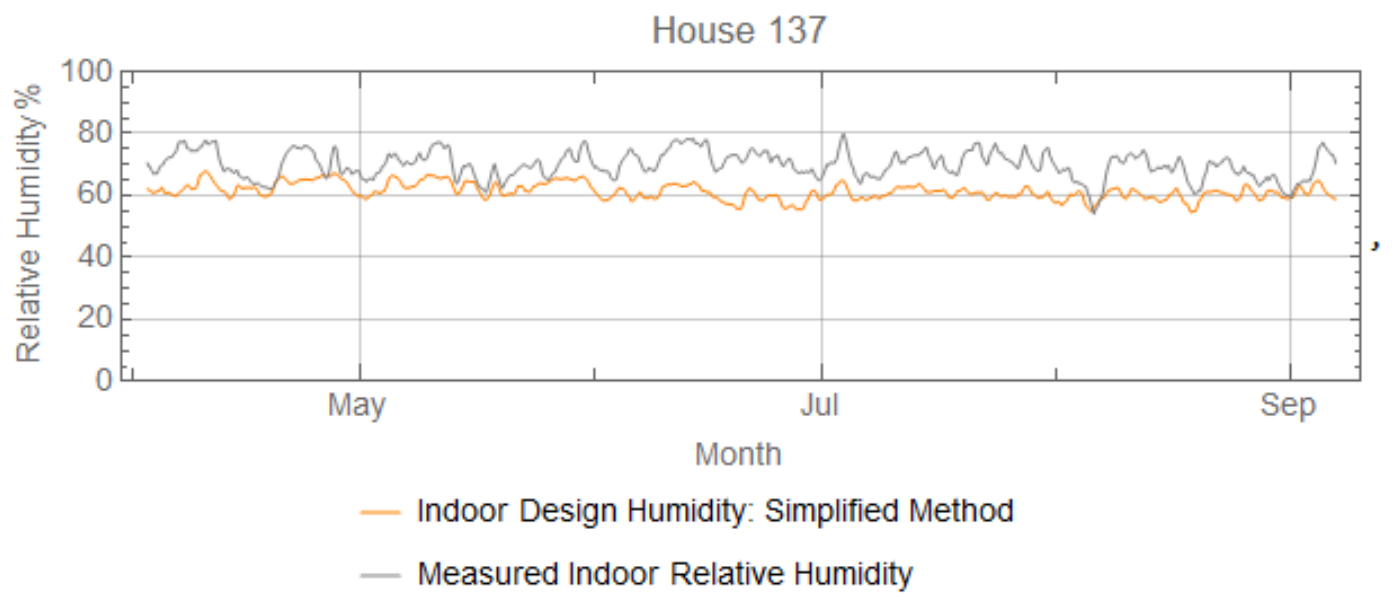

Figure 18 Indoor Design Humidity: Simplified Method and measured indoor relative humidity for House 137

From Figure 18 it can be clearly seen that particularly through the period of June - August the Simplified IDH and the measured indoor relative humidity follow a very similar trend with peaks and troughs occurring at the same time. However, it is 
also clear that in most instances, the measured indoor relative humidity is on average $10 \%$ higher.

\subsubsection{Indoor Design Humidity Simplified Method Trend 2}

The second identified trend applies to $30 \%$ of the assessed properties, see Appendix E. In this trend the Simplified IDH and the measured indoor relative humidity match more closely follow each other, differing by less than $5 \%$ for a majority of the measured period. House 136 (shown in Figure 19) in an example of this trend.

House 136

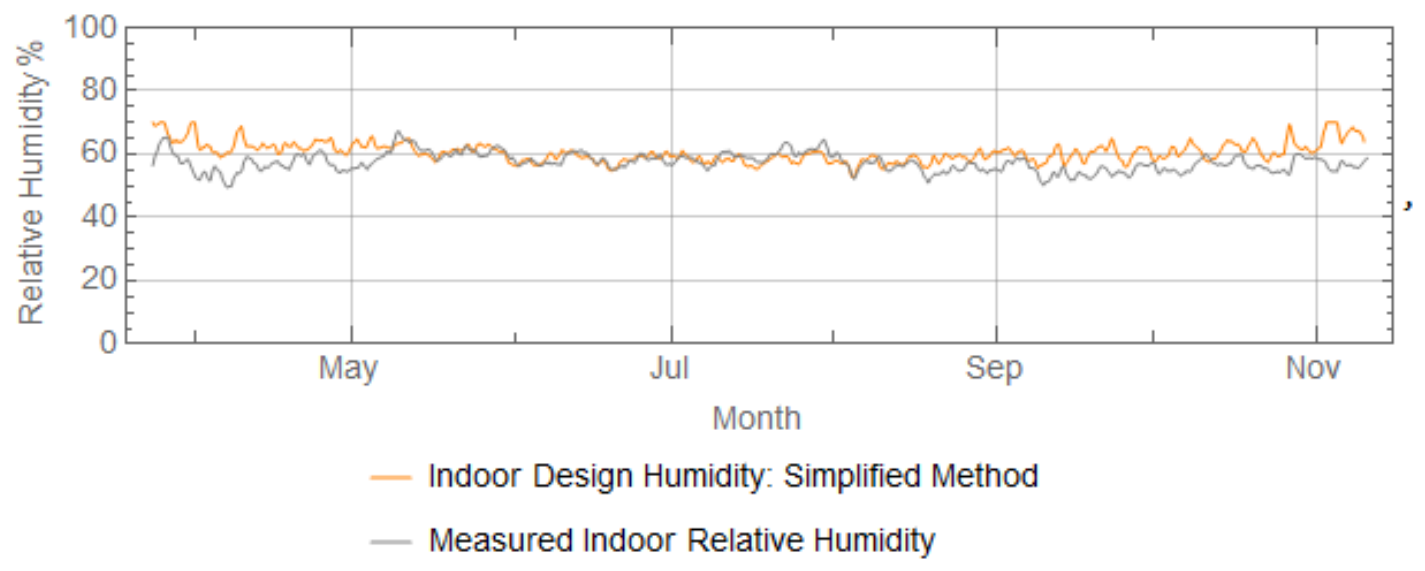

Figure 19 Indoor Design Humidity: Simplified Method and measured indoor relative humidity for House 136

The data from House 136 covers just seven months for the entirety of winter and several months on either side. Figure 19 covers from mid-May to mid-August, and the Simplified IDH and the measured indoor relative humidity follow each other within $5 \%$. During the months from approximately April to mid-May and mid-August to November the relative humidity only differs by around $10 \%$. Figure 19 and the graphs in Appendix E, it appears that the Simplified IDH is more accurate at predicting the relative humidity during the winter months as opposed to the summer.

\subsubsection{Indoor Design Humidity Simplified Method Trend 3}

The previous two trends discussed the similarities in the Simplified IDH and the measured indoor relative humidity however, there are several cases where the no similar pattern between either of these. This trend occurs in $22 \%$ of the assessed houses, shown in Appendix F. House 144 (Figure 20) is an example of these two sets of data not matching in terms of the general trend as well as the relative humidity. 


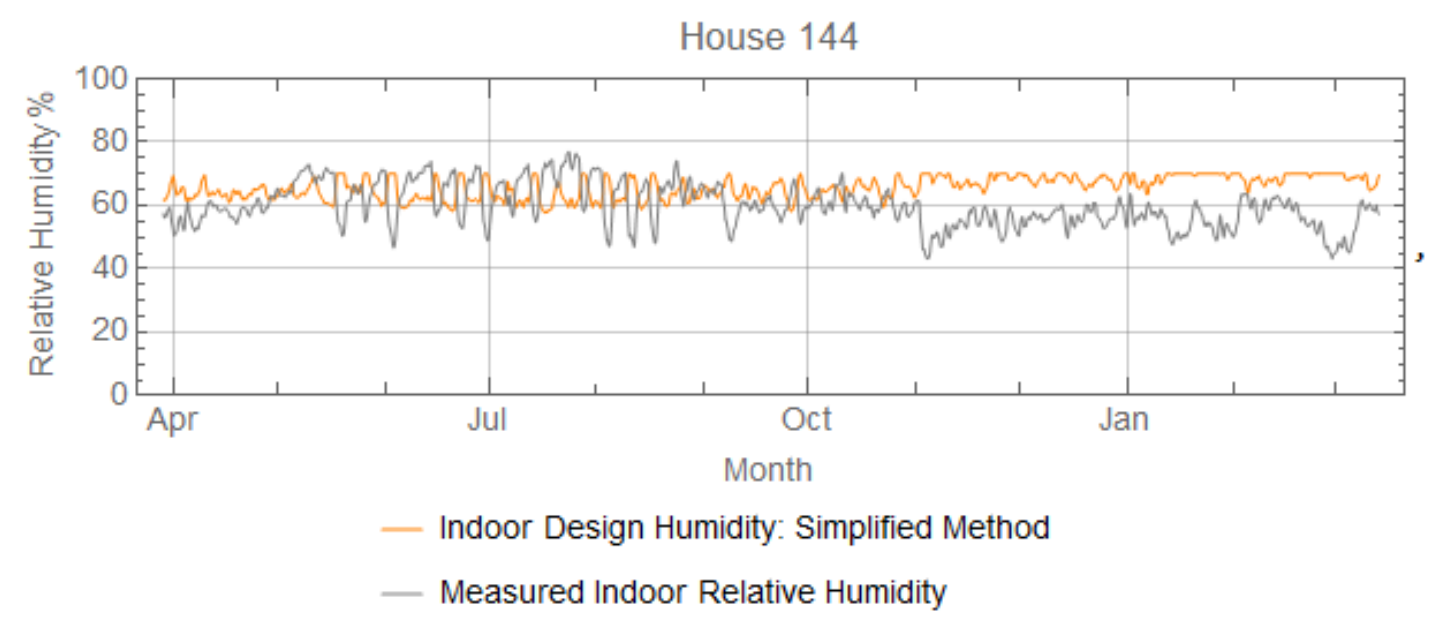

Figure 20 Indoor Design Humidity: Simplified Method and measured indoor relative humidity for House 144

Whilst this lack of a match in the general trend as well as the humidity prediction occurs most notably in House 138, it occurs in some form across approximately $22 \%$ of the assessed houses and is most notable over the summer months. This is clear in the graph shown in Figure 20 where there are some overlaps in the Simplified IDH and measured indoor humidity between May to October. However, despite these overlaps in the humidity prediction, the trends do not follow the same pattern. This can be seen where there are large peaks and troughs in the measured indoor humidity, however these are mirrored in the Simplified IDH most notably between mid-May to mid-August. Over this period the measured indoor humidity increases the Simplified IDH decreases and vice versa often resulting in a difference of over $10 \%$. Between November and March this difference increases to a maximum difference of $23 \%$. There is no defining housing characteristics gathered from information form the PHS, be it typology, location, or occupancy, that would indicate a house was more prone to experiencing this trend than any other house.

\subsubsection{Indoor Design Humidity Simplified Method Trend 4}

The final trend that has been identified is that the Simplified IDH tends to smooth out extreme daily fluctuations that are seen in the measured indoor humidity. This happens across $22 \%$ of the assessed houses, all of which have been shown together in Appendix G. An extreme example of this can be seen in House 113 shown in Figure 21. 
House 113

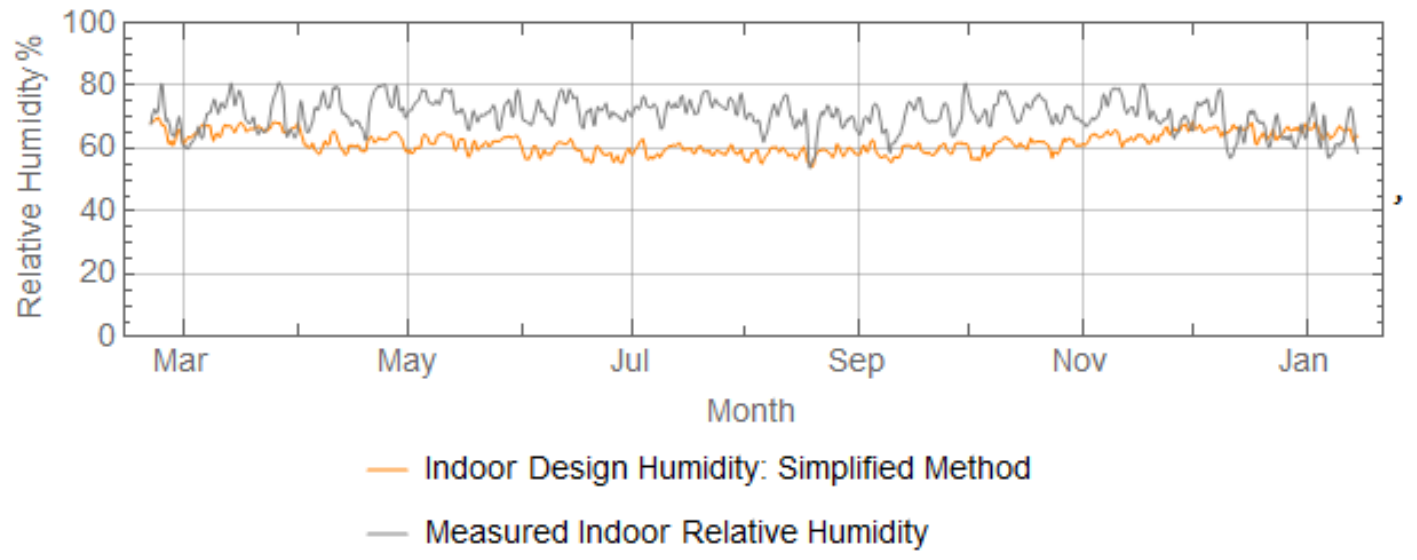

Figure 21 Indoor Design Humidity: Simplified Method and measured indoor relative humidity for House 113

As shown in Figure 21, the measured indoor relative humidity fluctuates by $27 \%$ between $54 \%$ and $81 \%$ throughout the entire measurement period. A fluctuation this large in the measured indoor relative humidity suggest that there could be periods when the mould growth conditions would be unfavourable. However, in contrast to this the Simplified IDH fluctuates by $13 \%$ between $55 \%$ and $68 \%$. This suggests that the Simplified IDH may be flattening out extreme fluctuations in relative humidity. This flattening out of the relative humidity may negatively impact the assumptions made regarding the periods of favourable and unfavourable mould growth conditions that are being experiences. This in turn could impact the mould growth predictions, as discussed in Johansson et al. (2013) where mould retardation factors can greatly impact the rate of mould growth.

\subsubsection{Lower and Upper limits of $\mathbf{4 0 \%}$ and $\mathbf{7 0 \%}$ Relative Humidity}

The Simplified IDH specifies that in no instance shall the relative humidity drop below $40 \%$ or shall exceed $70 \%$. Both of these values are based upon the $\mathrm{T}_{024 \mathrm{~h}}$ thus assuming that the temperature and relative humidity have some influence on each other. The minimum of $40 \%$ relative humidity is never applied across any of the NZ houses which was to be expected because this lower relative humidity limit is only applied when the $\mathrm{T}_{024 \mathrm{~h}}$ is below $-10^{\circ} \mathrm{C}$. Whilst New Zealand can experience colder outdoor temperatures, these are generally only experienced sporadically in Central Otago and some Alpine areas, however, temperatures of below $-10^{\circ} \mathrm{C}$ frequently occur in populated parts of North America, as illustrated in Figure 2. Additionally, the measured indoor relative humidity does frequently drop below $40 \%$ in both New Zealand and North America, often at times when the temperature is above $-10^{\circ} \mathrm{C}$.

Utilising the measured indoor relative humidity and the simplified IDH, the aforementioned occurs over a handful of the sample of houses throughout the country, thus indicating that the Simplified IDH assumption that $40 \%$ relative humidity is only achieved when outdoor temperatures drop below $-10^{\circ} \mathrm{C}$ is not consistent with the measured data. In the instances in which the measured relative humidity was recorded at $40 \%$ or lower, the Simplified IDH specified anywhere from $52 \%$ relative humidity to 
the maximum of $70 \%$. An example of this occurring can be seen in House 103 shown in Figure 22. From the Simplified IDH formula and the connection to $\mathrm{T}_{024 \mathrm{~h}}$ This would indicate that, the $\mathrm{T}_{024 \mathrm{~h}}$ would be anywhere from $2^{\circ} \mathrm{C}$ up to and in excess of $20^{\circ} \mathrm{C}$.

The upper relative humidity limit of $70 \%$ is applied when $\mathrm{T}_{024 \mathrm{~h}}$ exceeds $20^{\circ} \mathrm{C}$ which occurs frequently throughout many regions of New Zealand predominately in the summer months. The Simplified IDH is specified, following this rule, to be $70 \%$ at some stage throughout the year for $66 \%$ of the assessed properties. Most commonly this limit was applied in the summer months as these were the time periods where the $\mathrm{T}_{024 \mathrm{~h}}$ frequently exceeded $20^{\circ} \mathrm{C}$. However, when this maximum of $70 \%$ relative humidity was applied under the Simplified IDH, the measured humidity was often much lower than 70\%. House 103 (shown in Figure 22) is an example of this situation occurring in which, over the summer months, the measured relative humidity drops to as low as $40 \%$ whilst the Simplified IDH is specified at the maximum of $70 \%$. The areas of interest have been circled on the graph shown below in Figure 22.

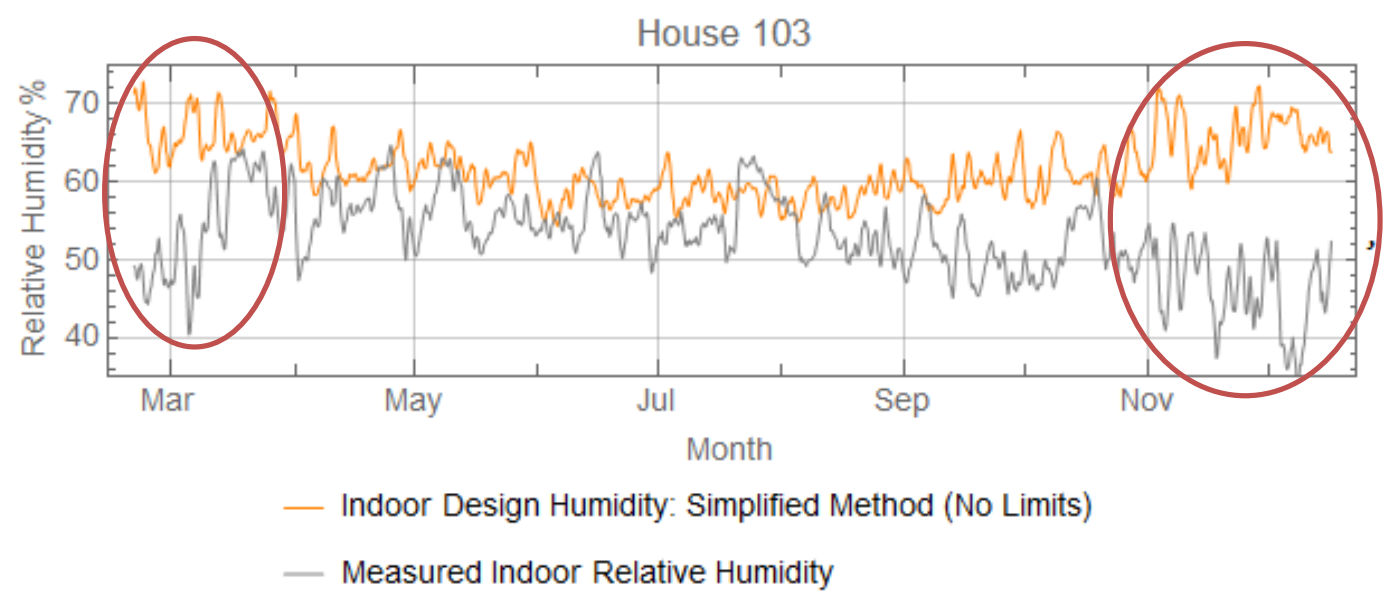

Figure 22 Indoor Design Humidity: Simplified Method and measured indoor relative humidity for House 103

In contrast to this there were many instances in which the measured indoor humidity was over $70 \%$ relative humidity, however, the Simplified IDH did not specify the maximum $70 \%$ relative humidity. This indicates that a relative humidity of $70 \%$ can be achieved without the outdoor temperature being in excess of $20^{\circ} \mathrm{C}$. An example of this occurring is shown in Figure 23 where House 116 shows that for the majority of the year the measured indoor humidity is in excess of $70 \%$ however, in no instance does the Simplified IDH specify the maximum $70 \%$. 
House 116

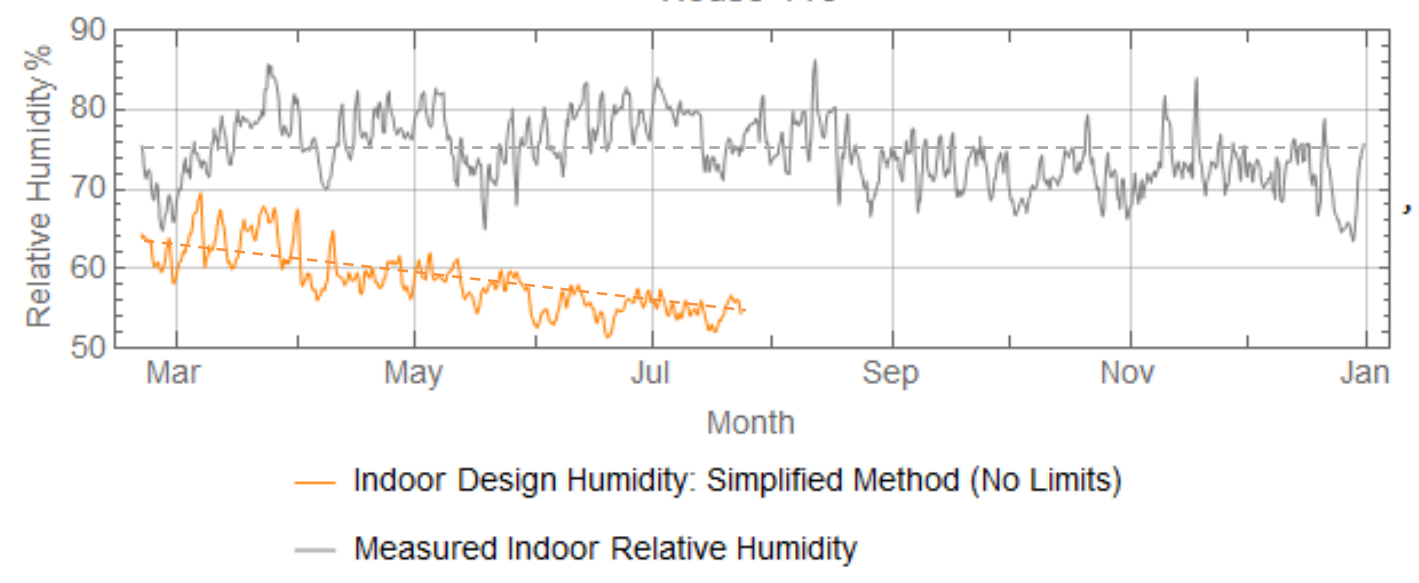

Figure 23 Indoor Design Humidity: Simplified Method and measured indoor relative humidity for House 116

Figure 23 shows a close to a full year of data for the measured indoor conditions. However, there is only approximately six months of external data and therefore predictions for the Simplified IDH can only span six months. From Figure 23 it can be seen that as the outdoor temperature drops as winter approaches, the difference between the measured relative humidity and the Simplified IDH increases. Throughout the measured period, the trend line (indicated on the graph) for the measured relative humidity is flat whilst the Simplified IDH trend line slopes downwards.

\subsubsection{Removing Limits}

From the above analysis it can be seen that the assumption made in the Simplified IDH regarding the fixed upper and lower relative humidity limits and their connection to the $T_{024 h}$, are not always suitable for a New Zealand context. Therefore, a secondary analysis was undertaken. This secondary analysis removed the $40 \%$ and $70 \%$ limits and instead implemented the $40 \%+\left(T_{024 h}+10\right)$ relative humidity formula across all outdoor temperatures.

Through removing the upper and lower limit, the trends did not change significantly, there were serval reasons for this. Firstly, removing the lower limit of $40 \%$ relative humidity is not required because, as discussed, this lower limit was never applied to any of the houses within the sample. Removing the upper limit of $70 \%$ also did not greatly alter the Simplified IDH as under the new $40 \%+\left(T_{024 h}+10\right)$ formula, $\mathrm{T}_{024 \mathrm{~h}}$ would have to exceed $20^{\circ} \mathrm{C}$ in order to achieve above $70 \%$ relative humidity.

Whilst this does occur frequently in New Zealand during summer days, the $T_{024 \mathrm{~h}}$ also includes the outdoor temperature at night which is likely to be significantly lower. With the $40 \%+\left(T_{024 h}+10\right)$ formula, the maximum Simplified IDH experienced by any house throughout the country was $80 \%$ but in these instances the measured indoor relative humidity was not $80 \%$, often being up to $20 \%$ lower at $60 \%$. 
Figure 24 assessed whether removing the lower and upper limit of $40 \%$ and $70 \%$ would mean that the average difference between the measured indoor humidity and the Simplified IDH would reduce.

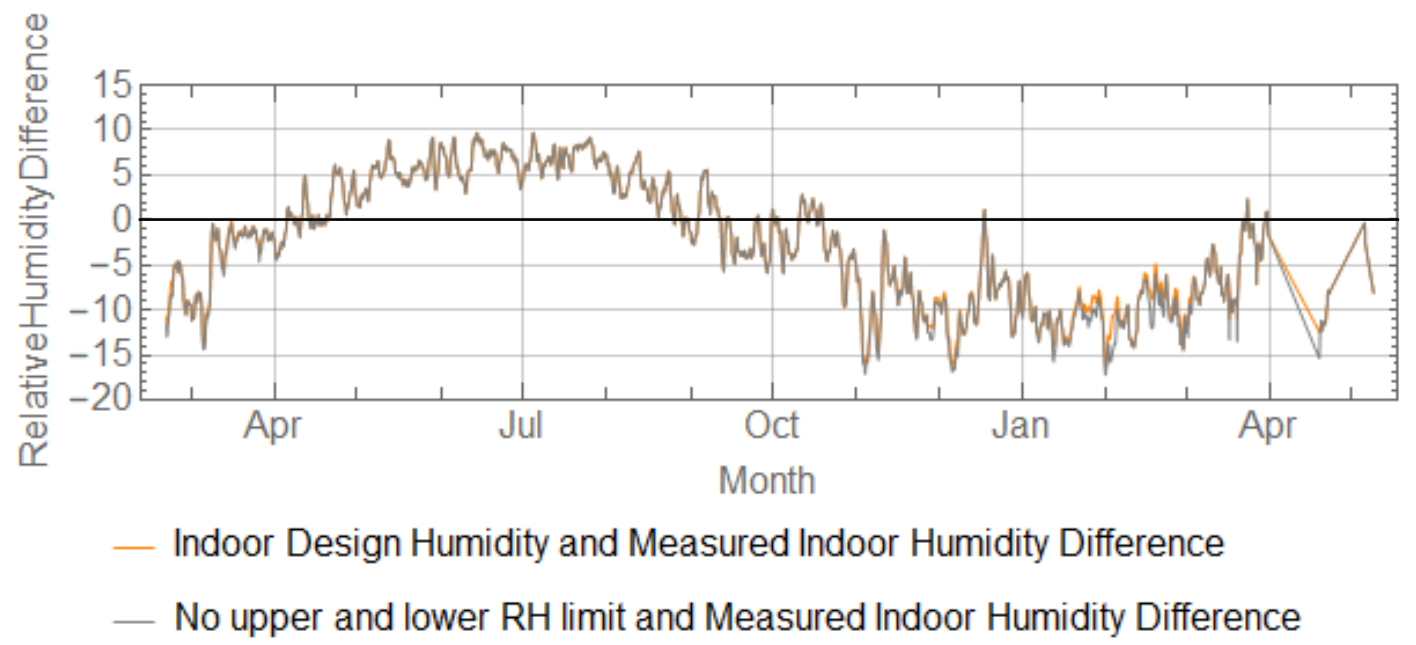

Figure 24 The average difference between the Simplified IDH and the Measured Indoor Humidity and the average difference between the Simplified IDH with no upper or lower limit and the Measured Indoor Humidity across all assessed properties

From Figure 24, it is clear to see that removing these limits had little to no impact on the average difference. This was due to the measured indoor relative humidity rarely exceeding $70 \%$ or dropping below $40 \%$. 


\section{Chapter 8 Chapter Eight - Analysis of Intermediate Indoor Design Humidity}

Whilst the IDT is only able to be determined using one technique, the IDH can be established by implementing one of three techniques. The Simplified IDH has been analysed in the previous chapter, and the Full Parameter Calculation method is out of the scope of this research as it is unable to be analysed using data from the PHS as discussed in section 4.2 and Table 12. This chapter shall analyse the Intermediate IDH.

The Intermediate IDH implements parameters that the Simplified IDH did not consider. By including these other parameters, this theoretically increases the accuracy as Vereecken \& Roels (2014) established that the more parameters a model implements, the more accurate it can become. However, in contrast, an increase in parameters can also raise the risk of error if the inputs are unknown, and assumptions need to be made. The Intermediate IDH inputs include Design Ventilation Rate, determined using the room volume, and Moisture Generation Rate, determined by the number of occupants. This method of determining moisture generation does not include other everyday household activities, such as the presence of fish tanks or indoor plants or the impact of cooking or drying clothes indoors. 


\subsection{Application of Indoor Design Humidity: Intermediate Method}

Additional inputs needed to be gathered to apply the Intermediate IDH, and these generally required assumptions to be made. The three key inputs are:

1. Moisture Generation Rate: Based on the number of occupants, which in turn are based on the number of bedrooms within the house.

2. Design Ventilation Rate:

a. Based on the volume of the building.

b. The building infiltration is based on the type of construction.

To determine the Moisture Generation Rate, the number of occupants is assumed to equal to the number of bedrooms plus one e.g. a three-bedroom house would have four occupants. ASHRAE Standard 160 then states what the Moisture Generation Rate would equate to dependent upon the number of occupants. Using information gathered from the PHS, and the placement of temperature and relative humidity sensors in bedrooms, reasonable assumptions could be drawn regarding the number of bedrooms of each house. This, in turn, allowed for a Moisture Generation Rate for each house to be determined.

Determining the Design Ventilation Rate was more complex than the Moisture Generation Rate and required several assumptions. The Design Ventilation Rate is determined by two factors: the volume of the building $\left(\mathrm{m}^{3}\right)$ and the construction of the building. To determine the building volume, both the floor area and the stud height needed to be known or assumed. The PHS categorised each of the buildings into one of five sizes categories, each with an area range of $50 \mathrm{~m}^{2}$. Due to the size category covering a $50 \mathrm{~m}^{2}$ range, the building floor area was assumed to be the middle point of the range, as given below in Table 15.

\begin{tabular}{ccc}
\hline Building size category & Area range & Area used \\
\hline Small & $<100 \mathrm{~m}^{2}$ & $100 \mathrm{~m}^{2}$ \\
\hline Medium & $100-150 \mathrm{~m}^{2}$ & $125 \mathrm{~m}^{2}$ \\
\hline Large & $150-200 \mathrm{~m}^{2}$ & $175 \mathrm{~m}^{2}$ \\
\hline Very Large & $200-250 \mathrm{~m}^{2}$ & $225 \mathrm{~m}^{2}$ \\
\hline Extra Large & $>250 \mathrm{~m}^{2}$ & $250 \mathrm{~m}^{2}$ \\
\hline
\end{tabular}

Table 15 Building size category from the PHS

Stud height was not gathered by the PHS; however, the building age was. Using the building age of each of the houses within the study, the standard stud height from that era was assumed to be the stud height. Using BRANZ research, the standard stud heights for each era are shown below in Table 16 (BRANZ, n.d.). Like the range in floor area, there was a range of stud heights over several time periods. However, for this study, the middle of the range was deemed to be an appropriate assumption, shown in Table 16. 


\begin{tabular}{lcc}
\hline Building Age & $\begin{array}{c}\text { Stud heights of that } \\
\text { era }(\mathbf{m})\end{array}$ & $\begin{array}{c}\text { Stud height used } \\
(\mathbf{m})\end{array}$ \\
\hline $\mathbf{1 8 8 0 s - 1 9 1 4}$ (Villa) & $3-3.6$ & 3.3 \\
\hline $\mathbf{1 9 1 4 - 1 9 2 0 s}$ (Bungalow) & $2.7-3$ & 2.85 \\
\hline $\mathbf{1 9 3 0 s - 1 9 4 5}$ (Art Deco) & $2.7-3$ & 2.85 \\
\hline $\mathbf{1 9 4 0 s - 1 9 6 0 s ~ ( S t a t e ~ H o u s i n g ) ~}$ & $2.4-2.7$ & 2.55 \\
\hline $\mathbf{1 9 7 0 s}$ & 2.4 & 2.4 \\
\hline $\mathbf{1 9 8 0 s}$ & 2.4 & 2.4 \\
\hline $\mathbf{1 9 9 0 s}$ - Present & $2.4-2.7$ & 2.55 \\
\hline
\end{tabular}

Table 16 Building age and typical stud height by era

To determine the building volume, the floor area and the standard stud height were multiplied. This is the best representation of the building volume that can be made using the PHS information.

Alongside the building volume, the buildings' construction and infiltration rate needed to be determined to specify a Design Ventilation Rate. ASHRAE Standard 160 provides two options for the construction: a standard construction or an airtight construction. As the PHS did not provide any specific information regarding each house's construction, it was assumed that each house would be a standard construction. It is worth noting that a number of the PHS buildings are relatively old, having been built in the 1900s, and therefore a standard construction of that time period would not equate to a standard modern construction. Issues regarding this and what this would mean for the building's infiltration are discussed in section 8.2.2.

Having determined the Moisture Generation Rate and the Design Ventilation Rate, the Intermediate IDH formula produces an indoor vapour pressure. To convert indoor vapour pressure into indoor relative humidity, humidity conversion formulas from Vaisala Oyj (2013) were utilised. To convert indoor vapour pressure into relative humidity, a temperature is needed. Therefore, for this study, the IDT was used as this would be in keeping with the scenario that none of the indoor variables are known.

\subsection{Input parameters of the Intermediate Method}

To understand where potential discrepancies may be arising when implementing the Intermediate IDH, it is important to understand how the inputs required for this method may differ from reality. Within the Intermediate IDH, three key inputs produce relative humidity: 24-hour running average outdoor vapour pressure, Design Moisture Generation Rate, and Design Ventilation Rate. The 24-hour running average outdoor vapour pressure is considered known as it can be calculated from outdoor temperature and relative humidity in a weather data file or, in this instance, the external tag monitor. This therefore leaves Design Moisture Generation Rate and Design Ventilation Rate as the inputs in which discrepancies could occur. 


\subsubsection{Design Moisture Generation Rate}

Unlike the Simplified IDH, which only considers the external environment's impact on the internal moisture content, the Intermediate IDH considers the additional moisture that the occupants produce. This is a critical factor to consider when predicting mould growth as discussed by Salonvaara (1998). The Design Moisture Generation Rate is based upon the number of expected occupants in a house, which is based on how many bedrooms are within a house. For design purposes, ASHRAE Standard 160 assumes a minimum of two occupants within a house and an additional occupant for every other bedroom.

There are two key factors within the Design Moisture Generation Rate; the number of occupants within a space, and the amount of moisture each occupant generates per day. Despite ASHRAE Standard 160 specifying that there is a base level of $5 \mathrm{~L} /$ day with an extra $1 \mathrm{~L} /$ day being produced per occupant (ASHRAE, 2016), there is a debate amongst building practitioners regarding moisture generation rates within households. There are many critical factors to consider when aiming to understand internal moisture generation, many of which are strongly reliant upon occupant behaviour. Behaviours such as drying clothes inside, cooking, and even pets' presence can alter the amount of internal moisture within a house. Consequently, no single value is universally considered the baseline for moisture generation, and estimates have values ranging from 4L/day to 23L/day (Ganda, 2017).

Ganda (2017) undertook a study investigating moisture generation in New Zealand houses and found that in a household of 2.7 occupants (the average number of occupants for a New Zealand household), the moisture generation rate is $4.2 \mathrm{~L}$ per person per day. Under ASHRAE Standard 160, a person has a moisture generation rate of $3 \mathrm{~L}$ per person per day thus suggesting a potential discrepancy in the rate of moisture generation in New Zealand houses compared to the generation rates that ASHRAE Standard 160 provide. However, it is also important to look at the assumptions that ASHRAE Standard 160 uses to develop the Moisture Generation Rate and how that relates to New Zealand houses. It is important to note that Ganda (2017) was only one recorded instance of the moisture generation of New Zealand houses and therefore further studies may further provide further suggestions on a difference or not.

Whilst the PHS did not provide direct data regarding how many people occupied each house, several of the tags did specify who was occupying the bedrooms. ASHRAE Standard 160 specifies the number of occupants without any distinction between adults and children, or the potential for different respiratory rates between these two groups. Based on the PHS information regarding each bedroom's occupancy and the ASHRAE Standard 160 assumed occupancy, Figure 25 was developed. Only 12 of the PHS houses had information within each tag on the number of occupants within that room therefore limiting the information provided in Figure 25. Figure 25 shows, within the sample of houses from the PHS, very few PHS houses matched the number of occupants that ASHRAE Standard 160 calculated. 


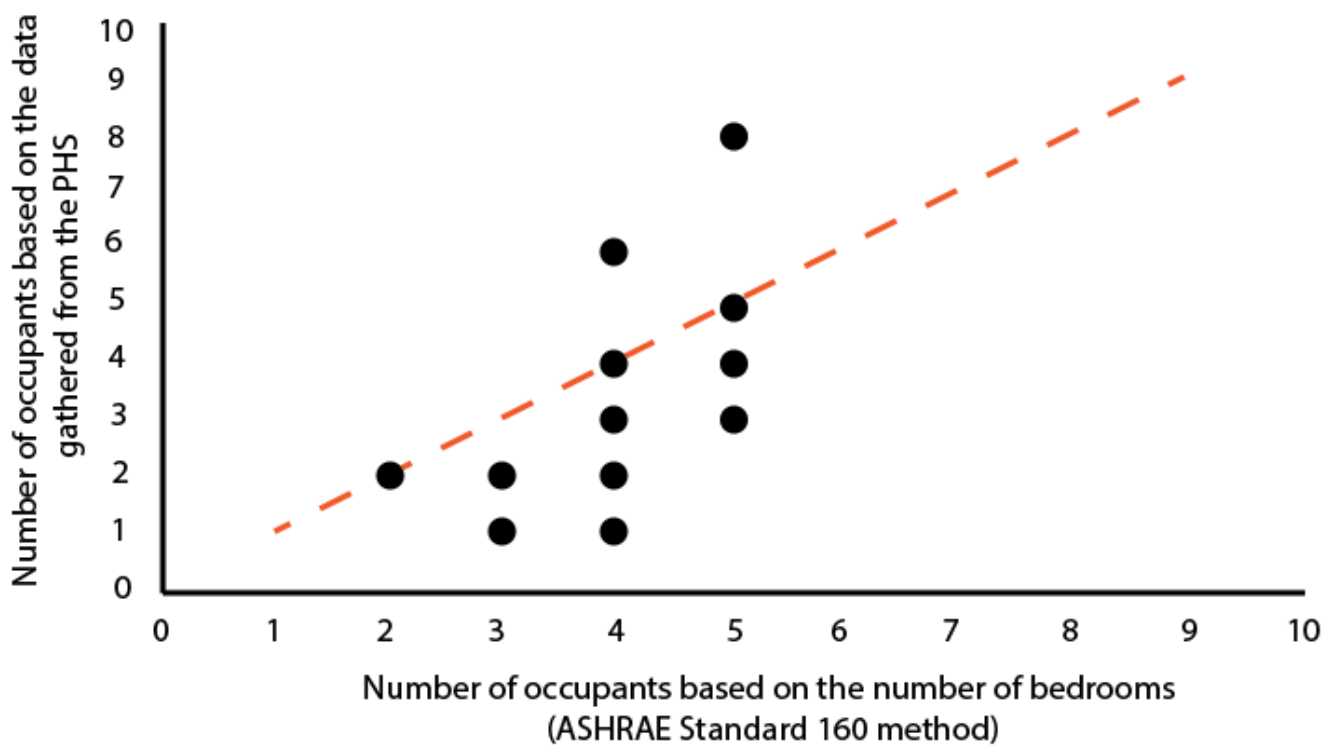

Figure 25 Number of occupants based on ASHRAE Standard 160 versus the number of occupants from the PHS (Authors own image)

Figure 25 would indicate that there is no apparent direct relationship between the number of bedrooms and the number of occupants from the sample of PHS houses, which in turn, would impact the amount of moisture generated. Despite this, it is essential to remember that ASHRAE Standard 160 was primarily developed as a design tool, and thus when a house is being built, there is no set number of occupants in the house. As the tenure of a house changes, the number of occupants, the type of occupants (children or adults), and the occupants' activities are likely to change. This is important to remember when looking at how ASHRAE Standard 160 can be altered to be more suitable for New Zealand houses. As occupancy can frequently change within tenure, an assumption does need to be made on how the house will be used and occupied. This therefore suggests that the current Design Moisture Generation assumption, whilst not entirely suitable for all houses, is a reasonable assumption.

\subsubsection{Design Ventilation Rate}

Just as the Intermediate Method looked more specifically at the moisture generation rate than the Simplified Method, the Intermediate Method also begins to consider the importance of ventilation in reducing excess moisture build-up. The Design Ventilation Rate is primarily based upon the volume of the building and the construction and infiltration of the building.

While the building volume can be unique for each house, the construction and the resulting infiltration are limited to one of two values specified by ASHRAE Standard 160. These are either a standard construction with $0.2 \mathrm{ACH}$ or an airtight construction with $0.1 \mathrm{ACH}$. There is no alternative scenario for houses with infiltration higher than $0.2 \mathrm{ACH}$, however, the graph shown in Figure 26 shows the blower door results in $\mathrm{ACH}$ at $50 \mathrm{~Pa}$ for various New Zealand houses over different periods. 


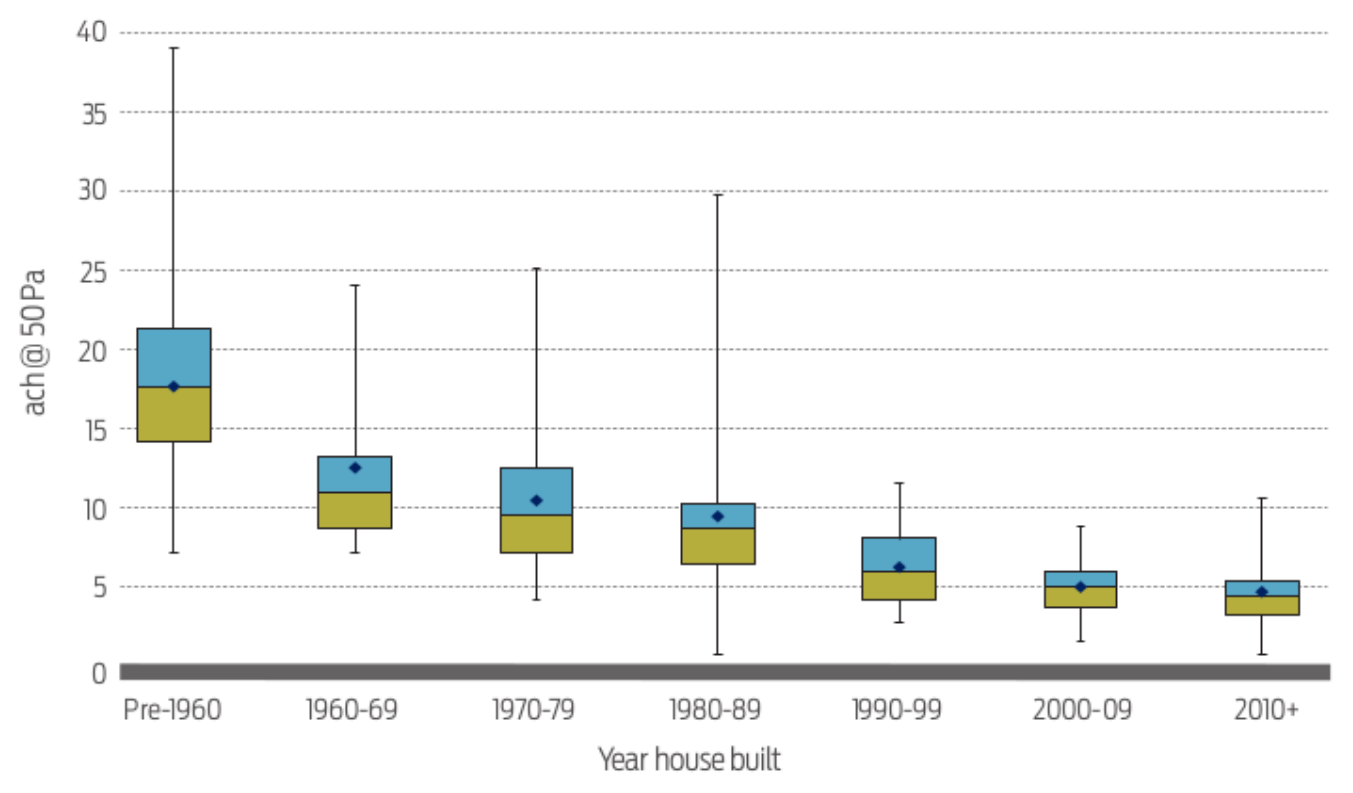

Figure 26 Graph showing an increase in airtightness of New Zealand houses over the years (Rupp \& McNeil, 2018)

The values presented in Figure 26 are blower door results reported at $50 \mathrm{~Pa}$ pressure which is generally greater than would typically be experienced under normal conditions. To translate these blower door results into typical in-service infiltrations at normal pressure levels, the blower door result should be divided by 20 . Whilst this does not factor in such variables as wind speed or direction, the location of leakage openings, or the site topography, it does begin to give an idea of typical infiltration rates amongst different houses across different time periods (McNeil, 2016). Using this rule of thumb and the blower door results shown in Figure 26, New Zealand houses built after 2010 typically experience 0.25 ACH whilst houses pre-1960 experience upwards of $0.85 \mathrm{ACH}$.

Based on this information, the $0.2 \mathrm{ACH}$ assumption that ASHRAE Standard 160 makes regarding a standard construction would not be suitable for even New Zealand houses built after 2010. Additionally, most of the houses within this study are built prior to 2010 and are thus likely to have an even higher infiltration rate. Consequently, the actual infiltration rate maybe double that specified by ASHRAE Standard 160, and thus, the Design Ventilation Rate does not correctly reflect the conditions within these New Zealand houses.

\subsection{Indoor Design Humidity: Intermediate Method Analysis}

By identifying the Design Moisture Generation Rate, the Design Ventilation Rate and implementing the Intermediate IDH formula, trends become apparent. Unlike the discussion of the IDT or the Simplified IDH, numerous inputs could be attributed to 
the trends and the patterns that are seen. All the graphs produced by the Intermediate IDH have been shown in Appendix $\mathrm{H}$.

\subsubsection{Maximum Indoor Design Humidity}

Whilst the Simplified IDH specified an absolute maximum of $70 \%$ relative humidity, the Intermediate IDH does not specify a maximum relative humidity. As a result of this, in $51 \%$ of the PHS houses, the Intermediate IDH is reportedly at, or exceeding, $100 \%$ at some point. An example of this trend is seen in House 113 (shown below in Figure 27), where the relative humidity is consistently specified in excess of $100 \%$, particularly in the summer periods (circled below in Figure 27). In House 113, the highest Intermediate IDH was reportedly $118 \%$, while the highest Intermediate IDH for all the houses was reportedly $148 \%$ in November in House 148.

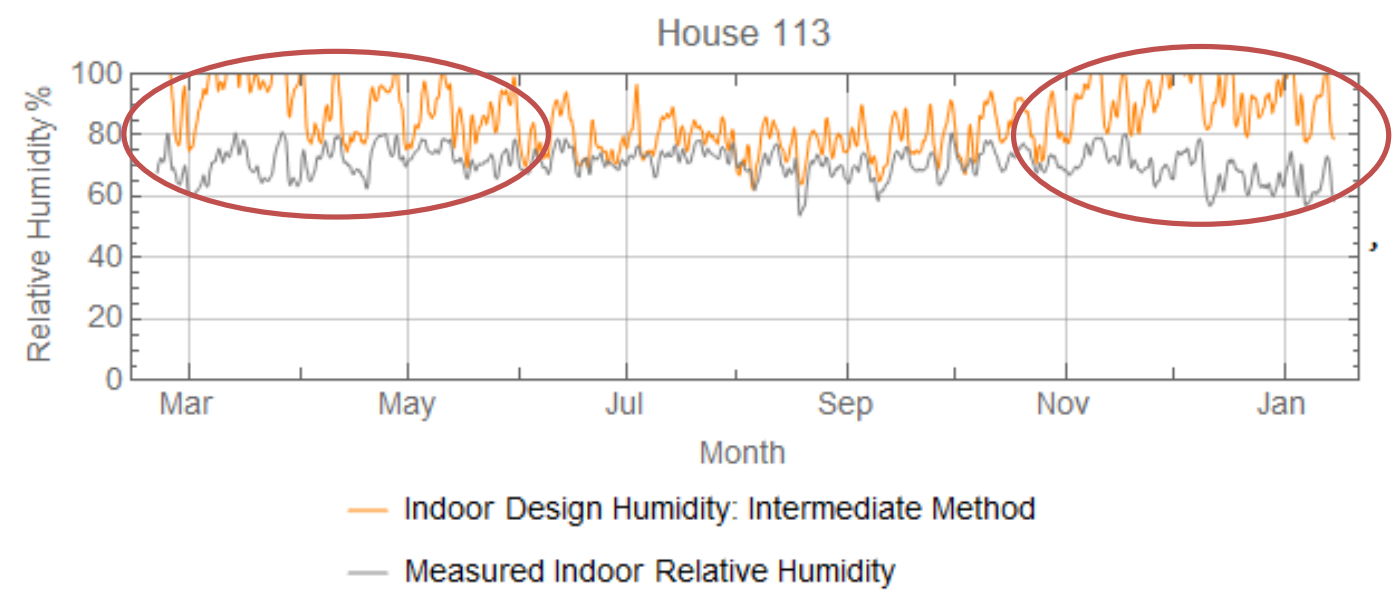

Figure 27 Indoor Design Humidity: Intermediate Method and measured indoor relative humidity for House 113

The reason for this occurring is evident when looking at the Intermediate IDH equation, which assumes that the indoor vapour pressure is directly proportional to the outdoor vapour pressure plus the moisture generated by the occupants. The influence of ventilation is also included, assuming minimum ventilation to prevent excessive internal moisture. When looking at all the houses across this study, the Intermediate IDH is consistently specified at a higher relative humidity than the measured indoor humidity. This indicates that the Intermediate IDH formula and the assumed inputs from ASHRAE Standard 160 are either overestimating the amount of moisture produced by occupants or underestimating the ventilation in the space. Looking back at the previous sections on the required inputs, the discussion demonstrates that both of these scenarios are entirely plausible in this sample of New Zealand houses.

When looking at the number of occupants ASHRAE Standard 160 assumes, compared to the number of recorded occupants from the PHS, the number of recorded occupants was lower $58 \%$ of the time. Therefore, this would indicate that the assumption from ASHRAE Standard 160 that the number of occupants directly correlates to the number of occupants is incorrect, at least for the PHS sample. On only eight occasions does the number of recorded occupants match the number of predicted occupants by ASHRAE Standard 160. Whilst it can be seen that this general 
rule of thumb of occupants is not the best fit for this sample of houses, it is essential to remember that ASHRAE Standard 160 is primarily used as a design tool, and the type of tenure can often dictate the number of occupants within a house. Throughout a buildings life, the number of occupants is likely to change as different groups and families occupy the space, and as a result, the moisture generation rate would always be changing. Therefore, whilst this assumption made by ASHRAE Standard 160 is not necessarily the best fit, little can be done to alter this to better reflect reality. By overestimating the number of occupants in a house whilst simultaneously under estimating the ventilation rate in the house, a moist environment with inadequate ventilation is being created.

\subsubsection{Revised Design Ventilation Rate}

Having acknowledged that although the Design Moisture Generation Rate is likely to change throughout a building life span and the different types of tenure, the Design Ventilation Rate's ability to be more appropriate was investigated. Under the Intermediate $\mathrm{IDH}$, there are only two rates of infiltration available: $0.2 \mathrm{ACH}$ for a standard construction or $0.1 \mathrm{ACH}$ for an airtight construction. As discussed in section 8.2.2, a typical New Zealand house has $0.25 \mathrm{ACH}$, with older houses increasing to 0.85 ACH (Rupp \& McNeil, 2018). A more customisable Design Ventilation Rate formula may be favourable in improving the formula's accuracy, allowing ASHRAE Standard 160 to be not only used in the design phase of new houses but also applied in the renovation of older houses. By rearranging the existing Design Ventilation Rate formulas (Equation 4 and Equation 5), Equation. 14 allows for the input of the $\mathrm{ACH}$ for each house:

$$
\mathrm{Q}=2.8 \times 10^{-4} V \cdot A C H
$$

Equation. 14

Where:

$$
\begin{aligned}
& \mathrm{V}=\text { Building volume in } \mathrm{m}^{3} \\
& \mathrm{ACH}=\text { Air changes per hour } \\
& \mathrm{Q}=\text { Design ventilation rate }
\end{aligned}
$$

When applying Equation. 14 and utilising the average $\mathrm{ACH}$ for a house of that time period, the average ventilation rate increased by $215 \%$ from the initial Design Ventilation Rate to the revised Design Ventilation Rate. Across every house, the revised Design Ventilation Rate was higher than the initial Design Ventilation Rate, which was expected as each house had a higher $\mathrm{ACH}$ than the originally specified $0.2 \mathrm{ACH}$. Using the revised Design Ventilation Rate, a second set of graphs showing a revised Intermediate IDH were developed, showing varying effects from house to house. In $54 \%$ of houses, the revised Design Ventilation Rate Intermediate IDH more closely aligned to the measured relative humidity data (shown in Appendix I); while in 29\% of houses the initial Design Ventilation Rate Intermediate IDH was more suitable (shown in Appendix J). In $17 \%$ of the houses, there was either no change between the two or for about half the measured period the revised was more suitable, and for the other half the initial Design Ventilation Rate Intermediate IDH was more suitable (shown in Appendix K). 
In $67 \%$ of the houses where the initial Intermediate IDH reached upward of $100 \%$ relative humidity, the revised Intermediate IDH was much more suitable. An example of this can be seen in House 129 and House 144 (Figure 28 and Figure 29).

House 129

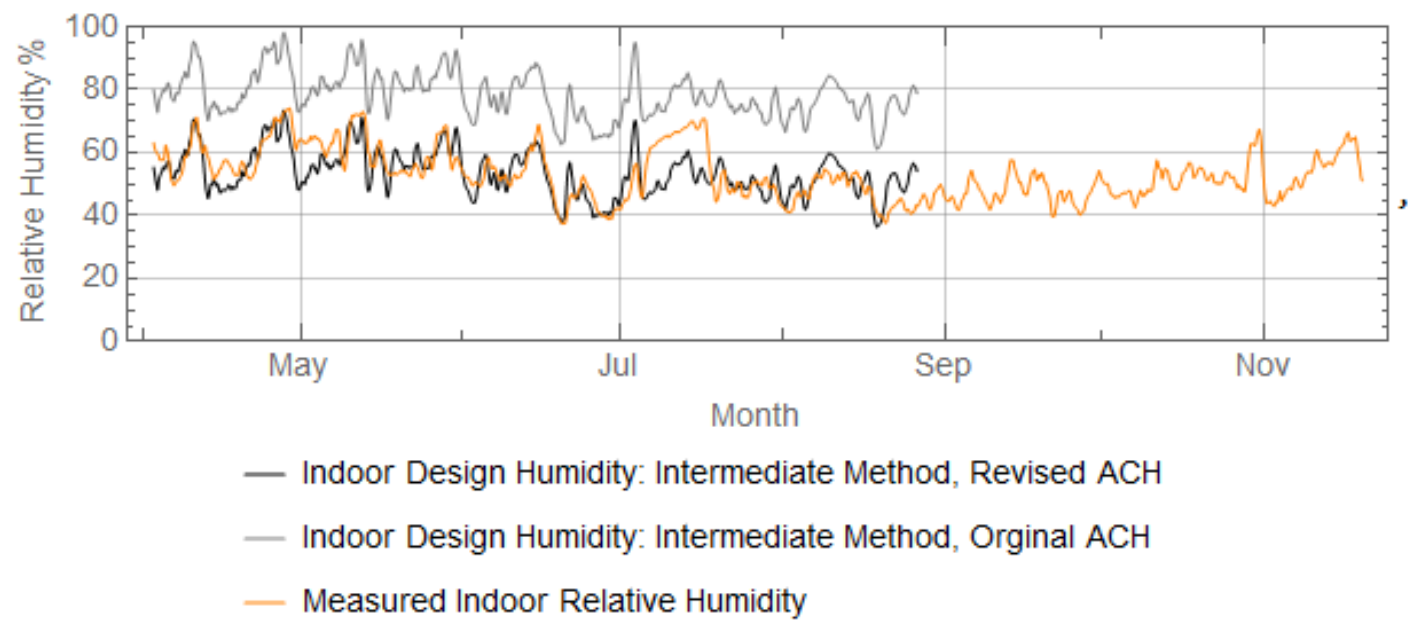

Figure 28 Indoor Design Humidity: Intermediate Method Original ACH and Revised ACH and measured indoor relative humidity for House 129

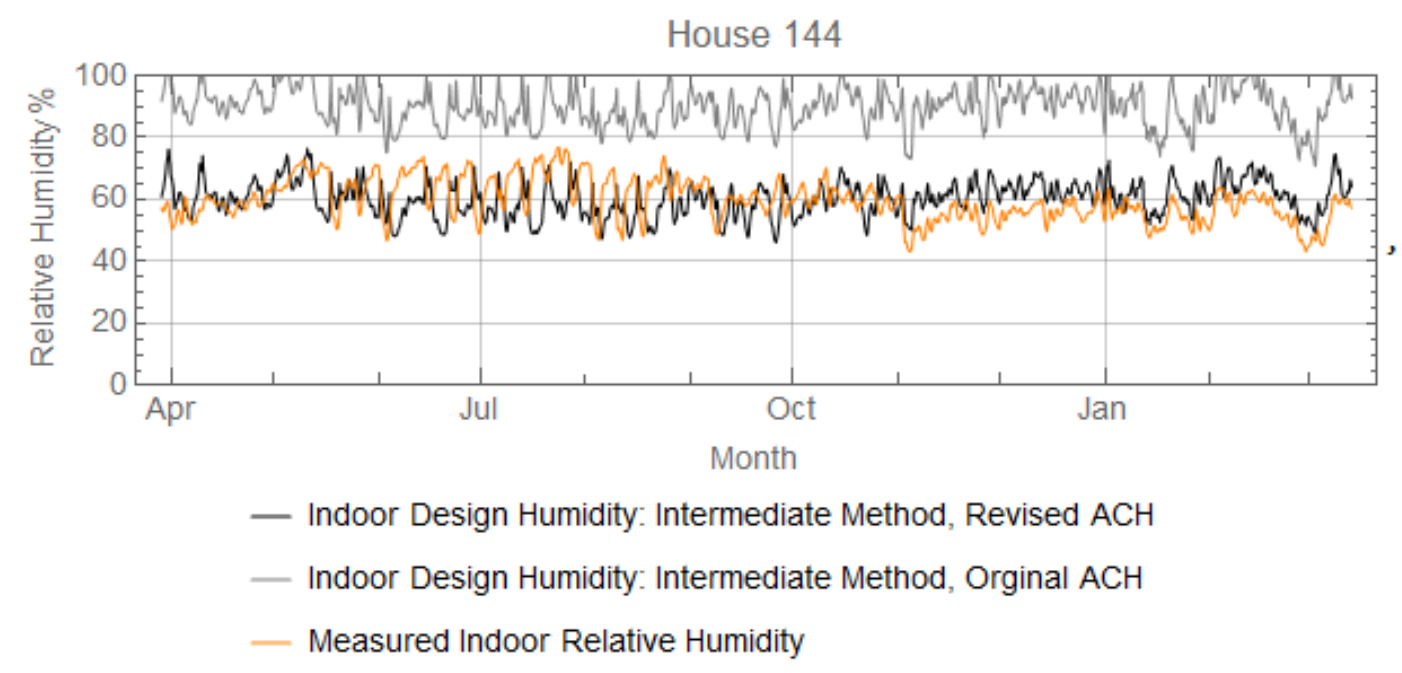

Figure 29 Indoor Design Humidity: Intermediate Method Original ACH and Revised ACH and measured indoor relative humidity for House 144

The graphs shown in Figure 28 and Figure 29 illustrate that the difference between the measured indoor relative humidity and the revised Intermediate IDH is less than the difference between the measured indoor relative humidity and the initial Intermediate IDH. In both instances, the revised Design Ventilation Rate ensured that the reported Intermediate IDH did not exceed $100 \%$ and was closer to the measured indoor relative humidity. However, in contrast to the scenarios seen in House 129 (Figure 28) and House 144 (Figure 29), in about 36\% of the sample the revised Design Ventilation Rate negatively impacted the Intermediate IDH, and the initial Intermediate 
IDH was a better fit. An instance of this can be seen in House 143 (shown in Figure 30 below).

House 143

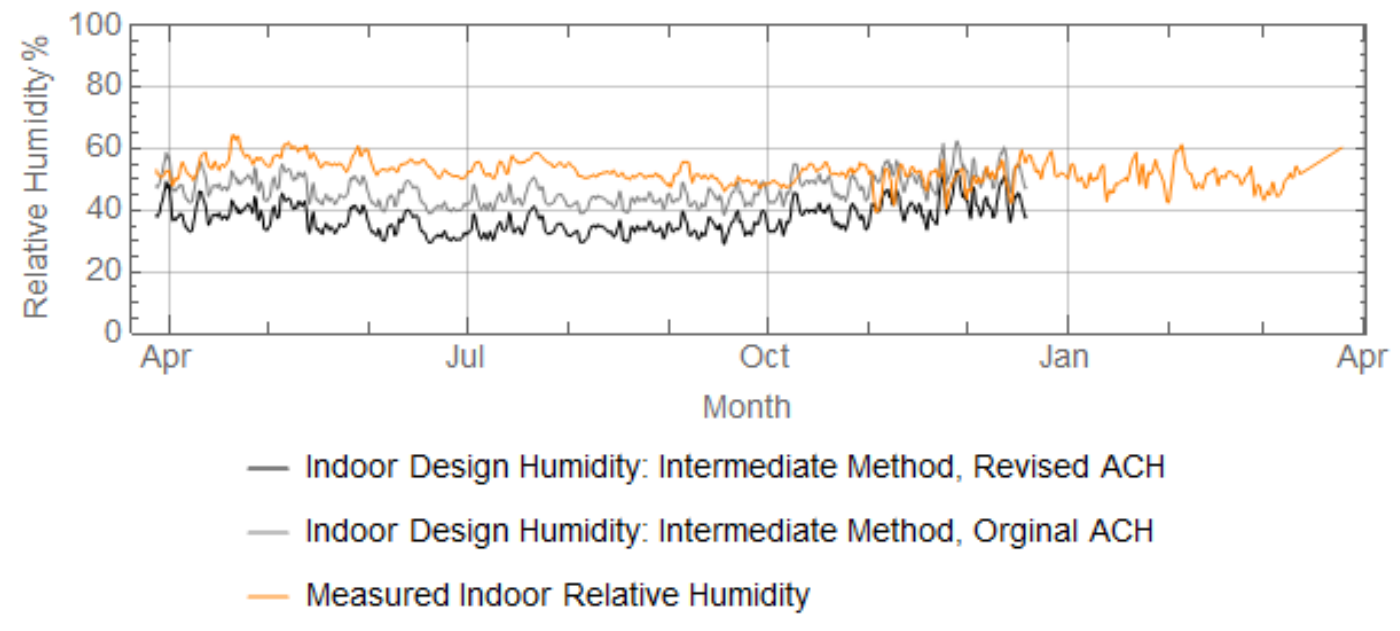

Figure 30 Indoor Design Humidity: Intermediate Method Original ACH and Revised ACH and measured indoor relative humidity for House 143

Figure 31 shows that average difference between the measured indoor humidity and the Intermediate IDH and the Revised ACH Intermediate IDH. Figure 31 shows that the Intermediate IDH with the ACH set out by ASHRAE Standard 160 has an average difference ranging from $-42 \%$ to $-2 \%$. However, the revised $\mathrm{ACH}$ for the Intermediate IDH shows that there is an average difference of $-20 \%$ to $21 \%$. This shows that on average across all of the assessed properties the revised $\mathrm{ACH}$ improved the Intermediate IDH.

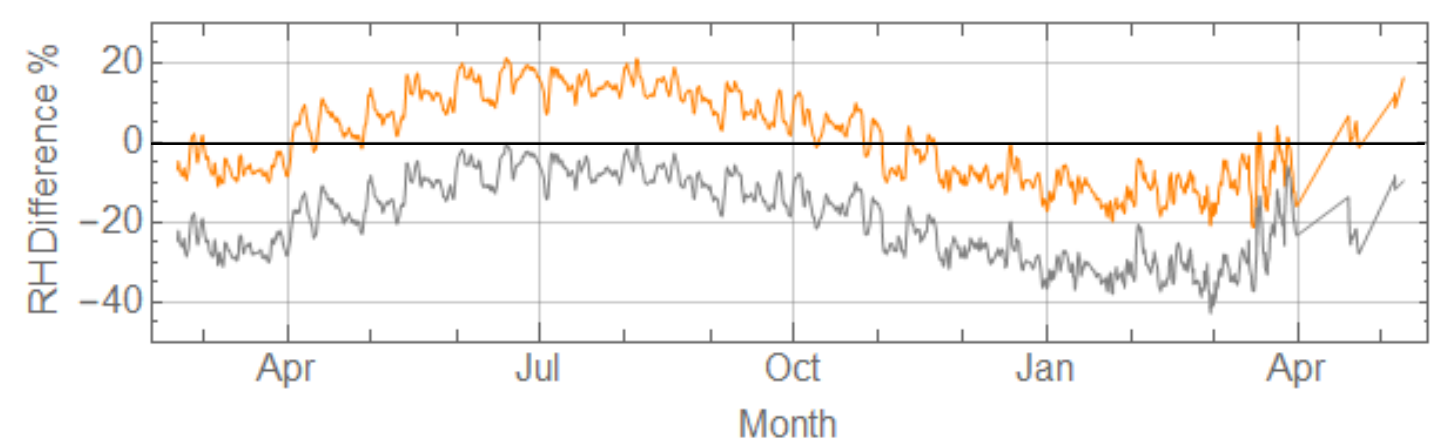

— Revised ACH Intermediate IDH and Measured Indoor Humidity Difference

— Intermediate IDH and Measured Indoor Humidity Difference

Figure 31 The average difference between the Intermediate IDH and the Measured Indoor Humidity and the average difference between the Revised ACH Intermediate IDH and the Measured Indoor Humidity across all assessed properties

The $36 \%$ of houses where the revised $\mathrm{ACH}$ was a worse fit than the initial $\mathrm{ACH}$ were hypothesised to be houses which had been renovated. When a 1960s house was initially built it would have had an infiltration rate of approximately $0.85 \mathrm{ACH}$, however if serious renovations had been undertaken on this house, such as new windows, it is 
likely to have become more airtight. The PHS did not record any information into whether house had been renovated and if so, what was undertaken and when. Consequently, this hypothesis was not able to be investigated further.

\subsubsection{Fluctuations in the Indoor Design Humidity}

Unlike what was seen in the Simplified IDH with the smoothing out of the measured indoor measured relative humidity, the Intermediate Method seemed to have a contrasting effect. The increased range in relative humidity with the use of Intermediate IDH is seen in 35\% of the houses. Additionally, as well as predicting a higher relative humidity across all the houses, the Intermediate IDH has a slightly more varied range in relative humidity than the measured indoor relative humidity. On average the Intermediate IDH ranged from $62 \%-98 \%$ whilst the measured indoor relative humidity ranged from $55 \%-73 \%$ as shown in Figure 32 .

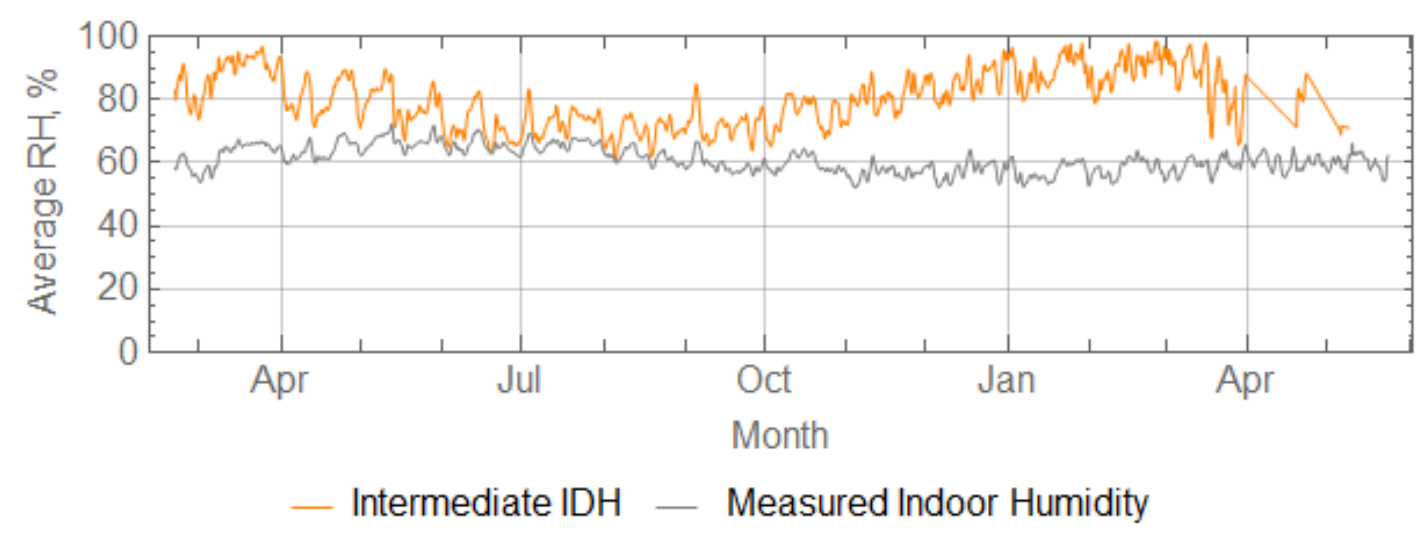

Figure 32 The average Intermediate IDH and the average measured indoor relative humidity of all the assessed properties

Whilst the average results shows a significant variance between the Intermediate IDT and the measured indoor relative humidity, and a more in depth example of this has been shown in House 104, shown in Figure 33. 
House 104

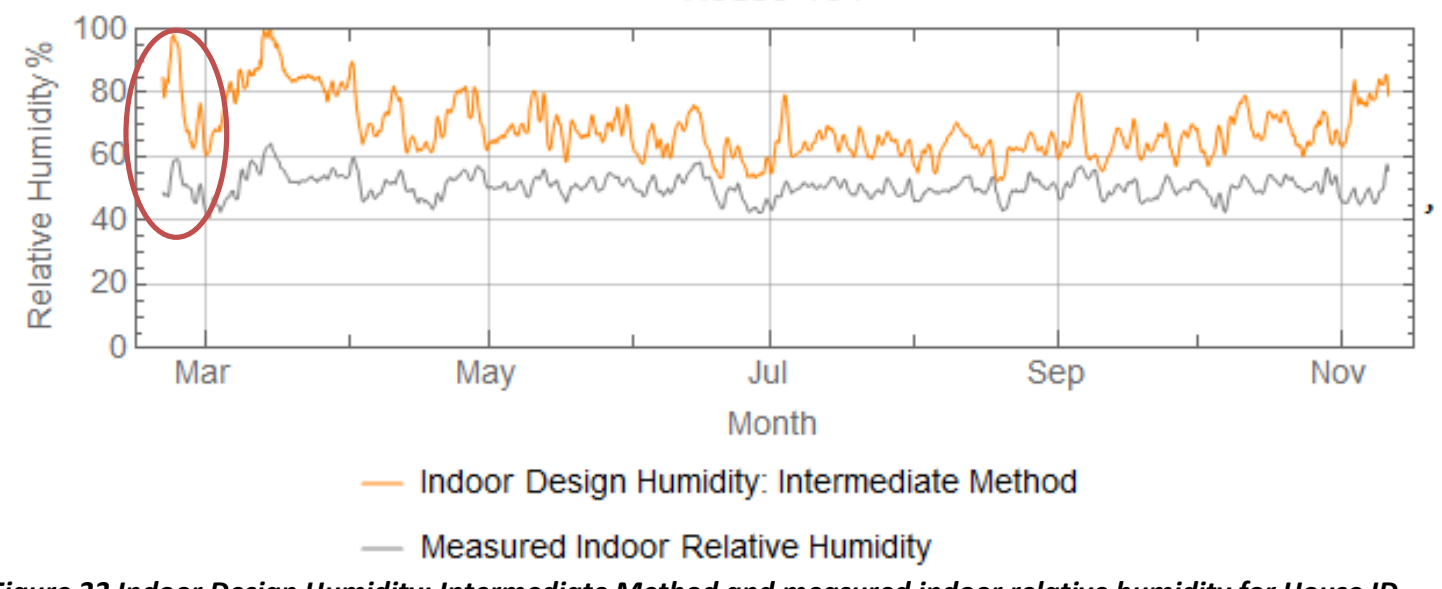

Figure 33 Indoor Design Humidity: Intermediate Method and measured indoor relative humidity for House ID 104

In House 104, the measured indoor relative humidity varied by $\pm 11 \%$ throughout the entire year, however, the Intermediate IDH fluctuated by up to $\pm 25 \%$ throughout the year. This is potentially significant when considering Vereecken \& Roels (2014) regarding the impact of mould retardation effects and periods of favourable and unfavourable mould growth conditions. The extreme fluctuations in the Intermediate IDH may result in several instances in which favourable mould growth conditions would be occurring however, these may not be occurring in the measured indoor relative humidity. However, when simultaneously looking at the measured indoor relative humidity over this same period, the conditions may suggest unfavourable mould growth. An instance of this has been highlighted in Figure 33 (circled in orange). Over this period highlighted in Figure 33, the Intermediate IDH is recorded at nearly $98 \%$ while the measured is $62 \%$ relative humidity. This is a difference of $36 \%$, and suggests that under the Intermediate $\mathrm{IDH}$, there is approximately $0.006 \mathrm{~kg} / \mathrm{m}^{3}$ more moisture in the space at that moment.

\subsubsection{Indoor Design Humidity: Simplified vs Intermediate Method}

Vereecken \& Roels (2014) discussed the benefits of more complex mould index models in which the increase in inputs can improve the accuracy of their predictions. However, Vereecken \& Roels (2014) also discussed the uncertainties of using these types of models when then inputs are unknown and need to be assumed. It was discussed that when inputs are unknown, the margin of error increases and the mould predictions become more inaccurate. The Simplified IDH utilised only one variable, $T_{024 h}$, which was gathered with a high degree of confidence and certainty. However, the Intermediate Method implements additional inputs with the aim of improving the accuracy of this model. To determine whether the increase in inputs improved the model, the Simplified Method and the Intermediate Method of IDH and the measured indoor relative humidity were plotted over the same time period (see Appendix $L$ ).

The analysis has shown that in 79\% of houses the Simplified IDH matches the measured indoor relative humidity better than the Intermediate IDH. This trend can 
be seen in House 104 (Figure 34 below), where both the Simplified IDH and the Intermediate IDH follow the same pattern as the measured indoor relative humidity, but the Intermediate IDH is consistently higher. This occurs throughout the whole year, with the Intermediate IDH never dropping below the Simplified IDH. The Simplified IDH has an average relative humidity of $14 \%$ higher than the measured indoor relative humidity throughout the measured period, while the Intermediate IDH is $31 \%$ higher.

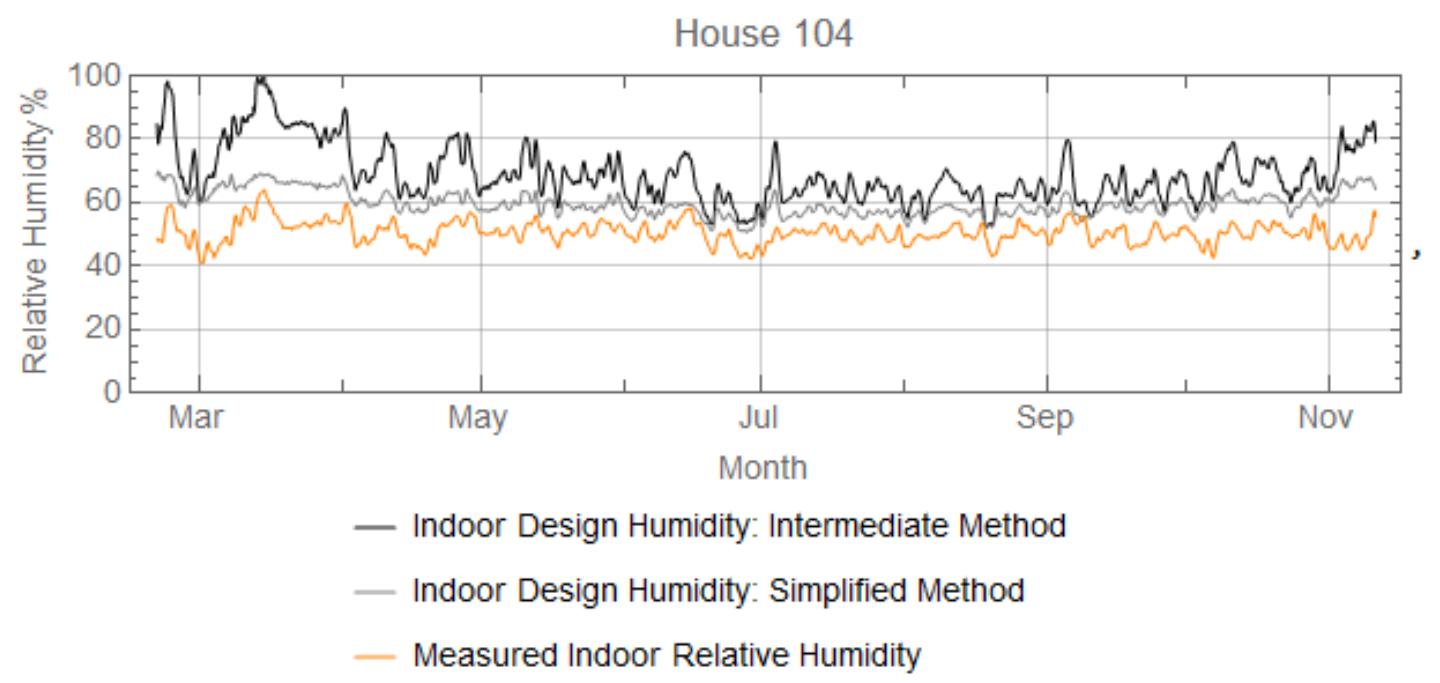

Figure 34 Indoor Design Humidity: Intermediate Method and Simplified Method, and measured indoor relative humidity for House 104

This trend supports Vereecken \& Roels' (2014) view regarding the number of inputs required for a mould prediction model and the consequent accuracy. Despite having a significant amount of information on each building from the PHS, several of the inputs required assumptions to be made when using the Intermediate Method throughout this study. Firstly, the Design Moisture Generation Rate assumed that the number of occupants within a house is directly related to the number of bedrooms. Secondly, the Design Ventilation Rate required an assumption about both the house's volume and the $\mathrm{ACH}$ of the house. These three critical inputs were all determined using reasonable assumptions, however, they are assumption none the less and therefore, there is still a degree of uncertainty surrounding them. Compare this idea with the knowledge that the Simplified IDH utilised a known variable, $\mathrm{T}_{024 \mathrm{~h}}$ and that this produced IDH which better reflected the measured indoor relative humidity, and the ideas that Vereecken \& Roels (2014) discussed are evident.

Figure 35 shows the average difference between the Simplified IDH and the measured indoor humidity and the average difference between the Intermediate IDH and the measured indoor humidity. 
Figure 35 shows that on average, across all the assessed properties the average difference for the Simplified IDH ranged from a $-15 \%$ to $10 \%$ difference whereas the Intermediate IDH ranged from a $-42 \%$ to $-2 \%$ difference. This therefore shows that on average the Simplified IDH was a closer match to the measured indoor relative humidity than the Intermediate IDH.

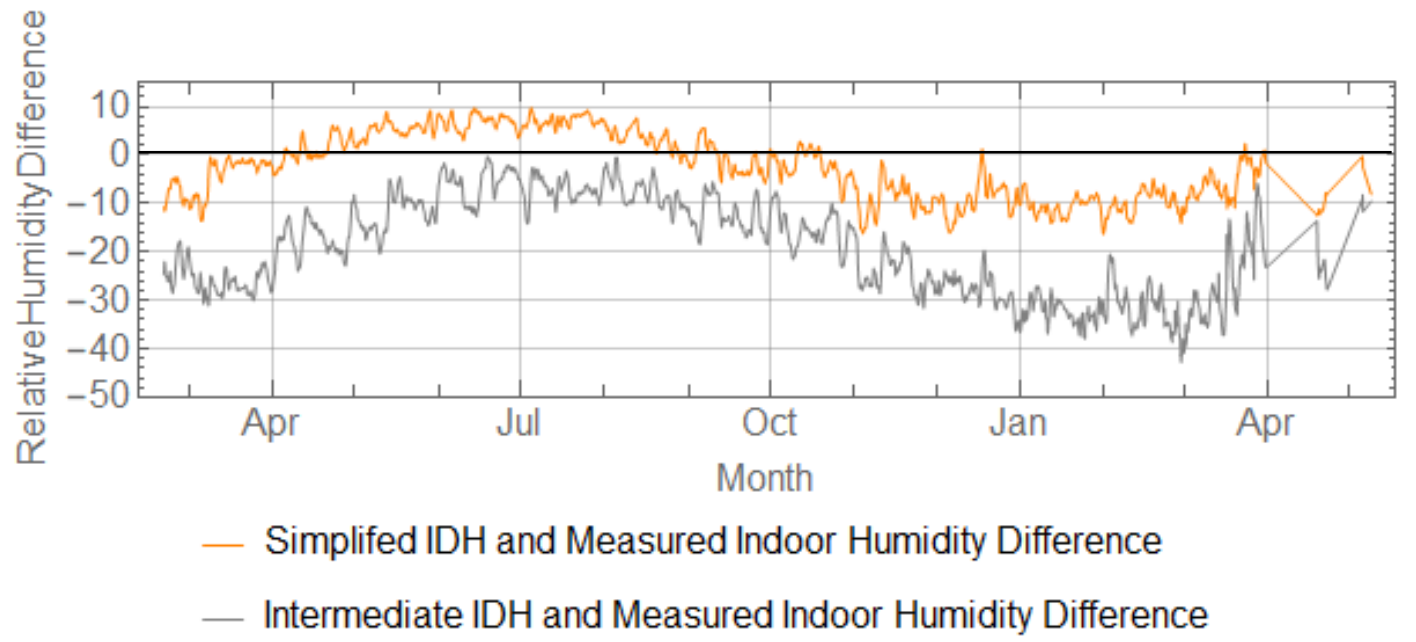

Figure 35 The average difference between the Simplified IDH and the measured indoor relative humidity and the Intermediate IDH and measured indoor relative humidity across all assessed properties

As with every trend, there is always an exception. In House 143, both the Intermediate IDH and the Simplified IDH produced very similar IDH throughout the measured period. Additionally, both the Simplified IDH and the Intermediate IDH closely matched the measured indoor relative humidity with no more than a $12 \%$ difference at any time throughout the year (shown below in Figure 36).

House 143

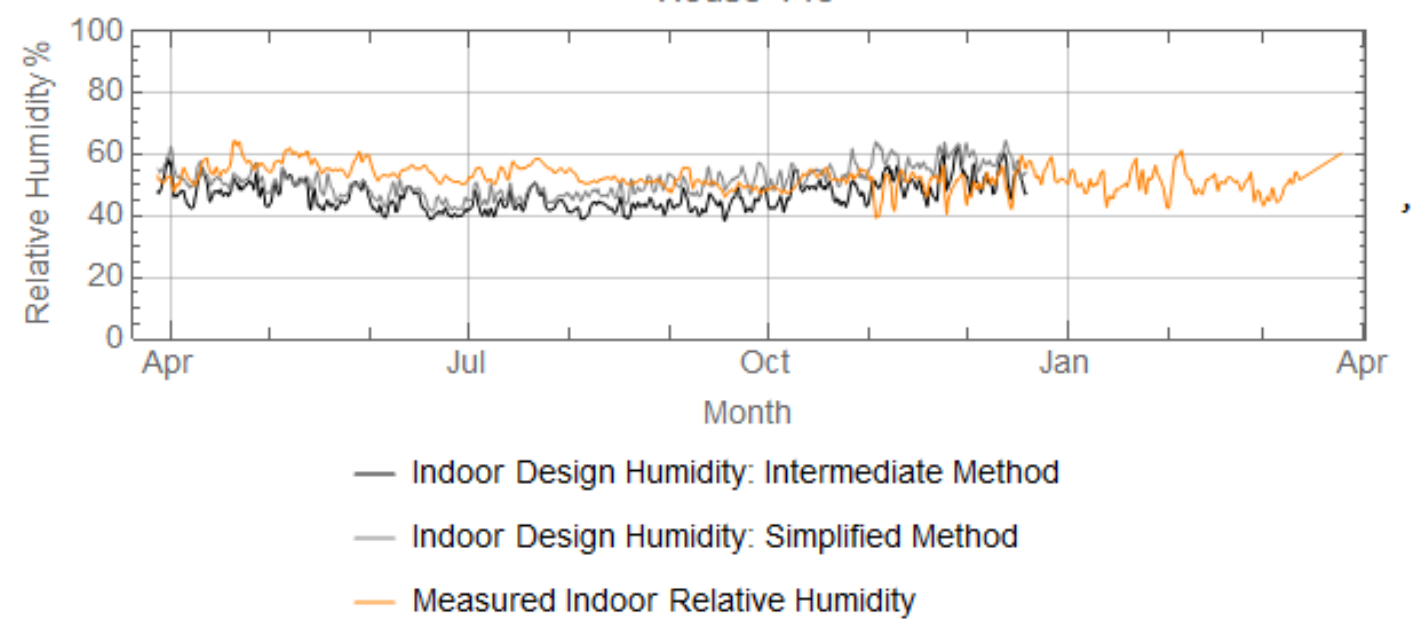

Figure 36 Indoor Design Humidity: Intermediate Method and Simplified Method, and measured indoor relative humidity for House 143 
Figure 36 would indicate that the assumptions made in the inputs required for the Intermediate IDH were accurate for this house. Similar assumptions to every other house within the study regarding the building volume and the Moisture Generation Rate would have been made about this building. However, the Design Ventilation Rate, which previously discussed was deemed a significant factor in these houses, may have been more accurately assumed. This particular house was one of the newer builds so the assumed infiltration rate was $0.2 \mathrm{ACH}$ is likely to be closer to what was actually being experienced in the house. This is unlikely to have been the case for the older houses within this study that were built in the 1920s, however, there is a possibility of older houses having been renovated and thus having an improved $\mathrm{ACH}$. Due to information not being available within the PHS regarding any possible renovations this hypothesis is not able to be confirmed. 


\section{Chapter 9 Comparative Mould Index Analysis}

Having determined that in all instances the Indoor Design Conditions specified by ASHRAE Standard 160 differ from the measured indoor conditions, the impact of this difference is to be assessed. Hygrothermal simulations of several houses were run over a three-year period, testing three different climates: the indoor measured, the IDT with Simplified IDH, and the IDT with Intermediate IDH.

Based on the hygrothermal simulation results, the surface material of each of the houses shall be assessed using the Viitanen (VTT) model and the mould index value. The mould index value is a six-point scale that determines the intensity of mould growth from one to six, with a value of three indicating unacceptable rates of mould growth (Viitanen, et al., 2015). The analysis in previous chapters also highlighted the potential significance of periods of unfavourable mould growth on mould retardation. The VTT model also accounts for the long dry periods in which mould growth can decrease, allowing for the significance of these periods to be assessed. For each of the houses, three mould indexes shall be produced for each of the different indoor climates. Each of these shall be compared over the three-year simulation period to understand whether the different methods of determining indoor conditions under ASHRAE Standard 160 and the measured conditions produce different mould indexes. 
The selection of houses was primarily determined by the tools used to run the hygrothermal simulation: WUFI Pro and the Mould Index VTT add on. WUFI Pro uses data gathered over a year and assumes that these conditions would be similar over the following two years to interpolate a three-year period. Consequently, houses that had closest to a full year's worth of recorded data were used so that the following two years' interpolation was as close as to be expected instead of seasons having to be assumed. Seven of the 53 houses fitted these criteria across five different New Zealand regions: Bay of Plenty, Gisborne, Otago, Canterbury, and Southland. Of these seven houses, the PHS recorded that each has varying extents of mould growth ranging from none to significant.

\subsection{Hygrothermal Simulations}

The process of running the hygrothermal simulation required gathering relevant data to accurately simulate the construction of each building. As previously established, three different internal conditions shall be simulated for each house. The measured indoor relative humidity and temperature are taken directly from the PHS data and shall be referred to as the Measured Conditions. The IDT and the Simplified IDH shall be referred to as the Simplified Method Conditions. The IDT and the Intermediate IDH and shall be referred to as the Intermediate Method Conditions. Each of the three internal conditions climate files are generated by Mathematica, using the same equations which were used to develop the previous chapters' graphs. Additionally, the external climate files were prepared for each house using the PHS data and the external tags associated with each house.

Having determined the external and internal climate for each house, the houses' construction was determined. As noted in Chapter 8, the PHS recorded minimal information regarding each house's construction, requiring assumptions to be made. Using the building's age and the cladding as specified in the PHS, the typical construction of that era and for that cladding type was selected. Due to a lack of information from the PHS, it was necessary to assume that no renovation had been undertaken on the wall construction. Consequently, the construction was specified as it would have been in the era that it was built. The three hygrothermal simulations were run for each house with the appropriate external and internal climates and construction. The VTT mould index can be applied anywhere throughout the wall's construction, however, as a default the indoor surface was assessed.

\subsection{Analysis of Hygrothermal Simulation}

Having run three hygrothermal simulations for each house under three different internal climate conditions, graphs of the VTT index and the mould indices of the three conditions were compared for each house. Each hygrothermal simulation was run over three years, including, an initial three month 'warm up' period. All seven of the graphs produced for the comparative mould index analysis are given in Appendix $M$. 


\subsubsection{Sensitivity of Intermediate Method Conditions}

The most evident trend that appears is that neither the Measured Conditions nor the Simplified Method Conditions predicted mould growth over the three-year simulation period for any of the seven houses. Instead, however, the only increase in the mould index came with the use of the Intermediate Method Conditions. Additionally, by using the Intermediate Method Conditions, all seven houses experienced some form of mould growth over the three years, with five of the houses experiencing unacceptable levels of mould growth with a mould index over three (See Section 4.1.2) An example of this has been shown in Figure 37 which shows the mould index for House 144.

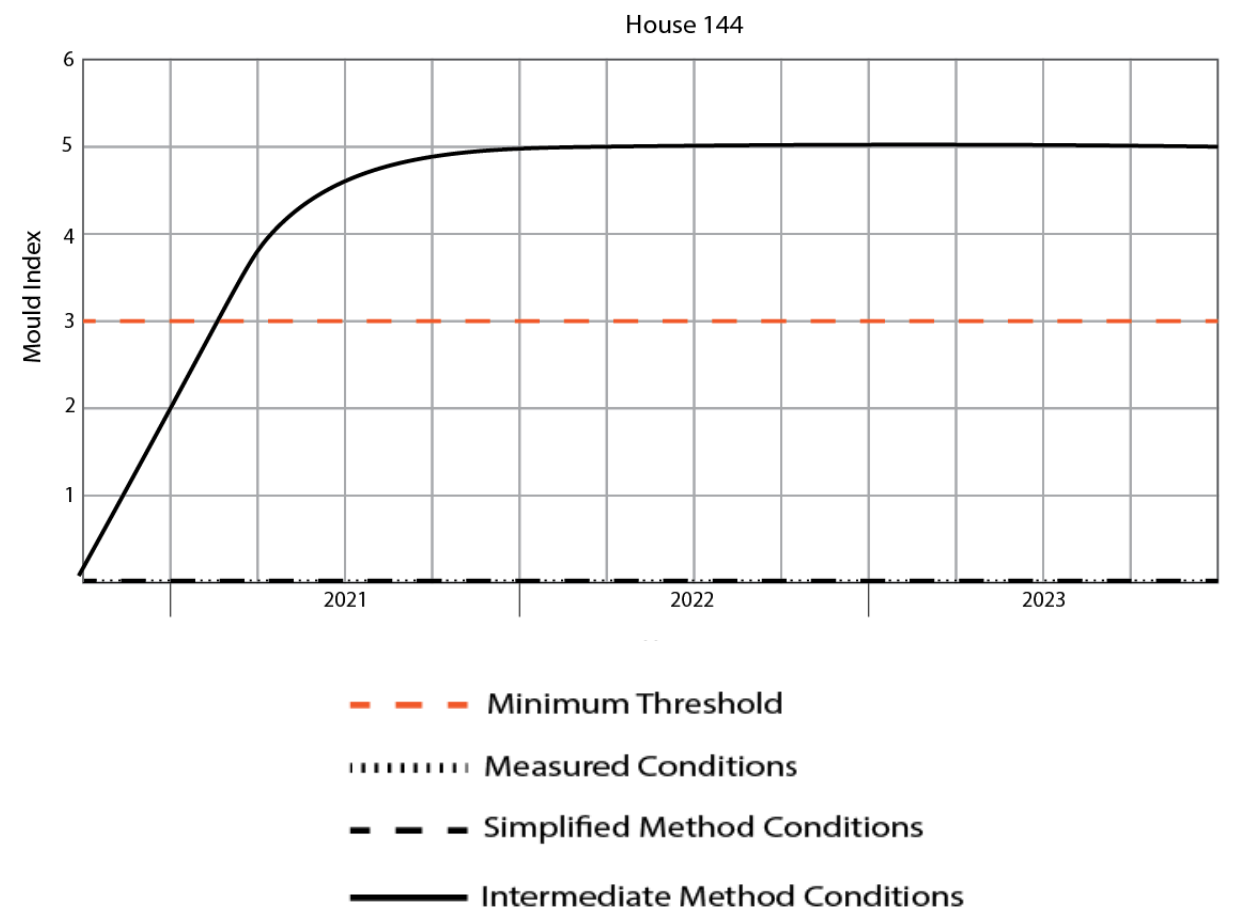

Figure 37 Mould index values of the three different internal conditions of House 144

Figure 37 shows using the Intermediate Method Conditions mould growth exceeds the minimum threshold of acceptable mould growth within approximately four months of the simulation beginning. At the end of the simulated first year, the mould index begins to level out at five, indicating mould coverage on over $70 \%$ of the measured surface.

Analysis in Chapter 6,7, and 8 showed that in both the IDT and the Simplified IDH, the conditions specified for House 144 were relatively similar to the measured conditions. In contrast to this however, the conditions specified in the Intermediate IDH exceeded the measured conditions, suggesting the Simplified IDH was more accurate than the Intermediate IDH. Figure 37 shows that the assumptions made when determining the Intermediate IDH also impacted the mould index as conditions under both the Measured and Simplified methods did not lead to mould growth. 
It was found that for all seven of these houses investigated, in every instance the Intermediate Method Conditions were further from the measured conditions than the Simplified Method Conditions, and in every instance the mould index was greatest under the Intermediate Method Conditions.

\subsubsection{Critical Relative Humidity}

A key factor which dictates the likelihood of mould growth is the critical relative humidity. Critical relative humidity is the threshold in which mould germination will occur at a particular temperature. Whilst there is much contention as to what the critical relative humidity is at various temperatures, it is generally understood that mould can grow at a wide variety of temperatures if the critical relative humidity is meet (Johansson, et al., 2013). Several different sources specifying the critical relative humidity at different points ranging from $65 \%$ to $80 \%$, however the VTT specifies critical relative humidity at $80 \%$. This means that when the relative humidity exceeds the $80 \%$ critical relative humidity at most temperatures, mould growth will occur. Understanding this principle clarifies why under both the Measured Conditions and the Simplified Method Conditions, mould does not occur. This principle is clearly demonstrated in House 148 (Figure 38).

Under the Simplified Method Conditions, ASHRAE Standard 160 caps the IDH at $70 \%$ therefore under these conditions the VTT critical relative humidity will never be met and thus mould will not grow. Furthermore, when looking at the Measured Conditions of House 148, whilst the relative humidity does frequently exceed the $70 \%$ maximum, it never exceeds the VTT $80 \%$ threshold for critical relative humidity. Based upon these two points, it is evident why these two conditions do not produce mould predictions. Figure 38 shows the internal surface relative humidity of House 148 under the Intermediate Method Conditions. When looking at this is it is evident why mould growth is experienced, and the mould index is such as shown in Figure 39.

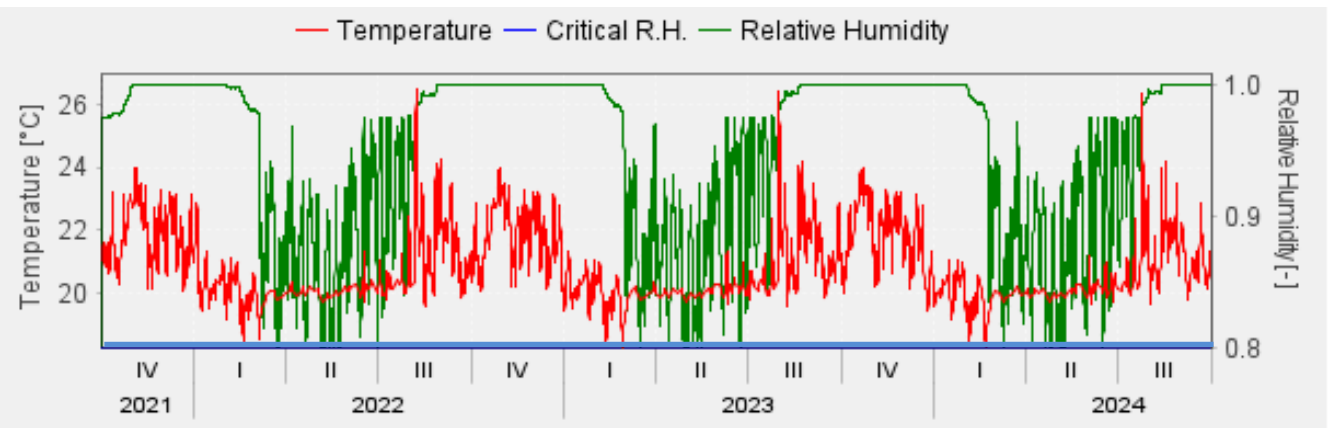

Figure 38 The critical relative humidity plotted against the internal surface relative humidity and temperature of House 148 


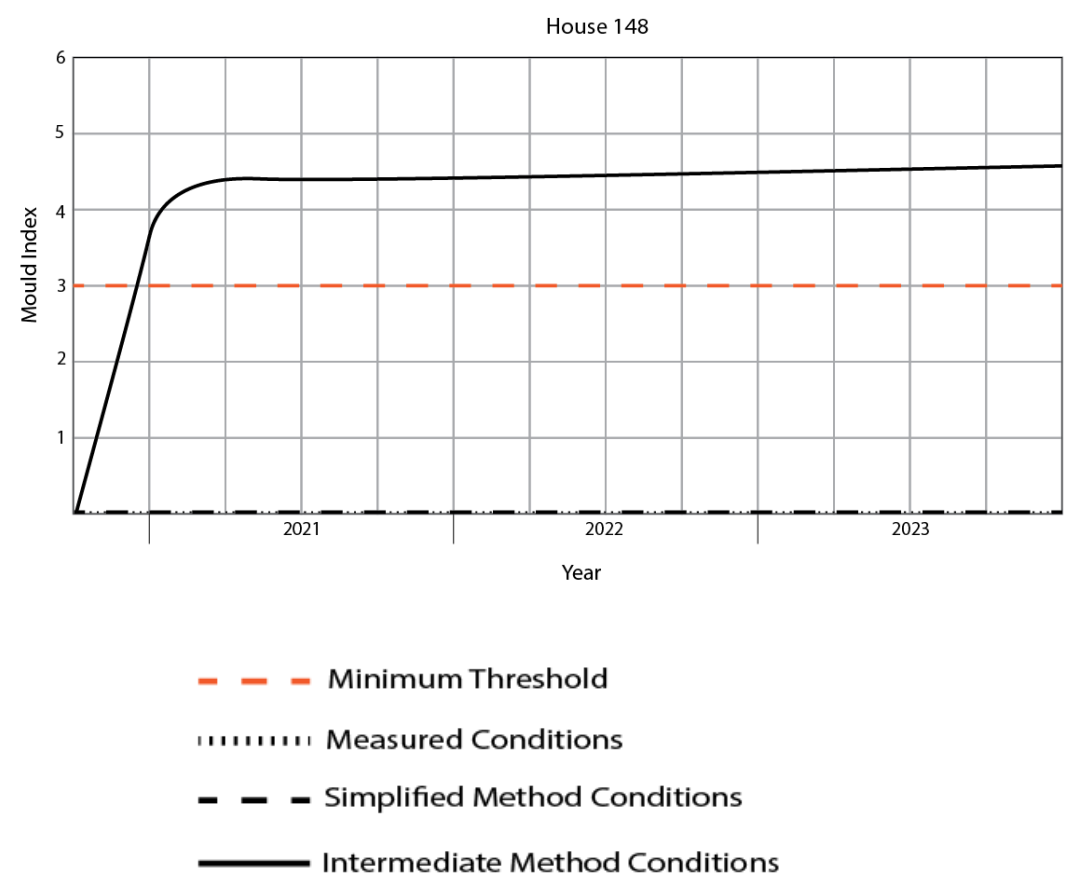

Figure 39 Mould index values of the three different internal conditions of House 148

The graph shown in Figure 38 shows that for almost all of the simulation period, the relative humidity exceeds the $80 \%$ critical relative humidity, and consequently Figure 39 shows the minimum mould index threshold of three is exceeded after just four months of the simulation. It is worth noting that WUFI correctly caps the relative humidity at $100 \%$ whilst the raw data from the Intermediate Method Conditions frequently exceeded $100 \%$. At these points WUFI specified a relative humidity of $100 \%$ and this can be seen to be occurring in Figure 38 for approximately half the simulation period.

Figure 38 also shows the fluctuation of surface temperatures throughout the simulation period but because the relative humidity always exceeds the critical relative humidity, mould continued to grow. This aligns with Johansson et al. (2013) who identified that mould growth can occur over a wide range of temperature providing the moisture conditions (relative humidity) is favourable.

\subsubsection{Periods of Mould Retardation}

A critical factor that dictated the need for this comparative mould index analysis was the understanding that both unfavourable and unfavourable period of mould growth can be experienced throughout a specified time period. This in turn can lead to periods of mould retardation when unfavourable conditions are experienced. Some form of mould retardation occurred in three of the seven assessed houses with an example of this being demonstrated through House 120 shown in Figure 40. 


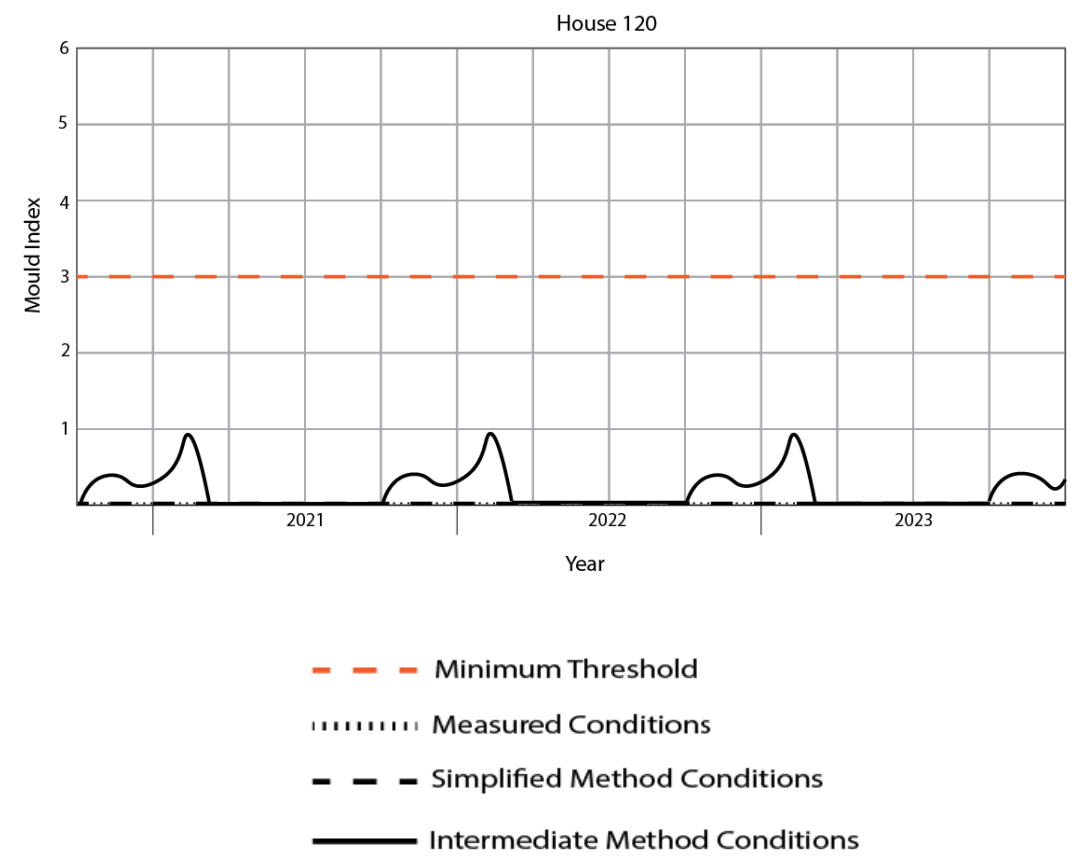

Figure 40 Mould index values of the three different internal conditions of House 120

Figure 40 shows that over the three-year simulation period, House 120 only ever experiences a maximum mould index of one, indicating the initial stages of mould growth where microscopic mould would begin to form. However, this only occurs for approximately half of the year, with the remaining half of the year experiencing a mould index of zero which indicates no growth.

The critical factor that dictates these periods of mould growth and mould retardation is the critical relative humidity. The graph shown below in Figure 41 shows the surface temperature and relative humidity of House 120. It can be seen from the graph that there are periods throughout the simulation period in which the surface relative humidity begins to exceed the $80 \%$ critical relative humidity. It is, at these times, that the mould index begins to increase. However, when the surface relative humidity begins to decrease and drop below $80 \%$ this is when mould retardation occurs. These peaks and troughs in the surface relative humidity exceeding the critical relative humidity closely match the mould index's peaks and troughs. 


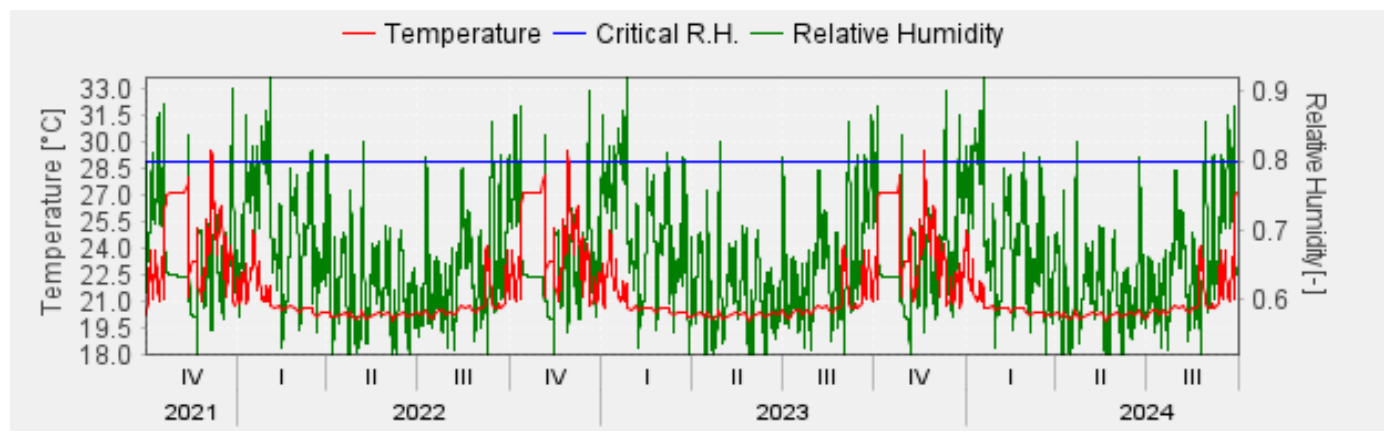

Figure 41 The critical relative humidity plotted against the internal surface relative humidity and temperature of House 120

As these periods in which the critical relative humidity is exceeded are brief and infrequent, unfavourable mould growth conditions are recurrent and mould growth on this surface never exceeds microscopic growth stages.

\subsection{Comparison to in-situ mould predictions}

The PHS included data regarding the extent of mould growth in each of the houses, however, this in not able to be directly compared to the WUFI mould predictions. The mould predictions produced from the hygrothermal simulation were created with whole house conditions and therefore are predictions for the whole house. In contrast to this, in the PHS presence of mould was described room by room. Consequently, in the instance that a wall in a single room in the PHS recorded a small level of mould, that same mould when spread out across the whole house may translate into microscopic levels of mould. This in turn may alter the pass or fail result of the wall construction.

Additionally, the PHS presence of mould used a qualitive description e.g. "large" or "extensive" to describe the spread. In contrast to this the VTT mould index describes mould growth on a qualitative level e.g., a mould index of five would indicate mould coverage on over $70 \%$ of the measured surface. As these two results utilise different measures to describe the presence and spread of mould growth they cannot be simply compared. 


\section{Chapter 10 Discussion}

This chapter discusses the findings of Chapters Six, Seven, Eight, and Nine and answers the research question outlined in Section 1.3 and the research objectives outlined in Section 1.4.1. Having applied ASHRAE Standard $160 \mathrm{IDH}$ and Simplified and Intermediate IDH across a sample of houses and comparing these internal conditions to the measured internal conditions, several observations regarding the suitability of this model's application in New Zealand were evident.

\subsection{Indoor Design Temperature}

When applying the IDT formula, a critical assumption that ASHRAE Standard 160 makes is that if the $T_{024 h}$ falls below $18.3^{\circ} \mathrm{C}$, then the indoor temperature would consequently fall below a 'comfortable' temperature and thus heating is required. ASHRAE Standard 160 assumes that the minimum heating setpoint for a space to be comfortable is $21.1^{\circ} \mathrm{C}$. Section 6.2 .2 outlines that this minimum heating setpoint of $21.1^{\circ} \mathrm{C}$ was applied in all but two houses, for $100 \%$ of the winter months but the measured indoor temperature only reached $21.1^{\circ} \mathrm{C}$ for $8 \%$ of the houses.

In contrast to ASHRAE Standard 160 assuming that all houses have some form of space heating to achieve this minimum of 21.1, the PHS indicated that only three quarters of the assessed properties had any form of space heating. Additionally, from the day to day variations seen in the measured indoor temperature for all properties, it is suggested that the space heating in these houses is not being utilised consistently throughout the year or at all. 
When the $\mathrm{T}_{024 \mathrm{~h}}$ exceeds $18.3^{\circ} \mathrm{C}$, ASHRAE Standard 160 applies another formula where the IDT is equal to $\mathrm{T}_{024 \mathrm{~h}}+2.8^{\circ} \mathrm{C}$. This formula is applied across $79 \%$ of the properties, most frequently in the summer months. Those $21 \%$ of houses which did not apply this formula are those which did not record temperature over summer. Section 6.2 .3 noted that on the occasions that the $T_{024 h}+2.8^{\circ} \mathrm{C}$ formula was applied, the daily trends matched the measured indoor temperature. This further reiterates that the ideas that the assessed properties are not effectively using their heating as it shows that to indoor temperature is highly dependent on the outdoor temperature.

Due to the Section 6.2 .4 demonstrating that when the $\mathrm{T}_{024 \mathrm{~h}}+2.8^{\circ} \mathrm{C}$ formula was applied the IDT matched the measured indoor temperature better, a secondary analysis was run. This secondary analysis removed the minimum heating setpoint of $21.1^{\circ} \mathrm{C}$ and instead applied $\mathrm{T}_{024 \mathrm{~h}}+2.8^{\circ} \mathrm{C}$ at all $\mathrm{T}_{024 \mathrm{~h}}$ temperature. The average difference between the IDT and the measured indoor temperature without the minimum heating setpoint ranged from $-2^{\circ} \mathrm{C}$ to $4^{\circ} \mathrm{C}$. In contrast, the average difference between the IDT and the measured indoor temperature with the minimum heating setpoint ranged from $-8^{\circ} \mathrm{C}$ to $1^{\circ} \mathrm{C}$.

\subsection{Indoor Design Humidity: Simplified Method}

As discussed in Section 7.1, the Simplified IDH assumes that there is a fixed lower and upper limit of $40 \%$ and $70 \%$ relative humidity based on the $\mathrm{T}_{024 \mathrm{~h}}$. Section 7.2 , outlined that the lower limit of $40 \%$ was not applied in any of assessed properties due to the fact that the Simplified IDH assumes that $40 \%$ relative humidity will only be achieved when the $\mathrm{T}_{024 \mathrm{~h}}$ drops below $-10^{\circ} \mathrm{C}$. As the $\mathrm{T}_{024 \mathrm{~h}}$ did not drop below $-10^{\circ} \mathrm{C}$ at any stage for any of the houses, the Simplified IDH was never $40 \%$. However, a measured indoor relative humidity of $40 \%$ or less was achieved in $20 \%$ of the assessed properties.

As outlined in Section 7.2.7 the upper limit of $70 \%$ was applied in $59 \%$ of houses however, on the occasions that $70 \%$ was specified by Simplified IDH, the measured indoor relative humidity ranged from $42 \%-81 \%$. This demonstrated that an indoor relative humidity of $70 \%$ is able to be achieved when the $T_{024 h}$ is below $20^{\circ} \mathrm{C}$ as ASHRAE Standard 160 assumes. This in turn suggests that for New Zealand houses, the assumption that certain levels of relative humidity are only achieved when the outdoor temperature is at a certain level, is not true.

Section 7.2.6 also discussed the implications of the Simplified IDH smoothing out fluctuations in the measured indoor relative humidity. By smoothing out fluctuations in the relative humidity, the Simplified IDH may be removing periods of favourable or unfavourable mould growth. These periods are important to consider when understanding the implications of applying this model and how its assumption impact the mould prediction results. 


\subsection{Indoor Design Humidity: Intermediate Method}

Whilst ASHRAE Standard 160 only specified one method of IDT, the IDH was able to be specified through the Simplified or the Intermediate Method with the Intermediate considering the implications of more parameters. It was important to investigate how, by using the same information, different IDH could be developed. The Intermediate IDH considers the impact of occupancy behaviour through the Moisture Generation Rate and the ventilation through the Design Ventilation Rate. Section 8.3 .1 noted that $51 \%$ of the assessed properties have an Intermediate IDH reportedly in excess of $100 \%$ and that this may be attributed to the assumptions within ASHRAE Standard 160 .

Section 8.2.1 discussed the assumptions made in the Moisture Generation Rate. The Moisture Generation Rate could be broken down into two key areas, the occupancy rate and the moisture generation rate per occupant. Firstly, it was found that ASHRAE Standard 160 overestimated the number of occupants in approximately $60 \%$ of the assessed properties. Whilst this does indicate that the assumption made to determine the occupancy is not accurate for New Zealand houses, it is important to note that the occupancy of a house can change with tenure and thus this was an assumption that could not altered. Secondly, ASHRAE Standard 160 assumed that the moisture generation rate per occupant was $3 \mathrm{~L}$ per person per day. However, Ganda (2017) suggested that the moisture generation rate of an occupant in New Zealand was 4.2 $L$ per person per day. This indicated that due to the difference in moisture generation rate per occupant, the behaviour of the occupants in New Zealand houses may differ from those where ASHRAE Standard 160 was developed.

Section 8.2.2 discussed the assumptions made in the Design Ventilation Rate. ASHRAE Standard 160 assumed that a construction was either airtight or a standard construction and consequently the infiltration rates was either $0.1 \mathrm{ACH}$ or $0.2 \mathrm{ACH}$ respectively. However, Rupp \& McNeil (2018) identified that the typical modern (post 2010) New Zealand house has an infiltration rate of $0.25 \mathrm{ACH}$ with older house (1920s) experiencing an infiltration rate of up to $0.85 \mathrm{ACH}$. In order to understand the implications of the infiltration rate, Section 8.3.2 altered the existing Design Ventilation Rate formula to allow for a unique $\mathrm{ACH}$ to be applied. A secondary analysis, referred to as the revised $A C H$, was run with new infiltration rates for each house based upon the age of the building. In $54 \%$ of the assessed properties it was found that the revised $\mathrm{ACH}$ Intermediate IDH matched the measured indoor relative humidity better than the initial Intermediate IDH. However, in $29 \%$ of the assessed properties the initial Intermediate IDH matched the measured indoor relative humidity better than the revised $\mathrm{ACH}$ Intermediate IDH. The instance of these $29 \%$ of houses was thought to be attributed to renovations having been taken place on older and hence the initial infiltration rate was a better match to the actual infiltration rate. Whilst this was hypothesised, the PHS did not contain any information on any significant renovation such as window replacements, and therefore could not be concluded. Overall, the average difference between the Intermediate IDH and the measured indoor relative humidity ranged from $-42 \%$ to $-2 \%$ whilst the average difference between the revised 
$\mathrm{ACH}$ Intermediate IDH and the measured indoor relative humidity ranged from $-20 \%$ to $21 \%$.

In contrast to the Simplified IDH smoothing out fluctuation in the measured indoor relative humidity, the Intermediate IDH fluctuated more than the measured indoor relative humidity. These fluctuations in the Intermediate IDH suggested that this method may be creating more periods of favourable or unfavourable mould growth than the measured indoor relative humidity. Consequently, these favourable or unfavourable mould growth period were found to significantly impact the mould prediction results, as discussed in Section 9.2.3.

When comparing the Simplified IDH and the Intermediate IDH it was found that in $79 \%$ of the assessed properties, the Simplified IDH matched the measured indoor relative humidity better. However, when comparing the Simplified IDH to the Intermediate IDH with the revised $\mathrm{ACH}$, it was found that in $64 \%$ of assessed properties the Simplified IDH matched the measured indoor relative humidity better. This suggested that when the parameters are known, the Intermediate IDH becomes a more suitable model.

\subsection{Mould Index}

The purpose of running a comparative mould index analysis was to understand how, by using the same information but two different methods, different mould predictions would be achieved. Section 9.1, outlined that using WUFI Pro and the VTT mould index, three internal conditions scenarios were run over seven of the assessed properties. These three different internal conditions scenarios were:

- The Measured Internal Conditions (using the measured indoor temperature and indoor relative humidity)

- The Simplified Internal Conditions (using the IDT and the Simplified IDH)

- The Intermediate Internal Conditions (using the IDT and the Intermediate IDH)

It is important to note that the seven houses that were assessed were in the $79 \%$ of houses that found that the Simplified IDH matched the measured indoor relative humidity better than the Intermediate IDH.

Section 9.2.1 outlined that the critical finding from the analysis was that a mould index of $>0$ occurred in all the houses when using the Intermediate Internal Conditions whilst a mould index of 0 occurred in all the houses when using the Measured or Simplified Internal Conditions. This was mainly found to be due to the critical surface relative humidity that was specified by WUFI of $80 \%$. Under the Simplified IDH, the relative humidity never exceeded $80 \%$ whilst under the measured indoor relative humidity rarely exceeded $80 \%$. By not exceeding the $80 \%$ critical surface relative humidity, mould did not grow. However, as previously established in Section 9.2.2, the Intermediate IDH frequently had a relative humidity in excess of $80 \%$. In all seven of the houses that were assessed in this section had an Intermediate 
of IDH of $100 \%$ over their simulation period. Therefore, it is clear as to why the Intermediate IDH predicted some form of mould growth in all seven houses.

There were several limitations to the level of analysis of Section 9.2 due to the nature of the results that were gathered. Firstly, only seven houses were able to be assessed under this analysis, and any conclusions that were drawn were limited. Ideally, a hygrothermal simulation would have been run for all the houses within the study in order to determine whether the conclusion made across the seven houses, translates to the other 47 houses.

Additionally, whilst the presence of mould was recorded with the PHS, it was not able to be simply compared to the mould index predictions due to several reasons. The mould predictions produced from the VTT, were created with whole houses conditions and were predictions for the whole house whilst the PHS presence of mould was described room by room. Consequently, if a wall in a room had a small level of mould under the PHS, that same mould spread out across the whole house may translate into microscopic levels of mould. Additionally, the PHS presence of mould was recorded with a qualitive description e.g. "large" or "extensive" to describe the spread. In contrast to this the VTT mould index describes mould growth on a qualitative level e.g., a mould index of five would indicate mould coverage on over $70 \%$ of the measured surface. As these two measures utilise different measures to describe the presence and spread of mould growth they cannot be simply compared.

\subsection{Connection to previous research}

The literature review in Section 2.8 outlined several references which the overall conclusions can relate to.

Firstly, Salonvaara (1998) discussed the importance in considering occupancy behaviours in mould prediction models. Within ASHRAE Standard 160, the Intermediate IDH was the only instance in which occupancy behaviour was considered. However, from the analysis in Section 8.2 , it was found that both the occupancy rate and the moisture generation rate per occupant assumptions in ASHRAE Standard 160 were not consistent with what is seen in New Zealand houses.

White and Jones (2017) identified that the presence of a heater in New Zealand houses does not necessarily equate to it use and Section 6.2.1 reiterated this idea. Due to the fluctuations seen in the measured indoor temperature, particularly throughout winter, it was concluded that despite three quarters of the assessed properties having some form of space heating, this was not being effectively used.

Johansson et al. (2013) discussed the implications of using steady state conditions in mould prediction models and how these types of conditions may not allow for periods of unfavourable and favourable mould growth to be experienced. Section 8.3.3 discussed how the Intermediate IDH fluctuated significantly more than the measured indoor relative humidity and consequently, may be experiencing periods of favourable or unfavourable mould growth. When looking at the mould prediction 
results from WUFI, it was seen that the Intermediate IDH was suggesting more periods of favourable mould growth than was the case with the measured indoor relative humidity.

Lastly, Vereecken \& Roels (2014) discussed the sensitivity of complex mould prediction models and the impact of parameters on results. They found that the more parameters that a model considers the more accurate it becomes, however, if these parameters are unknown and assumptions need to be made the margin of error increase. This idea was reiterated in Section 8.3.4 when discussing that in $79 \%$ of the assessed properties the Simplified IDH matched the measured indoor relative humidity better than the Intermediate IDH. It was found that parameters in the Intermediate IDH were largely based on assumption about the Design Ventilation Rate and Moisture Generation Rate thus resulting in this margin of error. When the Intermediate IDH parameters were revised, the number of houses where the Simplified was a better match reduced.

\subsection{Use of ASHRAE Standard 160 in New Zealand}

This research aimed to understand the suitability of ASHRAE Standard 160 in New Zealand. Having identified discrepancies between the conditions that ASHRAE Standard 160 predicts and reality and investigated these discrepancies there are a number of recommendations as to what they mean for the suitability of this standard in New Zealand.

Overall ASHRAE Standard 160 could still be suitably applied in a New Zealand context given several amendments which may be subject to further research:

- The minimum heating setpoint of $21.1^{\circ} \mathrm{C}$ is not applicable in New Zealand houses.

It has been shown that the application of the $\mathrm{T}_{024 \mathrm{~h}}+2.8^{\circ} \mathrm{C}$ formula across all outdoor temperatures produces more realistic results. Alternatively, further research could establish a more applicable minimum heating setpoint for New Zealand.

- Overall the Simplified IDH is a more favourable method of determining the IDH than the Intermediate IDH

It was found that overall, the Simplified IDH matched the measured indoor relative humidity better than the Intermediate IDH. This was concluded to be due to the fact that the assumptions in the Intermediate IDH did not reflect the reality of New Zealand houses. However, there is the possibility for the Intermediate IDH to be altered to better reflect the reality of New Zealand houses.

- The parameters under the Intermediate IDH are altered to better reflect the reality of New Zealand houses.

This research identified that the two main parameters, Design Moisture Generation and Design Ventilation Rate, do not reflect how New Zealanders ventilate and use their houses. By undertaking further research into refining 
these parameters, the application of the Intermediate IDH may become more suitable for New Zealand. 


\section{Chapter 11 Conclusions}

This research utilised data from the 2015 Pilot Housing Study to understand the suitability of the application of ASHRAE Standard 160 into a New Zealand context. Using external temperature data from 54 houses situated throughout New Zealand, ASHRAE Standard 160 was applied to establish an Indoor Design Temperature and an Indoor Design Humidity (Simplified Method and Intermediate Method) for each. This application of ASHRAE Standard 160 was then compared to the measured internal temperature and relative humidity for each house and discrepancies between these values were identified. Having identified discrepancies between the values, the trends were analysed in order to understand how the assumptions made when applying ASHRAE Standard 160 created these discrepancies and consequently how this impacted the application of this Standard in a New Zealand context. The following conclusions discuss whether this research methodology was able to meet the research objectives established in Section 1.4.1 and outline areas of possible future research.

\subsection{Research Objective One}

Research objective one aimed to identify existing research that had been undertaken on various mould prediction tools in order to understand the assumptions that are required within these tools and how discrepancies commonly arise because of these assumptions. This was done in order to understand the common reasons why discrepancies in mould prediction tools occur and to provide some guidance on the impact of potential assumptions in ASHRAE Standard 160. This objective identified three key assumptions which commonly lead to discrepancies occurring: 
- The sensitivity of complex mould prediction models due to the increase in the number of parameters. The goal of increasing the number of parameters within a model is to increase the accuracy of the mould predictions, however, when these parameters are not known and need to be assumed, this increase in parameter can negatively influence the mould predictions.

- The use of steady state conditions to not only develop a model but to specify a set of conditions does not allow for fluctuations in both temperature and relative humidity. This in turn means that the model fails to account for both periods of favourable and unfavourable mould growth. These periods of unfavourable mould growth are particularly relevant to consider as they are periods in which mould retardation can occur.

- Occupancy behaviour greatly influences the amount of moisture within a space, and humidity has been identified as one of the most critical conditions for mould growth. Therefore, by omitting the impact of occupants on the humidity within the space, the in-situ conditions are unlikely to match the theoretical conditions in regard to moisture generation.

\subsection{Research Objective Two}

Research objective two aimed to apply ASHRAE Standard 160 across a number of case study houses in order to identify discrepancies between the measured and theoretical internal conditions. Having gathered relevant data from the PHS, ASHRAE Standard 160 Indoor Design Temperature and Indoor Design Humidity (Simplified Method and Intermediate Method) were applied, and theoretical internal conditions were developed. These theoretical internal conditions were plotted alongside the measure internal conditions and several trends and discrepancies were established between these two datasets. Most notably the minimum indoor temperature setpoint of $21.1^{\circ} \mathrm{C}$ was applied for all but two houses for $100 \%$ of the winter months whilst the measured indoor temperature dropped significantly below this. Additionally, the assumed maximum and minimum relative humidity of $40 \%$ and $70 \%$ respectively also were not reflected in the measured indoor relative humidity with periods in excess of $70 \%$ relative humidity being experienced. The Intermediate Indoor Design Humidity also produced relative humidities (impossibly) in excess of $100 \%$ with a maximum relative humidity of $148 \%$ being reported in one instance. These discrepancies have been discussed in further detail in Chapter 6,7, and 8 .

\subsection{Research Objective Three}

Research objective three aimed to take the points established in research objective one and understand whether the discrepancies identified in research objective two can be attributed to these assumptions.

The most notable trend identified was that the Simplified IDH matched the measured indoor relative humidity better than the Intermediate IDH. This aligned strongly with the previously identified idea that as the number of parameters that a model utilises, the potential for errors to occur increases if the parameters are 
assumed. The intermediate IDH considers the Design Ventilation Rate and the Moisture Generation Rate, however, these two parameters were assumed, and further investigation identified that these assumptions did not reflect the reality of New Zealand houses.

The use of steady state conditions was evident when looking at the IDT and the Simplified IDH. Both conditions specified absolute limits in terms of the indoor temperature or the indoor relative humidity. Across all of the houses, when one of these steady state conditions was applied, the in-situ measurements rarely mirrored this. This was more clearly seen in the measured indoor temperature where the IDT specified a consistent $21.1^{\circ} \mathrm{C}$ for winter months in all but two of the houses. Over this period where $21.1^{\circ} \mathrm{C}$ was applied, the measured indoor temperature fluctuated and was frequently below this setpoint.

Whilst ASHARE Standard 160 Intermediate IDH did consider the implications of occupancy behaviour on the internal conditions, it was identified that not only did the assumed number of occupants not reflect New Zealand occupancy rates but the assumed moisture generation rate per occupant also differed.

\subsection{Research Objective Four}

Research objective four aimed to understand how the mould prediction result may be impacted due to any potential discrepancies between the theoretical and insitu internal conditions. In order to assess this hygrothermal simulations were undertaken using WUFI Pro and the VTT Mould Index model. Constructions of seven of the assessed properties were created based on PHS information regarding the buildings age and the cladding type. Utilising the age of the building, a typical construction of that era was developed and simulated. The hygrothermal simulation, simulated three different sets of internal conditions for the same construction. Having run the hygrothermal simulation, three different mould index values were presented for each of the houses over a three-year simulation period. By comparing the three mould index values of the different conditions, it became evident that the differences between the Measured Conditions and the Simplified Conditions, and the Intermediate Conditions were significant enough to impact the mould index values. Whilst in all seven houses the mould index values from the Simplified Conditions and the Measured Conditions remained at zero throughout the entire simulation period, the mould index values under the Intermediate Conditions superseded acceptable levels of mould growth in several instances. This also illustrated the previous conclusion that the Simplified Method was able to match the measured conditions much better than the Intermediate Method due to its lack of assumed parameters.

\subsection{Research Objective Five}

Research objective five aimed to understand how what had been identified in the previous research objectives meant for the suitability of the application of ASHRAE Standard 160 in a New Zealand context. It became evident that a number of the 
assumptions that are made when applying ASHRAE Standard 160, are not suitable for a New Zealand context. Section 10.6 identified what these findings mean for the suitability of ASHRAE Standard 160 in New Zealand as well as suggesting potential future research.

\subsection{Future Research}

Whilst undertaking this research, a number of areas in which future research can be undertaken became evident. Having established that ASHRAE Standard 160 would be able to be implemented in New Zealand given some amendments, the suggestions of future research are all governed towards these amendments.

It was identified in Section 8.2.2, that the assumed infiltration rate did not reflect the assessed properties and by altering this it improved the Intermediate IDH. However, in several instances it was hypothesised that the revised $\mathrm{ACH}$ was not as effective due to the possibility of renovations having occurred in older houses. Therefore, it is proposed in any future PHS studies that are undertaken, information on any renovations that have occurred, the extent of these renovations, and the dates of these renovations would be beneficial.

In addition to recording renovations that have occurred, it is also suggested that in future PHS studies, the number of occupants is recorded for all houses and whether or not these occupants are children, teenagers, adults, or elderly. Additionally, studies further exploring the conclusions found in Ganda (2017) regarding the moisture generation rate of occupants would be beneficial. Whilst Ganda (2017) did begin to suggest that the moisture generation rate of New Zealand occupants differed from that specified in ASHRAE Standard 160, this was only one case study. By furthering the research on moisture generation rates of New Zealand occupants, and having precise information of the number of occupants, a more refined Moisture Generation Rate can be developed.

Lastly, utilising the previous two recommendations of future research, an investigation into improving the formula of ASHRAE Standard 160 and customising this information for New Zealand would be beneficial. This research may include factors such as determining a more appropriate minimum heating setpoint than 21.1 and developing an alternative method to determining the Simplified IDH that does not use the $T_{024 h}$.

\subsection{Summary}

The research question aimed to understand the suitability of ASHRAE Standard 160 in New Zealand given the identified discrepancies between the conditions that ASHRAE Standard 160 predicts and reality. By utilising in-situ data from the PHS and applying ASHRAE Standard 160, a number of discrepancies between the theoretical and in-situ conditions became evident. Through use of previous research, the discrepancies that were identified were able to be attributed to a number of the assumption that made when applying ASHRAE Standard 160. In turn this identified 
several areas in which the assumptions that were made did not reflect the reality of New Zealand houses. These assumptions ranged from the general climate and the standard constructions of New Zealand houses as well as how New Zealanders condition and occupy their spaces. It was found that due to these assumptions, the theoretical conditions differed from the in-situ conditions and consequently, in the instance of the Intermediate Conditions, even had an impact on the mould prediction models.

This research began to suggest some areas in which these assumptions could be altered in order to reflect what is being seen in New Zealand houses. Future research could include understand how the New Zealand external environment impacts the internal environment as well as the influence of occupancy and construction in terms of moisture generation and ventilation rates. By understanding these factors and altering the assumptions this further could be used to develop the ASHRAE Standard 160 model to better reflect the reality of New Zealand houses. 


\section{Chapter 12 Works Cited}

Aien, S. et al., 2019. Predictive Performance of Hygro-Thermal Simulation Models: $A$ Case Study. s.l., Trans Tech Publications, pp. 401-407.

ASHRAE, 2001. ANSI/ASHRAE/IESNA Standard 90.1 -2001: Energy Standard for Buildings Except Low-Rise Residential Buildings, Atlanta: ASHRAE .

ASHRAE, 2009. ANSI/ASHRAE Standard 160-2009: Criteria for Moisture-Control Design Analysis in Buildings, Atlanta: ASHRAE.

ASHRAE, 2009. ASHRAE Handbook of Fundamentals, Atlanta: ASHRAE.

ASHRAE, 2016. ANSI/ASHRAE Standard 160-2016: Criteria for Moisture-Control Design Analysis in Building, Atlanta: ASHRAE.

ASHRAE, 2016. ANSI/ASHRAE Standard 62.1-2016: Ventilation for Acceptable Indoor Air Qualoty, Atlanta: ASHRAE.

ASHRAE, 2017. ASHRAE Standard 55-2017: Thermal Environment Conditions for Human Occupancy, Atlanta: ASHRAE.

Berger, J. et al., 2018. Analysis and improvement of the VTT mold growth model: application to bamboo fiberboard. Building and Environment, pp. 262-274.

Boland, A. et al., 2017. Doing a systematic review: $A$ student's guide. 2nd ed. London: SAGE Publishing.

BRANZ, 2018. Mould - Health and Safety. [Online]

Available at: http://www.level.org.nz/health-and-safety/mould/

BRANZ, 2020. BRANZ Research Now: Pilot Housing Survey 2018/2019 \#1 - Survey Methodology, Wellington: BRANZ. 
BRANZ, n.d. Renovate: The technical resource for industry. [Online]

Available at: https://www.renovate.org.nz/

[Accessed 2020].

Department of Building and Housing, 2011. Compliance Document for New Zealand Building Code Clause G5, Interior Environment, Wellington: Ministry of Business, Innovation, and Employment .

EECA, 2017. Low energy houses - Insulating your house. [Online]

Available at: https://genless.govt.nz/living/lower-energy-houses/insulating-yourhouse/damp-and-mould/

Fraunhofer , 2018. WUFI Mould Index VTT. [Online]

Available at: https://wufi.de/en/2017/03/31/wufi-mould-index-vtt/

Fraunhofer, 2018. WUFI. [Online]

Available at: https://wufi.de/en/

Fraunhofer, 2019. WUFI Pro. [Online]

Available at: https://wufi.de/en/software/wufi-pro/

Ganda, S., 2017. Moisture Generation in New Zealand Households, Wellington: s.n.

Glass, S., Gatland, S., Ueno, K. \& Schumacher, C., 2017. Analysis of Improved

Criteria for Mold Growth in ASHRAE Standard 160 by Comparison with Field

Observations. In: Advances in Hygrothermal Performance of Building Envelopes:

Materials, Systems and Simulations. s.l.:s.n., pp. 1-27.

HNZ, 2019. Controlling Mould. [Online]

Available at: https://kaingaora.govt.nz/assets/Tenants-and-

communities/Documents/Controlling-mould-in-your-house.pdf

Johansson, P., Bok, G. \& Ekstrand-Tobin, A., 2013. The effect of cyclic moisture and temperature on mould growth on wood compared to steady state conditions.

Building and Environment, Volume 65, pp. 178-184.

MBIE, 2019. Mould in damp buildings. [Online]

Available at: https://www.building.govt.nz/resolving-problems/resolution-

options/weathertight-services/signs-of-a-leaky-house/mould/

McNeil, S., 2016. The Nitty Gritty on Airtightness. BUILD, October/November, Issue 156, pp. 86-87.

Ministry of Business, Innovation, and Employment, 2017. Acceptable Solutions and Verification Methods For New Zealand Building Code Clause E3 Internal Moisture

(2nd Edition, Amendment 6), Wellington : Ministry of Business, Innovation, and Employment.

Ministry of Business, Innovation, and Employment, 2020. Building Code Complaince. [Online]

Available at: https://www.building.govt.nz/building-code-compliance/

[Accessed 2020].

O'Brien, A. \& McGuckin, C., 2019. The Systematic Literature Review Method: Trials and Tribulations of Electronic Database Searching at Doctoral Level, London: SAGE Publications, Ltd. 
Ojanen, T. et al., 2010. Mold growth modeling of building structures using sensitivity classes of materials. s.I., Proceedings Buildings XI, Florida.

Overton, G., 2019. Hygrothermal performance of New Zealand wall constructions meeting the durability requirements of the New Zealand Building Code. Canadian Journal of Civil Engineering, 46(10), pp. 1063-1073.

Reardon, J. \& Shaw, C., 1997. Evaluation of five simple ventilation systems suitable for houses without forced-air heating. Journal of Thermal Insualtion and Building Envelopes, Volume 20, pp. 191-198.

Riordan, F. \& Tsongas, G., 2016. Minimum Conditions for Visible Mold Growth. ASHRAE Journal, 58(9), pp. 32-43.

Ronnberg, R., Ruotsalainen, R. \& Majanen, A., 1989. The performance of ventilation systems in residental buildings and the effect of ventilatioin on health, comfort and satisfaction, s.l.: s.n.

Rupp, S. \& McNeil, S., 2018. Airtightness Trends. BUILD, June/July, Issue 166, pp. 90-91.

Smith, A. D. \& Mago, P. J., 2014. Effects of load-following operational methods on combined heat and power system efficiency. Applied Energy, Volume 115, pp. 337351.

Standards New Zealand , 2009. NZS4218:2009 - Thermal Insulation - Housing and Small Buildings, Wellington : Standards New Zealand .

TenWolde, A., 2008. ASHRAE Standard 160P - Criteria for Moisture Control Design Analysis in Buildings. ASHRAE Transcations, Volume 114, pp. 167-169.

Vaisala Oyj, 2013. Humidity Conversion Formulas - Calculation formulas for humidity, Helsinki: Vaisala Oyj.

Vereecken, E. \& Roels, S., 2012. Review of mould prediction models and their influence on mould risk evaluation. Building and Environment, Volume 51, pp. 296310.

Vereecken, E. \& Roels, S., 2014. Mould risk assessment for thermal bridges: What is the impact of the mould prediction model. s.I., XIII Conference on Durability of Building Materials and Components, pp. 599-606.

Vereecken, E., Vanoirbeek, K. \& Roels, S., 2015. Towards a more thoughtful use of mould prediction models: A critical view on experimental mould growth research. Journal of Building Physics, 39(2), pp. 102-123.

Viitanen, $\mathrm{H}$. et al., 2015. Mold Risk Classification Based on Comparative Evaluation of Two Established Growth Models. Energy Procedia, Volume 78, pp. 1425-1430.

White, V. \& Jones, M., 2017. Warm, dry, healthy? Insights from the 2015 House Condition Survey on insulation, ventilation, heating and mould in New Zealand houses, Wellington: BRANZ.

White, V., Jones, M., Cowan, V. \& Chun, S., 2017. BRANZ 2015 House Condition Survey: Comparison of house conditions by tenure, s.I.: BRANZ Study Report SR370. 


\section{Chapter 13 Appendices}

\subsection{Appendix A}

\begin{tabular}{|c|c|c|c|}
\hline \multirow[b]{2}{*}{ House \# } & \multicolumn{2}{|c|}{ Data Point Count } & \multirow[b]{2}{*}{ Yearly or Seasonal trend } \\
\hline & External & Internal & \\
\hline 100 & 3357 & 8001 & Seasonal \\
\hline 101 & 3594 & 8768 & Yearly \\
\hline 102 & 3851 & 7226 & Further excluded \\
\hline 103 & 6538 & 6354 & Yearly \\
\hline 104 & 9286 & 3648 & Yearly \\
\hline 106 & 4974 & 3448 & Seasonal \\
\hline 107 & 8602 & 6892 & Further excluded \\
\hline 108 & 8427 & 170 & - \\
\hline 110 & 3723 & 6152 & Seasonal \\
\hline 111 & 8348 & 6897 & Yearly \\
\hline 113 & 3788 & 8125 & Yearly \\
\hline 114 & 2292 & 7929 & - \\
\hline 115 & 834 & 3818 & - \\
\hline 116 & 8492 & 6859 & Seasonal \\
\hline 117 & 6370 & 7559 & Seasonal \\
\hline 118 & 5783 & 9312 & Seasonal \\
\hline 119 & 7829 & 517 & - \\
\hline 120 & 10220 & 7744 & Yearly \\
\hline 121 & 6179 & 8604 & Yearly \\
\hline 122 & 2843 & 3925 & - \\
\hline 124 & 7730 & 4064 & Yearly \\
\hline 125 & 4100 & 8036 & Yearly \\
\hline 126 & 5596 & 8183 & Seasonal \\
\hline 127 & 4033 & 405 & - \\
\hline 128 & 8783 & 10214 & Yearly \\
\hline 129 & 8736 & 8347 & Seasonal \\
\hline 130 & 7226 & 5560 & Seasonal \\
\hline 131 & 4837 & 4462 & Seasonal \\
\hline 134 & 10618 & 1502 & - \\
\hline 135 & 8668 & 8502 & Yearly \\
\hline 136 & 9696 & 8442 & Yearly \\
\hline 137 & 3792 & 10659 & Seasonal \\
\hline 138 & 5434 & 5588 & Yearly \\
\hline 139 & 8183 & 3792 & Seasonal \\
\hline 140 & 8042 & 7379 & Yearly \\
\hline 141 & 7969 & 2704 & - \\
\hline 142 & 3151 & 8485 & Yearly \\
\hline 143 & 3782 & 8331 & Yearly \\
\hline 144 & 8443 & 8063 & Yearly \\
\hline 145 & 5572 & 8419 & Seasonal \\
\hline 148 & 7498 & 8427 & Yearly \\
\hline 149 & 8508 & 3375 & Seasonal \\
\hline
\end{tabular}




\begin{tabular}{|c|c|c|c|}
\hline \multirow[b]{2}{*}{ House \# } & \multicolumn{2}{|c|}{ Data Point Count } & \multirow[b]{2}{*}{ Yearly or Seasonal trend } \\
\hline & External & Internal & \\
\hline 150 & 8125 & 8612 & Further excluded \\
\hline 151 & 8198 & 8828 & Seasonal \\
\hline 152 & 9053 & 8608 & Yearly \\
\hline 153 & 4857 & 5505 & Seasonal \\
\hline 154 & 7744 & 8669 & Seasonal \\
\hline 155 & 3560 & 6425 & Yearly \\
\hline 156 & 4788 & 4905 & Seasonal \\
\hline 157 & 6390 & 2139 & - \\
\hline 158 & 8934 & 2743 & - \\
\hline 159 & 7220 & 5783 & - \\
\hline 160 & 1502 & 3676 & - \\
\hline 161 & 8615 & 5872 & Seasonal \\
\hline 162 & 7929 & 9220 & Yearly \\
\hline 163 & 5559 & 1873 & - \\
\hline 164 & 10155 & 6806 & Yearly \\
\hline 167 & 8930 & 5792 & Further excluded \\
\hline 168 & 9360 & 6241 & Yearly \\
\hline 169 & 3078 & 5979 & Seasonal \\
\hline 170 & 5778 & 5783 & Seasonal \\
\hline 171 & 4022 & 9355 & Yearly \\
\hline 172 & 9192 & 5604 & Further excluded \\
\hline 173 & 6892 & 1432 & - \\
\hline 174 & 2559 & 6226 & - \\
\hline 175 & 5663 & 1956 & - \\
\hline 176 & 10304 & 3570 & - \\
\hline 177 & 8236 & 5006 & Seasonal \\
\hline 178 & 9096 & 4429 & Seasonal \\
\hline 179 & 3520 & 631 & - \\
\hline 180 & 5835 & 9088 & Yearly \\
\hline 181 & 1280 & 5260 & - \\
\hline
\end{tabular}




\subsection{Appendix B}

Application of Indoor Design Temperature as outlined in ASHRAE Standaard 160.

House 100

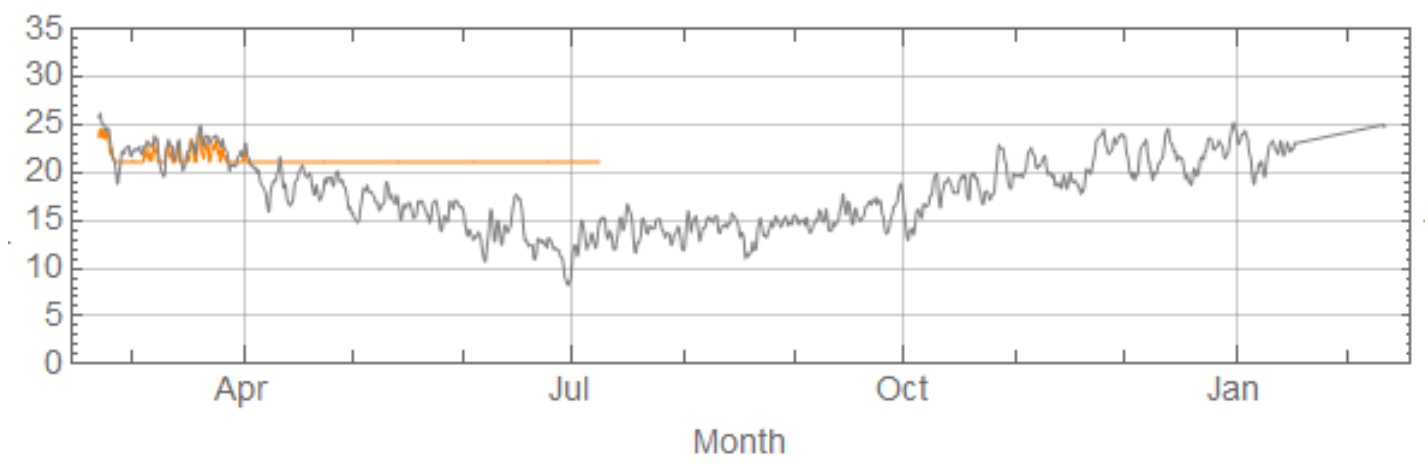

— Indoor Design Temperature

- Measured Indoor Temperature

House 101

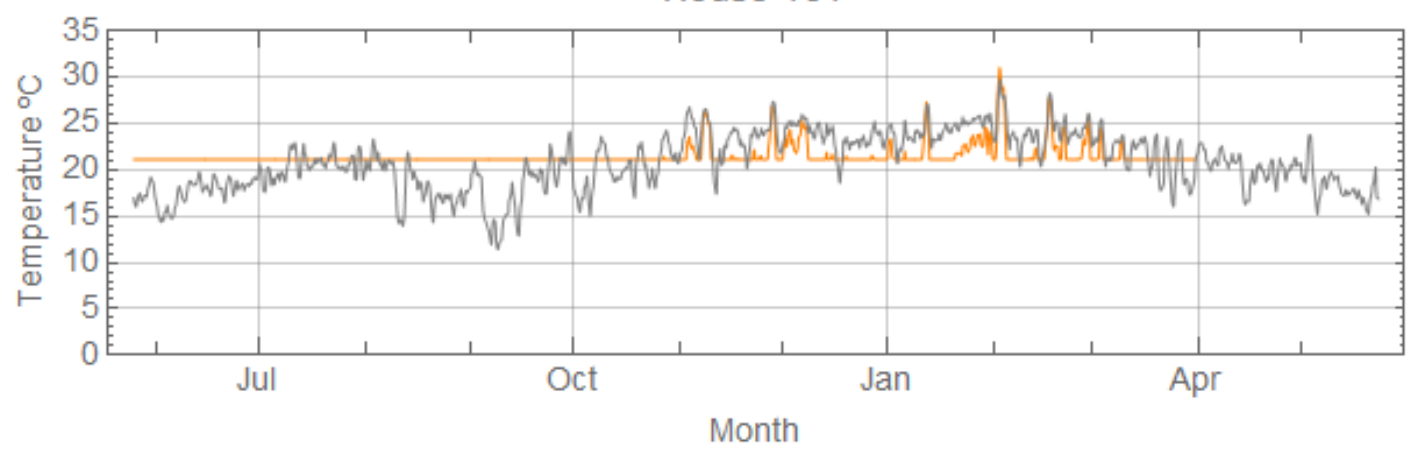

House 103

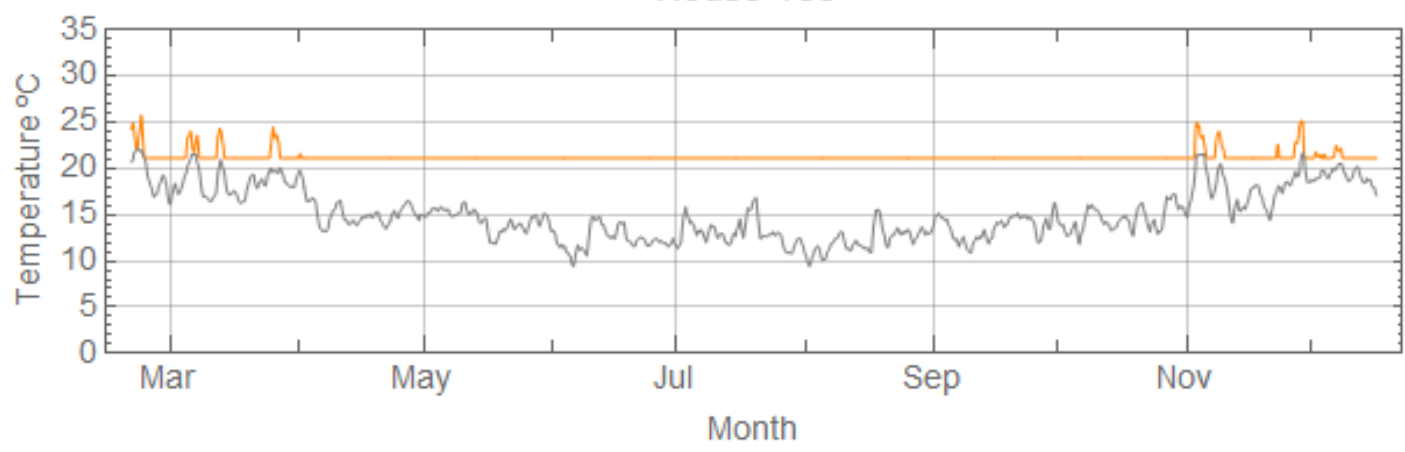


House 104

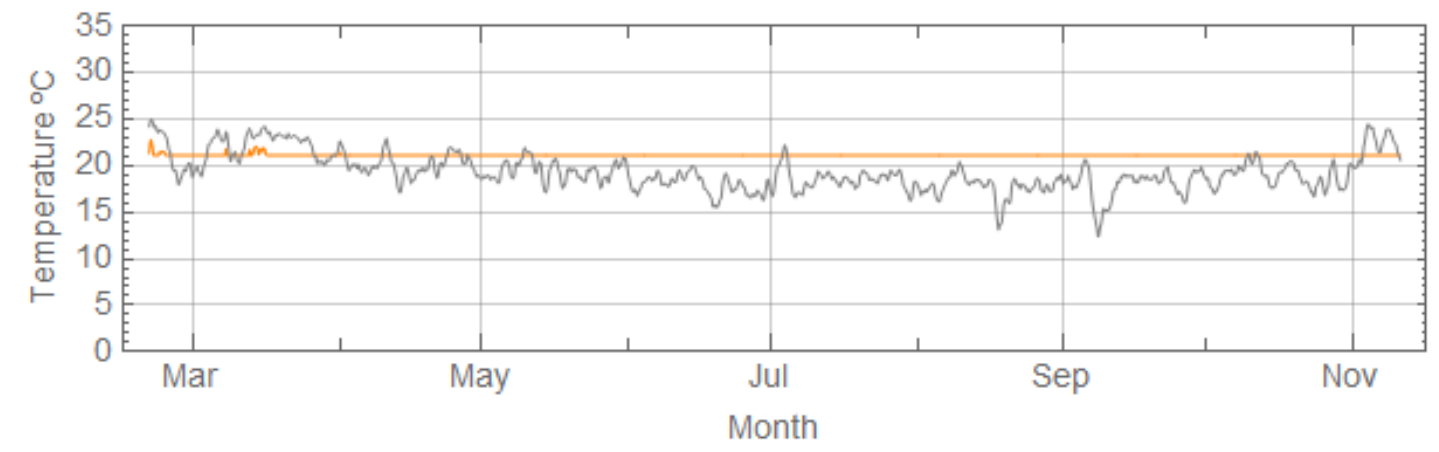

House 106

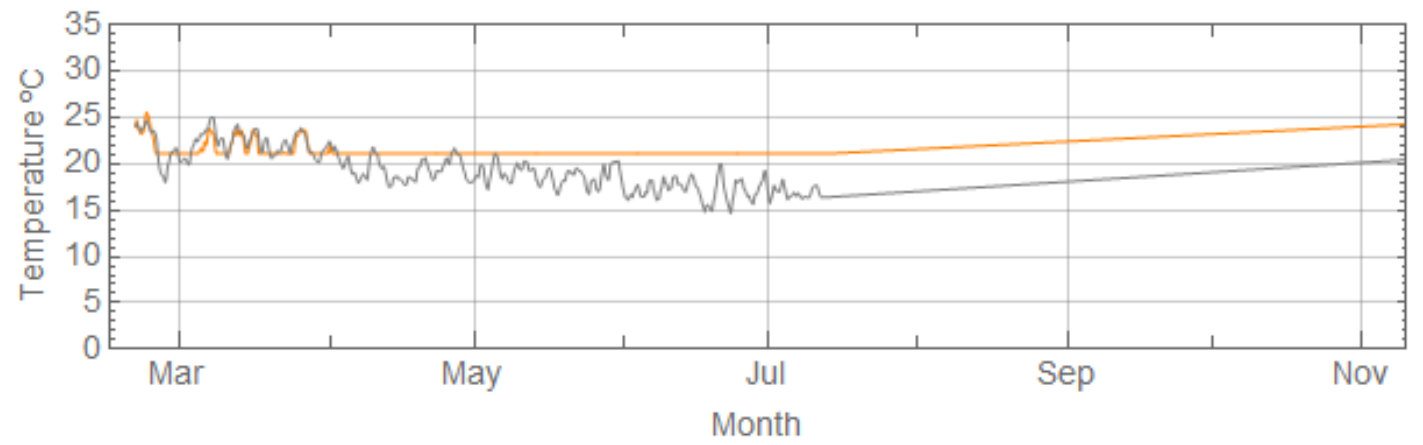

House 110

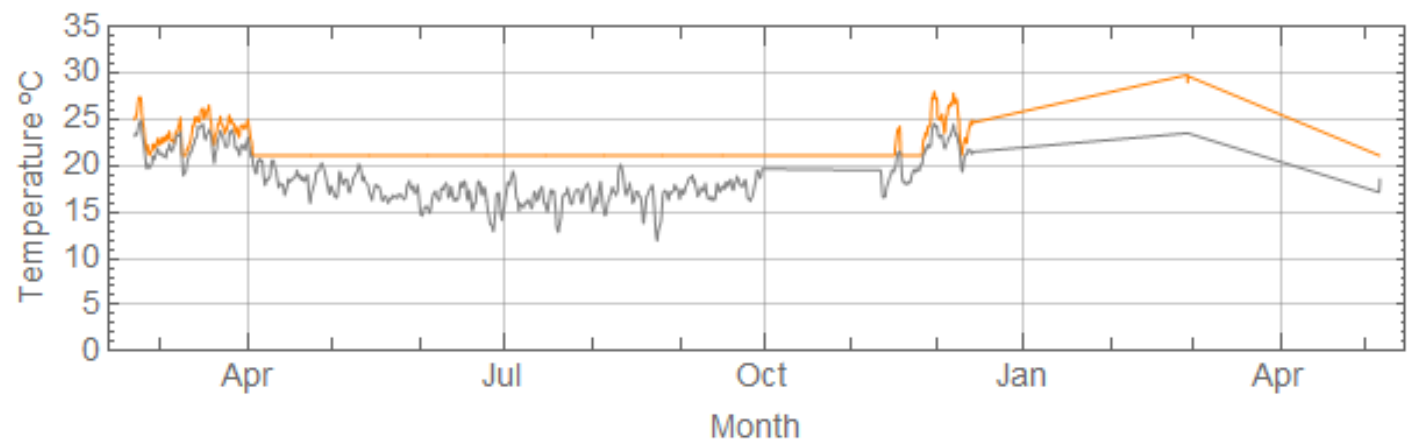

House 111

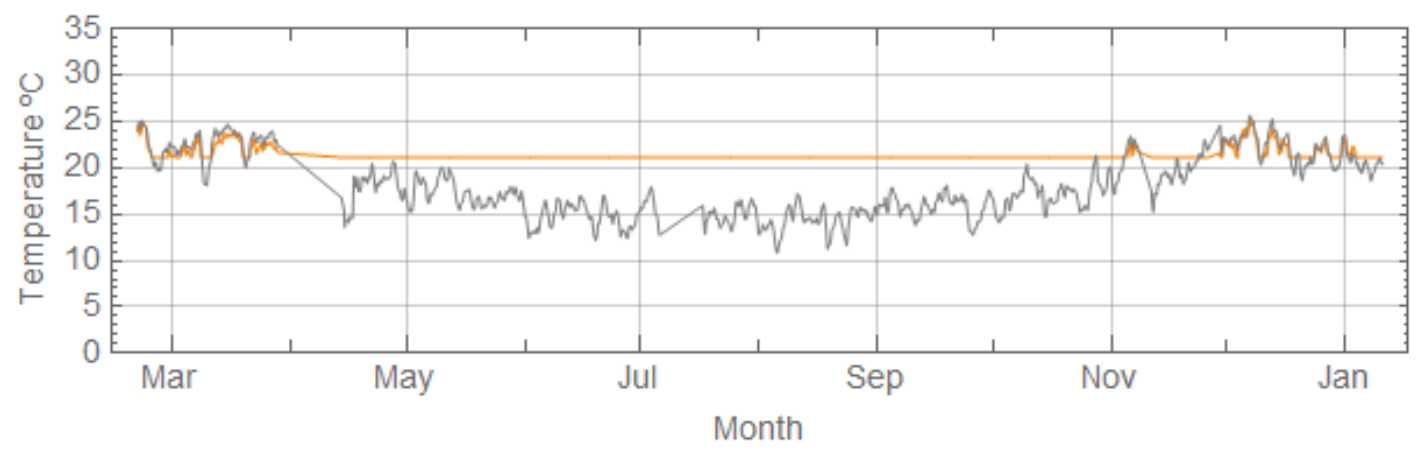


House 113

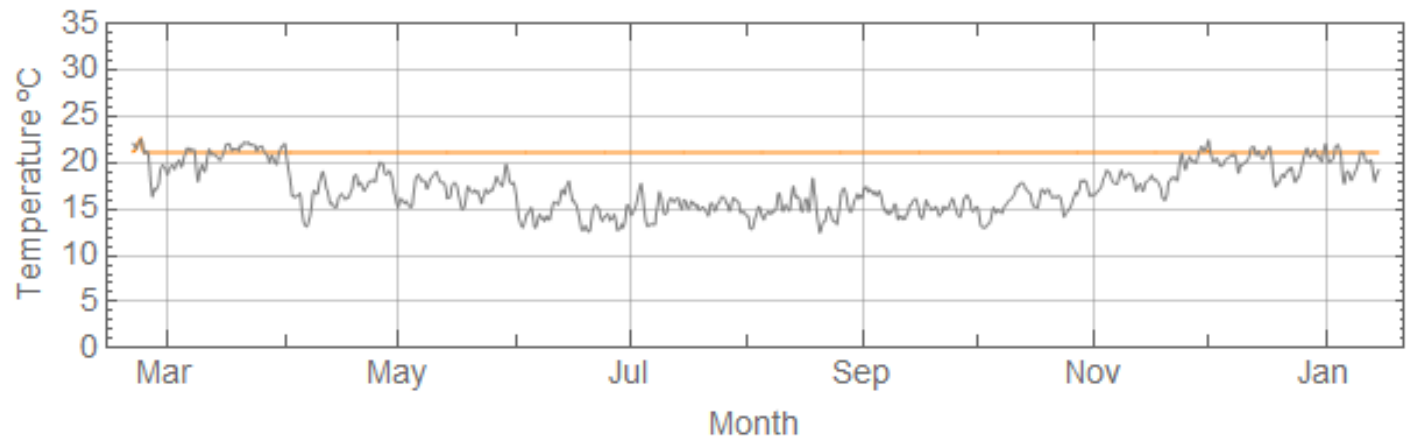

House 116

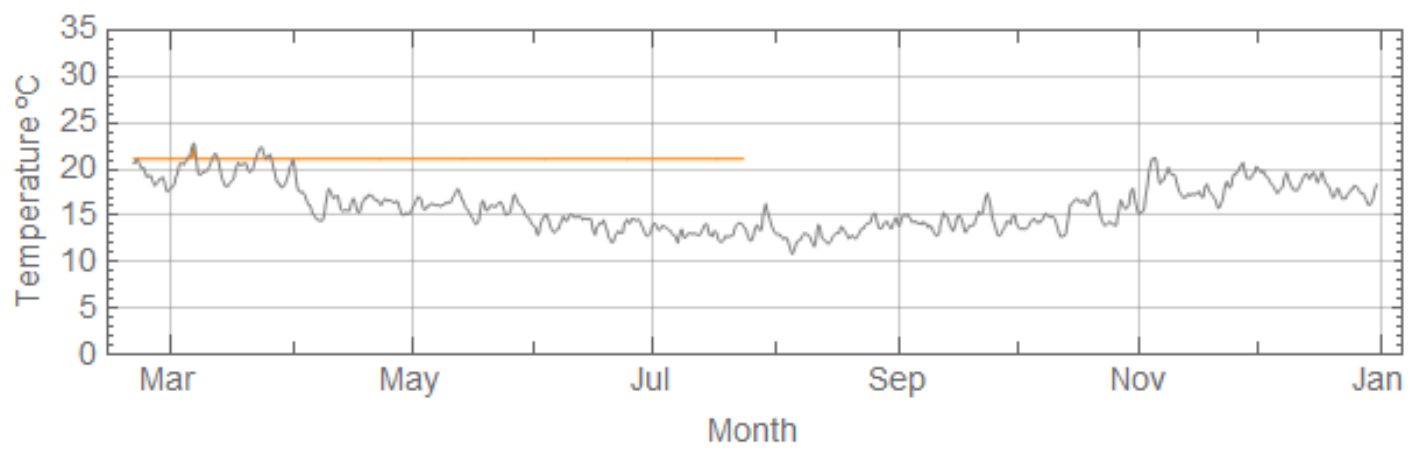

House 117

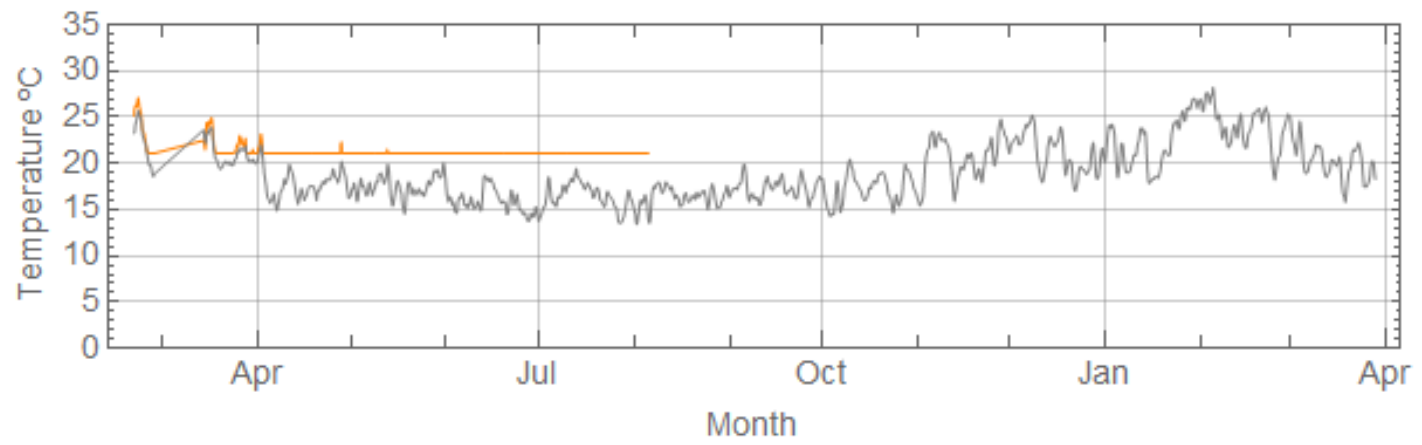

House 120

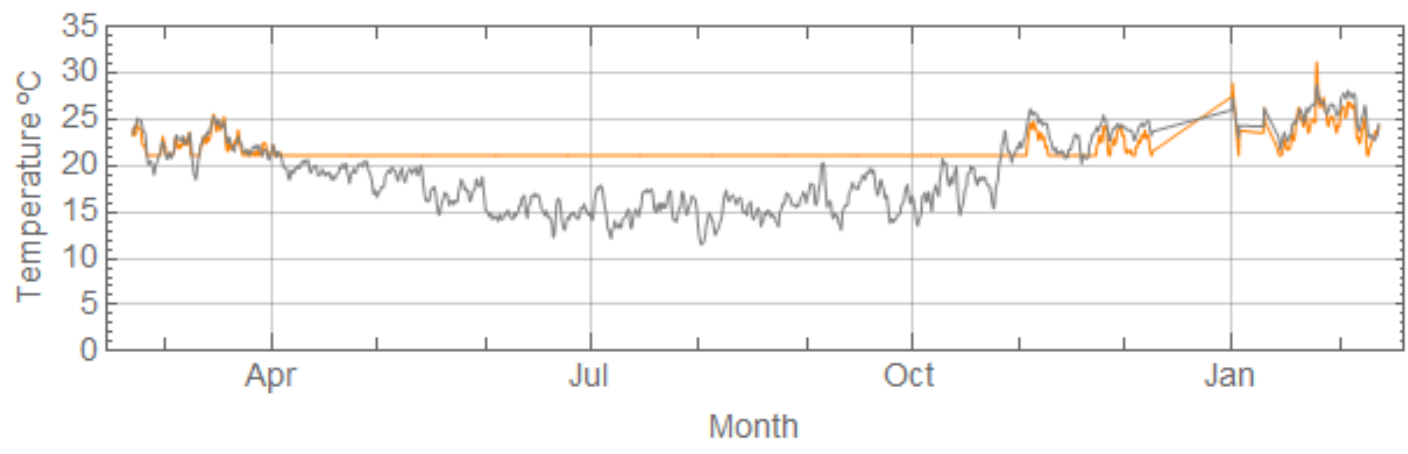


House 121

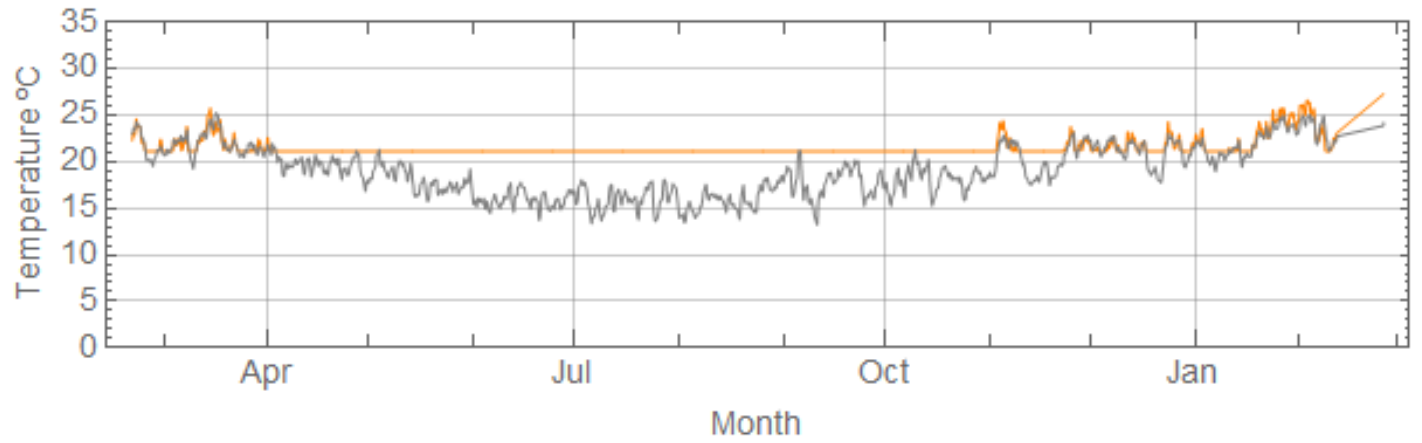

House 124

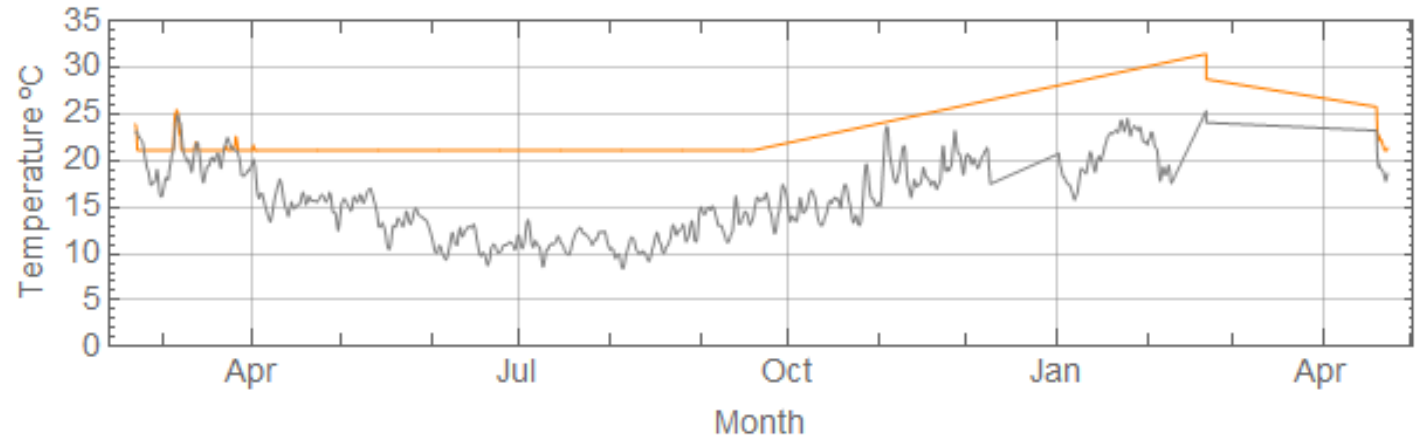

House 125

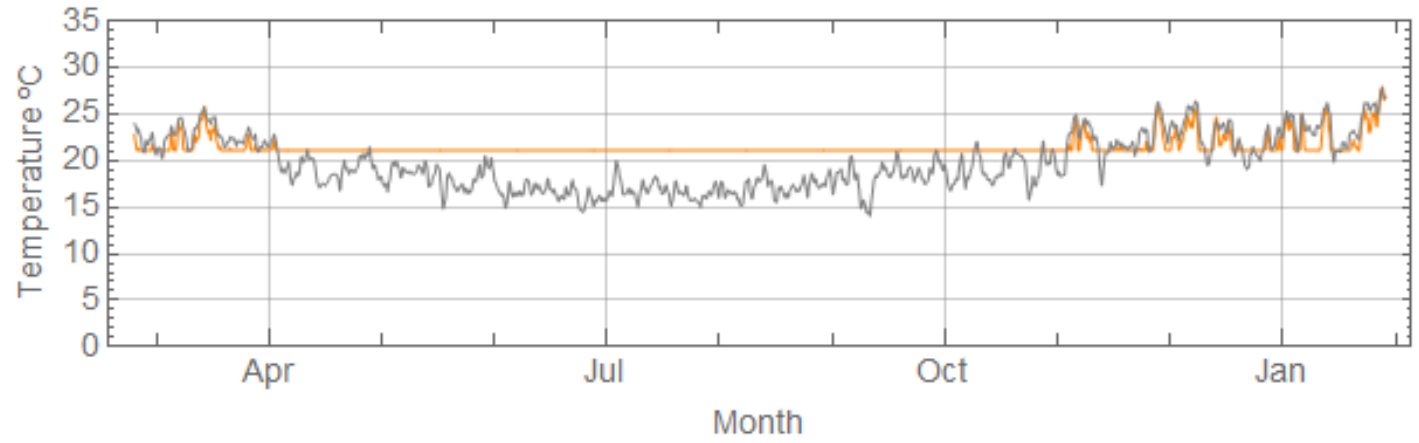

House 128

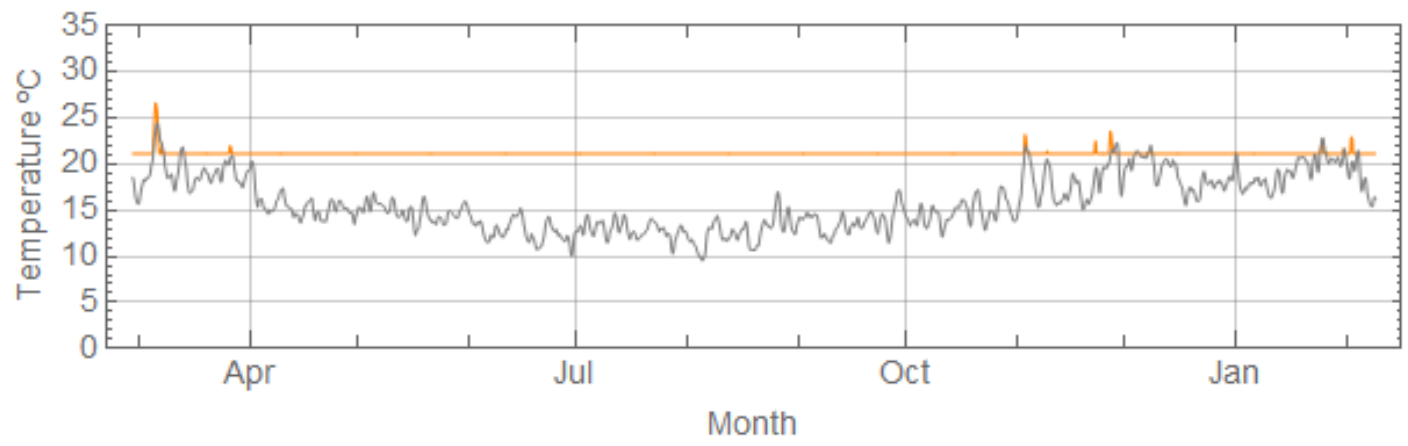


House 129

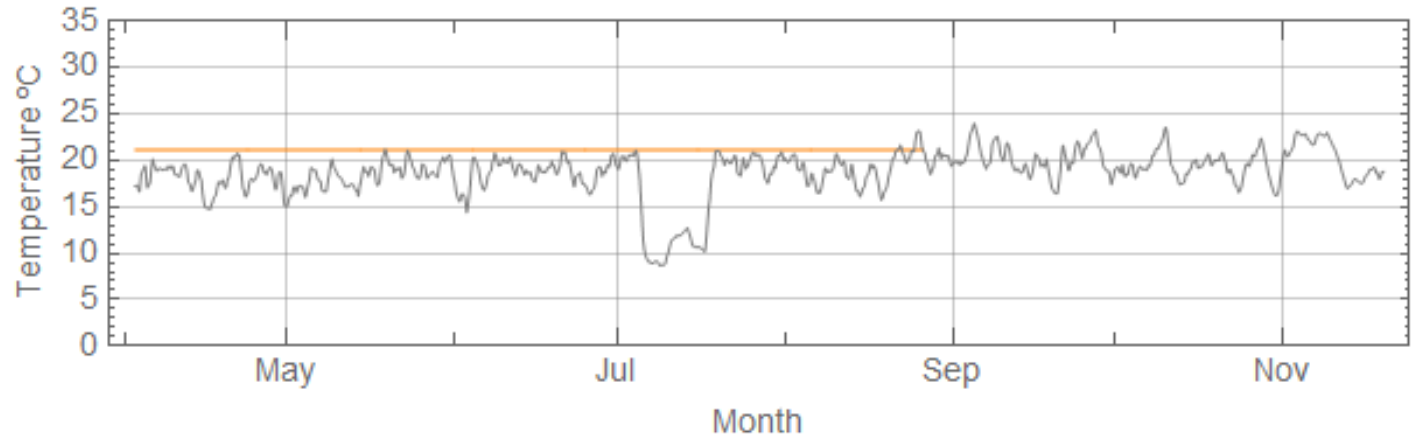

House 130

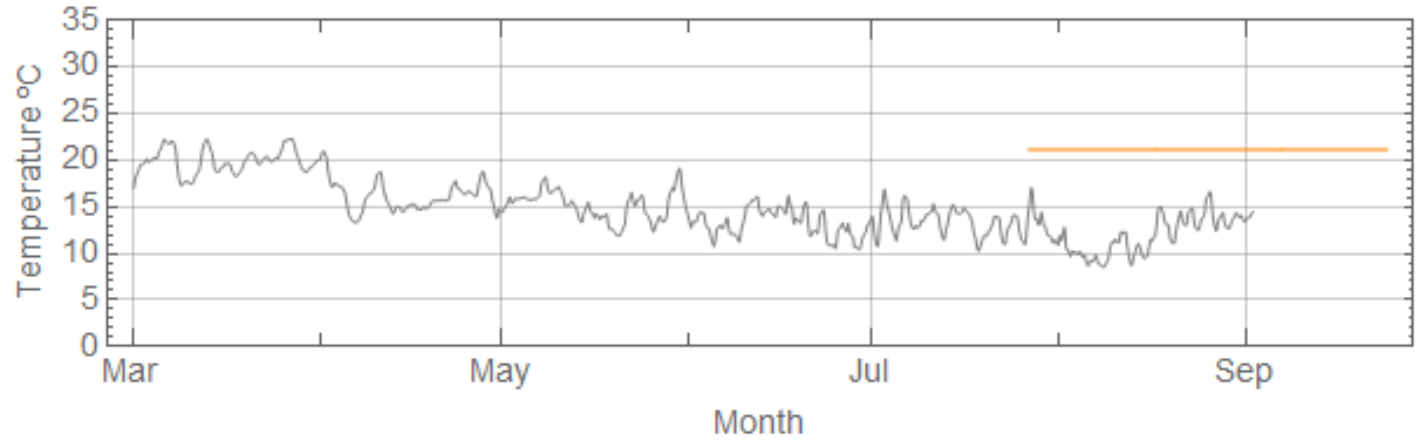

House 135

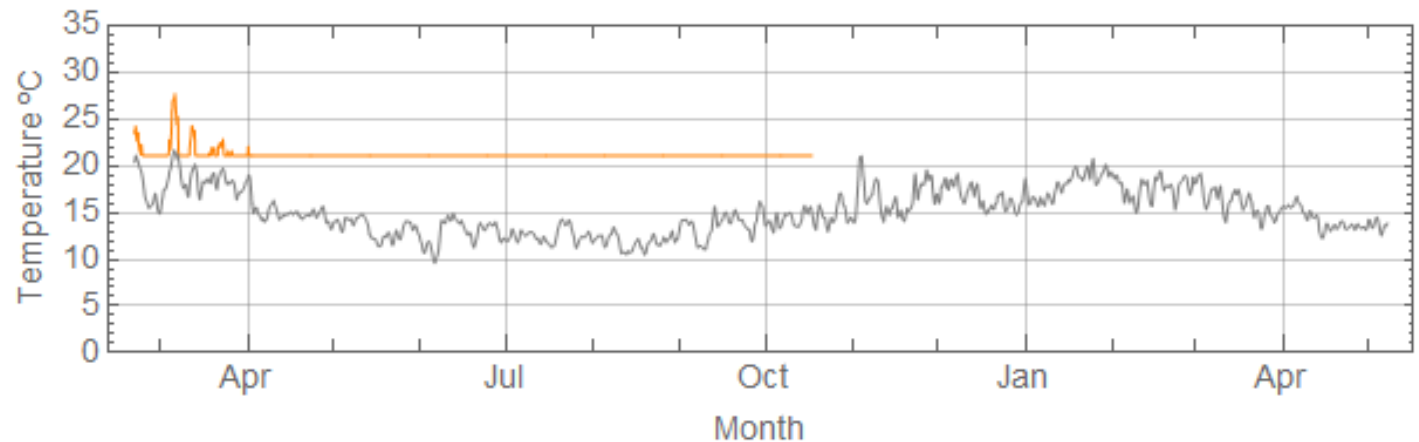

House 136

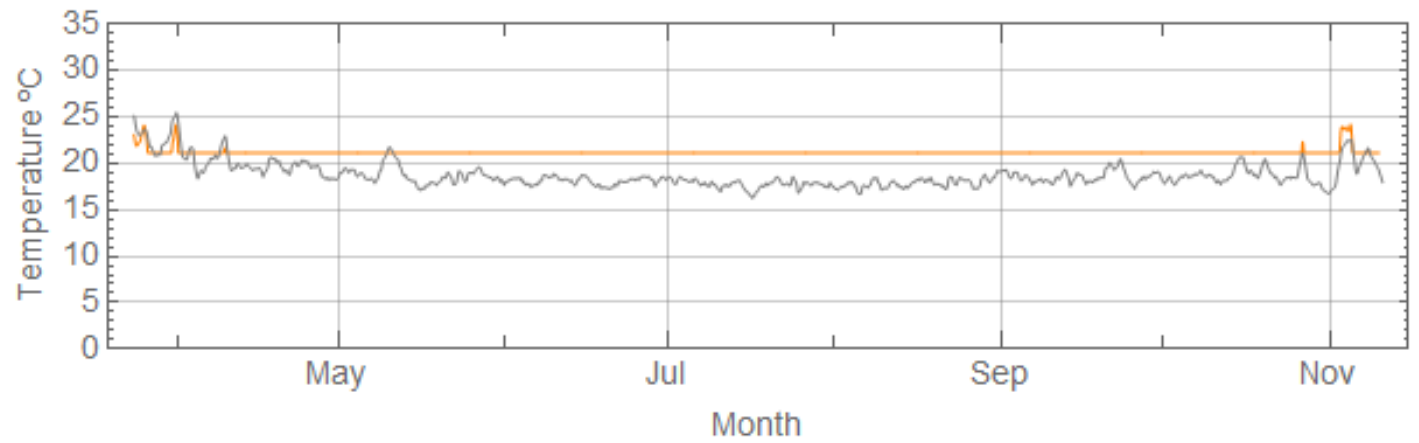


House 137

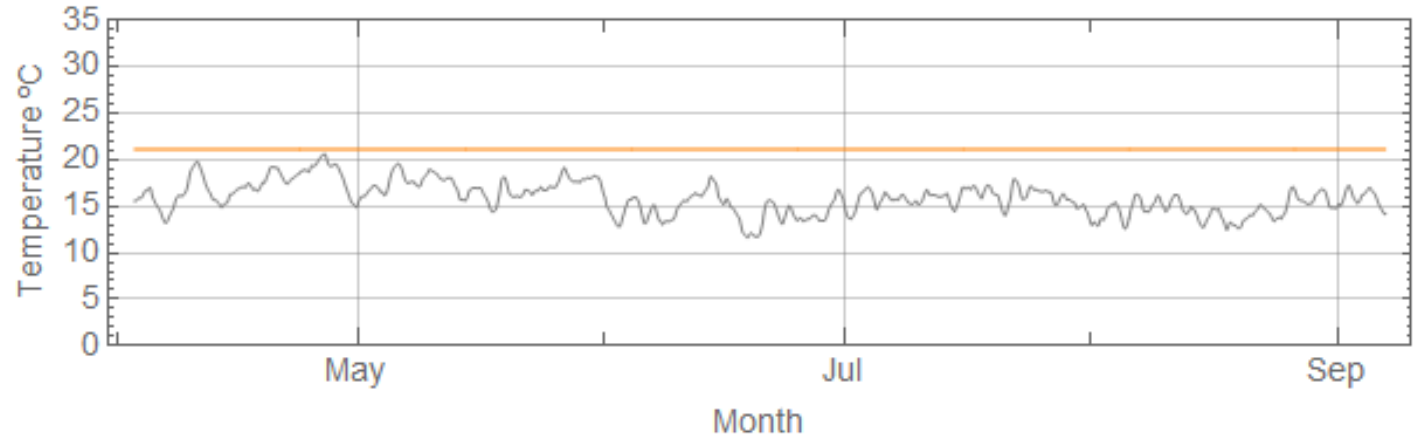

House 138

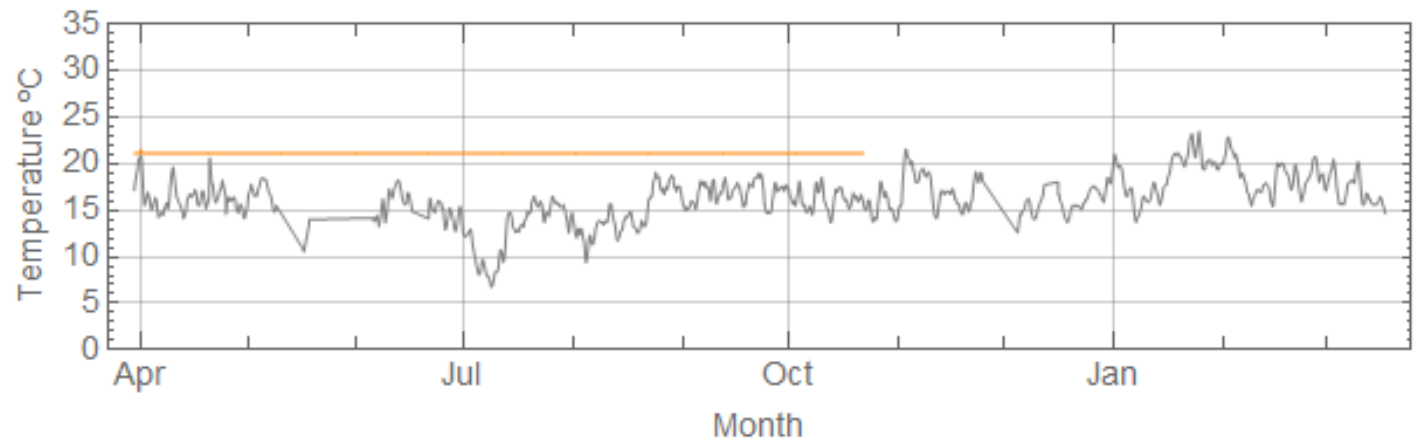

House 139

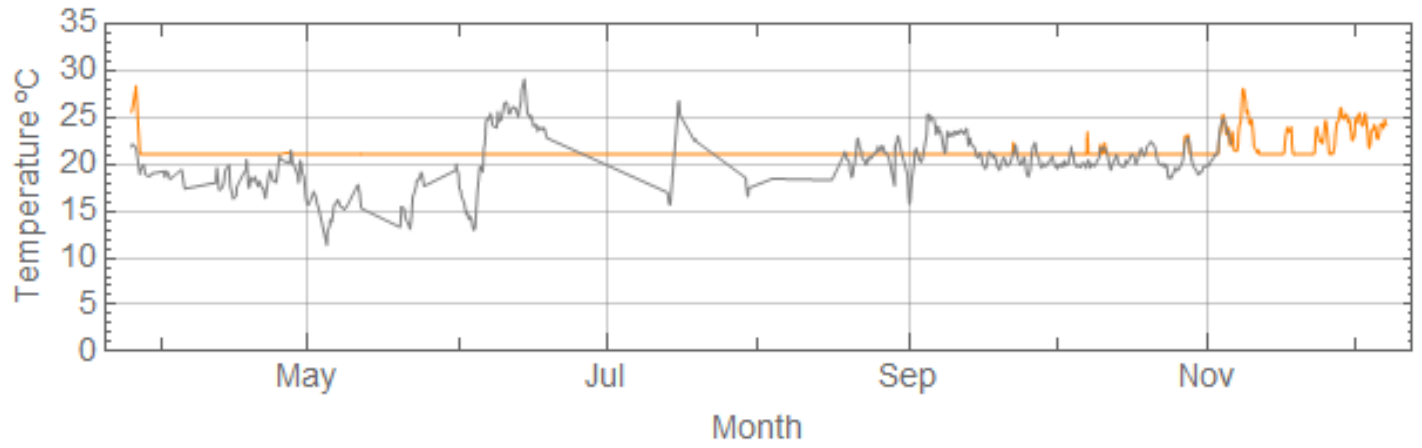

House 140

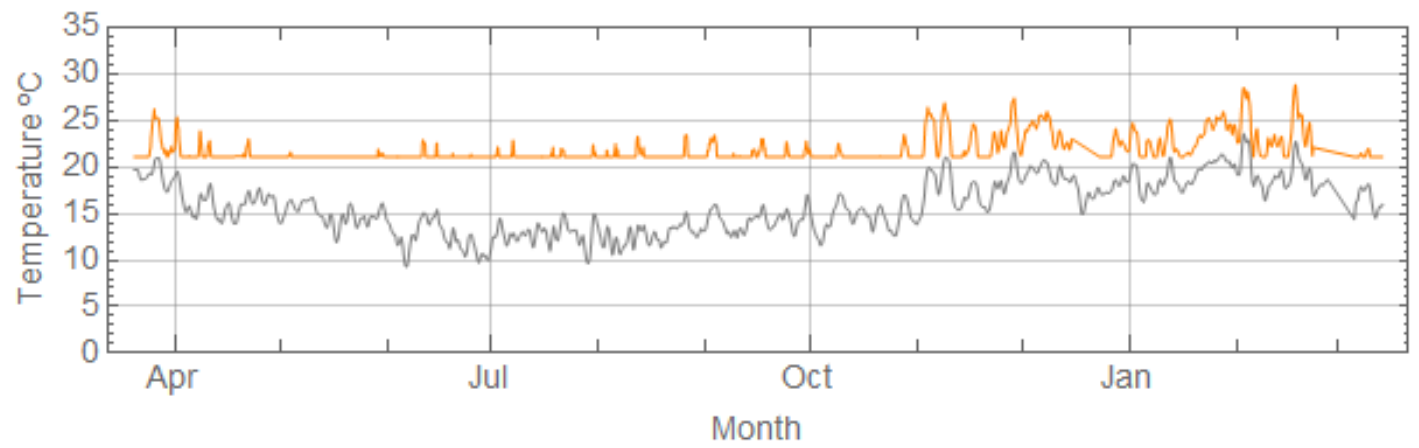


House 142

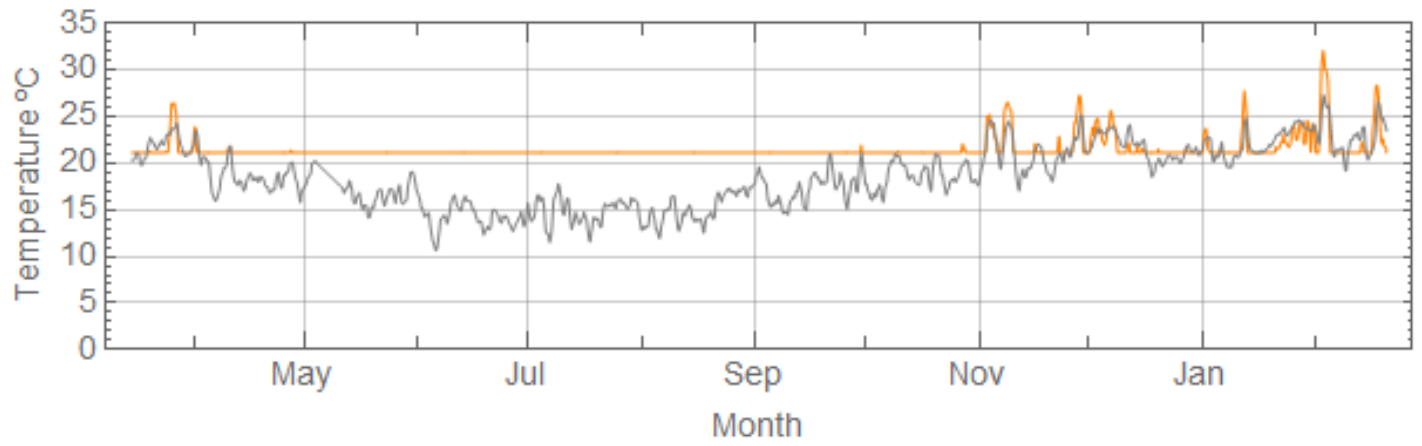

House 143

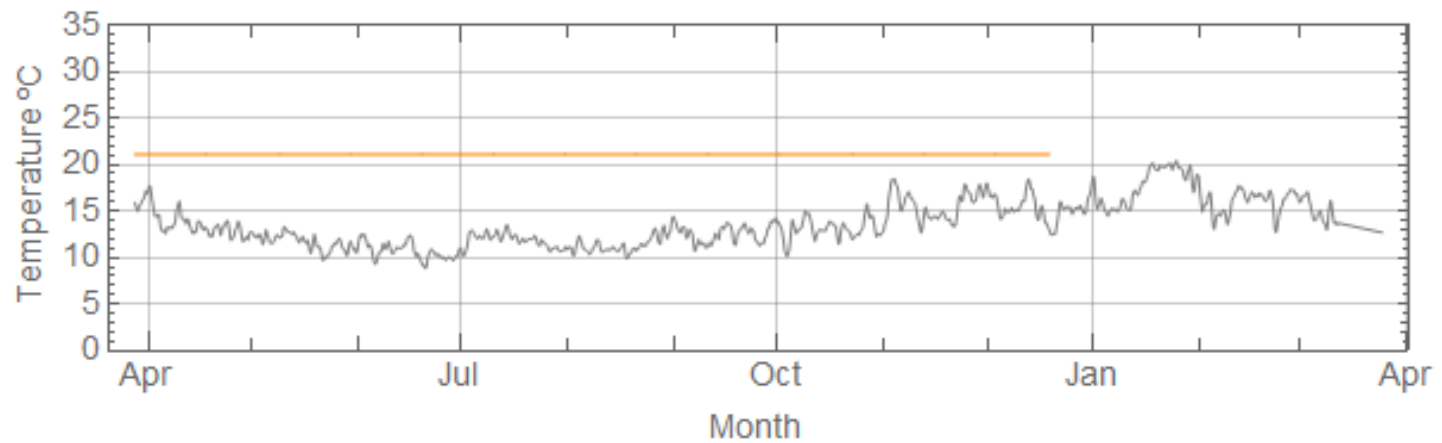

House 144

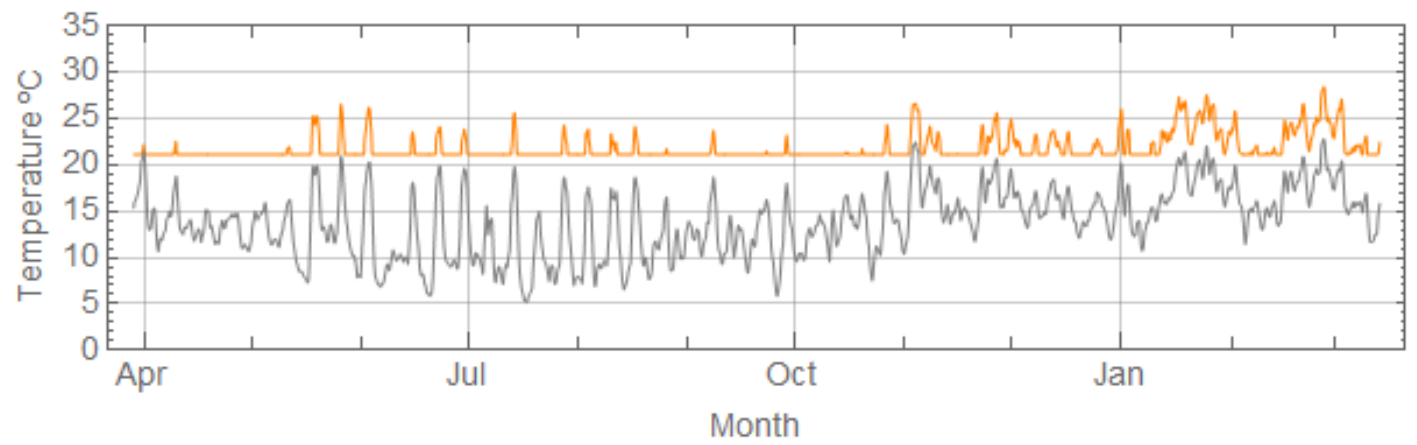

House 145

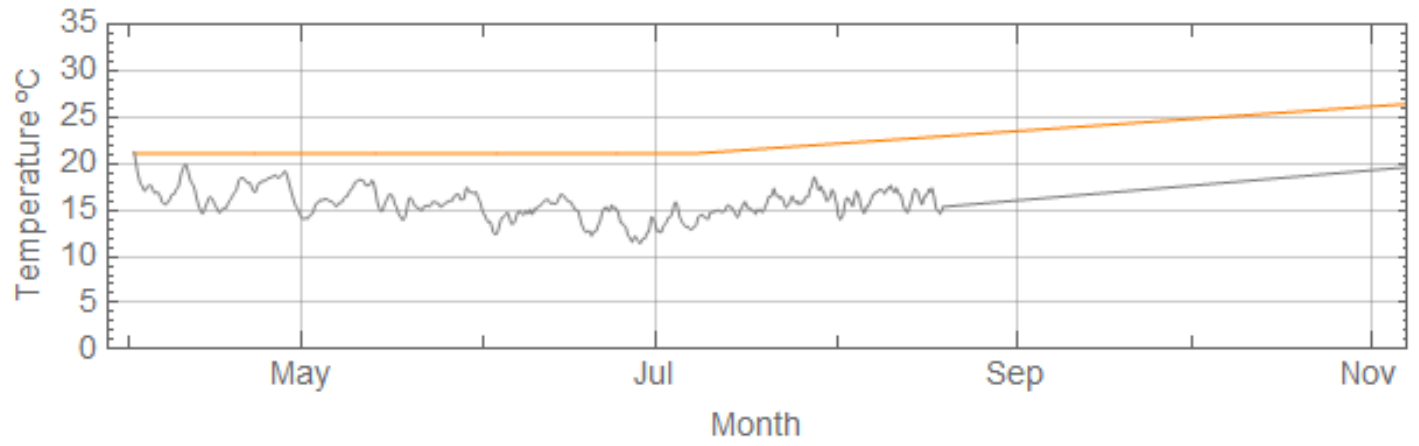


House 148

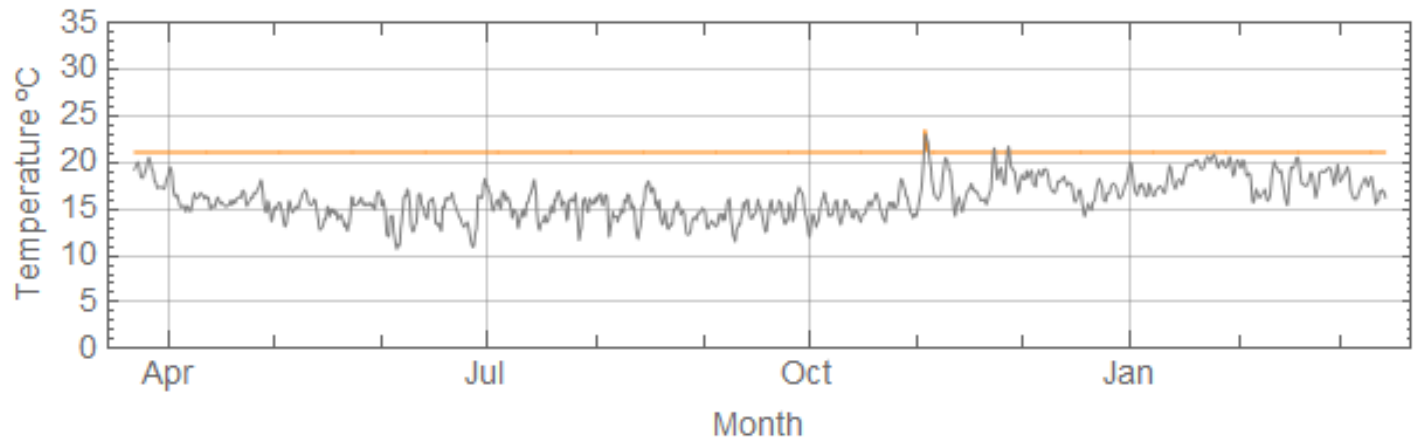

House 149

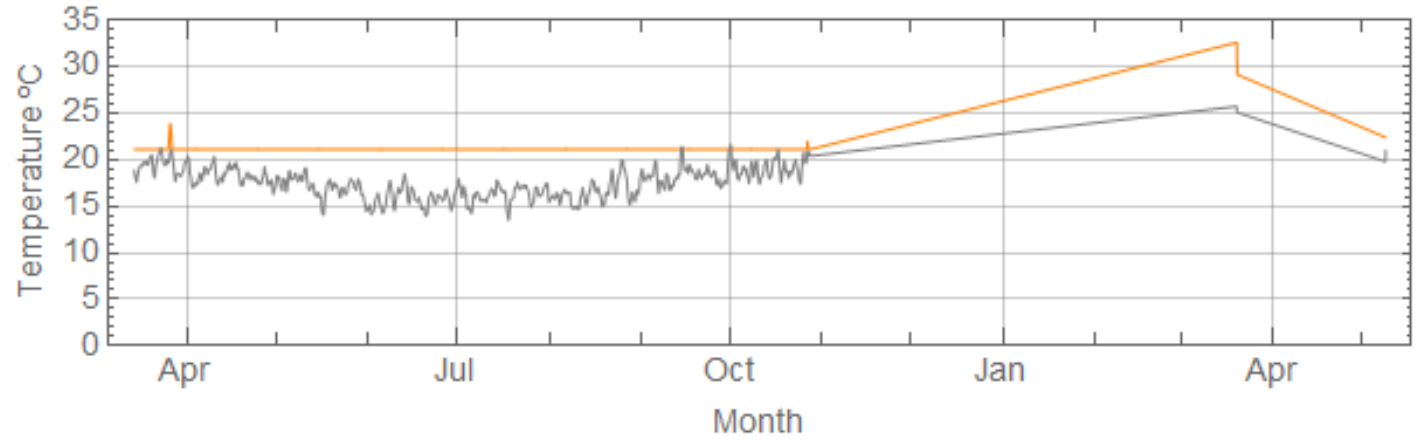

House 150

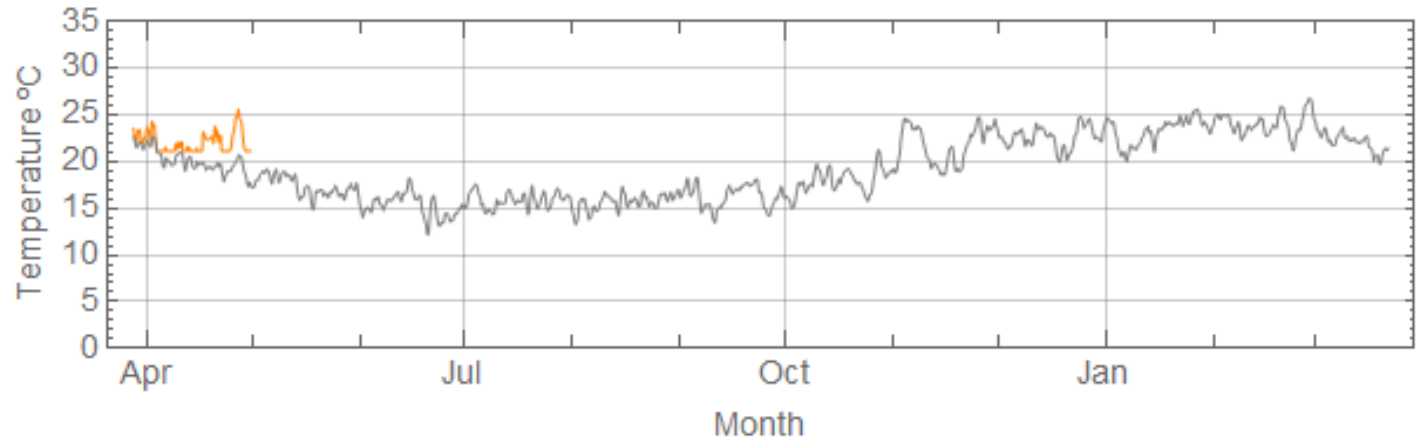

House 151

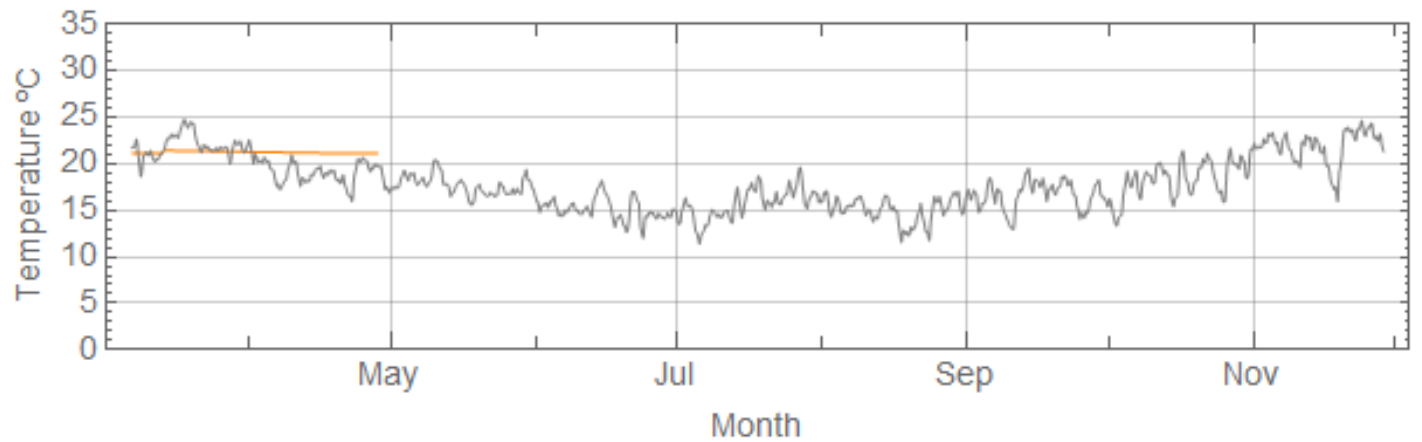


House 152

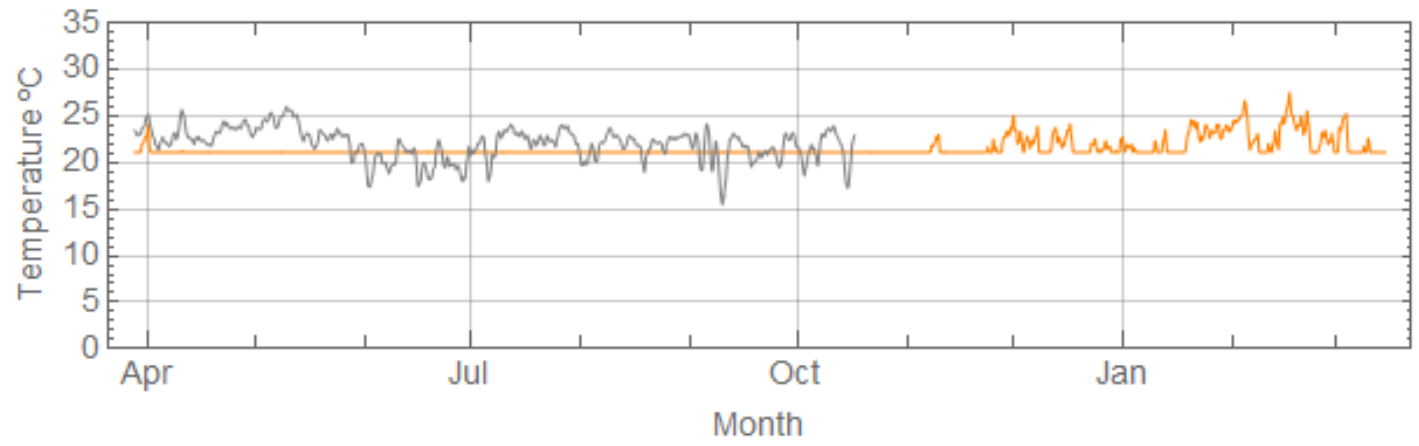

House 153

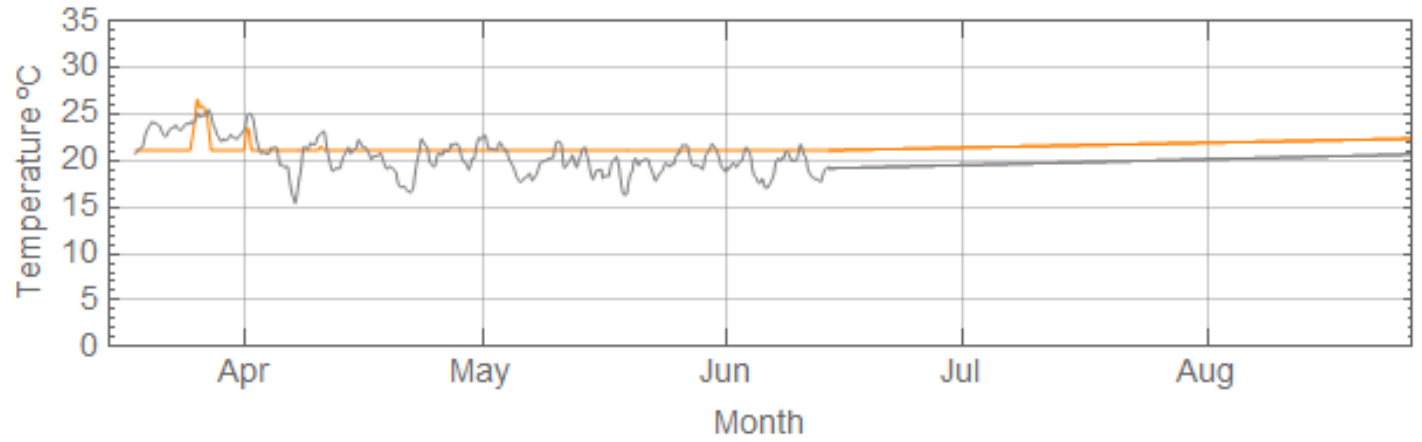

House 154

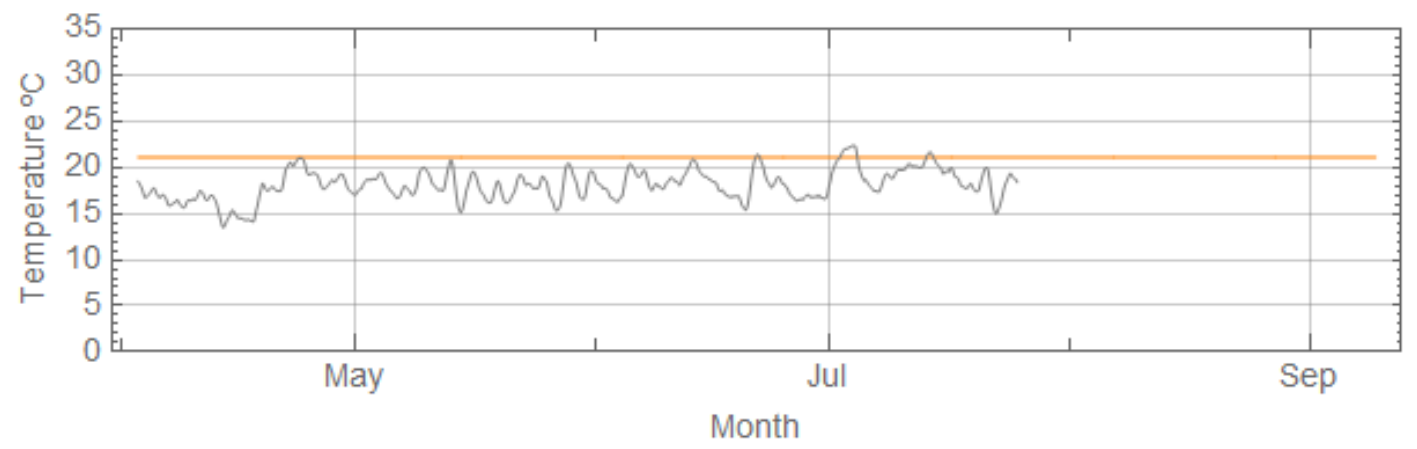

House 155

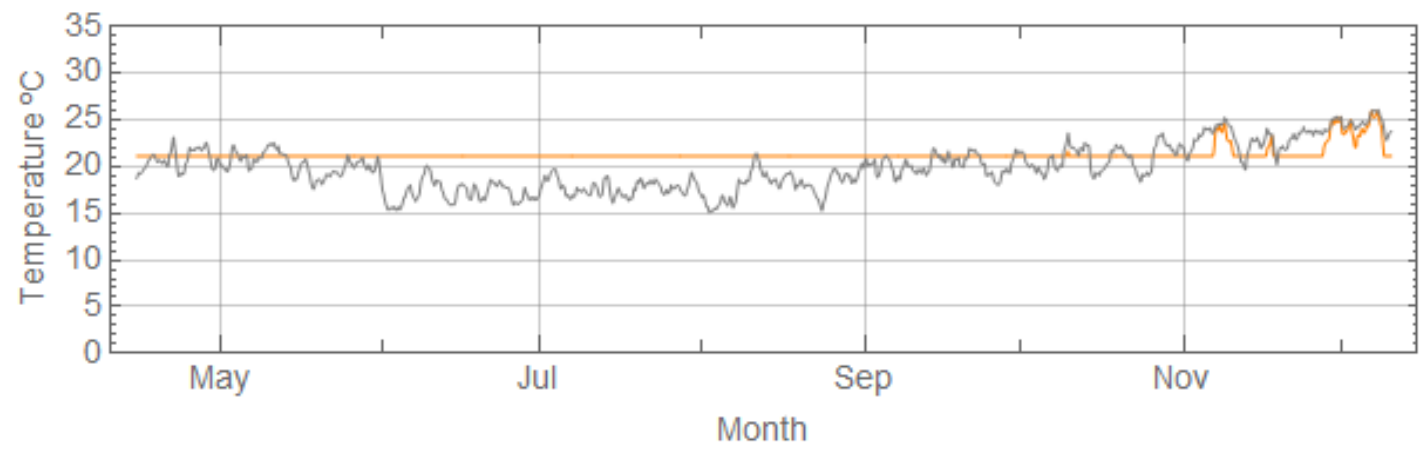


House 156

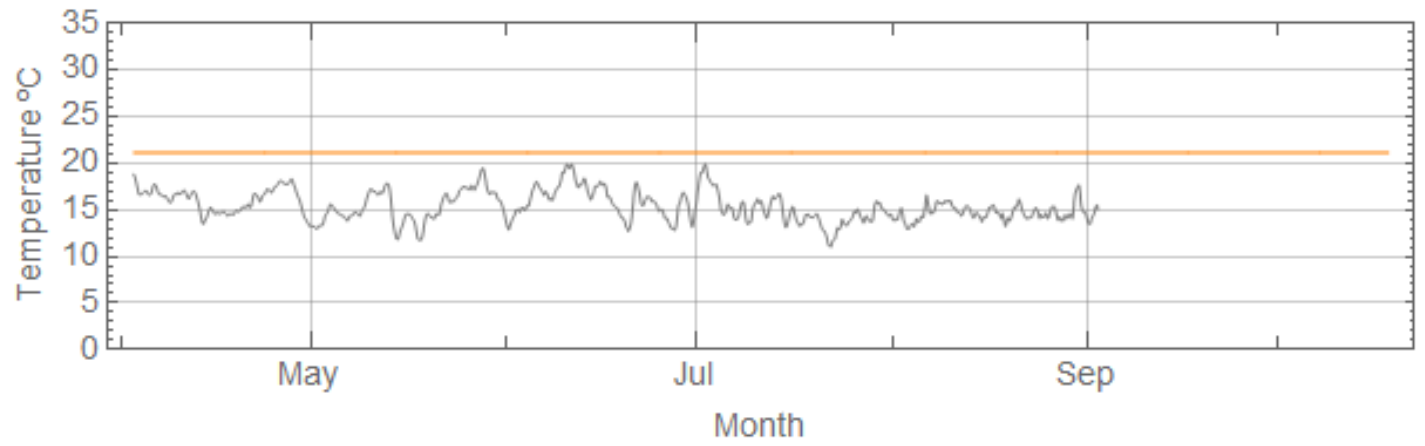

House 161

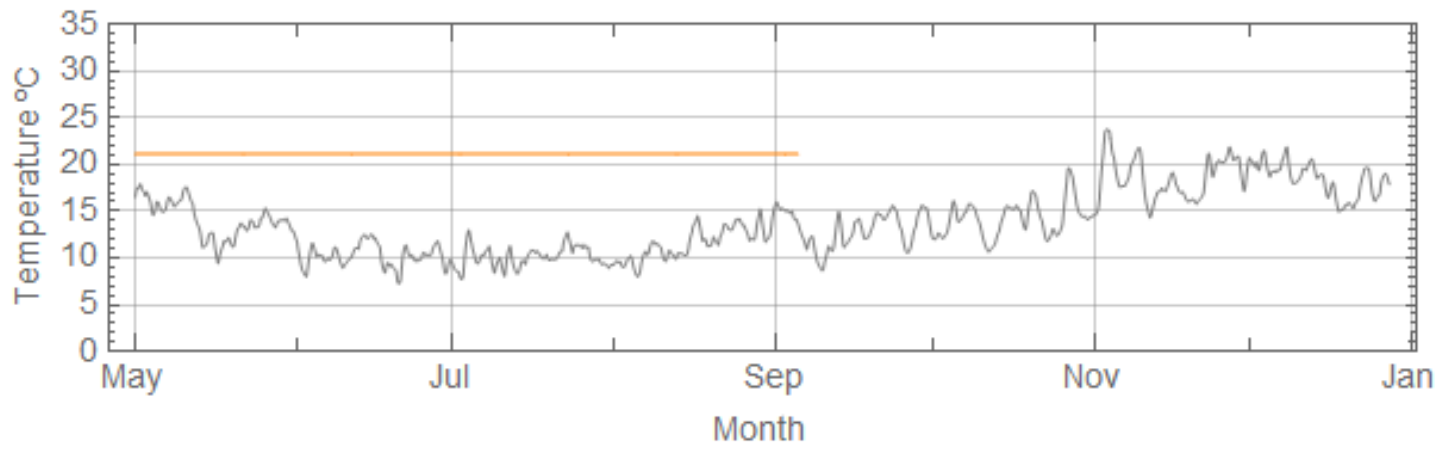

House 162

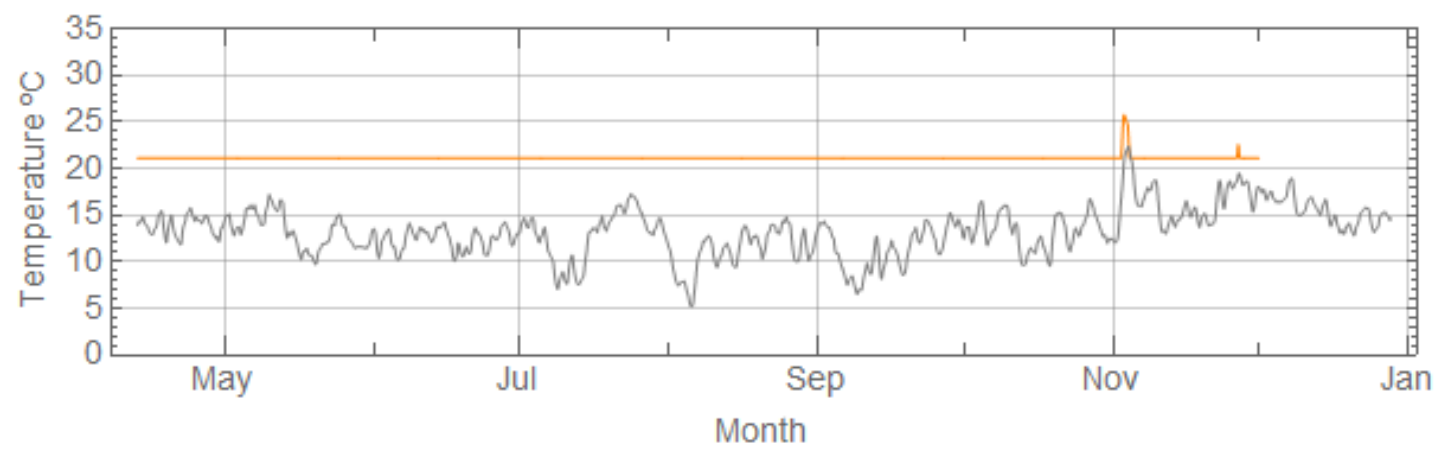

House 164

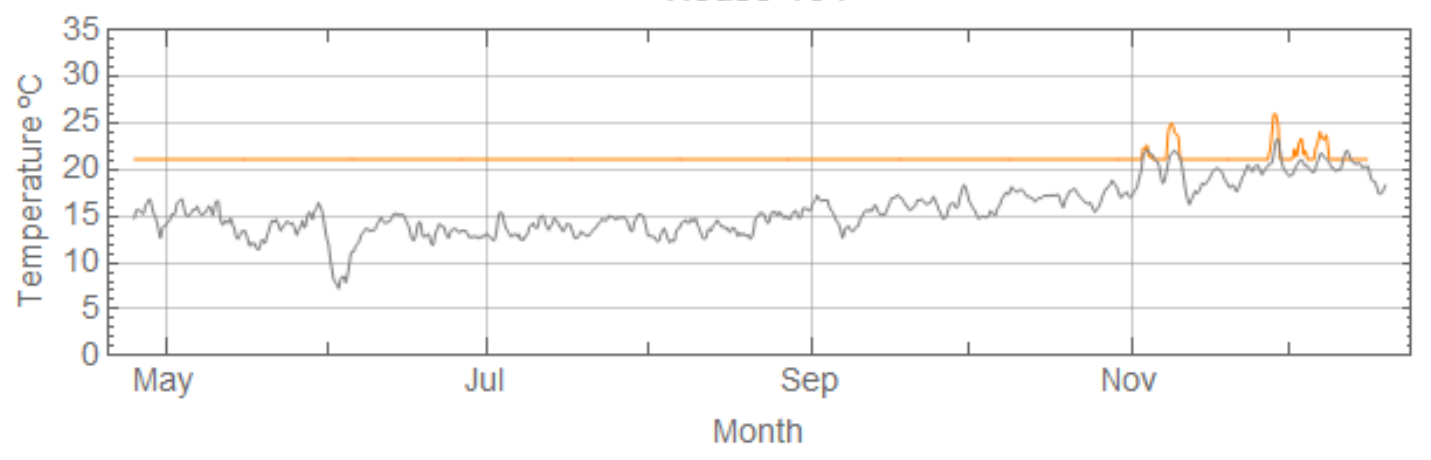


House 168

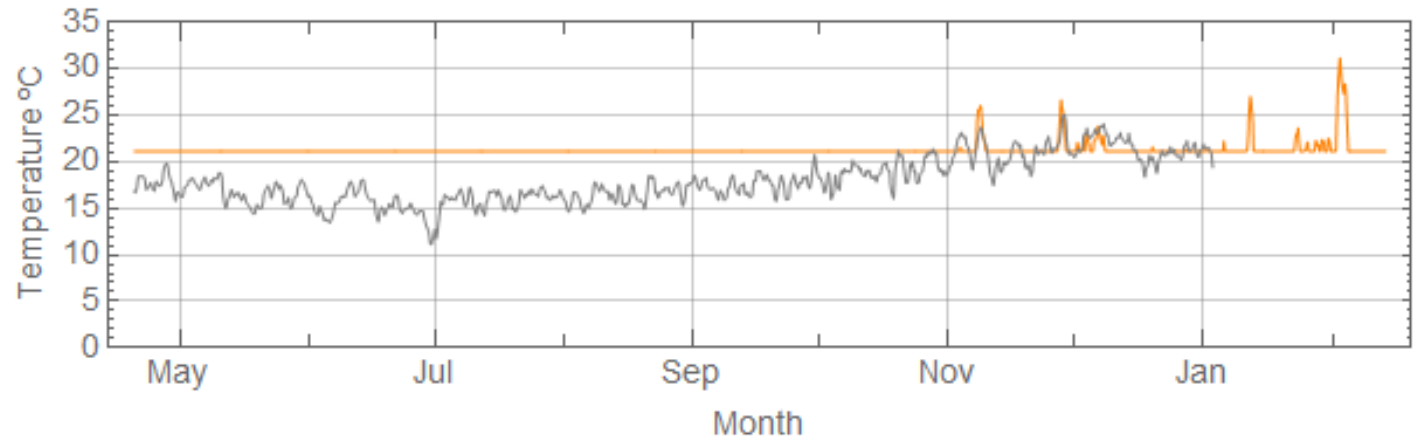

House 169

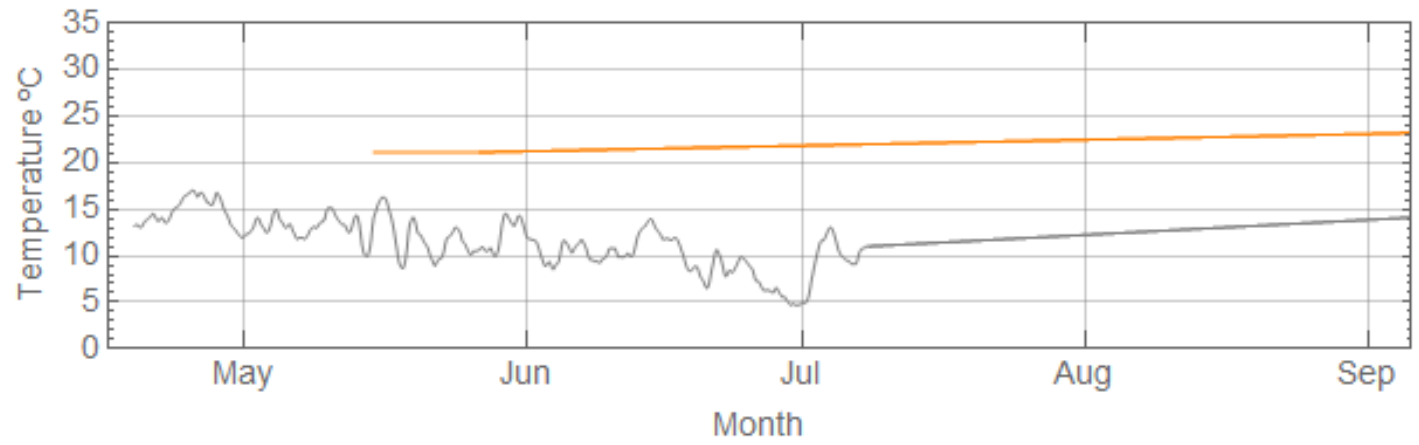

House 170

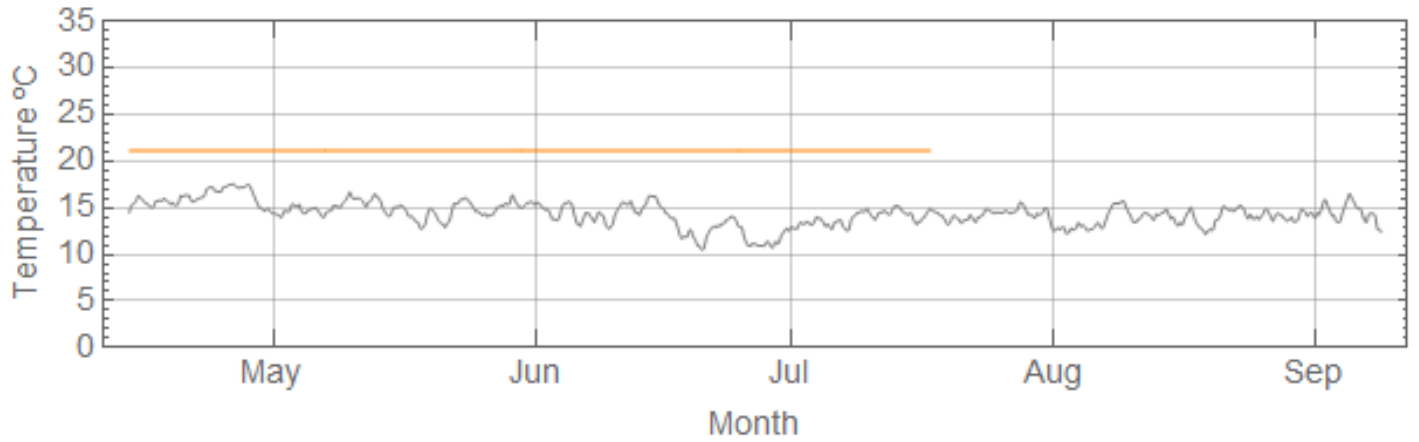

House 171

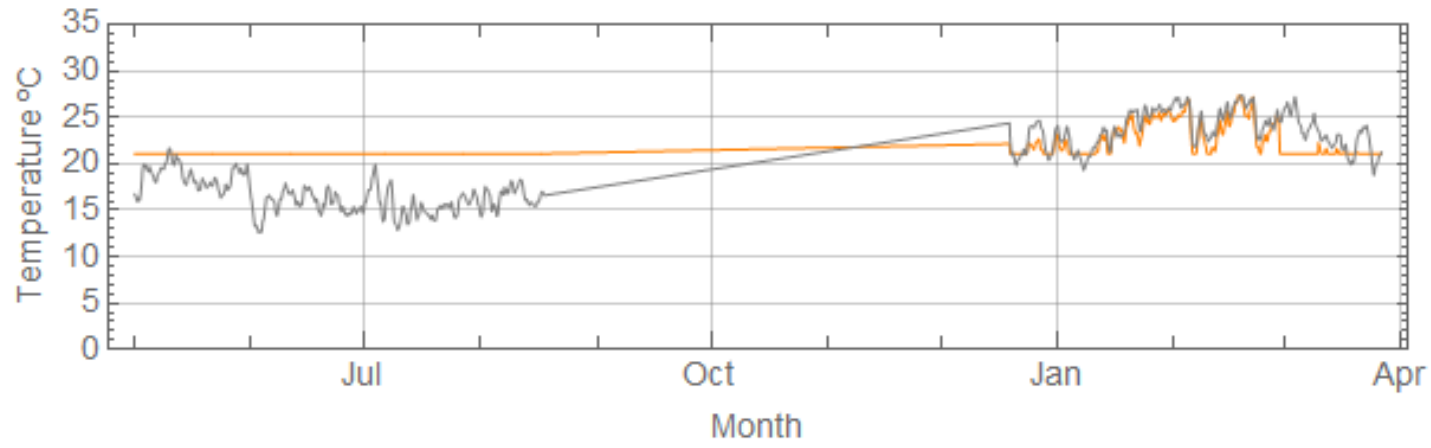


House 177

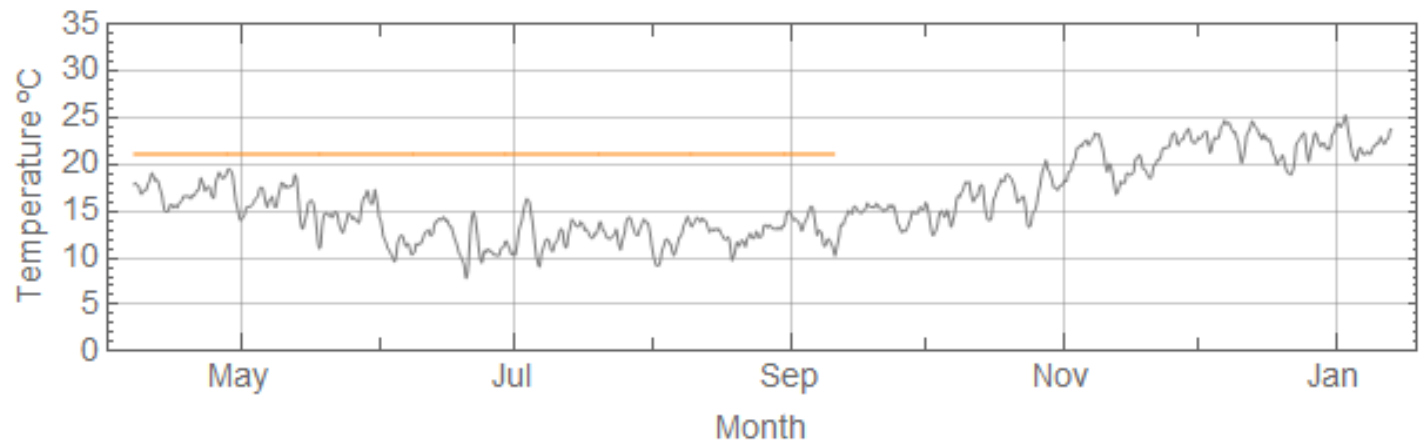

House 178

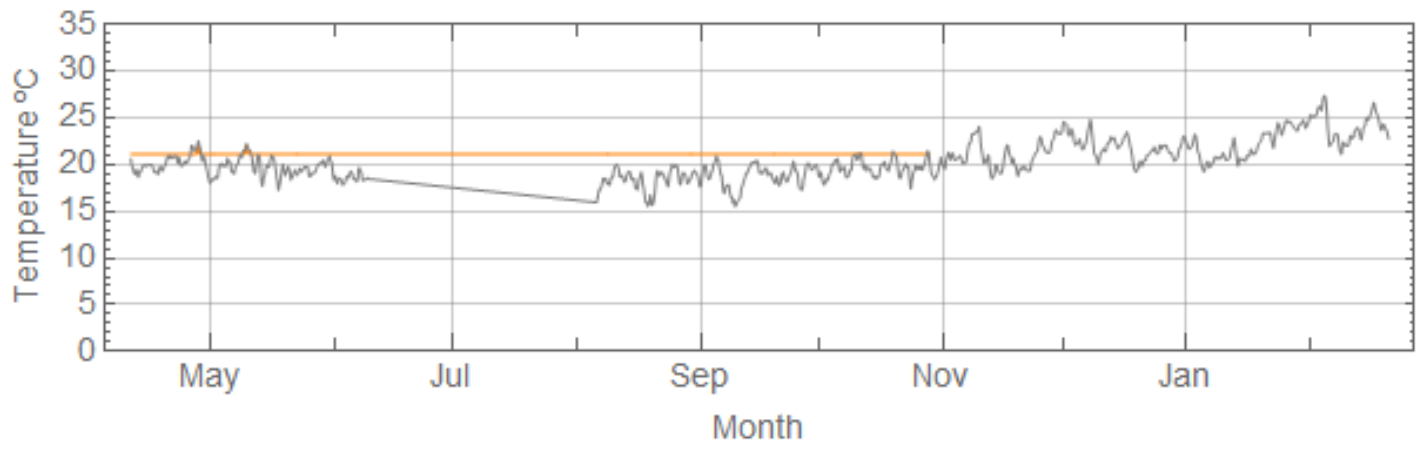

House 180

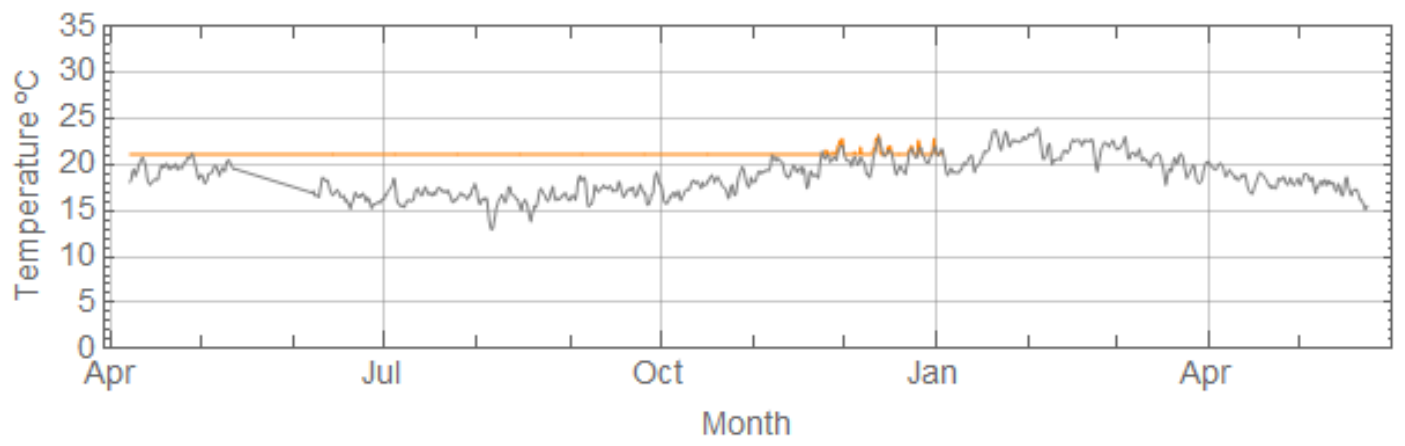




\subsection{Appendix C}

Application of Indoor Design Temperature as outlined in ASHRAE Standaard 160 with the lower limit of $21.1^{\circ} \mathrm{C}$ removed.

House 100

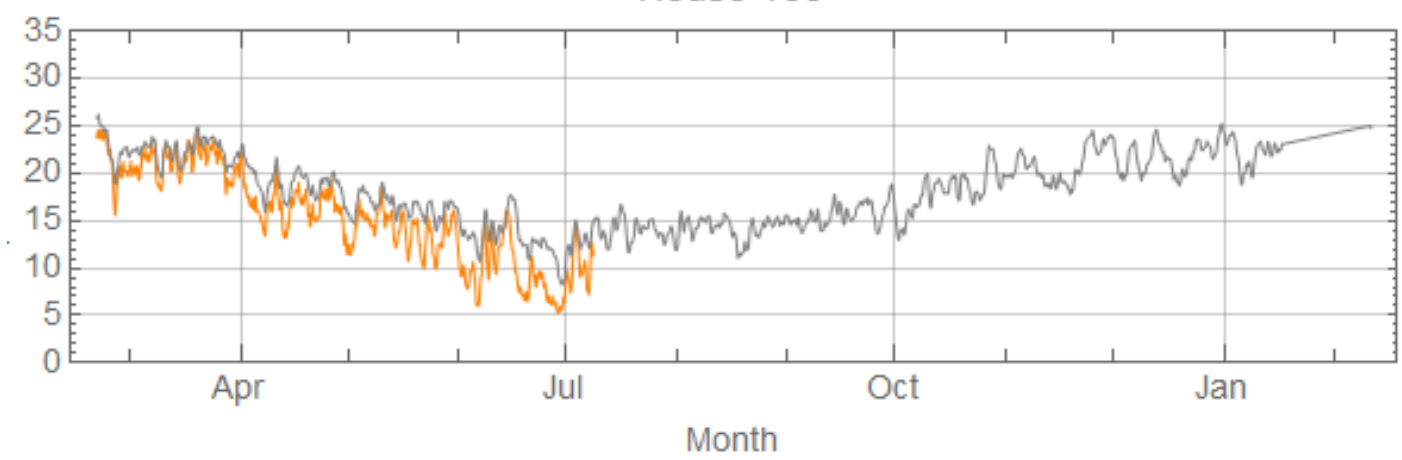

— Indoor Design Temperature

- Measured Indoor Temperature

House 101

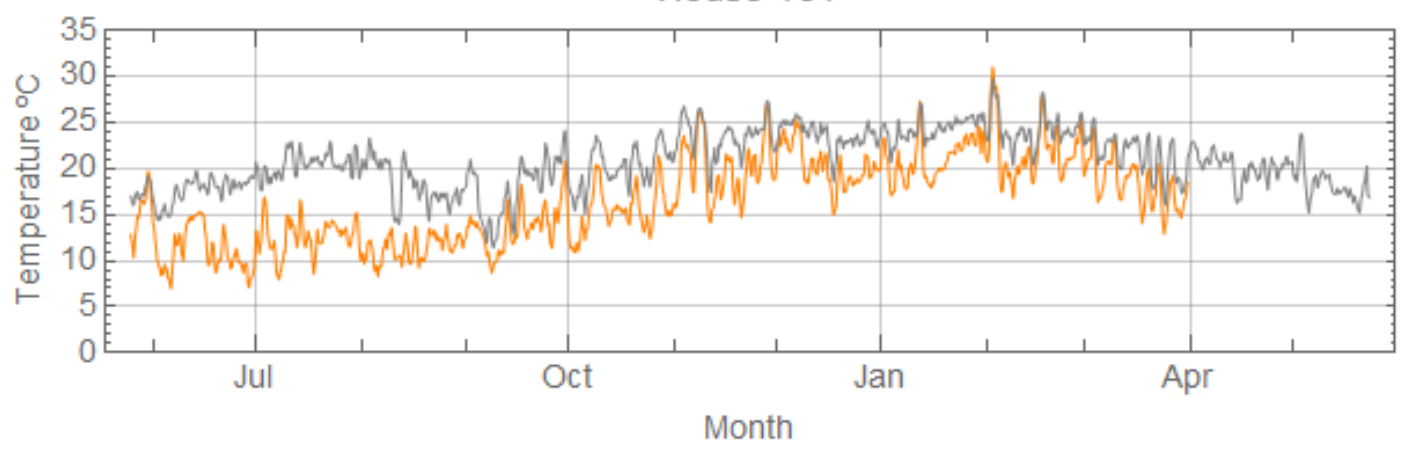

House 103

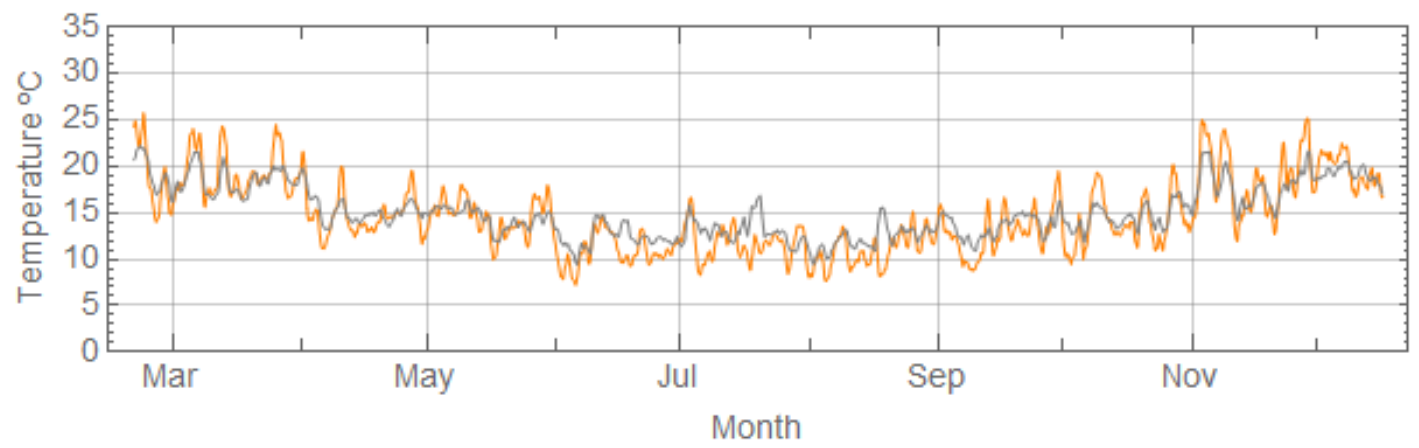


House 104

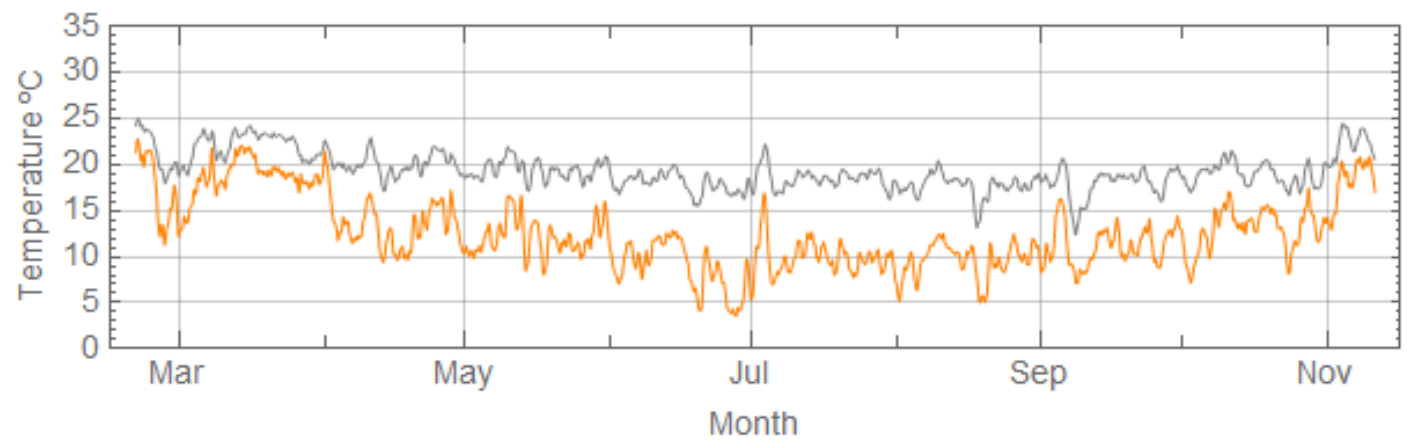

House 106

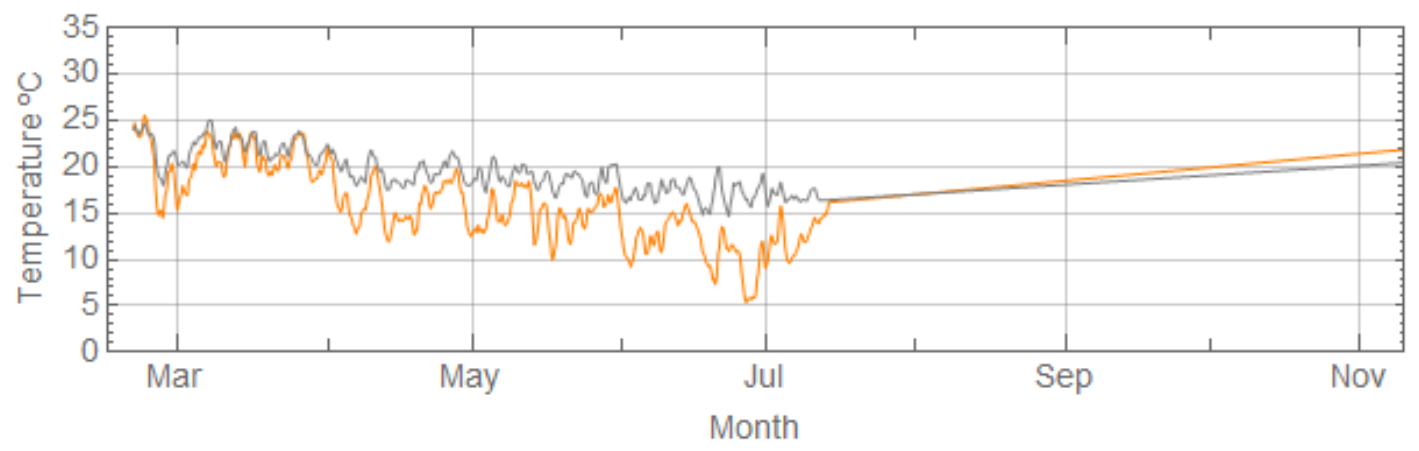

House 110

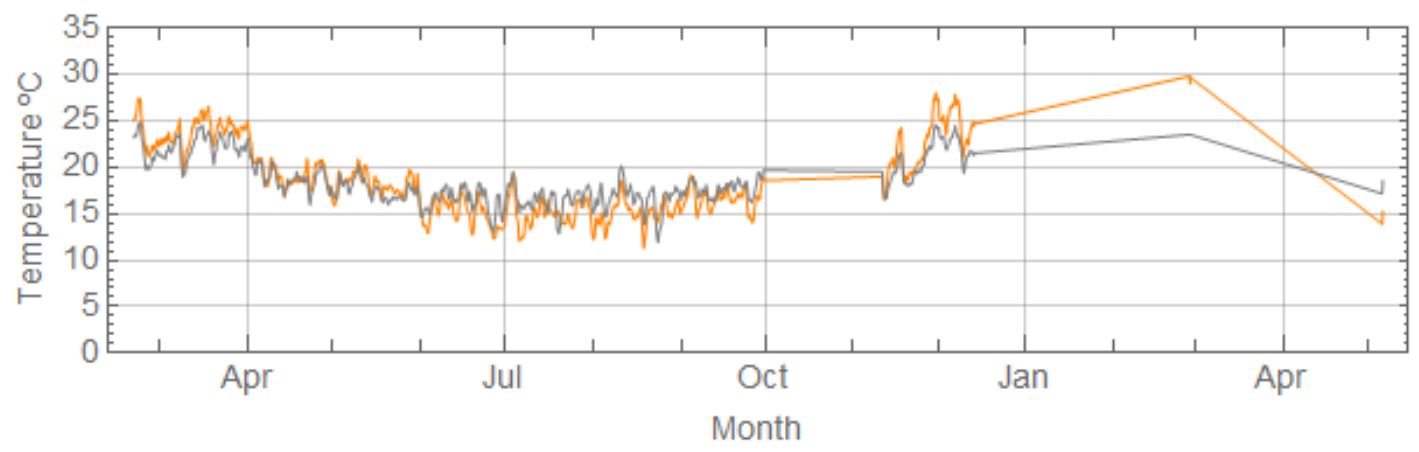

House 111

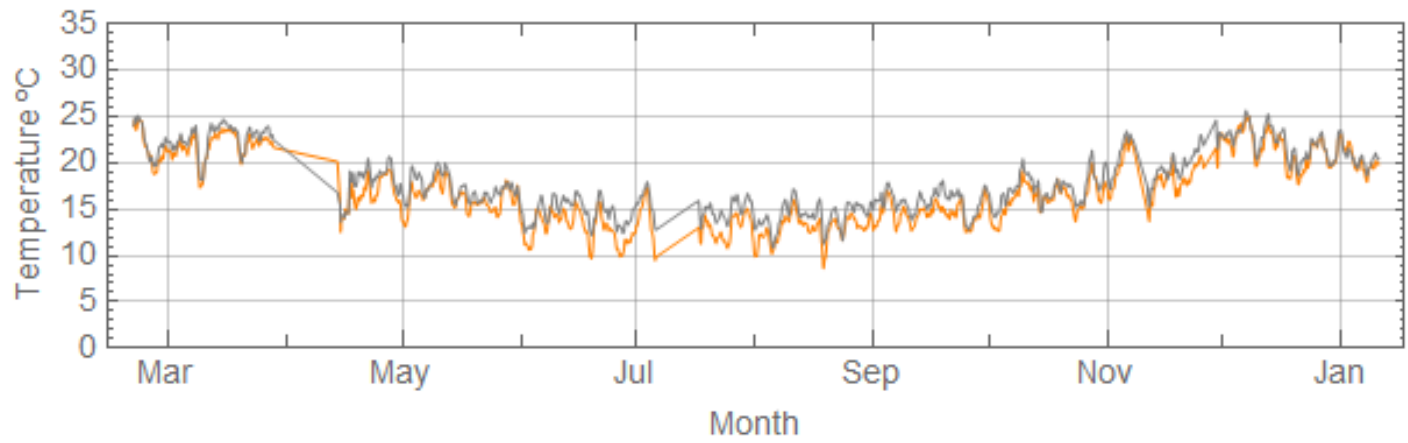


House 113

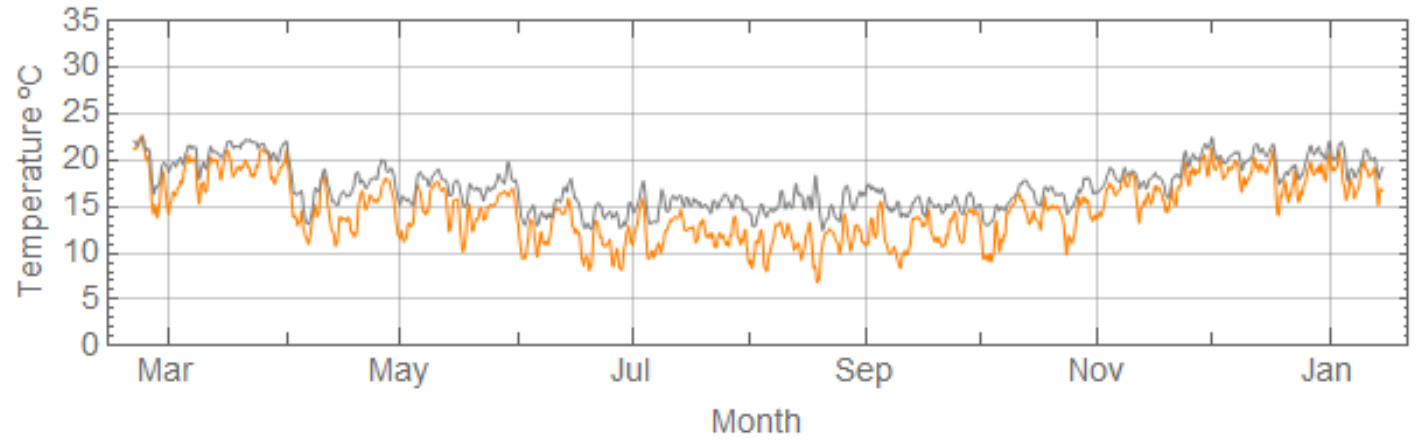

House 116

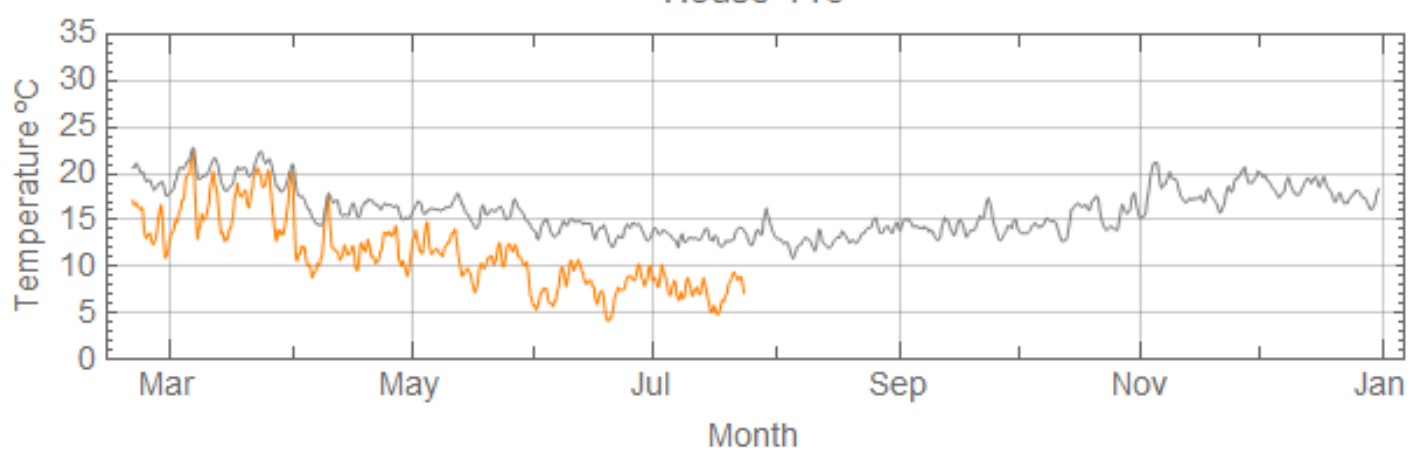

House 117

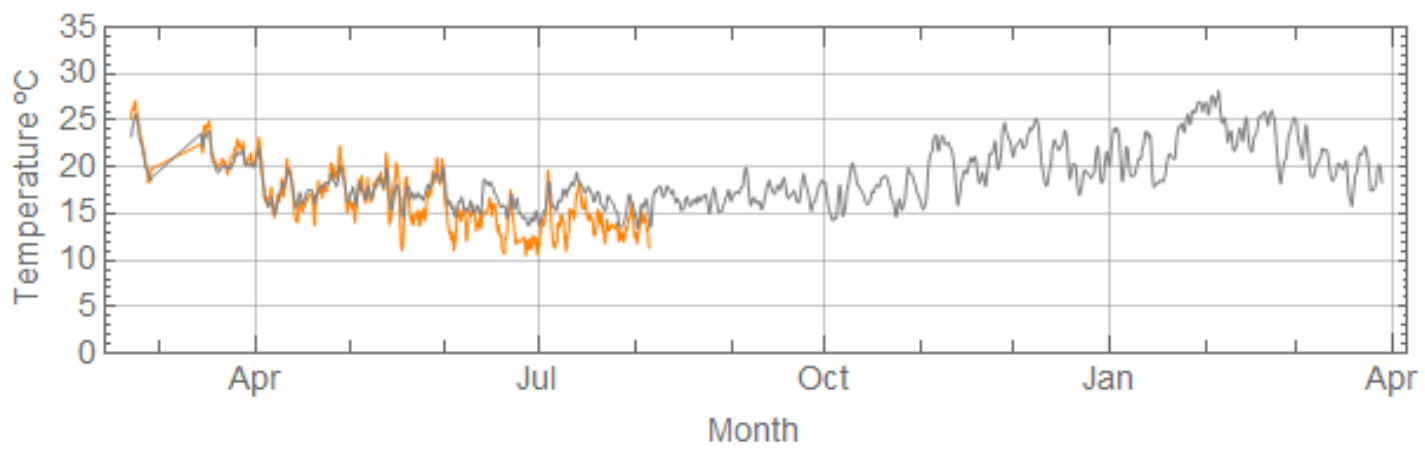

House 120

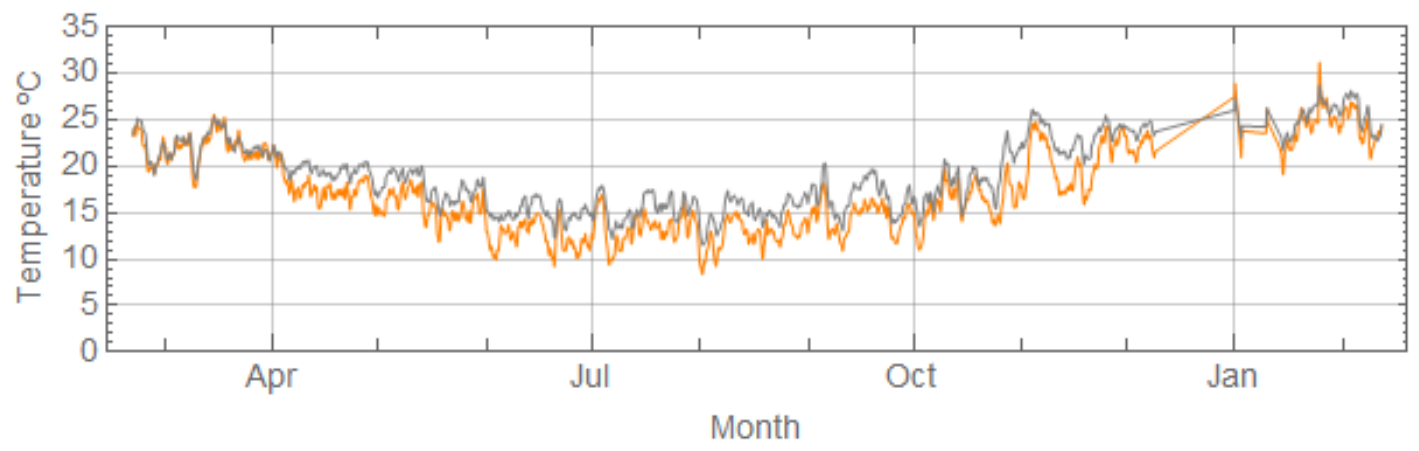


House 121

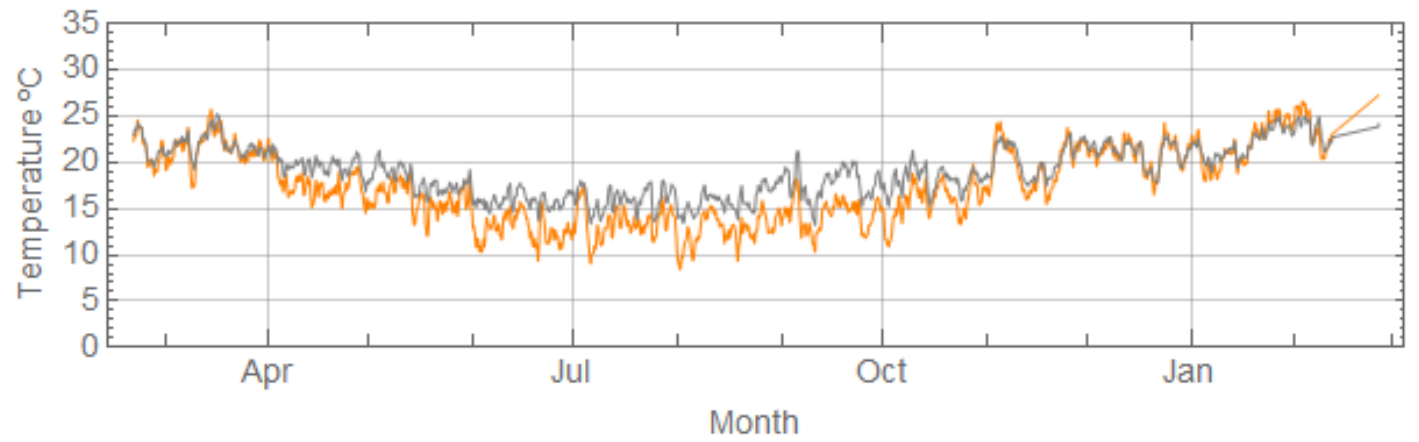

House 124

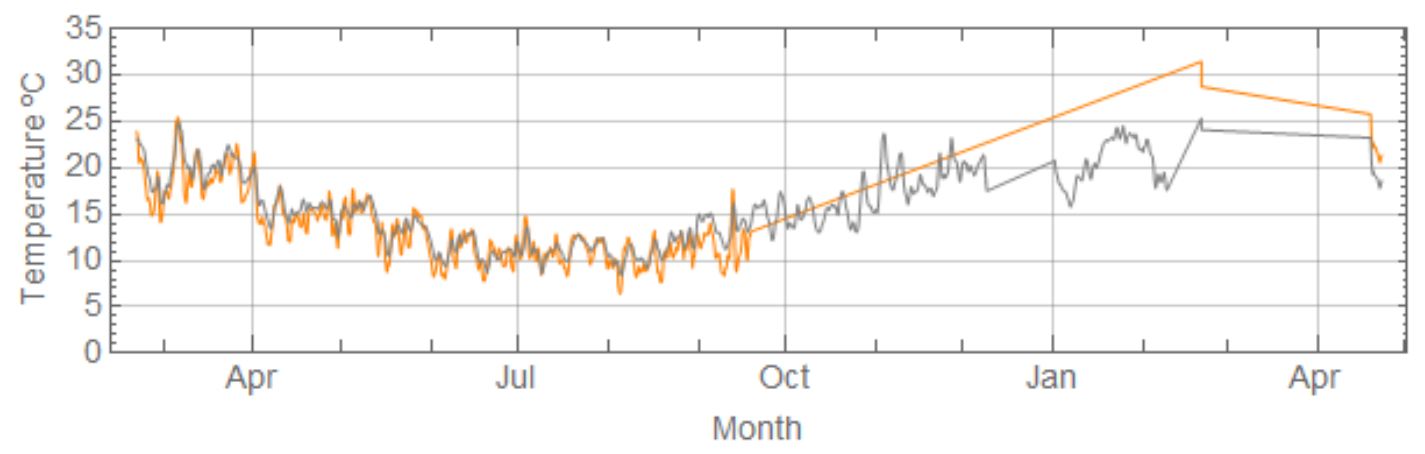

House 125

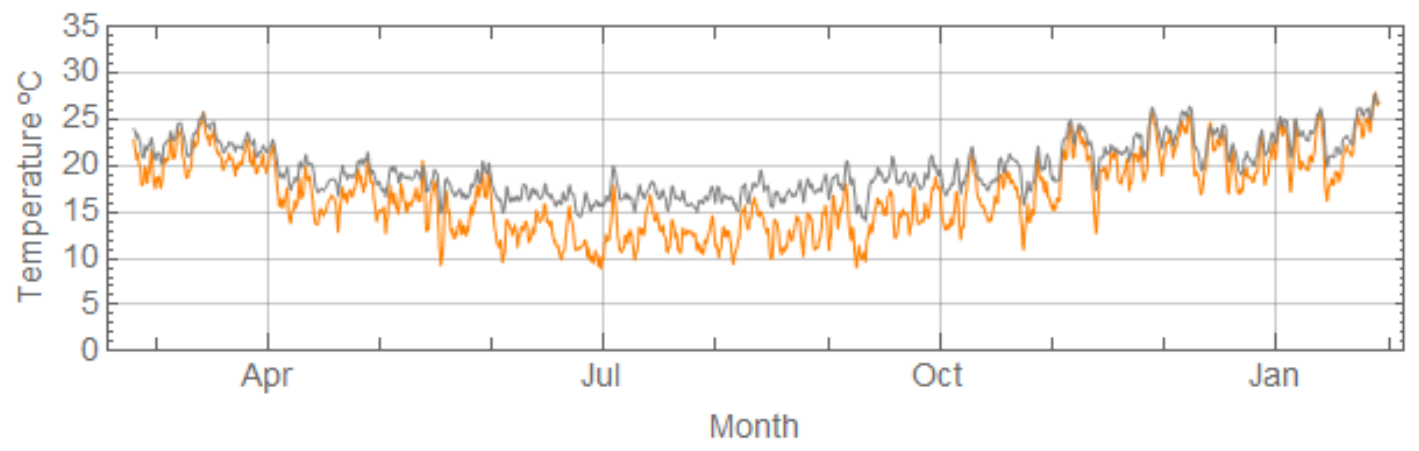

House 128

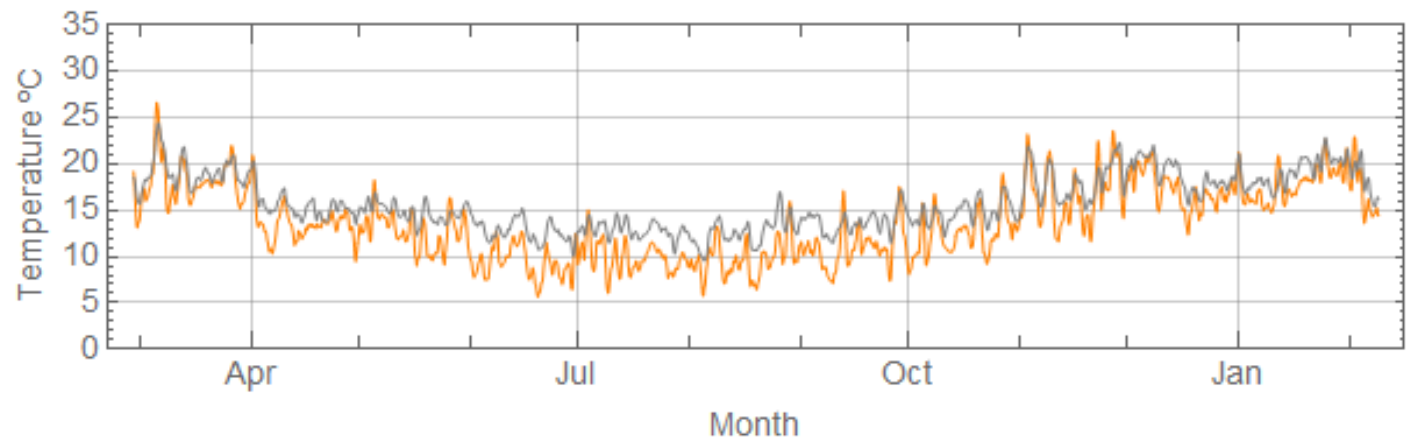


House 129

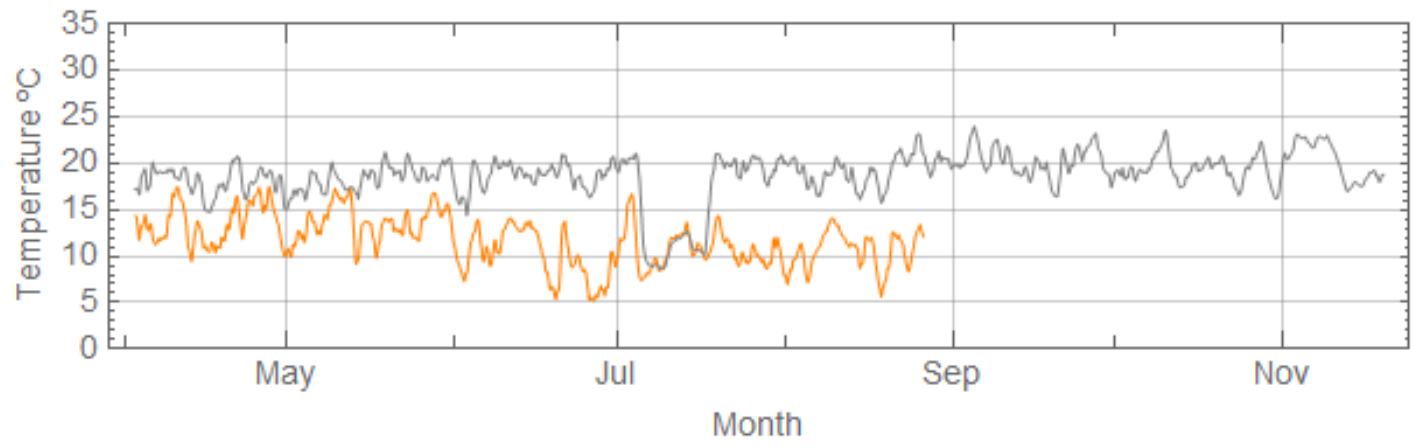

House 130

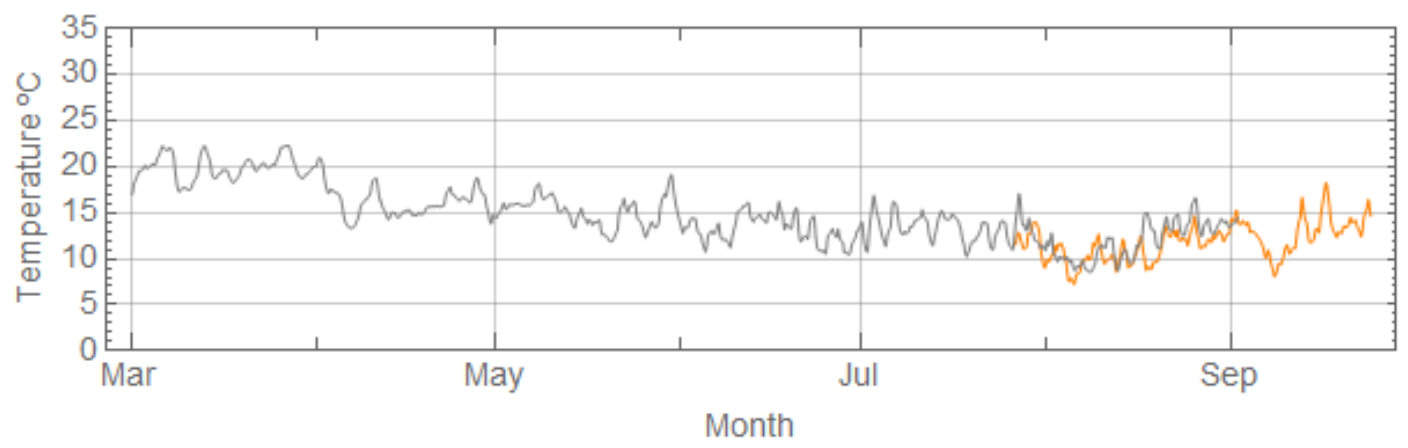

House 135

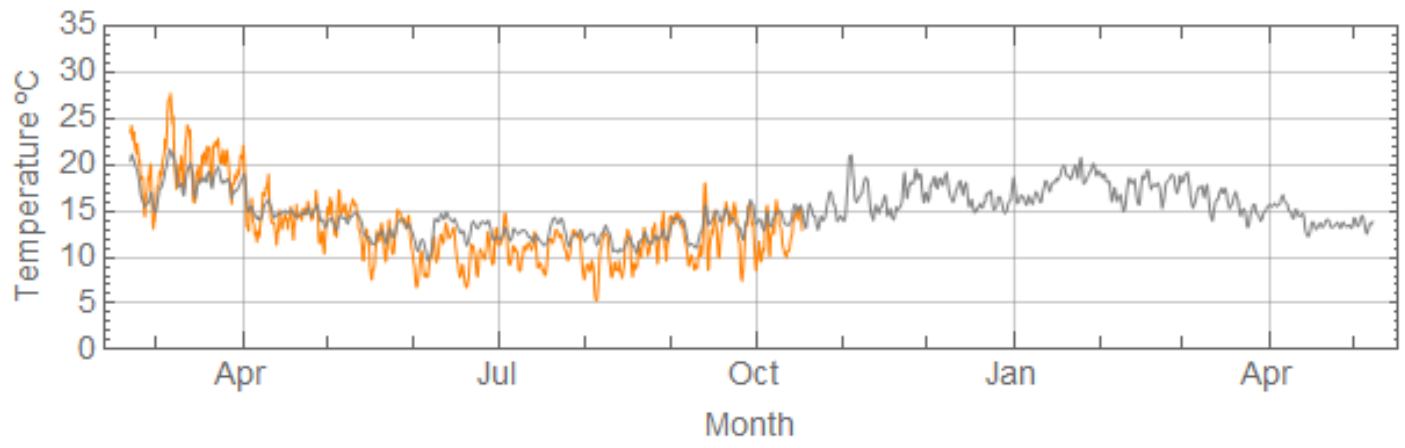

House 136

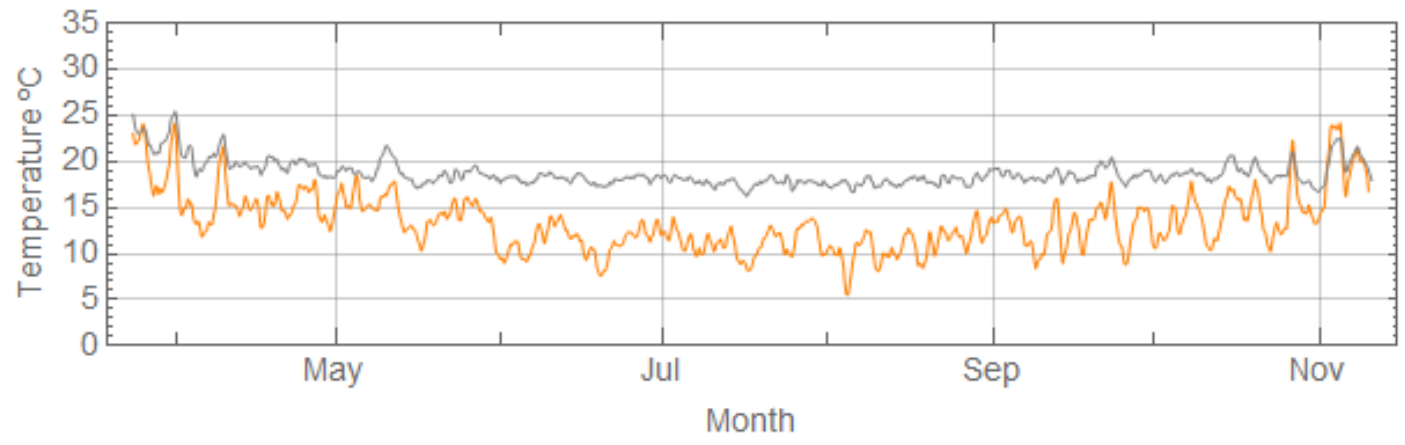


House 137

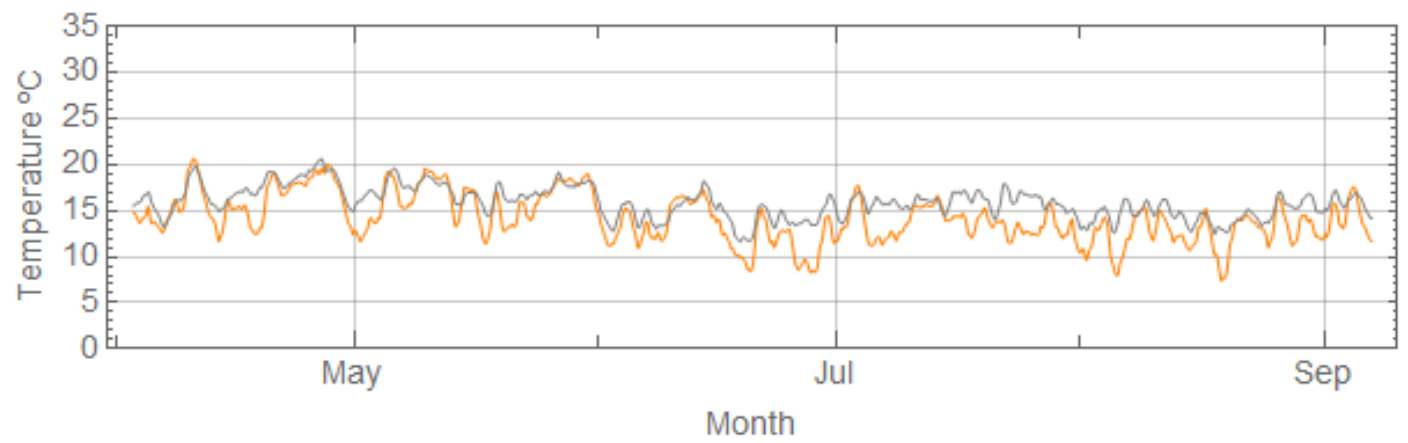

House 138

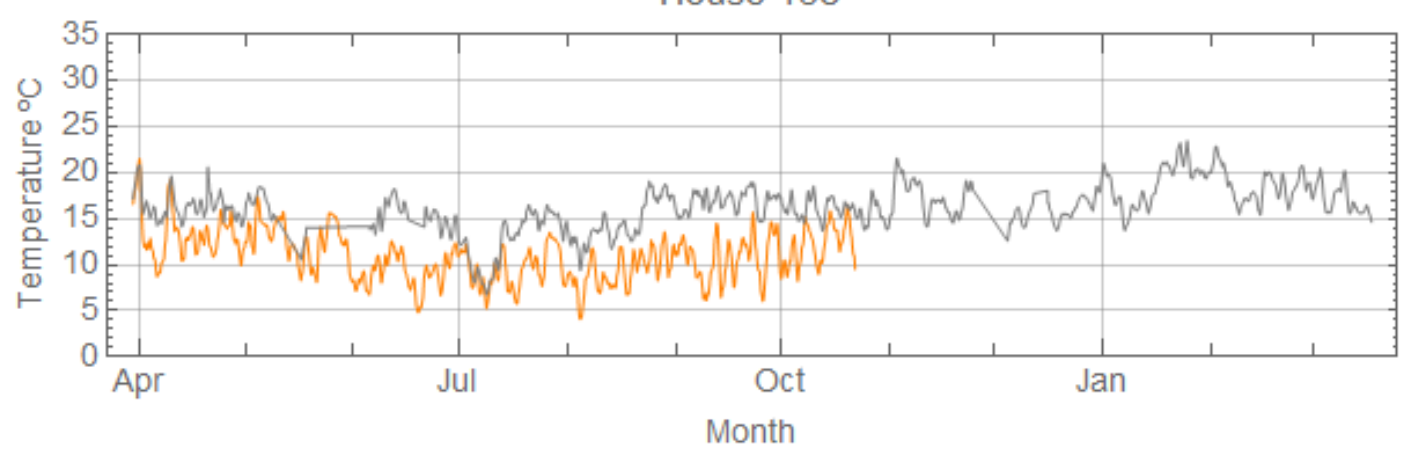

House 139

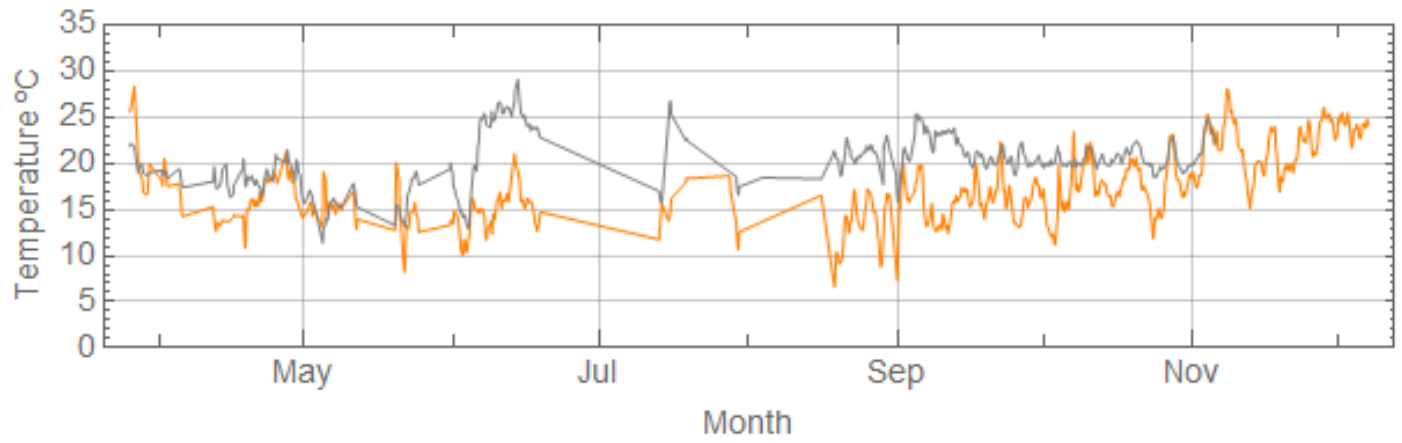

House 140

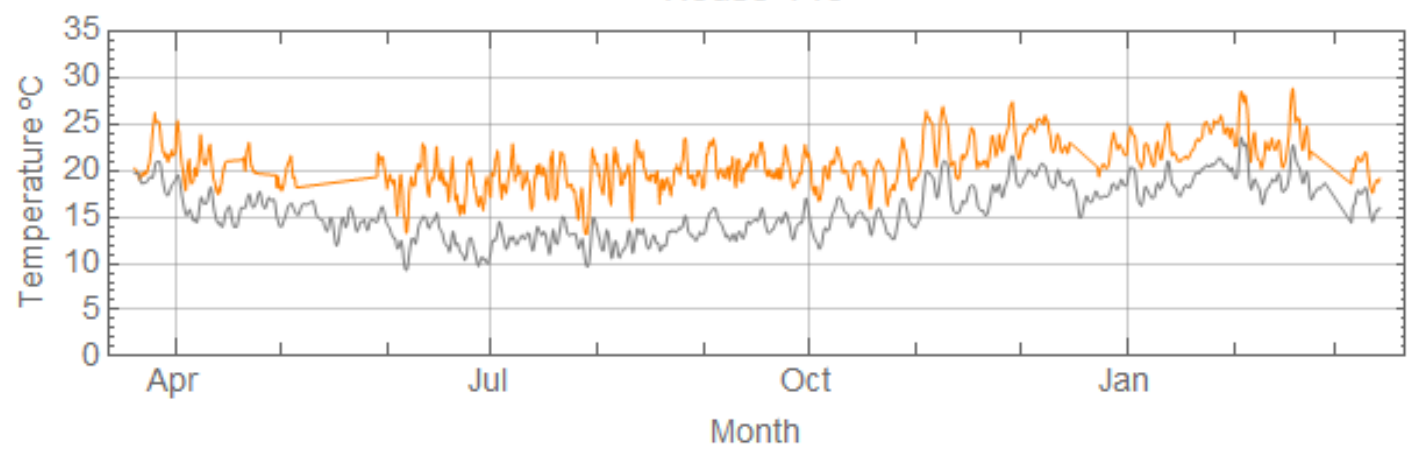


House 142

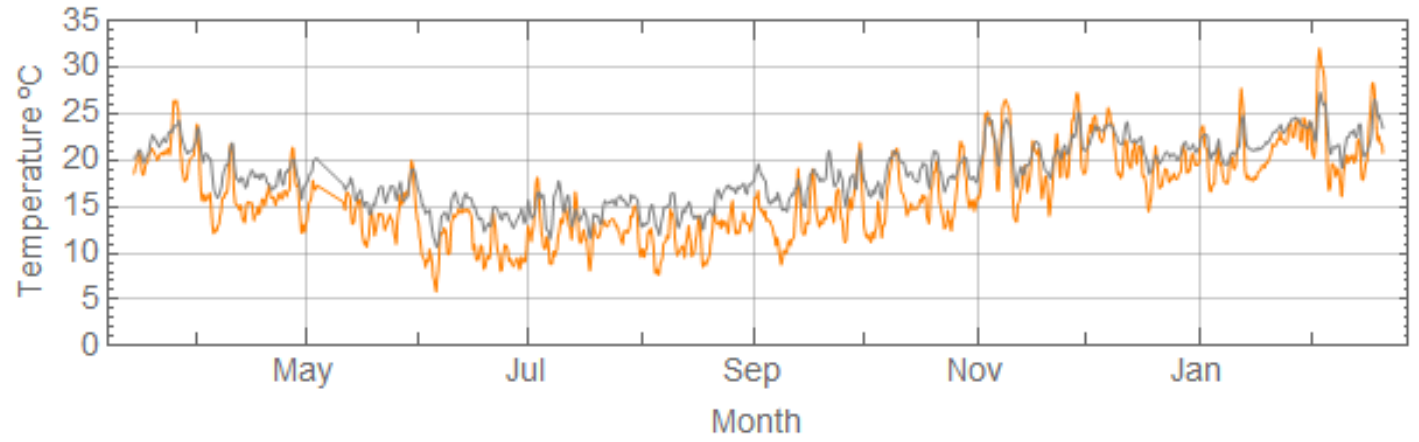

House 143

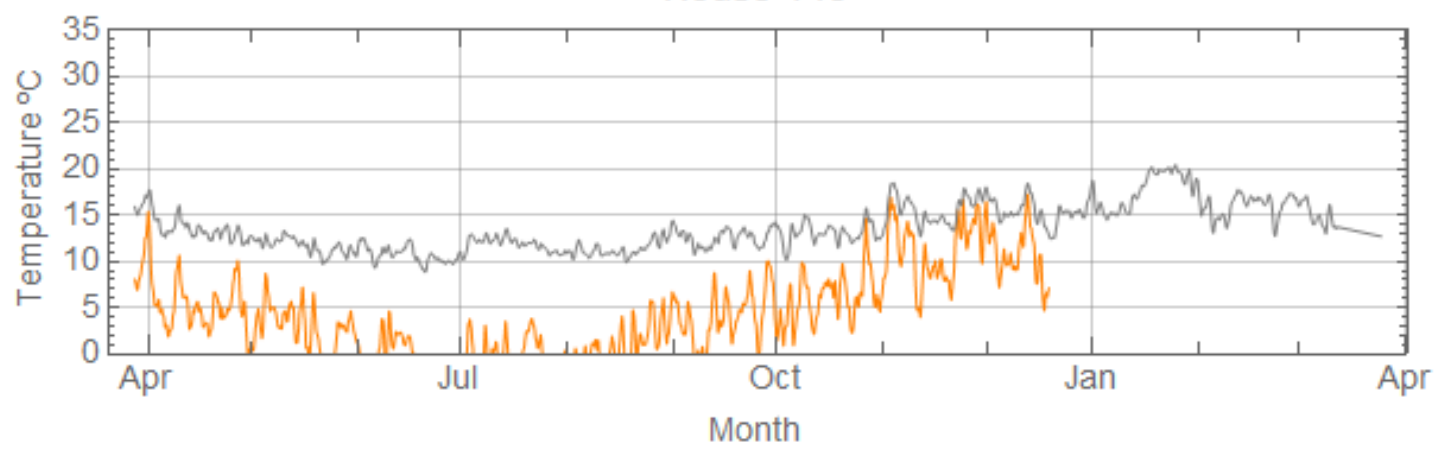

House 144

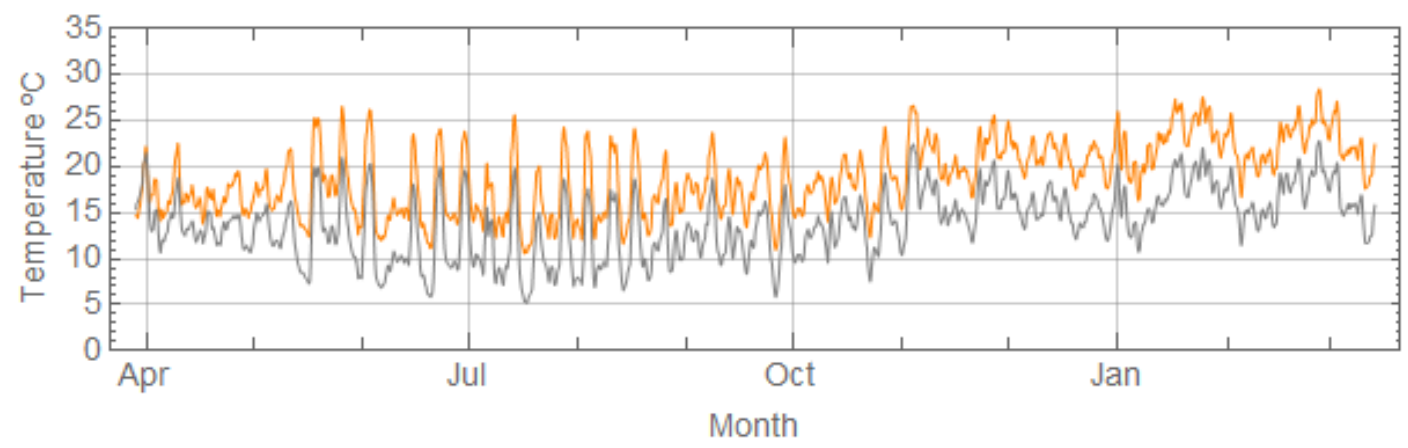

House 145

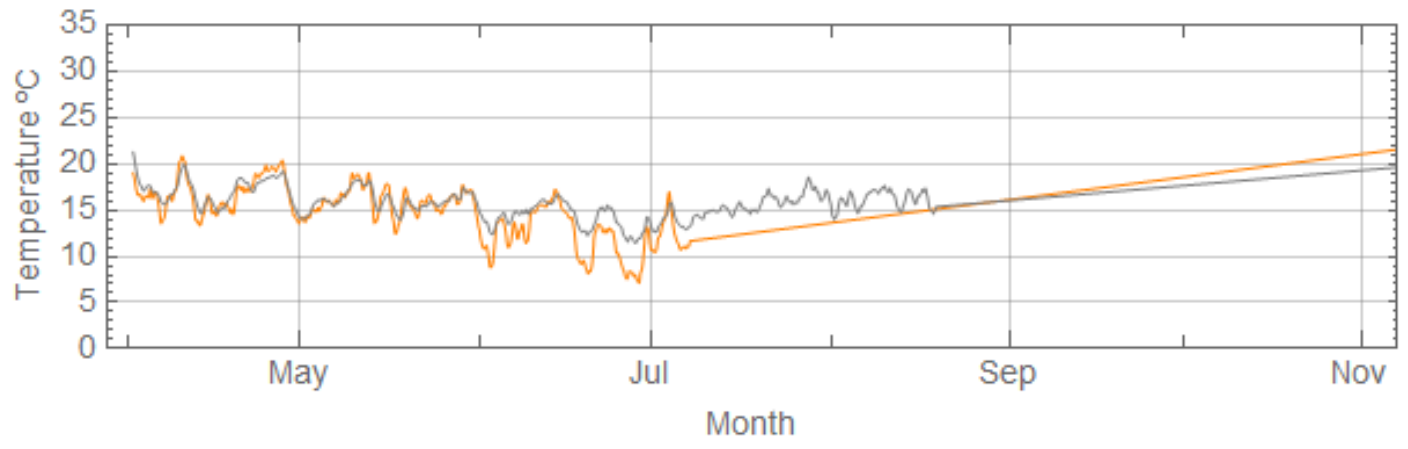


House 148

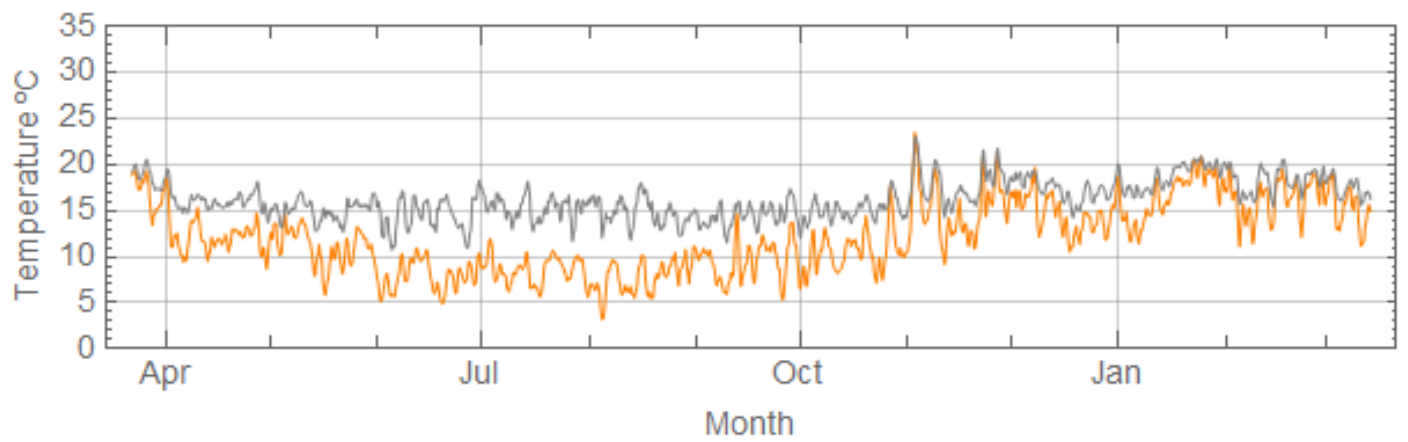

House 149

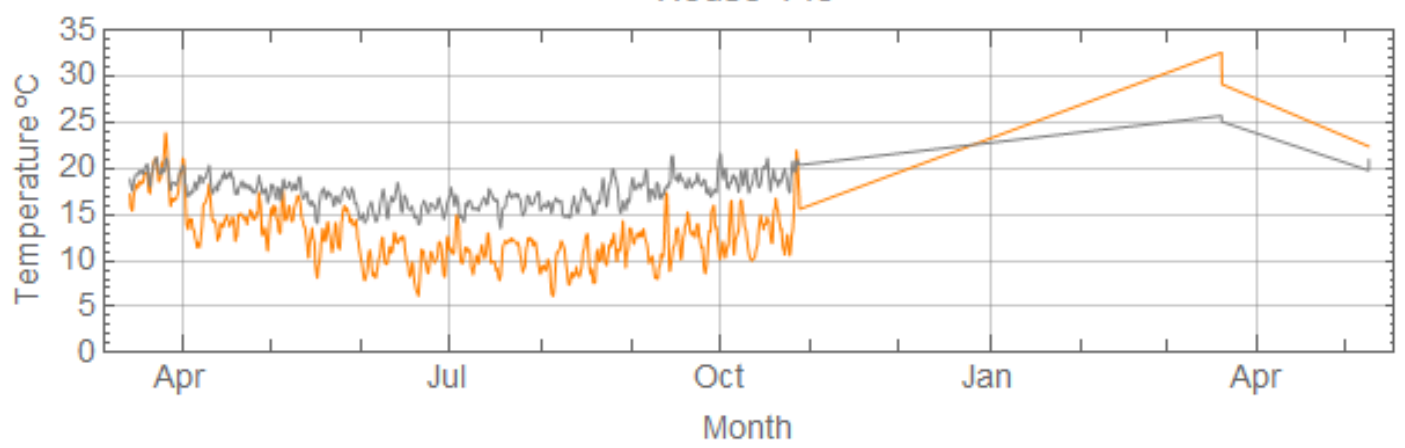

House 150

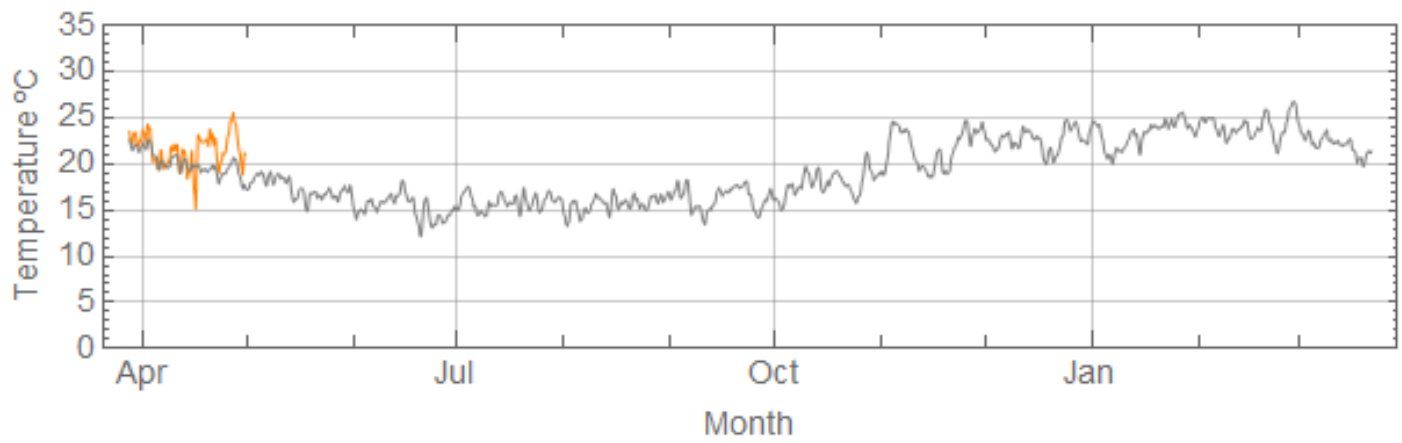

House 151

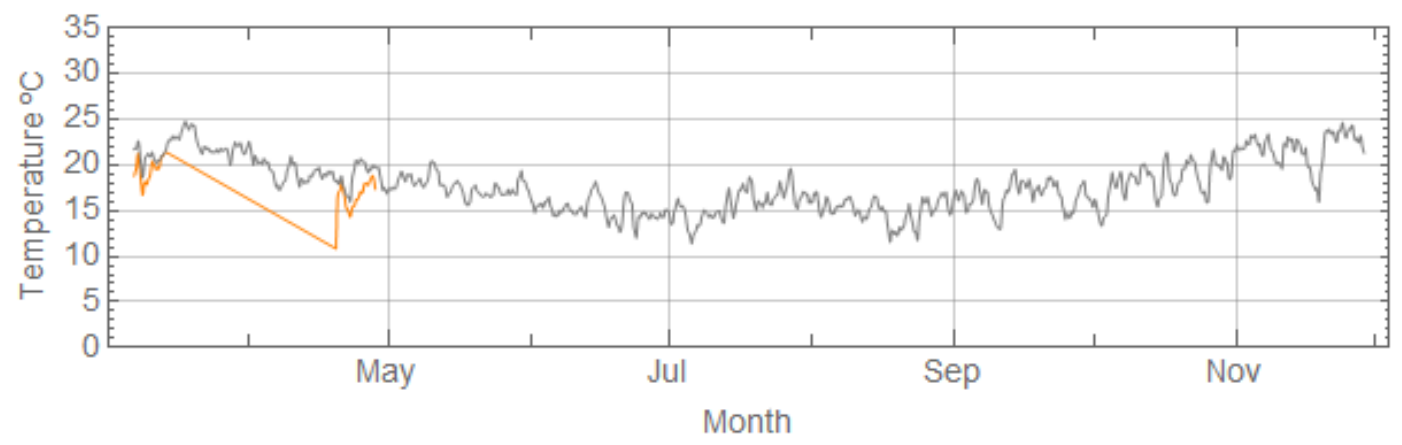


House 152

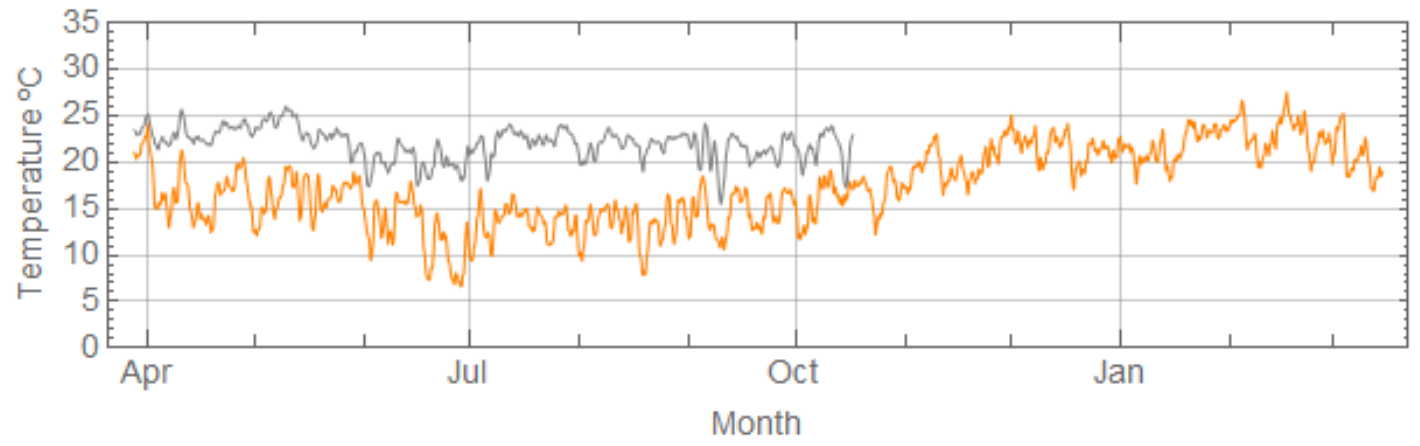

House 153

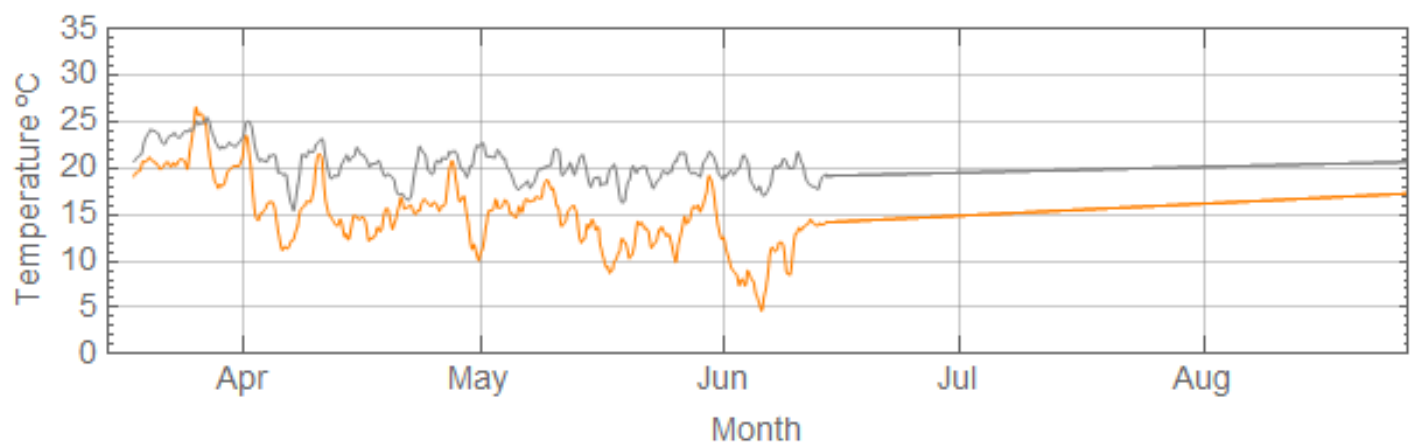

House 154

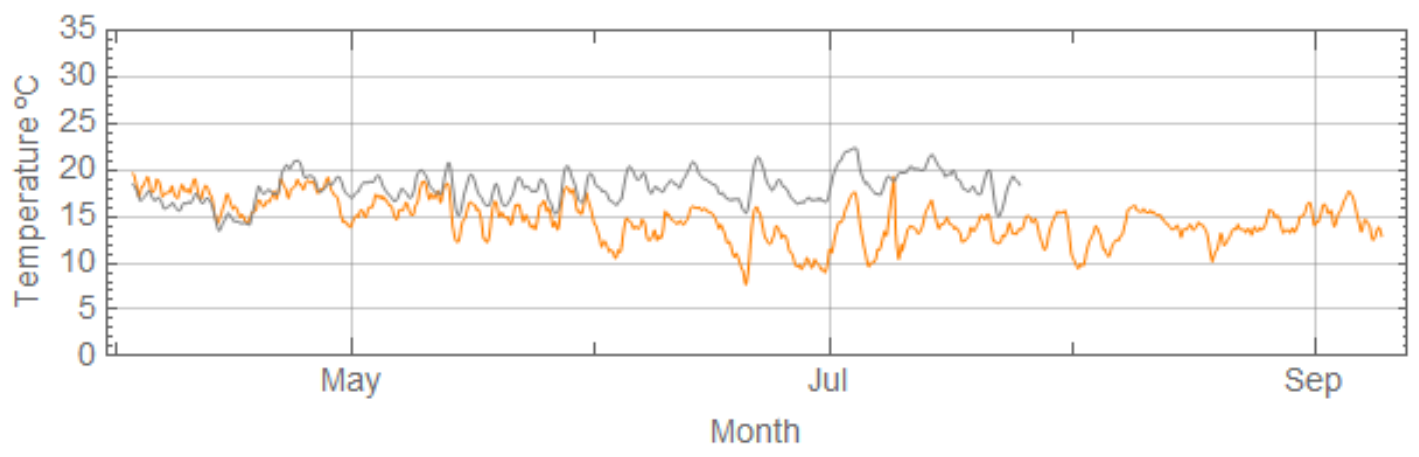

House 155

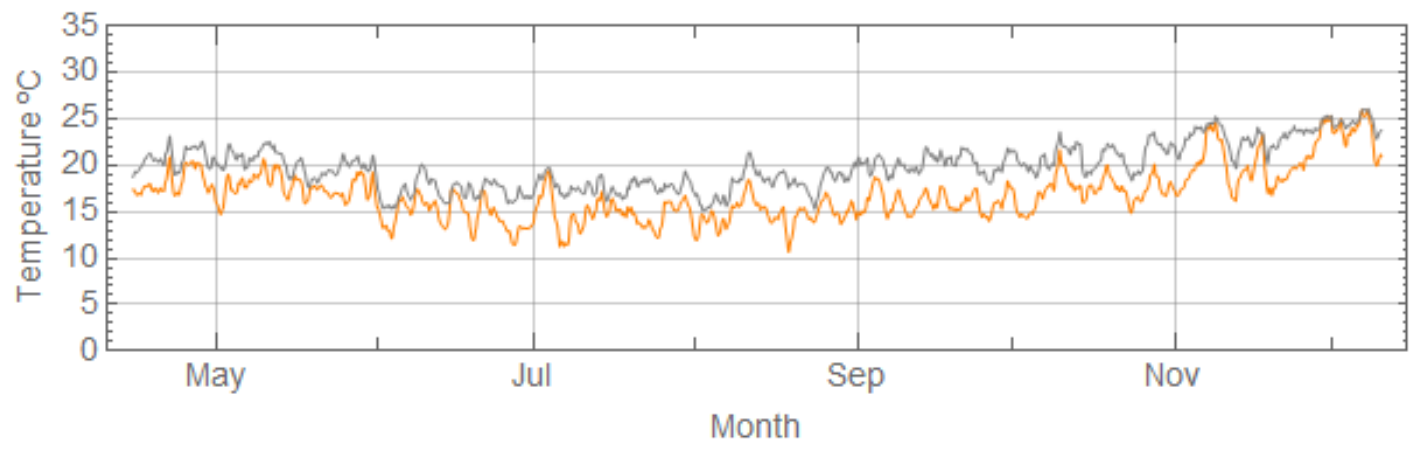


House 156

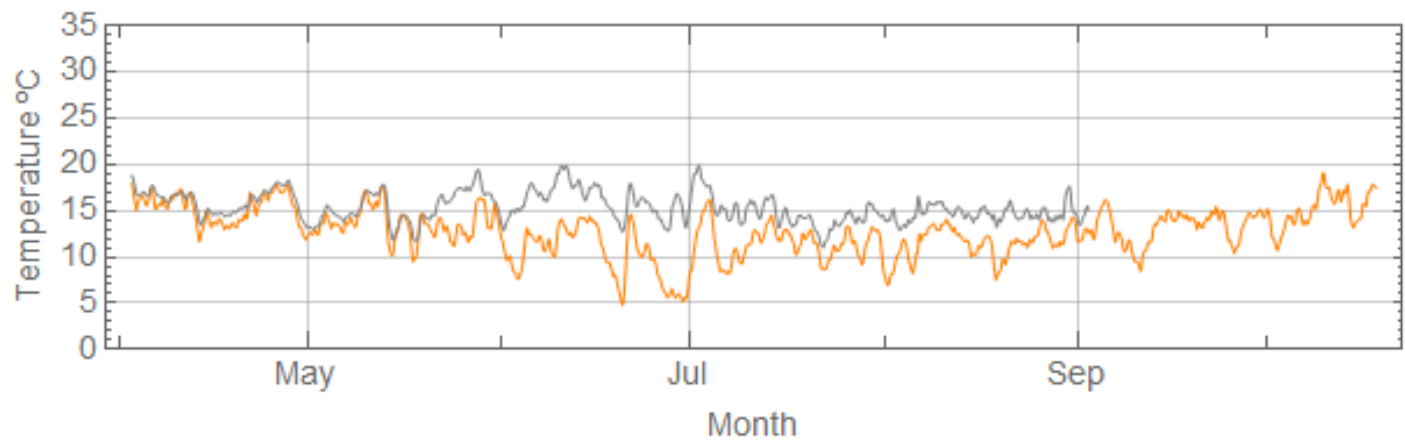

House 161

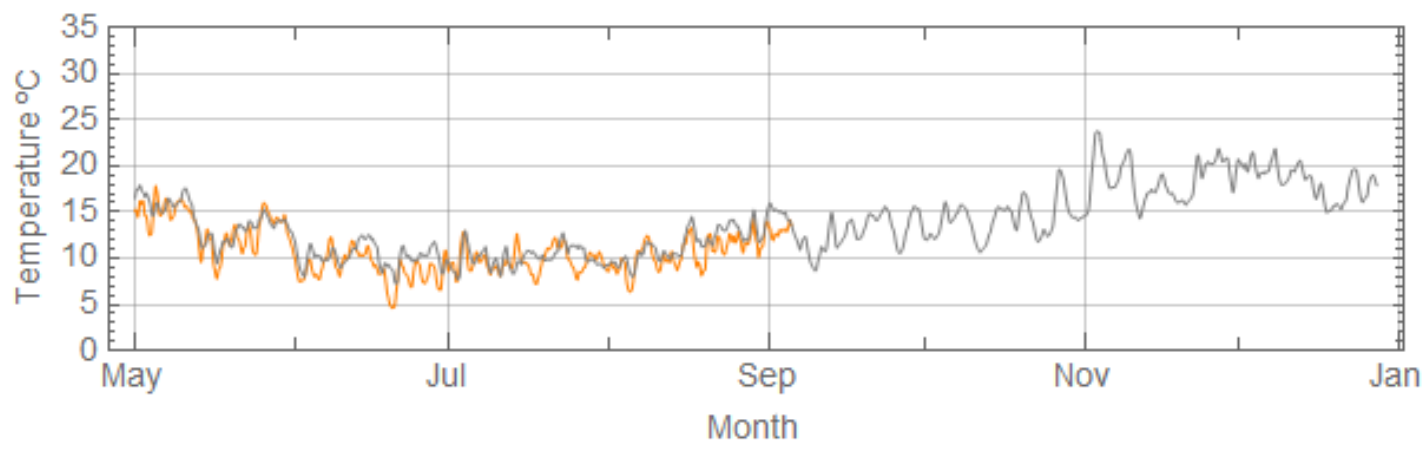

House 162

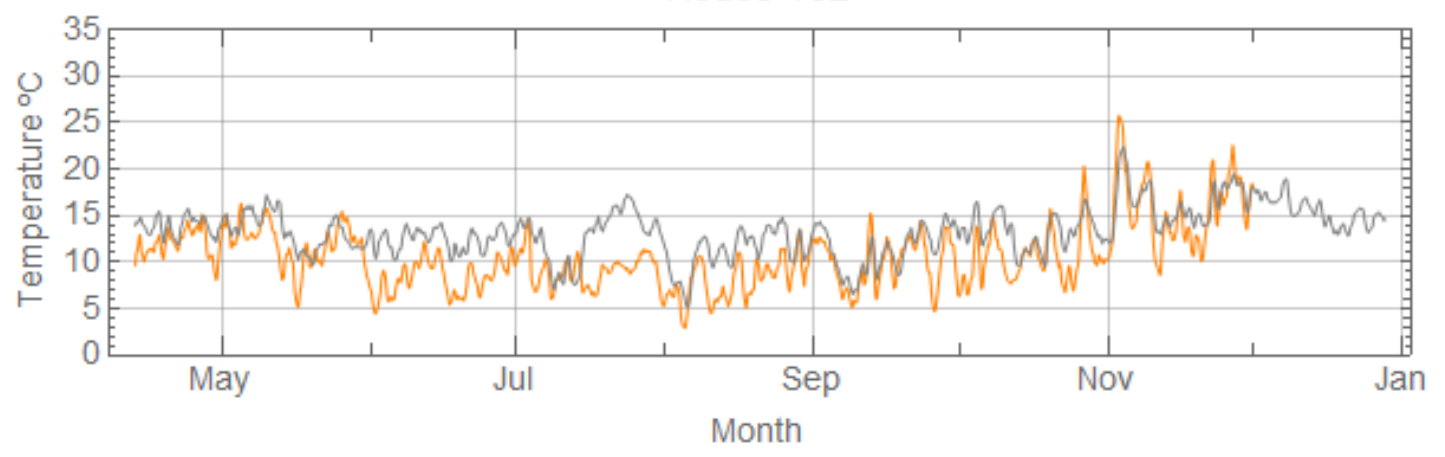

House 164

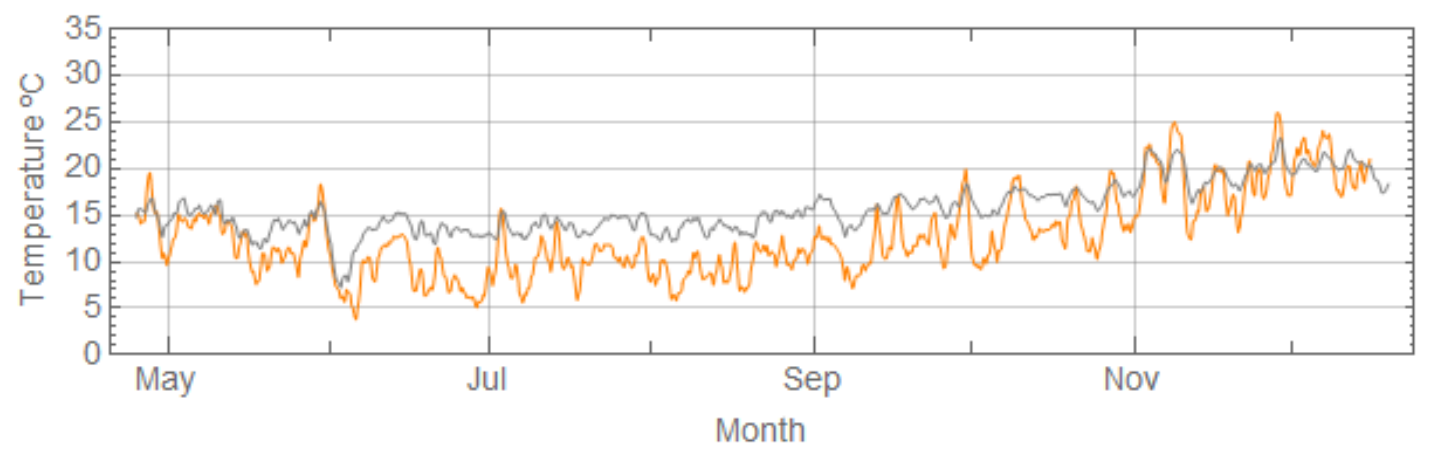


House 168

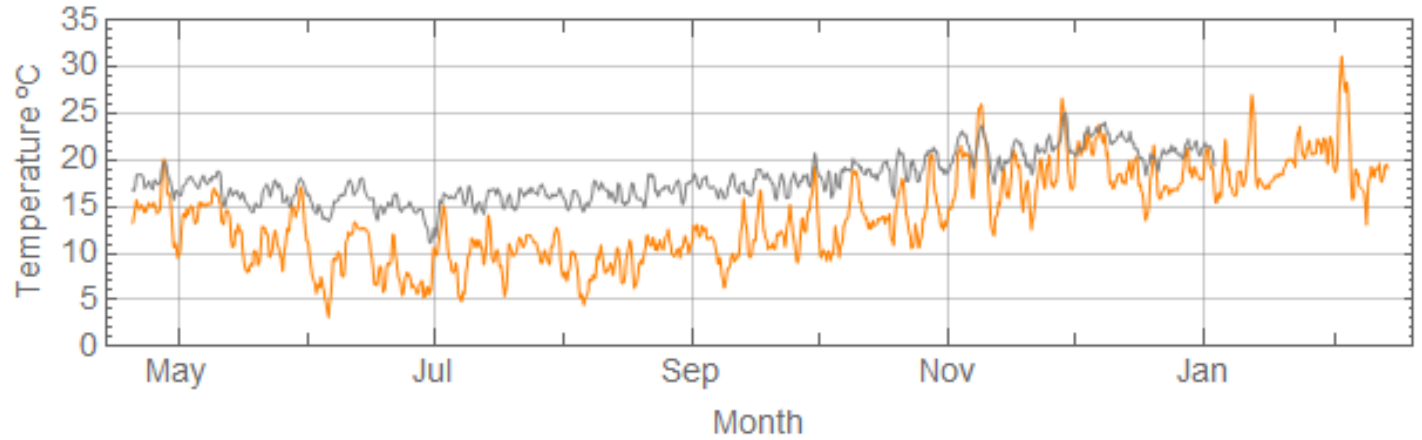

House 169

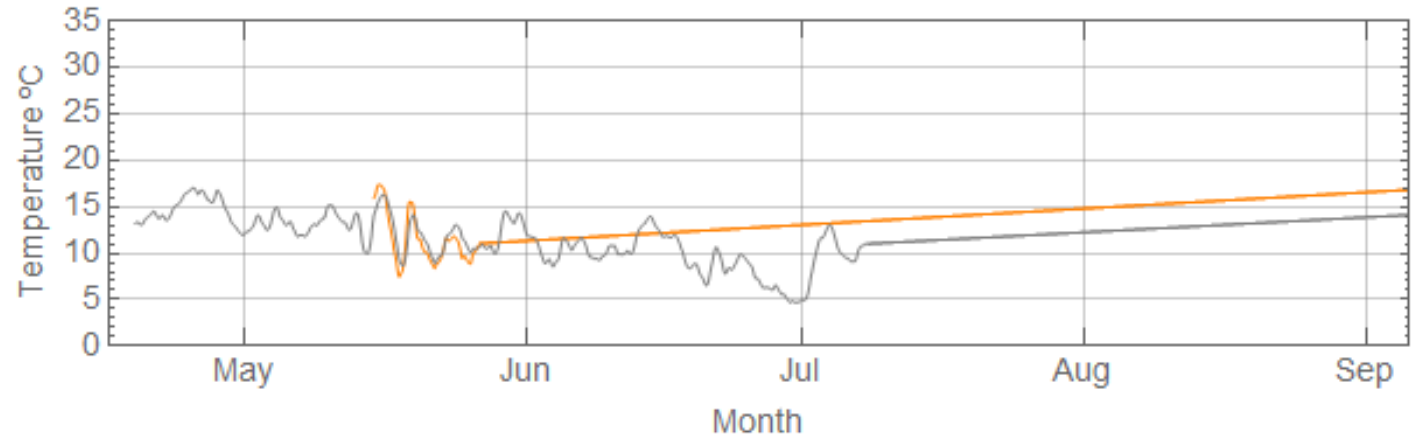

House 170

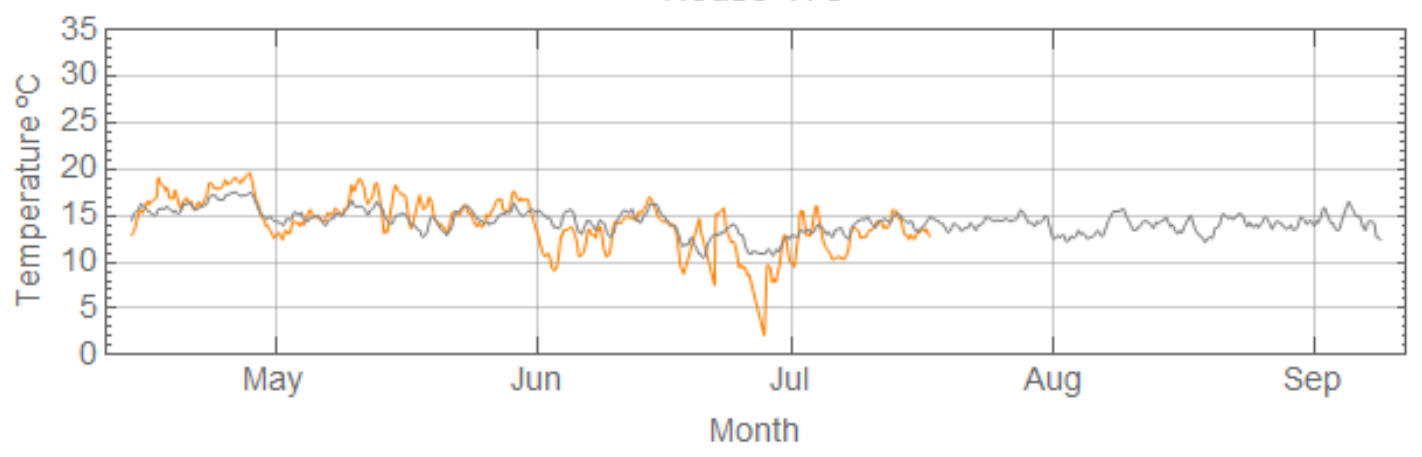

House 171

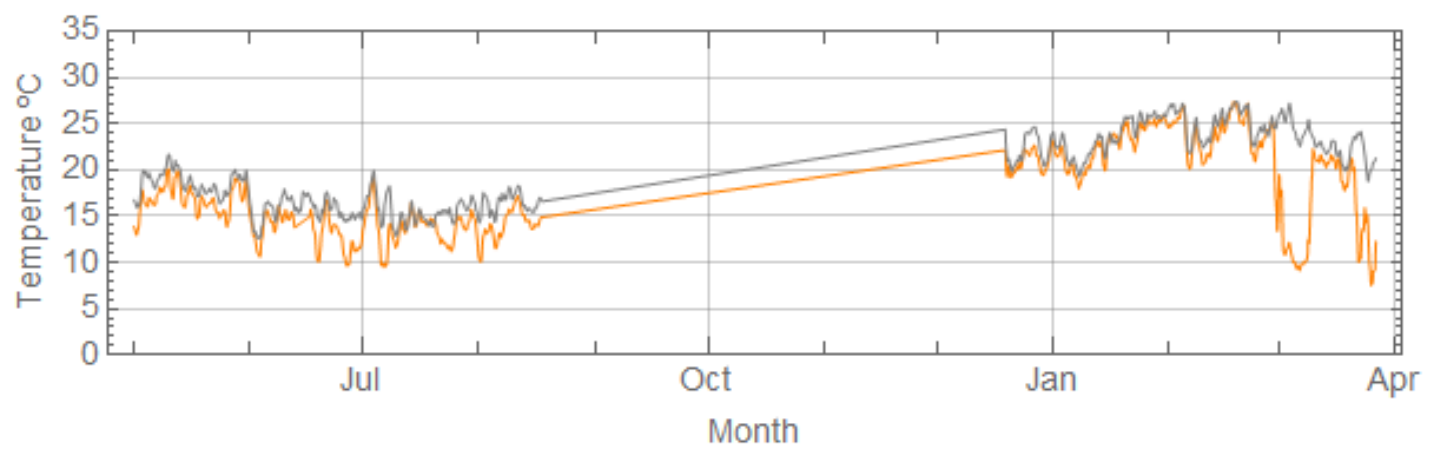


House 177

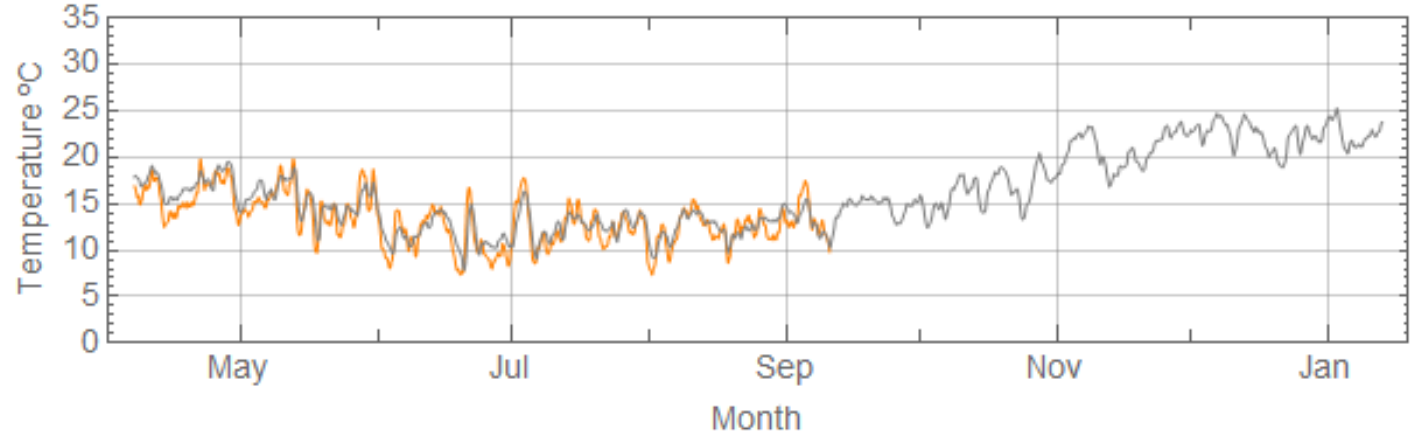

House 178

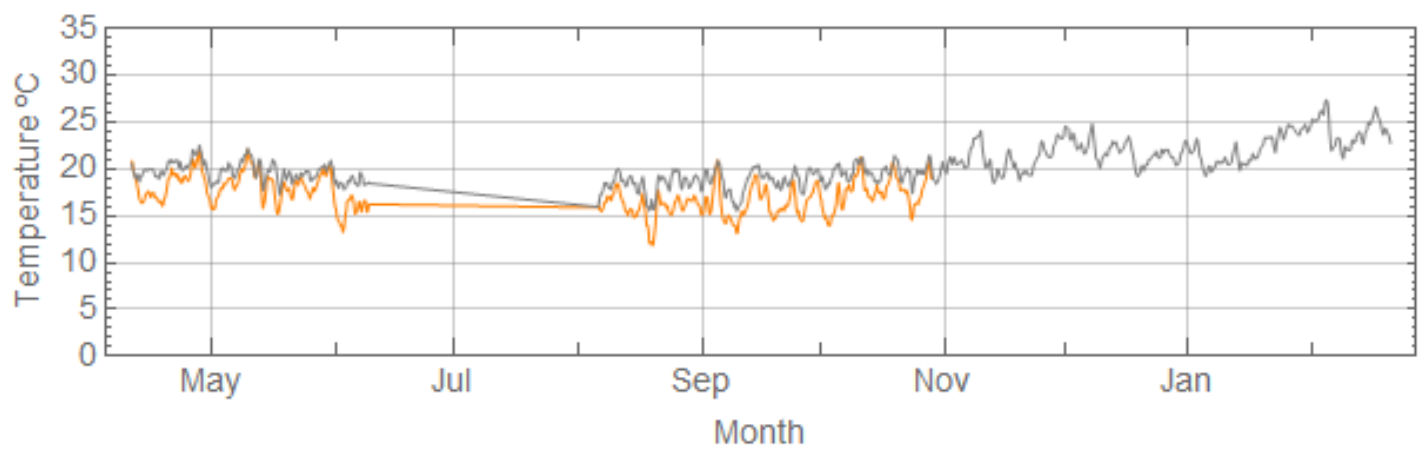

House 180

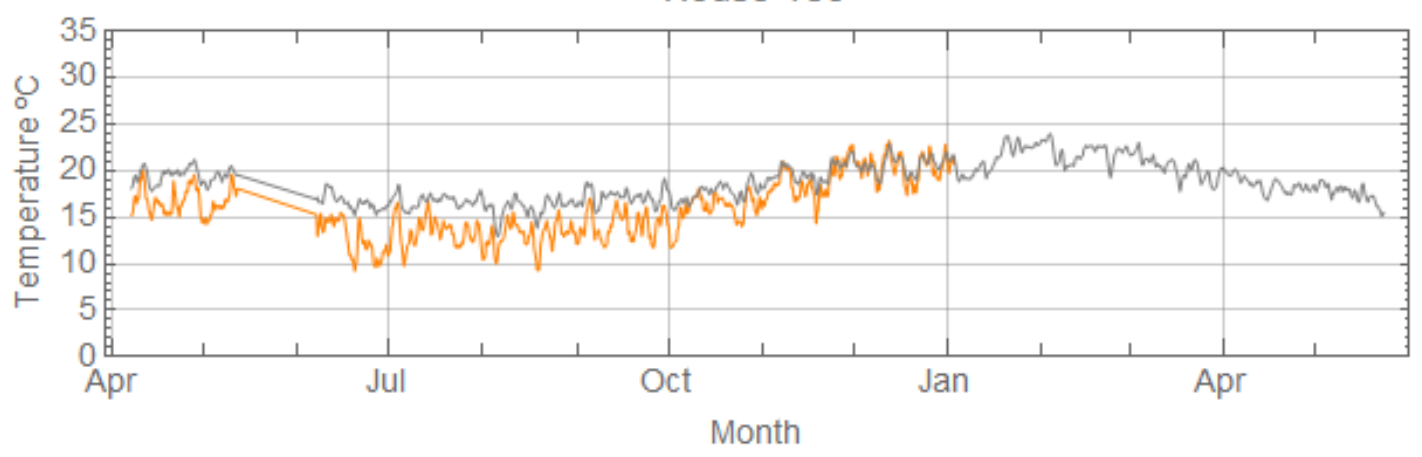




\subsection{Appendix D}

Application of Indoor Design Humidity: Simplified Method as outlined in ASHRAE Standard 160 showing Trend 1

House 104

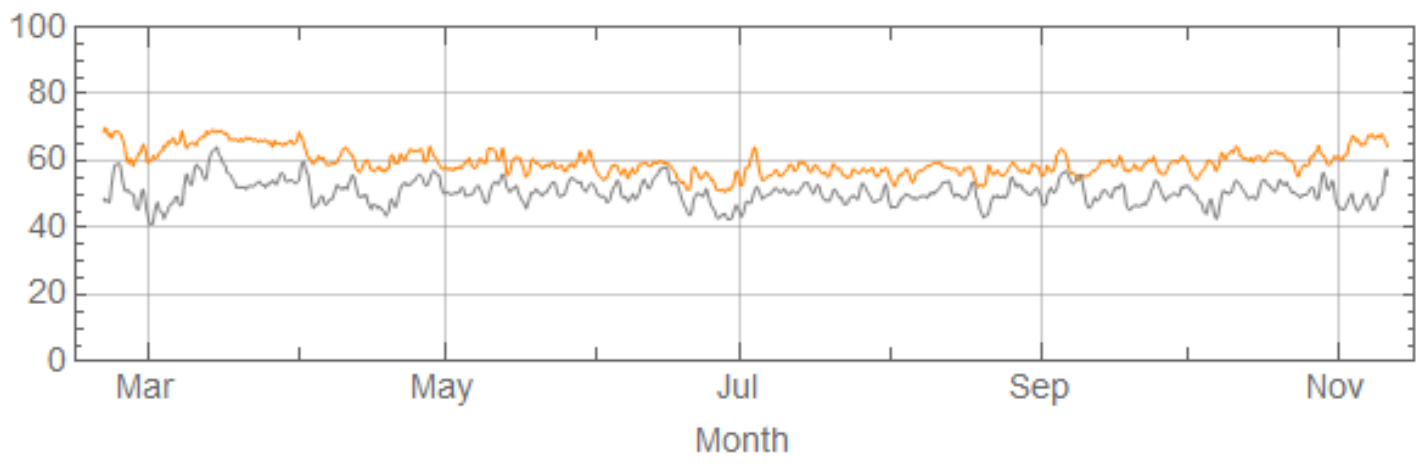

— Indoor Design Humidity: Simplified Method

— Measured Indoor Relative Humidity

House 111

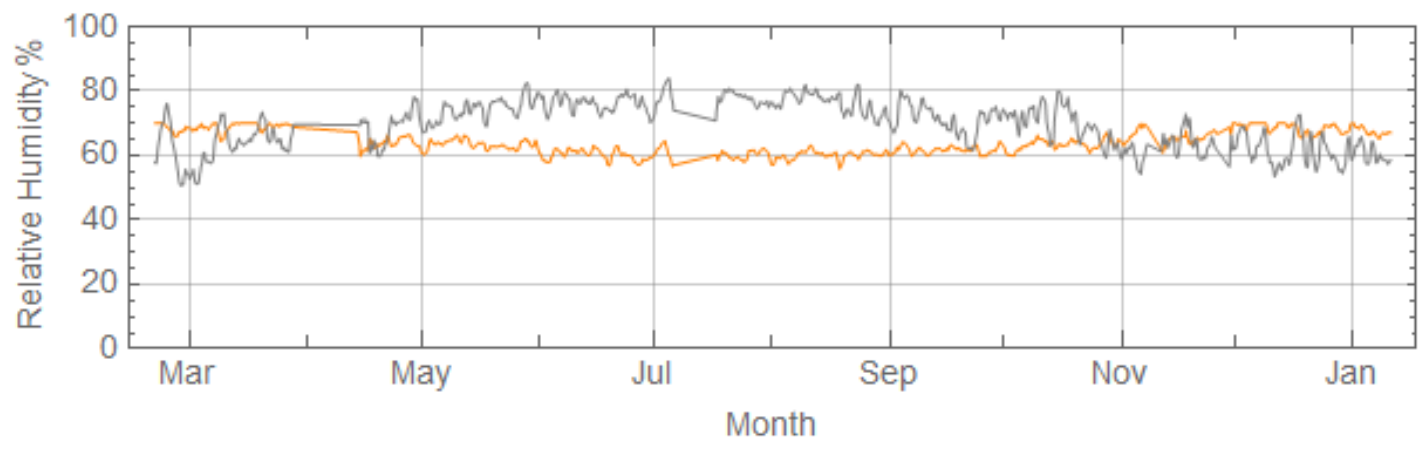

House 117

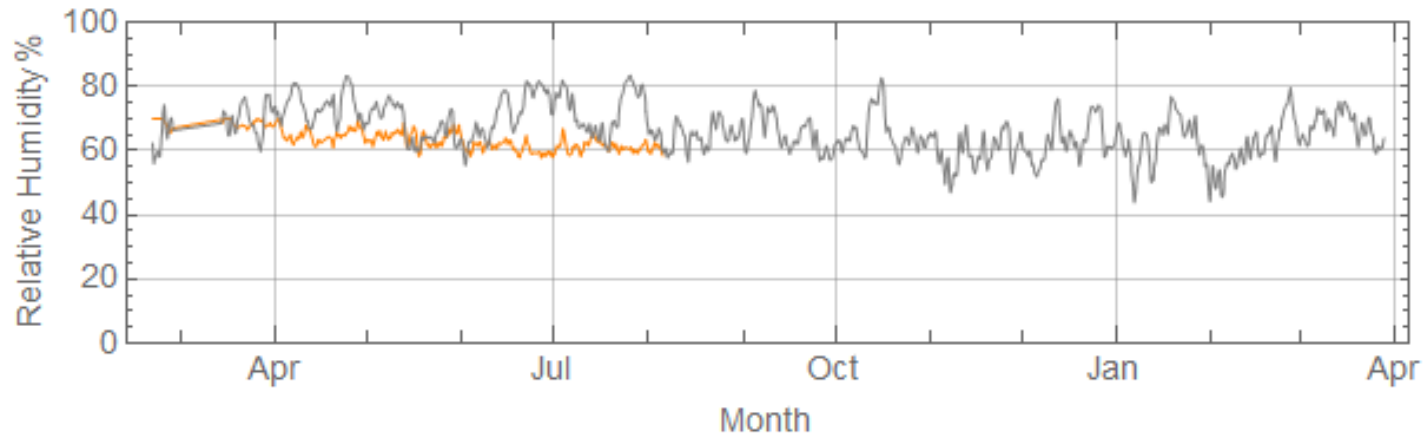


House 128

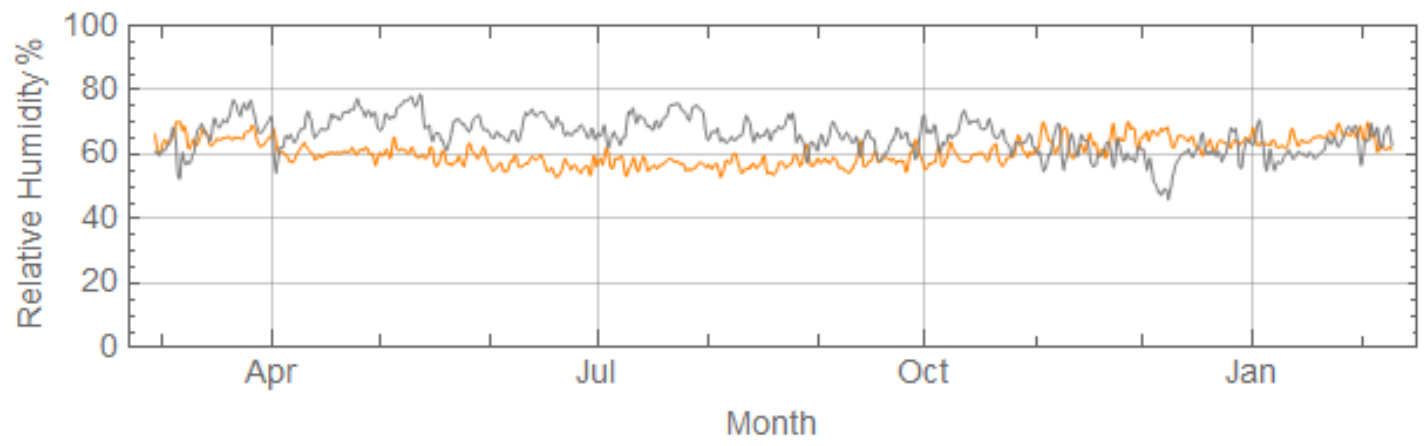

House 137

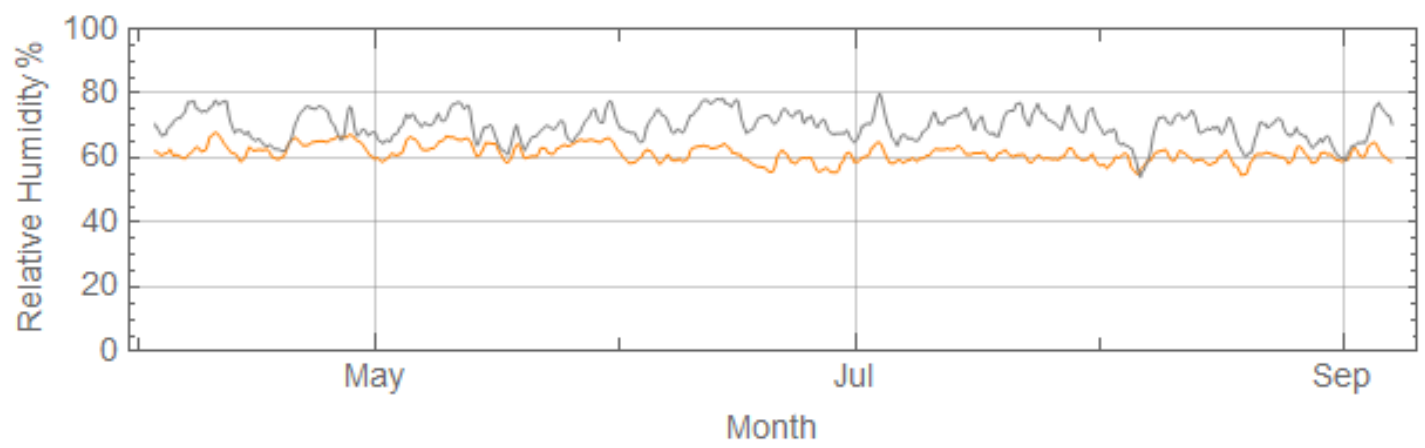

House 148

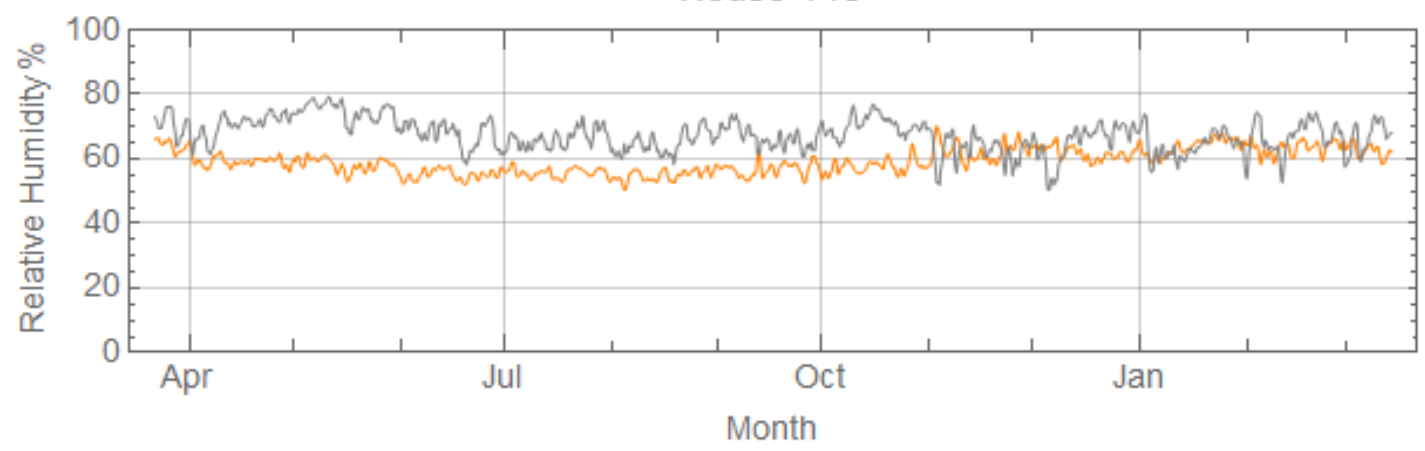

House 161

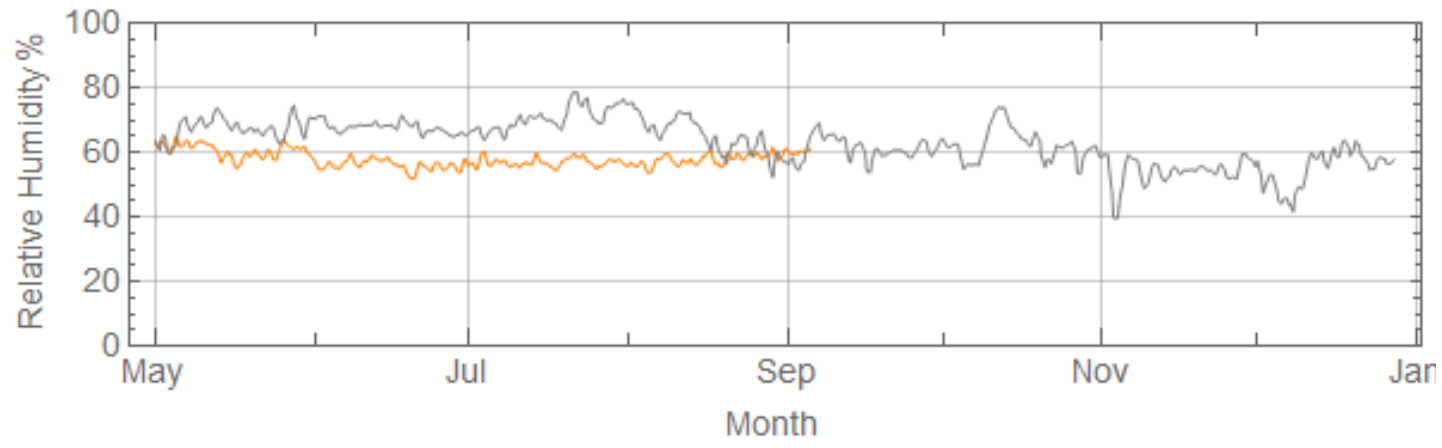


House 162

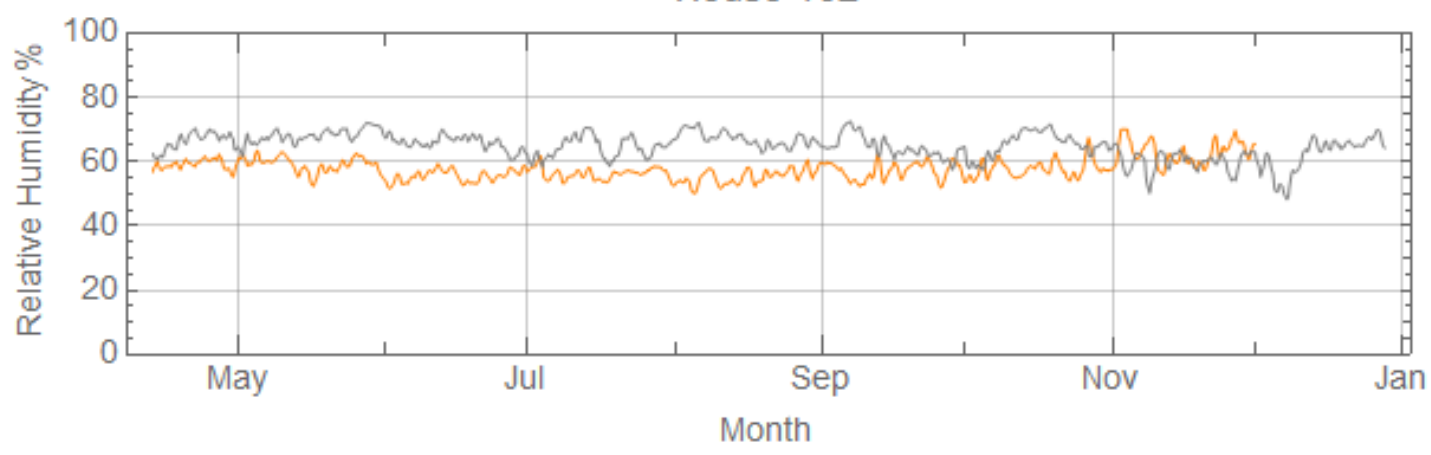

House 164

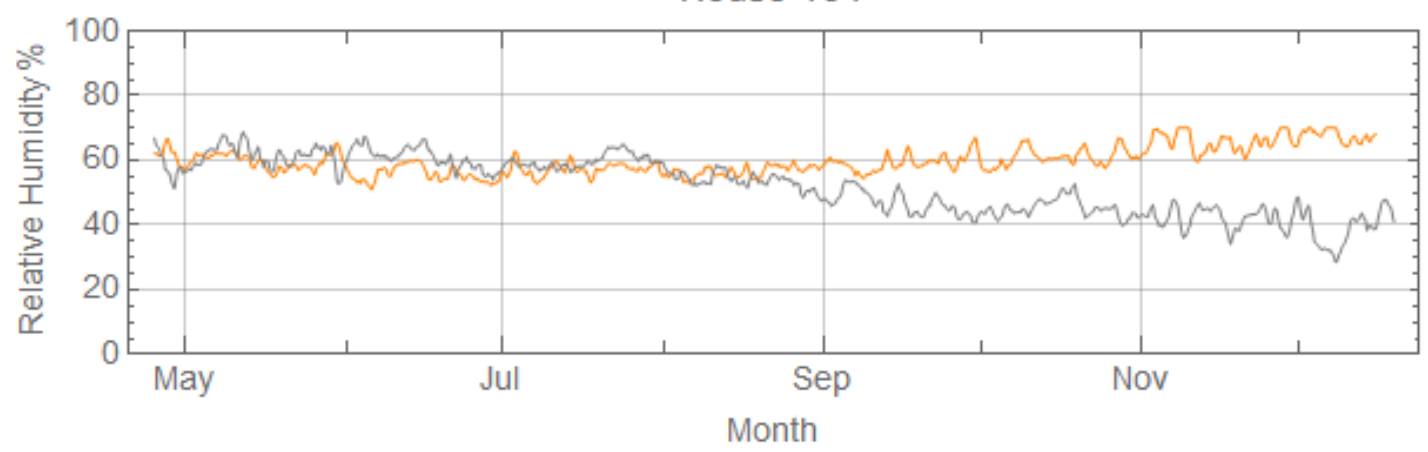

House 168

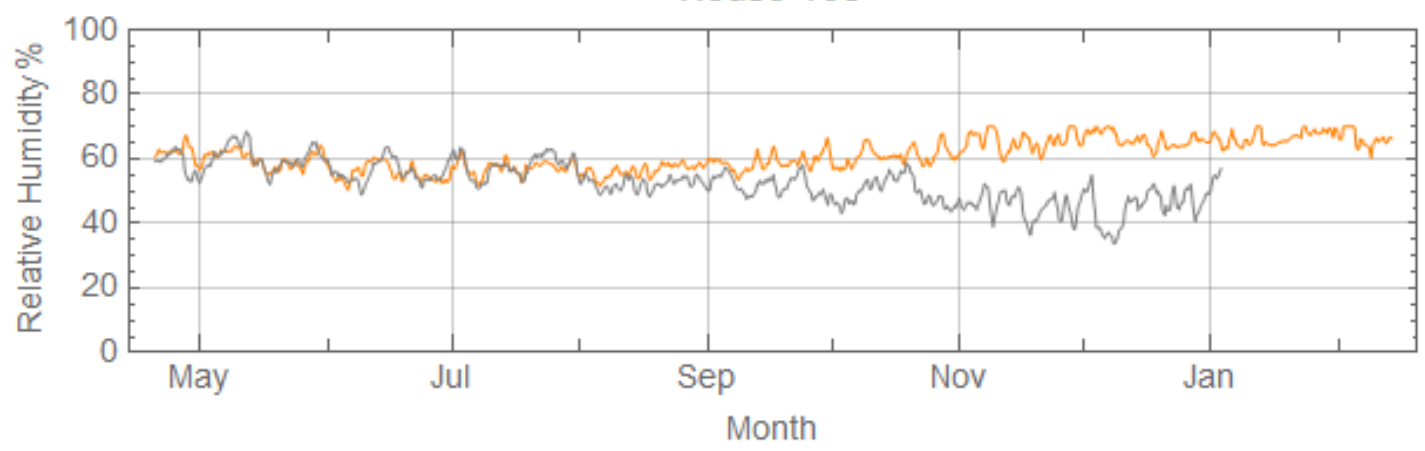

House 170

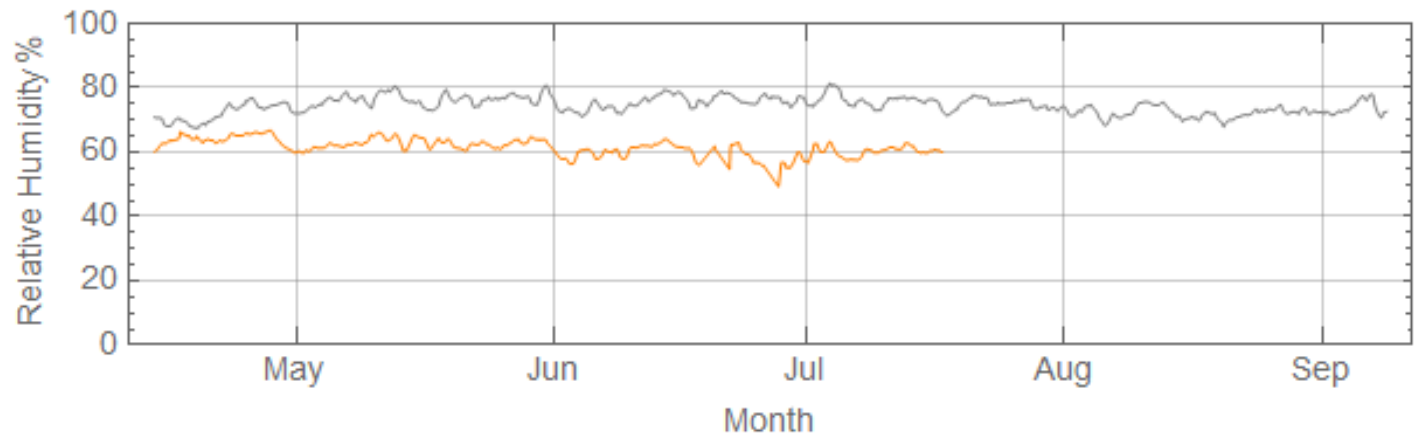


House 171

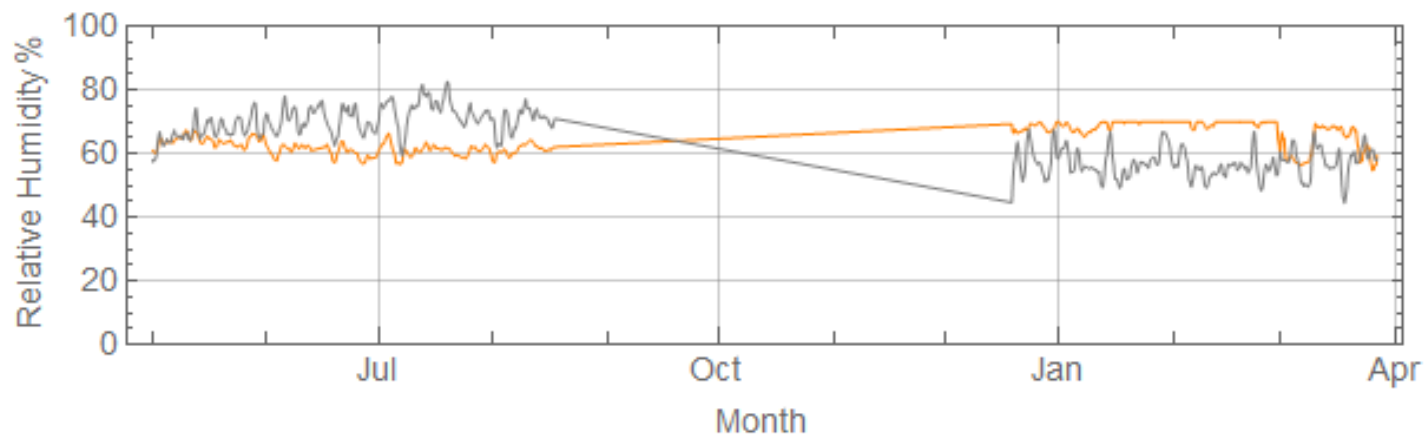

House 177

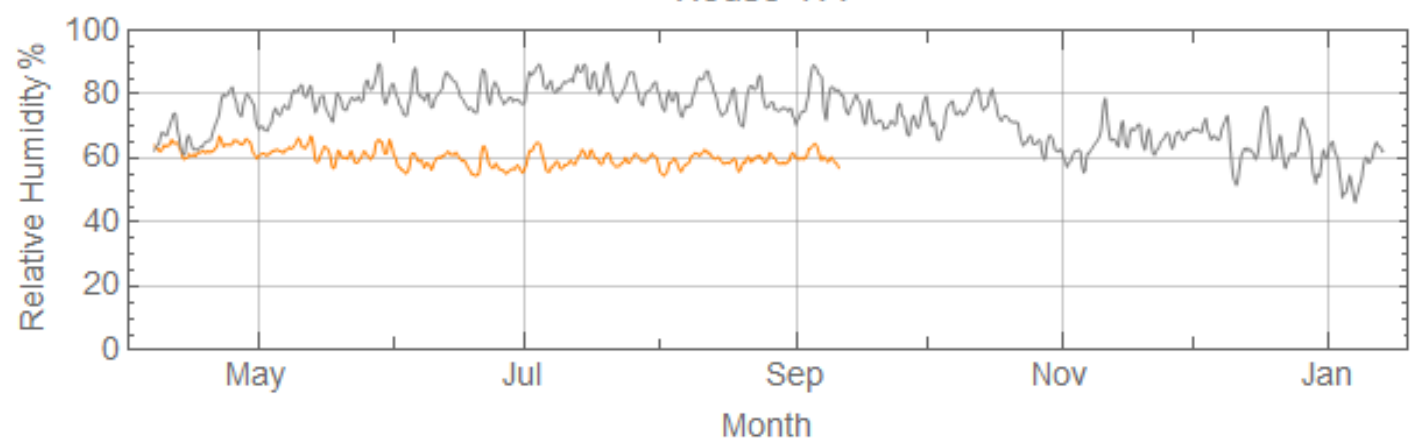




\subsection{Appendix E}

Application of Indoor Design Humidity: Simplified Method as outlined in ASHRAE Standard 160 showing Trend 2

House 106

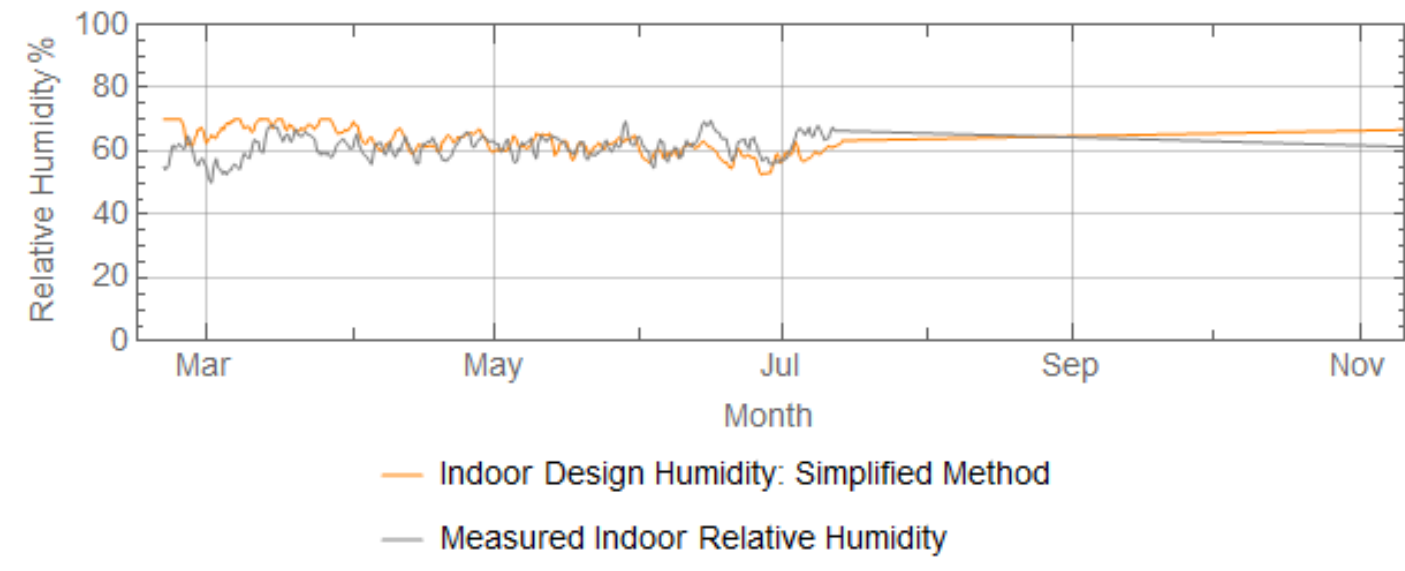

House 120

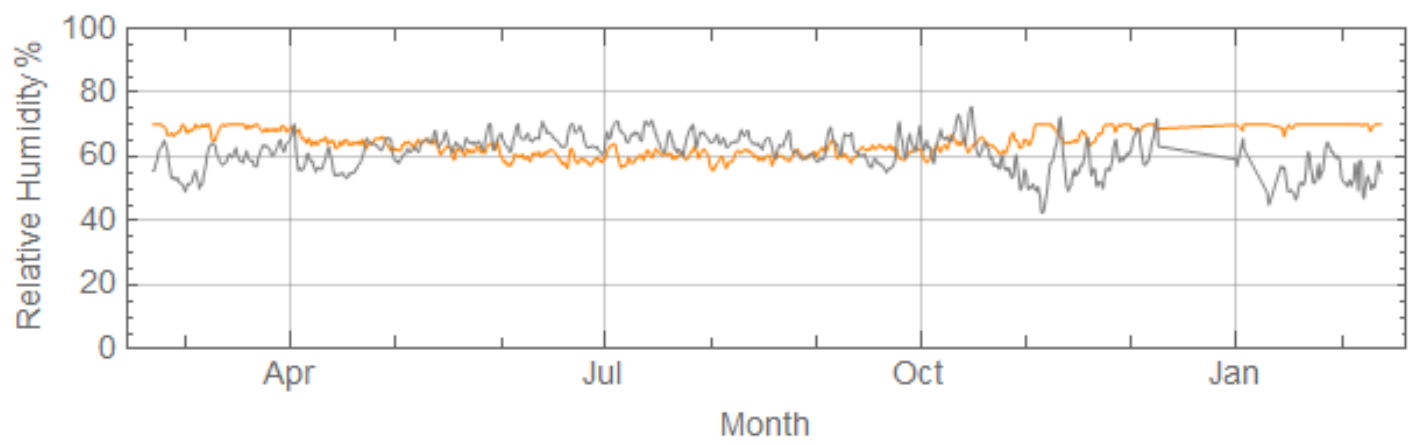

House 130

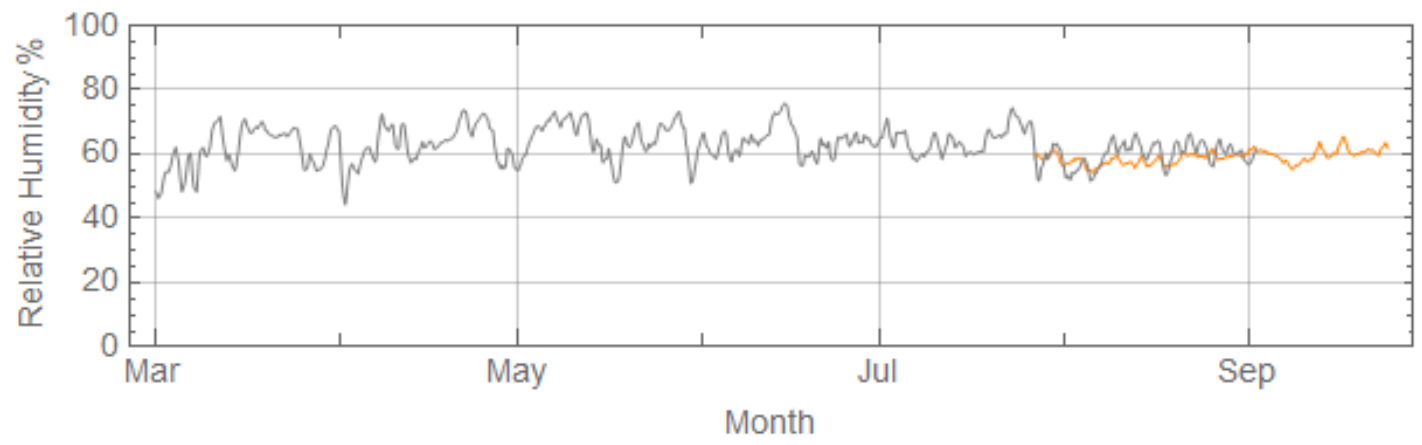


House 135

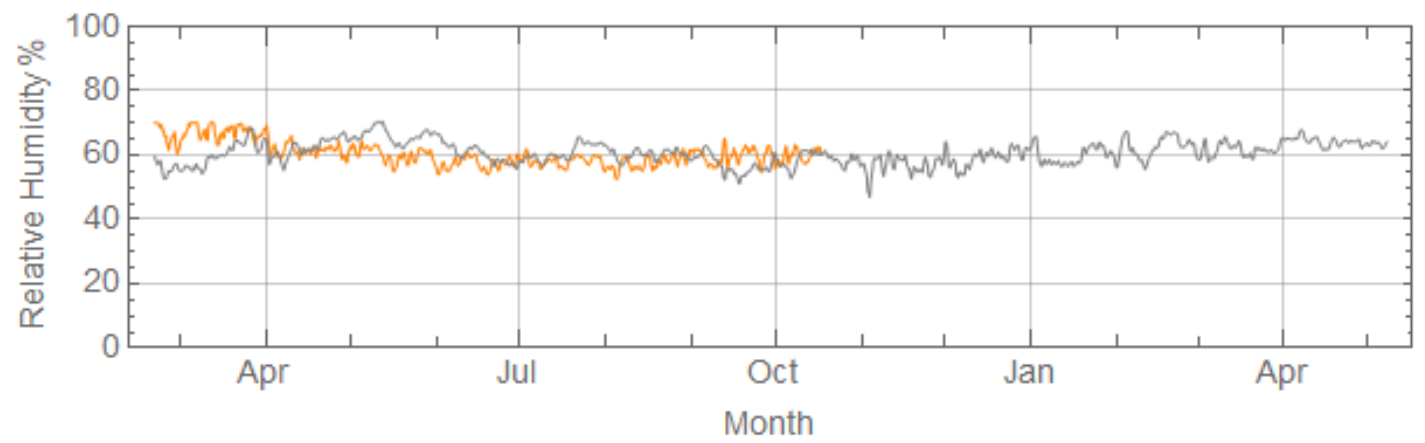

House 136

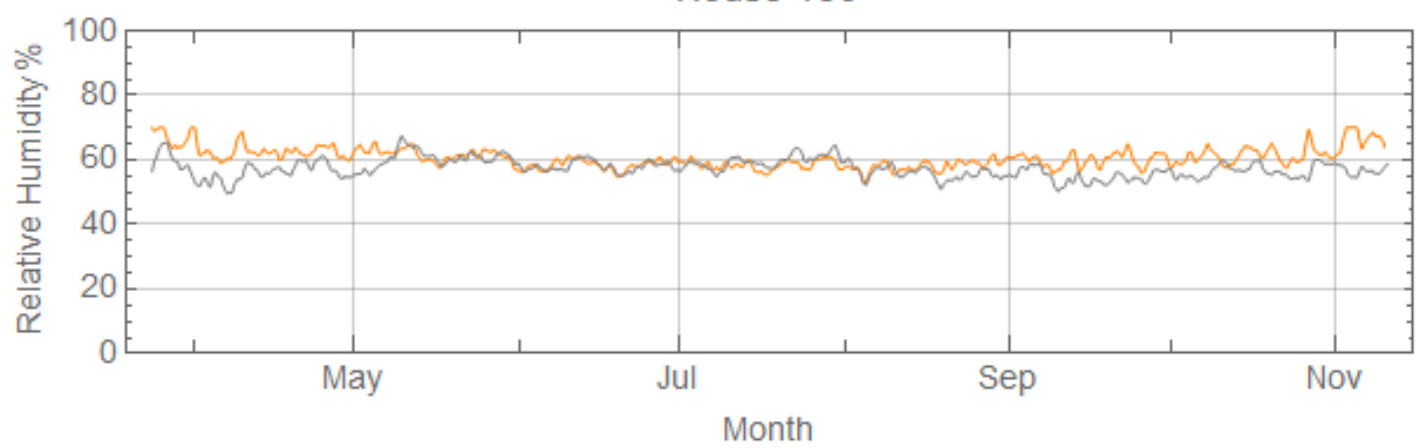

House 140

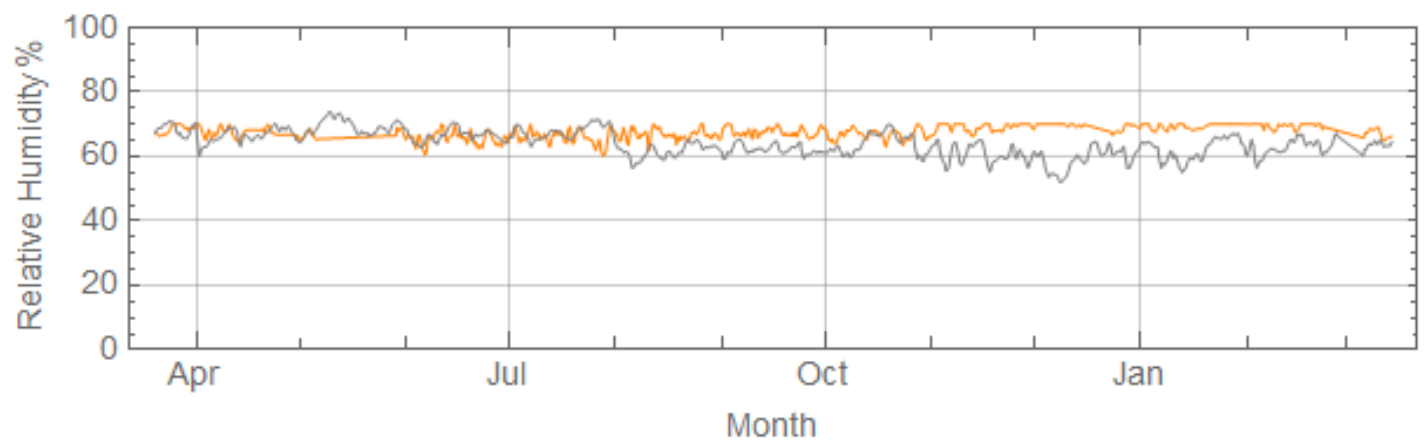

House 143

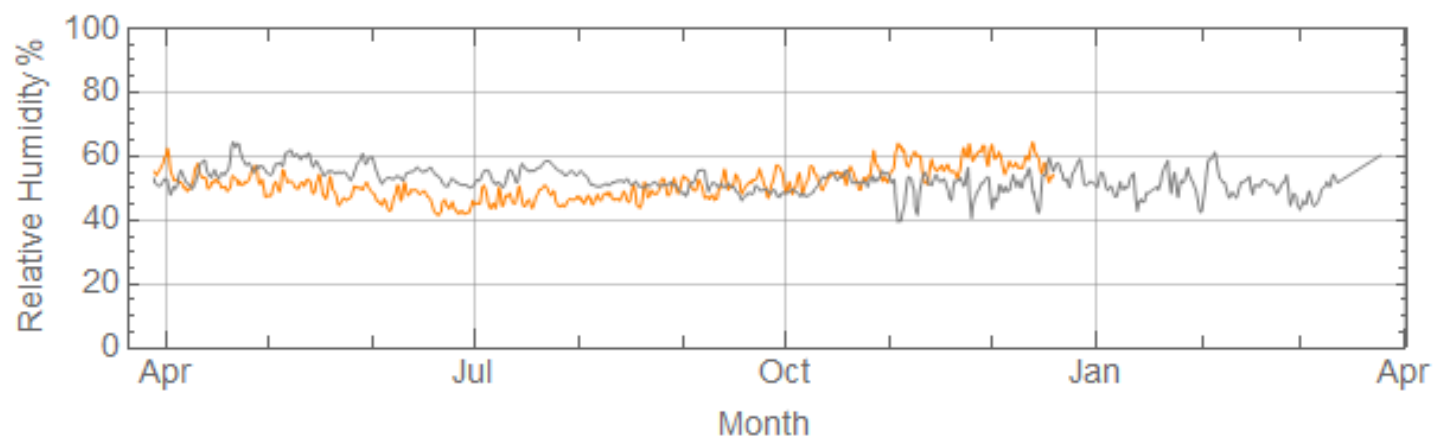


House 149

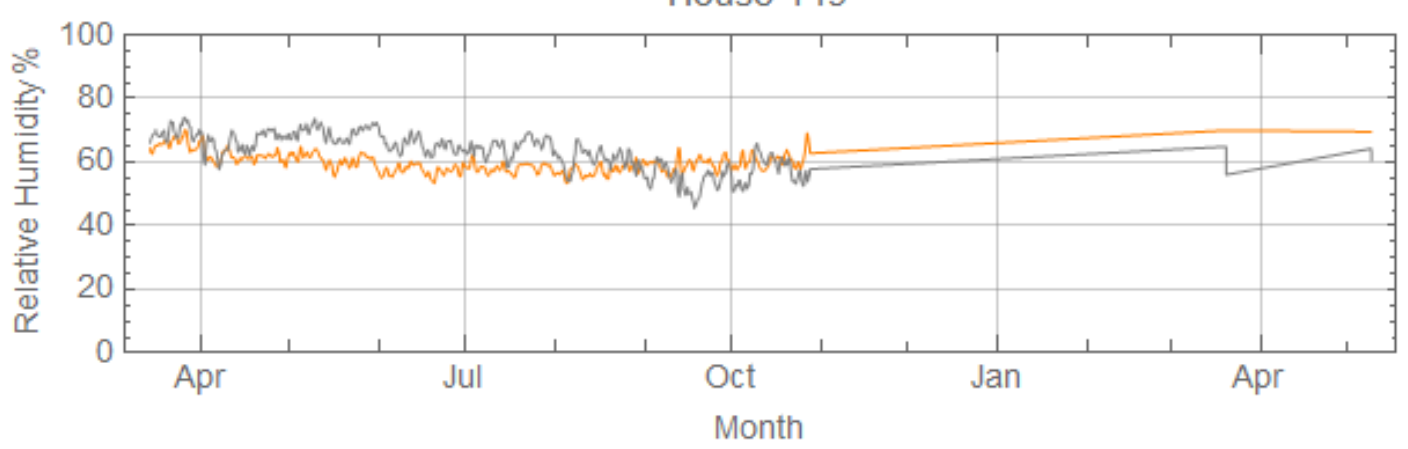

House 153

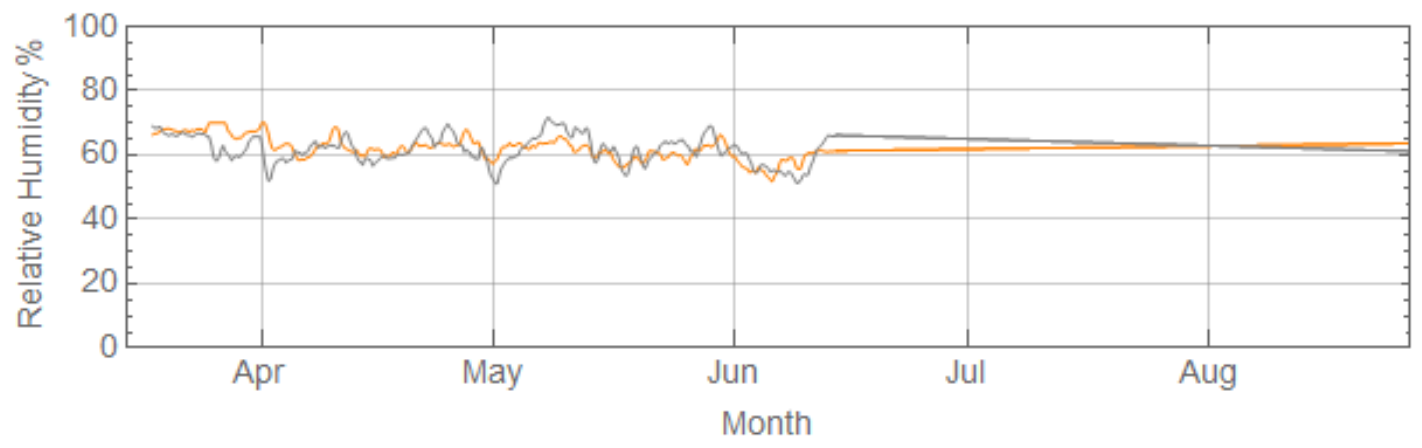

House 154

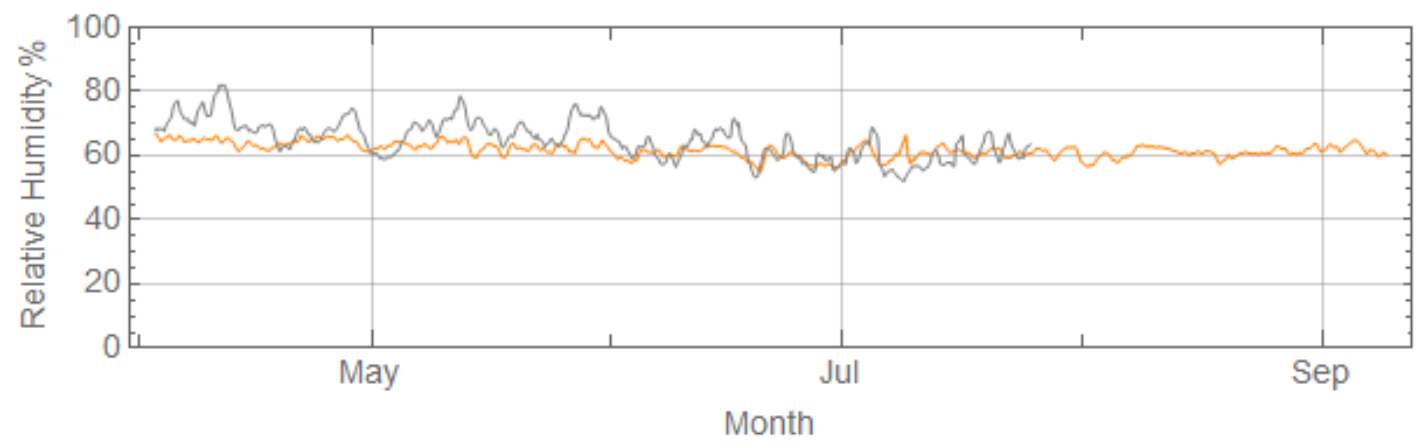

House 155

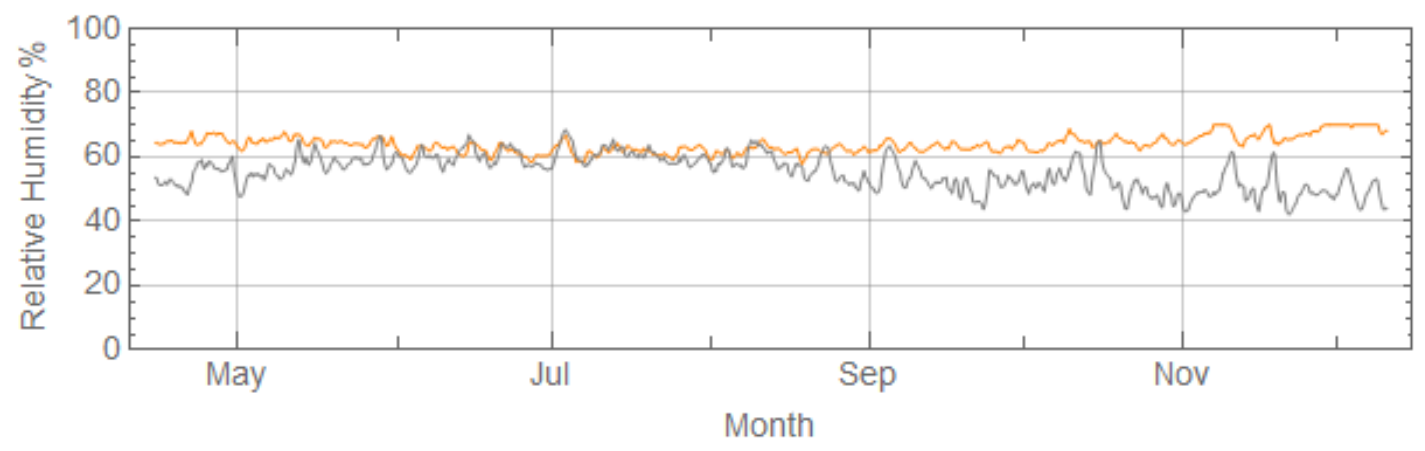


House 178

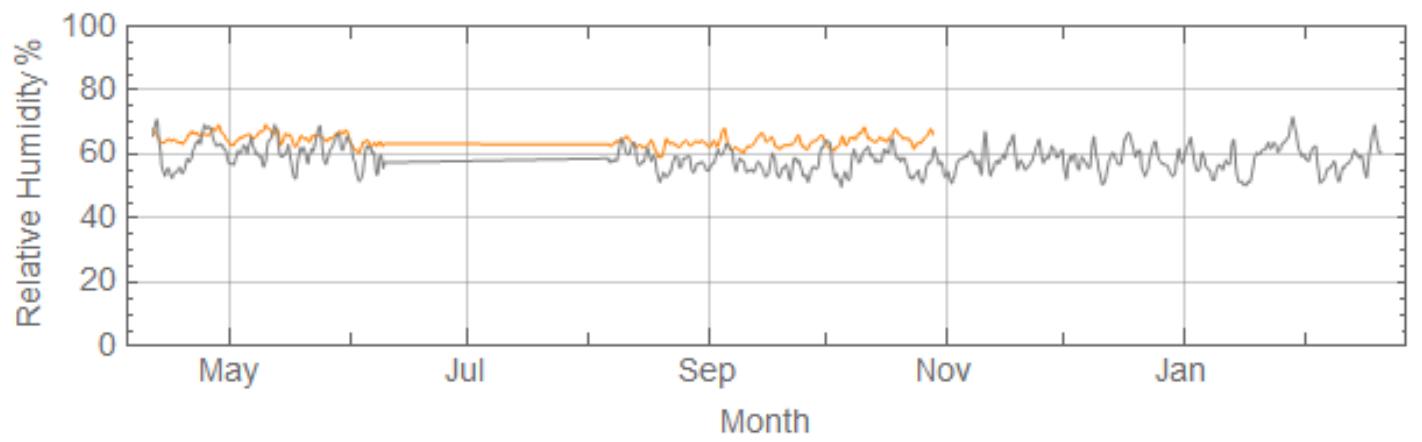

House 180

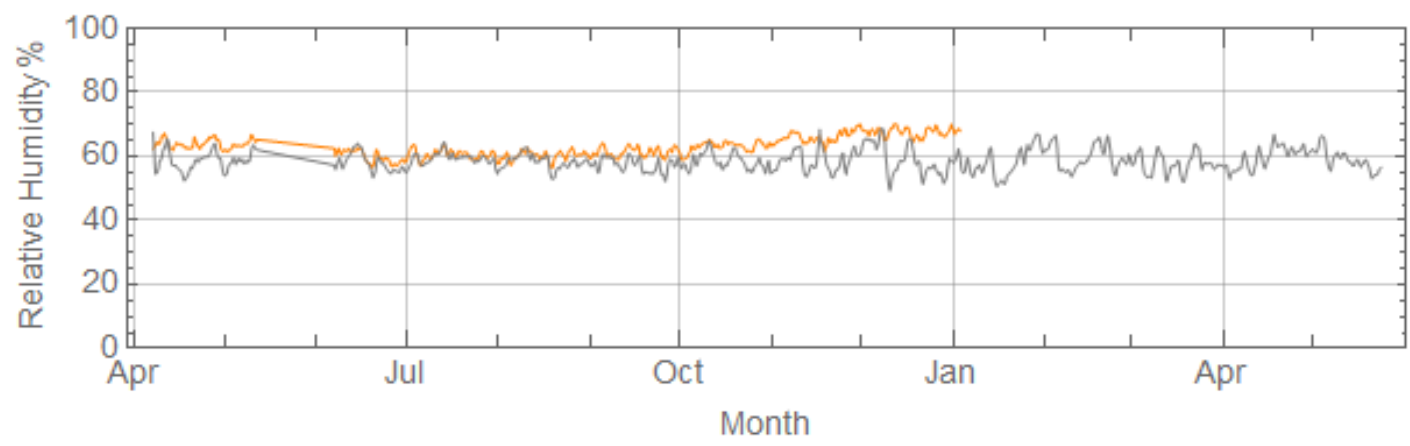




\subsection{Appendix F}

Application of Indoor Design Humidity: Simplified Method as outlined in ASHRAE Standard 160 showing Trend 3

House 110

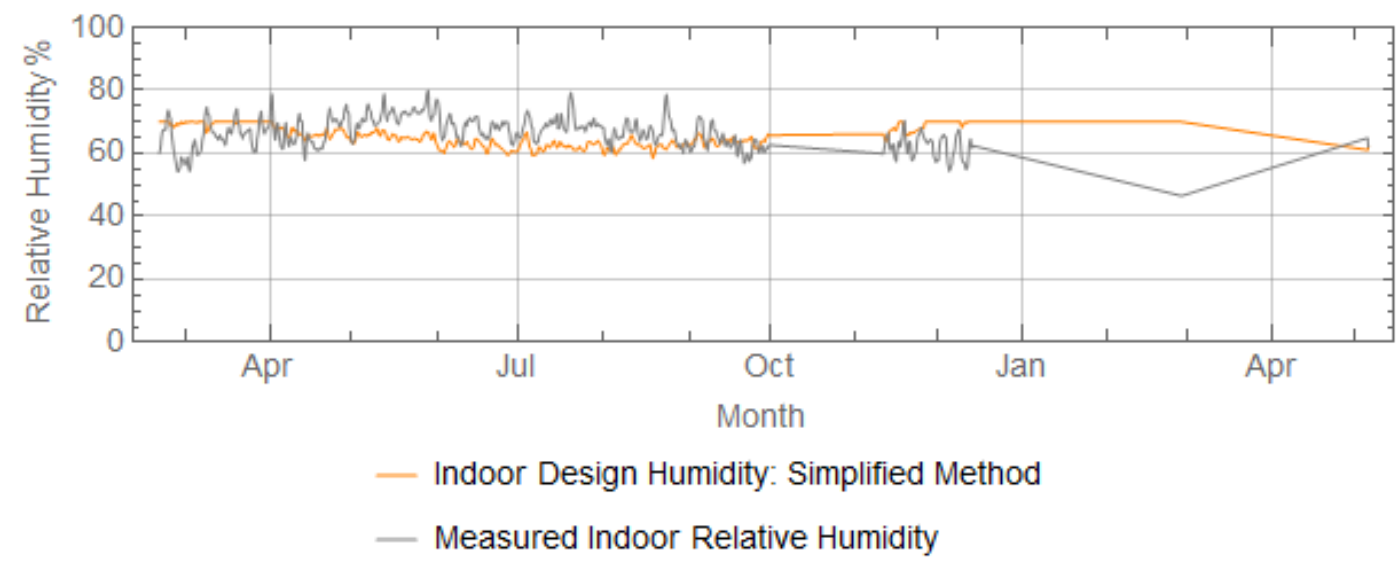

House 116

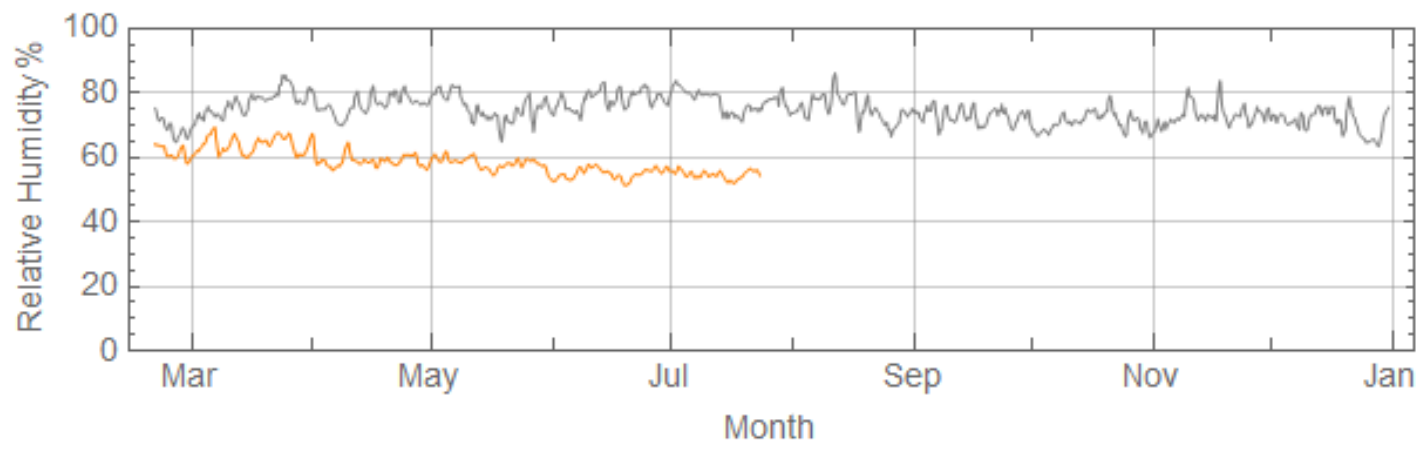

House 124

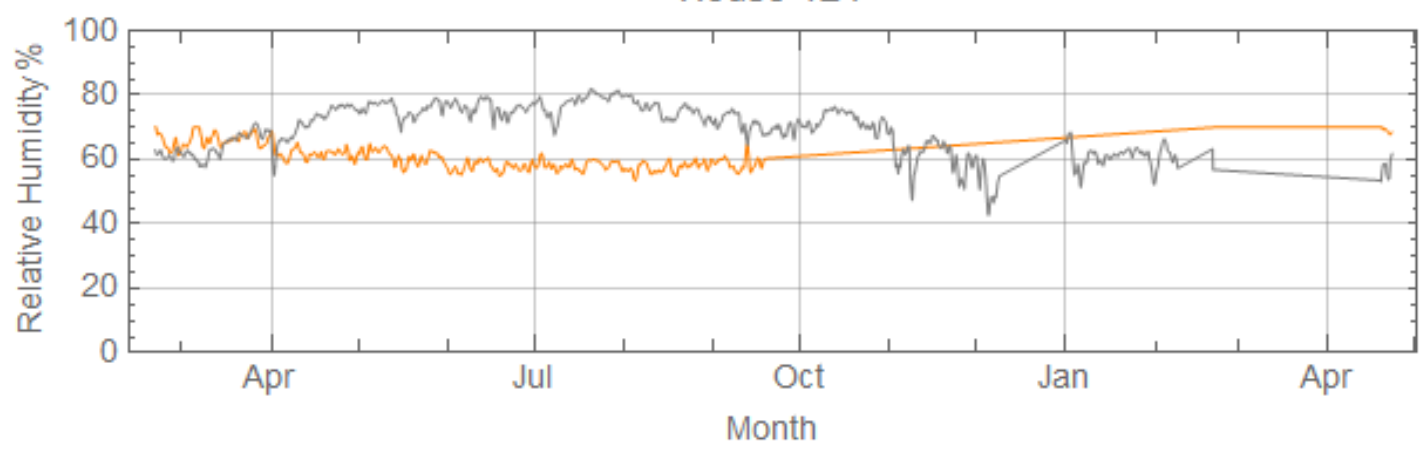


House 126

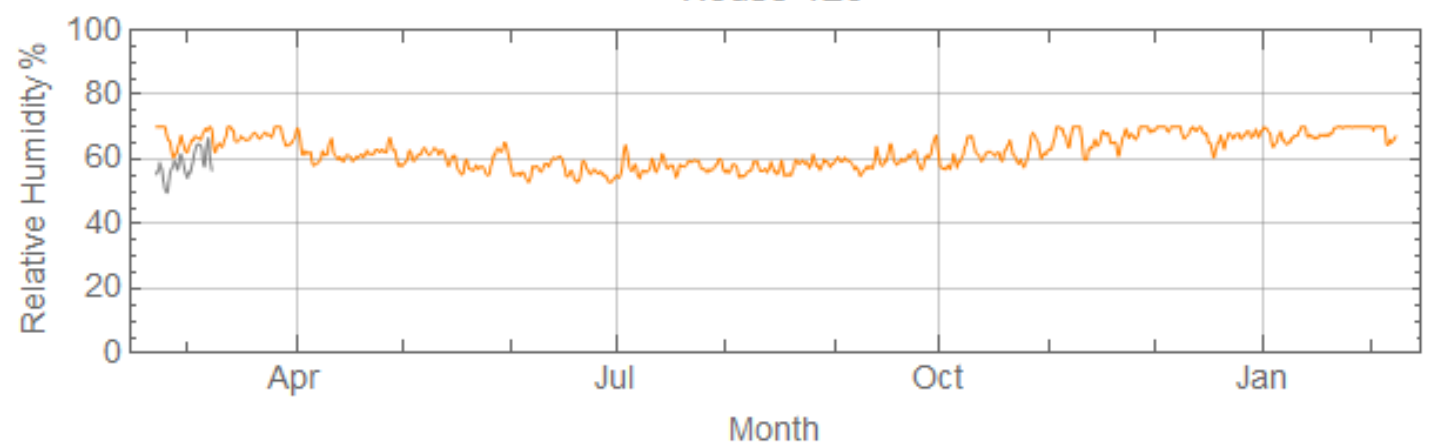

House 138

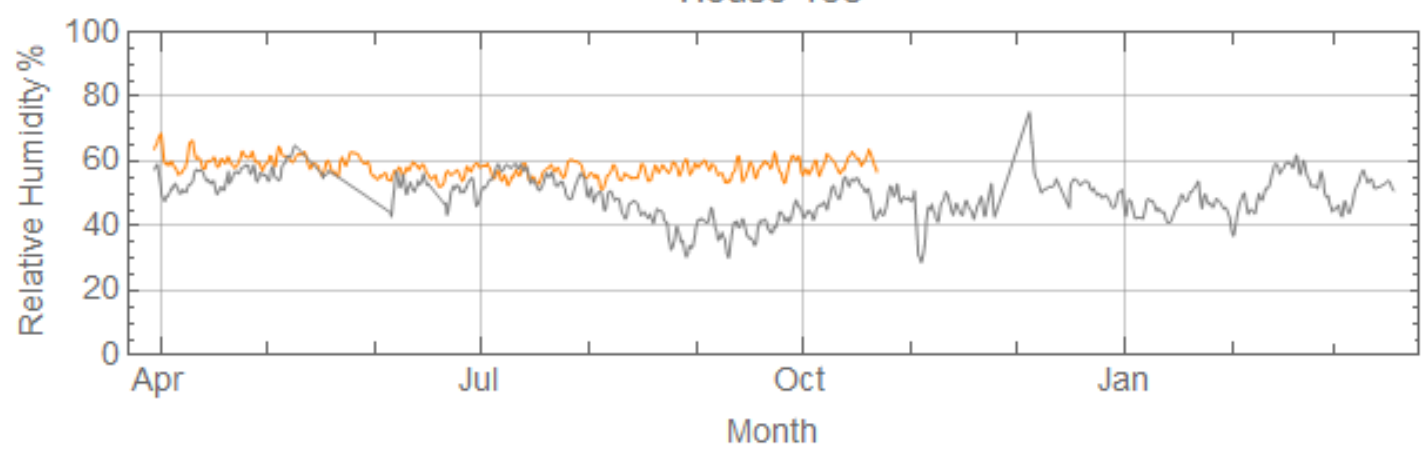

House 139

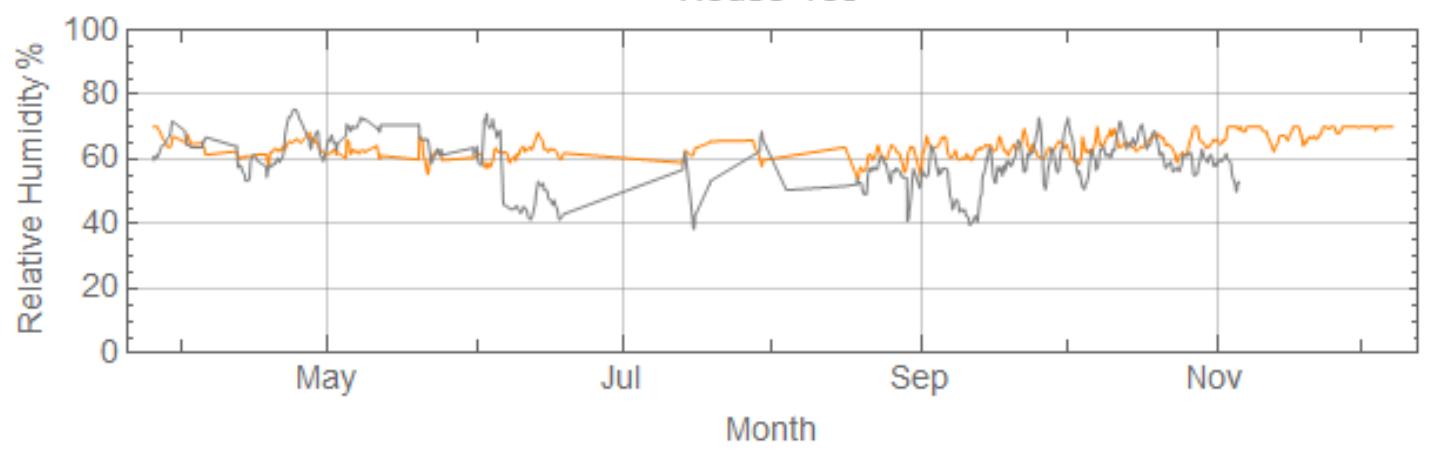

House 144

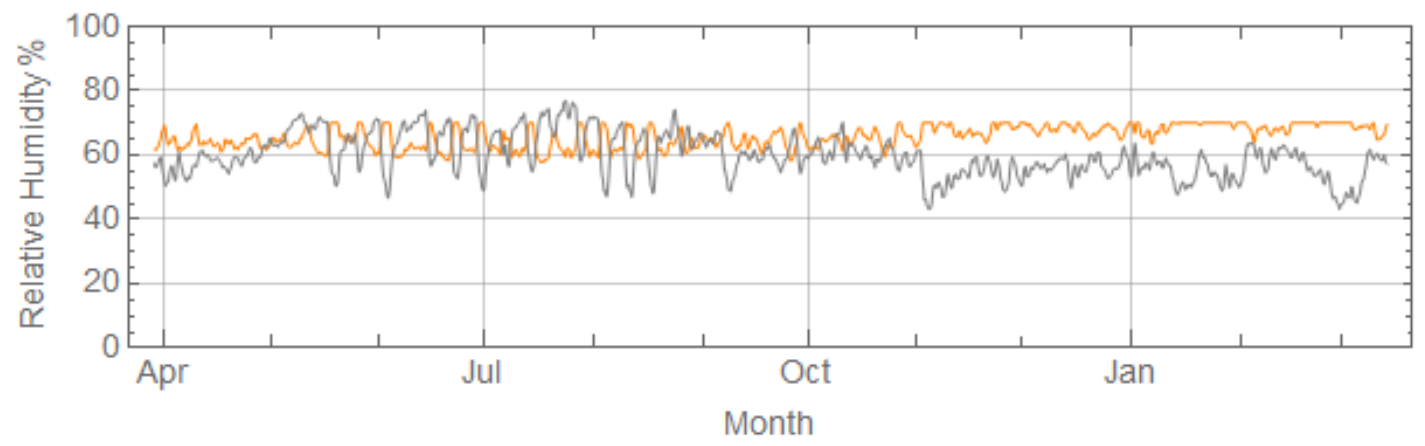


House 145

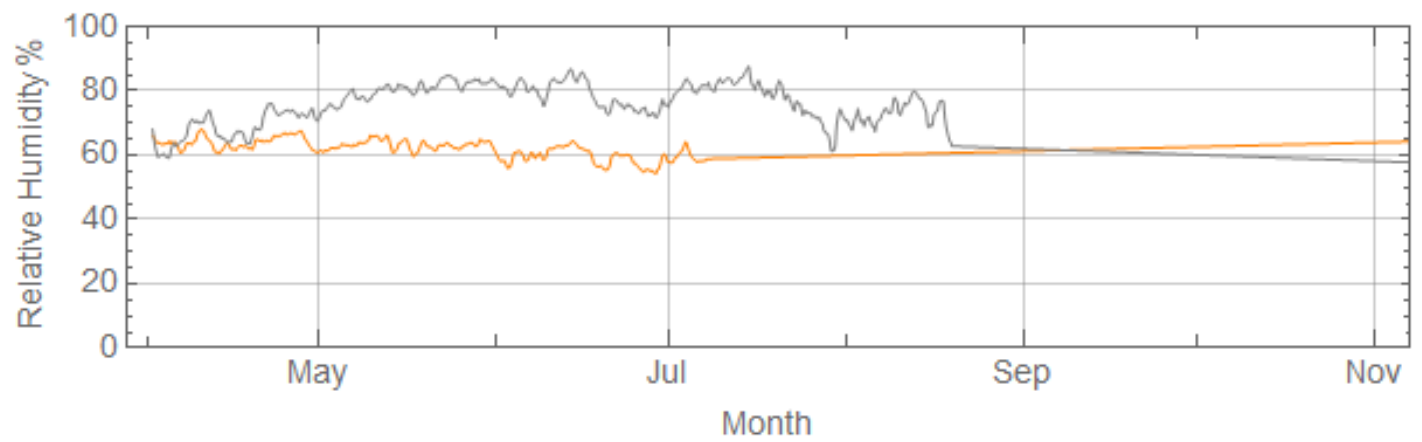

House 151

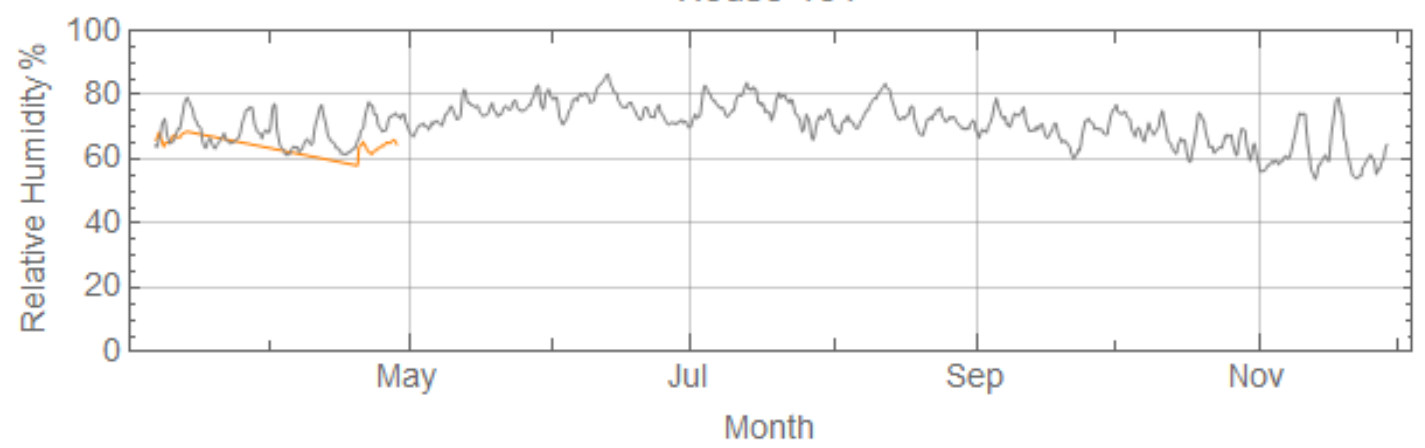

House 169

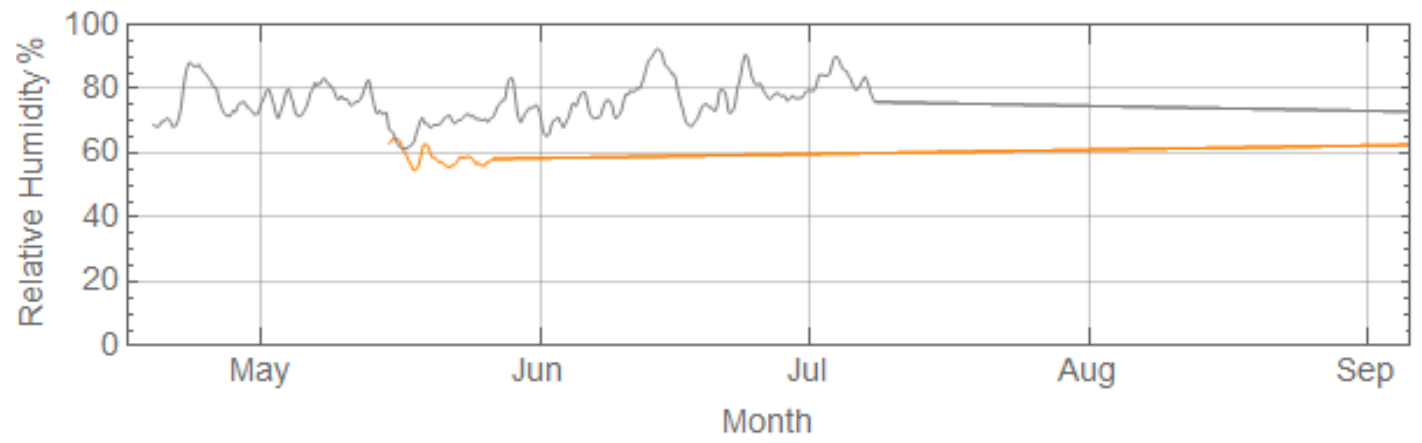




\subsection{Appendix G}

Application of Indoor Design Humidity: Simplified Method as outlined in ASHRAE Standard 160 showing Trend 4

House 100

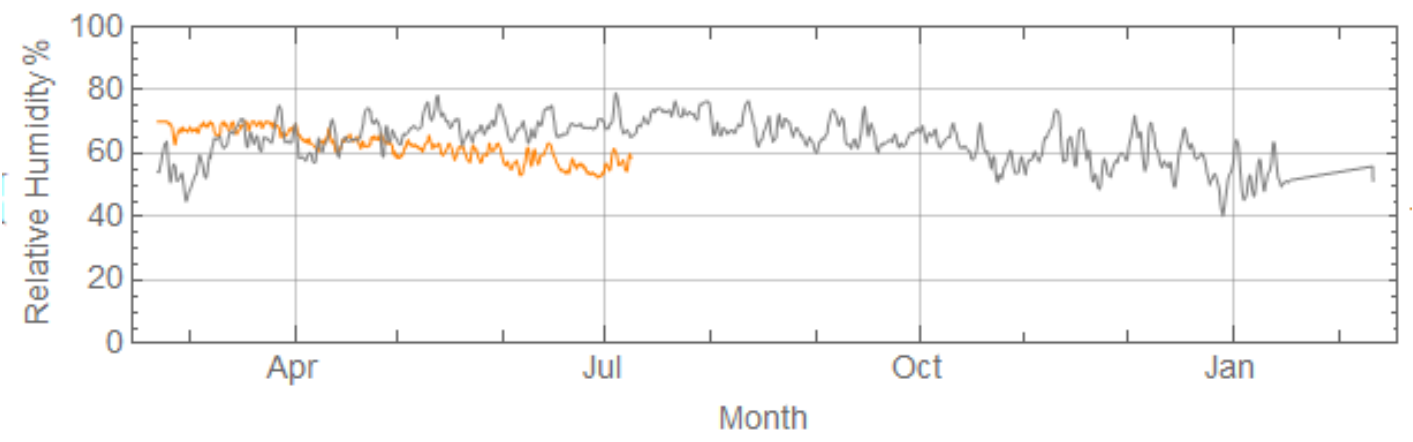

— Indoor Design Humidity: Simplified Method

— Measured Indoor Relative Humidity

House 101

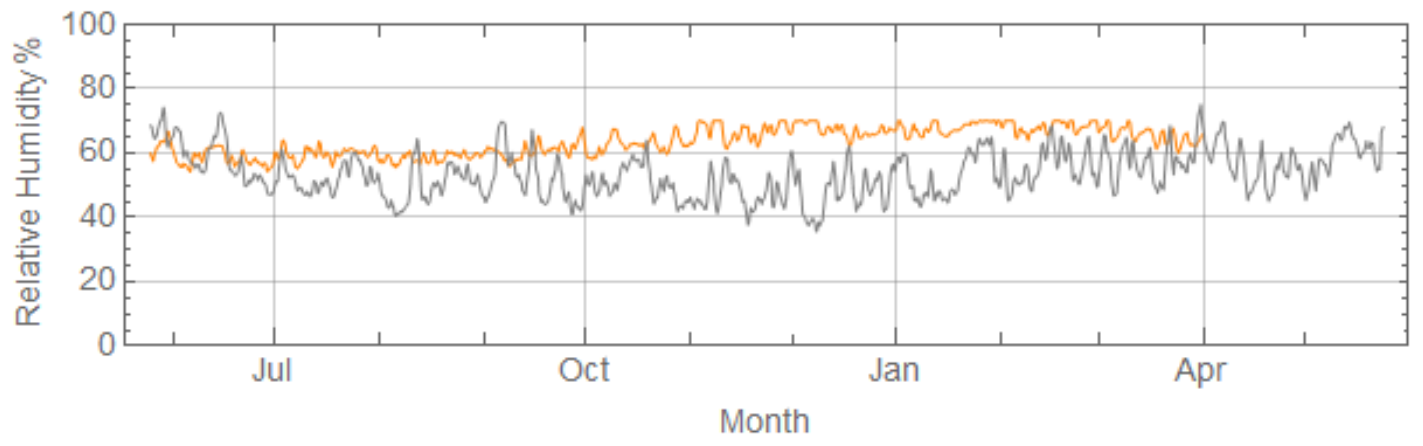

House 103

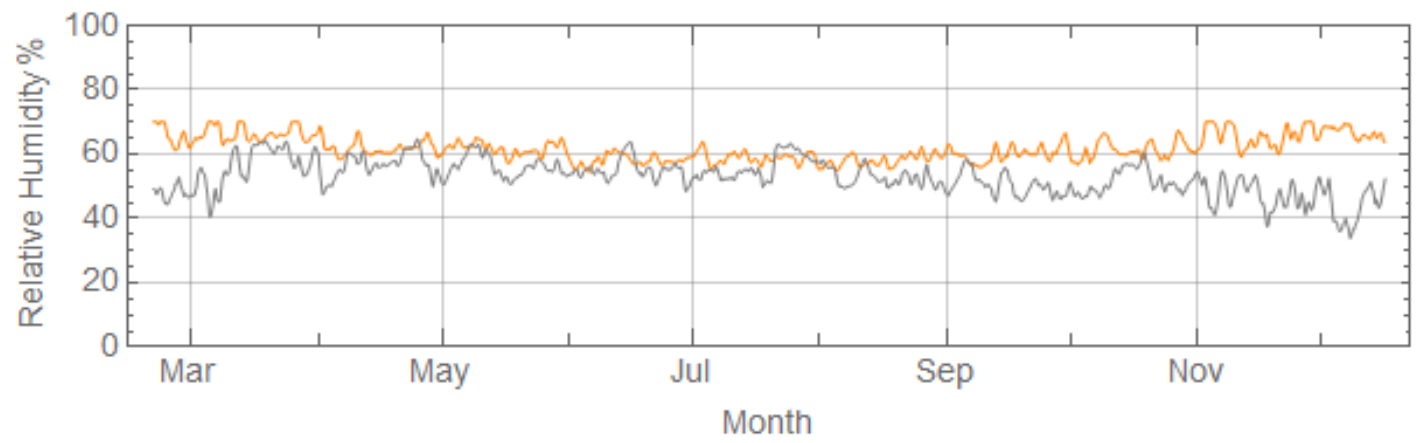


House 113

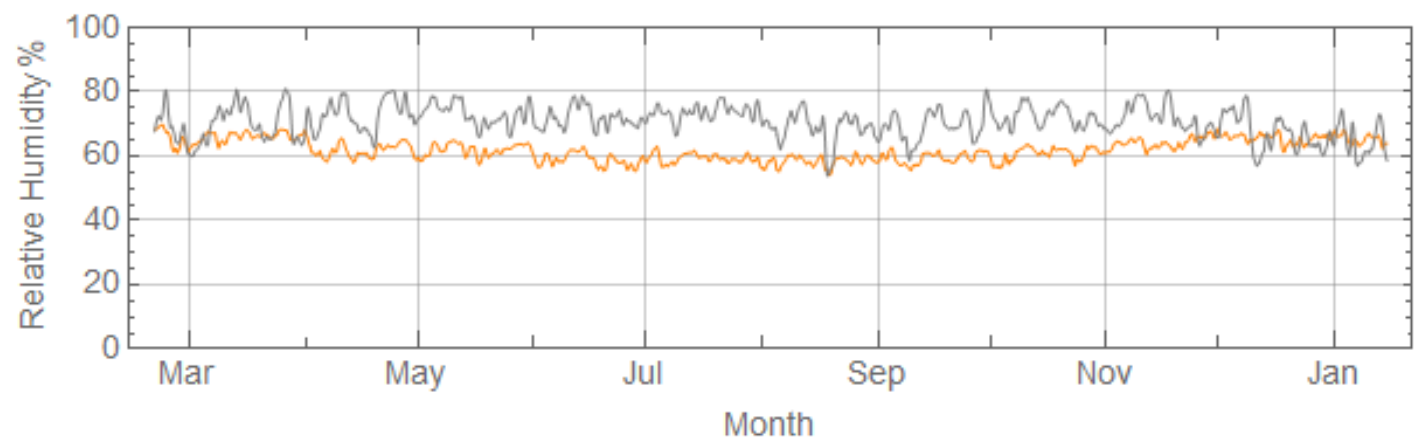

House 125

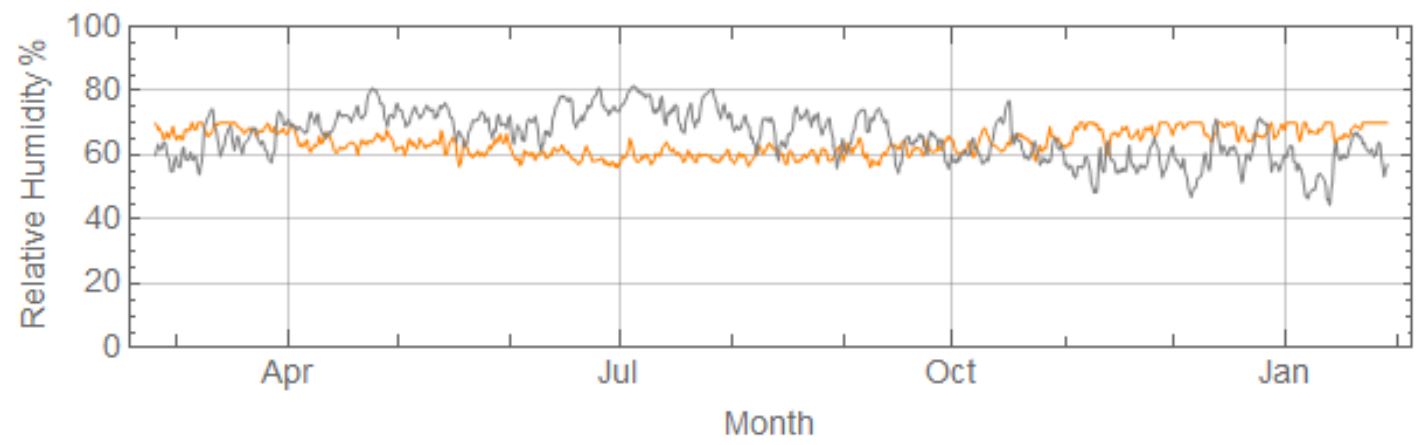

House 129

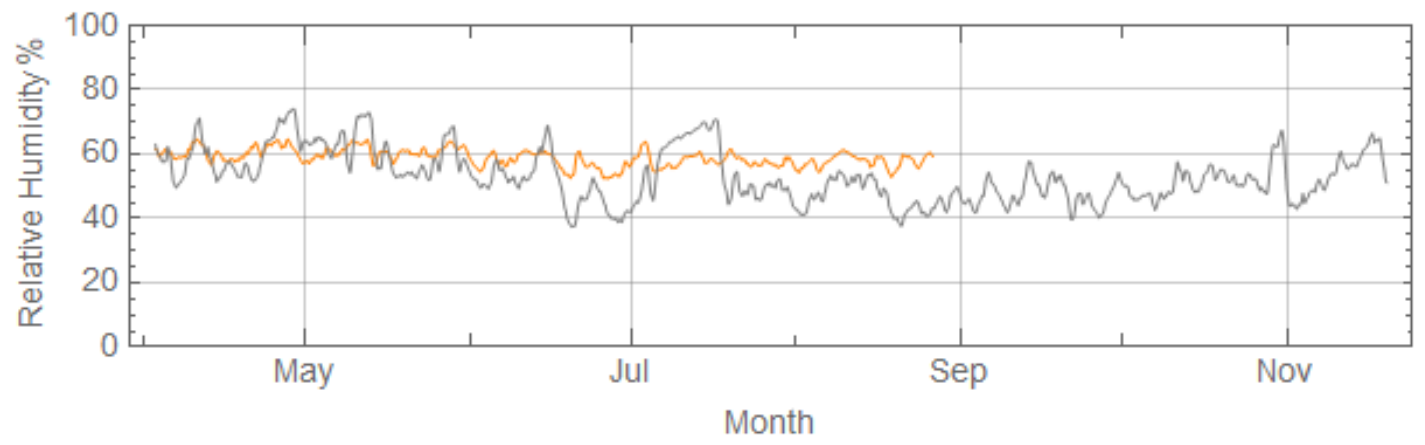

House 142

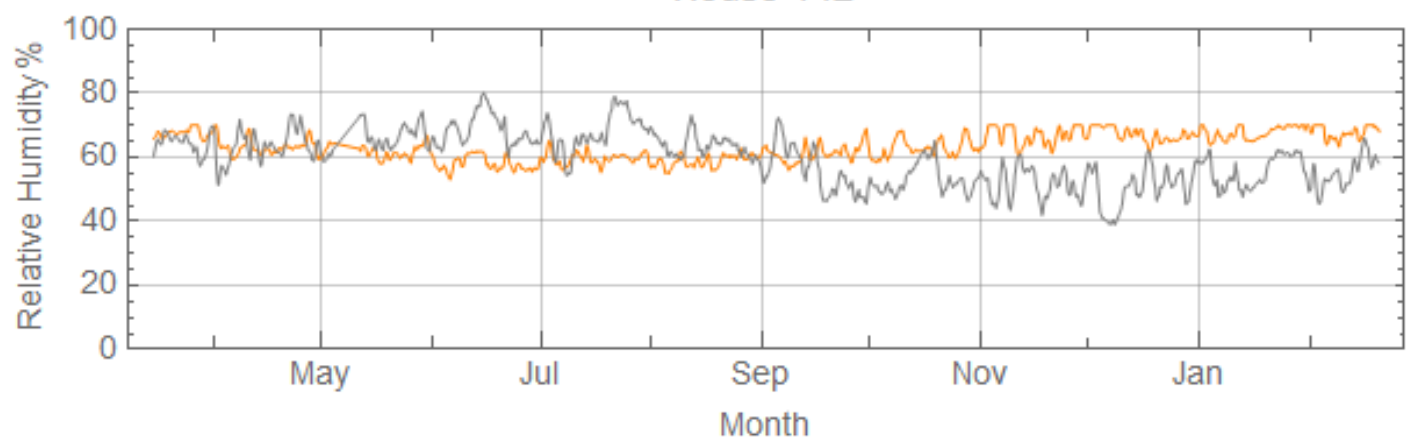


House 150

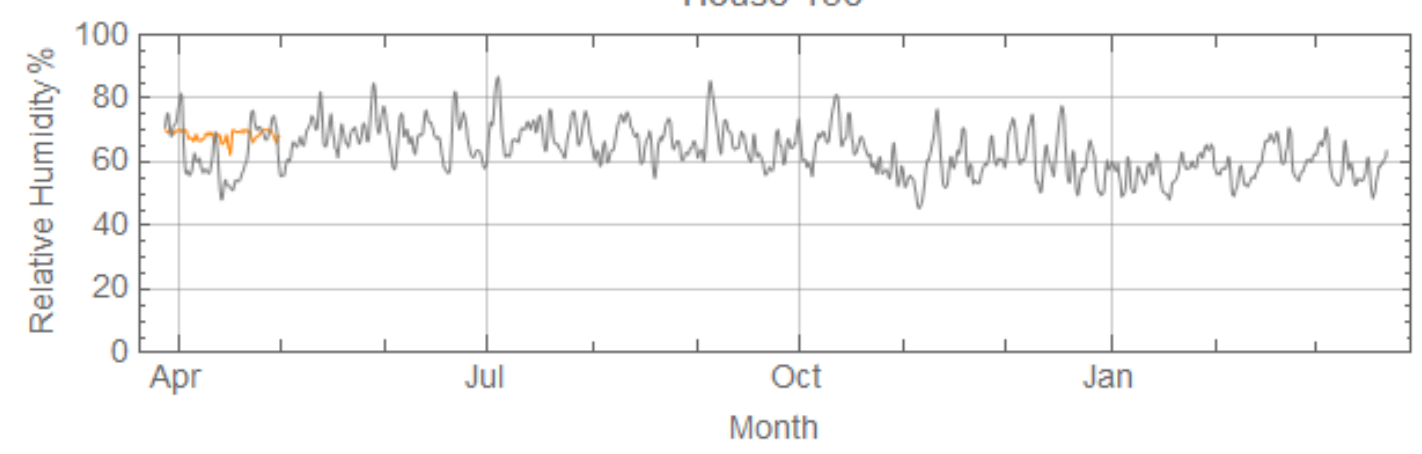

House 156

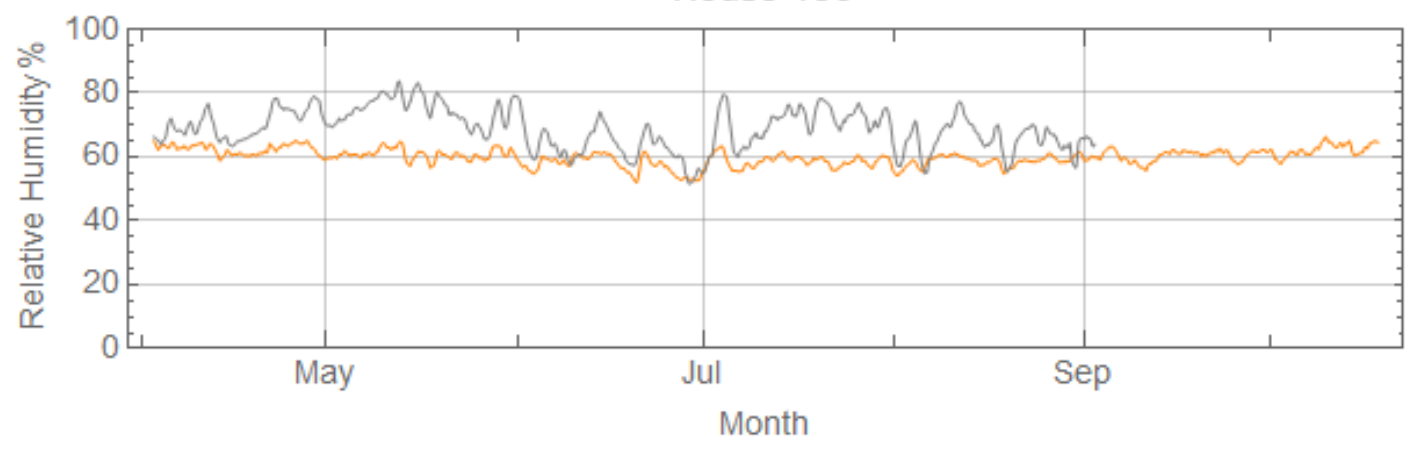




\subsection{Appendix H}

Application of Indoor Design Humidity: Intermediate Method as outlined in ASHRAE Standard 160

House 100

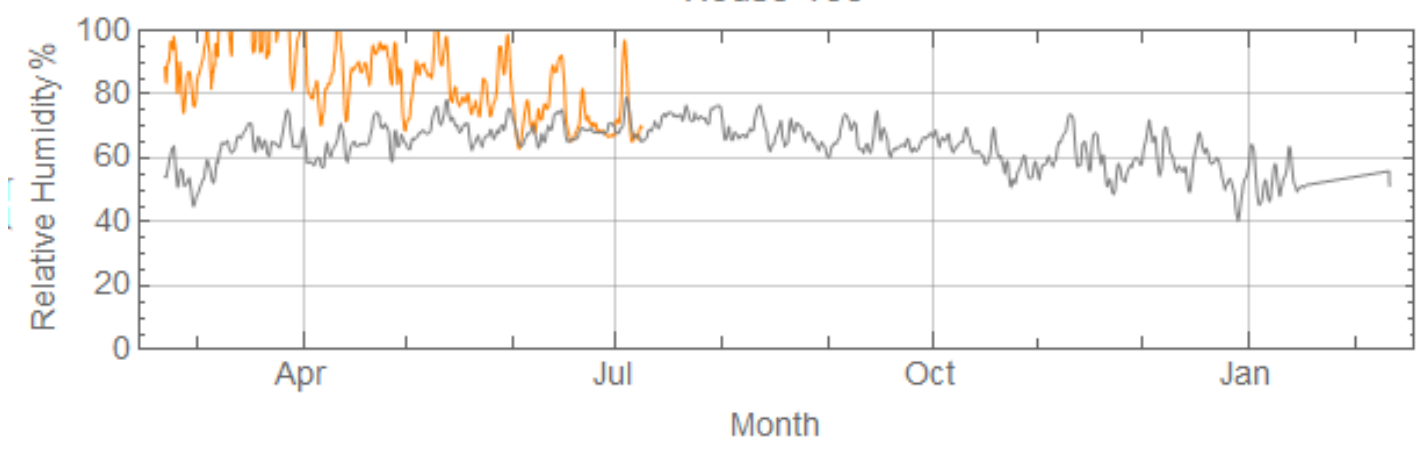

— Indoor Design Humidity: Intermediate Method

— Measured Indoor Relative Humidity

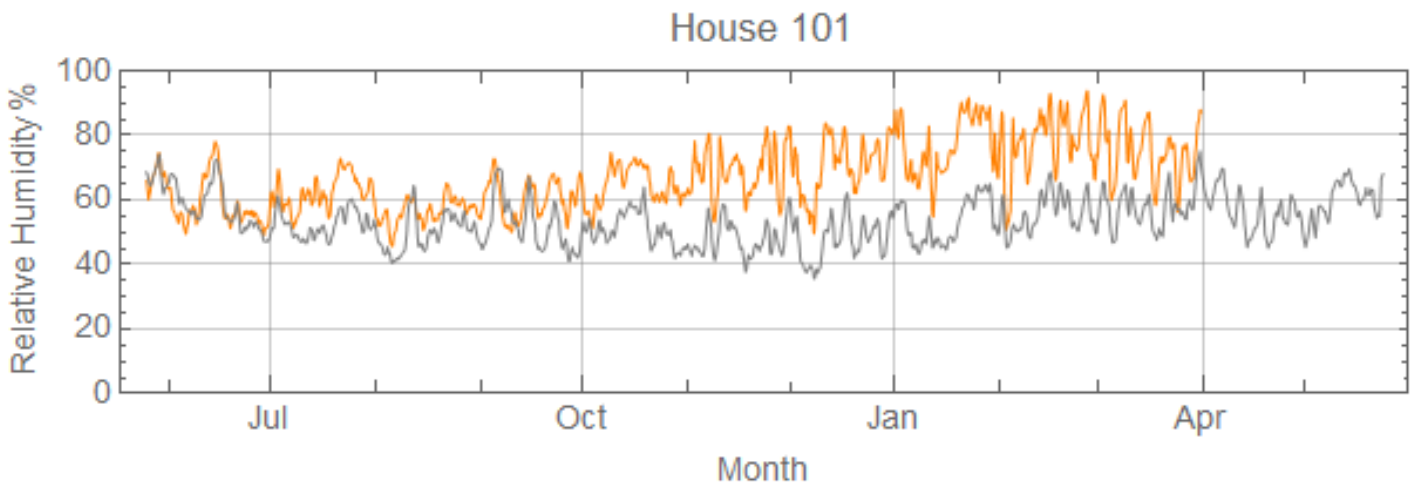

House 103

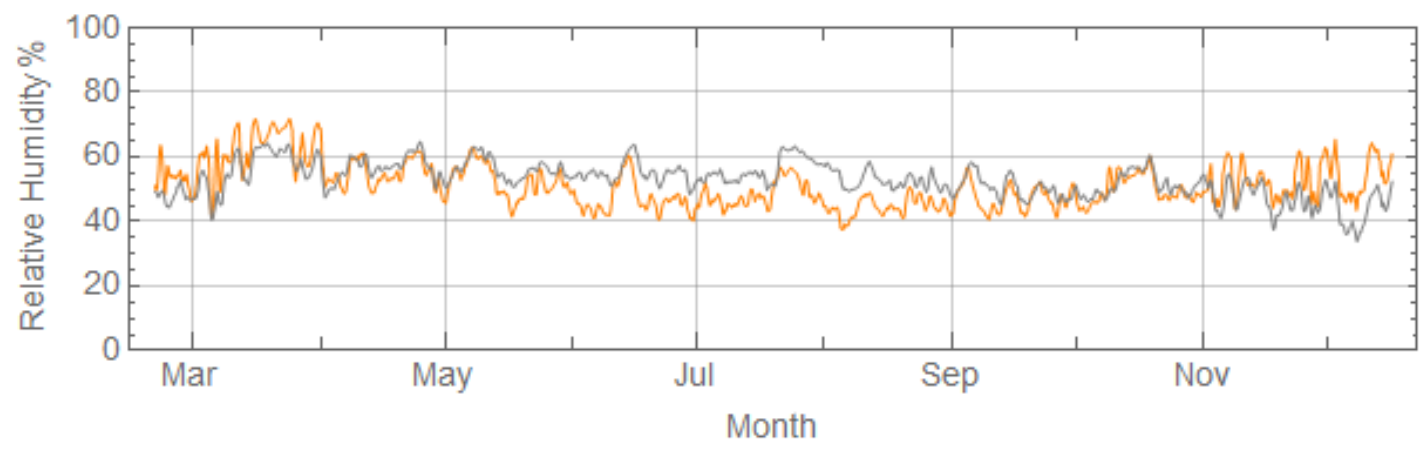


House 104

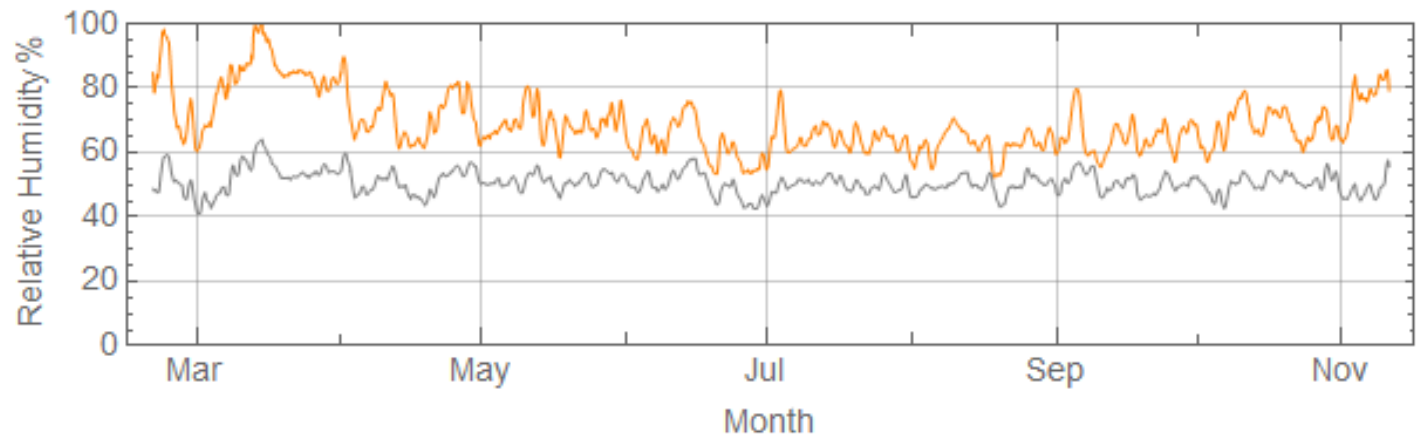

House 106

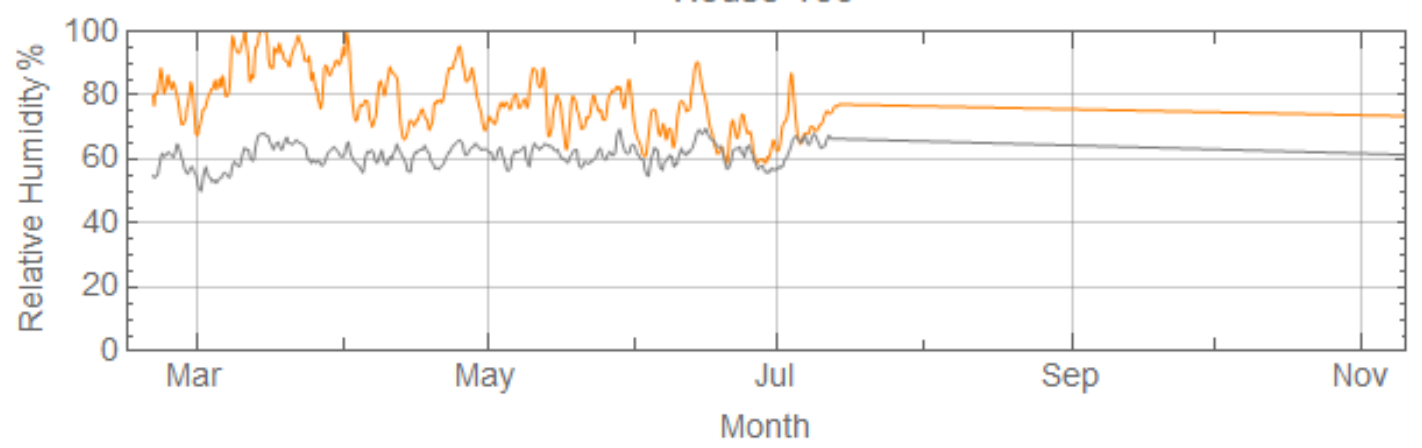

House 110

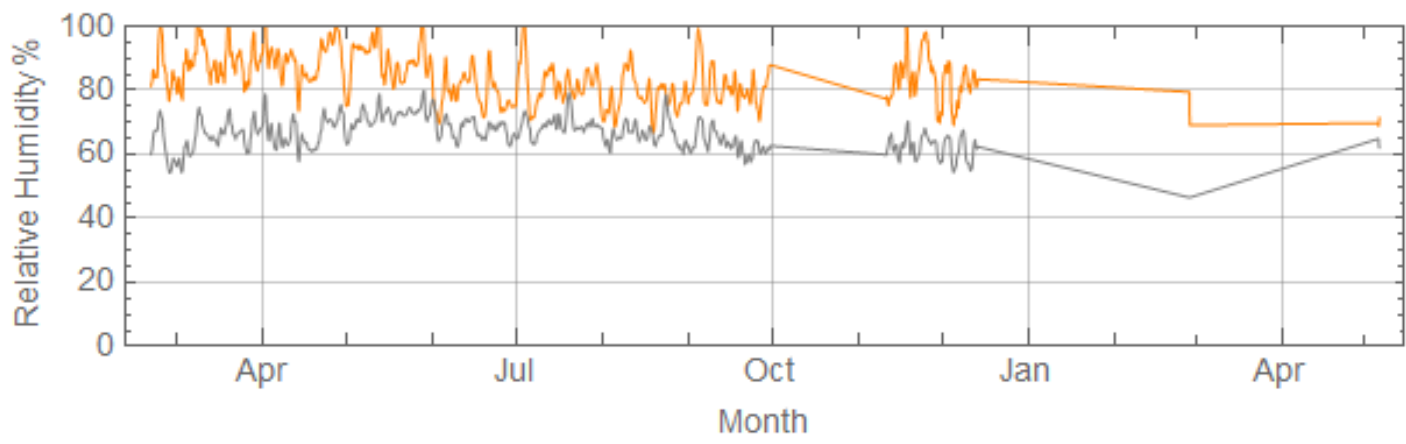

House 111

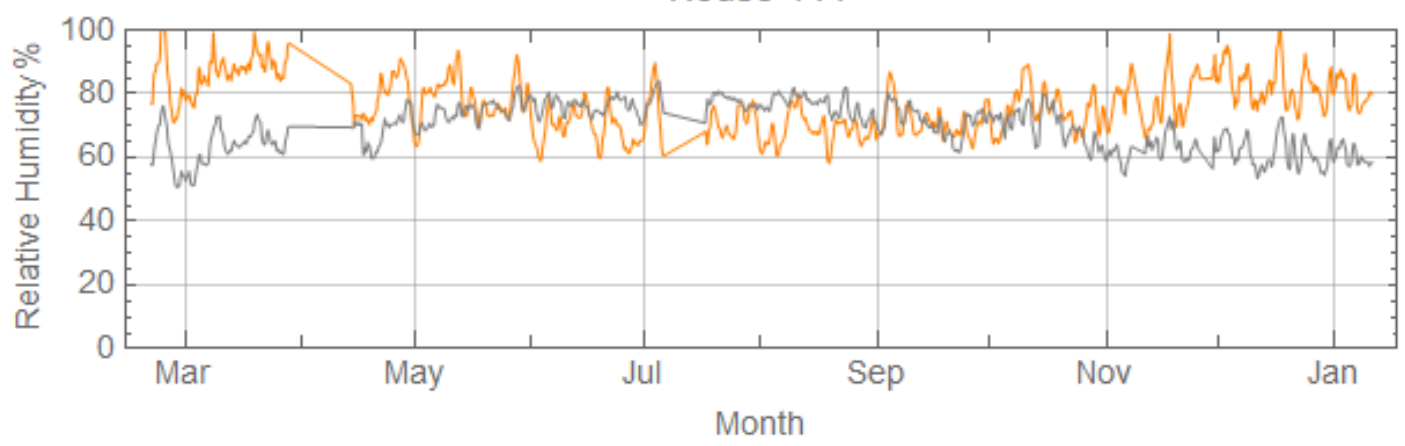


House 113

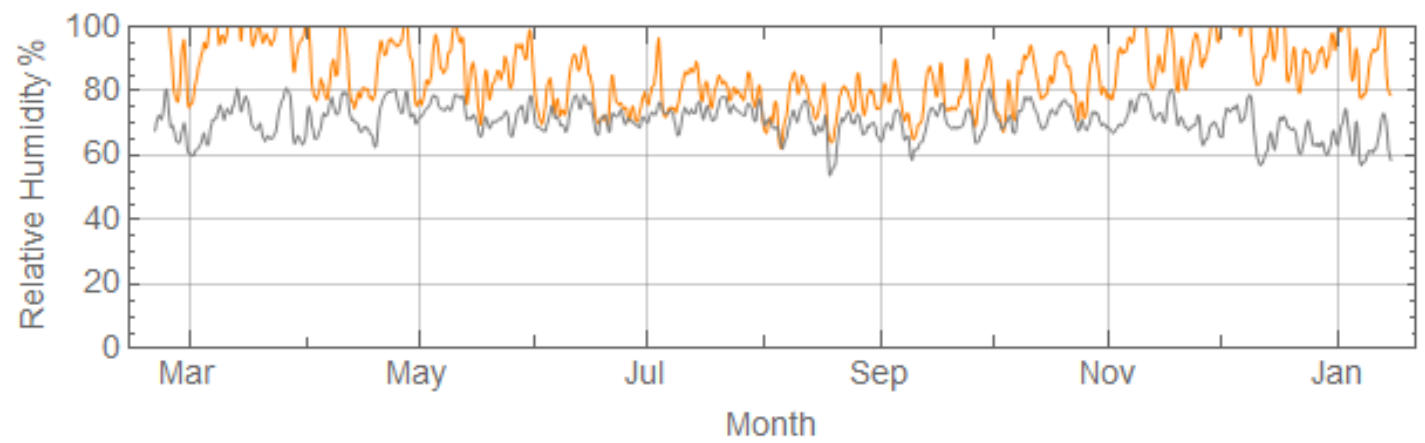

House 116

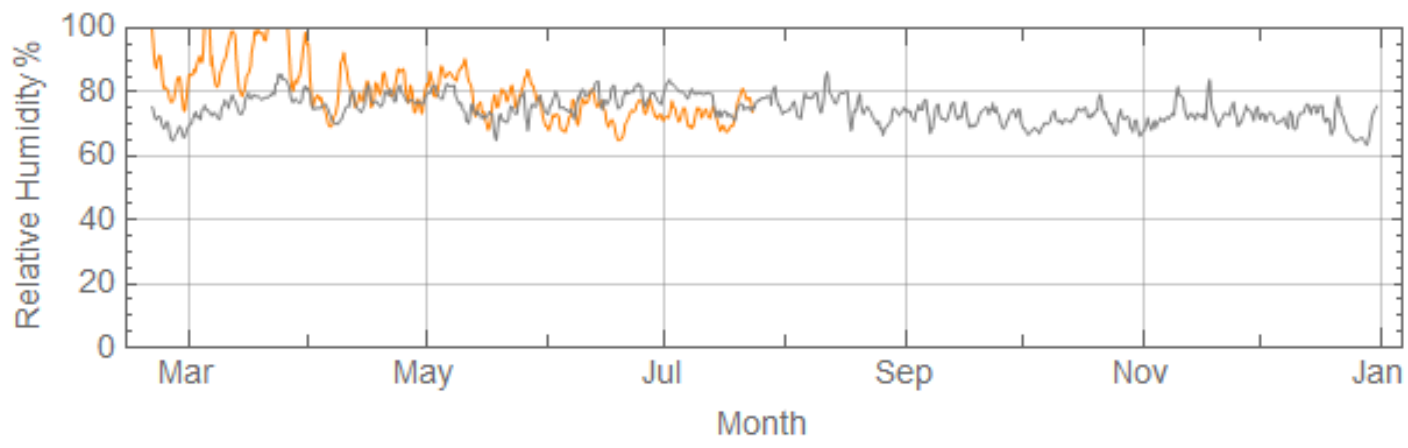

House 117

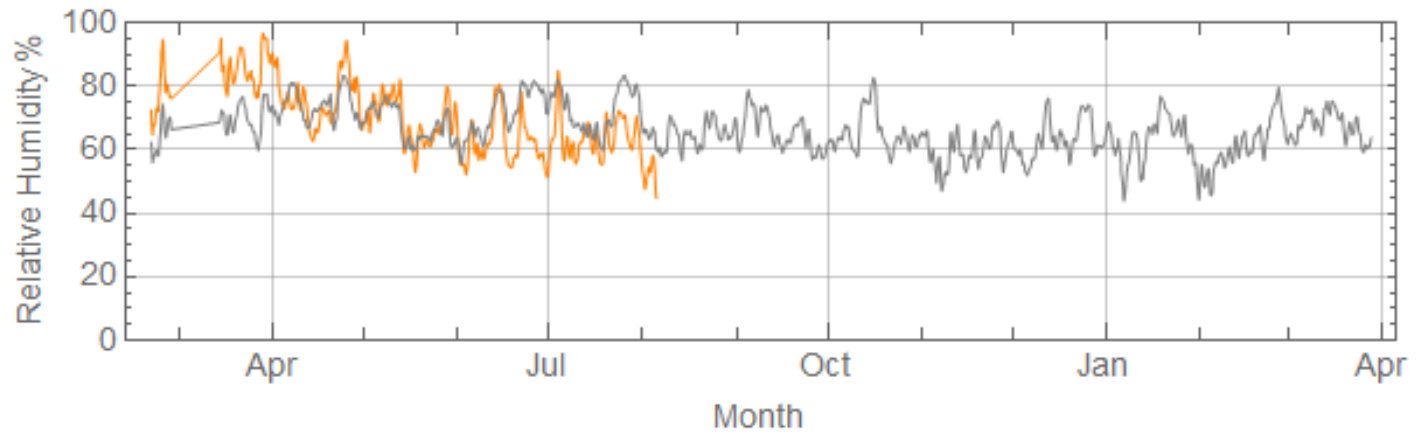

House 120

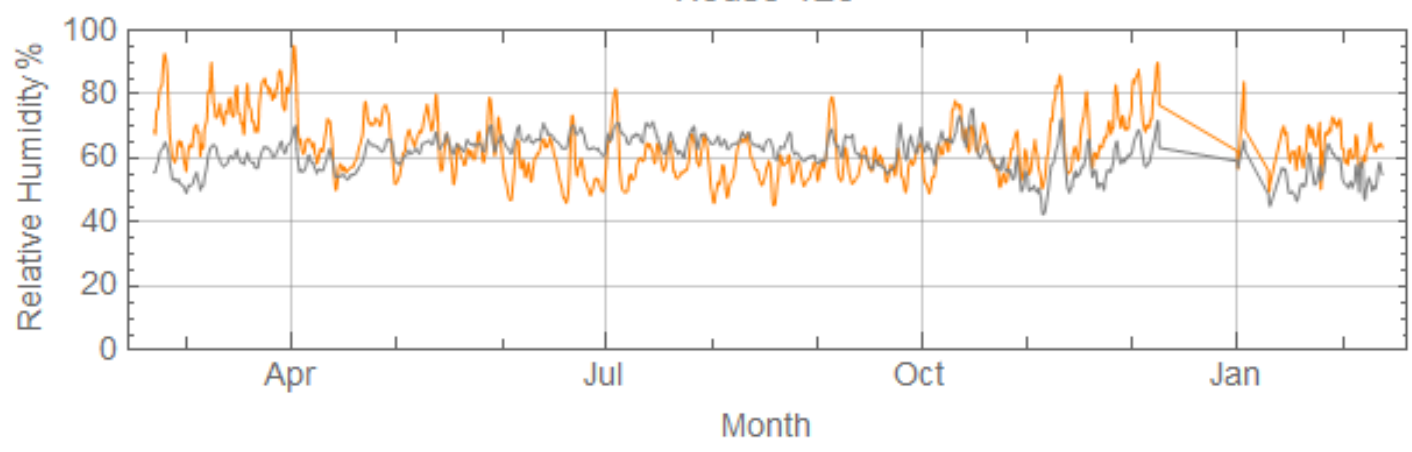


House 121

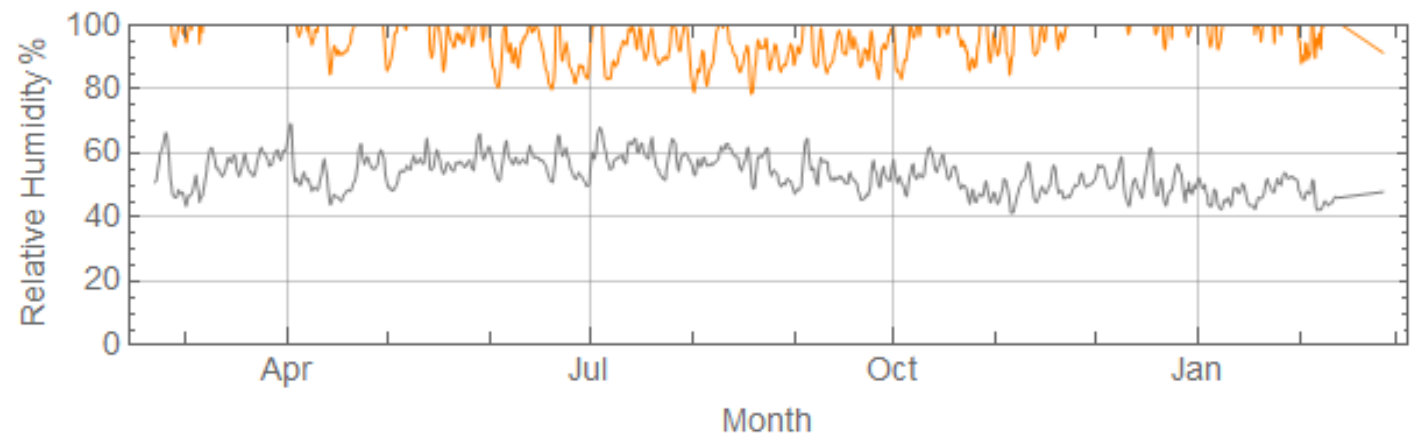

House 124

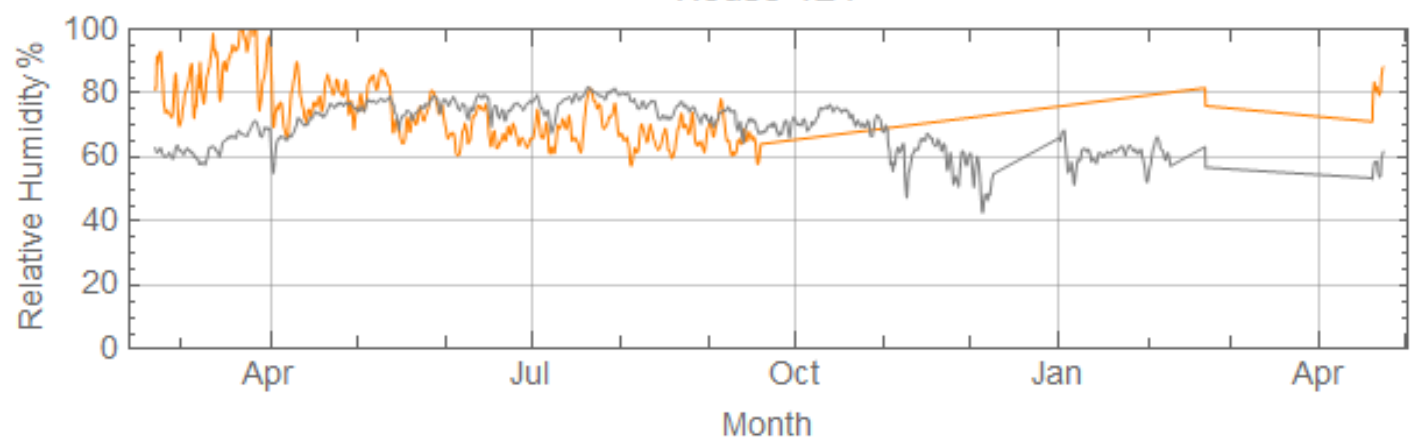

House 125

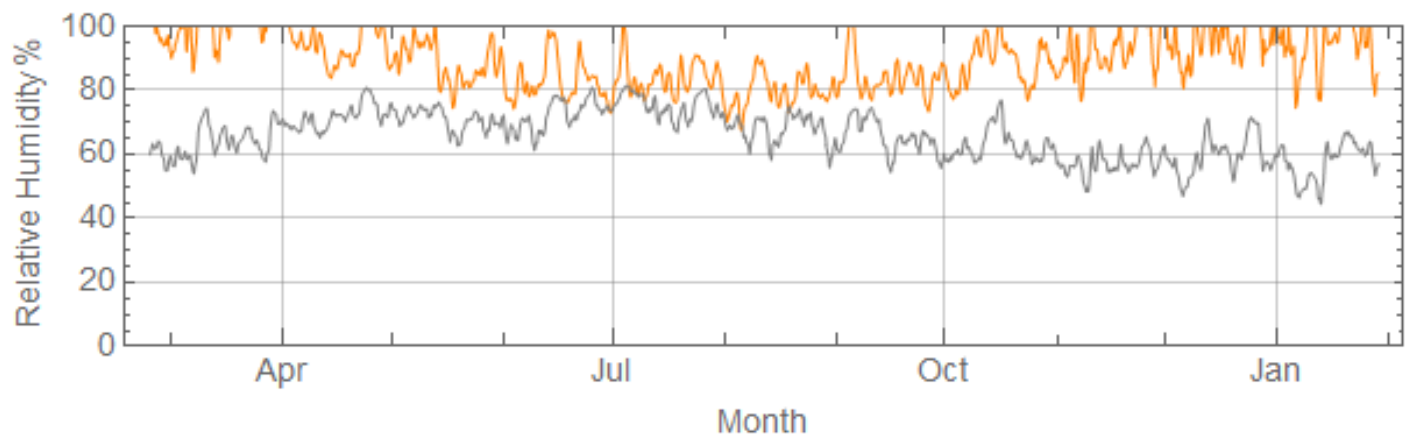

House 128

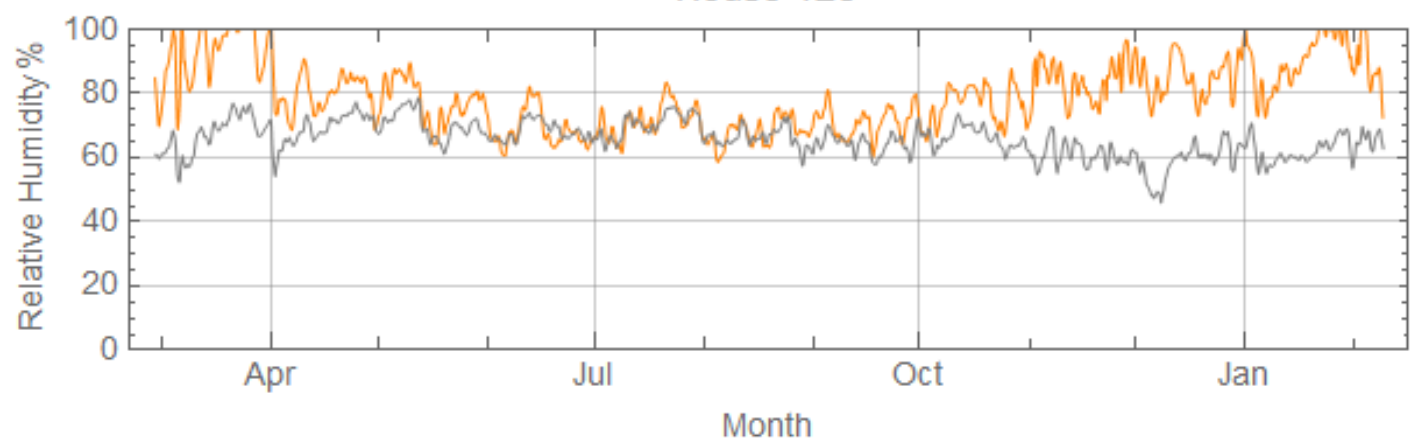


House 129

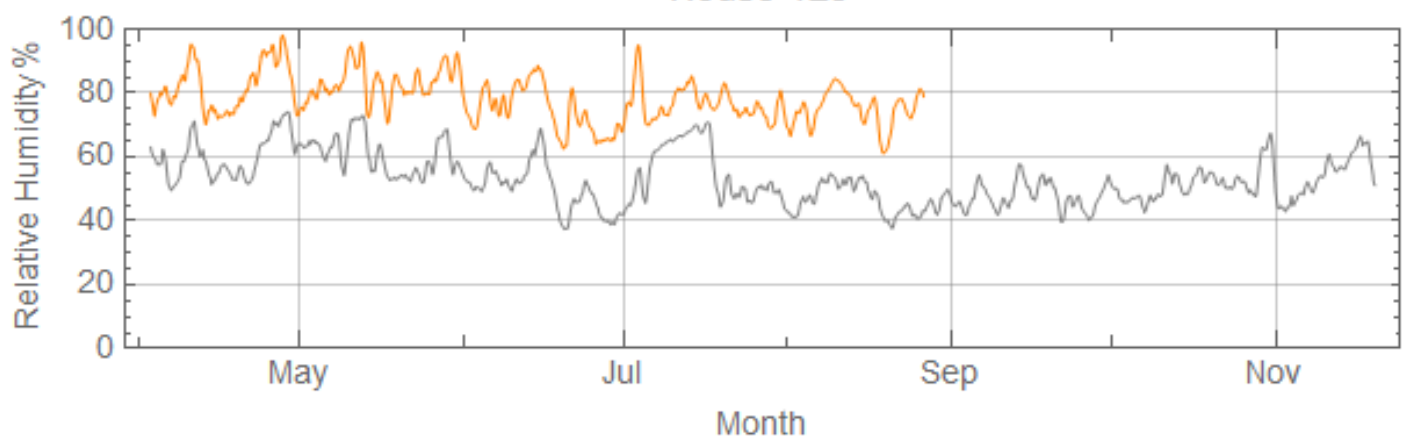

House 130

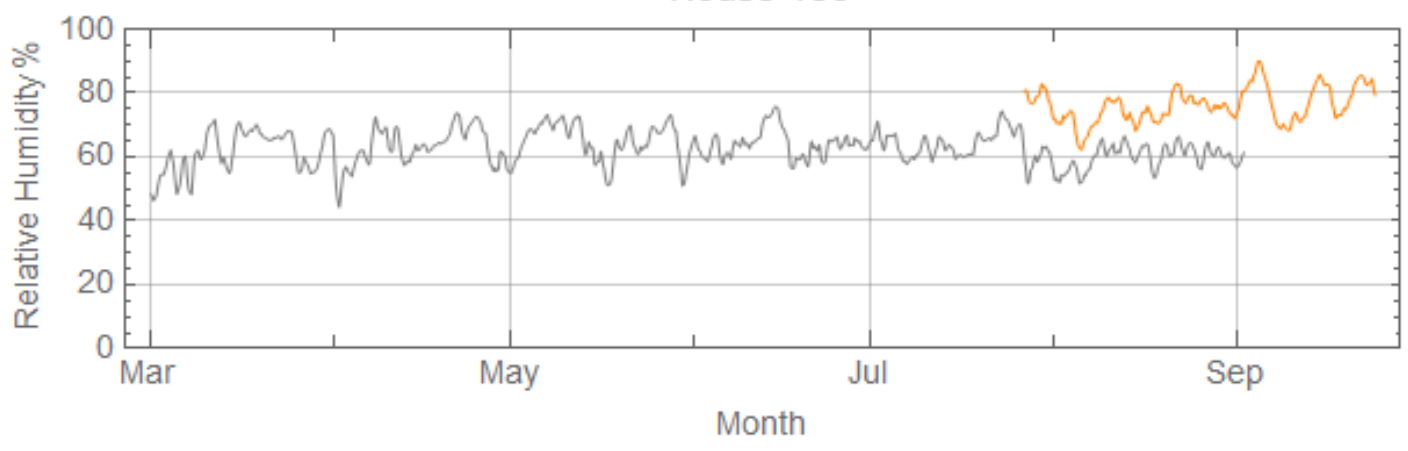

House 135

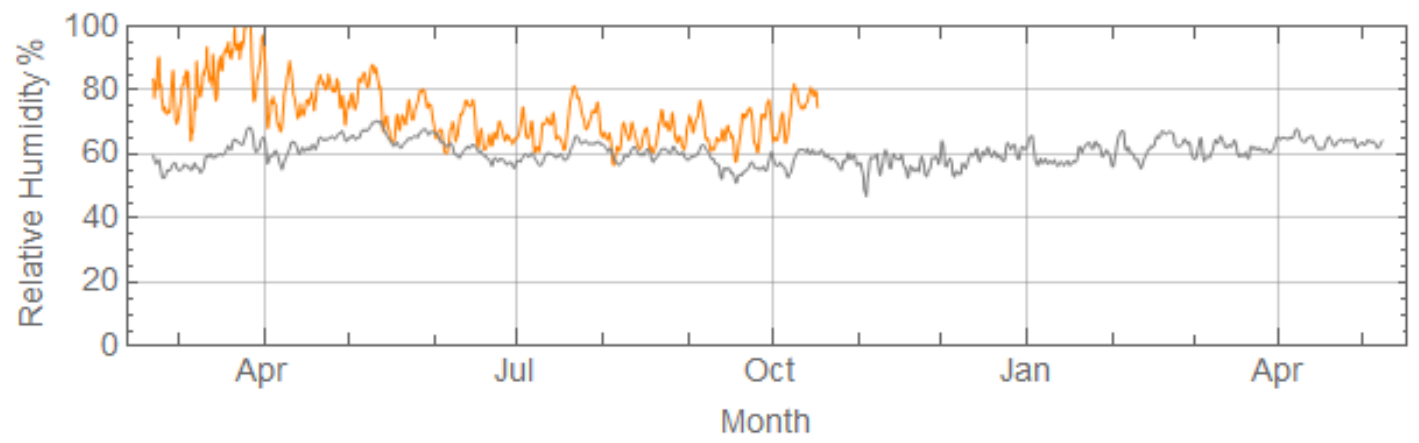

House 136

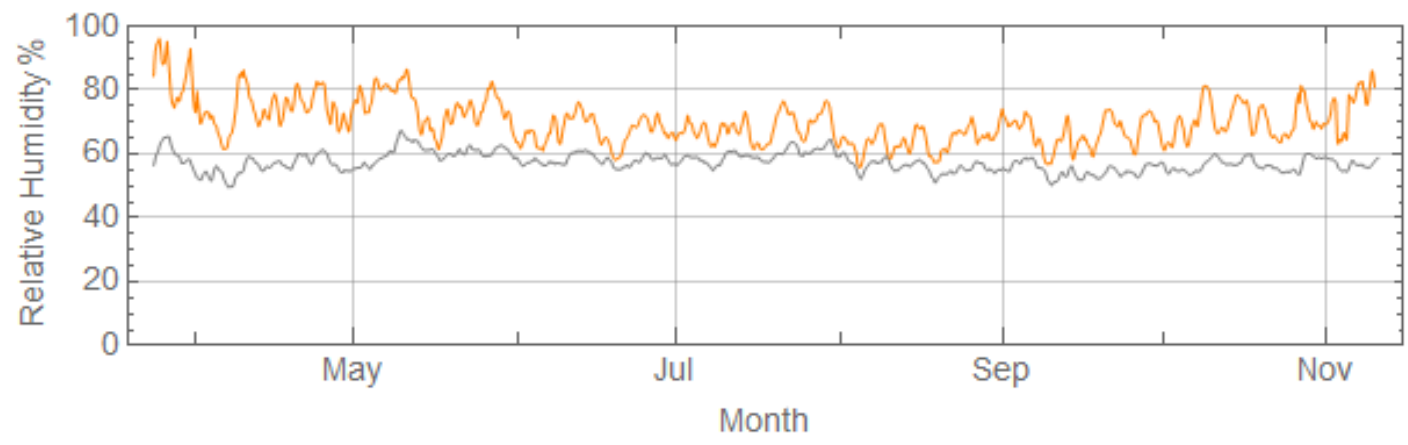


House 137

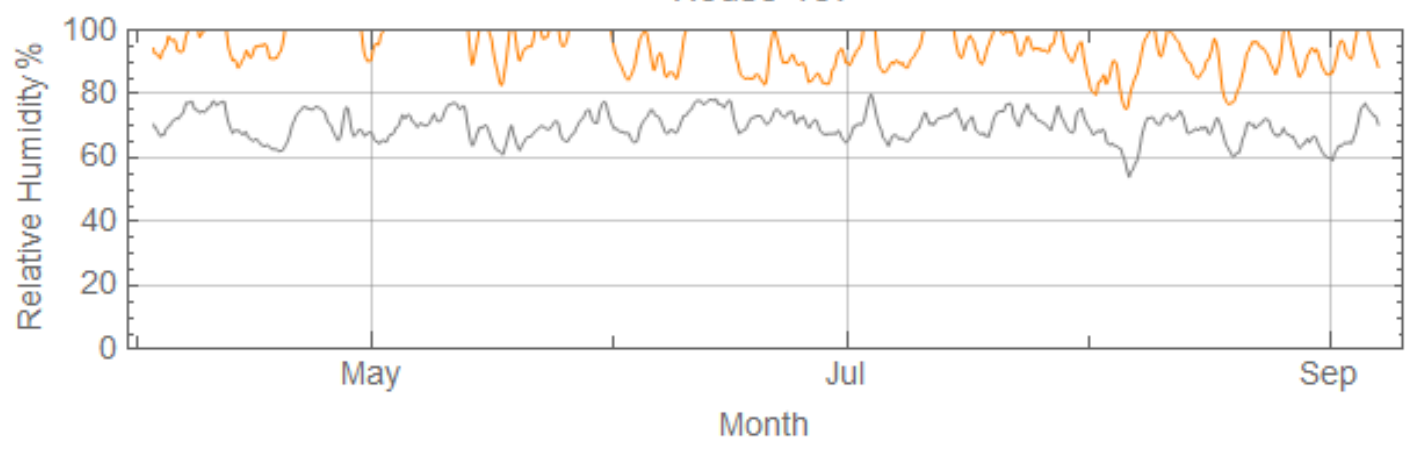

House 138

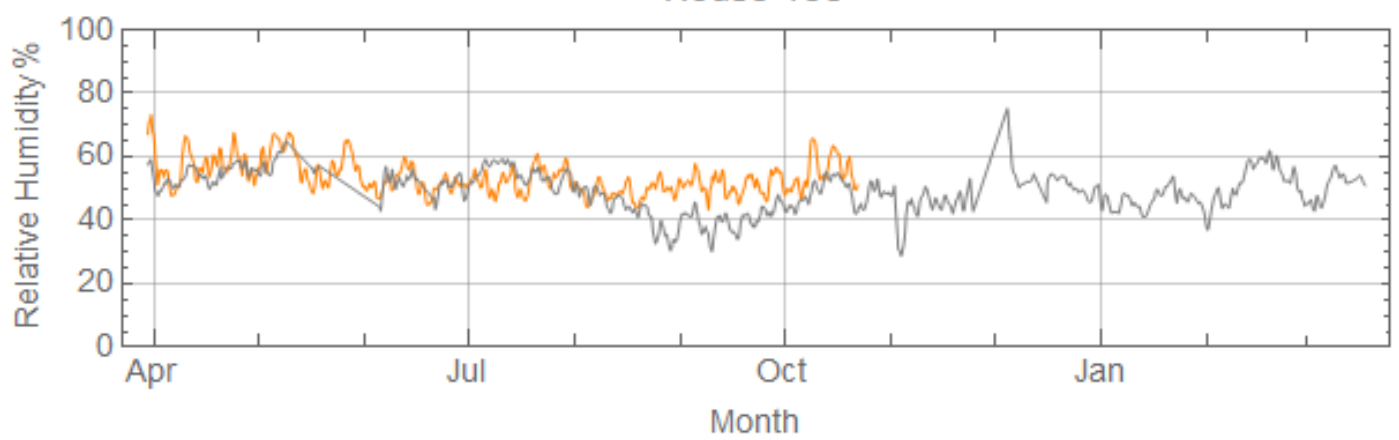

House 139

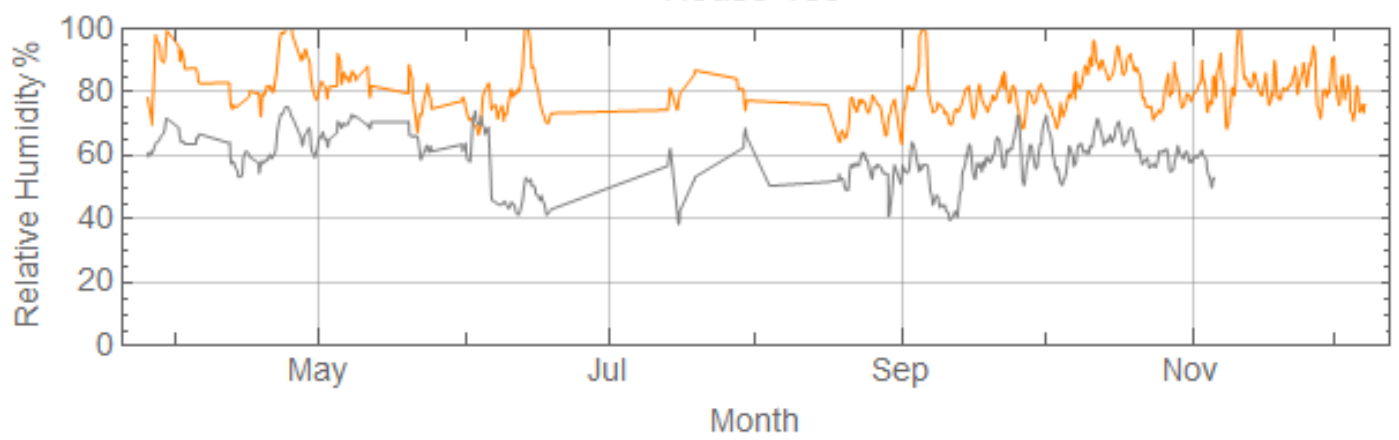

House 140

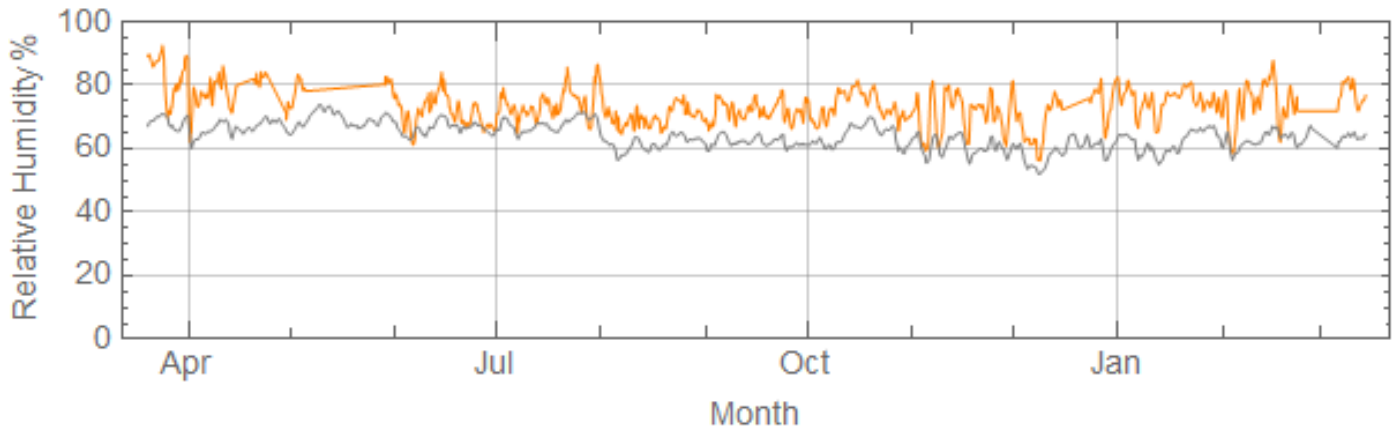


House 142

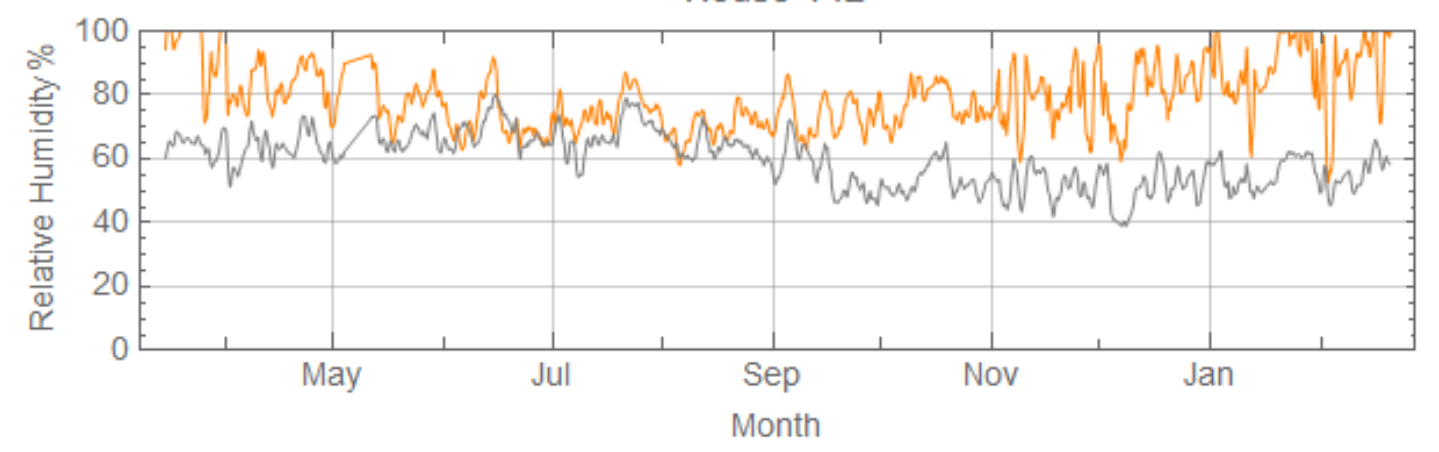

House 143

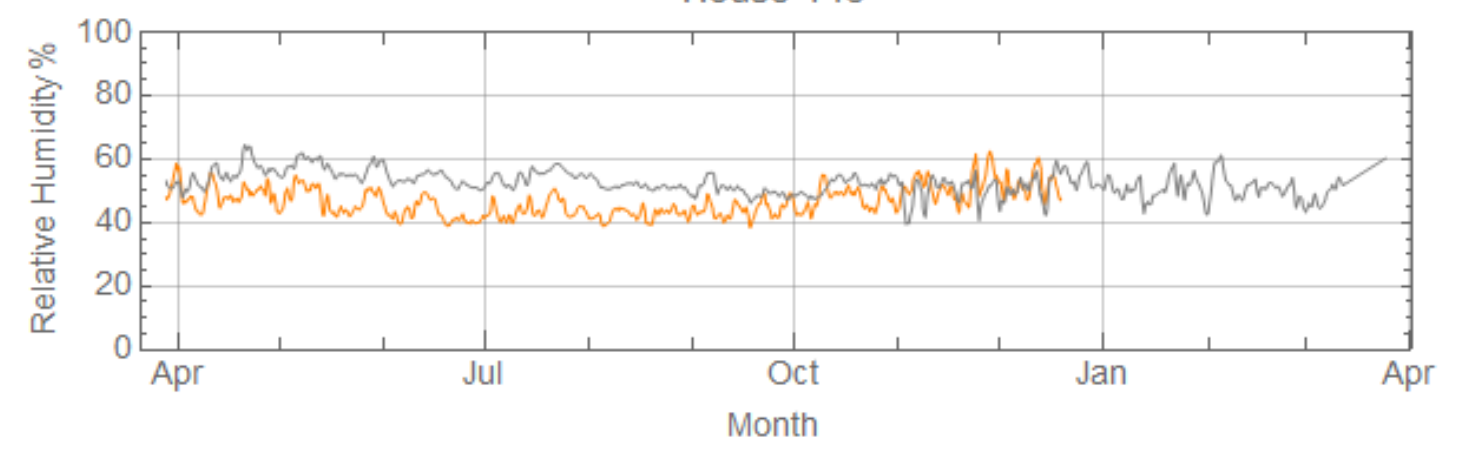

House 144

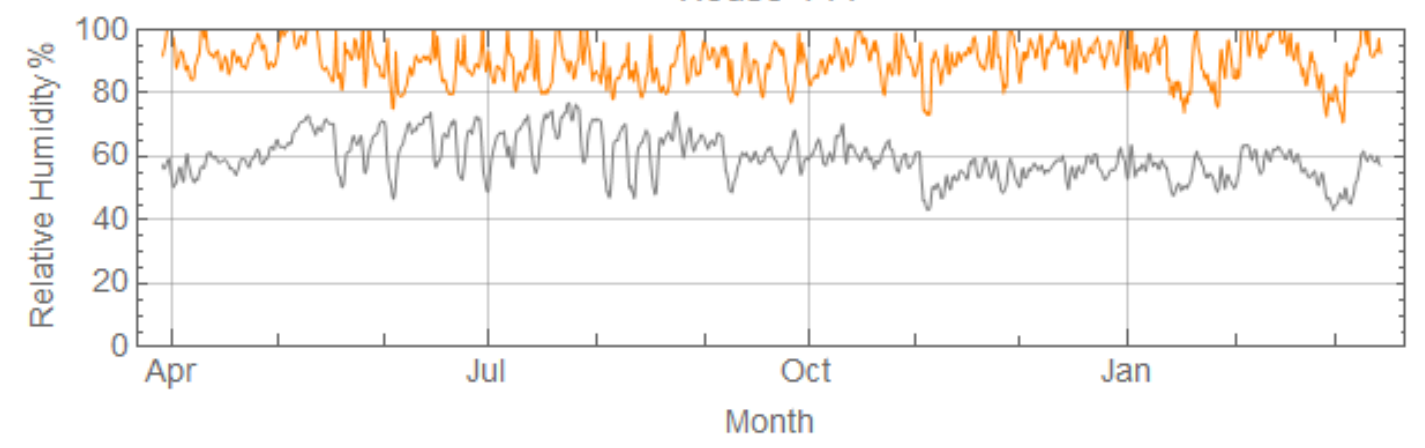

House 145

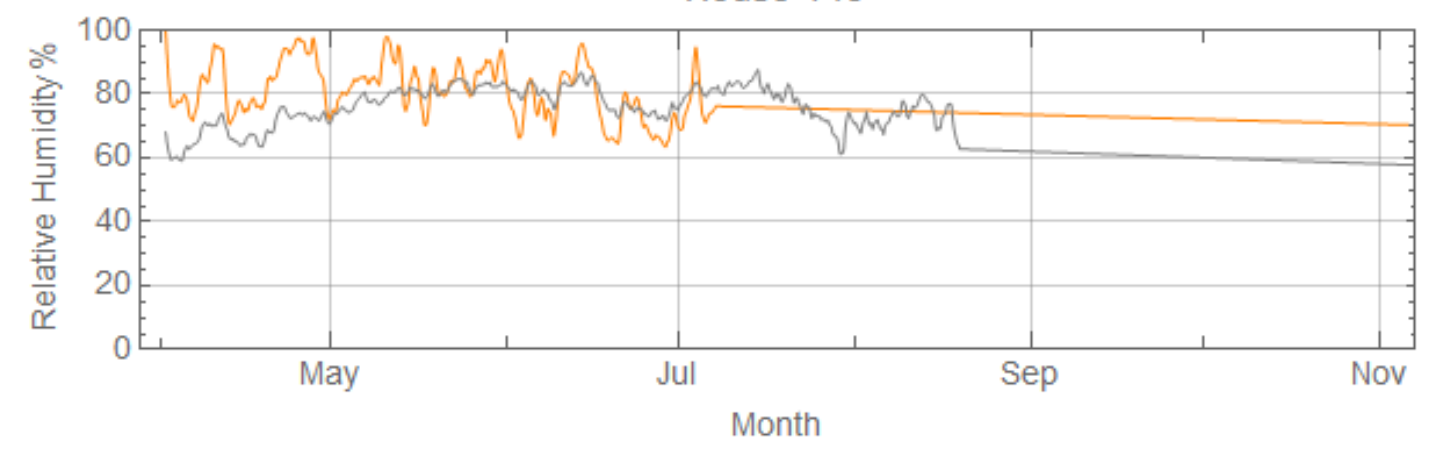


House 148

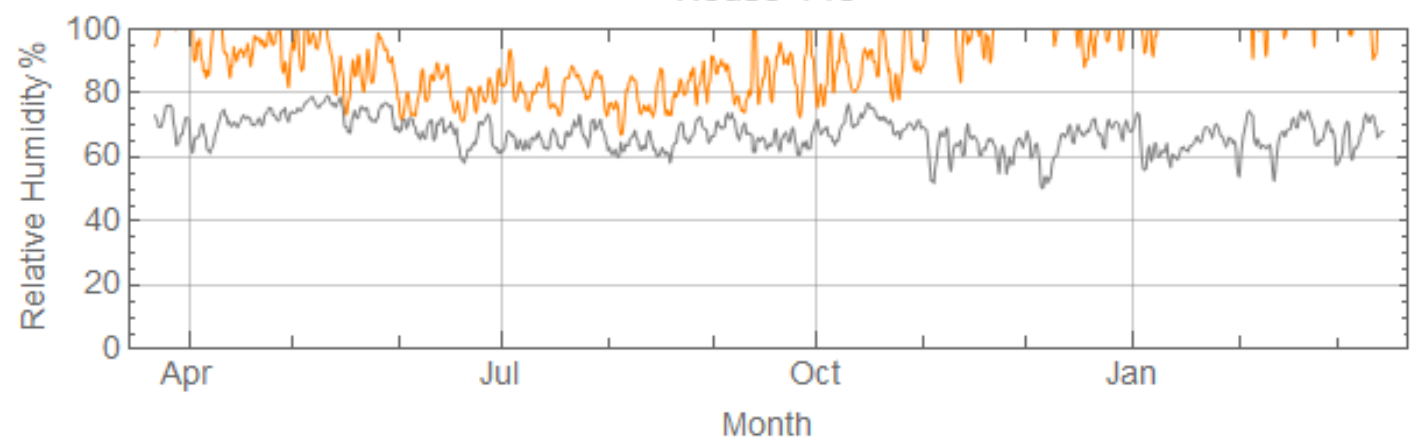

House 149

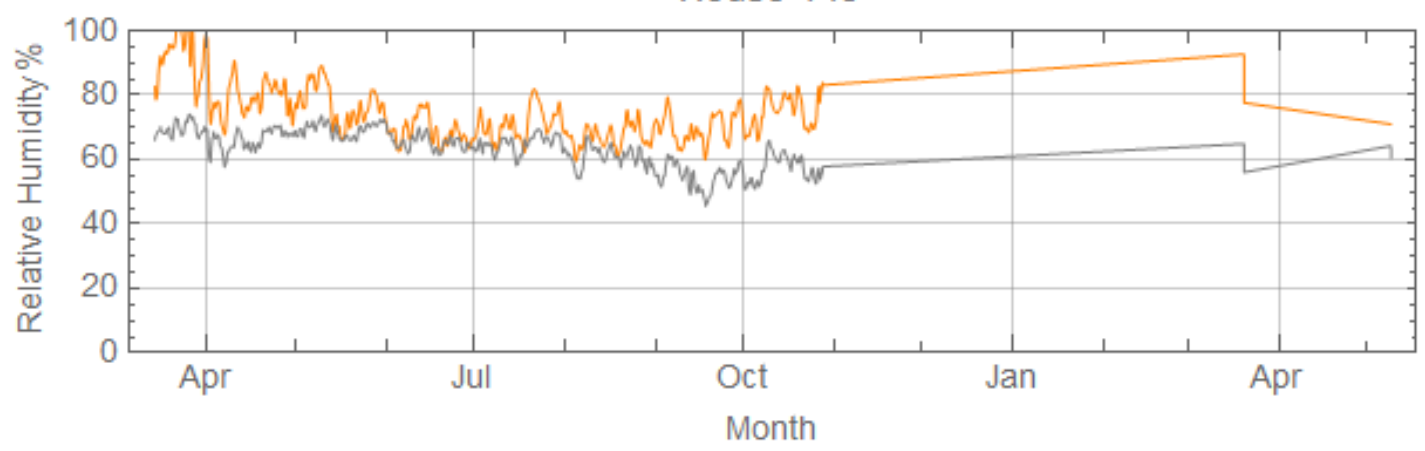

House 150

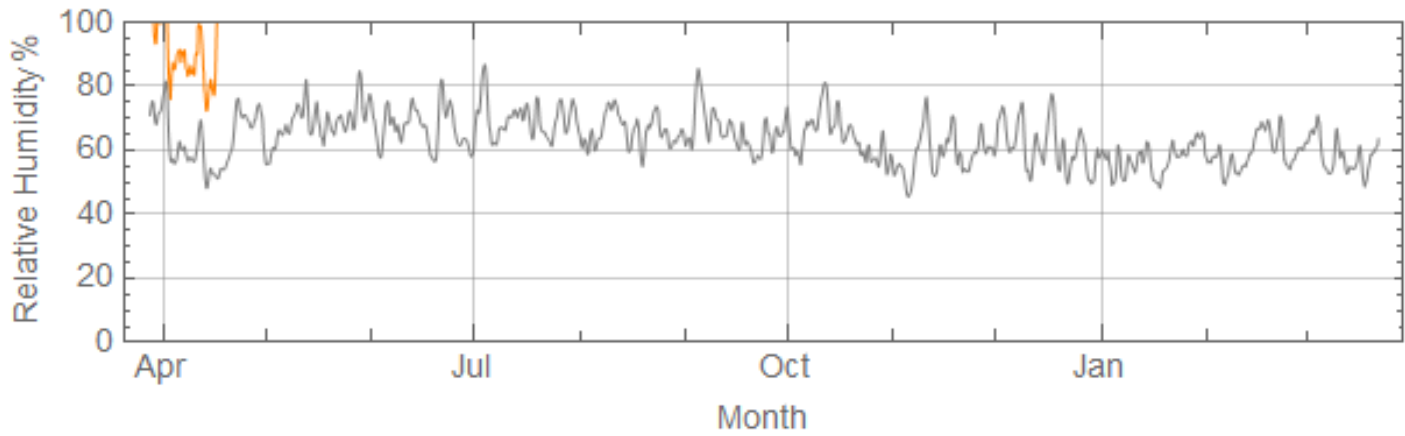

House 151

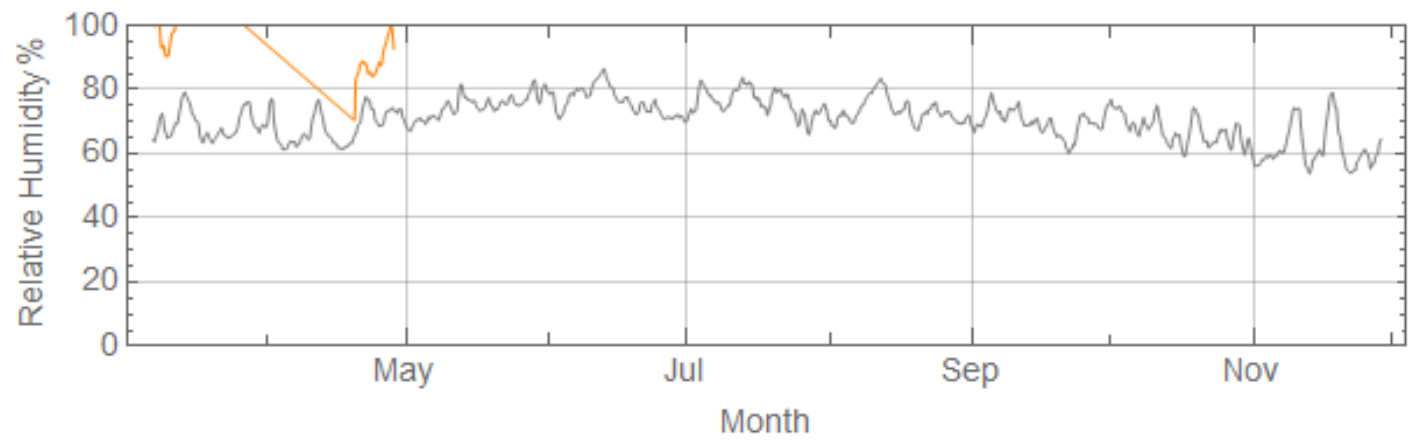


House 152

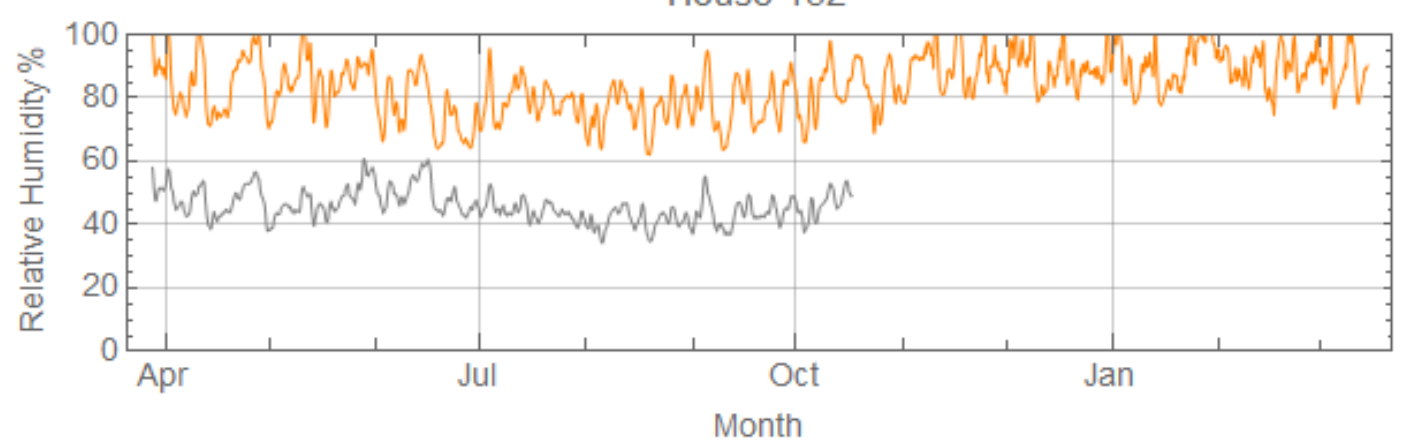

House 153

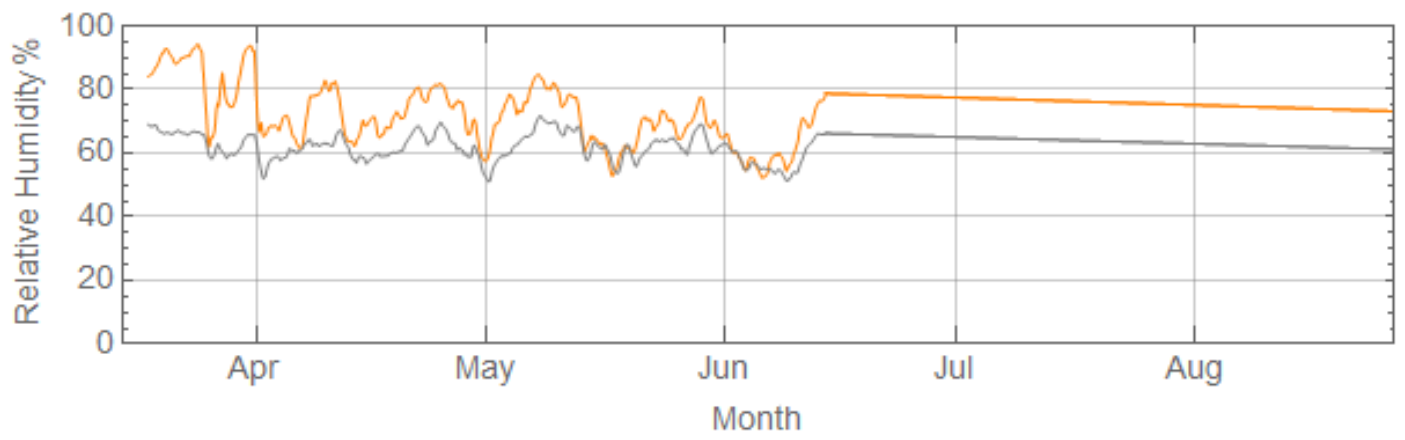

House 154

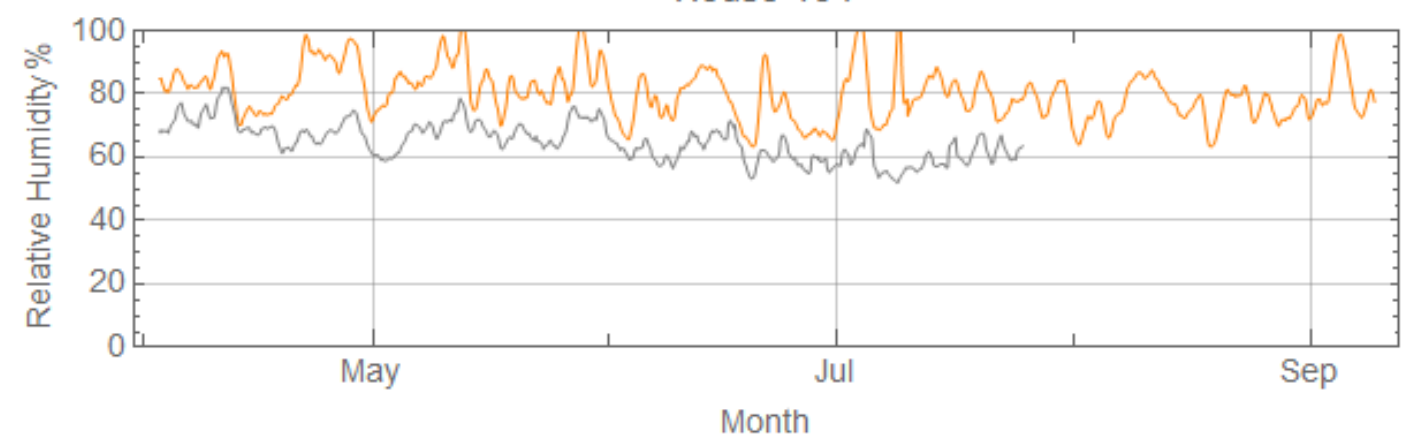

House 155

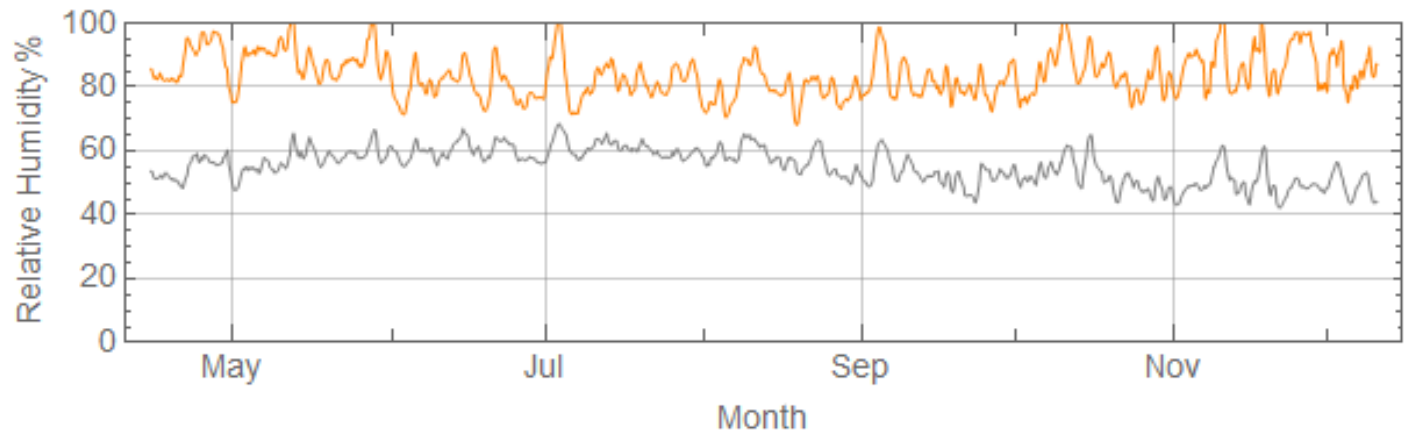


House 156

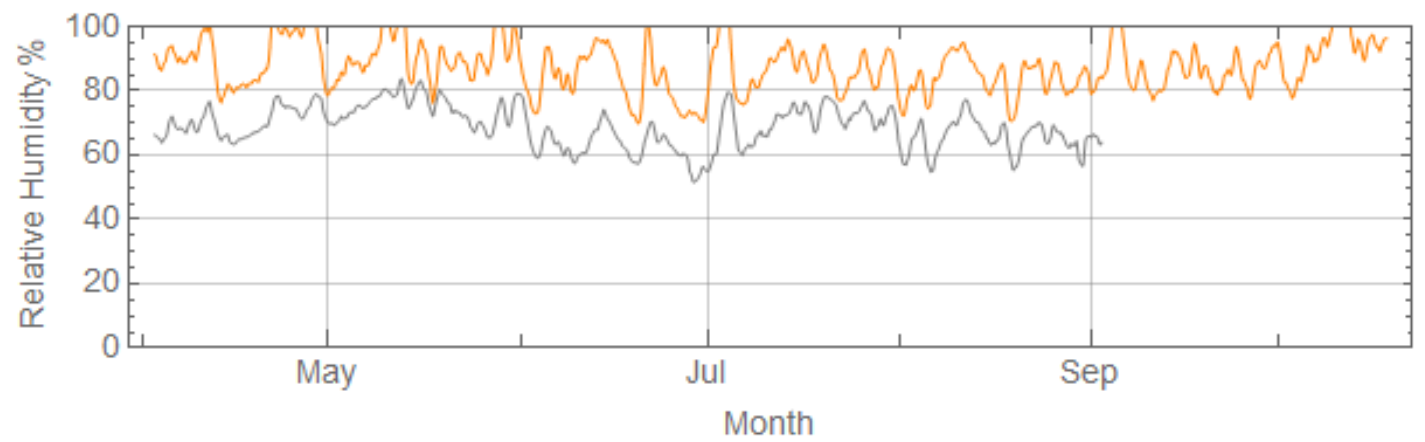

House 161

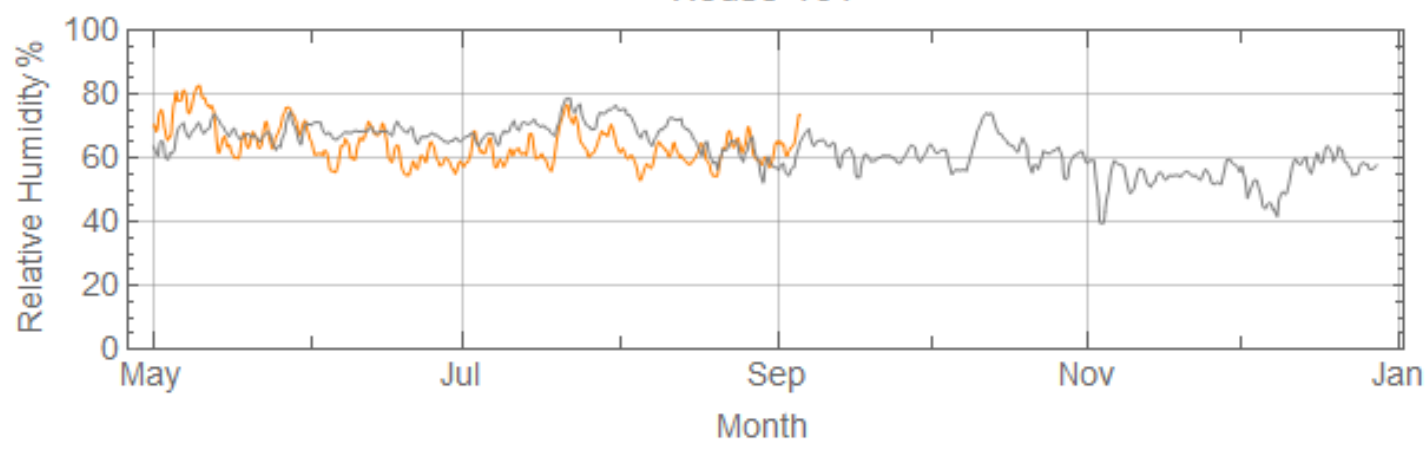

House 162

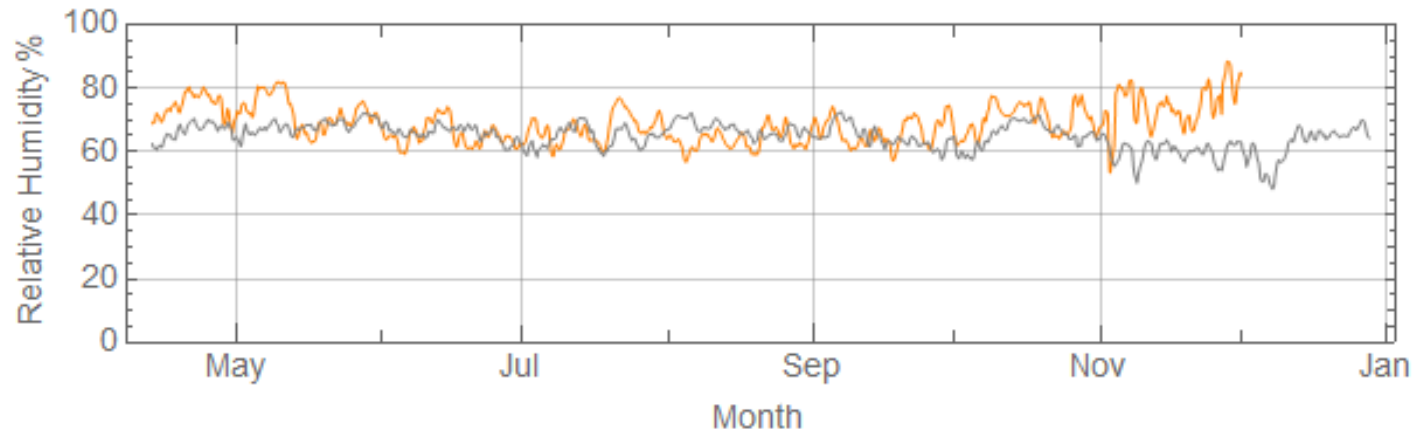

House 164

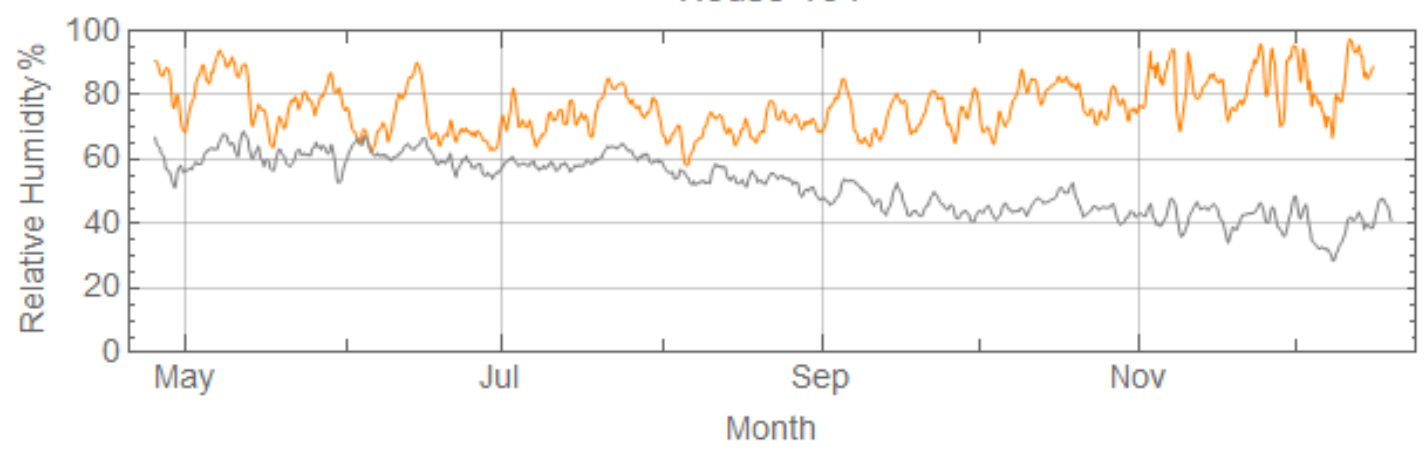


House 168

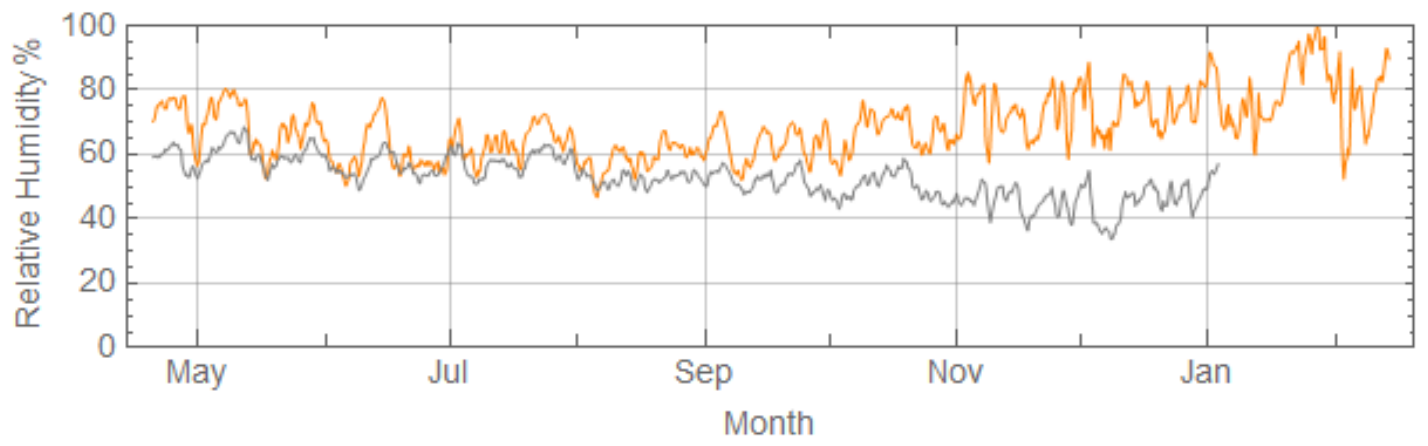

House 169

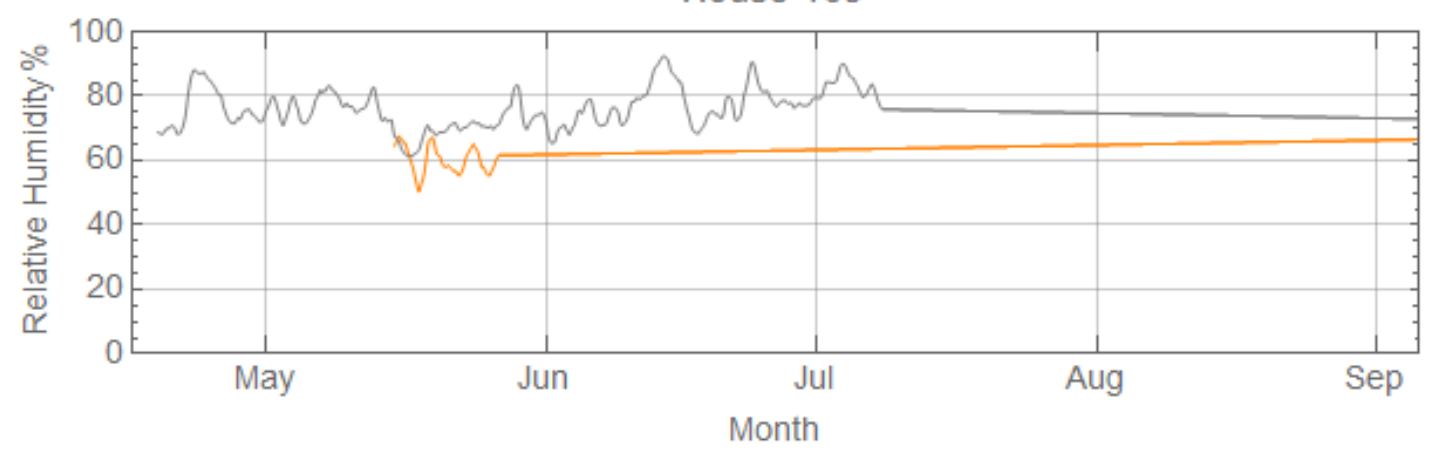

House 170

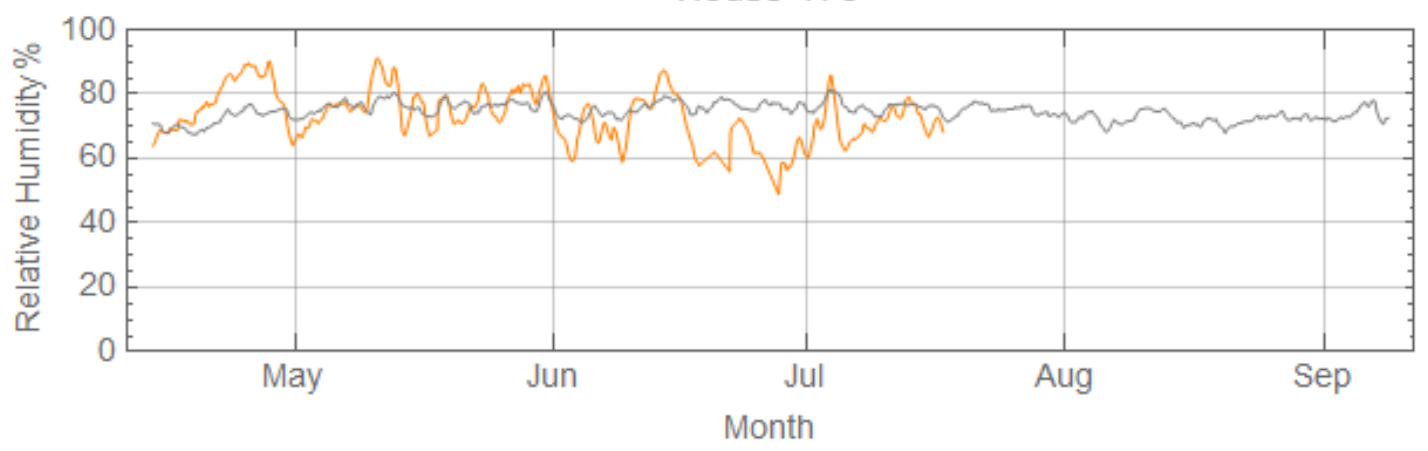

House 171

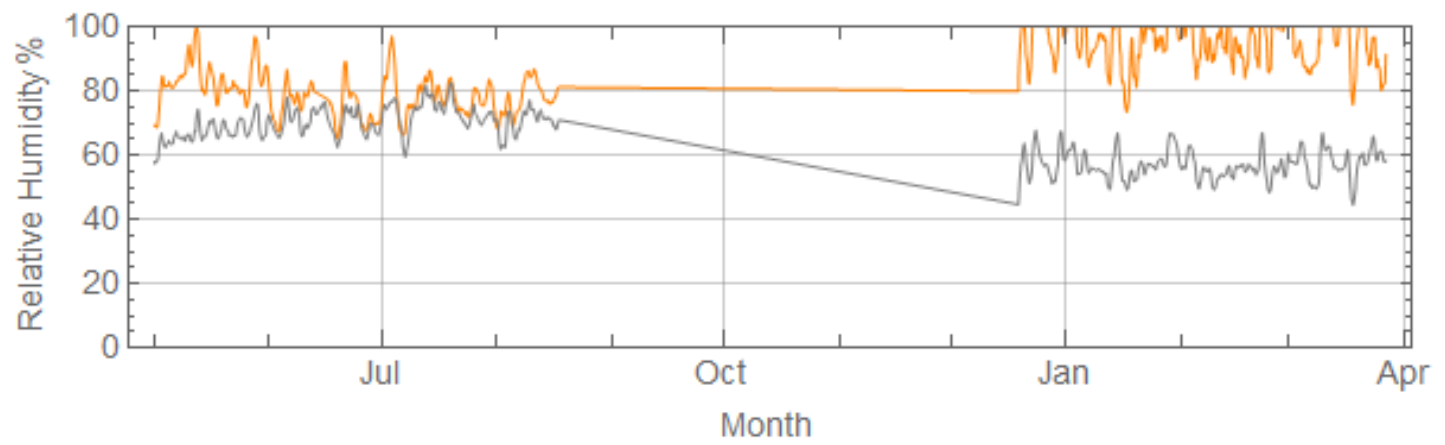


House 177

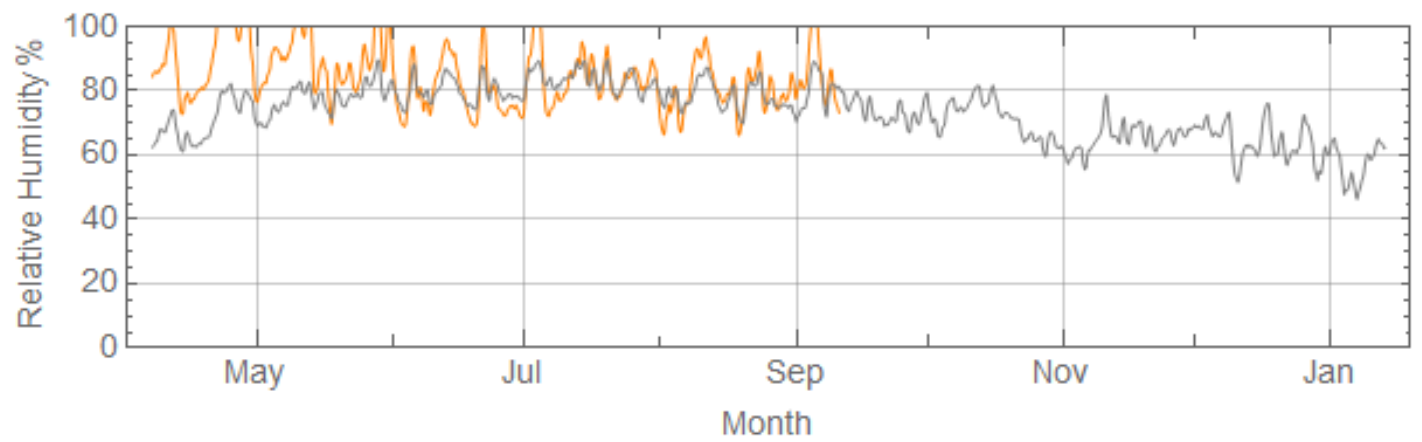

House 178

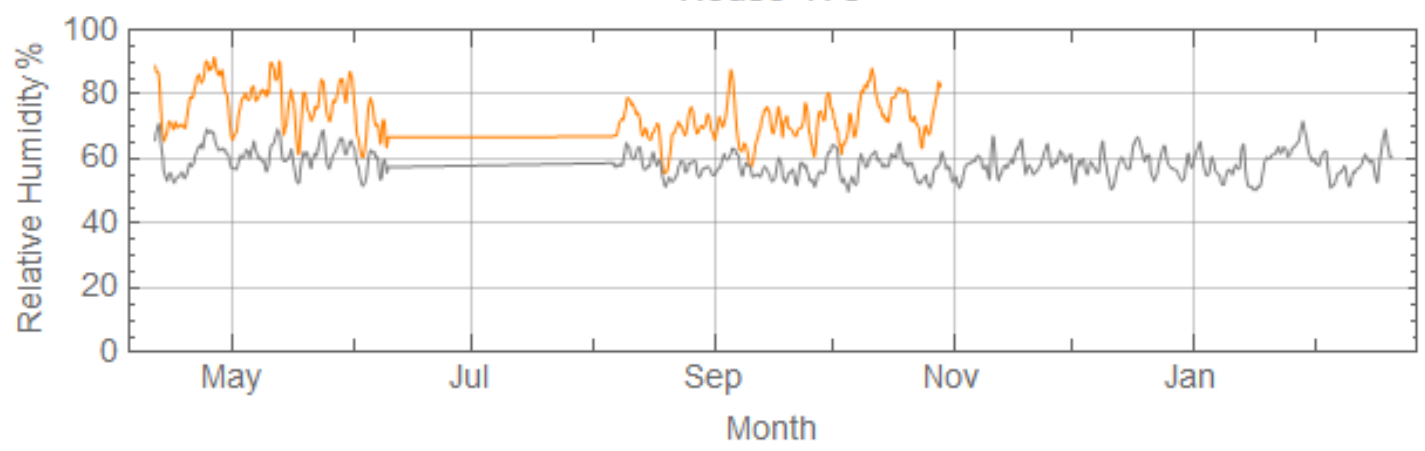

House 180

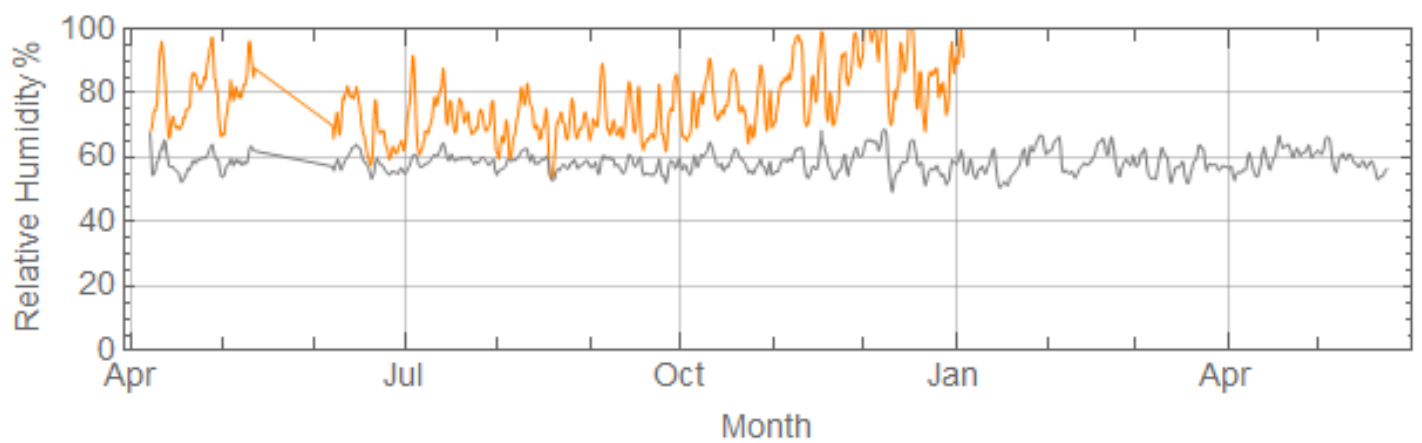




\subsection{Appendix I}

Application of Indoor Design Humidity: Intermediate Method with Revised ACH Trend 1

House 103

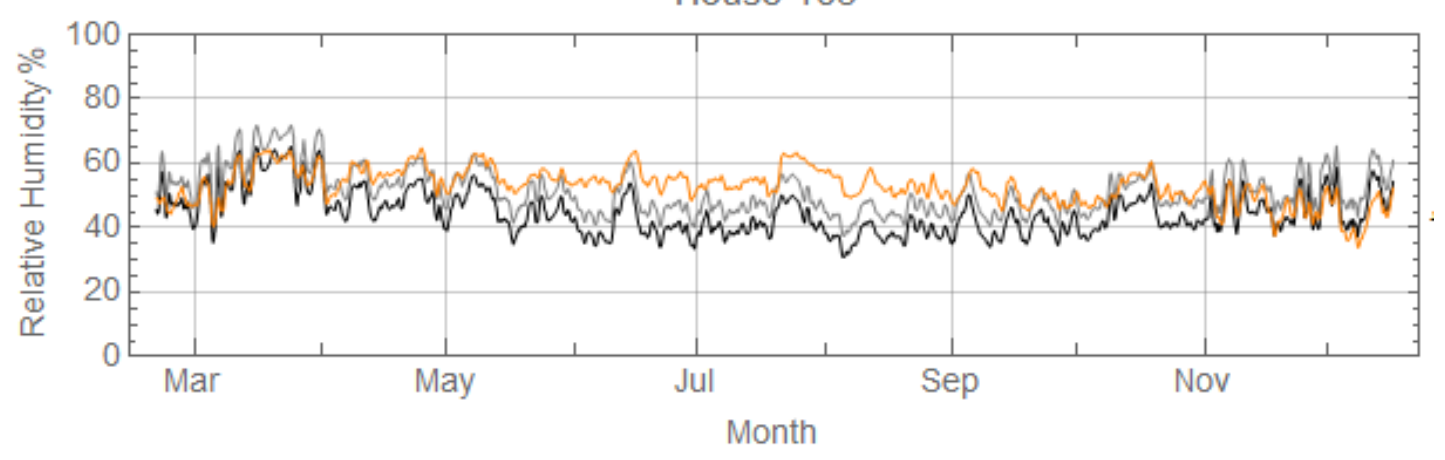

— Indoor Design Humidity: Intermediate Method, Revised ACH

— Indoor Design Humidity: Intermediate Method, Orginal ACH

— Measured Indoor Relative Humidity

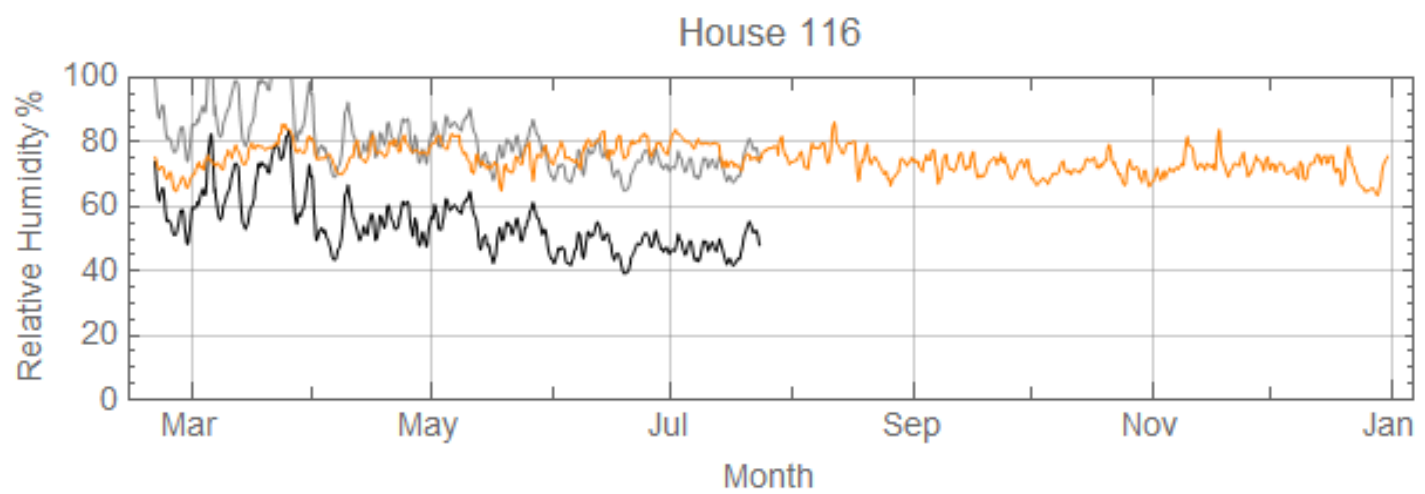

House 117

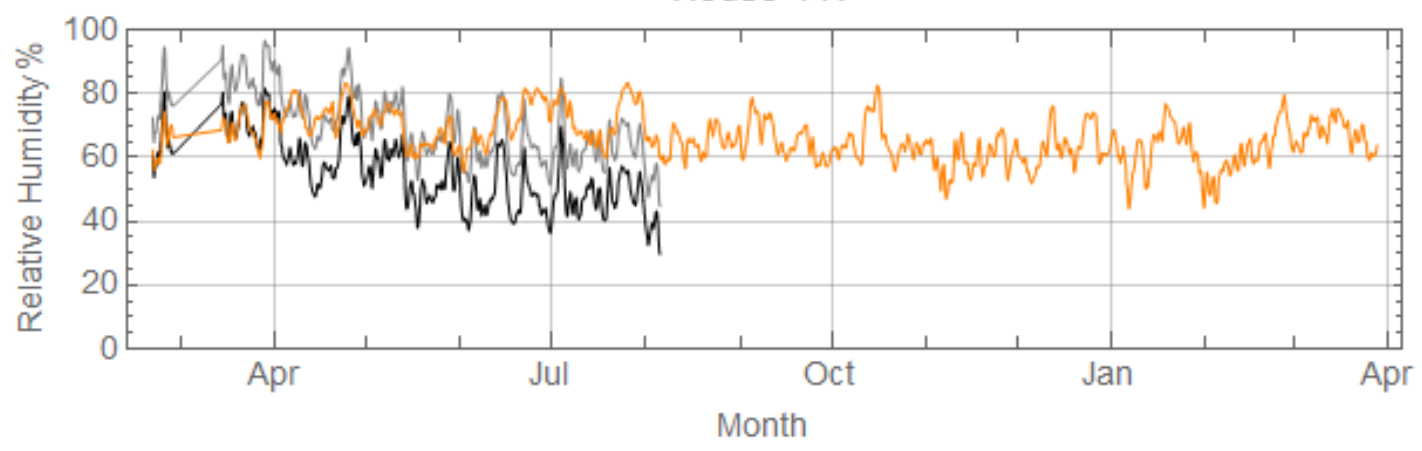


House 124

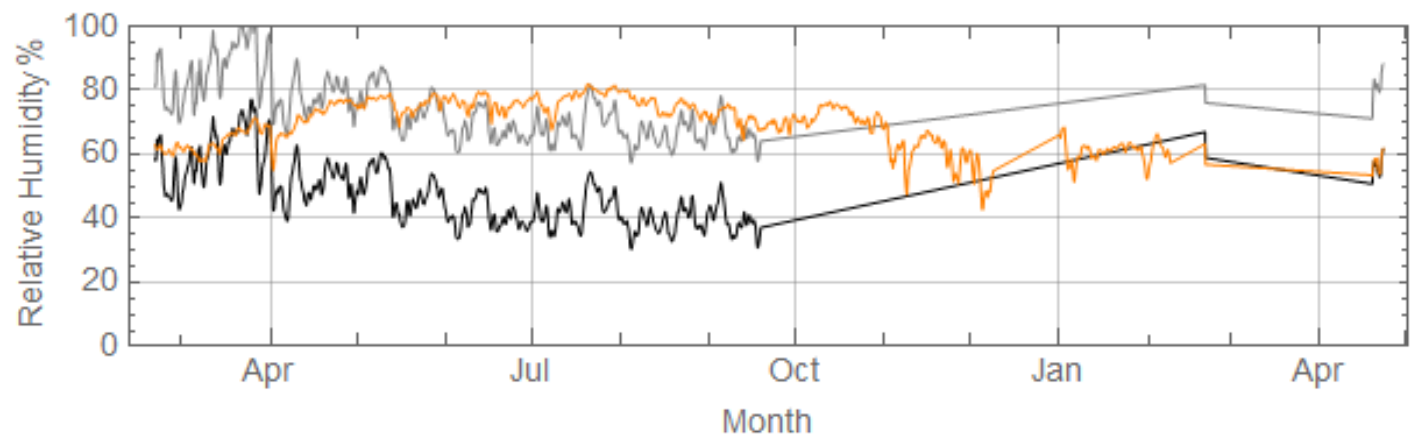

House 138

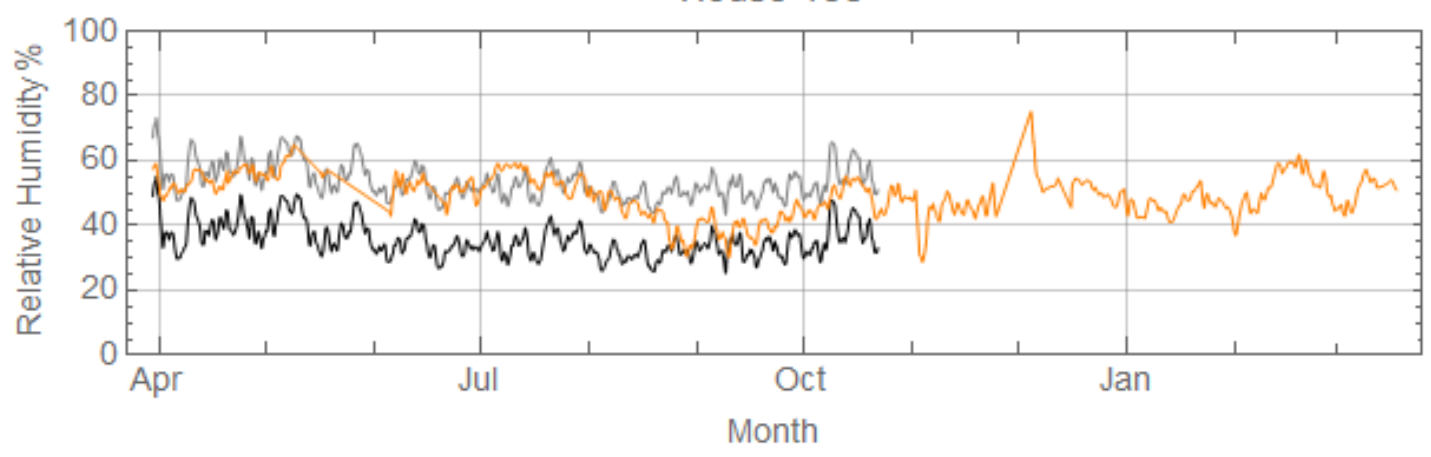

House 143

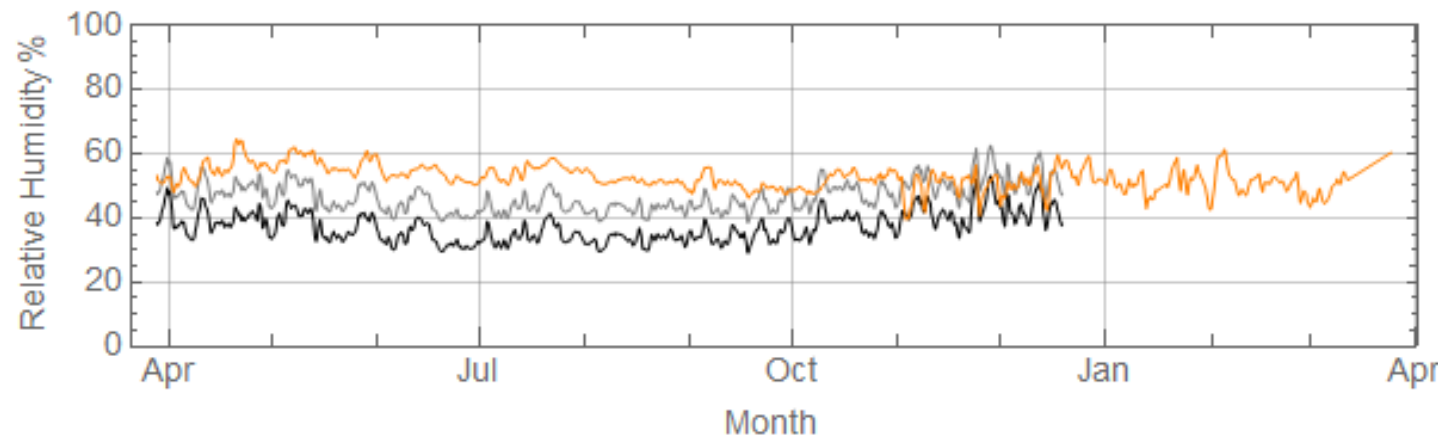

House 145

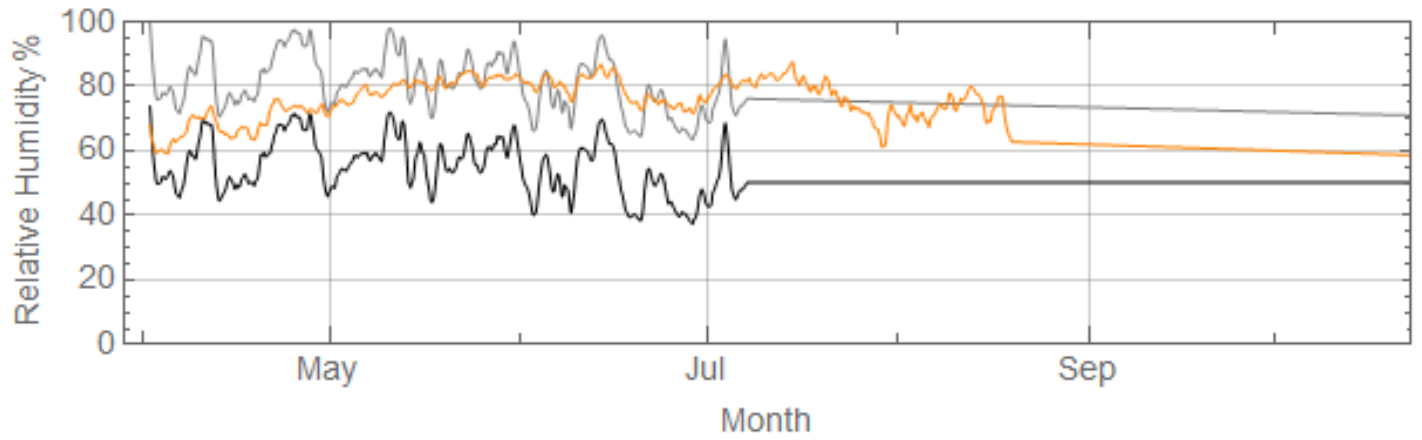


House 149

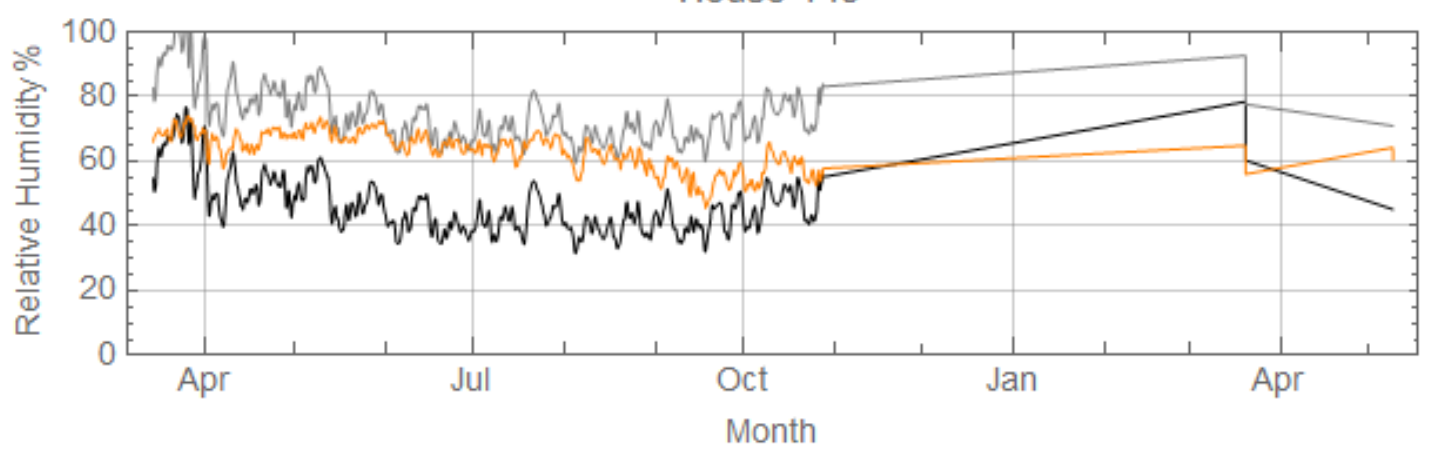

House 153

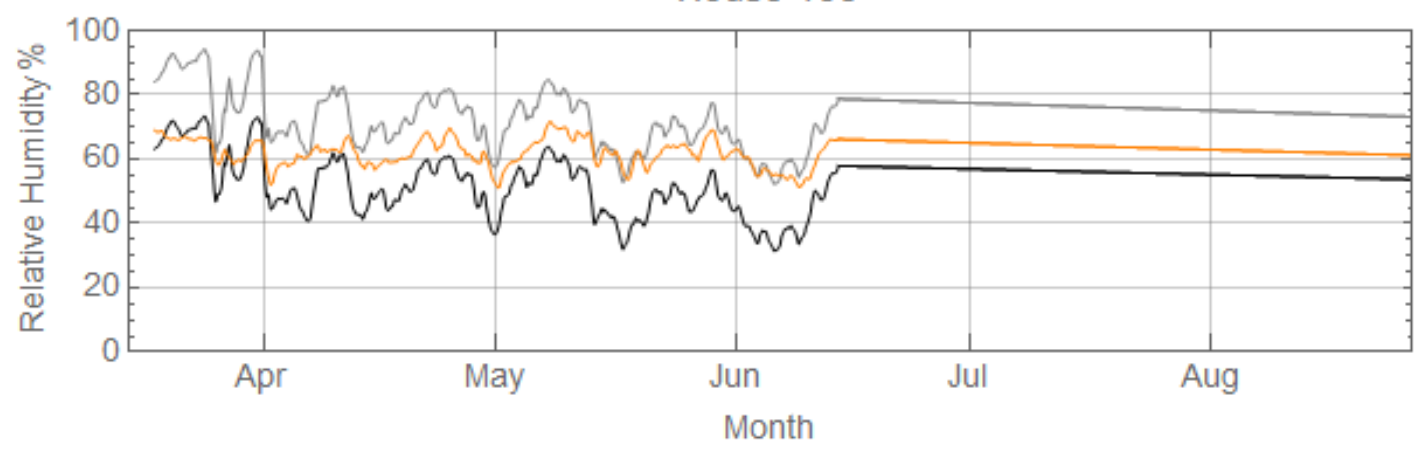

House 161

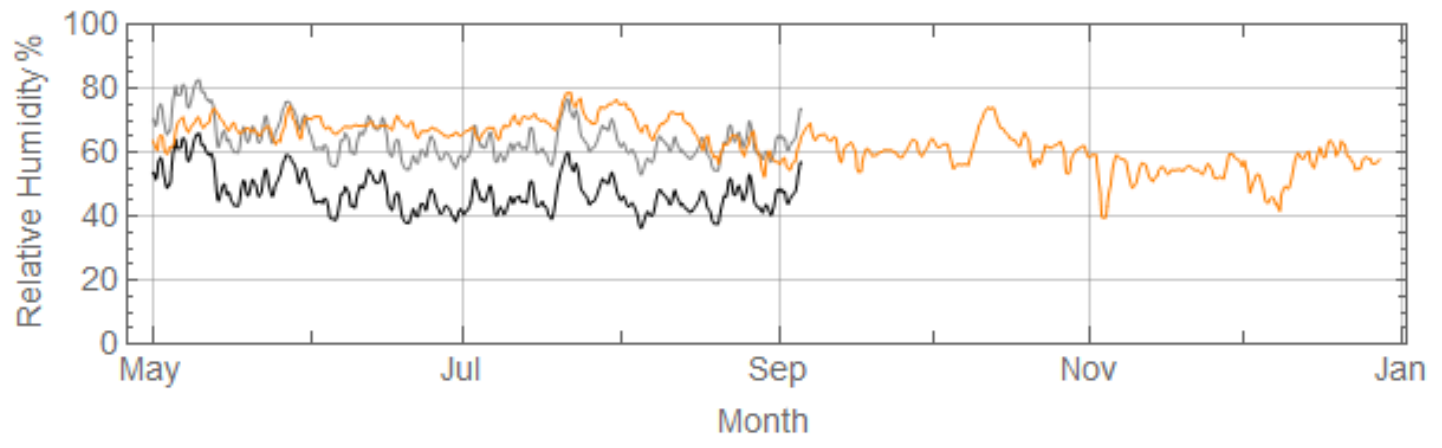

House 162

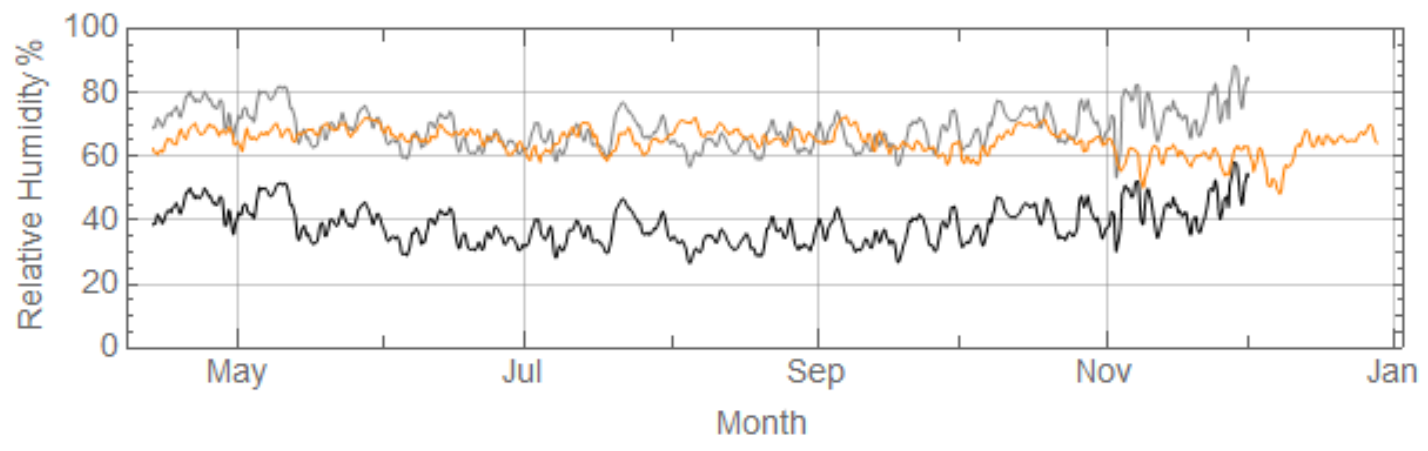


House 169

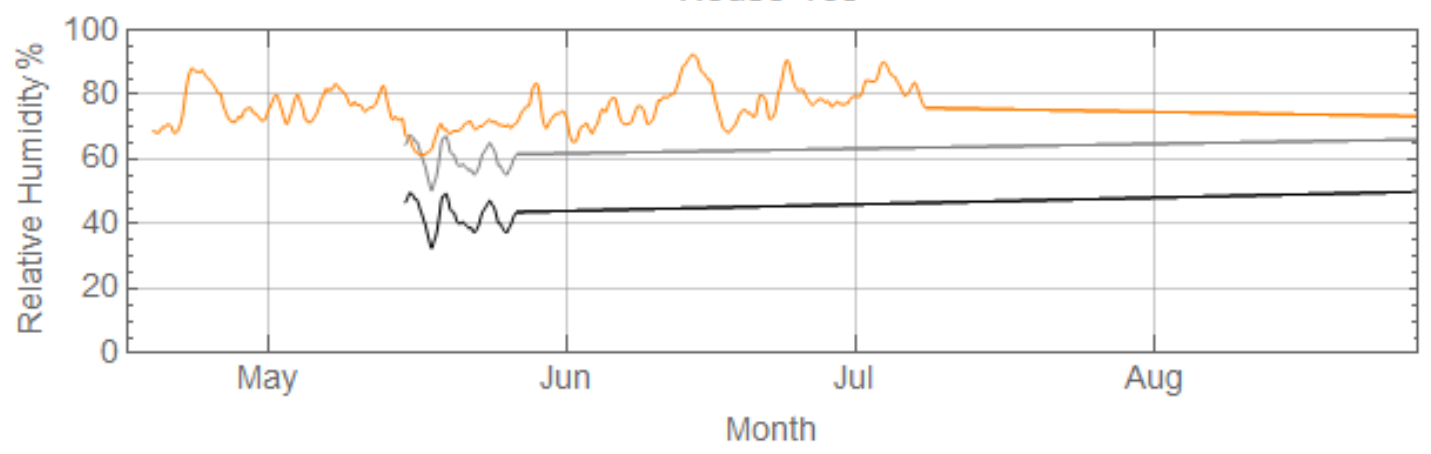

House 170

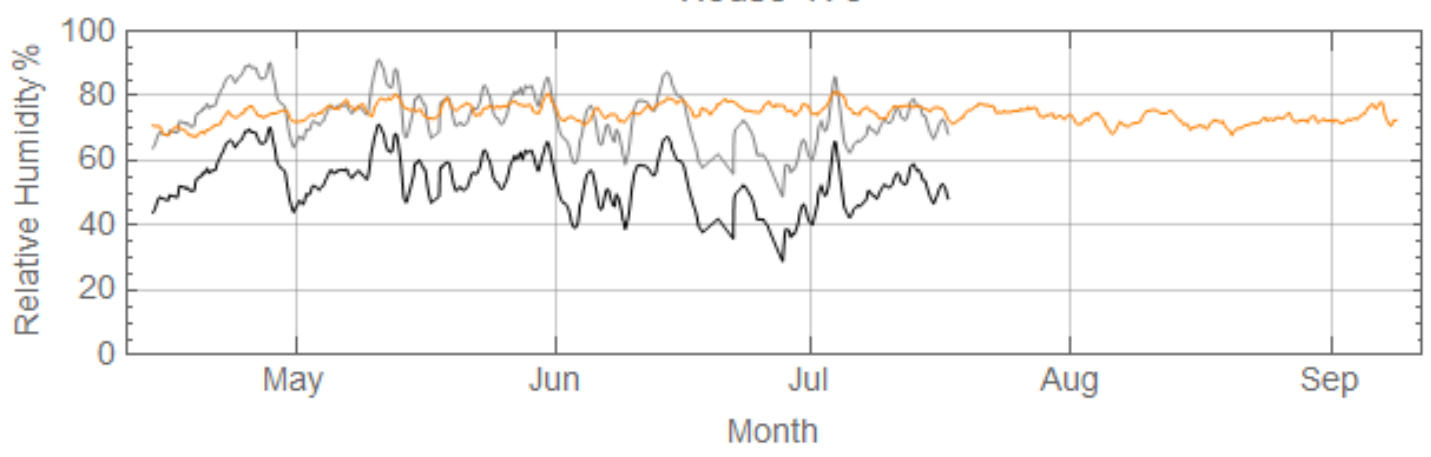

House 177

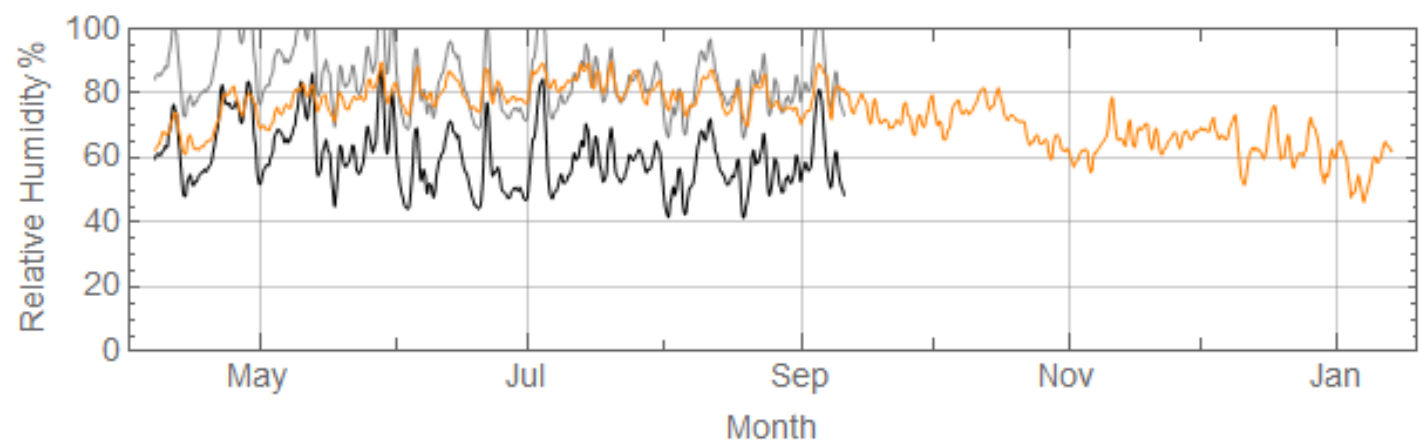




\subsection{Appendix J}

Application of Indoor Design Humidity: Intermediate Method with Revised ACH Trend 2

House 100

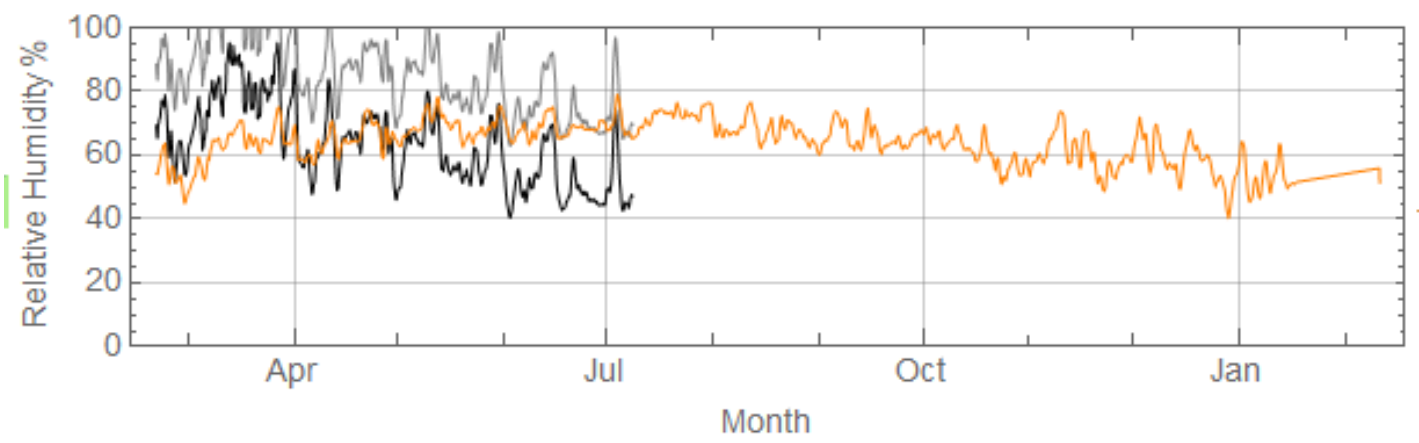

— Indoor Design Humidity: Intermediate Method, Revised ACH

— Indoor Design Humidity: Intermediate Method, Orginal ACH

— Measured Indoor Relative Humidity

House 101

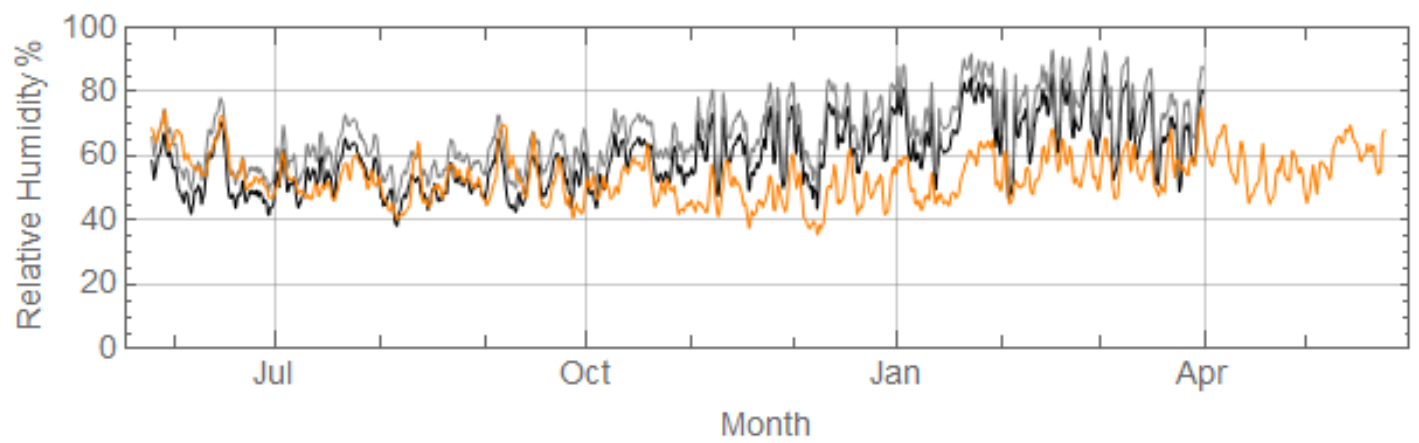

House 104

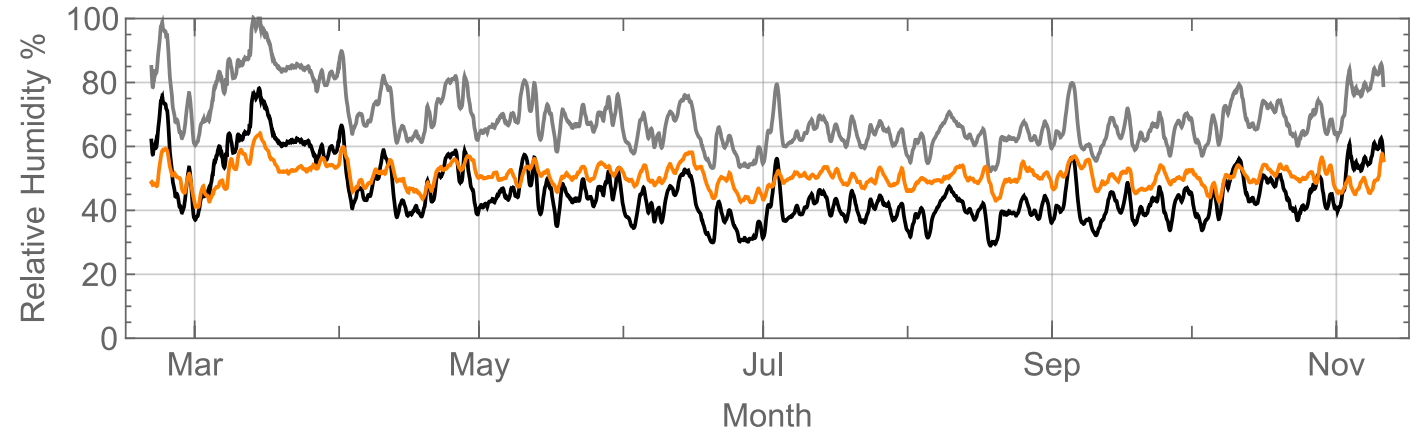


House 106

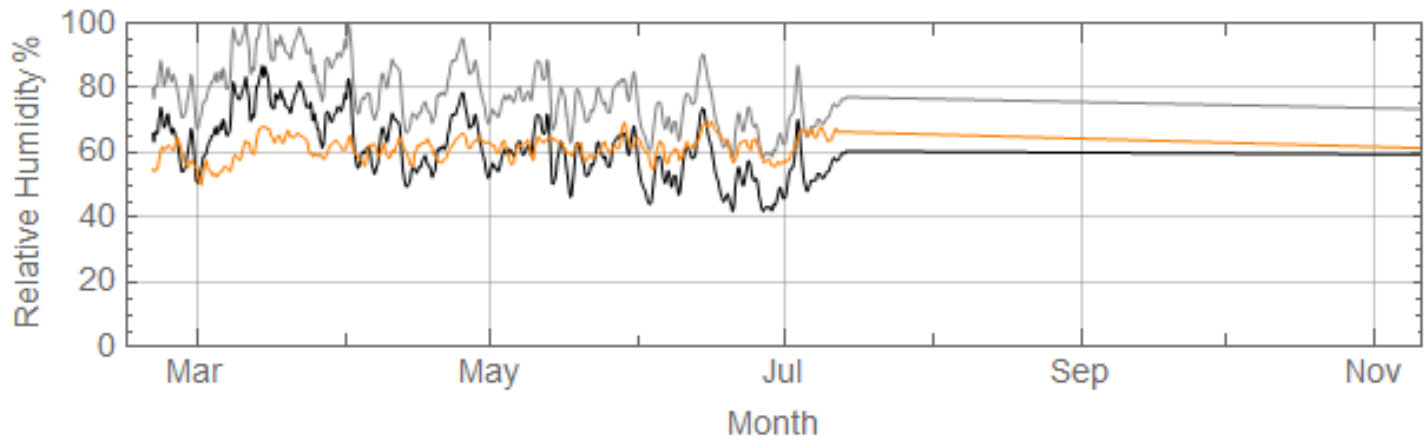

House 110

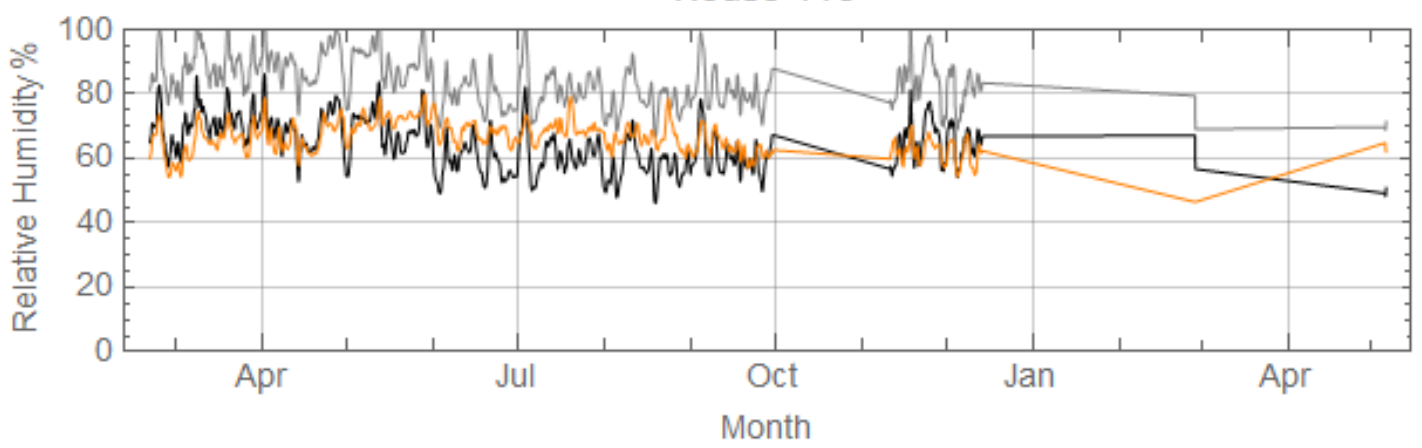

House 121

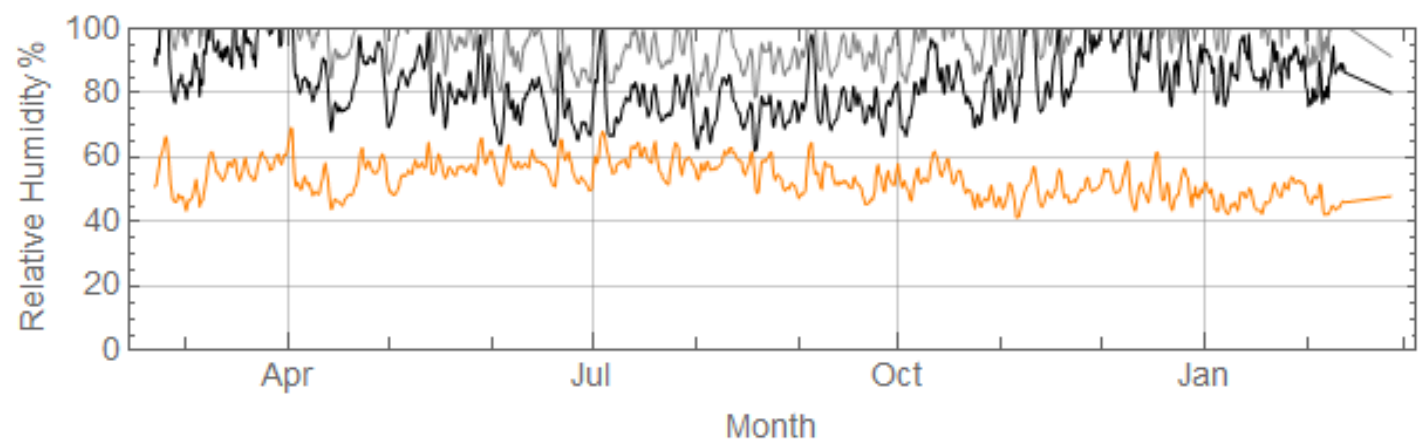

House 125

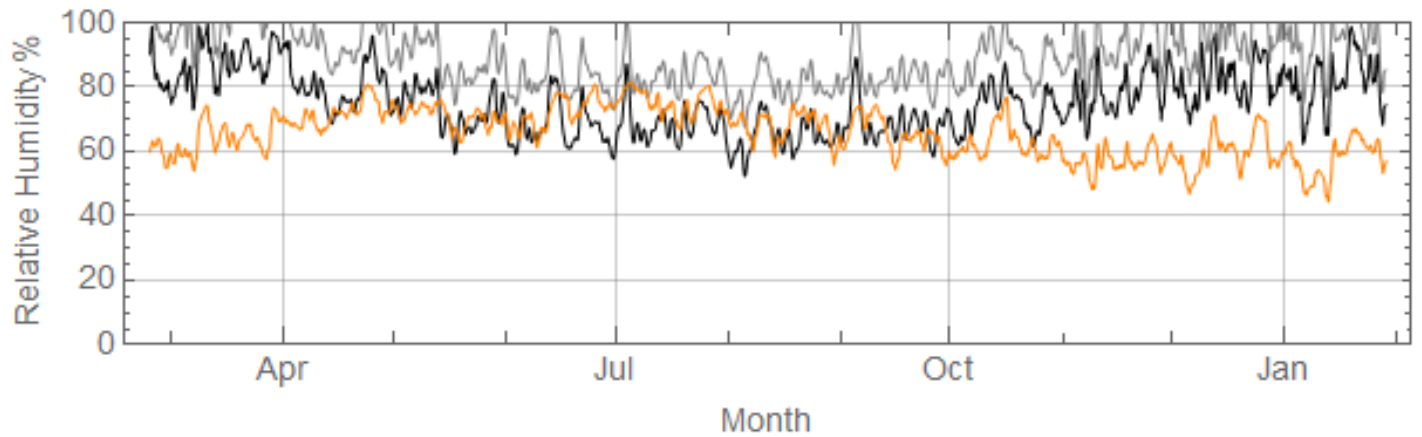


House 129

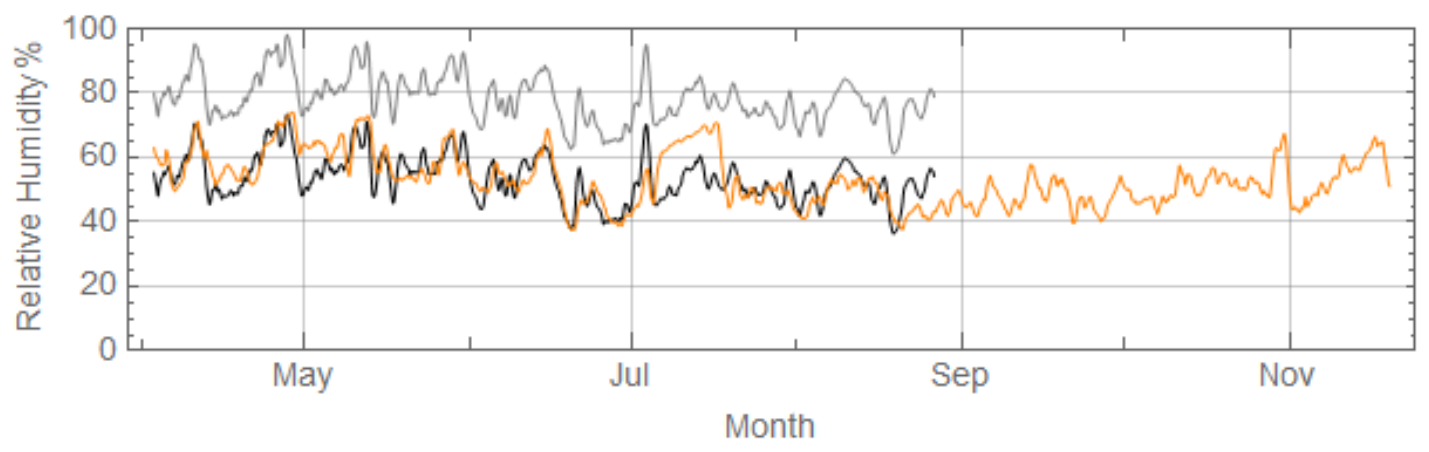

House 135

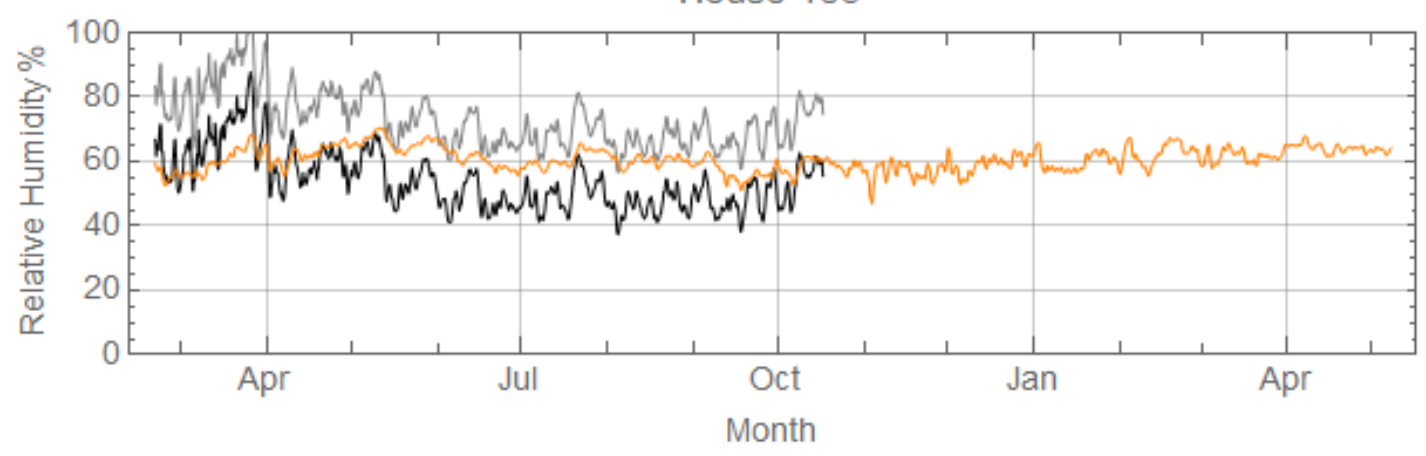

House 136

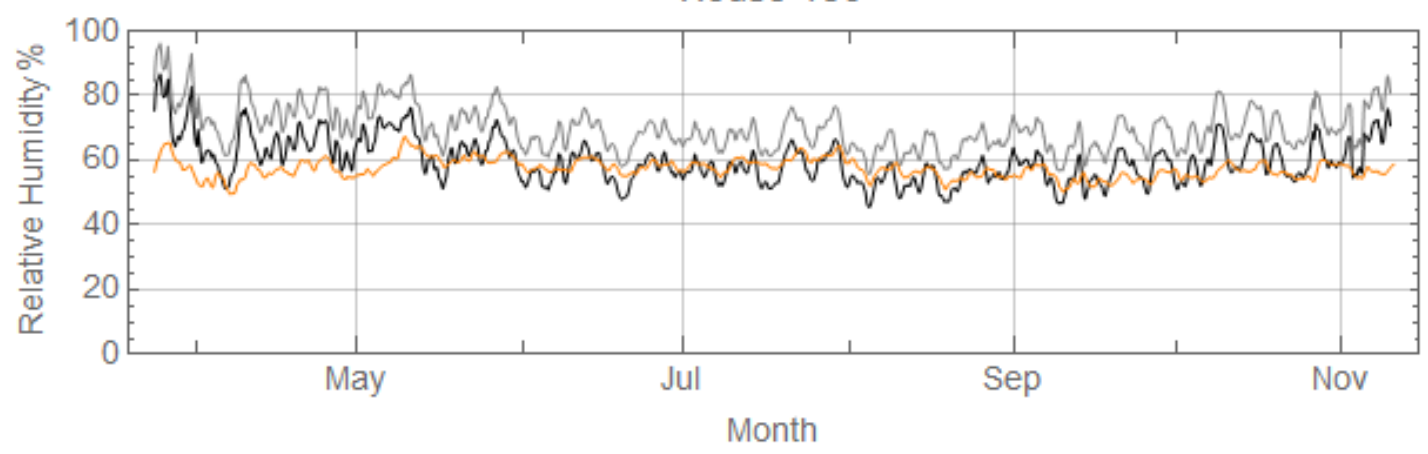

House 137

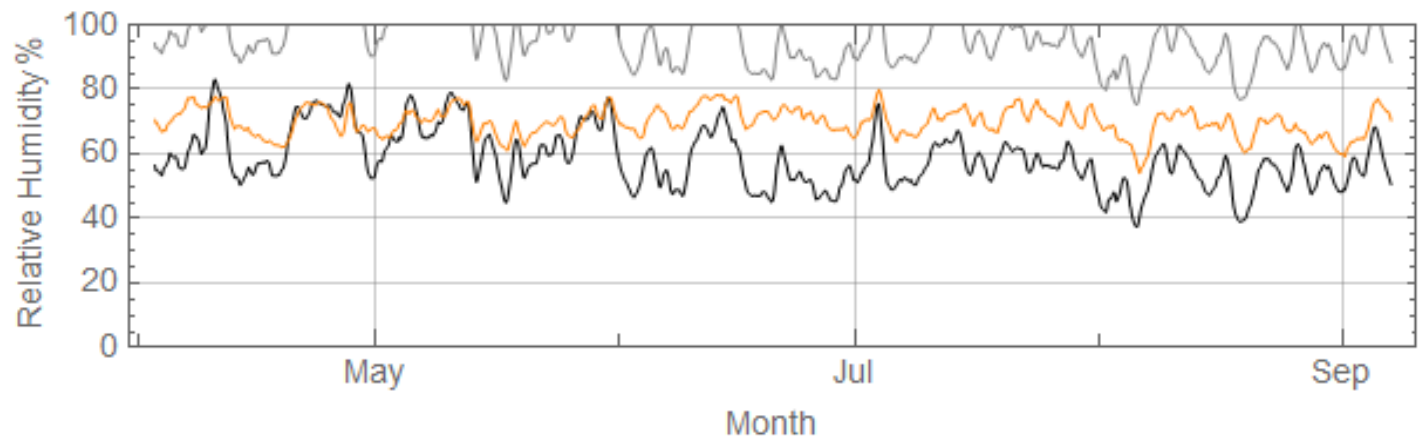


House 139

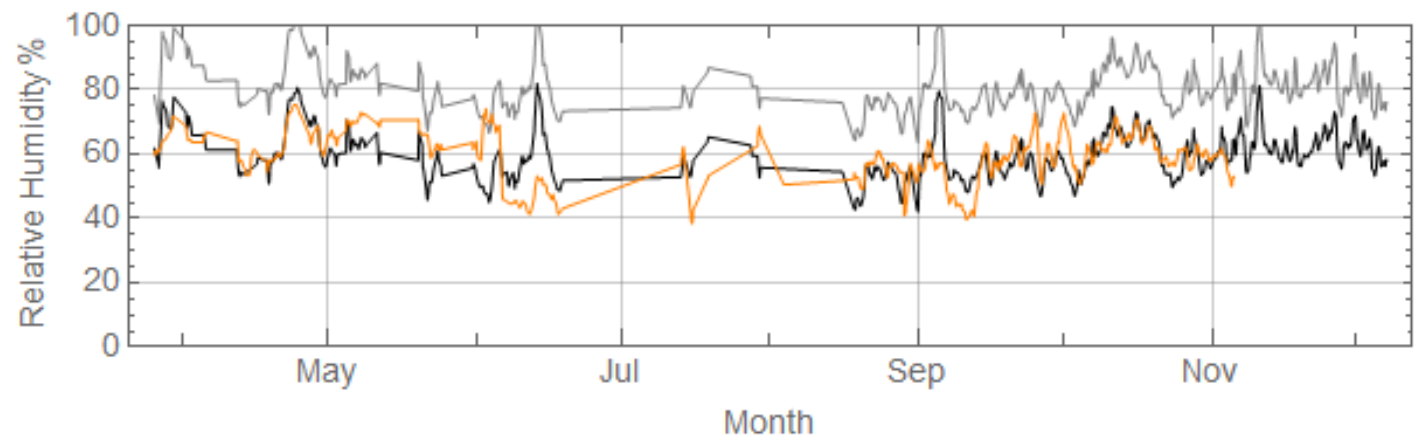

House 142

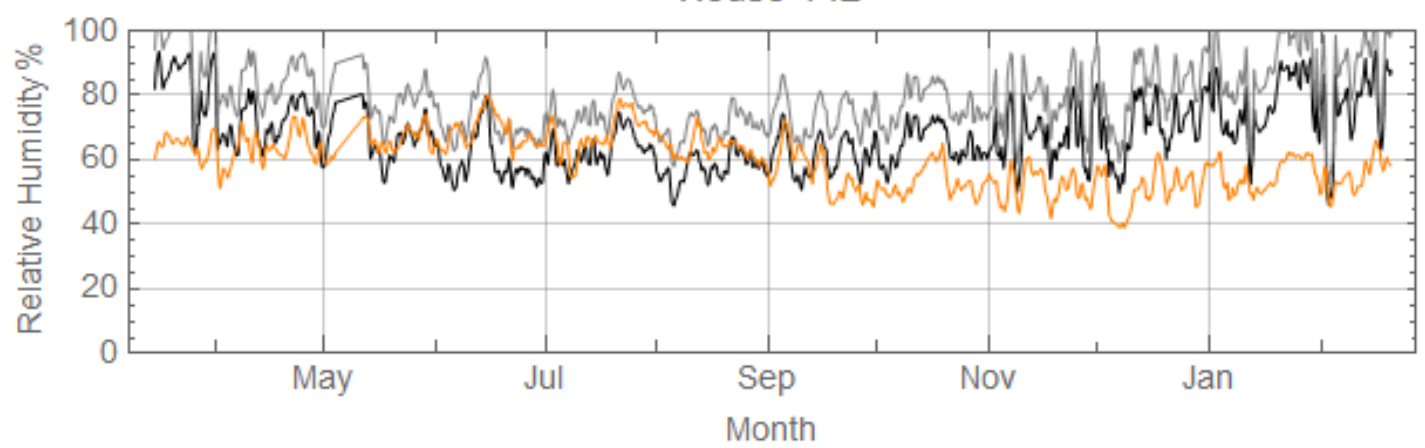

House 144

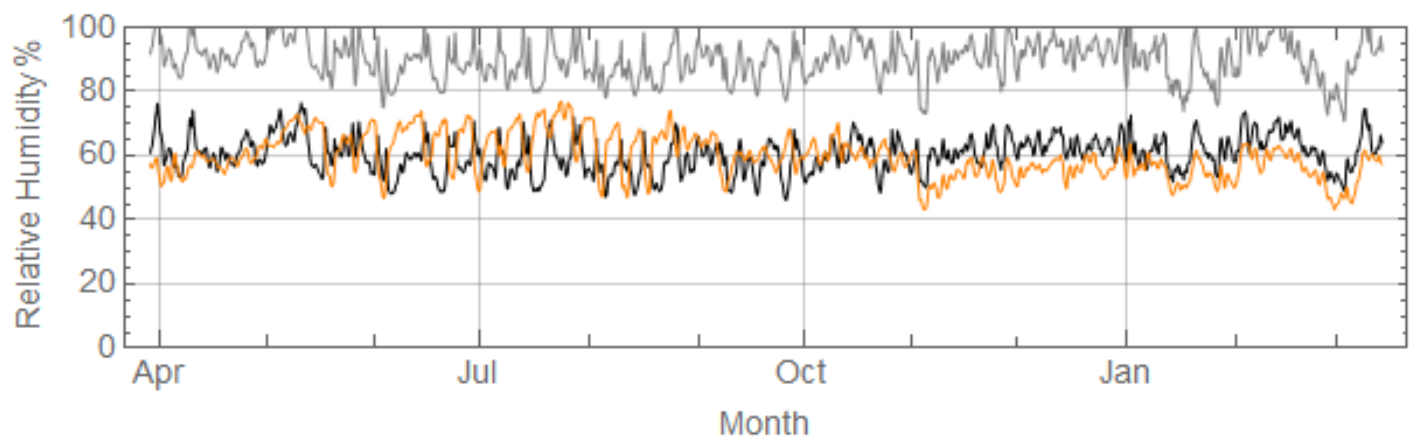

House 148

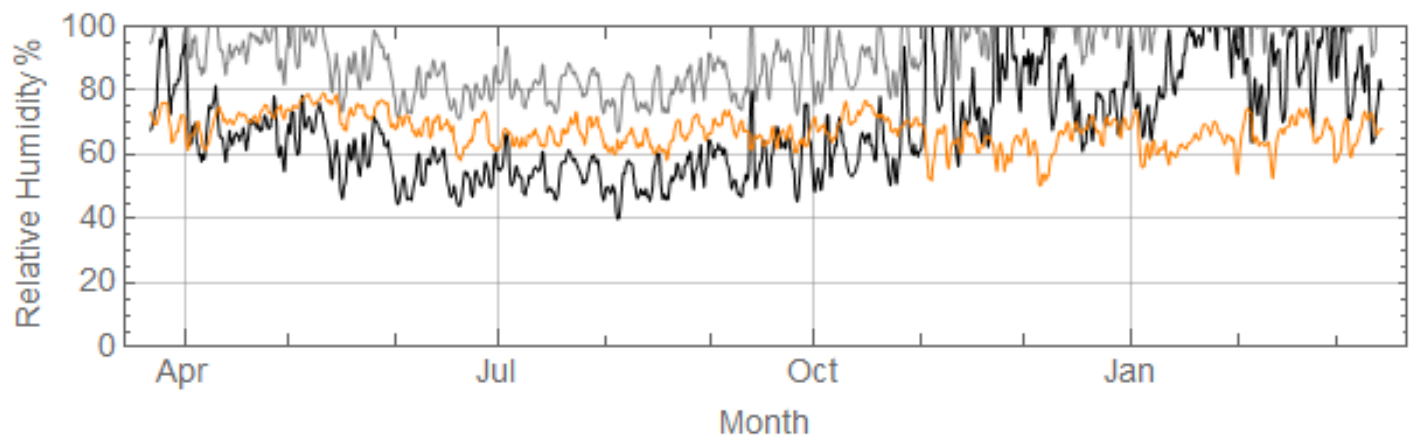


House 152

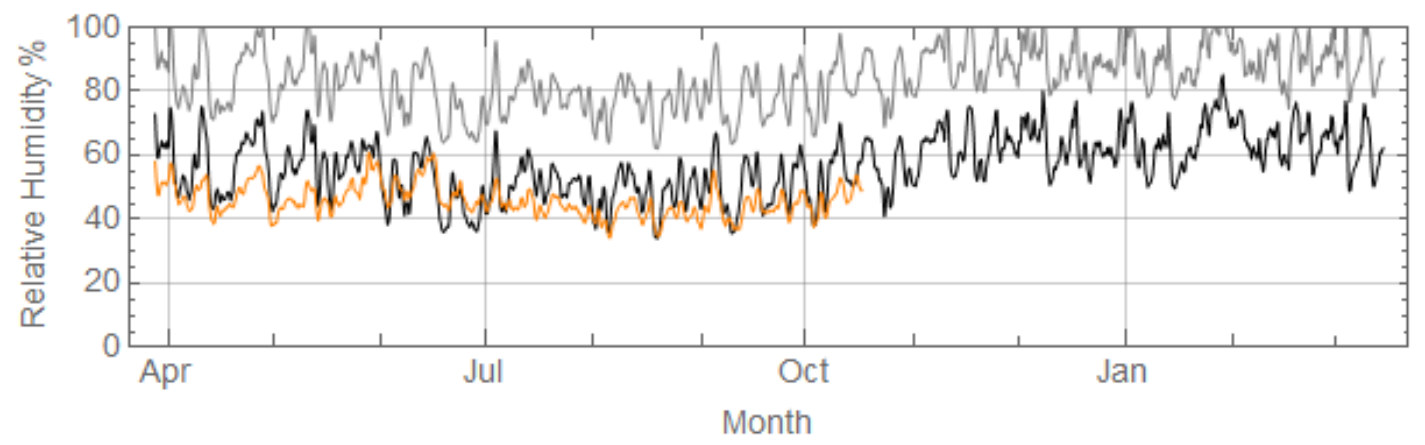

House 154

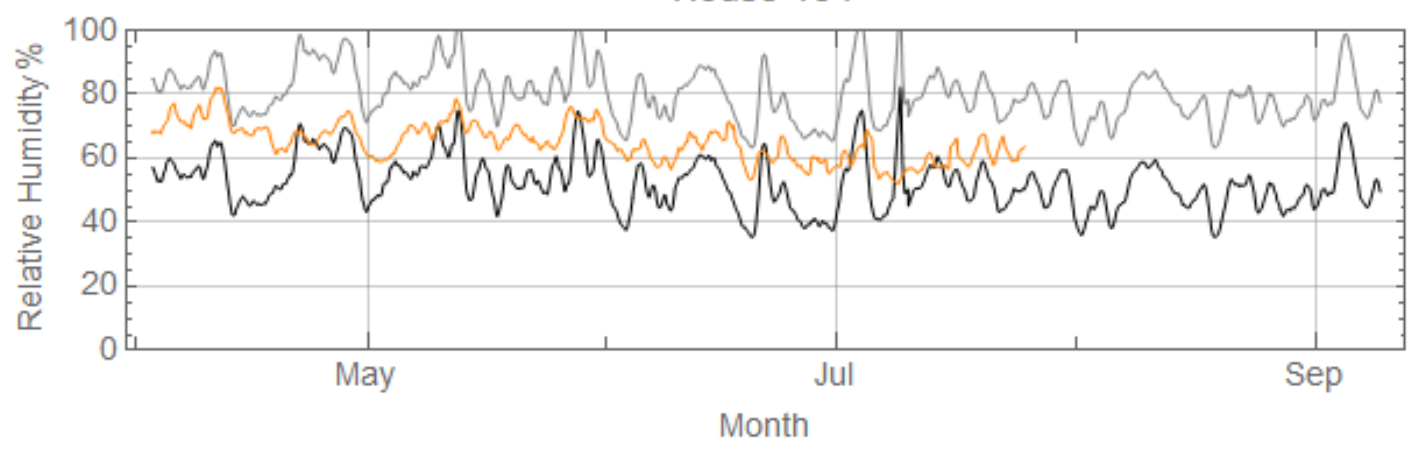

House 155

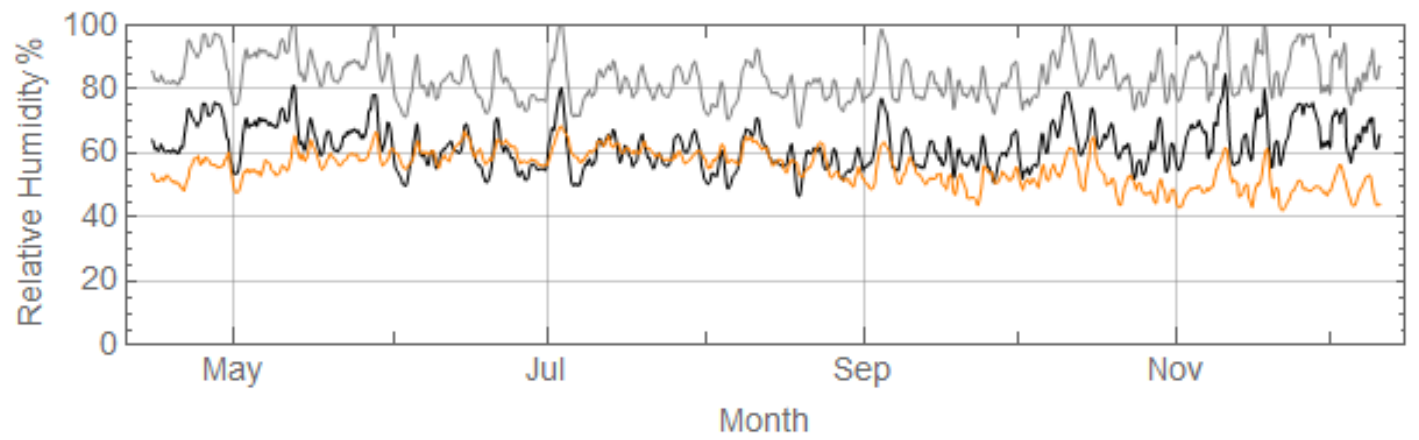

House 164

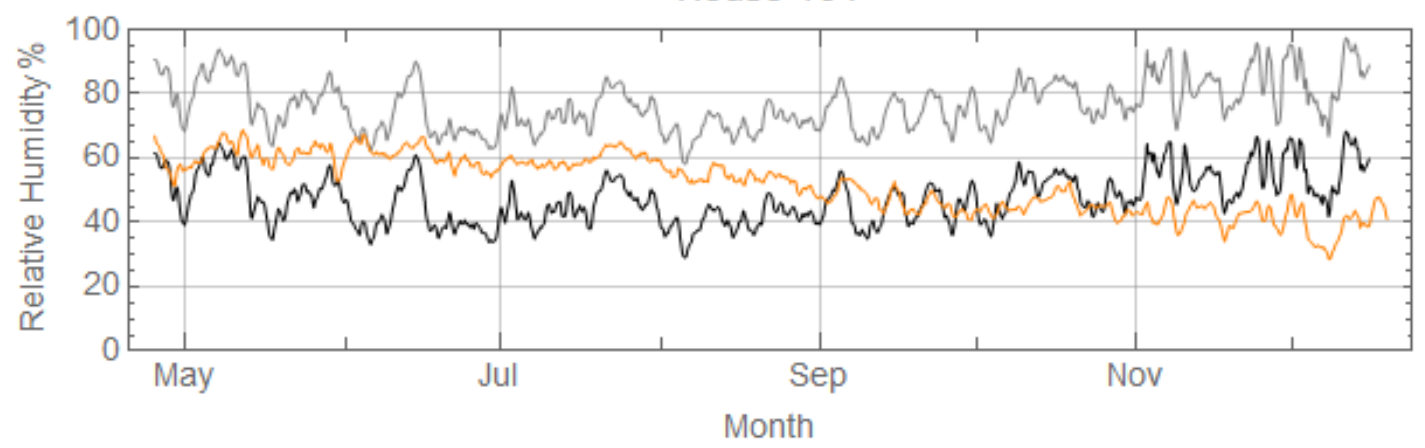


House 168

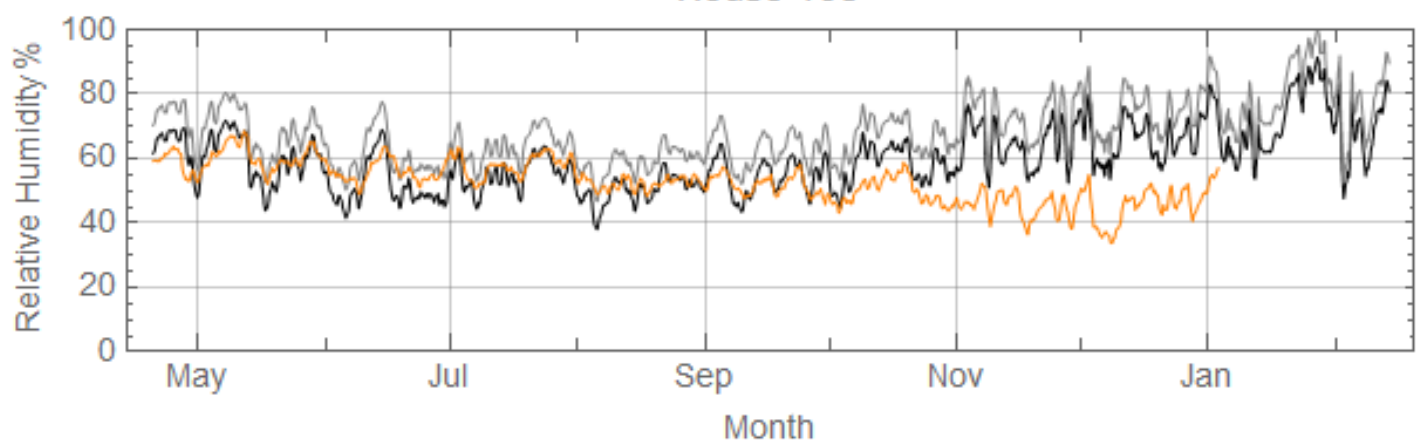

House 178

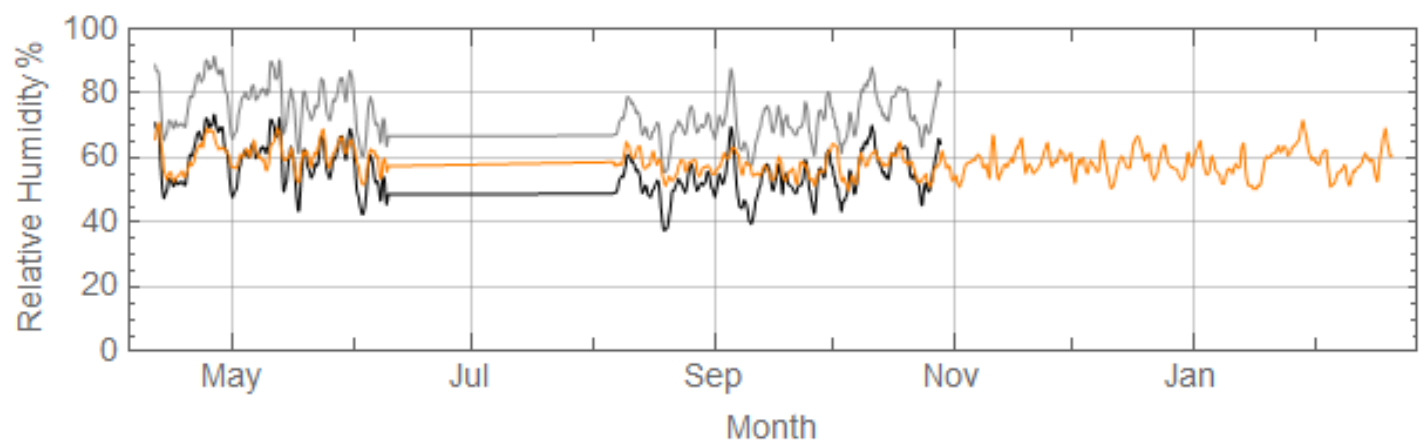

House 180

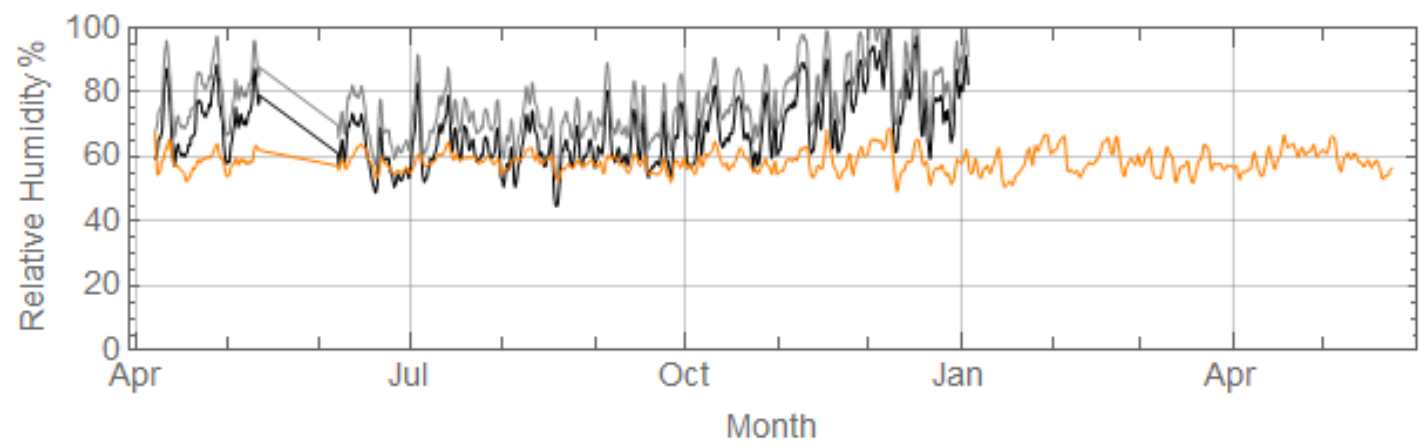




\subsection{Appendix K}

Application of Indoor Design Humidity: Intermediate Method with Revised ACH Trend 3

House 111

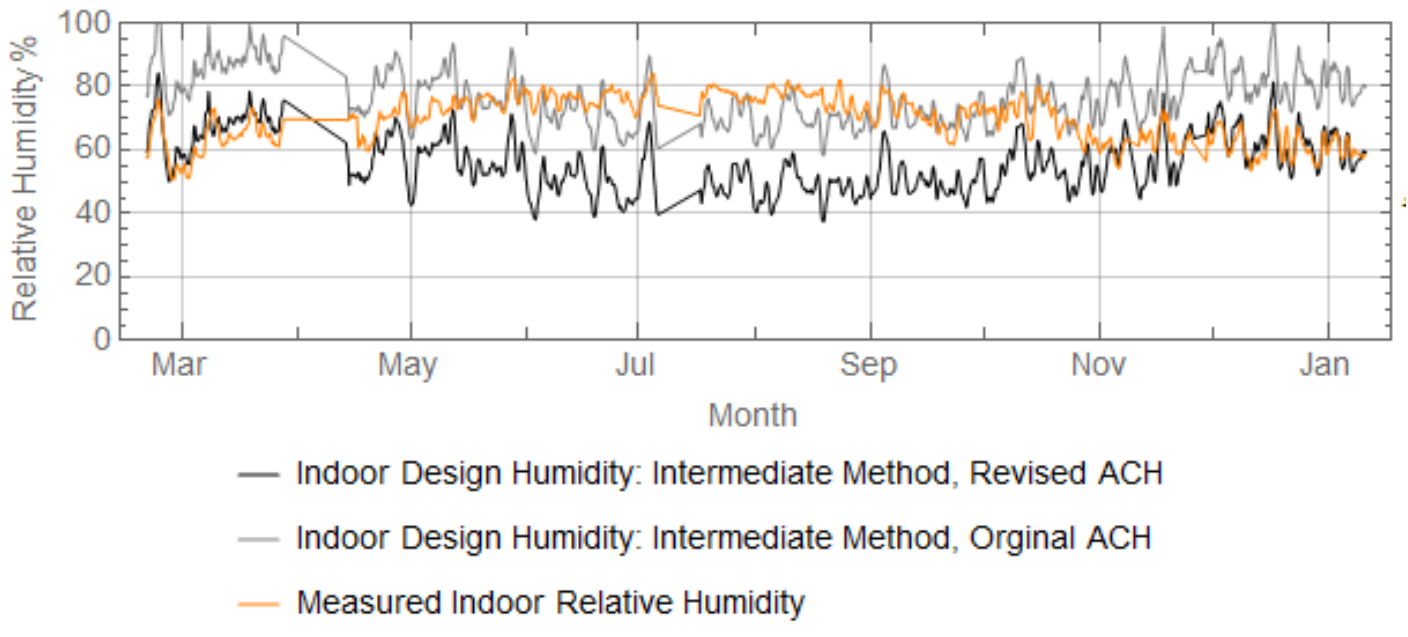

House 113

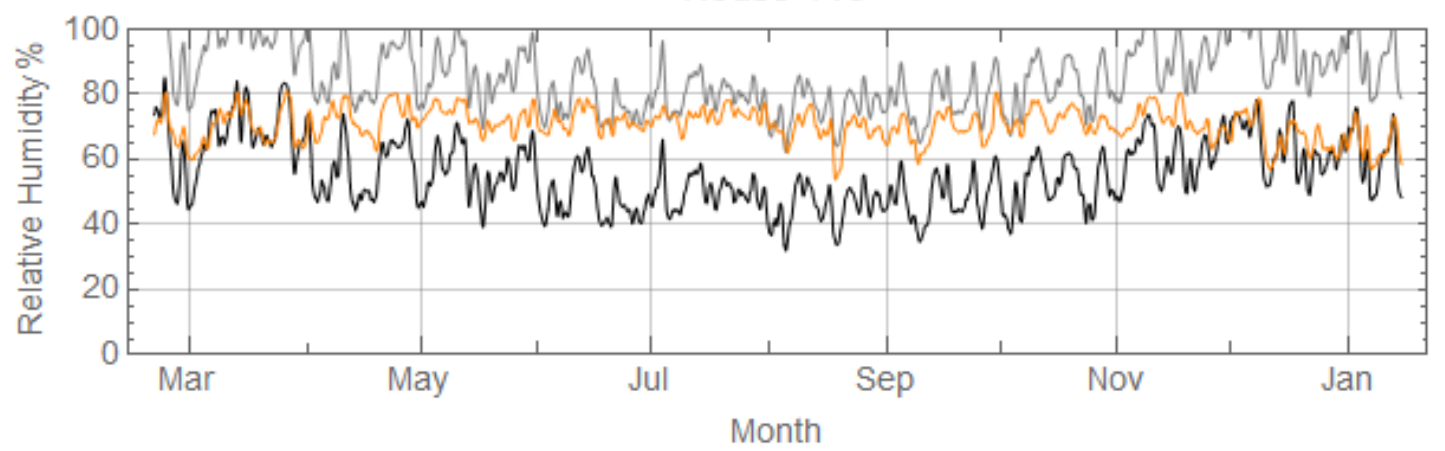

House 120

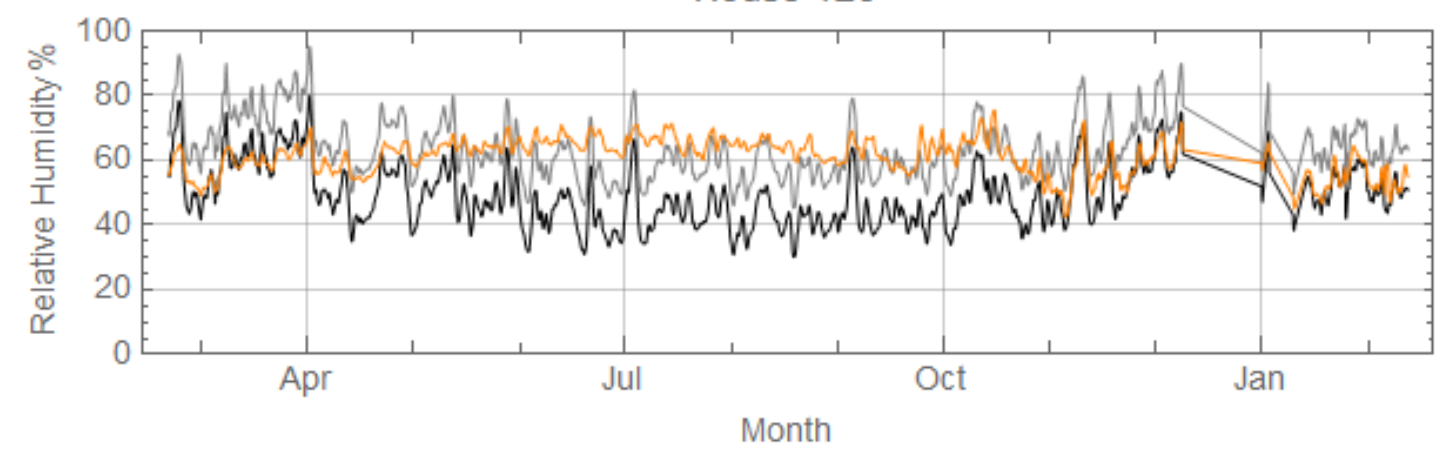


House 128

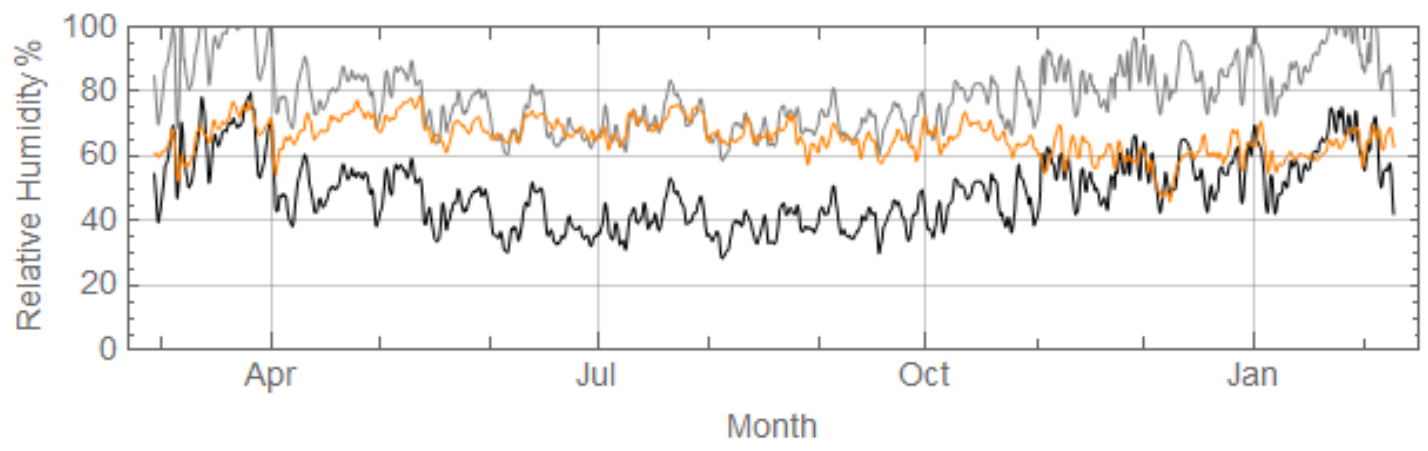

House 130

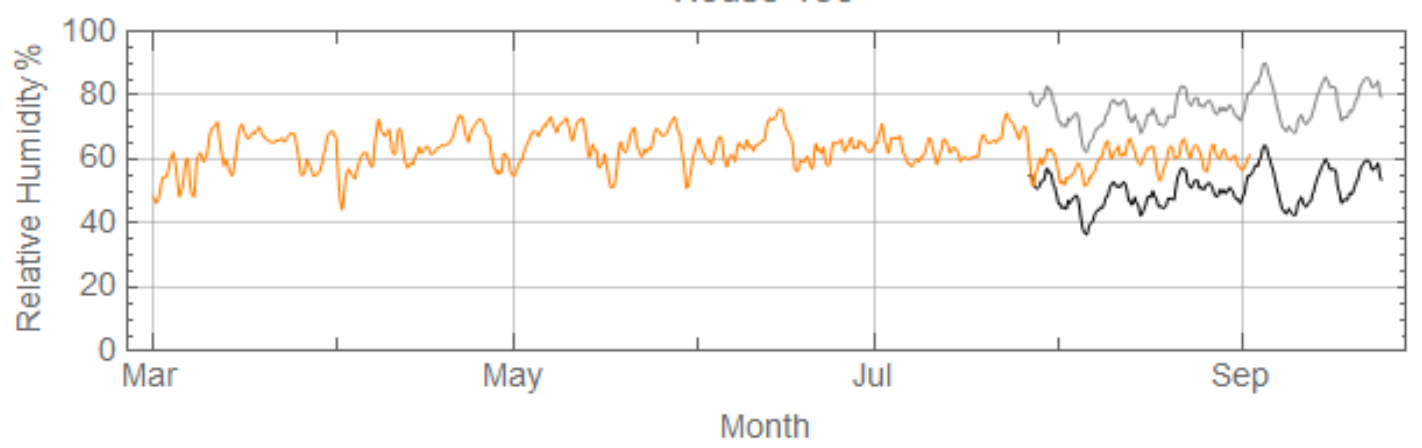

House 140

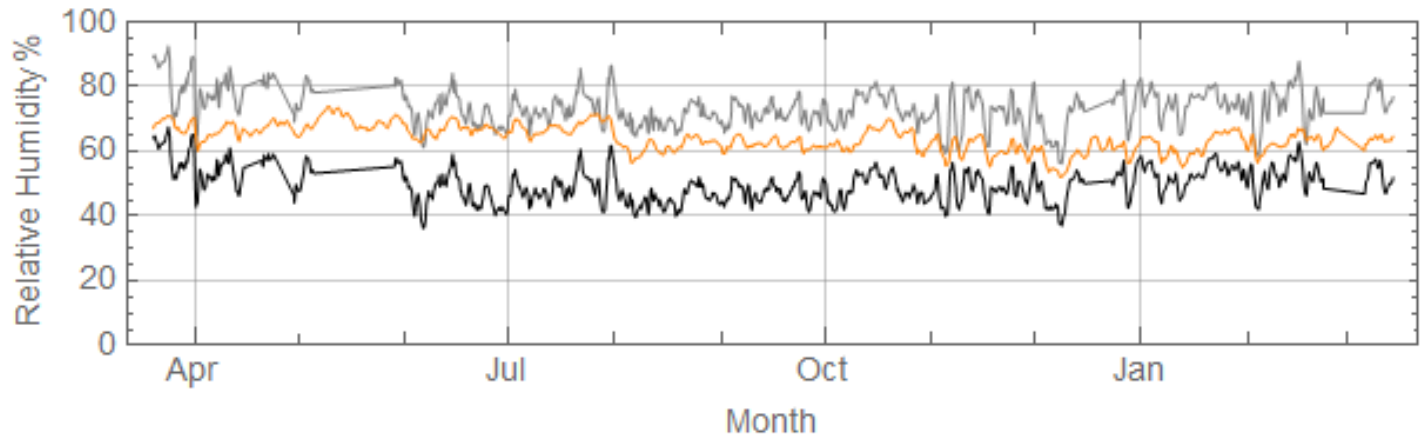

House 156

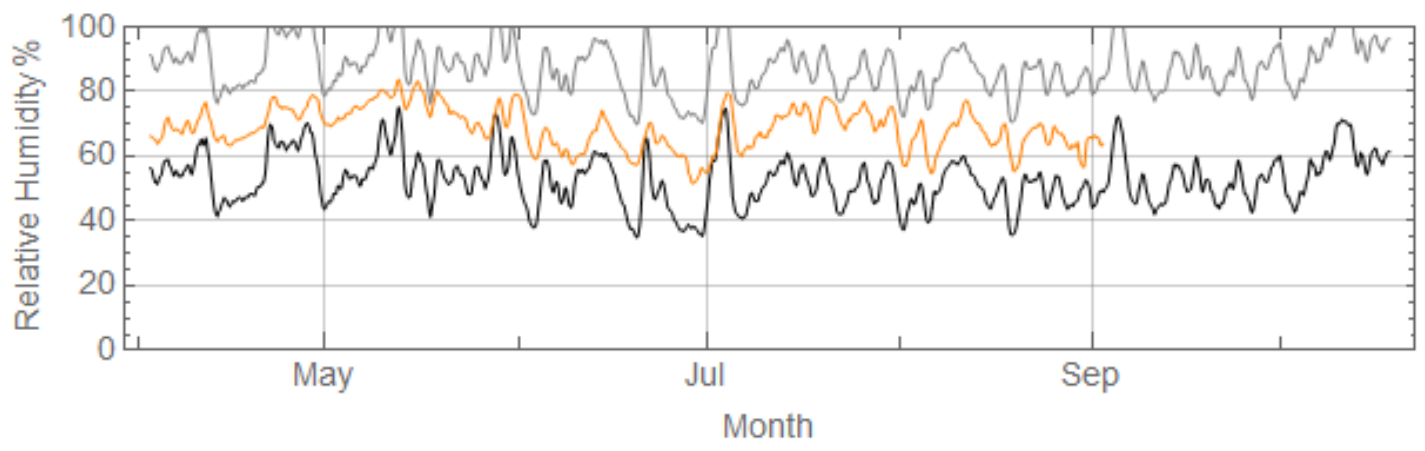


House 171

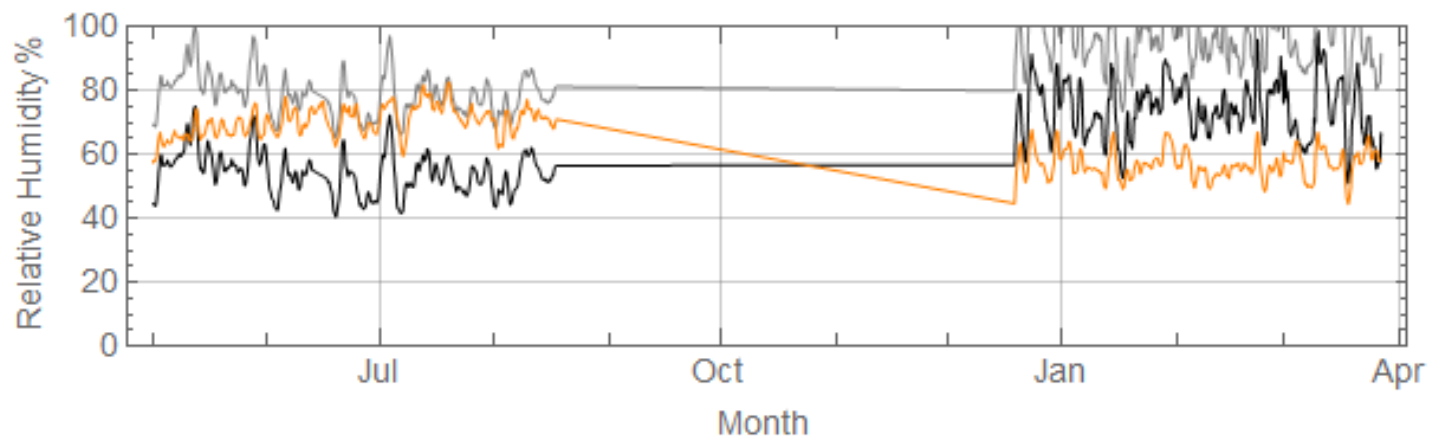

168 | Page 


\subsection{Appendix L}

Application of Indoor Design Humidity: Simplified Method and Intermediate Method

House 100

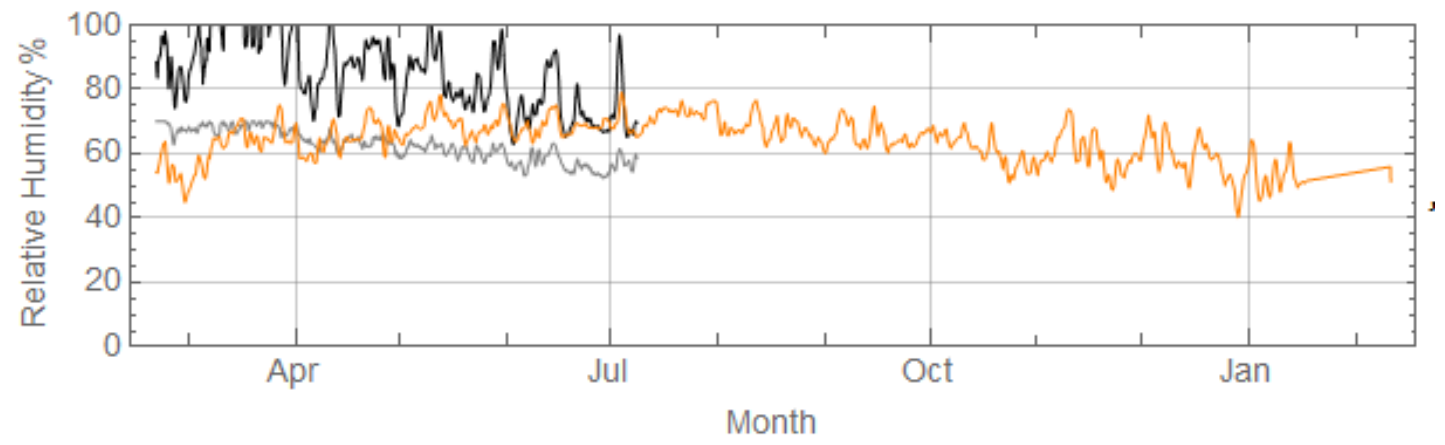

— Indoor Design Humidity: Intermediate Method

— Indoor Design Humidity: Simplified Method

— Measured Indoor Relative Humidity

House 101

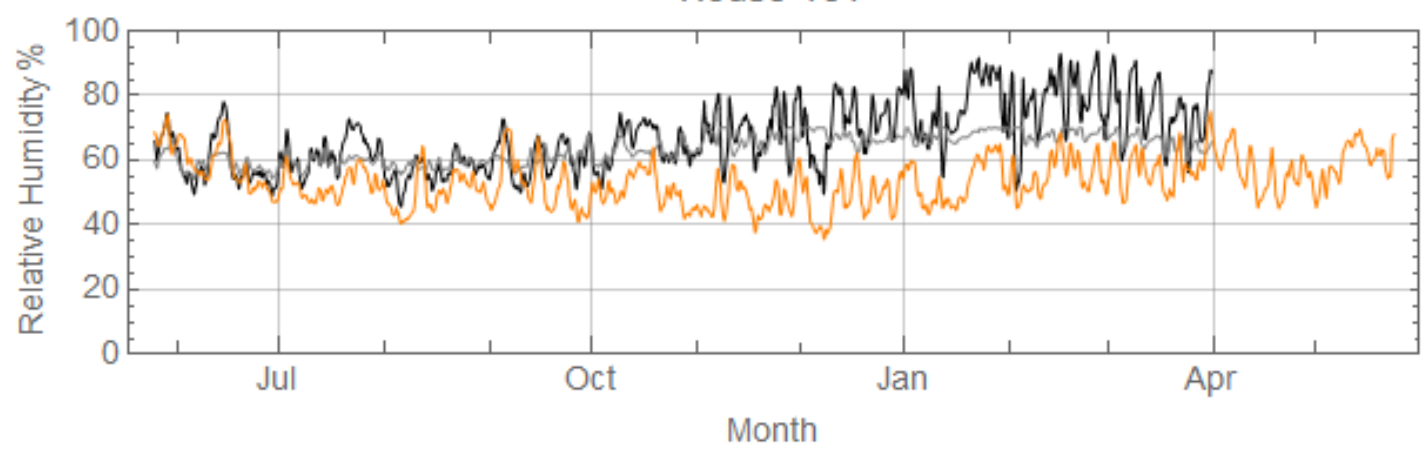

House 103

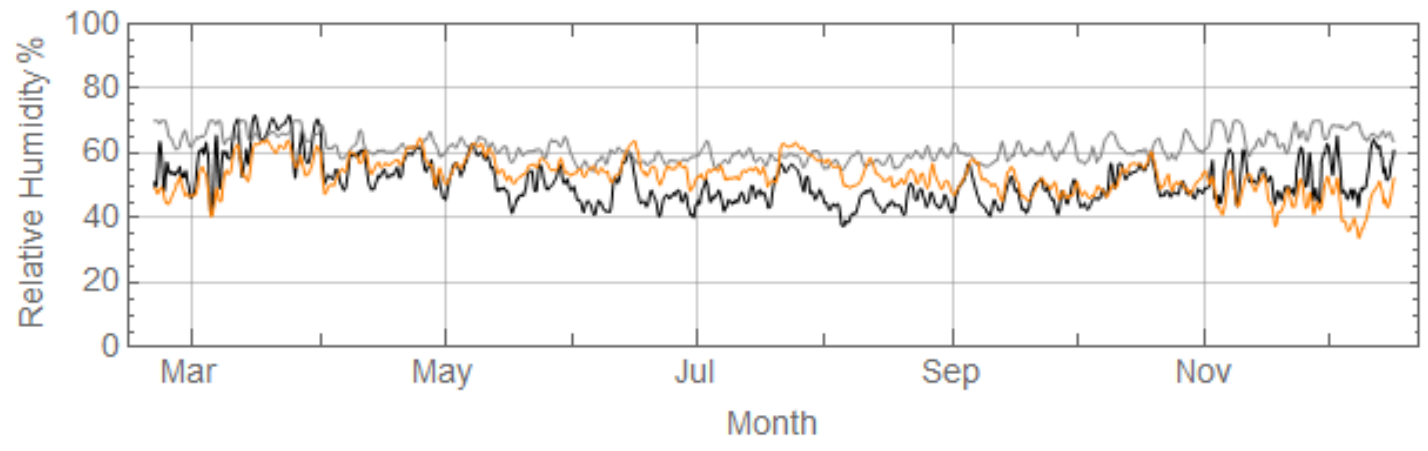


House 104

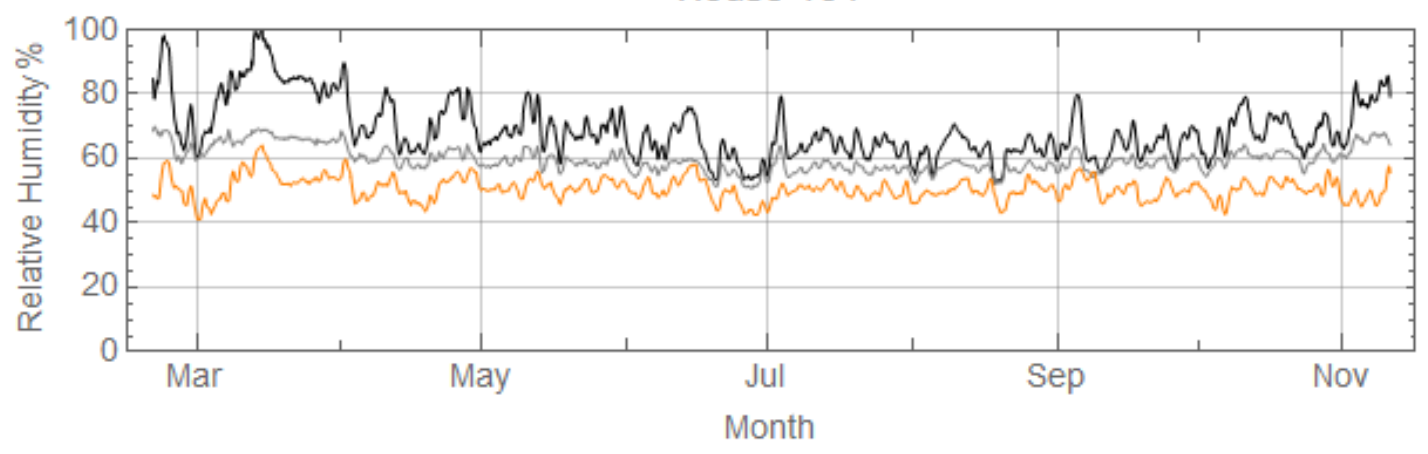

House 106

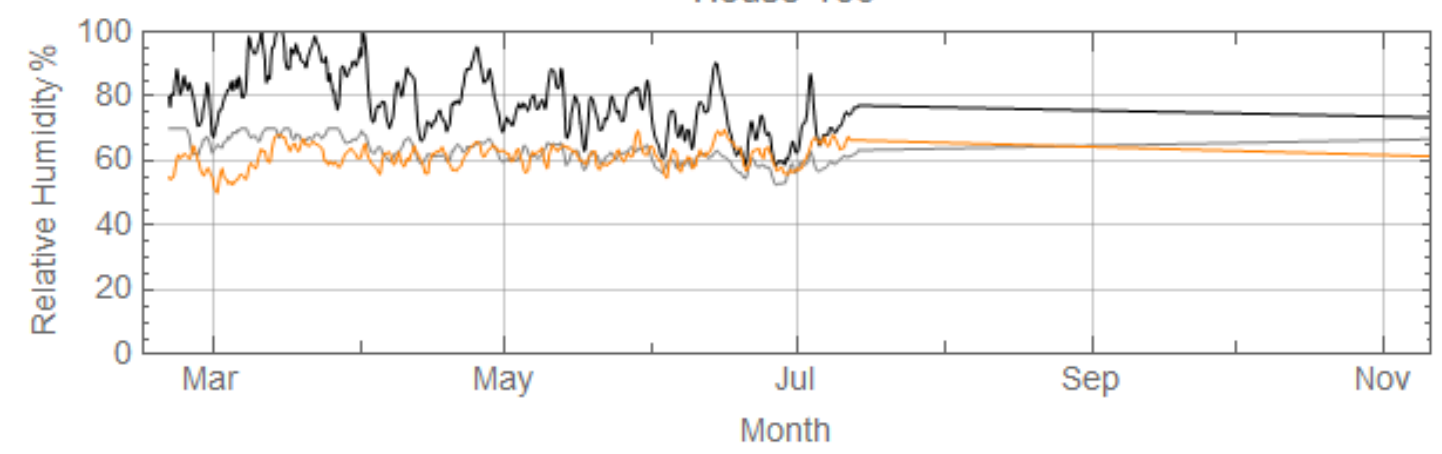

House 110

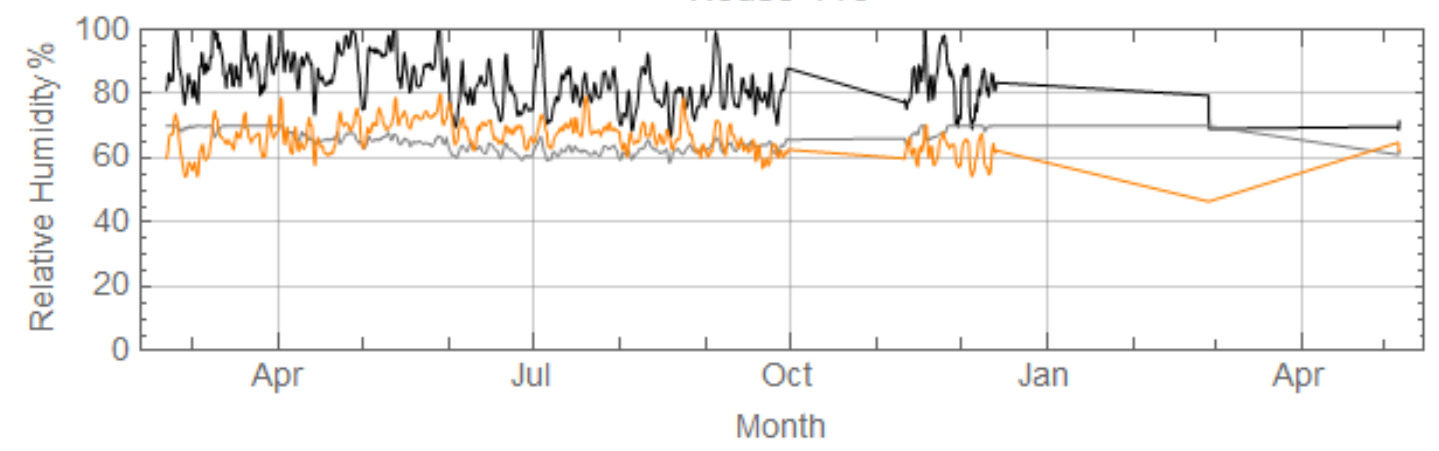

House 111

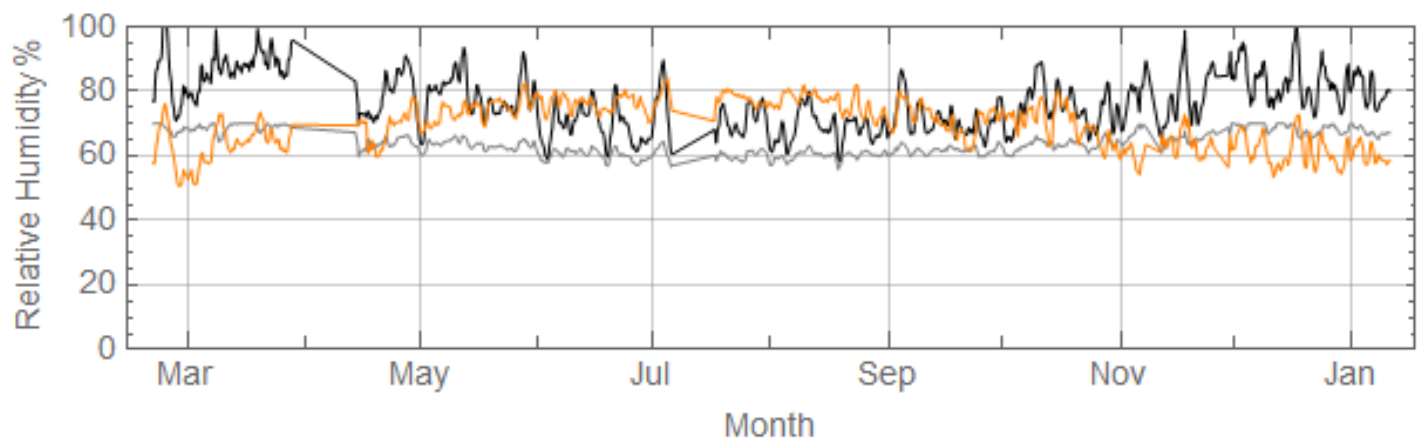


House 113

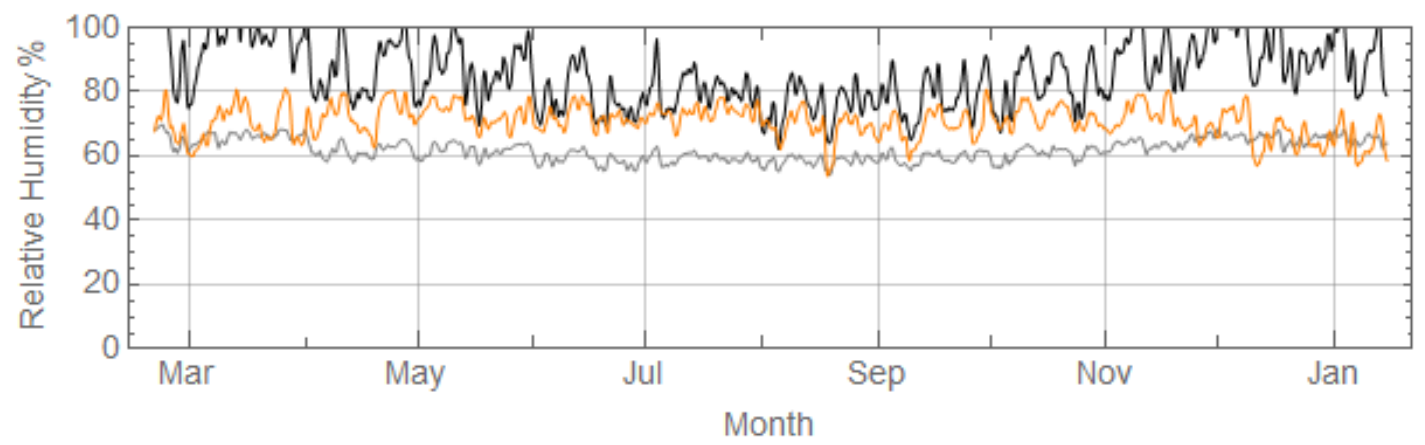

House 116

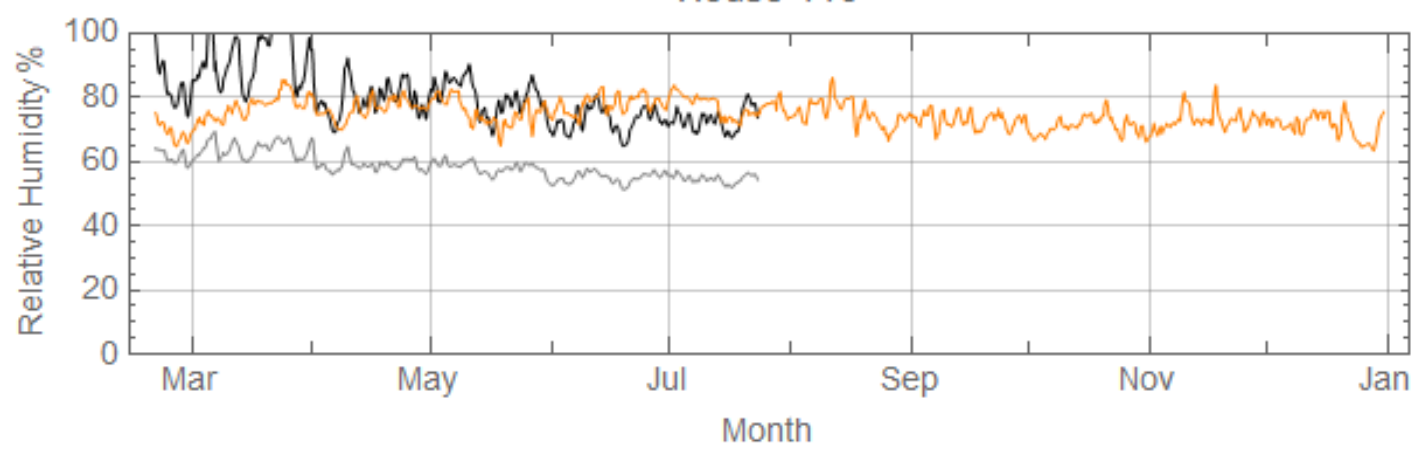

House 117

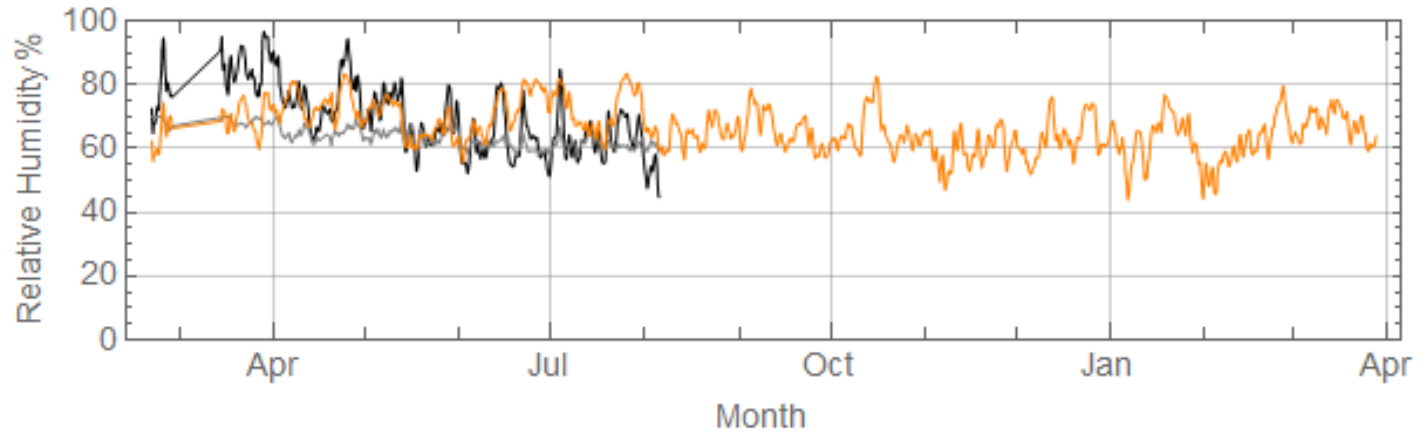

House 120

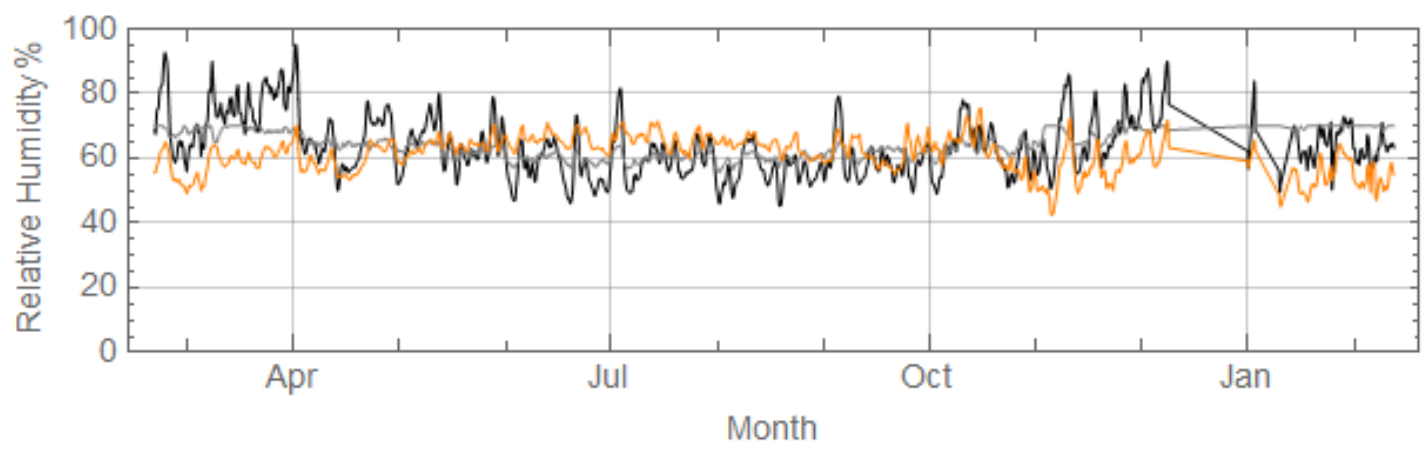


House 121

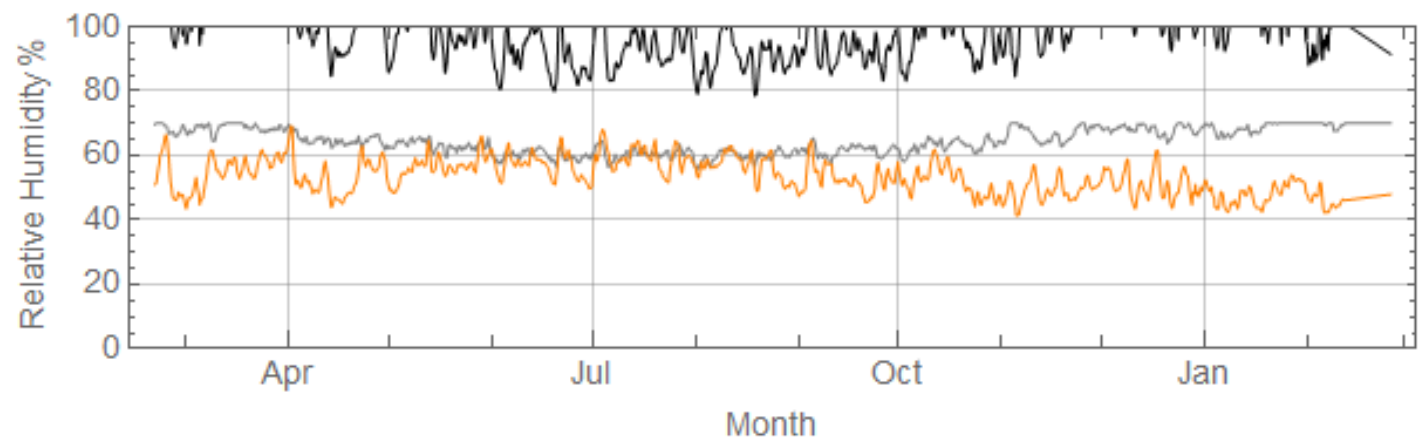

House 124

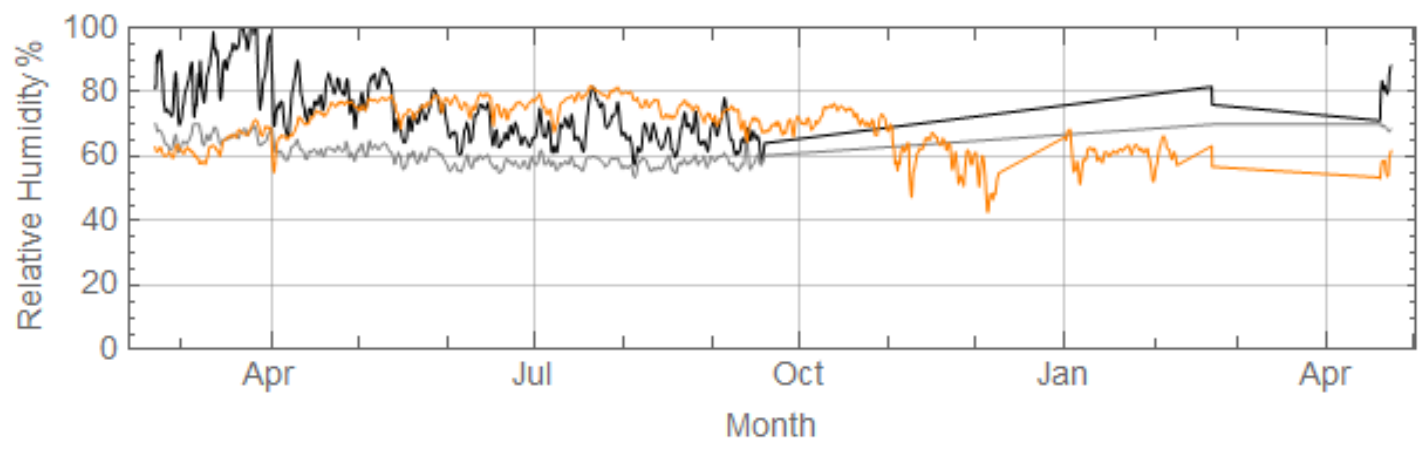

House 125

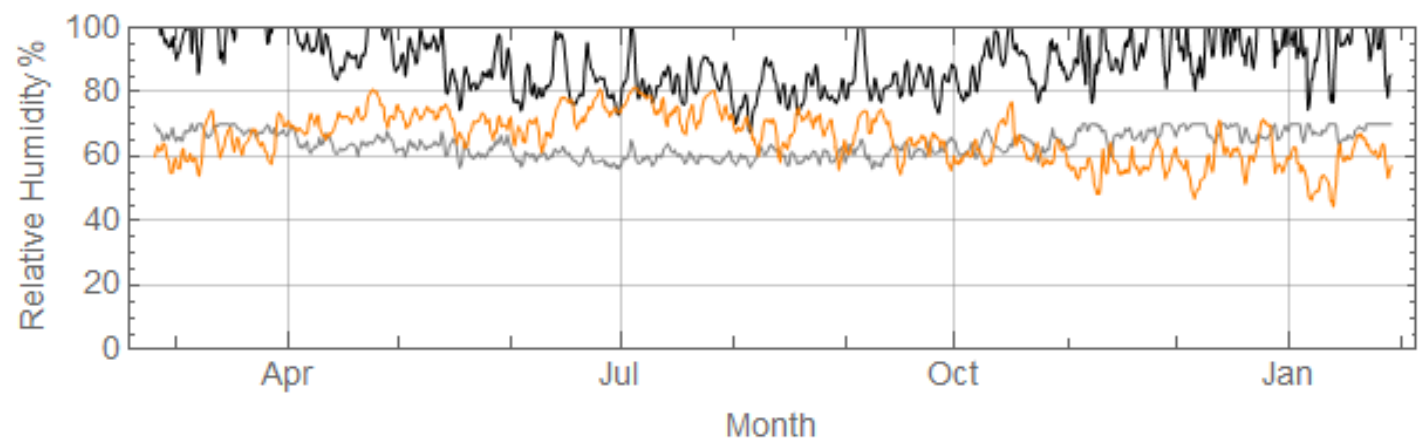

House 128

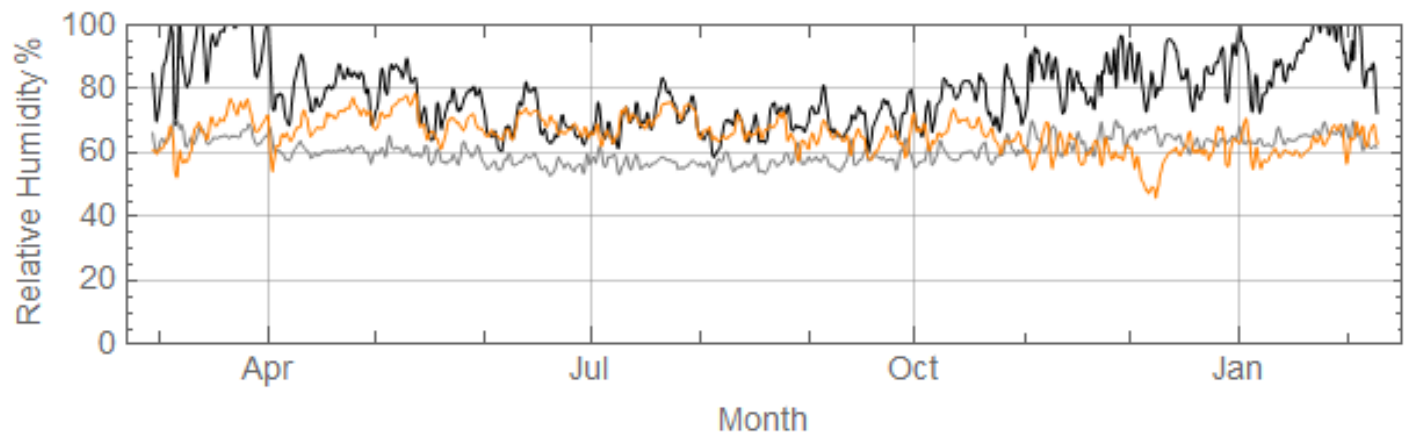


House 129

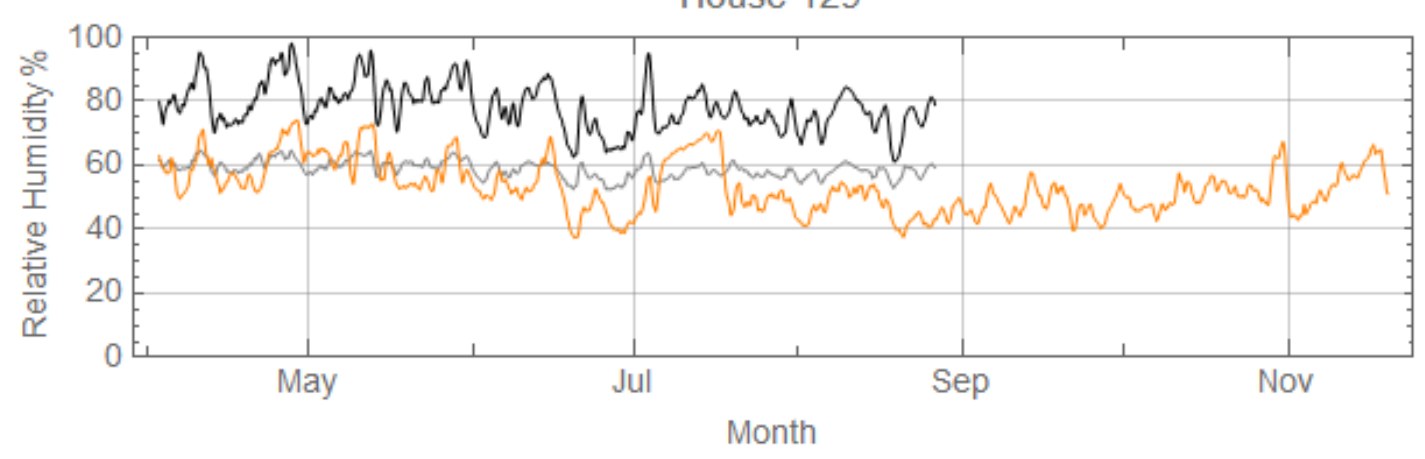

House 130

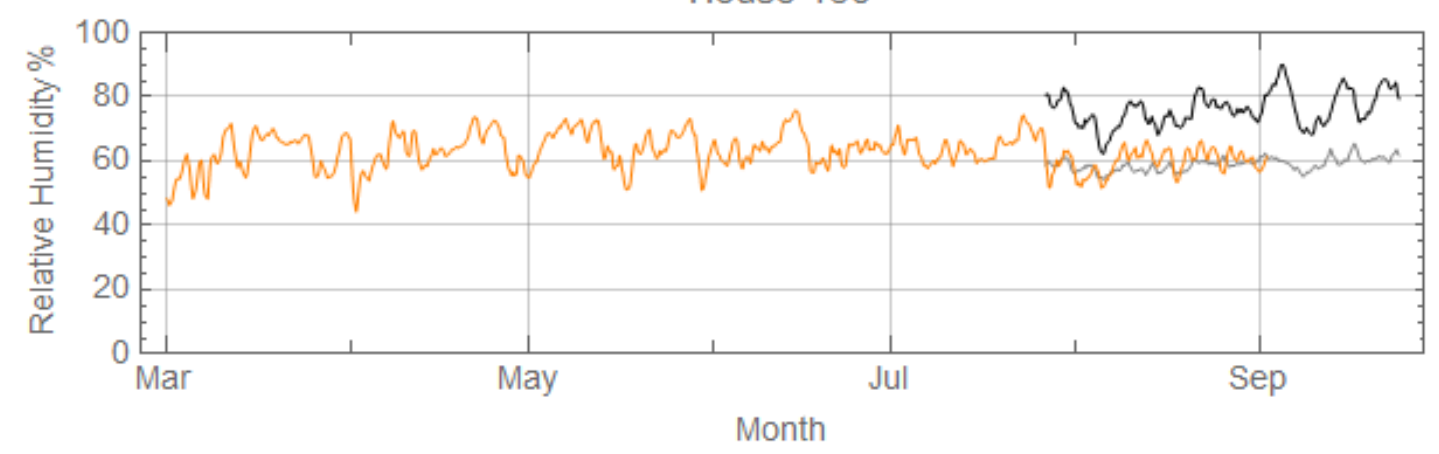

House 135

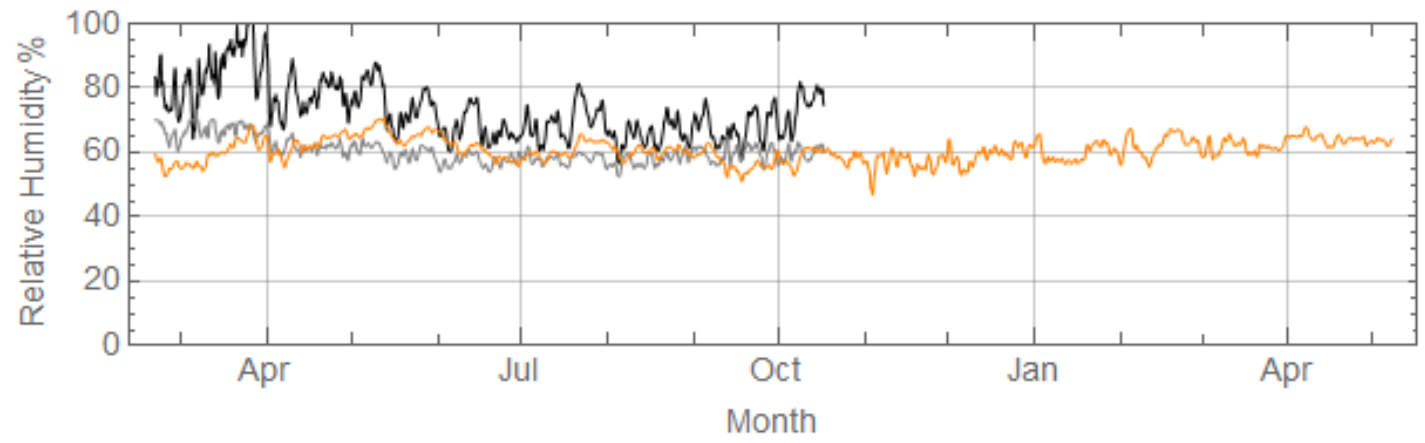

House 136

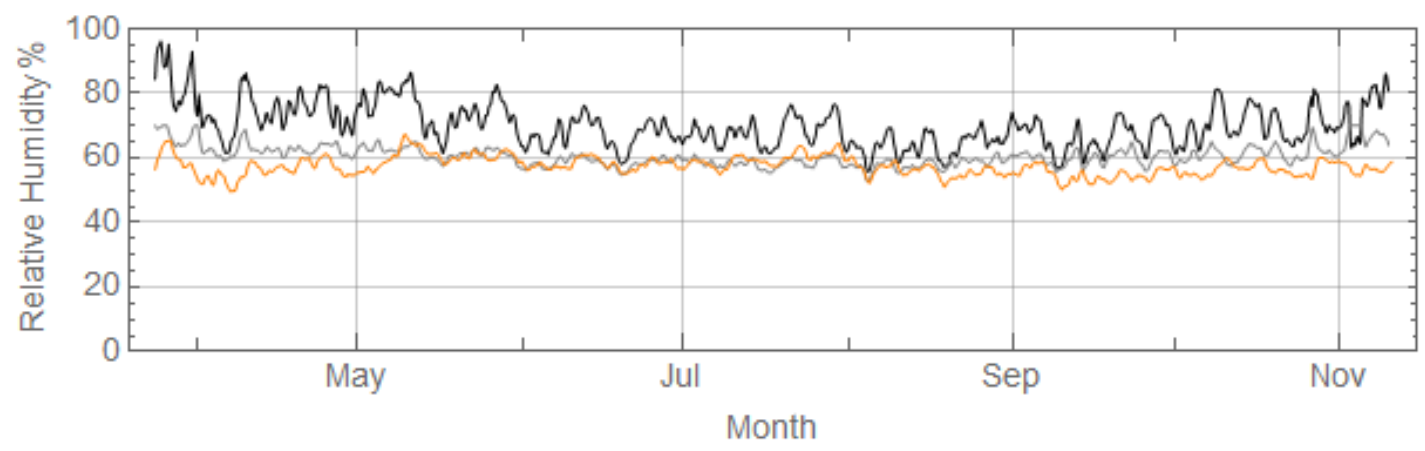


House 137

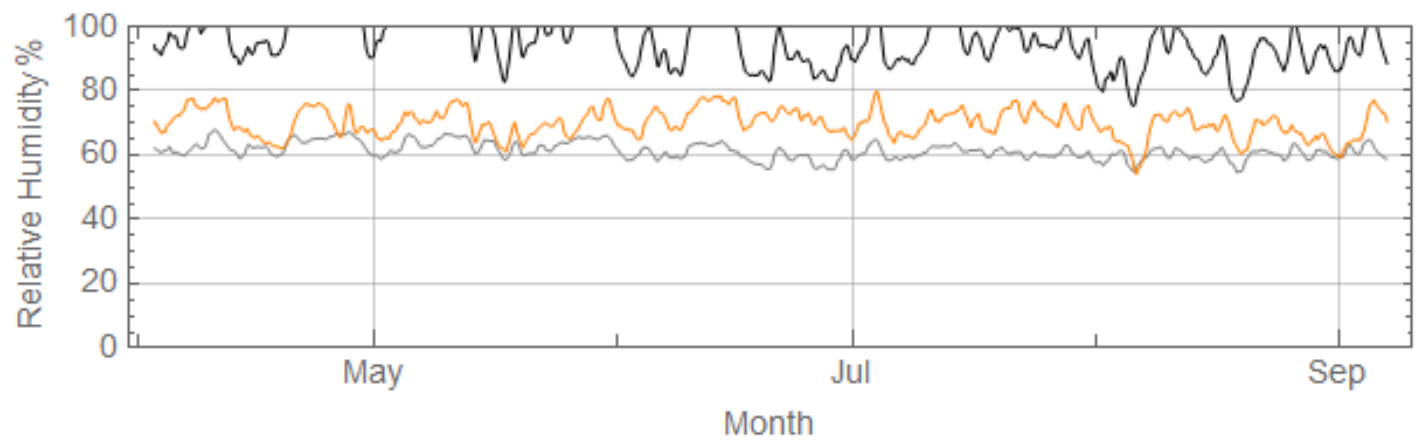

House 138

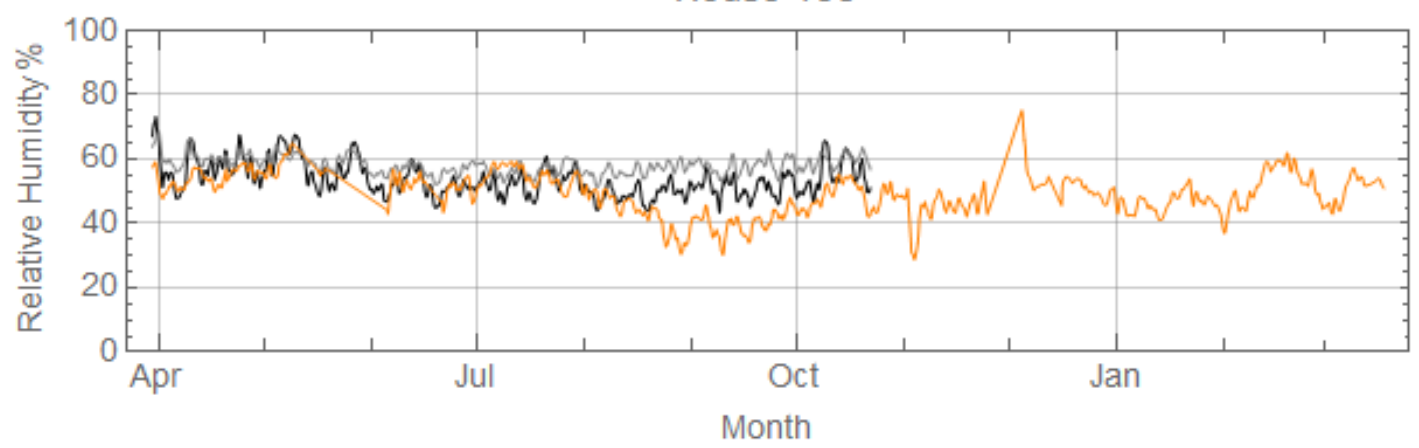

House 139

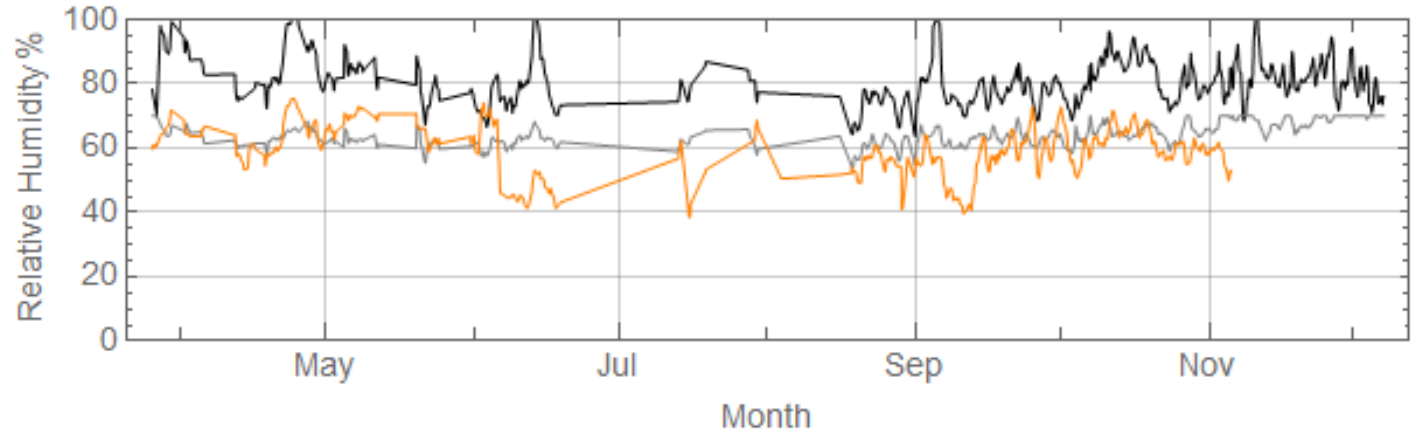

House 140

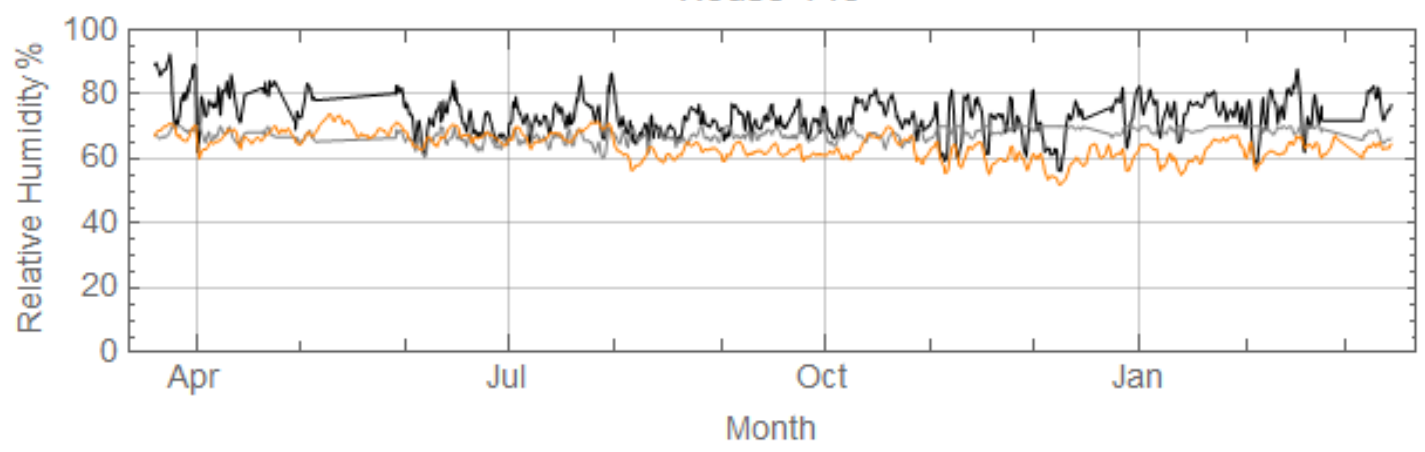


House 142

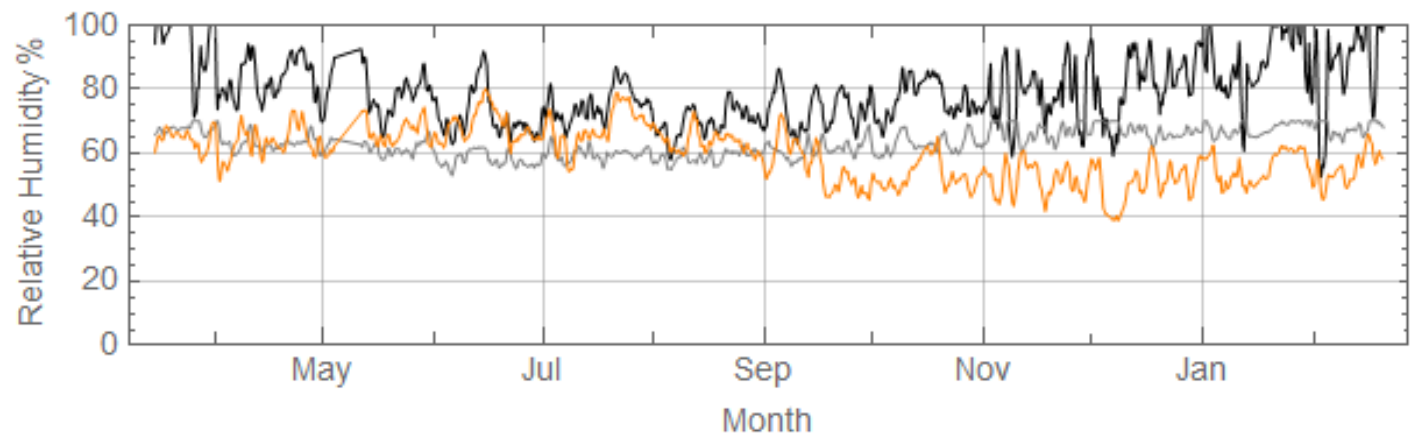

House 143

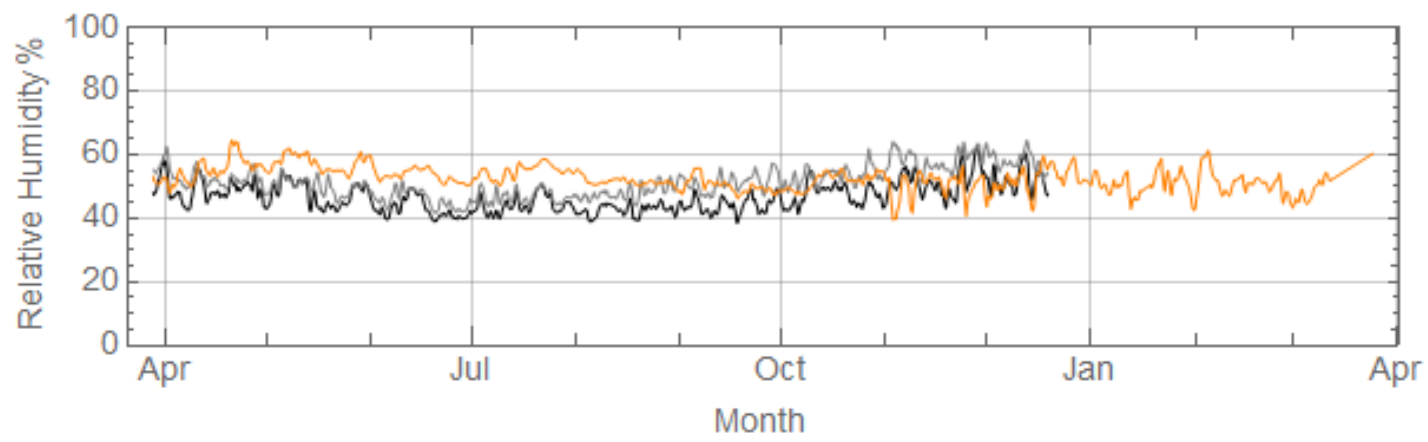

House 144

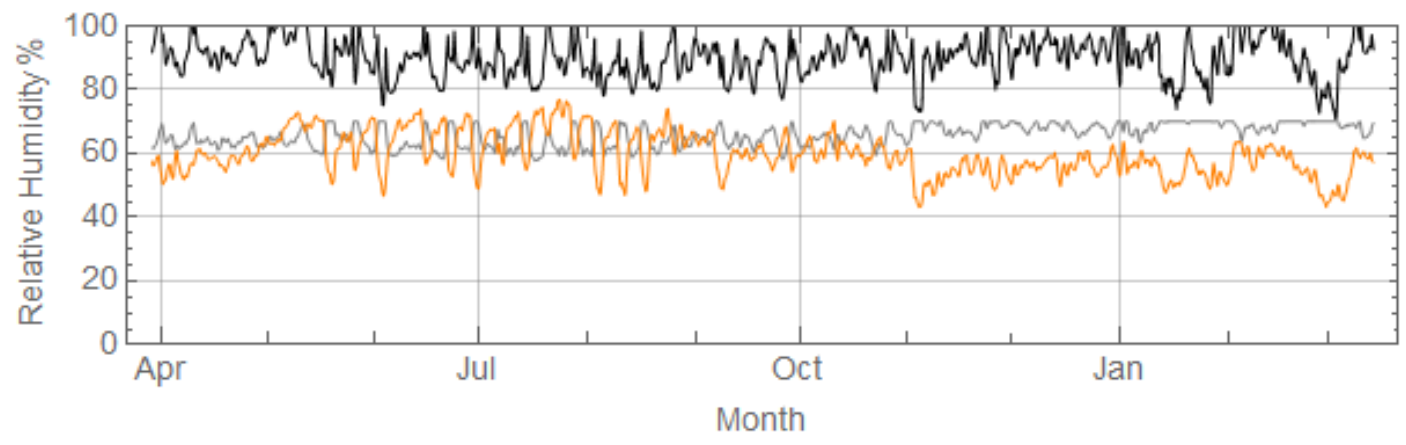

House 145

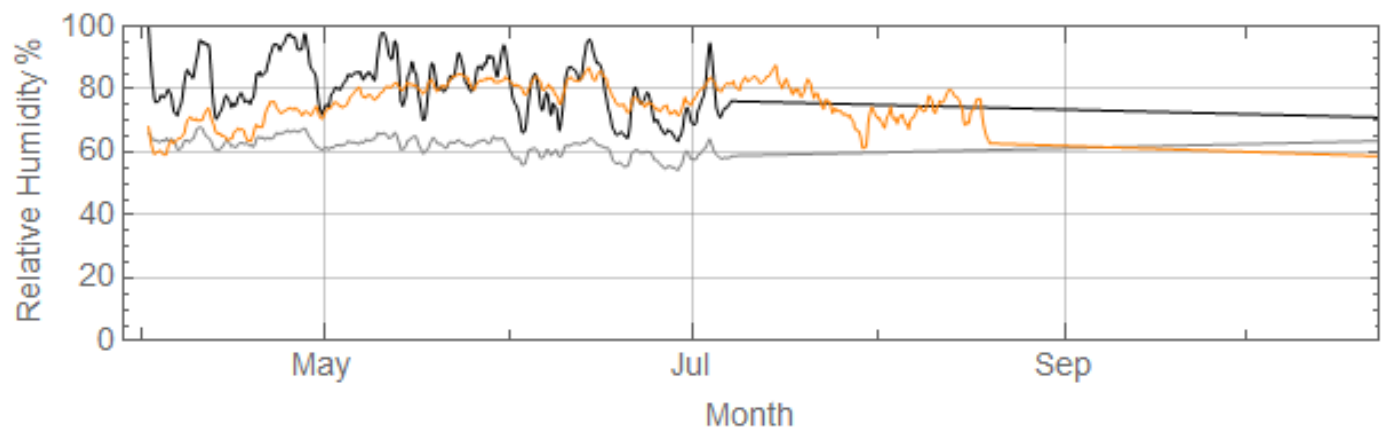


House 148

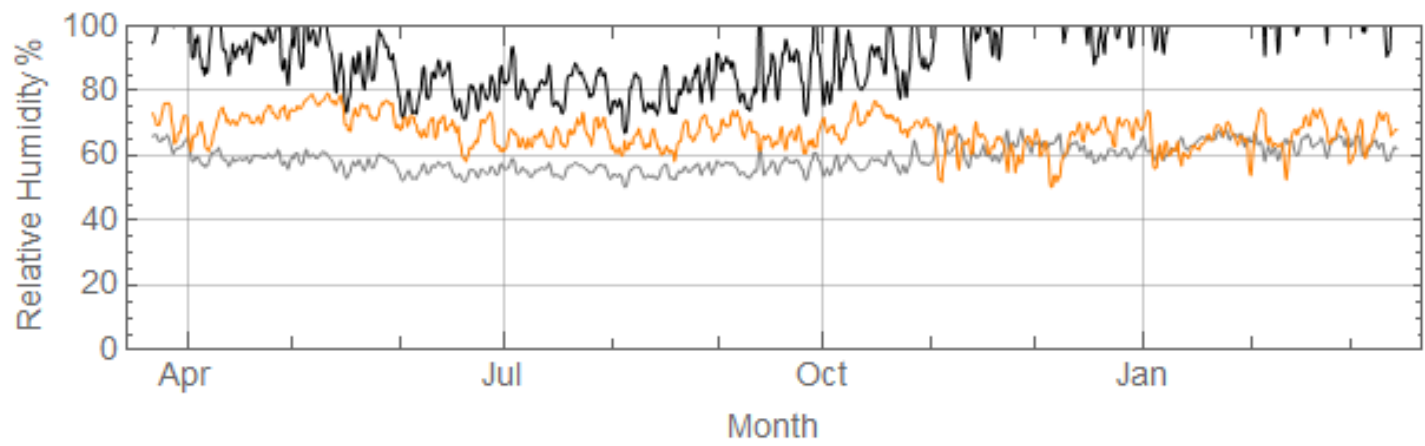

House 149

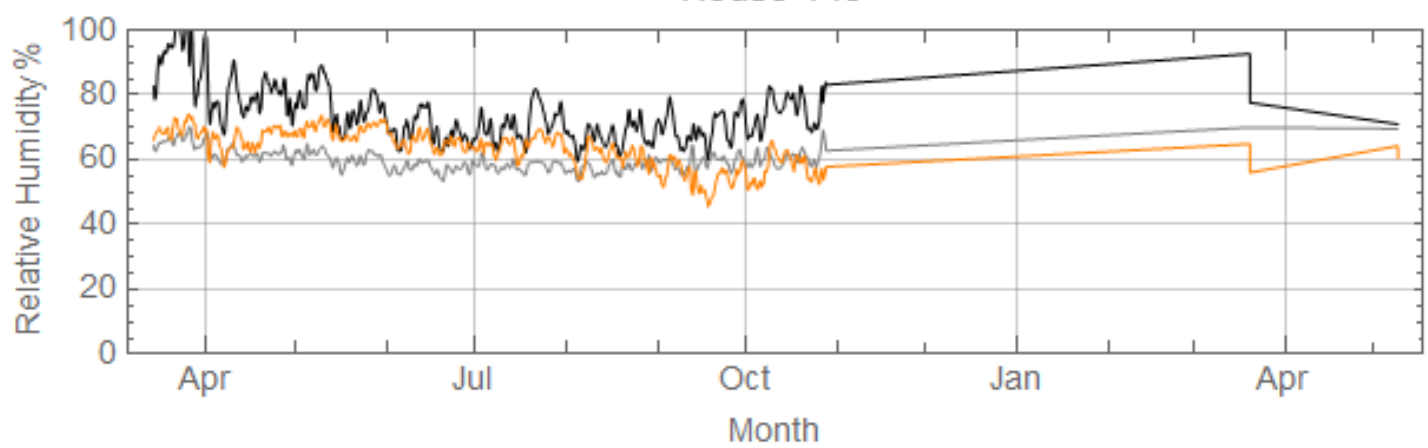

House 150

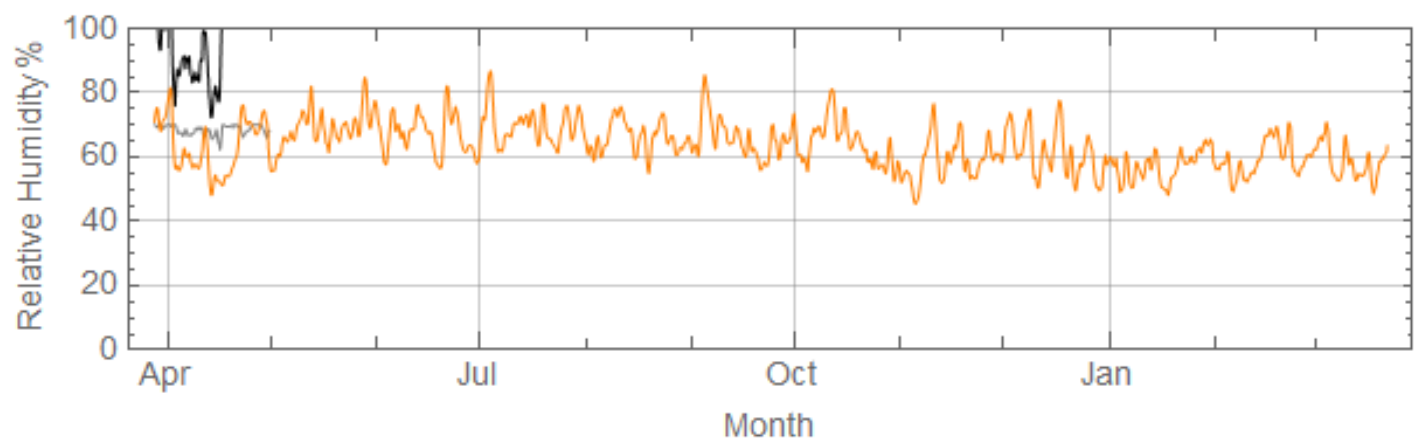

House 151

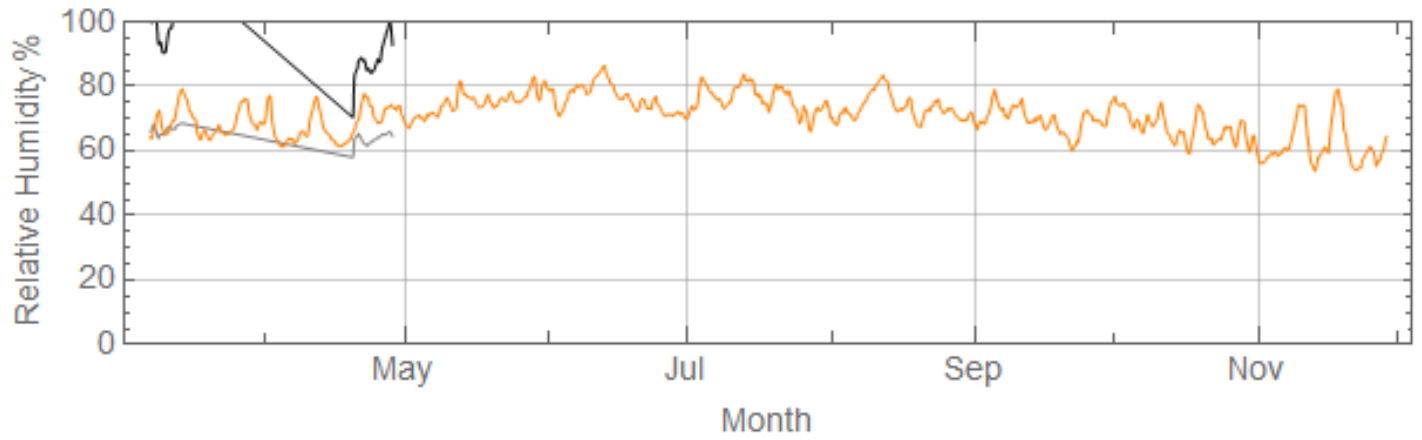


House 152

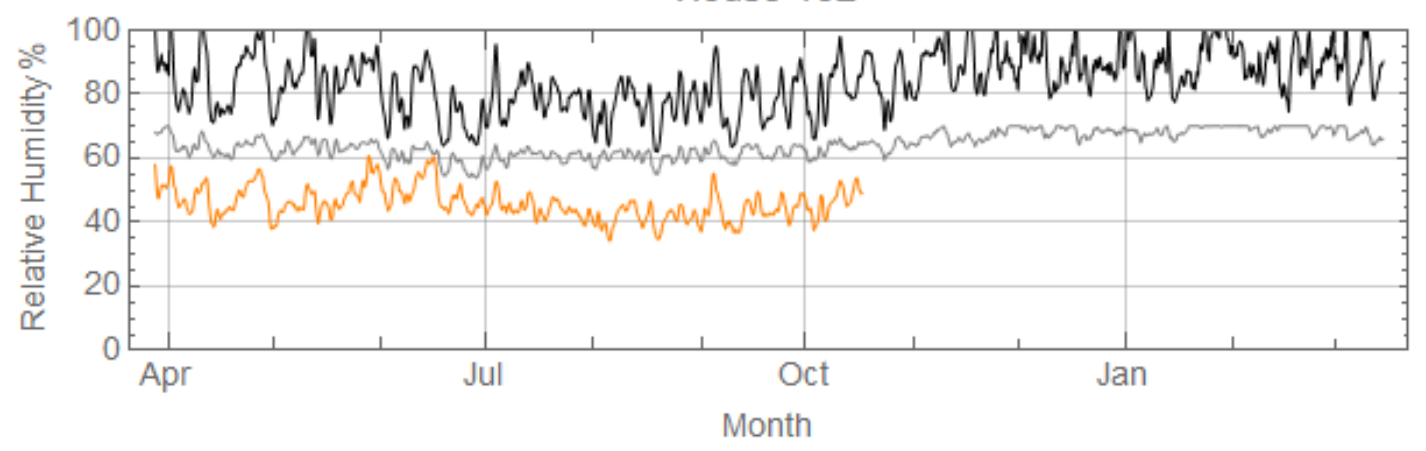

House 153

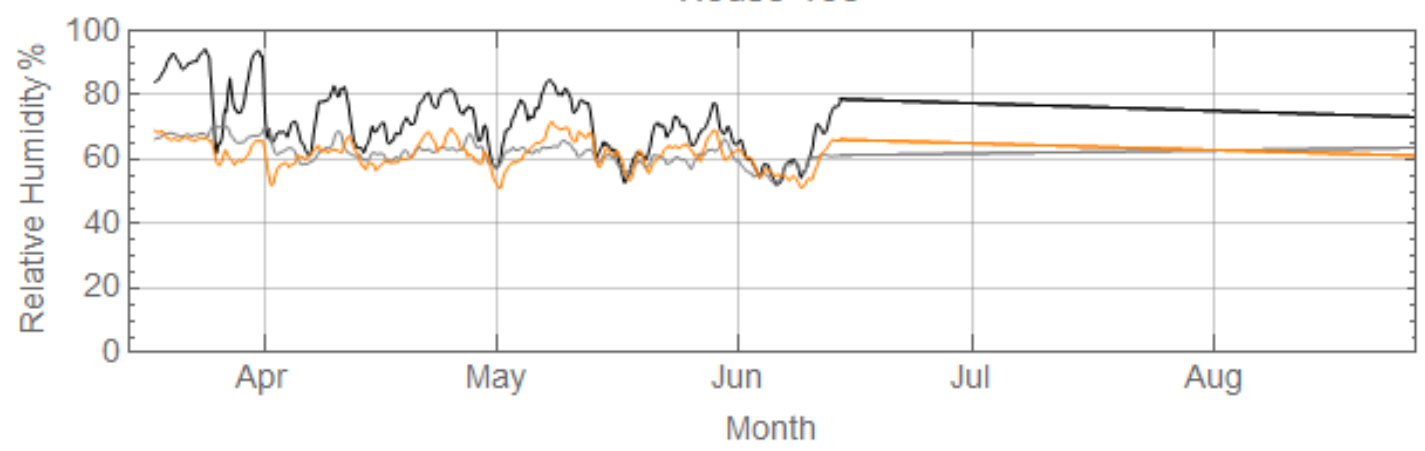

House 154

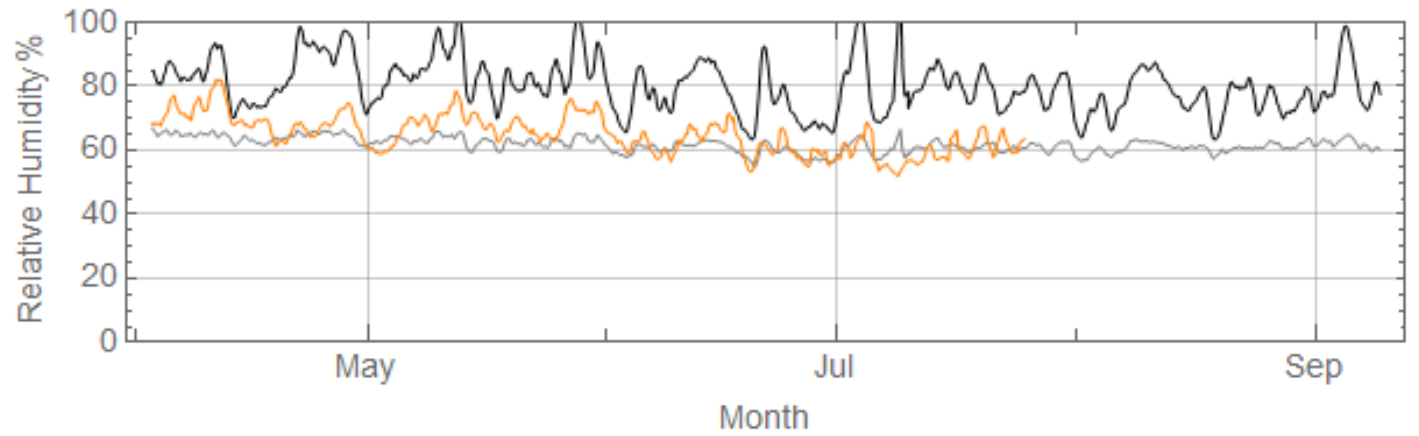

House 155

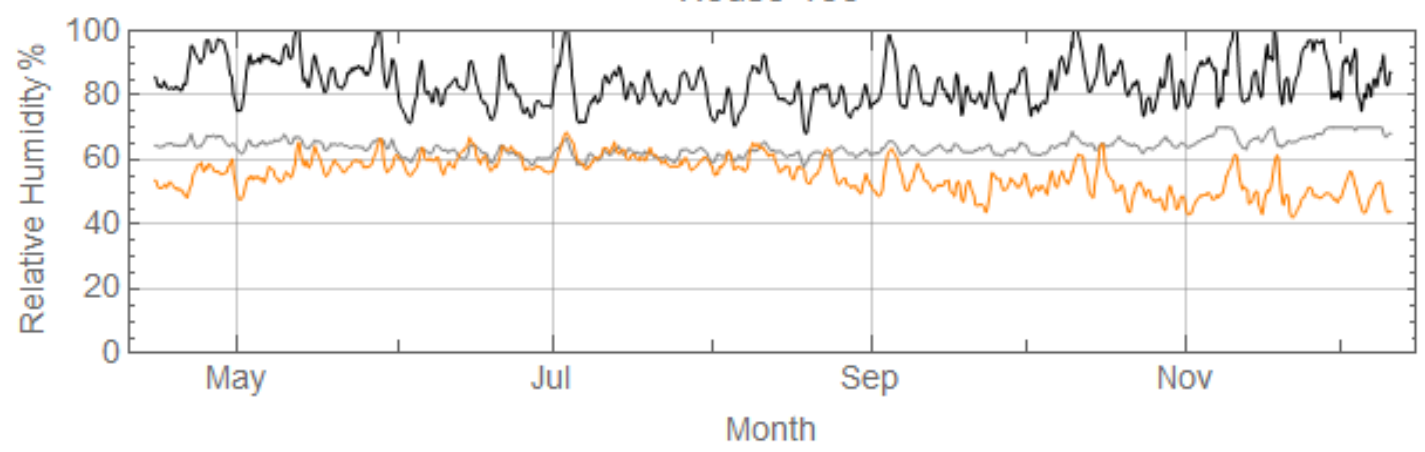


House 156

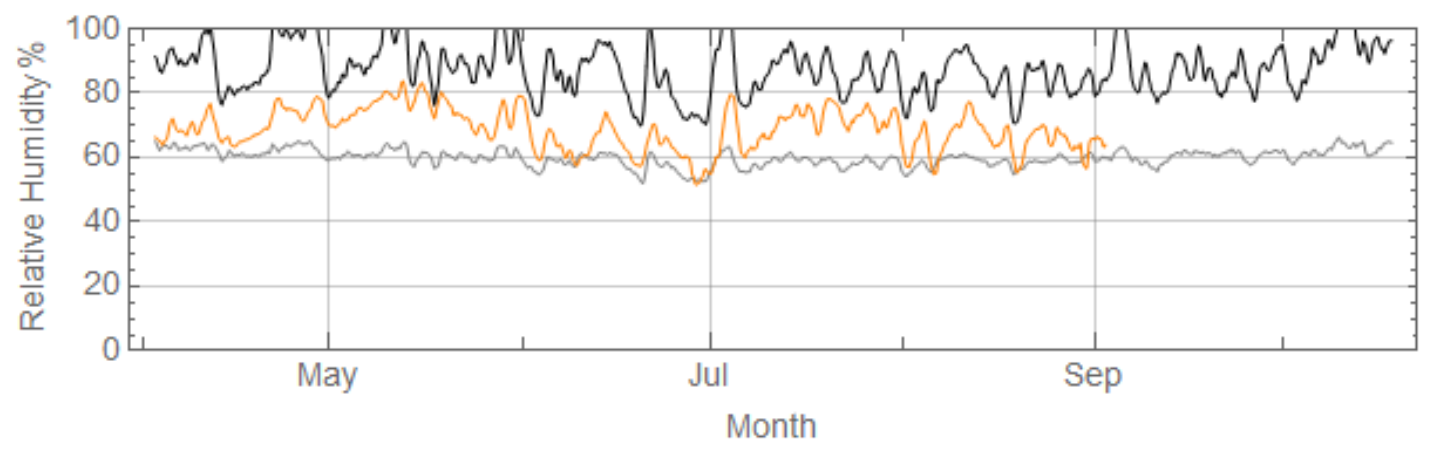

House 161

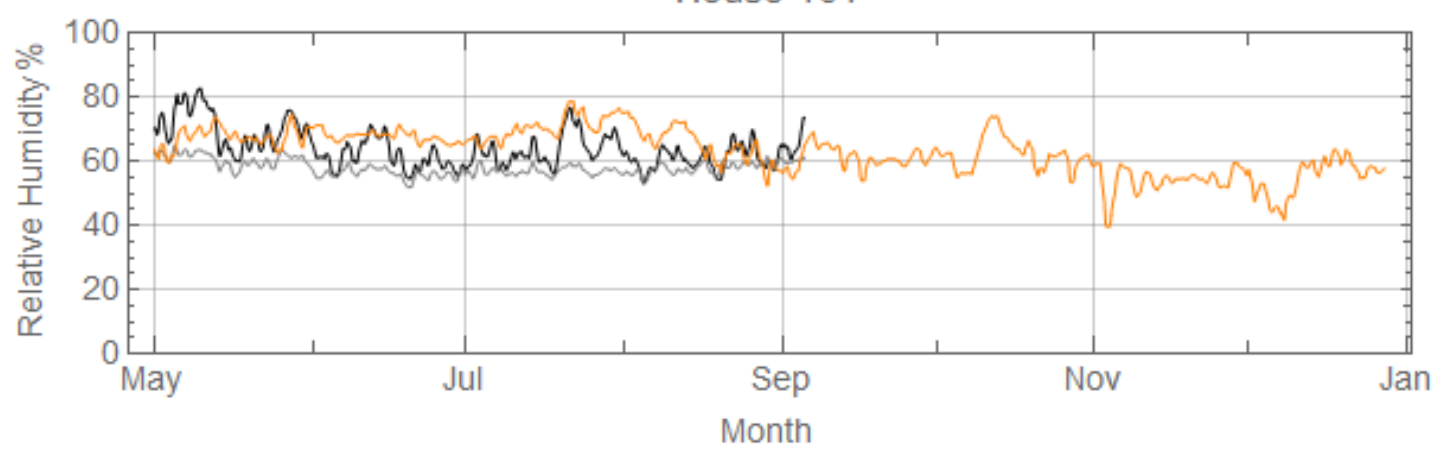

House 162

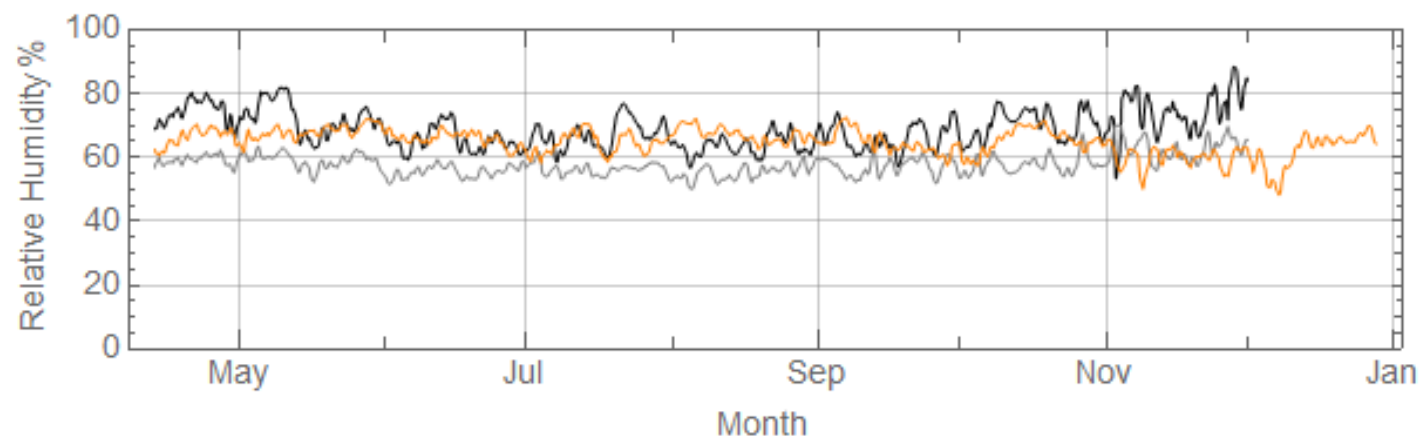

House 164

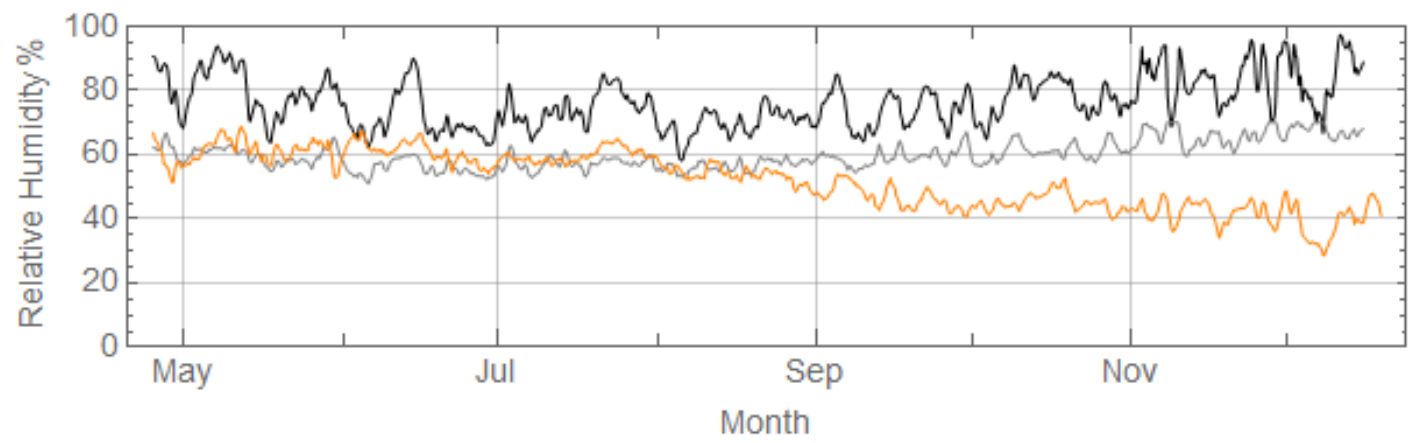


House 168

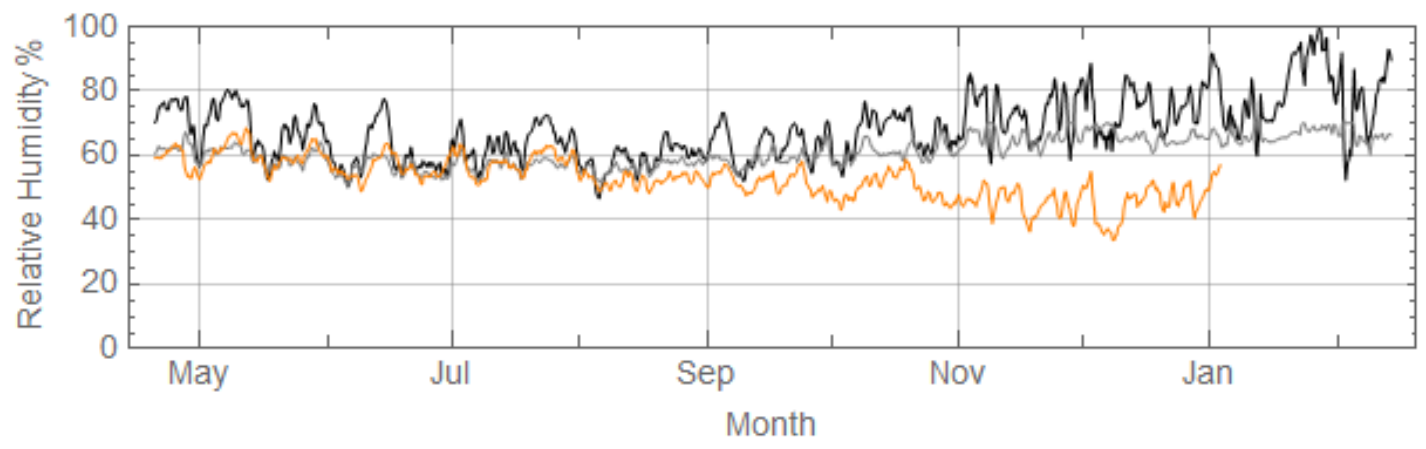

House 169

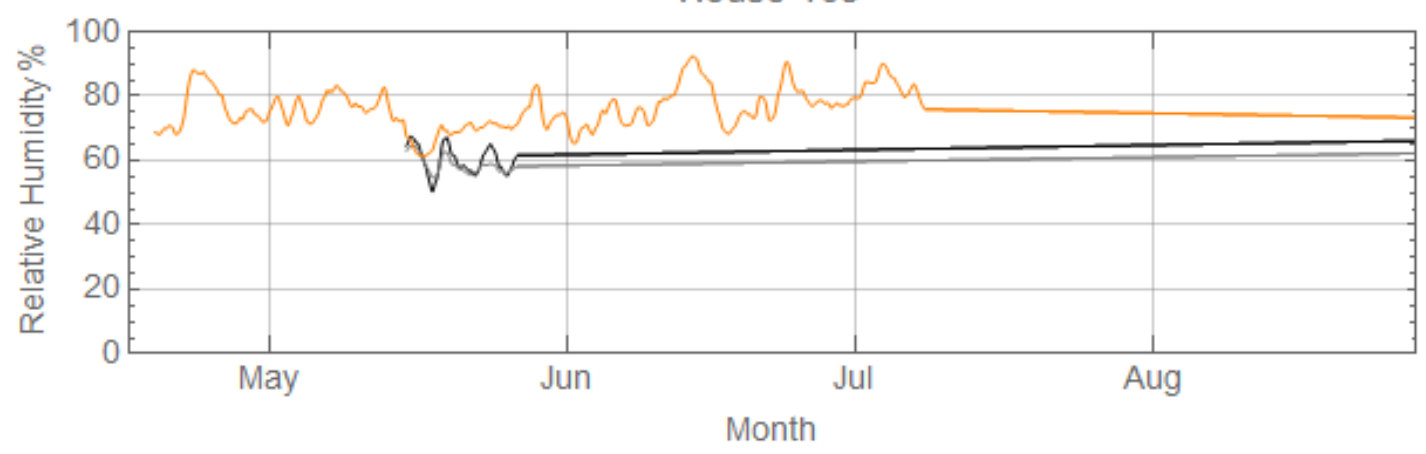

House 170

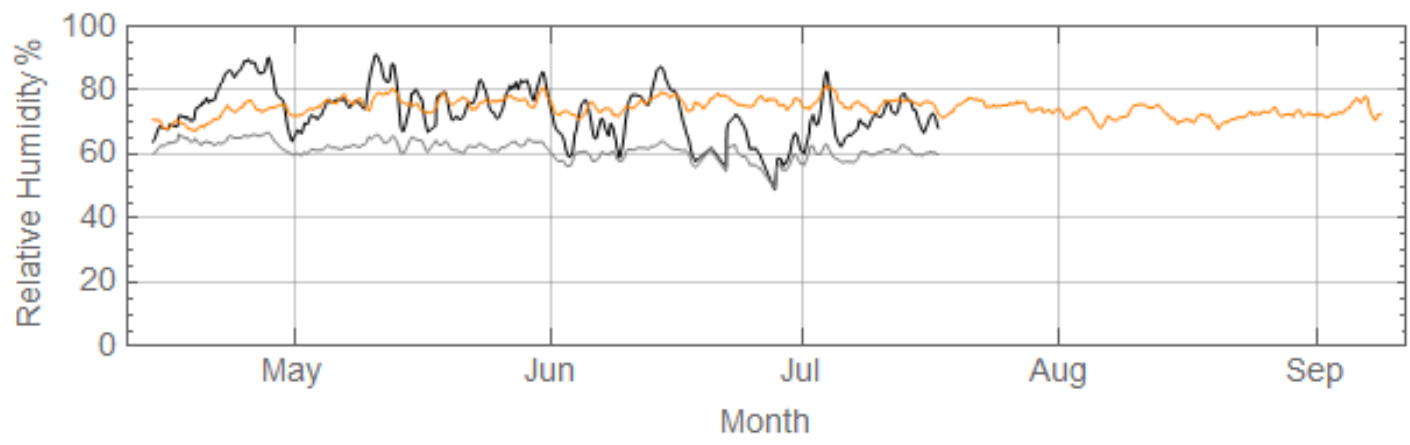

House 171

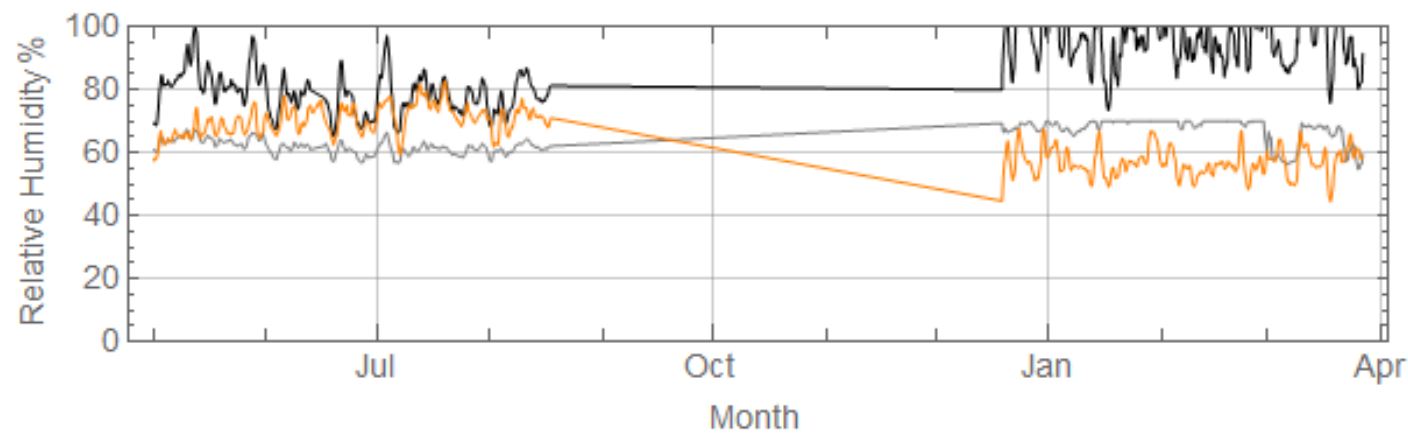


House 177

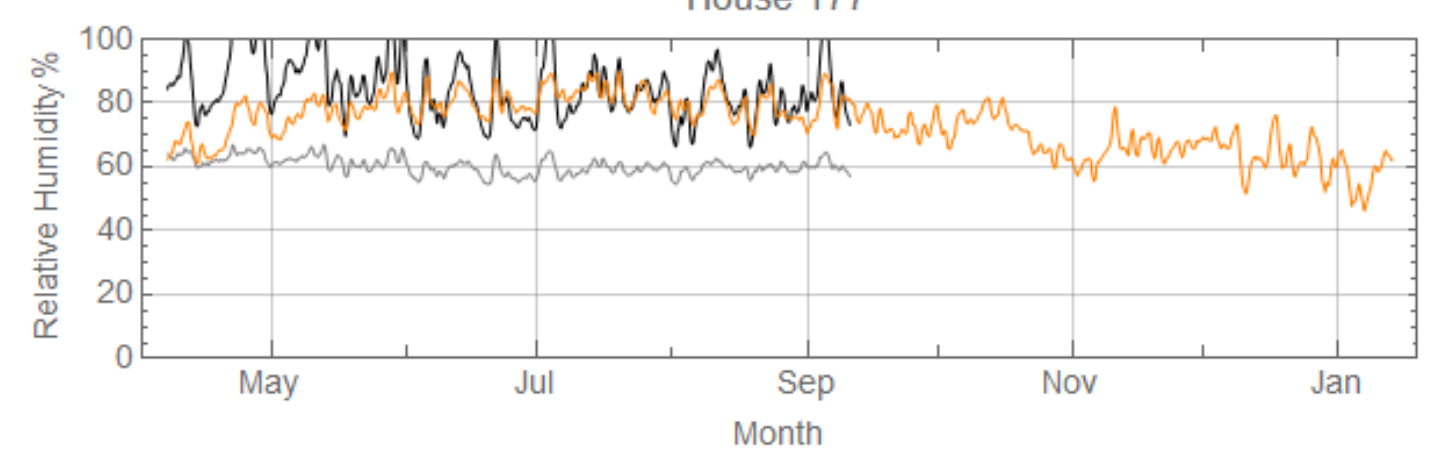

House 178

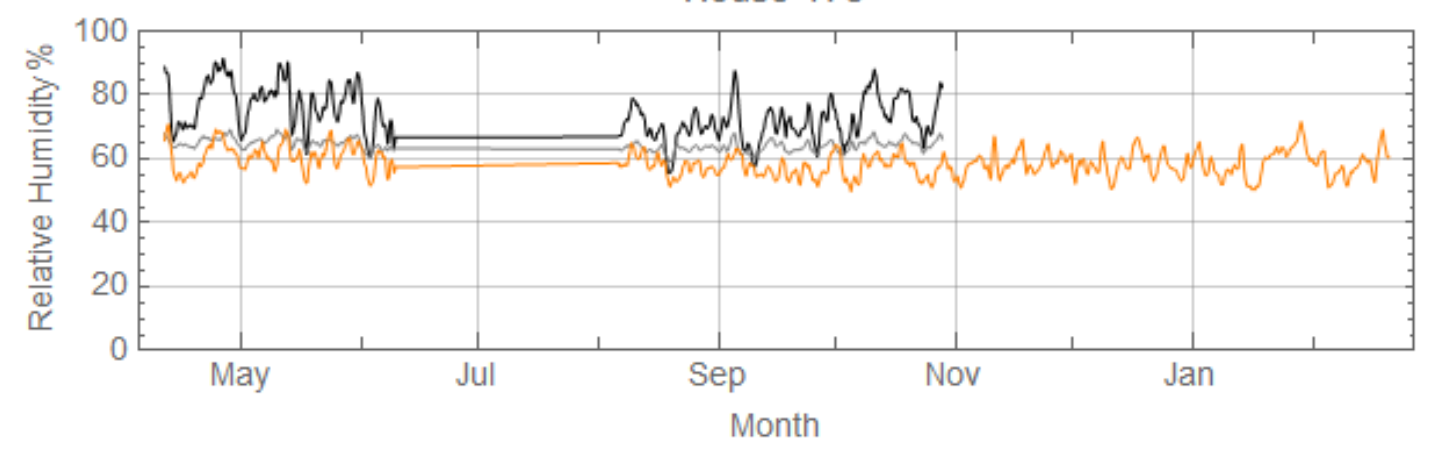

House 180

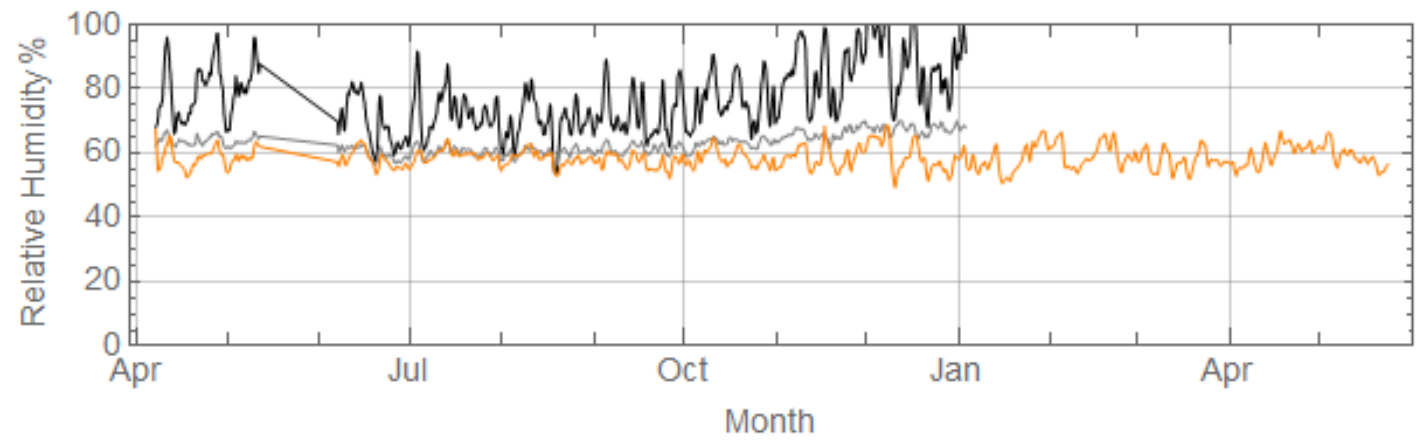




\subsection{Appendix M}
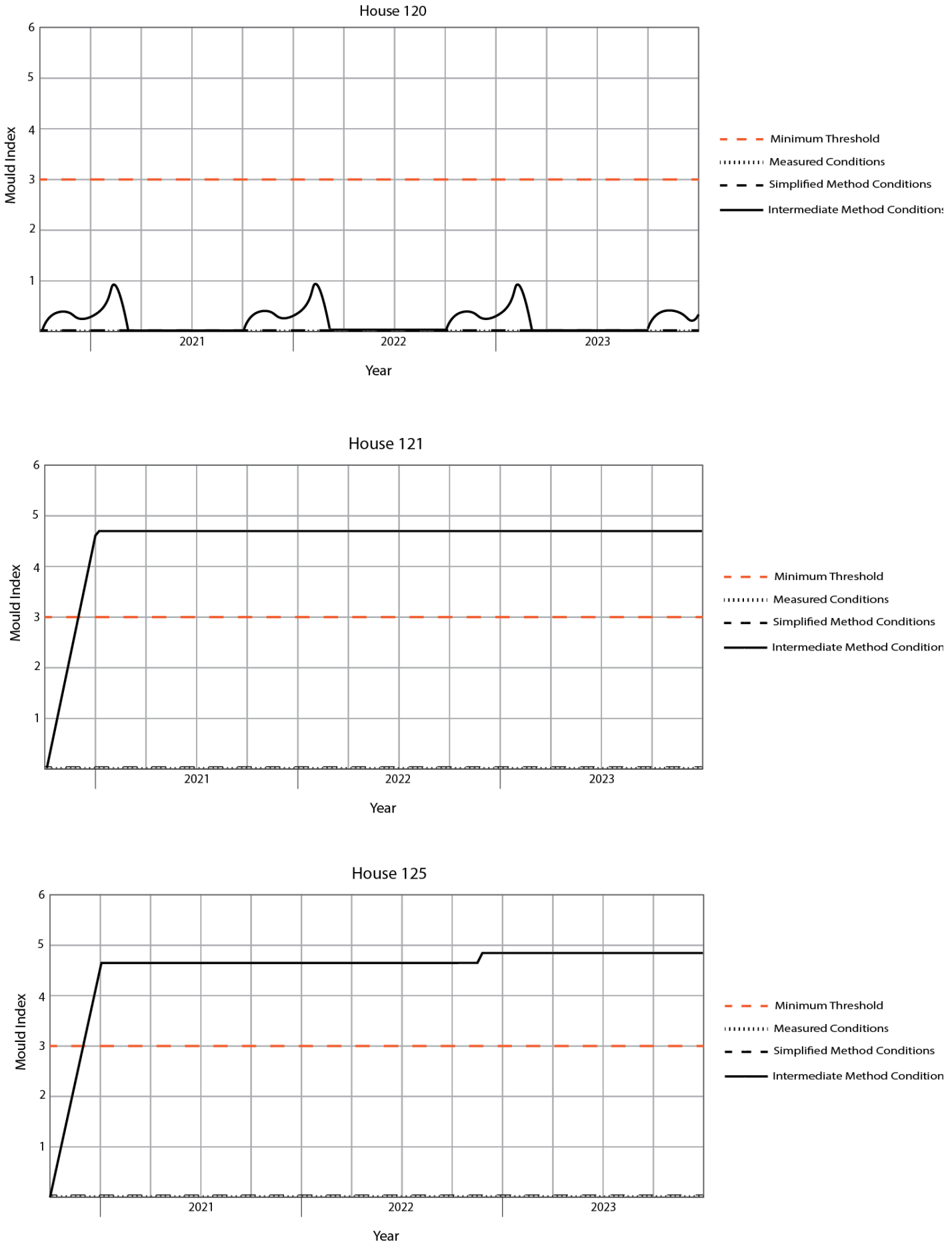

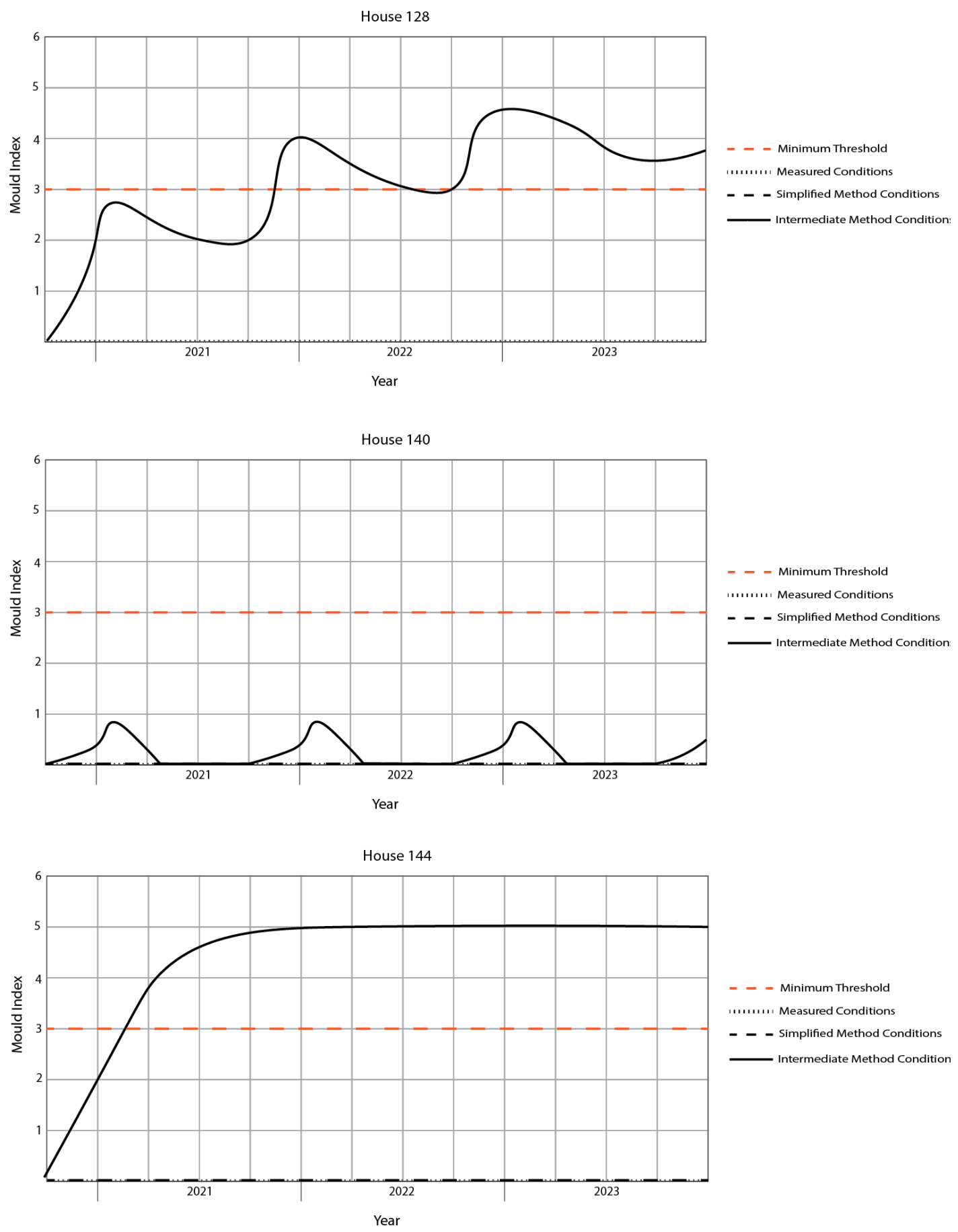


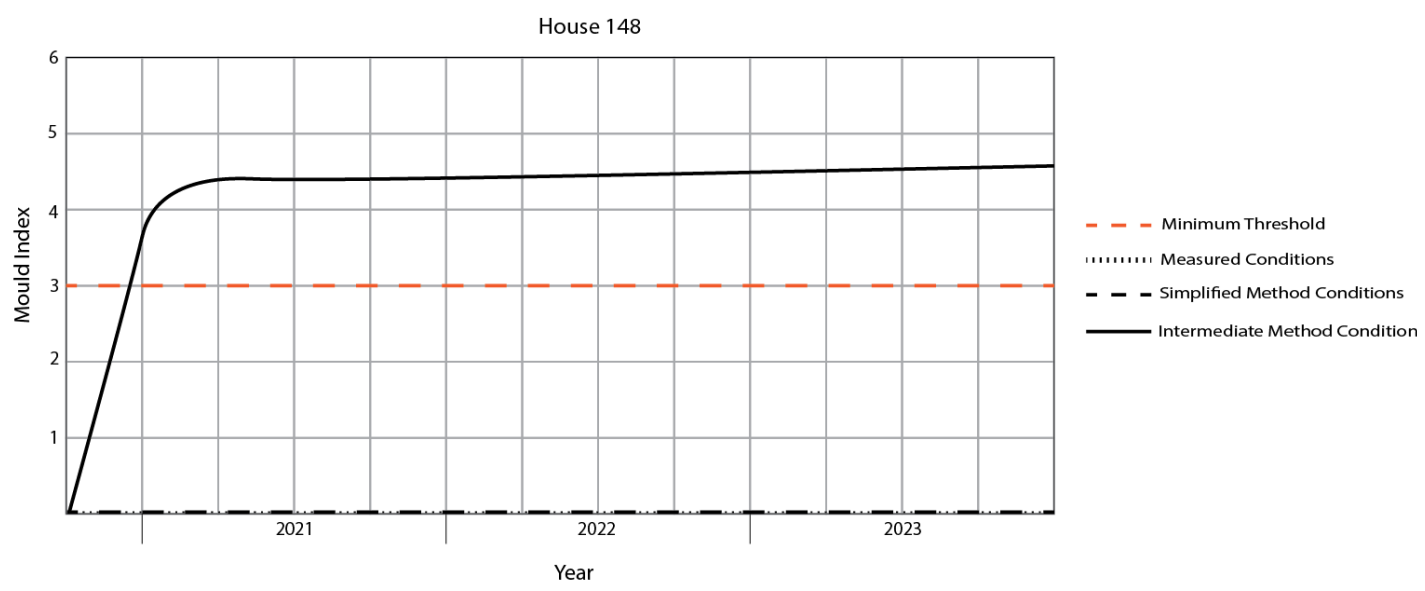

183 | P a ge 